FACULDADE DE SAÚdE PÚBLICA DA UNIVERSIDADE DE SÃo PAULO DEPARTAMENTO DE SAÚDE AMBIENTAL

COMUNIDADE FITOPLANCTÔNICA DA REPRESA DE GUARAPIRANGA: 1991-92. ASPECTOS ECOLÓGICOS, SANITÁRIOS E SUBSÍDIOS PARA REABILITAÇÃO DA QUALIDADE AMBIENTAL

\title{
ZULEIKA BEYRUTH
}

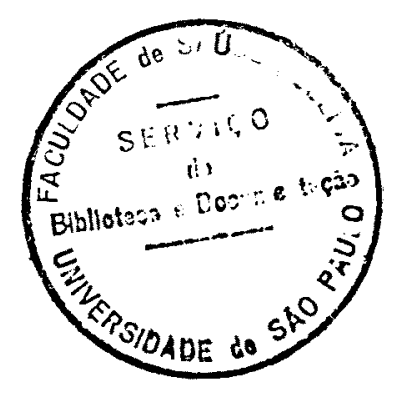

TESE APRESENTADA AO PROGRAMA DE PÓSGRADUAÇÃO EM SAÚDE AMBIENTAL DA FACULDADE DE SAÚDE PÚBLICA DA UNIVERSIDADE DE SÃO PAULO, COMO PARTE DOS REQUISTTOS PARA OBTENCCÃO DO GRAU DE DOUTOR EM SAÚDE PÚBLICA, AREA DE CONCENTRAÇÃO: SAÚDE AMBIENTAL ORIENTADOR: PROFESSOR DOUTOR ARISTIDES ALMEIDA ROCHA 


\section{AGRADECIMENTOS}

Este trabalho foi realizado com a colaboração de orientadores, colegas e amigos, para os quais é um prazer expressar meu reconhecimento:

Ao Professor Doutor Aristides Almeida Rocha, pela orientação, apoio, amizade, pelos muitos caminhos que se abriram em seu nome e especialmente pela confiança.

À Doutora Célia Leite Sant'Anna pela valiosa orientação nos caminhos da taxonomia ficológica, pelo inestimável auxílio durante a revisão da minuta da tese para aperfeiçoamento deste trabalho, pelo apoio irrestrito e pela amizade, inclusive nos momentos de decisão mais importantes.

Ao Doutor Pedro Caetano Sanches Mancuso pela preocupação com o estudo do fitoplâncton de represas de abastecimento, que resultou na idéia de desenvolver este trabalho, pelo valioso auxilio na revisão para aperfeiçoamento deste trabalho.

À Doutora Denise Navas Pereira, pela cuidadosa revisão da minuta deste trabalho e pela contribuição que tornou possivel acessar informações recentes, altamente relevantes, sobre a represa de Guarapiranga.

À Doutora Vera Lúcia de Moraes Huszar pelos conselhos na definição da dimensão do trabalho e dos critérios para seleção dos dados do projeto inicial a serem utilizados neste estudo, bem como pelo auxilio durante a fase de revisão que contribuiu de forma decisiva para 0 aperfeiçoamento deste trabalho.

Aos Doutores Samuel Murgel Branco e Gisela Yuka Shimizu pelos conselhos precisos, durante a avaliação da qualificação, sobre a definição das dimensões deste trabalho.

Aos pesquisadores do Instituto Botânico, que auxiliaram nas identificações de várias espécies de algas: Doutora Maria Tereza Paiva Azevedo, Doutora Miriam Borges Xavier, Doutora Laine Sormus e a todo o pessoal da Seção de Ficologia, pelo apoio e consideração demonstrados.

Aos doutores Carlos Eduardo Mattos Bicudo e Denise Bicudo pela disponibilidade de sua bỉlioteca, de seu auxilio e do auxilio de seus estagiários nas identificações de algumas das espécies encontradas.

À Doutora Maria Helena Maier pela colaboração e sugestões na avaliação da qualidade da água. 
À Doutora Marilza Cordeiro-Marino, pela inspiração ao mostrar a possibilidade e o valor de manter sempre, em qualquer situação, a coerência com os princípios éticos e o amor pelo trabalho.

À Doutora Suzana Sendacz pela revisão e conselhos tão oportunos.

À Eni Cardoso e à Ana Lúcia Brandimarte pela atenção e cuidado na revisão, bem como pela disponibilidade, apoio, solidariedade e amizade.

\section{Agradeço especialmente a}

Sueli Caleffi pelo apoio incondicional, pelo espírito de luta incansável, pela convivência agradável, pela amizade e carinho, que tornaram possível realizar esta aventura.

Eni Cardoso e Eliete Zanardi pelo carinho, amizade, confiança, pelas análises químicas e pelas horas sem fim de sono perdido, nas intermináveis madrugadas de trabalho após as coletas além dos sábados, domingos e feriados, sem as quais não teria sido possível produzir esta tese.

À Thais Janson Mercante pela colaboração nos trabalhos fotográficos.

Ao Gil Beyruth pelo trabalho de computação e artes gráficas na montagem das imagens das algas.

Ao Doutor José Luis Negrão Mucci e a Solange Martone Rocha pela amizade, bom humor e apoio, que ajudaram a tornar mais alegres e divertidos estes anos de trabalho.

Maria do Carmo, Maria Aparecida, Francisca e Marlene, do HSA, pelo apoio, pelo trabalho cuidadoso e incansável, e especialmente pelo bom humor e amizade.

À Engenheira Ana Alvim pela contribuição valiosa na informatização de análises estatísticas, pela amizade, apoio e por sempre conseguir melhorar meu humor quando as condições de trabalho estiveram adversas.

Ao Sr. Silvio, ao Alvarenga e aos demais motoristas pela ajuda incansável e pelas idéias para facilitar os trabalhos de campo.

Ao Edmilson, Rubens, Aninha, Serginho, Wandinha e Ilma pelos inúmeros cafezinhos compartilhados, pela amizade, carinho, bom humor e solidariedade que contribuíram para manter o moral elevado, mesmo nos momentos dificeis.

Aos professores, funcionários e estagiários do Departamento de Saúde Ambiental da Faculdade de Saúde Pública, pelo apoio, colaboração e convivência amiga no decorrer destes anos de trabalho. 
Ao Clube Náutico Paulista pelo apoio na primeira fase de coletas, especialmente ao Ceará, que nos guiou tão bem sobre as águas da represa, pela ajuda nos trabalhos de coleta e por nos ensinar muito sobre a represa e seus folclores.

À SABESP pelo apoio em parte das coletas e no fornecimento de dados de operação da represa, especialmente ao Engenheiro Constante Bombonato e à Doutora Maria Cecilia Paro e seus assistentes, pela solicitude em atender aos nossos pedidos.

Ao Instituto Astronômico e Geofisico, especialmente ao Doutor Frederico pelo fornecimento de dados climatológicos. À Seção de Hidrologia da CETESB pelos dados de hidrologia.

Ao 12 Batalhão do Corpo de Bombeiros da Guarapiranga pelo apoio, na segunda fase das coletas, em especial ao cabo Giovani e a todo o pessoal da aquática, tanto por facilitarem a mobilização, como pela ajuda nos trabalhos de coleta.

À Diretoria da Faculdade de Saúde Pública e ao CNPq, pela bolsa de estudos concedida entre 1991 e 1995, que tornaram mais fácil atravessar este periodo.

À minha mãe, Nina e ao meu pai José, por me ensinarem que qualidade de vida é direito de todos os seres vivos.

Ao meu marido Rubinho, aos meus filhos Danilo, Murilo e Gil por tornarem minha vida tão preciosa, maravilhosa e divertida, agradeço especialmente pela paciência em dividirem minhas atenções e meu tempo, com "a tese", por tantos anos, sempre me incentivando e apoiando.

Às matas, cachoeiras e todas as águas, pelas quais minha paixão não tem fim. 


\section{RESUMO}

A represa de Guarapiranga faz parte da sub-bacia do alto Tietê e situa-se entre a Região Metropolitana de São Paulo e cidades vizinhas: Itapecerica da Serra e Embu-guaçu, SP $\left(23^{\circ}\right.$ $43^{\prime} \mathrm{S}$ e $46^{\circ} 32^{\prime} \mathrm{W}$ ). Sua bacia estende-se ainda pelos municípios de Embu e Cotia. Foi construída em 1906 pela barragem do rio Guarapiranga, com o objetivo de regularizar as vazões contribuintes e ampliar a produção de energia elétrica em Santana do Parnaiba. Em 1926 passou a servir ao abastecimento público e atualmente suas finalidades são: controle de enchentes, geração de energia, recreação e abastecimento. É responsável pelo atendimento da demanda hídrica de $60 \%$ da população da Região Metropolitana de São Paulo, sendo o segundo sistema produtor da Companhia de Saneamento Básico do Estado de São Paulo, suprindo 21 bairros da cidade de São Paulo e também Taboão da Serra, Osasco e Carapicuíba. Nas últimas décadas a qualidade de suas águas vem sendo submetida a séria deterioração, em virtude da intensa ocupação e usos inadequados do solo de sua bacia de drenagem, bem como dos crescentes aportes de esgotos, que incrementaram sua eutrofização e o desenvolvimento explosivo da comunidade fitoplanctônica.

Este trabalho relata aspectos ecológicos, sanitários e indica ações para um manejo mais adequado da represa de Guarapiranga, a partir da análise da comunidade fitoplanctônica e suas relações com as variáveis ambientais, estudadas no período entre maio de 1991 e julho de 1992. Os dados foram obtidos em campanhas semanais de amostragem em dois pontos da área de água aberta superficial da represa.

Neste estudo foram analisadas as características e flutuações da comunidade fitoplanctônica (riqueza, densidade, bioárea, biovolume, diversidade de espécies, uniformidade, estratégias adaptativas, bem como taxas de alteração).

Propôs-se um método para avaliação da persistência dos grupos analisados, que mostrou-se eficiente, especialmente para a avaliação sanitária.

Foram analisadas simultaneamente as características climatológicas e hidrológicas atuantes na represa e também os aspectos fisicos e químicos da qualidade da água (temperatura, profundidade, transparência, cor, turbidez, condutividade, potencial hidrogeniônico, oxigênio dissolvido, demanda bioquímica de oxigênio, alcalinidade, dureza, teor de sólidos totais em suspensão, fósforo solúvel reativo, fosfato total, nitrogênio amoniacal, nitrato, sulfato, cloreto, cálcio, potássio, silício, sódio, magnésio, manganês, cobre, alumínio, ferro e zinco).

Os resultados mostraram a ocorrência de 240 táxons, sendo que as clorococales e as zignemaficeas destacaram-se pela riqueza de espécies. 
A comunidade demonstrou os efeitos da eutrofização, através da alta produção algácea expressa pelas elevadas densidades e biovolumes, especialmente de espécies indicadoras de eutrofização. Os fatores climáticos e a influência antrópica (expressa pela eutrofização, operação hidráulica e controle algáceo) atuaram como as principais forçantes de alterações da comunidade fitoplanctônica. Os dados obtidos para a estação de coleta mais próxima da barragem e captação de água para abastecimento - denominado ponto 1- mostraram a influência da urbanização de suas margens, e os obtidos na estação mais a montante - ponto 4 indicaram as influências de desmatamentos recentes. Observou-se que as chuvas promovem entrada de nutrientes e contaminantes, magnificando os resultados da degradação ambiental. Estes ingressos de nutrientes favorecem um maior desenvolvimento algáceo. Entre os efeitos da degradação na qualidade da água, o mais deletério é o ingresso de teores elevados de metais, entre estes o alumínio, citado na literatura médica por sua relação com doenças neurológicas crônicas como o mal de Alzheimer. $\mathrm{O}$ risco à saúde humana é discutido neste trabalho. $\mathrm{O}$ teor deste metal mostrou correlação negativa com densidade, bioárea e riqueza de espécies do fitoplâncton.

A espécie que mais se destacou na represa, em densidade e biomassa, foi Dictyosphaerium ehrenberghianum. Criptoficeas e zignemaficeas mostraram maior taxa de alteração das comunidades, devido às aplicações de sulfato de cobre para o controle algáceo, realizadas na área de captação para abastecimento - ponto 1. Rhizosolenia eiriensis mostrou correlação negativa com o teor aplicado deste algicida, o que pode indicar sensibilidade desta espécie ao controle. Espécies de Mougeotia contribuiram expressivamente para a densidade e o biovolume total das algas em água aberta, durante as fases de maior movimentação, periodos estes de intensa pluviosidade. A estabilidade da comunidade fitoplanctônica foi espressa por algumas fases de equilibrio verificadas apenas na estação de captação, bem como pela persistência de penales nesta estação e de volvocales na estação a montante. Diatomáceas atingiram seu auge nos periodos de inverno, clorococales e zignemaficeas, no verão. $O$ aumento da disponibilidade de nutrientes por aporte da bacia ou por senescência das algas, especialmente de clorococales e zignemafíceas no verão e a concentração de nutrientes durante a seca mais intensa, favoreceram o desenvolvimento de Cyanophyceae/Cyanobacteria como Aphanocapsa, Synechoccocus, Oscillatoria e Pseudoanabaena.

As florações de cianoficeas são discutidas sob o aspecto ecológico e sanitário, incluindo os riscos à saúde humana. As espécies que se destacaram em biovolume ou densidade são, em geral, relatadas na literatura como indicadoras de ambiente eutrofizado. Espécies oportunistas, 
r-estrategistas tiveram seu desenvolvimento favorecido no ambiente estudado, não sendo encontradas quantidades expressivas de espécies estritamente K-estrategistas. A teoria ecológica que mostrou-se mais adequada, provendo maior quantidade de informação foi a teoria do não equilibrio, com a aplicação do teste da hipótese do distúrbio intermediário.

A qualidade ambiental e em especial a da comunidade fitoplanctônica, foi analisada quanto às características sanitárias. A partir dos resultados obtidos e considerando-se também a realidade atual das forças econômicas, políticas e sociais atuantes, propõe-se medidas de melhoramento do manejo e qualidade ambiental, estabelecendo-se prioridades de curto, médio e longo prazo para sua aplicação.

Este estudo permitiu concluir que a represa de Guarapiranga é um ambiente de alta taxa de transferência de matéria e energia que as recebe, transforma em biomassa planctônica e as exporta, configurando-se desta forma uma reciclagem muito intensa. Esta reciclagem intensa e o elevado potencial de autodepuração permitem concluir que ações para o melhoramento da qualidade ambiental podem apresentar resultados favoráveis a curto prazo. A importância da eficiência destas ações relaciona-se ao melhoramento da qualidade da água fornecida à população humana, bem como da qualidade de vida dos usuários da represa. 


\begin{abstract}
Guarapiranga reservoir belongs to Tietê basin, is located at the Metropolitan Area of São Paulo City, surrounded by other neighbours small Cities as Itapecerica da Serra and Embuguaçu, SP ( $23^{\circ} 43^{\prime} \mathrm{S}$ and $\left.46^{\circ} 32^{\prime} \mathrm{W}\right)$. There are two other towns in its basin, Embu and Cotia. The dam was built in 1906, in the Guarapiranga river, in order to provide electric power and to regulate the flow. It started to supply water to São Paulo City in 1926. Nowadays this reservoir which is the second one of São Paulo State's Basic Sanitary Company, provides water to $60 \%$ of São Paulo's Metropolitan Region population, attending 21 districts of São Paulo and another towns, as Osasco and Carapicuiba. It has beeing also used for electric energy production and people recreation. The water quality decreased in the last decades, due to the intensive people migration from other states, attracted to São Paulo's economic development. This demographic growth increased the water's as well as the land uses and occupation, the degradation of the basin, and also the explosive development of the algae of its waters. This thesis discuss the ecological and sanitary aspects and indicate adequate management measures, supported by the analysis of the phytoplanktonic community and its relationships with the environmental variables, through data weekly sampled from may 1991 to july 1992. The analysis of the phytoplanktonic community characteristics and flutuations (richness, density, bioarea, biovolume, species diversity, eveness, survivor species strategies, alteration rates, and community stability - testing a new method to evaluate community persistance, which showed to be useful), as well as physical and chemical parameters to evaluate the water quality (temperature, depth, transparency, color, turbidity, conductivity, hidrogenionic potencial, dissolved oxygen, biological oxygen demand, alkalinity, hardness, total suspended solids, and $\mathrm{PO}_{4}^{-3}, \mathrm{TP}, \mathrm{NH}_{4}{ }^{+}, \mathrm{NO}_{3}{ }^{-}, \mathrm{SO}_{4}{ }^{-2}, \mathrm{Cl}, \mathrm{Al}, \mathrm{Ca}, \mathrm{Fe}, \mathrm{K}, \mathrm{Mg}, \mathrm{Mn}, \mathrm{Na}, \mathrm{Si}$ and $\mathrm{Zn}$ ) were carried out from two surface sampling stations in the open water. The analysis showed 240 species, detaching Chloroccocales and Zignemaphyceae by their richness. The community showed eutrofication effects through the high algae productivity, expressed by density and biovolume, specially of high trophic level indicator species. The climatic events and anthropic influences, showed by the eutrophication and hidraulic management, as well as showed by the algae control through copper sulphate were the major umpelling forces promoting phytoplanktonic community changes. Station 1 , which was the closest station to the dam and intake for supply, showed the urbanization influence of the surrounding areas as well as of the copper sulphate applications, which were carried out only in this station. The station 4, upper in the reservoir, showed the effects of recent deforestation in its border region.
\end{abstract}


Among these effects of the water quality degradation, the most deleterious one, is the input of elevated concentrations of heavy metals as aluminum, related in the medical literature, as responsible for Alzheimer's disease. These inputs occurred during high pluviosity periods, and they are related to a deforestation recently carried out at the basin. The rainy season, which promoted these nutrient and contaminant inputs, favoured also the intensive phytoplankton growth. Dictyosphaerium ehrenberghianum was the specie which showed the highest density and biovolume. Cryptophyceae and Zignemaphyceae showed higher alteration rates due to the copper sulphate, and Rhizosolenia eiriensis showed negative correlation with the applied concentration of this algicide. Mougeotia species contributed expressively to the density and biovolume in the open water, due to the intensive water movement during the higher pluviosity periods. The stability of the community was attained in some phases in the station 1 , the lentic one but never in the station 4, the most lotic one. Pennales showed high persistance in the station 1 , and Volvoccales in the station 4, throughout this study. Diatoms attained its higher values in cold-dry periods, in the winter and Chloroccocales and Zygnemaphyceae, during the warmer-wet periods in the summer. The inputs of nutrients from the basin and/or the senescence of the algae, specially Chlorococcales and Zygnemaphyceae in the summer and the ionic concentration during the most intensive dry periods favoured the growth of Cyanophyceae/Cyanobacteria like Aphanocapsa, Synechoccocus, Oscillatoria and Pseudoanabaena spp. The species which showed the highest productivity are often mentioned in the literature as indicators of eutrophication. Oportunistic species, r-strategists had its development favoured in this environment. The ecological theory, which showed to be more useful and gave more information, was the "non equilibrium" theory, with the Hipothesis of the Intermmediate Disturbance test. The environmental and phytoplankton qualities and sanitary characteristics were analysed. The results obtained, as well as economic, political and social present forces were considered in order to propose management measures for improvement of the environmental quality, priorized to be applied in short, medium and long time. This study showed that Guarapiranga reservoir is an environment with high level of energy and material transference, receiving, changing it in living biomass, and exporting its contents to other environments, in this case, our homes. The recycling is very fast, therefore any improvement of the sanitary level at the basin and at the water will be reflected immediatly in the distributed water supply, as well as in the life quality of the users. 
COMUNIDADE FITOPLANCTÔNICA DA REPRESA DE GUARAPIRANGA: 1991-92. ASPECTOS ECOLÓGICOS, SANITÁRIOS E SUBSIDIOS PARA REABILITAÇÃO DA QUALIDADE AMBIENTAL.

\section{ERRATA (PÁGINA 1 DE 3)}

\begin{tabular}{|c|c|c|c|}
\hline & & $\begin{array}{l}\left(\mathbf{A}^{*}\right)=\text { acrescentar } \\
\left(\mathbf{R}^{*}\right)=\text { remover } \\
\left(\mathbf{S}^{*}\right)=\text { substituir }\end{array}$ & \\
\hline PÁGINA & PARÁGRAFO & ALTERAÇÃO & $\begin{array}{l}\text { SUBSTITUIR POR } \\
\text { OU ACRESCENTAR }\end{array}$ \\
\hline 9 & $1_{-}^{0}$ & Figura $2\left(S^{\star}\right)$ & Figura 3 \\
\hline 10 & $1^{\overline{0}}$ & Figura $2\left(S^{\star}\right)$ & Figura 2 e 3 \\
\hline 10 & $6^{\overline{0}}$ & Figura $2\left(\mathrm{~S}^{\star}\right)$ & Figura 3 \\
\hline 12 & $2^{-}$ & Figura 3 (S*) & Figura 2 \\
\hline 13 & $4_{-}^{\circ}$ & Figura $16\left(S^{\star}\right)$ & Figura 22 \\
\hline 17 & $2_{-}^{-}$ & Figura $4\left(S^{\star}\right)$ & Figura 3 \\
\hline 27 & $1^{-}$ & os diagramas $\left(S^{\star}\right)$ & o diagrama \\
\hline 28 & $2^{0}$ & $0.0002)$. No $\left(S^{\star}\right)$ & $0.0002) ;$ no \\
\hline 29 & $1_{-}^{0}$ & $P=0)$. No $\left(S^{\star}\right)$ & $P=0) ;$ no \\
\hline 48 & $7_{-}^{0}$ & 23 e respectivamente $\left(R^{\star}\right)$ & \\
\hline 49 & $3^{\circ}$ & Tabelas 14 a $21\left(\mathrm{~S}^{\star}\right)$ & Tabelas $15,17,19$ e 21 \\
\hline 61 & $5_{-}^{\circ}$ & Tabelas 32 e $32\left(S^{\star}\right)$ & Tabelas 31 e 32 \\
\hline 62 & $3^{-0}$ & t2. $\operatorname{Em}\left(S^{\star}\right)$ & t2; em \\
\hline 62 & $6_{-}^{\overline{0}}$ & bicaudatus. $\operatorname{Em}\left(\mathrm{S}^{\star}\right)$ & bicaudatus; em \\
\hline 63 & $3_{-}^{-}$ & pulchellum. Em (S*) & pulchellum; em \\
\hline 64 & $1_{-}^{-}$ & ehrenberghianum. Em $\left(\mathrm{S}^{\star}\right)$ & ehrenberghianum; em \\
\hline 64 & $5^{\circ}$ & minutissima. Em $\left(\mathbf{S}^{\star}\right)$ & minutissima; em \\
\hline 65 & $3^{-0}$ & vulgaris. $\operatorname{Em}\left(\mathrm{S}^{\star}\right)$ & vulgaris; em \\
\hline 66 & $1_{-}^{0}$ & eiriensis. $\operatorname{Em}\left(\mathrm{S}^{\star}\right)$ & eiriensis; em \\
\hline 66 & $6^{\circ}$ & nas figuras apresentadas $\left(\mathbf{R}^{\star}\right)$ & \\
\hline 66 & $\mathbf{5}_{-}^{\circ}$ & granulata. Em (S*) & granulata; em \\
\hline 79 & $2_{-}^{0}$ & Figura $3\left(\mathbf{R}^{\star}\right)$ & \\
\hline 88 & $\mathbf{1}_{-}^{0}$ & $\operatorname{E~AS}\left(\mathbf{S}^{*}\right)$ & $\mathbf{E} \mathbf{A}$ \\
\hline 92 & $4_{-}^{0}$ & Monorapidium $\left(\mathbf{S}^{\star}\right)$ & Monoraphidium \\
\hline 177 & $9^{\circ}$ & $\mathbf{p}\left(\mathbf{R}^{\star}\right)$ & \\
\hline 180 & $6_{-}^{-}$ & Drum \& Hopkins ( $A^{\star}$ data) & 1965 \\
\hline 180 & $5_{-}^{-}$ & Drury \& Nisbet ( $A^{*}$ data $)$ & 1973 \\
\hline 182 & $3_{-}^{\overline{0}}$ & Henry $\left(A^{*}\right.$ data $)$ & 1990 \\
\hline 183 & $1_{-}^{-0}$ & Klemer ( $A^{*}$ data $)$ & 1991 \\
\hline 179 & $10^{\circ}$ & Cooke \& Gould ( $A^{*}$ data) & 1991 \\
\hline$A-6$ & & $\left(\mathbf{A}^{*}\right)$ & A-6.7 \\
\hline A-6 & & $\left(\mathbf{A}^{\star}\right)$ & A-6.8 \\
\hline
\end{tabular}




\section{.ZZULEEIKA BEYRUTH}

COMUNIDADE FITOPLANCTONNICA DA REPRESA DE GUARAPIRANGA: 1991-92. ASPECTOS ECOLÓGICOS, SANITÁRIOS E SUBSÍDIOS PARA REABILITAÇÃO DA QUALIDADE AMBIENTAL.

\section{ERRATA (PÁGINA 2 DE 3)}

A-6.7

TABELA 6 - CORRELAÇÕES ENTRE AS VARIÁVEIS AMBIENTAIS ABIÓTICAS DURANTE O PERIODO DE ESTUDO, TESTE DE SPEARMAN (SIEGEL, 1975). NIVEL CONSIDERADO: $P>=0.050$. REPRESA DE GUARAPIRANGA - PONTOS 1 E 4 , 1991-92.

Temperatura da água (TAG); profundidade (PROF); transparência ao disco de Secchi (SEC); cor (COR);turbidez (TUR); condutividade (CON); $\mathrm{pH}(\mathrm{pH})$; oxigênio dissolvido (OD); demanda bioquímica de oxigênio (DBO); alcalinidade (ALC); dureza (DUR); sólidos totais $\mathrm{em}$ suspensão (SOT); fósforo solúvel reativo $\left(\mathrm{PO}_{4}^{-3}\right)$; fósforó total (PT); amônlo $\left(\mathrm{NH}_{4}^{+}\right)$; nitrato $\left(\mathrm{NO},{ }^{-}\right)$.Precipitação de 24 (P24); 72 (P72) e 168 horas (P168) anteriores às coletas; vazão afluente natural (ANA), recalcada (ARE) e total (AT); na vazão para abastecimento (EAB); elevação (ELE) e volume (VOL); precipitação média mensal (P); excedente hídrico (EXC); escoamento básico (ESC): deficiência hidrica do solo (DEF); radiação solar (RAD); insolação (INS); velocidade dos ventos (VEN); aplicação de sulfato de cobre do dia anterior (SA) e do dia da coleta (S) Ponto $4 \downarrow$ (P4).

PONTO 4

\begin{tabular}{|c|c|c|c|c|c|c|c|c|c|c|c|c|c|c|c|c|}
\hline & TAG & PROF & SEC & COR & TUR & CON & $\mathrm{pH}$ & OD & $\mathrm{DBO}$ & ALC & DUR & $\mathrm{PO} 4$ & POT & SOT & $\mathrm{NH}_{4}$ & $\mathrm{NO}_{3}$ \\
\hline \multicolumn{17}{|l|}{ P24 } \\
\hline & $N$ & $N$ & -0.63 & $\mathbf{N}$ & $N$ & $N$ & $N$ & $\mathbf{N}$ & $\mathrm{N}$ & $N$ & $N$ & -0.29 & $N$ & $\mathbf{N}$ & $N$ & $N$ \\
\hline \multirow[t]{2}{*}{ P72 } & & & 0.00 & & & & & & & & & 0.05 & & & & \\
\hline & 0.37 & $\mathrm{~N}$ & -0.55 & 0.38 & $N$ & $N$ & $N$ & -0.50 & $N$ & $N$ & $\mathbf{N}$ & $\mathrm{N}$ & $\mathrm{N}$ & $\mathbf{N}$ & $\mathrm{N}$ & $N$ \\
\hline \multirow[t]{2}{*}{ P168 } & 0.01 & & 0.00 & 0.00 & & & & 0.00 & & & & & & & & \\
\hline & 0.31 & $N$ & $N$ & 0.34 & $N$ & $\mathrm{~N}$ & $N$ & -0.32 & $N$ & $N$ & 0.42 & $N$ & $N$ & $N$ & $N$ & $N$ \\
\hline \multirow[t]{2}{*}{ ANA } & 0.02 & & & 0.01 & & & & 0.02 & & & 0.02 & & & & & \\
\hline & $N$ & $N$ & $\mathrm{~N}$ & $\mathrm{~N}$ & $\mathrm{~N}$ & $N$ & $N$ & $\mathrm{~N}$ & $N$ & $N$ & $\mathrm{~N}$ & $N$ & $N$ & $\mathbf{N}$ & $N$ & $N$ \\
\hline \multicolumn{17}{|l|}{ ARE } \\
\hline \multicolumn{17}{|l|}{ AT } \\
\hline \multirow{3}{*}{ EAB } & $\mathrm{N}$ & $\mathrm{N}$ & -0.40 & 0.29 & 0.28 & $N$ & -0.33 & $N$ & $N$ & $N$ & $\mathrm{~N}$ & $N$ & $\mathrm{~N}$ & $\mathrm{~N}$ & $\mathrm{~N}$ & $\mathbf{N}$ \\
\hline & & & 0.00 & 0.03 & 0.04 & & 0.01 & & & & & & & & & \\
\hline & $N$ & $N$ & $\mathrm{~N}$ & $N$ & $N$ & $\mathrm{~N}$ & $N$ & $N$ & $\mathrm{~N}$ & $N$ & $N$ & $N$ & $N$ & $\mathbf{N}$ & $\mathbf{N}$ & $\mathbf{N}$ \\
\hline \multirow[t]{2}{*}{ ELE } & $\mathbf{N}$ & $N$ & $\mathbf{N}$ & $\mathbf{N}$ & $\mathbf{N}$ & $\begin{array}{l}-0.36 \\
0.01\end{array}$ & $N$ & $\mathbf{N}$ & $\mathbf{N}$ & $\begin{array}{l}-0.32 \\
0.02\end{array}$ & $\begin{array}{l}0.37 \\
0.00\end{array}$ & $\mathbf{N}$ & $N$ & $\mathbf{N}$ & $\mathbf{N}$ & $\mathbf{N}$ \\
\hline & -0.33 & 0.58 & $N$ & $\mathrm{~N}$ & $N$ & -0.38 & $N$ & $N$ & $\mathbf{N}$ & $N$ & $\mathrm{~N}$ & $\mathbf{N}$ & $N$ & $\mathrm{~N}$ & $\mathbf{N}$ & $\mathbf{N}$ \\
\hline \multirow[t]{2}{*}{ VOL } & 0.02 & 0.00 & & & & 0.01 & & & & & & & & & & \\
\hline & -0.33 & 0.58 & $\mathbf{N}$ & $\mathrm{N}$ & $\mathrm{N}$ & -0.37 & $N$ & $N$ & $\mathrm{~N}$ & $N$ & $\mathrm{~N}$ & $\mathbf{N}$ & $N$ & $\mathbf{N}$ & $\mathbf{N}$ & $\mathbf{N}$ \\
\hline \multirow[t]{2}{*}{$\mathbf{P}$} & 0.02 & 0.00 & & & & 0.01 & & & & & & & & & & \\
\hline & 0.60 & $\mathrm{~N}$ & -0.57 & 0.33 & $\mathrm{~N}$ & $\mathrm{~N}$ & $\mathrm{~N}$ & -0.30 & $\mathbf{N}$ & $\mathbf{N}$ & 0.61 & $\mathbf{N}$ & $\mathrm{N}$ & -0.53 & $\mathbf{N}$ & $\mathbf{N}$ \\
\hline \multirow[t]{2}{*}{ ETP } & 0.00 & & 0.00 & 0.01 & & & & 0.03 & & & 0.00 & & & 0.00 & & \\
\hline & $\mathrm{N}$ & $N$ & $\mathrm{~N}$ & $\mathbf{N}$ & $N$ & $N$ & $N$ & $\mathrm{~N}$ & $N$ & $N$ & $\mathrm{~N}$ & $\mathrm{~N}$ & $\mathrm{~N}$ & $\mathrm{~N}$ & $N$ & $\mathrm{~N}$ \\
\hline EXC & 0.54 & -0.29 & -0.52 & 0.30 & $N$ & $N$ & $N$ & -0.28 & $\mathrm{~N}$ & $N$ & 0.53 & $N$ & $\mathbf{N}$ & -0.43 & $N$ & $N$ \\
\hline \multirow[t]{2}{*}{ ESC } & 0.00 & 0.03 & 0.00 & 0.03 & & & & 0.04 & & & 0.00 & & & 0.01 & & \\
\hline & 0.54 & $N$ & -0.42 & $N$ & $N$ & $\mathbf{N}$ & $N$ & $N$ & $N$ & $N$ & $\mathrm{~N}$ & $N$ & $N$ & $N$ & $N$ & -0.58 \\
\hline \multirow[t]{2}{*}{ RAD } & 0.00 & & 0.00 & & & & & & & & & & & & & 0.00 \\
\hline & 0.60 & -0.32 & -0.53 & 0.44 & $N$ & $\mathbf{N}$ & $N$ & -0.28 & $N$ & $N$ & 0.59 & $N$ & $N$ & $N$ & $N$ & $N$ \\
\hline \multirow[t]{2}{*}{ INS } & 0.00 & 0.02 & 0.00 & 0.00 & & & & 0.04 & & & 0.00 & & & & & \\
\hline & $\mathbf{N}$ & $N$ & 0.29 & $\mathbf{N}$ & $\mathrm{N}$ & $\mathbf{N}$ & $\mathbf{N}$ & 0.30 & $N$ & $\mathrm{~N}$ & $N$ & $\mathbf{N}$ & $\mathbf{N}$ & $\mathbf{N}$ & $N$ & $\mathbf{N}$ \\
\hline \multirow[t]{2}{*}{ VEN } & & & 0.03 & & & & & 0.03 & & & & & & & & \\
\hline & $N$ & $\mathrm{~N}$ & $N$ & $\mathrm{~N}$ & $\mathrm{~N}$ & $N$ & $\mathrm{~N}$ & $N$ & $N$ & $\mathrm{~N}$ & $N$ & $\mathbf{N}$ & $N$ & $N$ & $N$ & $\mathrm{~N}$ \\
\hline \multirow[t]{2}{*}{ DEF } & & & & & & & & & & & & & & & & \\
\hline & -0.28 & $N$ & 0.34 & -0.35 & -0.43 & $\mathrm{~N}$ & 0.36 & $N$ & $N$ & 0.29 & $N$ & $\mathrm{~N}$ & $N$ & 0.43 & $\mathrm{~N}$ & $\mathbf{N}$ \\
\hline \multirow[t]{2}{*}{ SA } & 0.04 & & 0.01 & 0.01 & 0.00 & & 0.01 & & & 0.03 & & & & 0.00 & & \\
\hline & 0.43 & $\mathbf{N}$ & -0.47 & $N$ & $\mathrm{~N}$ & $\mathbf{N}$ & $\mathrm{N}$ & -0.31 & $N$ & 0.33 & 0.48 & $N$ & $\mathrm{~N}$ & $N$ & 0.36 & -0.31 \\
\hline$S$ & 0.00 & & 0.00 & & & & & 0.02 & & 0.01 & 0.01 & & & & 0.01 & 0.02 \\
\hline
\end{tabular}


COMUNIDADE FITOPLANCTÔNICA DA REPRESA DE GUARAPIRANGA: 1991-92. ASPECTOS ECOLÓGICOS, SANITÁRIOS E SUBSÍDIOS PARA REABILITAÇĀO DA QUALIDADE AMBIENTAL.

\section{ERRATA (PÁGINA 3 DE 3)}

TABELA 6 - CORRELAÇÕES ENTRE AS VARIÁVEIS AMBIENTAIS ABIÓTICAS DURANTE $O$ PERÍODO DE ESTUDO, TESTE DE SPEARMAN (SIEGEL, 1975). NÍVEL CONSIDERADO: $P>=0.050$. REPRESA DE GUARAPIRANGA - PONTOS $1 \mathrm{E} 4,1991-92$.

Sulfato $\left(\mathrm{SO}_{4}^{-2}\right)$; cloro $\left(\mathrm{Cl}^{-}\right)$; aluminio (Al); cálcio (Ca); cobre (Cul); ferro (Fe); potássio (K); magnćsio (Mg); manganês (Mn); sódio (Na); silício (Si); zinco (Zn); Precipitação de 24 (P24); 72 (P72) e 168 horas (P168) anteriores às coletas; vazão afluente natural (ANA), recalcada (ARE) e total (AT); na vazão para abastecimento (EAB); elevação (ELE) e volume (VOL); precipitação média mensal (P); excedente hídrico (EXC); escoamento básico (ESC); deficiência hídrica do solo (DEF); radiação solar (RAD); insolação (INS); velocidade dos ventos (VEN); aplicação de sulfato de cobre do dia anterior (SA) e do dia da coleta (S). Ponto $4 \downarrow$ (P4).

\begin{tabular}{|c|c|c|c|c|c|c|c|c|c|c|c|}
\hline & $\mathrm{SO} 4$ & $\mathrm{Cl}$ & $\mathrm{Al}$ & $\mathrm{Ca}$ & $\mathrm{Fe}$ & $k$ & $\mathrm{Mg}$ & $\mathrm{Mn}$ & $\mathrm{Na}$ & $\mathrm{Si}$ & $\mathrm{Zn}$ \\
\hline P24 & $\mathrm{N}$ & $\mathrm{N}$ & $N$ & $N$ & $N$ & $N$ & $\mathrm{~N}$ & $N$ & $\mathrm{~N}$ & $N$ & $\mathrm{~N}$ \\
\hline $\mathrm{P} 72$ & $N$ & $\mathrm{~N}$ & $N$ & $\begin{array}{l}0.49 \\
0.00\end{array}$ & $\begin{array}{l}-0.41 \\
0.00\end{array}$ & $\begin{array}{l}0.45 \\
0.00\end{array}$ & $\begin{array}{l}0.39 \\
0.00\end{array}$ & $N$ & $\begin{array}{l}0.23 \\
0.09\end{array}$ & $N$ & $N$ \\
\hline P168 & $\mathrm{N}$ & $N$ & $\mathrm{~N}$ & $\begin{array}{l}0.48 \\
0.00\end{array}$ & $N$ & $\begin{array}{l}0.46 \\
0.00\end{array}$ & $\begin{array}{l}0.36 \\
0.01\end{array}$ & $\mathrm{~N}$ & $\begin{array}{l}0.28 \\
0.05\end{array}$ & $N$ & $N$ \\
\hline ANA & $N$ & $\mathrm{~N}$ & $\mathrm{~N}$ & $\mathrm{~N}$ & $N$ & $\mathbf{N}$ & $\mathrm{N}$ & $N$ & $\mathrm{~N}$ & $N$ & $N$ \\
\hline ARE & $\mathrm{N}$ & $N$ & $N$ & $\mathrm{~N}$ & $N$ & $\mathbf{N}$ & $N$ & $N$ & $N$ & $N$ & $N$ \\
\hline AT & $N$ & $N$ & $\begin{array}{l}0.28 \\
0.04\end{array}$ & $N$ & $N$ & $N$ & $\mathrm{~N}$ & $N$ & $N$ & $N$ & $N$ \\
\hline $\mathrm{EAB}$ & $N$ & $\mathbf{N}$ & $N$ & $N$ & $N$ & $N$ & $N$ & $N$ & $N$ & $N$ & $N$ \\
\hline EFT & $N$ & $N$ & $\begin{array}{l}0.33 \\
0.02\end{array}$ & $N$ & $\begin{array}{l}0.31 \\
0.02\end{array}$ & $N$ & $N$ & $N$ & $N$ & $\mathrm{~N}$ & $N$ \\
\hline ELE & $\mathrm{N}$ & $\begin{array}{l}-0.68 \\
0.00\end{array}$ & $\mathbf{N}$ & $\begin{array}{l}-0.41 \\
0.00\end{array}$ & $\begin{array}{l}0.47 \\
0.00\end{array}$ & $\begin{array}{l}-0.35 \\
0.01\end{array}$ & $\begin{array}{l}-0.47 \\
0.00\end{array}$ & $N$ & $\begin{array}{l}-0.69 \\
0.00\end{array}$ & $\mathbf{N}$ & $\mathbf{N}$ \\
\hline VOL & $N$ & $\begin{array}{l}-0.68 \\
0.00\end{array}$ & $\mathbf{N}$ & $\begin{array}{l}-0.42 \\
0.00\end{array}$ & $\begin{array}{l}0.47 \\
0.00\end{array}$ & $\begin{array}{l}-0.35 \\
0.01\end{array}$ & $\begin{array}{l}-0.47 \\
0.00\end{array}$ & $\mathrm{~N}$ & $\begin{array}{l}-0.69 \\
0.00\end{array}$ & $\mathrm{~N}$ & $N$ \\
\hline $\mathbf{P}$ & $\mathrm{N}$ & $\begin{array}{l}0.39 \\
0.00\end{array}$ & $N$ & $\begin{array}{l}0.53 \\
0.00\end{array}$ & $N$ & $\begin{array}{l}0.43 \\
0.00\end{array}$ & $\begin{array}{l}0.57 \\
0.00\end{array}$ & $\mathbf{N}$ & $\begin{array}{l}0.45 \\
0.00\end{array}$ & $\mathbf{N}$ & $N$ \\
\hline ETP & $\mathbf{N}$ & $\mathbf{N}$ & $\mathbf{N}$ & $\mathbf{N}$ & $N$ & $\mathrm{~N}$ & $\mathrm{~N}$ & $\mathrm{~N}$ & $\mathbf{N}$ & $N$ & $\mathrm{~N}$ \\
\hline EXC & $N$ & $\begin{array}{l}0.32 \\
0.02\end{array}$ & $N$ & $\begin{array}{l}0.45 \\
0.00\end{array}$ & $N$ & $\begin{array}{l}0.33 \\
0.02\end{array}$ & $\begin{array}{l}0.49 \\
0.00\end{array}$ & $N$ & $\begin{array}{l}0.35 \\
0.01\end{array}$ & $N$ & $\mathbf{N}$ \\
\hline ESC & $\begin{array}{l}-0.33 \\
0.02\end{array}$ & $\begin{array}{l}-0.38 \\
0.01\end{array}$ & $\mathrm{~N}$ & $\mathrm{~N}$ & $N$ & $\mathbf{N}$ & $\mathrm{N}$ & $\mathrm{N}$ & $\begin{array}{l}-0.36 \\
0.01\end{array}$ & $N$ & $N$ \\
\hline RAD & $N$ & $\begin{array}{l}0.43 \\
0.00\end{array}$ & $N$ & $\begin{array}{l}0.50 \\
0.00\end{array}$ & $N$ & $\begin{array}{l}0.48 \\
0.00\end{array}$ & $\begin{array}{l}0.50 \\
0.00\end{array}$ & $\begin{array}{l}0.41 \\
0.00\end{array}$ & $\begin{array}{l}0.46 \\
0.00\end{array}$ & $\begin{array}{l}-0.36 \\
0.01\end{array}$ & $\begin{array}{l}-0.31 \\
0.02\end{array}$ \\
\hline INS & $N$ & $\mathbf{N}$ & $N$ & $\begin{array}{l}-0.43 \\
0.00\end{array}$ & $N$ & $\begin{array}{l}-0.34 \\
0.01\end{array}$ & $\begin{array}{l}-0.35 \\
0.01\end{array}$ & $N$ & $\begin{array}{l}-0.28 \\
0.04\end{array}$ & $\mathrm{~N}$ & $\mathrm{~N}$ \\
\hline VEN & $\mathrm{N}$ & $N$ & $N$ & $N$ & $N$ & $N$ & $\mathrm{~N}$ & $N$ & $N$ & $N$ & $N$ \\
\hline DEF & $N$ & $N$ & $\begin{array}{l}-0.46 \\
0.00\end{array}$ & $\mathrm{~N}$ & $\begin{array}{l}-0.28 \\
0.04\end{array}$ & $\mathbf{N}$ & $\begin{array}{l}-0.34 \\
0.01\end{array}$ & $N$ & $\mathrm{~N}$ & $N$ & $\begin{array}{l}0.31 \\
0.02\end{array}$ \\
\hline SA & $\mathbf{N}$ & $\begin{array}{l}-0.31 \\
0.02\end{array}$ & $\mathrm{~N}$ & $\begin{array}{l}0.30 \\
0.03 \\
\end{array}$ & $\mathrm{~N}$ & $\begin{array}{l}0.36 \\
0.01 \\
\end{array}$ & $\mathrm{~N}$ & $\begin{array}{l}0.35 \\
0.01 \\
\end{array}$ & $\mathbf{N}$ & $\mathrm{N}$ & $\begin{array}{l}0.28 \\
0.04 \\
\end{array}$ \\
\hline
\end{tabular}

De acordo,

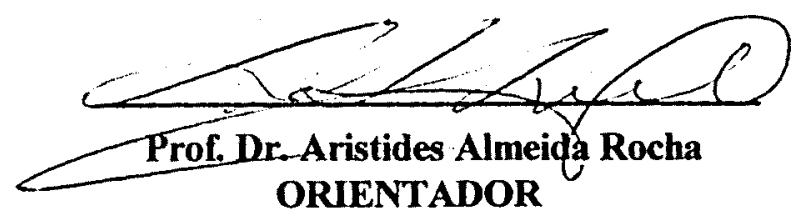




\section{ÍNDICE}

1. INTRODUÇÃO

2. ÁREA DE ESTUDO

3. OBJETIVOS

4. MATERIAIS, MÉTODOS E ESTRATÉGIA DE ESTUDO

4.1. COMUNIDADE FITOPLANCTOONICA

4.2. VARIÁVEIS ABIÓTICAS

4.3. TRATAMENTO DOS DADOS

4.3.1. ÍNDICE DE PERSISTENCIA DAS ESPÉCIES

5. RESULTADOS

5.1. ASPECTOS CLIMATOLÓGICOS

5.2. QUALIDADE ABIÓTICA DA ÁGUA

5.3. COMUNIDADE FTTOPLANCTOONICA DA REPRESA DE GUARAPIRANGA

5.3.1. COMPOSIÇÃO

5.3.2. FREQUÊNCIA DE OCORRÊNCIA

5.3.3. CARACTERISTICAS MORFOLÓGICAS FUNCIONAIS OUESTRATÉGIAS ADAPTATIVAS 533.1. DMENSÃODOS ORGANISMOS: ANÁL LSEDA VARIACX̃OOENTRE ASESPÉCIES 53.3.2. DIMENSÃO DOS ORGANISMOS - ANÁLISE DA VARIAÇÃO TEMPORAL 53.3.3. ANÁLISE DA MOTIIDADE

5.3.3.4. ANÁLUSE DAS FORMAS

5335. ANÁLISE DO ENVOLTORIOOUPAREDE CELULAR

5.3.4. DENSIDADE BIOÁREA, BIOVOLUME E DOMINÂNCIA

5.3.4.1. TOTAL GERAL 51

53.4.2 VARIAÇÃO TEMPORALDADOMINÂNCIA

5.3.5. RIQUEZA, DIVERSIDADE, UNIFORMIDADE E TAXAS DE ALTERAÇÃO
DA COMUNIDADE

5.3.6. RELAÇŌES ENTRE O FITOPLÂNCTON E A QUALIDADE ABIÓTICA DA

ÁGUA

5.3.7. SAZONALIDADE

5.3.8. ANÁLISE DOS COMPONENTES PRINCIPAIS

\begin{tabular}{ll} 
5.3.9. TESTE DE HENDRICKSON & 72 \\
\hline
\end{tabular}

6. DISCUSSÃO

5.3.10. INDICE DE PERSISTÊNCIA DAS ESPÉCIES

6.1. QUALIDADE AMBIENTAL ABIÓTICA

\begin{tabular}{l} 
6.2. COMUNIDADE FITOPLANCTÓNICA \\
\hline
\end{tabular}

6.2.1. METODOLOGIAS DE AVALIAÇÕES QUANTTTATIVAS

6.2.2. COMPOSIÇÃO FLORISTICA

6.2.3. ESTRATÉGIAS ADAPTATIVAS E A SEQUENCIA DE DOMINÂNCIA

6.2.4. CARACTERISTICAS DA COMUNIDADE FITOPLANCTÔNICA

6.2.5. DISTRIBUIÇÃO ESPACIAL

$\begin{array}{ll}\text { 6.2.6. SAZONALIDADE } & 104\end{array}$

6.2.6.1. SAZONALIDADE DO FITOPLÂNCTON E TEORIAS ECOLÓGICAS

6.26.1.1. TEORIA DO EQUII IBRRO-HIPÓTESE RAZAO-RECURSO

6.6.12 TEORIA DO NÃO EQUILIBRIO-HIPÓTESE DO DISTÚRBIO INTERMEDIÁRم 122

6.2.7. HOMOGENEIDADE DO NÚMERO DE ESPÉCIES E DA TAXOCENOSE

6.2.8. ESTABILIDADE DA COMUNIDADE $\quad 125$

6.3. ANÁLISE INTEGRADA: COMPONENTES PRINCIPAIS (VARIÁVEIS AMBIENTAIS) E ESPÉCIES
MAIS REPRESENTATIVAS DA COMUNIDADE FITOPLANCTÓNICA

6.4. ASPECTOS SANTTÁRIOS

6.4.1. QUALIDADE ABIÓTICA DA ÁGUA

6.4.2. ESPÉCIES INDICADORAS DA QUALIDADE AMBIENTAL $\quad 134$

6.4.3. ALGAS POTENCIALMENTE PREJUDICIAIS AOS USOS DA ÁGUA 6.4.3.1. CIANOFICEAS

6.4.4. INDICADORES PRÉVIOS DO DESENVOLVIMENTO EXCESSIVO DO FITOPLÂNCTON
E DAS CIANOFICEAS

6.4.5. ALGAS POTENCIALMENTE PREJUDICIAIS AO TRATAMENTO DA ÁGUA
PARA ABASTECIMENTO

$\begin{array}{ll}\text { 6.4.6. CONTROLE ALGÁCEO } & 161\end{array}$

7. SUBSIDIOS E MEDIDAS PARA REABILITAÇÃO DA QUALIDADE AMBIENTAL 164

8. UTILIZAÇÃO E APROVEITAMENTO ECONÔMICO DA BIOMASSA ALGÁCEA 168

9. CONCLUSOOES $\quad 171$

$\begin{array}{ll}\text { 10. REFERENCIAS BIBLIOGRÁFICAS } & 176\end{array}$ 
1. OPERAÇÃO HIDRÁULICA DO SISTEMA DE GUARAPIRANGA A-1

2. BALANCYO HIDRICO 1991-92 A-2

3. VARIAÇÃO TEMPORAL DOS PARÂMETROS CLIMATOLÓGICOS E CONTROLE DE ALGAS A-3

4. VARIAÇÃO TEMPORAL DOS PARÂMETROS FÍSICOS E QUIMICOS - PONTO 1

5. VARIAÇÃO TEMPORAL DOS PARÂMETROS FISICOS E QUIMICOS - PONTO $4 \quad$ A-5.1 a A-5.2

6. CORRELAÇÕES ENTRE AS VARIÁVEIS ABIÓTICAS - PONTOS 1 e $4 \quad$ A-6.1 a A-6.6

7. CARACTERISTICAS DAS ESPÉCIES - PONTO 1 A-7

8. CARACTERISTICAS DAS ESPÉCIES - PONTO 4

9. CORRELAÇŐES ENTRE AS CARACTERISTICAS DAS ESPÉCIES - PONTOS 1 e 4

10. VARIAÇÃO TEMPORAL DAS CARACTERISTICAS DA COMUNIDADE FTIOPLANCTONNICA. PONTO 1 A-10

11. VARIAÇÃO TEMPORAL DA RIQUEZA DE ESPÉCIES DO FITOPLÂNCTON. PONTO $1 \quad$ A-11

12. VARIAÇÃO TEMPORAL DAS CARACTERISTICAS DA COMUNIDADE FITOPLANCTÓNICA. PONTO 4 A-12

13. VARIAÇÃO TEMPORAL DA RIQUEZA DE ESPÉCIES DO FITOPLÂNCTON - PONTO 4

14. VARIAÇÃO TEMPORAL DA DENSIDADE DO FITOPLÂNCTON- PONTO 1

15. VARIAÇÃO TEMPORAL DAS ESTRATÉGIAS DO FITOPLÂNCTON (DENSIDADE) - PONTO 1 A-15

16.VARIAÇÃO TEMPORAL DO BIOVOLUME DO FITOPLÂNCTON - PONTO $1 \quad$ A-16

17. VARIAÇÃO TEMPORAL DAS ESTRATÉGIAS DO FITOPLÂNCTON (BIOVOLUME) - PONTO $1 \quad$ A-17

18. VARIAÇÃO TEMPORAL DA DENSIDADE DO FITOPLÂNCTON-PONTO 4

19. VARIAÇÃO TEMPORAL DAS ESTRATÉGIAS DO FTTOPLÂNCTON (DENSIDADE) - PONTO 4

20. VARIAÇÃO TEMPORAL DO BIOVOLUME DO FITOPLÂNCTON - PONTO $4 \quad$ A-20

21. VARIAÇÃO TEMPORAL DAS ESTRATÉGIAS DO FITOPLÂNCTON (BIOVOLUME) - PONTO $4 \quad$ A-21

22. CORRELAÇÕES ENTRE AS VARIÁVEIS ABIÓTICAS E AS DO FTTOPLÂNCTON - PONTO 1 A-22

23. CORRELAÇÕES ENTRE AS VARIÁVEIS ABIÓTICAS E AS DO FITOPLÂNCTON - PONTO 1

24. CORRELAÇÕES ENTRE AS VARIÁVEIS ABIÓTICAS E AS DO FITOPLÂNCTON - PONTO 4 A-24

25. CORRELAÇð̋ES ENTRE AS VARIÁVEIS ABIÓTICAS E AS DO FITOPLÂNCTON - PONTO 4 A-25

26. RESULTADOS DA ANÁLISE DE COMPONENTES PRINCIPAIS - PONTO 1 A-26

27. RESULTADOS DA ANÁLISE DE COMPONENTES PRINCIPAIS - PONTO 4

28. RESULTADOS DO TESTE DE HENDRICKSON A-28

29. VARIAÇÃO TEMPORAL DA DENSIDADE DAS ESPÉCIES EM FREQUEANCIA RELATIVA-PONTO 1 A-29

30. VARIAÇÃO TEMPORAL DO BIOVOLUME DASESPÉCIES EM FREQUENCIA RELATIVA-PONTO 1 A-30

31. VARIAÇÃO TEMPORAL DA DENSIDADE DAS ESPÉCIES EM FREQUENCCTA REIATTVA-PONTO 4 A-31

32. VARIAÇÃO TEMPORAL DO BOVOLUME DAS ESPÉCIES EM FREQUENNCIA RELATIVA-PONTO4 4 A-32

33. DOMINÂNCIA, ABUNDÂNCIA E OCORRENCIA MAIS EXPRESSSIVAS NO FTTOPLÂNCTON A-33

34. MEDIANAS DOS PARÂMETROS FISICOS E QUIMICOS A-34

35. MEDIANAS DOS PARÂMETROS BIOLÓGICOS. PONTO 1 A-35

36. MEDIANAS DOS PARÂMETROS BIOLÓGICOS. PONTO $4 \quad$ A-36 


\section{FIGURAS}

1. AMÉRICA dO SUL, BRASIL, SÃo PAULO, GRANDE SÃo PAULO E RÊdE HIDROGRÁFICA DO ESTADO DE SÃO PAULO

FIGURA 1

2. REPRESA DE GUARAPIRANGA - IMAGEM DE SATÉLITE - ÁREA URBANA

FIGURA 2

3. REPRESA DE GUARAPIRANGA - DEMARCAÇÃO DOS PONTOS DE COLETA

FIGURA 3

4. REPRESA DE GUARAPIRANGA - DIAGRAMAS CLIMÁTICOS DE 1991 -1992

FIGURA 4

5. REPRESA DE GUARAPIRANGA - BALANÇO HIDRICO

FIGURA 5

6. DISTRIBUIÇÃO TEMPORAL DAS CLASSES DE TAMANHO DAS ESPÉCIES DO PONTO 1

FIGURA 6

7. DISTRIBUIÇÃO TEMPORAL DAS CLASSES DE TAMANHO DAS ESPÉCIES DO PONTO 4

FIGURA 7

8. DISTRIBUIÇÃO TEMPORAL DOS ÍNDICES DA ESTRUTURA DA COMUNIDADE FITOPLANCTÔNICA DO PONTO 1

FIGURA 8

9. DISTRIBUIÇÃO TEMPORAL DOS fNDICES DA ESTRUTURA DA COMUNIDADE FITOPLANCTÓNICA DO PONTO 4

FIGURA 9

10. DISTRIBUIÇÃO TEMPORAL DOS GRUPOS SISTEMÁTICOS DO PONTO 1

FIGURA 10

11. DISTRIBUIÇÃO TEMPORAL DOS GRUPOS SISTEMÁTICOS DO PONTO 4

FIGURA 11

12. QUADRO-RESUMO DA DINÂMICA TEMPORAL DA COMUNIDADE

FITOPLANCTONNICA DO PONTO 1

FIGURA 12

13. QUADRO-RESUMO DA DINÂMICA TEMPORAL DA COMUNIDADE

FITOPLANCTÓNICA DO PONTO 4

FIGURA 13

14. ANÁLISE DOS COMPONENTES PRINCIPAIS

- VARIÁVEIS AMBIENTAIS DO PONTO 1

FIGURA 14

15. ANÁLISE DOS COMPONENTES PRINCIPAIS, POSIÇÃO DAS CAMPANHAS

FIGURA 15

16. ANÁLISE DOS COMPONENTES PRNCIPAIS

- VARIÁVEIS AMBIENTAIS DO PONTO 4

FIGURA 16

17. ANÁLISE DOS COMPONENTES PRINCIPAIS, POSIÇðO DAS CAMPANHAS

FIGURA 17

18. QUADRO RESUMO DA DINÂMICA TEMPORAL - POR COLETAS - DA COMUNIDADE

FITOPLANCTÓNICA DA REPRESA DE GUARAPIRANGA, 1991-92. PONTO 1. FIGURA 18 19. QUADRO RESUMO DA DINÂMICA TEMPORAL - POR COLETAS - DA COMUNIDADE

FITOPLANCTÓNICA DA REPRESA DE GUARAPIRANGA, 1991-92. PONTO 4. FIGURA 19

20. ANÁLISE DAS FLORAÇŐES. PONTO 1

FIGURA 20

21. ANÁLISE DAS FLORAÇÕES. PONTO 1

FIGURA 21

22. IMAGENS DE ALGUMAS ESPÉCIES DE ALGAS ENCONTRADAS NA

REPRESA DE GUARAPIRANGA $1991-92$

FIGURA 22 


\section{INTRODUÇÃO}

As algas do fitoplâncton constituem o primeiro elo da cadeia alimentar planctônica e ao lado das macrófitas aquáticas e algas do perifiton iniciam a fase biológica do ciclo dos nutrientes nos ambientes aquáticos, permitindo seu ingresso na cadeia alimentar. Produzem parte considerável do oxigênio dissolvido na água, essencial aos organismos aeróbios, além de prover alimento para os consumidores primários incluindo protozoários, insetos, organismos do zooplâncton e peixes, servindo ainda aos organismos da cadeia detritivora tais como virus, bactérias e fungos, tanto de substrato como de alimento. Dois terços da superfície terrestre são cobertos por água e como o fitoplâncton é a vegetação das águas superficiais, torna-se responsável pela produção primária na maior parte da superficie terrestre. Segundo Reynolds (1993) a produção primária planctônica repõe atualmente cerca de $70 \%$ do oxigênio do planeta.

A produtividade primária nos ambientes aquáticos reflete imediatamente o grau de eutrofização da água, resultante da poluição atmosférica, da contribuição dos tributários e do uso e ocupação das bacias de captação, pois ao lado dos organismos da cadeia detritívora, as algas e as macrófitas livre-flutuantes são os primeiros organismos a assimilarem nutrientes e contaminantes diretamente da água. As algas são os produtores primários mais significativos nos ambientes em que predomina a água aberta, ou seja, sem influência acentuada das margens.

Segundo Rocha (1992), cada espécie de alga está relacionada a outras espécies e requer diferentes características estruturais, fisicas, químicas e biológicas intrínsecas ao seu habitat. Quanto maior a complexidade da cadeia alimentar, mais tamponada ou estabilizada será a comunidade, protegida contra alterações ambientais que promovam flutuações no tamanho das populações (Price, 1973, apud Rocha, 1992). Teoricamente uma maior diversidade do fitoplâncton torna disponivel uma maior variedade alimentar para os elos superiores da cadeia trófica, permitindo maior complexidade das relações intra- e inter-específicas no ambiente aquático e o sustento de uma fauna mais diversificada.

A análise da estrutura desta comunidade, principalmente em represas, permite avaliar os efeitos de alterações ambientais, inclusive das originadas por atividades antrópicas desenvolvidas nas bacias de drenagem destes corpos d'água.

A região sul do Brasil, especialmente São Paulo e neste estado a região denominada Grande São Paulo, por concentrar uma das maiores economias do pais, foi alvo de intensa migração interna e de origem externa ao país desde o século passado. A partir da década de 50 
a migração interna intensificou-se mais ainda, desencadeando um processo acelerado de ocupação, sem planejamento e infra-estrutura quanto aos aspectos de saneamento básico e do uso e ocupação do solo.

O estado de São Paulo tem uma rede hidrográfica extremamente rica, na qual destaca-se o rio Tietê, tanto pela extensão, quanto pela presença de inúmeros afluentes e das grandes cidades situadas ao longo de seu percurso.

Nos fins do século passado e início do atual, a abundância de corpos d'água em relação à densidade populacional levou as autoridades responsáveis a superestimarem o potencial de autodepuração dos corpos d'água, destinando-os à recepção de esgotos domésticos e industriais, havendo pouca preocupação em garantir e preservar a qualidade das águas nas regiōes próximas da cidade de São Paulo. Várias represas construídas para exploração energética tornaram-se depositárias dos esgotos da cidade, entre elas a Billings e Isolina, que evidenciam atualmente os problemas de poluição gerados por esta política de utilização dos corpos d'água.

Os hábitos culturais e religiosos das três principais raças formadoras de nossa população, incluem a crença na purificação através da água, tanto material como espiritual, que alia-se à idéia de que a água é um recurso inesgotável, capaz de assimilar a deposição de toda sorte de rejeitos, resultando em comportamentos e hábitos da população que também contribuem para a deterioração da qualidade de nossos ecossistemas aquáticos.

Os problemas decorrentes destas formas de utilização alcançaram uma dimensão tão grande nos últimos anos, que as instituições governamentais não tem conseguido efetuar qualquer processo de melhoramento efetivo de grande porte nas represas localizadas em áreas urbanizadas.

Atualmente ocorrem deficiências no abastecimento de água para a população em caso de queda prolongada na pluviosidade e esporadicamente por dificuldades de manejo das represas que estão com a qualidade da água comprometida. As dificuldades no abastecimento, reportadas por Helou e Silva (1988) decorrem de alguns fatores como: falhas nos equipamentos de adução e distribuição, redução na disponibilidade de potência dos equipamentos de adução, variações na demanda e erros na sua previsão, bem como da dificuldade ou até impossibilidade de tratamento, decorrente de altos niveis de poluição no manancial utilizado.

A necessidade crescente de água para o abastecimento faz com que os recursos hídricos da bacia do Alto Tietê tornem-se insuficientes para seu atendimento, notando-se a 
impossibilidade de utilizar novas fontes de qualidade adequada e em maior escala, o que leva à opção pela busca de recursos hídricos em regiões mais distantes e, portanto, a um maior custo ambiental, político e econômico. Ao sul das regiões mais próximas à Grande São Paulo, estes recursos encontram-se na direção da Serra do Mar e portanto na Mata Atlântica, em rios que ao atingirem a baixada litorânea, integram os sistemas de manguezais. A Mata Atlântica e os manguezais paulistas são ambientes que já correm sérios riscos, quanto à sua própria existência e conservação. Este risco amplia-se com a expansão e o estabelecimento de povoamentos.

Experiências como a construção da Estrada dos Imigrantes, na própria Serra do Mar, mostram que tão logo haja oferta de emprego na construção civil e estradas de acesso, imediatamente novos povoados se estabelecem, independente da existência de infraestrutura básica necessária. Desta forma, também durante a construção de barragens e implantação de sistemas de represas, a formação de novos núcleos habitacionais e a expansão dos já existentes, constituem um risco considerável em áreas ambientalmente frágeis e que deveriam ser protegidas.

A decisão de recuperar ou preservar bacias hidrográficas, destinadas ou não ao abastecimento, pode implicar em altos custos, envolvendo profundas modificações em situações já estabelecidas e a necessidade de impedir distorções quanto ao uso e ocupação do solo. Entretanto, o custo operacional necessário ao tratamento da água de represas poluídas e para a obtenção de água proveniente de regiőes mais distantes, pode ser muito superior ao custo da reabilitação ou recuperação da qualidade da água das represas já existentes. A viabilidade da recuperação depende de um desempenho político responsável, a longo prazo, envolvendo ações que devem ser realizadas a partir do estabelecimento de prioridades distribuidas adequadamente ao longo do tempo e que envolvam a participação da população.

Em vista das condições relatadas é necessário e urgente investir em pesquisa, para criação de tecnologias adequadas à cada região, possibilitando a ampliação do período de utilidade das represas já existentes, otimizando a produção de cada sistema e maximizando a obtenção de água. A represa de Guarapiranga é um exemplo das situações mencionadas, podendo servir como modelo para o desenvolvimento de novas tecnologias de recuperação e preservação da qualidade deste recurso. A evolução da qualidade da água neste reservatório reflete a tendência de evolução da qualidade de vida das populações instaladas em sua bacia e esta situação é comum às outras represas em condições semelhantes.

Embora já existam planos formulados, destinados ao aproveitamento da água do Sistema Capivari-Monos por bombeamento e reversão do fluxo da água deste sistema para a 
Guarapiranga, um estudo mais profundo das condições atuais relacionando a qualidade da água com a comunidade fitoplanctônica pode orientar previsões sobre as respostas do sistema, tanto em função da diluição e do aumento do potencial do sistema, quanto de outras alterações que venham a ocorrer com o novo aporte. Se o processo de eutrofização não declinar, pode-se prever que em alguns anos, mesmo a diluição, decorrente do aumento nos aportes de água, seja insuficiente para manter a qualidade necessária ao consumo humano.

Este estudo sobre a comunidade fitoplanctônica pretende contribuir para ampliar o conhecimento existente sobre esta represa, fornecendo subsídios para a proposição de novas tecnologias de manejo e conservação. Faz parte de um estudo mais amplo desenvolvido ao longo de todo um ciclo sazonal, no qual também foram obtidos dados físicos, químicos (Caleffi e col., 1994; Beyruth e col., no prelo); bacteriológicos (dados inéditos) e da comunidade zooplanctônica (Caleffi, 1994).

O principal problema ambiental da represa de Guarapiranga é sua eutrofização. $O$ desenvolvimento excessivo desta comunidade em ambientes submetidos à eutrofização acelerada, tem sido um dos principais problemas para os diversos usos das águas. A queda da qualidade da água gera deficiências no abastecimento e uma das mais graves conseqüências da eutrofização acelerada nesta represa, tem sido o aumento da população algácea, tanto pelas dificuldades que gera ao tratamento, como pela qualidade inadequada ao consumo do produto final.

Em águas eutrofizadas podem ocorrer florações de algas, que produzem mau aspecto, aumento da turbidez, sendo ainda comum a ocorrência de sabor e odor característico de algumas espécies (Chaves, 1978; Branco, 1986 e Beyruth e col., 1992) e do proveniente da oxidação da matéria orgânica durante a decomposição da sua biomassa, havendo também a possibilidade de produção de toxinas, uma vez que há linhagens de algumas espécies de algas, especialmente de cianoficeas, responsáveis pela sua produção (Olson, 1952; Palmer, 1960; Gorham, 1964, 1965; Hammer, 1968; Darley, 1982; Margalef, 1983; Bold e Wine, 1985 e Beyruth e col., 1992). Além disto, a presença de floraçð̃es pode causar a mortandade de peixes, tanto devido à deficiência de oxigênio que se instala após o colapso da floração, como devido à presença de toxinas. A abundância de algumas espécies de algas dificulta o tratamento da água destinada ao abastecimento por causarem entupimento de filtros. Estes impedimentos acarretam aumento do custo operacional e do tempo dispendido no tratamento, incluindo problemas para os quais ainda não há solução viável em termos financeiros e de esforço, como por exemplo, a remoção do sabor e das toxinas. 
Uma das maiores dificuldades na utilização de algas como indicadores de poluição é sua identificação no nível de espécie (Rocha, 1992). Em estudos sanitários o fitoplâncton é de importância fundamental como indicativo da qualidade da água e possibilita a realização de previsões a partir de alterações ambientais. Se o estudo for realizado até o nível de espécie, a qualidade da informação adquirida amplia-se consideravelmente, pois as espécies fitoplanctônicas podem servir para indicar desde a qualidade do produto água para abastecimento até o grau de dificuldade apresentado para o tratamento da água bruta, o potencial de produção de toxinas algáceas e a possibilidade de manejo através da biomanipulação utilizando o fitoplâncton para manutenção de um nível satisfatório de qualidade, tanto sob os aspectos de eutrofização como da limitação dos níveis de toxicidade biogênica natural (de origem algácea) e/ou artificial (de origem antrópica - p.ex. metais pesados e biotóxicos). Permitem também a avaliação da capacidade de bioacumulação de substâncias tóxicas pelas espécies indicadoras, cujo exame informa sobre a toxicidade potencial para o ecossistema.

Os estudos taxonômicos do fitoplâncton possibilitam maior precisão na avaliação da possibilidade do cultivo das espécies, cuja produção intensiva permita sustentar aquiculturas de interesse econômico, como a piscicultura e/ou de interesse sanitário, bem como a exportação de nutrientes e a oligotrofização da água. Possibilita também a utilização de espécies que participem ativamente nos processos de autodepuração e que subsidiem outras formas de manejo destinadas ao melhor aproveitamento dos recursos disponiveis e à reabilitação da qualidade desta água para os diversos usos, inclusive para consumo humano.

O potencial reprodutivo e a biomassa são aspectos importantes a considerar nas avaliações quantitativas do fitoplâncton. $O$ potencial reprodutivo pode ser avaliado pelo número de células presentes, uma vez que a maior parte das células das algas, apresenta capacidade de reprodução vegetativa, por divisão celular. A biomassa pode ser estimada através do biovolume de cada espécie, sendo imprescindível em estudos sanitários de águas destinadas ao abastecimento, por ser de imediata aplicação na avaliação da eficiência da decantação, dos processos de filtração e aplicação de produtos químicos durante os processos de tratamento.

Uma das principais dificuldades das empresas encarregadas do controle ambiental ou empresas de consultoria, quanto ao estudo quantitativo do fitoplâncton, são provocadas pela ausência de normas técnicas metodológicas específicas ao estudo com enfoque sanitário. Desta forma, a comparação entre métodos quantitativos de análise do fitoplâncton pode contribuir para o esclarecimento de alguns problemas laboratoriais rotineiros. 
O desenvolvimento algáceo excessivo em lagos e represas promove problemas na utilização da água tanto para consumo humano, por promover sabor e odor desagradáveis e pelo potencial de toxicidade como para alguns tipos de consumo industrial, por impedir que a qualidade da água oferecida seja satisfatória. Além disto, também ocorrem efeitos deletérios aos usos para a recreação e a pesca. Estes problemas geram um aumento considerável nos custos econômicos e sociais das comunidades usuárias, além de restringir os aspectos de utilização para recreação, contato primário e paisagístico. A propósito, nos últimos anos houve um declínio considerável do número de sócios e freqüentadores dos clubes situados às margens da represa de Guarapiranga, devido à poluição das águas, o que levou alguns diretores de clubes a apoiarem a pesquisa de campo neste trabalho.

As poderosas pressões econômicas e sociais, decorrentes de problemas de abastecimento de água, tornam necessária e urgente a compreensão dos fatores que regulam as variações na distribuição e produtividade do fitoplâncton, espacial e temporalmente (Reynolds, 1993).

A urgência de providências freqüentemente tem induzido pesquisadores e técnicos, responsáveis pelo manejo de reservatórios, a concentrarem esforços e atenção na utilização de medidas restritivas do desenvolvimento algáceo através do emprego de algicidas, em detrimento do controle das causas da eutrofização. Estas medidas envolvem interferências na própria represa, tais como a utilização do sulfato de cobre, que pode acarretar prejuizos às comunidades aquáticas e aos usos das águas. As águas da região de São Paulo, são caracterizadas como muito moles ou moles, pelos padrões de dureza e alcalinidade, podendo com isto acarretar o aumento da toxicidade do cobre para organismos aquáticos, inclusive peixes, conforme descrito em Damato e col. (1989). Estes autores relatam também a toxicidade do cobre para crustáceos e moluscos, que com as algas fazem parte da dieta alimentar de peixes, portanto o uso deste produto pode ter consequiências deletérias para a cadeia trófica. Além disto, a água pode tornar-se impalatável quando a concentração de cobre ultrapassar $5 \mathrm{mg} \cdot \mathrm{I}^{-1}$ (Branco, 1986).

De forma geral, o controle preventivo dos problemas de tratamento, de acordo com a disponibilidade financeira e tecnológica, tem enfocado principalmente a exploração da heterogeneidade espacial, a regulação do período de residência da água, o controle da população algácea, a mistura artificial da água, bem como a otimização da produção de biomassa utilizável. Porém, enquanto permanecerem as condições que promovem a eutrofização acelerada, a probabilidade de fracasso permanece alta. 
Estudos mais aprofundados sobre a comunidade fitoplanctônica e suas relações com 0 ambiente podem proporcionar subsídios para programas de proteção e até mesmo de recuperação de mananciais (Rocha, 1984).

A estratégia de desenvolvimento de um ecossistema, ou seja, sua sucessão ecológica pode ser definida como um processo ordenado de desenvolvimento das comunidades, envolvendo alterações na estrutura e nos processos da comunidade ao longo do tempo, sendo direcional e portanto previsível, segundo Odum (1971). Resulta na modificação do ambiente pela comunidade e embora as alterações fisicas do ambiente determinem o padrão e o ritmo das alterações, impondo com freqüência limites à possibilidade de desenvolvimento biológico, este processo culmina num ecossistema estabilizado, capaz de manter por unidade de energia disponivel, a máxima biomassa, o máximo conteúdo de informação (diversidade) e a função simbiótica entre organismos.

Na sucessão autogênica, as mudanças sucessivas decorrem da ação da própria bióta sobre o habitat e na sucessão alogênica, as mudanças decorrem dos efeitos de fatores externos (Tansley, 1935 apud Drury e Nisbet, 1973).

Num ambiente tão sujeito a alterações alogênicas como a represa de Guarapiranga, dificilmente a comunidade fitoplanctônica teria condições de apresentar processos autogênicos efetivos de sucessão. As principais perturbações ambientais esperadas nesta represa são geradas pelos efeitos das alterações climáticas, variações nos aportes de nutrientes e operação hidráulica da represa.

O tempo de geração das algas pode ser de algumas horas até alguns dias (Eppley, 1972 apud Harris, 1986). Esta escala de tempo e a freqüência das perturbações ambientais previsiveis, permitem a investigação de hipóteses ecológicas que consideram interações entre a comunidade fitoplanctônica e as variáveis ambientais.

Os aspectos ecológicos foram então discutidos a partir das teorias do equilibrio - Hipótese Razão-Recurso (Tilman, 1985, Tilman e col., 1982) e do não equilíbrio - Hipótese do Distúrbio Intermediário (Sommer e col. 1993). Além disso investigou-se a possibilidade de aplicar os testes destas hipóteses para detectar indicadores prévios da ocorrência de florações ou desenvolvimento abundante de cianoficeas. Estas hipóteses constituem as duas linhas mestras da maior parte dos estudos sobre as relações entre as comunidades vegetais e seu ambiente, por proverem informações extremamente úteis, tanto para a ampliar o conhecimento da dinâmica das interações organismos e ambiente, como por fornecerem subsídios para decisões de manejo ambiental. Estas hipóteses estão entre as mais utilizadas em investigações 
do fitoplâncton, apresentando-se bem consolidadas na literatura ecológica. Além disso os testes destas hipóteses são aplicáveis aos dados obtidos neste estudo.

A unidade taxonômica - espécie - pode não estar diretamente vinculada com a unidade ecológica - nicho (Allen e Starr, 1982, apud Harris, 1986). A aparente ausência de diversificação de nicho entre espécies, especialmente nos ambientes aquáticos de água aberta, pode indicar tanto a falta de medida adequada do nicho, como a possibilidade do compartimento taxonômico utilizado não estar correspondendo a uma entidade ecológica significativa.

As dificuldades taxonômicas encontradas em trabalhos de identificação de espécies de comunidades complexas, como é o caso da represa de Guarapiranga, também devem ser consideradas. Desta forma, tamanho de célula, taxa de crescimento ou velocidade de sedimentação poderiam constituir melhores critérios ecológicos para a compreensão da dinâmica da comunidade em relação ao ambiente. Para permitir esta investigação, as análises foram efetuadas quanto às dimensões celulares e número de células, permitindo estimar o potencial de crescimento vegetativo; investigou-se também as diversas estruturas adaptativas apresentadas pelas espécies, indicativas da capacidade de aproveitamento dos recursos e da estratégia de sobrevivência favorecida em cada período ou condiçăo ambiental.

A análise da alteração da comunidade correlacionada às variáveis ambientais, fornece informações sobre os fatores preponderantes na limitação da comunidade num determinado ambiente e para o caso do fitoplâncton, mostra quanto da variância da alteração nesta comunidade pode ser atribuída à variaçðes climáticas, no suprimento de recursos e à atividade dos consumidores primários. Por tratar-se de uma informação excelente no caso de necessidade de manejo ambiental, este estudo abrangeu tal análise, investigando quais os fatores mais importantes na determinação dos padrões de alterações da comunidade fitoplanctônica neste reservatório. 


\section{2. ÁREA DE ESTUDO}

A represa de Guarapiranga faz parte como sub-bacia, da bacia do Alto Tietê (Figura 1), ligando-se a esta através do canal do rio Pinheiros (Figura 2). Localiza-se a $23^{\circ} 43^{\prime} \mathrm{S}$ e $46^{\circ} 32^{\prime}$ W a uma altitude de $742 \mathrm{~m}$. A área inundada é de $33.981 \mathrm{~km}^{2}$ e a bacia contribuinte perfaz um total de $631.000 \mathrm{~km}^{2}$ (Santos e col., 1985).

Mancuso (1992) estimou para o período entre julho de 1987 e junho de 1988, que a represa recebia de seus contribuintes naturais $13.193 \mathrm{~m}^{3} . \mathrm{s}^{-1}$ de água e $0.465 \mathrm{~m}^{3} . \mathrm{s}^{-1}$ de esgoto doméstico, totalizando $13.604 \mathrm{~m}^{3} \cdot \mathrm{s}^{-1}$. Ou seja, $0.60 \%$ do volume médio da represa era reposto por dia, sendo que $3.42 \%$ deste valor era constituído por esgotos, cuja tendência nos últimos anos foi de elevar-se. Houve um aumento na concentração de poluentes provenientes dos córregos situados ao norte da bacia, junto à represa nas margens direita (córrego São José e rio Bonito) e esquerda (córregos Guavirutuba e Itupu), mas as contribuições dos rios Embumirim e Embu-guaçu não apresentaram alteração significativa em números absolutos quanto aos teores de fosfato total $\left(624 \mathrm{~kg} \cdot\right.$ dia $\left.^{-1}\right)$ e nitrogênio total $\left(158 \mathrm{~kg}^{-1 i a^{-1}}\right)$ entre 1982 e 1989 , COBRAPE (1991).

O nível operacional mínimo é de $726.37 \mathrm{~m}$ e o máximo é de $736.62 \mathrm{~m}$ (Helou e Silva, 1987). O nível máximo atinge $737.60 \mathrm{~m}$ e o mínimo $723.12 \mathrm{~m}$, a vazão afluente média é de $11.8 \mathrm{~m}^{3} \cdot \mathrm{s}^{-1}$, a vazão captada média entre 1972 e 1986 foi de $10.6 \mathrm{~m}^{3} . \mathrm{s}^{-1}$, o volume de armazenamento total é de $197631.10^{3} \mathrm{~m}^{3}$ e o volume de armazenamento útil é de $191610.10^{3}$ $\cdot \mathrm{m}^{3}$. O volume médio total é de $194643.10^{3} . \mathrm{m}^{3}$, sendo que o tempo de retenção médio, segundo a CETESB (1992), é de aproximadamente 110 a 143 dias, com alguma variação, considerando-se que neste cálculo não foram incluídas as contribuições da precipitação pluviométrica direta, a evaporação, a evapotranspiração das populações de macrófitas, as contribuições das águas carreadas e percoladas da bacia de drenagem, bem como as entradas de água subterrânea, mais difíceis de quantificar.

A superficie média do espelho d'água, para os níveis usuais é da ordem de $33 \mathrm{~km}^{2}$ e para o nivel máximo é de $35 \mathrm{~km}^{2}$ (COBRAPE, 1994). A profundidade máxima é de $13 \mathrm{~m}$, a média de $5.7 \mathrm{~m}$, o perímetro total é de $85 \mathrm{~km}$ (Kleerekoper, 1939). Desta forma, o índice de desenvolvimento das margens, que define a relação entre o perímetro das margens por área de espelho d'água ẻ de 4.05, quando o nível máximo é atingido.

A bacia da represa abrange os seguintes municípios da Grande São Paulo: São Paulo (211

$\mathrm{km}^{2}$ ), Itapecerica da Serra $\left(183 \mathrm{~km}^{2}\right)$, Embu-guaçu $\left(162 \mathrm{~km}^{2}\right)$, Embu $\left(41 \mathrm{~km}^{2}\right)$ e Cotia (33 $\mathrm{km}^{2}$ ), segundo Melchor e col. (1974). O município de São Paulo contorna toda a margem 
direita e mais da metade da margem esquerda da represa (70\% do perímetro), sendo o restante contornado pelos municípios de Embu-guaçu (27\%) e Itapecerica da Serra (3\%). Os municípios de Embu e Cotia embora participem da bacia de drenagem, não se limitam com suas margens. Seus principais tributários são os rios Embu-mirim, Embu-guaçu, das Lavras e Parelheiros, recebendo mais 50 riachos aproximadamente (Figura 2).

A represa foi construída no início do século, em 1906, pela barragem do rio Guarapiranga e de seus afluentes, com o objetivo de regularizar as vazões contribuintes e ampliar a produção de energia elétrica em Santana do Parnaíba (CETESB, 1991). Não houve desmatamento prévio ao seu preenchimento (Maier e Takino, 1985) e mergulhadores do corpo de bombeiros relatam que os troncos e galhadas ainda permanecem no fundo em algumas regiões da represa, apesar do tempo decorrido.

Em 1926 passou a servir ao abastecimento de água para a cidade de São Paulo e atualmente contribui com aproximadamente $25 \%$ dentre os principais reservatórios que abastecem a Região Metropolitana de São Paulo, suprindo cerca de 3.5 milhões de pessoas dos municípios de: São Paulo (21 bairros), Taboão da Serra, Osasco e Carapicuíba (Silva e col., 1986), o que perfaz 60\% da população da Região Metropolitana de São Paulo, sendo no presente, o segundo sistema produtor da Companhia de Saneamento Básico do Estado de São Paulo - SABESP (COBRAPE, 1991)

Suas finalidades atuais são descritas por Helou e Silva (1987) como abastecimento, controle de enchentes, geração de energia e recreação.

Atualmente tem uma vazão utilizada de $10.6 \mathrm{~m}^{3} \cdot \mathrm{s}^{-1}$, coincidente com sua vazão regularizada, recebendo desde 1972 uma contribuição adicional de $5001 . \mathrm{s}^{-1}$ do Alto Capivarí por bombeamento (Silva e col, 1986). Segundo Mancuso (1992), a vazão contribuinte calculada a partir das médias mensais do período entre julho de 1987 e junho de 1990, considerando a contribuição dos afluentes responsáveis por $89 \%$ do volume total, perfaz 13.79 $\mathrm{m}^{3} . \mathrm{s}^{-1}$, valor que engloba a contribuição natural e dos esgotos.

Os valores de volume de água utilizada variam em função da demanda e disponibilidade de água acumulada, porém quase a totalidade de suas águas destina-se ao abastecimento público, o restante sendo lançado através de um canal para o rio Pinheiros, quando há necéssidade, para o controle de enchentes (Figura 2).

A represa de Guarapiranga pode ser considerada polimítica em relação à mistura vertical anual, segundo Wright (1936). Essa mistura decorre principalmente da ação das correntes 
internas nos canais dos rios formadores e da ação dos ventos, mas também é influenciada pelos efeitos das atividades náuticas praticadas em suas águas (Branco e Rocha, 1977).

Segundo a classificação climática de Köeppen, a bacia hidrográfica encontra-se em sua maior extensão na categoria $\mathrm{Cfb}$, com regime climático do tipo úmido anual e temperaturas brandas (Santos e Santo Paulo, 1985). O clima de São Paulo (SP) quanto ao domínio climático, é mesotérmico brando, quanto ao sub-domínio climático, caracteriza-se como superúmido, na variedade climática apresenta sub-seca (entre junho e agosto), sendo do tipo tropical (Nimer, 1977). Kleerekoper (1939) refere-se a esta zona, onde situa-se a represa de Guarapiranga, como sub-tropical em que os meses de temperatura média baixa, coincidem com os de precipitação mínima.

Os índices pluviométricos anuais médios encontram-se em torno de 1350 e $1400 \mathrm{~mm}^{-a n o} \mathrm{o}^{-1}$ na área de estudo, mas em direção ao sul da bacia, elevam-se gradualmente atingindo 2000 mm.ano-1 ${ }^{-1}$ Estes altos índices aliados às características topográficas do solo, e do seu uso e ocupação, são fatores que agravam os processos erosivos, concentrados especialmente nas áreas degradadas pela remoção da vegetação e nas áreas de mineração de areia ao longo de seus tributários, especialmente o rio Embu-mirim, segundo Beyruth (1994b).

A umidade relativa média do ar é de $83 \%$, a temperatura média é de $17.8^{\circ} \mathrm{C}$, as médias mínimas diárias são de $13.8^{\circ} \mathrm{C}$ e as médias máximas são de $24.3^{\circ} \mathrm{C}$. O vento predominante é o sudoeste, porém os ventos são brandos em $90 \%$ do tempo segundo Melchor e col. (1974).

Segundo o artigo PARA SALVAR... (1992), as temperaturas não apresentam influência do calor da metrópole e a qualidade do ar é boa, entretanto num dia de intensa poluição atmosférica, durante uma das coletas, encontrou-se uma nuvem escura pairando sobre a água, diminuindo a visibilidade a ponto de impedir a navegação para montante, para o "terceiro lago" da represa. Esta situação pode tornar-se mais freqüente com o desmatamento acelerado que tem ocorrido à sua volta, tornando-a suscetivel a esse tipo de influências.

A topografia da bacia é bastante acidentada, especialmente a oeste. Seus pontos mais elevados encontram-se a aproximadamente $930 \mathrm{~m}$ e os mais baixos a $700 \mathrm{~m}$ (Melchor e col., 1974). O vale principal é fechado, caracterizando um reservatório de forma alongada; a Leste e ao Sul são encontradas algumas planícies margeando a represa. Estes autores reportam que a região é constituída por uma superficie plana a levemente inclinada, esculpida em micaxisto e gnaisses das formações pré-cambrianas regionais e esta peneplanície estende-se até as colinas tabuliformes da bacia sedimentar paulistana. A drenagem é dendrítica, padrão típico, desenvolvido sobre rochas de resistência uniforme ou em estruturas sedimentares horizontais. 
A morfologia de bacias de represas é usualmente dendrítica, estreita e alongada por serem geralmente formadas na base de bacias de drenagem e vales de rios, como é o caso, e desta forma contribui para a magnificação das influências do uso e ocupação do solo, segundo Wetzel (1990).

Dados do IBGE (1989), mostram que a população urbana ocupava 9,9 \% da área da bacia em 1988. A população dos municípios envolvidos duplicou da década de 80 para a de 90 e continua aumentando. Desta forma a bacia de drenagem deste reservatório sofre atualmente pressões intensas, originadas pela expansão das áreas urbanas. A Figura 3 mostra a extensão da mancha urbana em 1984.

Estima-se atualmente que a população da bacia seja superior a 577 mil habitantes (COBRAPE, 1991). Esta ocupação desenvolveu-se principalmente por uma população carente, desprovida de recursos próprios suficientes para instalação da infraestrutura sanitária mínima, que desta forma constrói favelas em loteamentos clandestinos, lançando seus dejetos diretamente nos corpos d'água desta bacia.

A situação agravou-se a partir do vigor da lei de proteção dos mananciais, pois as instituições governamentais responsáveis, com o intuito de dificultar a ocupação da bacia, não forneceram estruturas de saneamento básico suficientes. Para piorar este quadro, algumas indústrias também instalaram-se nesta região, lançando a maior parte de seus efluentes "in natura" para os rios. Outra importante contribuição para a deterioração da qualidade da água é a extração mineral, destacando-se a mineração de areia exercida nas margens de alguns tributários da represa (COBRAPE, 1991), causando desmatamento, erosão e assoreamento, contribuindo para urbanização, pela oferta de empregos na extração e comercialização do produto, Beyruth (1994b). Os efeitos da deterioração ambiental também são percebidos através da queda da diversidade da fauna ictiica, segundo relatos dos pescadores da região, levando à dominância acentuada de peixes de pequeno porte, sem valor comercial, que tornouse perceptivel a partir da década de 80.

Palmer (1960), em estudos sobre o fitoplâncton da represa, já naquela época alertava para os riscos da eutrofização em decorrência do aumento da população instalada na bacia de drenagem, que se aliada a um decréscimo da turbidez, poderia alterar profundamente o desenvolvimento da população algácea, que em condições propícias quanto ao teor de nutrientes e iluminação, proliferaria excessivamente, causando sabor e odor à água, redução da velocidade de filtração e diminuição do periodo de detenção do cloro residual no sistema de distribuição. Este autor ressalta que a queda decorrente da eficiência do tratamento, pode 
transformar estes organismos em fontes de nutrientes para o desenvolvimento de organismos heterótrofos na tubulação.

O declínio da qualidade da água da represa de Guarapiranga começou a ficar evidente na década de 70, segundo os relatórios da qualidade das águas da CETESB. Rocha (1984), após estudos na represa, também alertava para o crescente processo de eutrofização e vaticinava sobre o futuro incremento de processos de floração de algas.

No início da década de 80 , florações de algas passaram a influenciar o processo de tratamento da água destinada ao abastecimento, causando entupimento de filtros e lentidão na filtração, comprometendo a qualidade do produto final, conferindo-lhe sabor e odor desagradáveis e induzindo a deficiências no suprimento. Há relatos de que o custo dos produtos químicos lançados na represa para controle algáceo, perfaziam U\$ 1000000.00 por ano na década de 80 e atualmente atinge a cifra de U\$8400000.00, correspondendo a $25 \%$ do custo total de produtos químicos aplicados para potabilizar a água (COBRAPE, 1995).

Em 1990 houve um surto de gastroenterite, associado por consumidores e médicos (comunic. pessoal) à ingestão da água da Guarapiranga, que apresentava alta densidade de Anabaena solitaria (Figura 16), uma cianoficea potencialmente produtora de toxinas, inviabilizando o tratamento adequado através dos métodos convencionais (Beyruth e col., 1992). Para a remoção das toxinas e do sabor e odor, a quantidade de carvão, necessária ao tratamento, seria tão grande que inviabilizaria o tratamento, devido ao custo e à estrutura oferecida pelas estações de tratamento (comunic. pessoal do Dr. Pedro Sanches Mancuso, responsável, na época, pelos laboratórios da SABESP).

Segundo Mancuso (1992) a alta densidade do fitoplâncton constitui o principal problema desta represa quanto ao tratamento da água. A freqüência de florações algáceas agrupada em períodos de 5 anos é a seguinte:

\begin{tabular}{|lcl|}
\hline PERÍODO & FREQÜÊNCIA & GRUPO DE ALGAS \\
$1972-1976$ & 02 & DIATOMÁCEAS \\
$1977-1981$ & 03 & CIANOFÍCEAS \\
$1982-1986$ & 07 & CIANOFÍCEAS E CLOROFÍCEAS \\
$1987-1991$ & 08 & CLOROFÍCEAS, DIATOMÁCEAS \\
& & E CIANOFÍCEAS \\
\hline
\end{tabular}


Entretanto, somente a partir de 1982 este fenômeno passou a ser recorrente. Desde então, os episódios mais críticos de florações têm sido registrados na estiagem e no verão:

\begin{tabular}{|c|c|c|c|}
\hline ANO & MÊS & $\begin{array}{l}\text { ORGANISMOS PREDOMINANTES } \\
\left(>2000 \text { UPA.ML }^{-1}\right)\end{array}$ & EFEITO \\
\hline 1982 & 10 a 12 & Anabaena sp & sabor, odor, oclusão de filtros \\
\hline 1983 & 01 a 04 & Anabaena sp & sabor, odor, oclusão de filtros \\
\hline 1984 & 04 & Synedra sp Rhizosolenia sp & oclusão de filtros \\
\hline 1988 & 08 & Mougeotia sp & queda na taxa de filtração \\
\hline 1989 & 06 e 07 & Synedra sp & oclusão de filtros \\
\hline \multirow[t]{2}{*}{1991} & 01 e 02 & Dictyosphaerium $\mathrm{sp}$ & \\
\hline & & Oscillatoria quadripunctulata & sabor e odor \\
\hline
\end{tabular}

Destes quadros pode-se concluir que o número de ocorrências de florações tem aumentado significativamente, advertindo para as conseqüências da continuidade dos processos de degradação.

O emprego do sulfato de cobre para controle da população algácea intensificou-se, especialmente a partir da primeira floração de Anabaena solitaria ocorrida nos últimos meses de 1990 (Beyruth e col., 1992). A aplicação do sulfato de cobre tem sido feita em quantidades que aumentam em progressão geométrica, passando de 1.5 toneladas em 1981 para 123.0 toneladas em 1982 e 63.0 toneladas apenas no primeiro trimestre de 1983 (CETESB, 1983). Em agosto de 1992 a SABESP passou a utilizar peróxido de hidrogênio para o controle das cianoficeas, porém há relatos de que já se avolumam as densidades de algumas cianoficeas, provavelmente resistentes a este produto, favorecidas pela diminuição das outras espécies com os mesmos requisitos ambientais. No final de 1994 registrou-se novamente floração de cianoficeas nesta represa.

A SABESP realiza o monitoramento regular da qualidade da água desta represa, com o objetivo de orientar o tratamento da água destinada ao consumo. Este monitoramento não tem cunho de pesquisa limnológica destinada a encontrar soluções para as causas e conseqüências da degradação ambiental; presta-se apenas para orientar ações destinadas ao controle algáceo, da cor, odor e sabor da água e os dados obtidos não são divulgados.

A Companhia de Tecnologia de Saneamento Ambiental (CETESB) realiza o monitoramento da qualidade da água desde 1972, em 3 pontos da represa: no canal de 
captação, no rio Embu-mirim e no rio Embu-guaçu, cujos resultados são publicados anualmente nos relatórios de qualidade das águas interiores do Estado de São Paulo. Em 1983 foi publicado o relatório de um estudo sobre a eutrofização da represa de Guarapiranga e em 1992, foi publicado outro relatório preliminar de uma pesquisa realizada entre outubro de 1991 e fevereiro de 1992 sobre a eutrofização e contaminação por metais (CETESB, 1983, 1992). Devido a atual preocupação com a ocorrência de toxicidade algácea na água de abastecimento, foram realizados testes biológicos, a partir dos quais a CETESB produziu um relatório de avaliação toxicológica com ênfase no problema de algas tóxicas e algicidas (CETESB, 1995).

Atualmente vários documentos estão sendo gerados através do Programa de Saneamento Ambiental da Bacia do Guarapiranga, pela Unidade de Gerenciamento do Programa sobre a qualidade da água, alguns aspectos da biota, do controle algáceo e do tratamento para abastecimento, baseados em dados já existentes (COBRAPE, 1994a, 1994b e 1995). O Programa de Saneamento Ambiental da Bacia do Guarapiranga abrange vários projetos e atividades (COBRAPE, 1991) que serão financiados pelo Banco Mundial juntamente com o Governo do Estado de São Paulo. Alguns já estão em andamento e espera-se que todos os projetos tenham prosseguimento durante esta gestão governamental.

Além dos trabalhos mencionados, estudos abordando a comunidade fitoplanctônica desta represa foram realizados por Kleerekoper (1939), Rocha (1984), Xavier e col., (1985) e Pereira (1987). Mais recentemente foram defendidas duas teses: a primeira, de mestrado, sobre a comunidade fitoplanctônica foi defendida em 1994, em São Carlos - USP, estando em fase de revisão e ainda não se encontra disponível nas bibliotecas. A mais recente, é de doutorado e versa sobre algas tóxicas e algicidas na represa de Guarapiranga (Zagatto, 1995). 


\section{OBJETIVOS}

Este estudo da comunidade fitoplanctônica do reservatório de Guarapiranga teve por objetivos:

1. identificar as espécies de algas presentes em suas águas;

2. avaliar a variação quali e quantitativa dos organismos da água superficial ao longo de um ciclo sazonal e sua relação com os fatores ambientais abióticos;

3. acompanhar detalhadamente as alterações da comunidade fitoplanctônica que comparadas às alterações ambientais possam indicar os fatores determinantes das alterações da comunidade fitoplanctônica, especialmente a ocorrência de florações de espécies problemáticas ao tratamento da água para abastecimento;

4. determinar as condições que propiciam a ocorrência de florações;

5. registrar a ocorrência de organismos fitoplanctônicos potencialmente prejudiciais aos processos convencionais de tratamento da água;

6. avaliar as consequiências dos efeitos da aplicação do sulfato de cobre sobre a comunidade algácea e a possível ocorrência de organismos resistentes;

7. determinar os organismos que podem ser utilizados como indicadores de poluição: tanto aqueles que ocasionam problemas ao tratamento da água, como os indicadores da ocorrência subseqüente de organismos problemáticos, bem como organismos indicadores da "oligotrofização" ou reabilitação;

8. determinar as formas de vida e as estratégias adaptativas favorecidas neste ambiente;

9. formular propostas para reabilitação da qualidade da água, tanto sob os aspectos sanitários como para manutenção da qualidade física, química e biológica deste ambiente, a partir dos resultados das investigações realizadas;

10. comparar métodos de estimar a densidade e o biovolume das espécies do fitoplâncton;

11. avaliar a pertinência de um método recém elaborado de determinação da persistência dos grupos de organismos fitoplanctônicos (Índice de Persistência das Espécies) para estudos ecológicos e sanitários; 


\section{MATERIAIS , MÉTODOS E ESTRATÉGIA DE ESTUDO}

\subsection{COMUNIDADE FITOPLANCTÔNICA}

O período de vida dos organismos fitoplanctônicos é de alguns dias a semanas, tornando a sucessão, reversão ou alterações da comunidade, muito rápidas. Estudos com o propósito de investigar os fatores que levam a grandes alterações desta comunidade, devem ser realizados com uma frequiência compativel à detecção desses fatores. Para tanto, decidiu-se coletar água em dois pontos do corpo central da represa de Guarapiranga, semanalmente, durante ao menos um ciclo sazonal completo, acompanhando as alterações da comunidade algácea e as ambientais.

Os pontos de coleta foram selecionados dentre os 4 pontos do corpo central da represa, estudados por Beyruth e col. (no prelo), elegendo-se os pontos que apresentaram as maiores diferenças quanto aos índices da estrutura da comunidade, no conjunto das dez primeiras campanhas de amostragem e mantendo-se a denominação utilizada no estudo mencionado, de forma a permitir comparações com trabalhos posteriores. Estes pontos situam-se em água aberta, isto é no corpo central da represa, distantes da influência imediata das margens. $O$ ponto 1 situa-se nas proximidades da barragem, próximo da área de captação de água para abastecimento. $\mathrm{O}$ ponto 4 situa-se mais a montante, entre a margem direita e a Ilha dos Eucaliptos (Figura 4).

As campanhas de coleta foram iniciadas em maio de 1991 e estenderam-se por 56 semanas até julho de 1992. As coletas estão descritas no texto, inseridas nas tabelas e figuras, designadas pela sigla do mês e número da coleta, conforme exposto a seguir:

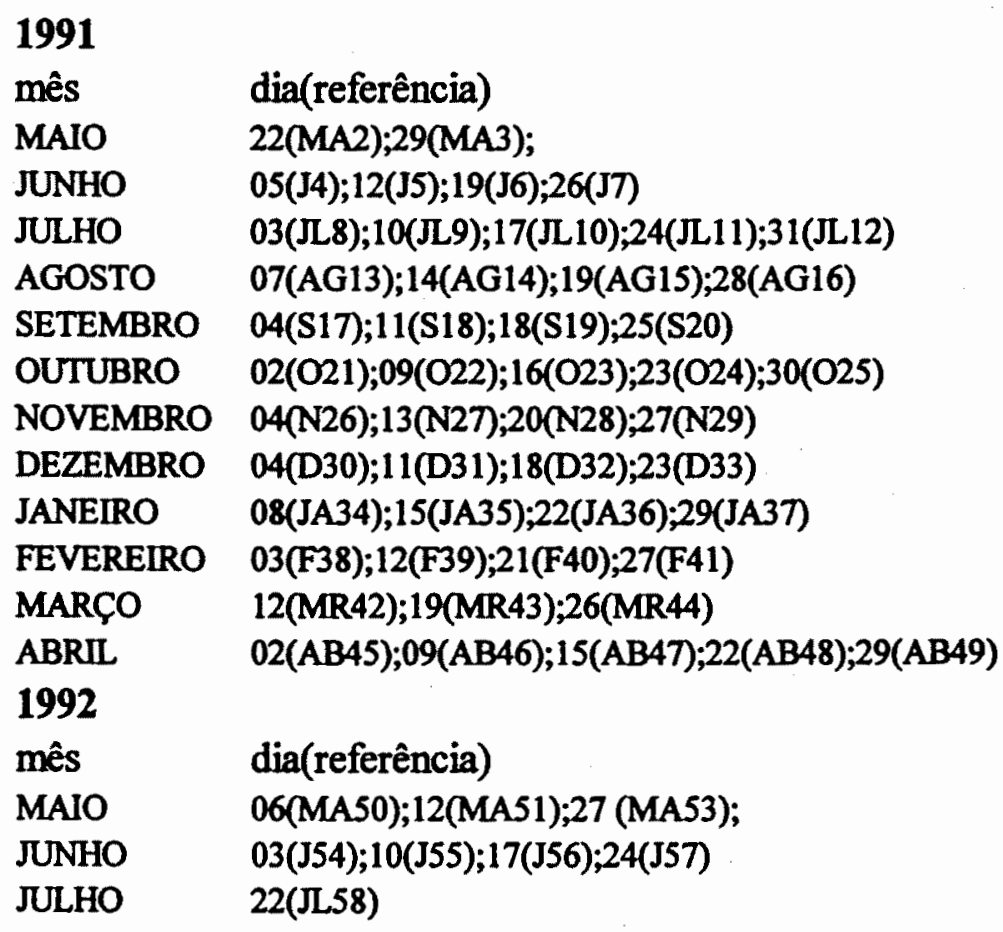


O lançamento semanal e até mesmo diário do sulfato de cobre nesta represa para o controle algáceo, efetuado nos períodos de maior abundância algácea, conforme relato de técnicos da SABESP, foi outro fator que levou a esta periodicidade de estudos. $O$ acompanhamento dos efeitos deste processo intensivo permite determinar quais organismos são mais resistentes à sulfatação.

As algas foram identificadas sempre que possível, até o nível infragenérico, através da literatura especializada, no Instituto de Botânica da Secretaria do Meio Ambiente, sob a supervisão da Dra. Célia Leite Sant'Anna, considerando-se as caracteristicas morfométricas das fases vegetativa e reprodutiva.

Durante as coletas foram obtidas amostras com auxilio de rede de $20 \mu \mathrm{m}$ de abertura de malha, arrastada desde $0.50 \mathrm{~m}$ do fundo da represa até a superficie. As amostras foram vertidas em frascos de polietileno, preservadas com solução de lugol acético na proporção de 1:100, segundo Sournia (1978) e mantidas em ambiente com iluminação reduzida, sob temperatura baixa. Estas amostras foram utilizadas para as determinações qualitativas, com auxilio de microscópio binocular, ocular micrométrica e câmara clara, da Carl Zeiss. Estas análises foram realizadas através da observação do material entre lâmina e lamínula, desenhos com auxilio de câmara clara, procedimento repetido para cada espécie encontrada, até que não surgissem novas espécies na amostra.

As amostras de fitoplâncton total foram coletadas na sub-superficie da água, a aproximadamente 20 centímetros de profundidade, para as determinações quantitativas, realizadas com auxilio de microscópio invertido da Carl Zeiss e câmara de sedimentação pelo método Utermöhl (Vollenweider, 1974). O tempo de sedimentação foi de 4 horas para cada 1 $\mathrm{ml}$, conforme Nauwerck (1963, In: Sournia, 1978).

Segundo Hasle (In: Sournia, 1978) em estudos de distribuição sazonal, há vantagens na utilização de um volume constante na contagem ao longo do ano, para os cálculos de diversidade, já que o número de espécies freqüentemente varia com o tamanho da amostra, como também é relatado por Margalef (1983). Eloranta (1993) também manteve constantes o método de contagem e o volume de amostra, de forma a obter resultados comparáveis de riqueza de espécies e diversidade.

A importância de obter dados comparáveis de riqueza e diversidade em avaliações sanitárias, justifica a opção de manter constante o volume de água examinado, embora este método possa causar alguma perda de informação sobre a composição florística, ou sobre a biomassa, especialmente no que se refere às espécies raras. 
Quando o objetivo da investigação é obter uma estimativa do volume total de fitoplâncton, apenas as espécies mais abundantes apresentam interesse (Hasle In: Sournia, 1978). Desta forma, atendendo à disponibilidade de tempo para o processamento das amostras e obtenção de resultados significativos, sabendo-se que o reservatório estudado tem caracteristicas de ambiente eutrofizado e portanto, apresenta fitoplâncton abundante, optou-se por realizar a contagem, utilizando-se sub-amostras de $2 \mathrm{ml}$ da água bruta da represa.

$\mathrm{Na}$ intenção de comparar as informações obtidas através destes diferentes métodos quantitativos, decidiu-se por estimar:

- a densidade através do número de células e do número de indivíduos;

- a biomassa através da bioárea e do biovolume.

Para as avaliações de densidade realizou-se a contagem de um transecto da câmara, enumerando-se os indivíduos (células, cenóbios e colônias) encontrados em 200 campos, sob aumento de 400 vezes, seguida do rastreamento da câmara inteira sob aumento de 250 vezes à procura de outros táxons, que não houvessem sido detectados na contagem do transecto e que apresentassem densidade igual ou superior ao fator de multiplicação do transecto para $1 \mathrm{ml}$. Com este procedimento evitou-se utilizar fatores diferentes para contagem de cada amostra. A contagem do transecto em maior aumento permitiu estimar a densidade dos organismos menores e o rastreamento permitiu a deteç̧ão de espécies maiores e/ou mais raras.

Optou-se pela contagem do número de células devido à variedade do número de células encontradas em cada filamento e à presença de células isoladas de espécies filamentosas. As colônias amorfas com forma ou volume inconstante apresentaram grande variação nas dimensões, como por exemplo as espécies de Aphanocapsa, Botryococcus, Coelastrum, Dictyosphaerium, Gloeocystis e outras clorococales coloniais não identificadas. $O$ método de medição adotado impede a estimativa acurada da espessura deste tipo de organismo, pois as formas coloniais amorfas achatam-se ao serem colocadas sobre superfícies sólidas e os aparelhos utilizados não permitem medir espessura. Desta forma, considerou-se que para estas colônias a espessura corresponde à largura, definindo-se como "unidade de organismo" uma área padrão, correspondente a $169 \mu \mathrm{m}^{2}$ e para volume, "unidade de volume" correspondente a $1150.35 \mu \mathrm{m}^{3}$, medidas definidas pelo retículo de Whipple, acoplado a uma das oculares do microscópio utilizado para contagem.

Considerando-se que o número de células indica o potencial reprodutivo, o número de colônias para as espécies de volume inconstante não pode ser comparado ao daquelas espécies cujas dimensões são relativamente constantes e que constituem a grande maioria. 
Pressupondo-se que a dimensão celular de cada espécie seja relativamente constante, em volumes padronizados de cenóbio ou colônia haveria o mesmo número de células. Desta forma, recorreu-se à utilização de unidades fixas para contagem destas colônias, para estimar o número de células. Entretanto, a integridade e manutenção da forma destas colônias/cenóbios pode estar relacionada à estabilidade física do ecossistema, bem como à disponibilidade de nutrientes. Para verificar esta possibilidade registrou-se também o número destas colônias durante as contagens, utilizado para comparações com os resultados das contagens por número de células.

Durante as contagens determinou-se a área ocupada pelos organismos, para estimativa da biomassa por espécie em cada estação e período, com auxilio de retículo de Whipple, conforme mencionado. Estas medições foram complementadas pelas obtidas durante as análises taxonômicas, para cálculo do biovolume através das fórmulas geométricas descritas em Carvalho (1970) e Wetzel e Likens (1991). A partir destes dados também calculou-se o primeiro maior eixo ou maior dimensão linear - GALD ou MDL - e segundo maior eixo SGALD de cada indivíduo, conforme Lewis e Riehl (1982), correspondentes às medianas das medições efetuadas durante as contagens. Estas medianas foram utilizadas para estimar a bioárea através da Unidade Padrão de Área por mililitro (UPA.ml ${ }^{-1}$ ) que corresponde a 400 $\mu \mathrm{m}^{2} . \mathrm{ml}^{-1}$ e é utilizada pela SABESP e CETESB (Branco, 1986), instituições destinadas ao controle da água para abastecimento.

$\mathrm{Na}$ análise da estrutura da comunidade fitoplanctônica utilizou-se os seguintes índices, conforme Odum (1971) e Margalef (1974):

- densidade total da amostra e freqüência relativa por táxon em número de células (DC) por mililitro de água da represa (cél.ml-1 ${ }^{-1}$ ), bioárea total (BA) e freqüência relativa da bioárea expressas em UPA por mililitro (UPA $\mathrm{ml}^{-1}$ ), biovolume total $(\mathrm{BV})$ e freqüência relativa do biovolume expressos em micrômetros cúbicos por mililitro $\left(\mu \mathrm{m}^{3} \cdot \mathrm{ml}^{-1}\right)$ e densidade de organismos (DO), expressos em densidade total e freqüência relativa de organismos por mililitro (org.ml-1).

- a riqueza específica, ou número de táxons, correspondente ao número de unidades taxonômicas encontrado em cada amostra (S).

- a diversidade específica foi estimada pelo índice de Shannon-Wiener a partir dos dados de densidade (bits.cel ${ }^{-1}$ ou bits.org $^{-1}$ ) e biomassa (bits.UPA ${ }^{-1}$ ou bits. $\mu \mathrm{m}^{-3}$ ). A uniformidade foi estimada através do índice de Pielou (1975, apud Odum, 1971). 
Para cada coleta e ponto, as três espécies que apresentaram as freqüências relativas mais elevadas também foram consideradas importantes como indicadoras da qualidade ambiental, procedimento que demonstrou-se adequado para avaliação de impactos (Beyruth, 1994a).

Para verificar se as comunidades de cada área amostral permaneciam constantes ao longo do tempo, quanto ao número de grupos taxonômicos e quanto à existência de coincidências positivas de táxons dentro de cada conjunto de dados, aplicou-se os testes $M$ e $Q$ de Hendrickson (1978).

A separação em lotes de dados teve como objetivo a procura das causas ambientais que determinaram ou favoreceram a heterogeneidade do número de espécies (teste $M$ ) e das taxocenoses presentes (teste Q), para cada componente da comunidade (classes, ordens). Estes testes qualitativos complementam a análise da alteração da comunidade, indicando rupturas na estrutura da comunidade. A deteç̧ão de alterações ou rupturas é importante pois indica o grau de efetividade do impacto de distúrbios ambientais.

As alterações temporais na comunidade foram estimadas a partir do indice da soma das diferenças entre amostras temporalmente seqüenciais, pertencentes a uma mesma estação de coleta ou índice de modificação da comunidade (Lewis, 1978b e Reynolds, 1993).

Elaborou-se um método tentativo denominado Índice de Persistência das Espécies (IPE), para avaliar a capacidade de persistência das espécies em cada conjunto amostral. $O$ método proposto está descrito no item tratamento de dados e a eficiência dessa avaliação é discutida a partir dos resultados obtidos.

Cardoso e Beyruth (1990) encontraram pico de condutividade no início das chuvas após um longo período de deficiência hídrica do solo nesta mesma bacia hidrográfica - para o rio Embu-mirim e um lago marginal - associado a alterações marcantes na qualidade da água, 0 que levou à escolha do balanço hídrico, como o primeiro determinante de alterações abióticas, e conseqüentemente das bióticas, a ser investigado neste estudo, utilizado para delimitar periodos e separar lotes de dados. A aplicação de sulfato de cobre para controle algáceo, constituiu o segundo critério de separação dos dados em periodos, para investigar as causas de alteração da comunidade fitoplanctônica.

Selecionou-se as dominantes e abundantes (Lobo e Leighton, 1986):

a) Dominantes: as que ocorreram em densidade ou biomassa iguais ou superiores a $50 \%$ do total da amostra;

b) Abundantes: as que ocorreram em densidade ou biomassa igual ou superior a média da amostra; 
A freqüência de ocorrência foi determinada pela porcentagem de ocorrência da espécie em relação ao total de amostras de cada ponto de amostragem [número de ocorrências da espécie.(100).56-1 $]$, separando-se as espécies com freqüência de ocorrência superior a $50 \%$.

Estas três últimas avaliações foram utilizadas para a determinação das espécies indicadoras da qualidade ambiental, por constituírem as espécies mais representativas do período de estudo.

As espécies foram agrupadas em classes de tamanho conforme o primeiro maior eixo (GALD):
a) Nanoplâncton: $<20$ um
b) Microplâncton: $>20$ até 200 um
c) Macroplâncton: $>200$ um

Foram consideradas as seguintes classes de biovolume:

a) Classe 1: até 100 um $^{3}$

b) Classe 2: $>100$ até $1000 \mathrm{um}^{3}$

c) Classe 3: $>1000$ até $10000 \mathrm{um}^{3}$

d) Classe 4: $>10000 \mathrm{um}^{3}$

Para completar a avaliação do desempenho das algas quanto à capacidade de aproveitamento dos recursos, superação dos gradientes ambientais, proteção contra predação, potencial de permanecer em suspensão, etc., efetuou-se a análise das estratégias adaptativas mais evidentes dentre as apresentadas pelas espécies encontradas. Desta forma foram separadas as densidades e os biovolumes de organismos com e sem capacidade de promover a renovação da água ao seu redor, por apresentarem potencial de movimento próprio ou de mobilizar a água circundante, considerando-se para tanto, os organismos dotados de flagelo. Também foram separadas as densidades e biovolumes de organismos com e sem envoltório rigido bem como as densidades e biovolumes das diferentes formas: unicelulares, coloniais/cenobiais e filamentosas; estratégias capazes de influir na velocidade de sedimentação e no aproveitamento dos recursos.

Procedeu-se à avaliação das espécies indicadoras, tanto sob o aspecto sanitário como ecológico. Considera-se indicadoras as espécies que ocorreram em períodos determinados, cuja densidade ou biovolume, ocorrência ou desaparecimento associaram-se a alterações da qualidade ambiental (Rocha, 1992) e as três primeiras espécies mais freqüentes nas amostras de cada ponto, que em geral constituem bons indicadores da qualidade geral do ecossistema. 


\subsection{VARIÁVEIS ABIÓTICAS}

As características da bacia de drenagem, tais como uso e ocupação do solo, informações climáticas e também sobre a morfometria do corpo d'água e sulfatação, foram obtidas na SABESP (Companhia de Saneamento Básico do Estado de São Paulo), ELETROPAULO (Eletricidade do Estado de São Paulo S.A.), CETESB (Companhia de Tecnologia de Saneamento Ambiental), EMPLASA (Empresa Metropolitana de Planejamento da Grande São Paulo S.A.) e IAG-USP (Instituto Astronômico e Geofisico da Universidade de São Paulo). Os parâmetros analisados foram: direção e velocidade do vento (VEN), pluviosidade do dia de coleta (P), de 24 horas (P24), de 72 horas (P72) e de 168 horas (P168), insolação (INS), radiação solar (RAD), total de água afluente pelos tributários (AFL), total efluente (EFL), elevação correspondente ao nível da coluna d'água (ELE) e volume (VOL). A forma de avaliação dos efeitos da pluviosidade baseou-se em experiências anteriores nesta bacia hidrográfica, tendo-se verificado diferenças nos efeitos das chuvas acumuladas de 24,72 e 168 horas (Beyruth, 1989).

Dados obtidos no campo durante as coletas:

- Temperaturas do ar (TAR) e da água (TAG) na sombra, utilizando termômetro de mercúrio graduado em décimo de grau centígrado $\left({ }^{\circ} \mathrm{C}\right)$;

-Transparência ao disco de Secchi (SEC) de 25 centímetros de diâmetro (m);

-Profundidade da coluna d'água (PROF), com cordas de poliuretano marcadas ( $0.5 \mathrm{~m}$ );

-Oxigênio dissolvido (mg. $\mathrm{l}^{-1} \mathrm{de} \mathrm{O}_{2}$ );

-Demanda bioquímica de oxigênio ( $m g .1^{-1}$ de $\mathrm{O}_{2}$ );

Para análise de oxigênio dissolvido (OD) e demanda bioquímica de oxigênio (DBO) coletou-se $150 \mathrm{ml}$ de água em vidro âmbar com tampa chanfrada; as amostras para OD foram preservadas no campo, levadas para o laboratório e analisadas imediatamente. As de DBO foram levadas para o laboratório e mantidas em estufa a $20^{\circ} \mathrm{C}$ por 5 dias e então preservadas e analisadas imediatamente. Para as análises do teor de oxigênio dissolvido utilizou-se o método de Winkler modificado segundo APHA-AWWA-WPCF (1989);

A água necessária para as demais análises foi transportada em frascos de poliuretano previamente lavados com ácido cloridrico e enxaguadas com água destilada e posteriormente com água deionizada, procedendo-se às seguintes análises nos laboratórios do Departamento de Saúde Ambiental da Faculdade de Saúde Pública da USP:

-potencial hidrogeniônico $(\mathrm{pH})$ com medidor DMPH-2-Digimed;

-Turbidez (TUR) com turbidímetro Hach (UNT - unidade nefelométrica de turbidez); 
- Cor (COR) com comparador Hellige Aqua Tester (mg. $\mathrm{l}^{-1} \mathrm{Pt}$ );

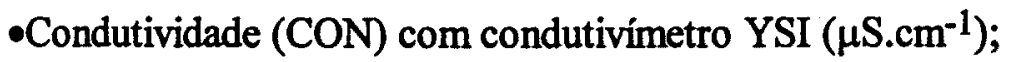

-Sólidos totais em suspensão (SOT) por gravimetria $\left(\mathrm{mg} . \mathrm{l}^{-1}\right)$;

Análises realizadas através de métodos titulométricos:

-Alcalinidade (ALC) por titulação potenciométrica com nitrato de prata (mg.1-1 $\left.\mathrm{CaCO}_{3}\right)$;

-Dureza (DUR) por titulometria com EDTA (mg.l-1 $\left.\mathrm{CaCO}_{3}\right)$;

- Fosfato solúvel reativo $\left(\mathrm{PO}_{4}\right)^{-3}$ e fosfato total $(\mathrm{PT})$ através dos métodos descritos por

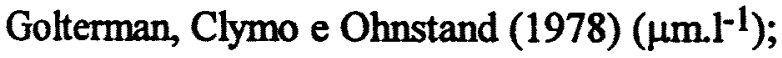

Para as demais análises de nutrientes e elementos traço a água foi filtrada em papel de filtro Wathman qualitativo $\mathrm{n}$. 1 e separadas em duas alíqüotas de $250 \mathrm{ml}$, uma foi fixada com $\mathrm{HNO}_{3}$ e a outra com $\mathrm{H}_{2} \mathrm{SO}_{4}$ p.a. concentrados para concentração final de 1:1000. Estas amostras foram mantidas refrigeradas até serem analisadas nos laboratórios da Seção de Radioquímica e Química Analítica do Centro de Energia Nuclear na Agricultura (CENA) da USP, onde foram realizadas as seguintes determinações:

-Amônia $\left(\mathrm{NH}_{4}\right)^{+}$por espectrofotometria-turbidimetria através do método de Nessler, com espectrofotômetro Micronal (mg. $\left.\mathrm{l}^{-1}\right)$;

- Nitrato $\left(\mathrm{NO}_{3}\right)^{-}$e cloreto $(\mathrm{Cl})^{-}$por espectrofotometria de emissão e absorção atômica de chama, com espectrofotômetro AES-Perkin Elmer (mg. $\mathrm{l}^{-1}$ );

-Alumínio (Al), bário $(\mathrm{Ba})$, boro $(\mathrm{Bo})$, cobre $(\mathrm{Cu})$, cromo $(\mathrm{Cr})$, ferro $(\mathrm{Fe})$, magnésio $(\mathrm{Mg})$, manganês $(\mathrm{Mn})$, sódio $(\mathrm{Na})$, sílica $(\mathrm{Si})$, zinco $(\mathrm{Zn})$ e níquel $(\mathrm{Ni})$ através de espectrofotometria de emissão atômica com plasma induzido, com AR-ICP-AES Jarrell, Ash (mg. $\left.1^{-1}\right)$.

Os métodos utilizados para as determinaçð̃es fisicas e químicas foram os preconizados no APHA-AWWA-WPCF (1989).

\subsection{TRATAMENTO DOS DADOS}

O estudo dos atributos da comunidade fitoplanctônica e dos fatores ambientais foi realizado através dos métodos da estatística descritiva. Verificou-se assimetria da distribuição das frequêências, para todos os parâmetros avaliados neste estudo, optando-se então pelo uso da mediana, que considerando a distribuição das medidas, caracteriza o centro do conjunto de dados. A mediana é indicada para amostras com distribuição assimétrica de freqüências, caso em que há contra-indicação para o uso da média amostral e além disto, apresenta a vantagem 
de eliminar a influência de desvios pronunciados devido a máximas e/ou mínimas extremas, que poderiam alterar em muito o uso da média (Zar, 1974).

Para estimar a relação entre as variáveis bióticas e abióticas e selecionar as variáveis a serem utilizadas na matriz ambiental, utilizou-se os resultados obtidos na análise das correlações não paramétricas de Spearman (Siegel, 1975), eliminando-se as variáveis redundantes, escolhendo-se uma dentre as que apresentaram alta correlação positiva ( $r s>0.50$ ) com probabilidade de erro $(\mathrm{P})$ igual ou menor que $5 \%$. Para não haver perda de informação adquirida, quando os valores medianos das variáveis abióticas estiveram abaixo do limite de detecção do método empregado, estes dados foram substituídos pelo valor imediatamente inferior daquele considerado limite, no método de análise. Os valores da mediana foram utilizados para substituir os dados ausentes, na matriz ambiental.

Além da análise das correlações não paramétricas de Spearman, utilizou-se também a análise multivariada de componentes principais, para verificar as relações entre os diversos parâmetros analisados (Ter Braak, 1986).

Os seguintes programas para os cálculos estatísticos aplicados foram utilizados:

- conjunto de programas elaborados pelo Dr. Jean Valentin da UFRJ, para determinação dos índices de diversidade de Shannon-Wiener, uniformidade e riqueza específica.

-Statgraphics versão 5.0. para os cálculos das estatísticas descritivas e para a determinação das correlações não paramétricas (Zar, 1974 e Siegel, 1975).

-FITOPAC versão 2.0 elaborado pela equipe do Departamento de Botânica, UNICAMP para a análise de agrupamentos (Legendre e Legendre, 1983).

-CANOCO, versão.2.2, para a análise dos componentes principais utilizando os dados ambientais transformados em LOG $(x+1)$ e a distância euclideana (Ter Braak, 1986, 1987 e 1988).

-SUCESS programa elaborado pela Enga. Ana Alvim da CETESB para cálculo da soma das diferenças entre amostras, ou taxa de alteração entre amostras temporalmente sucessivas (Lewis, 1978b).

-HENDRIX elaborado por Zuleika Beyruth e Enga. Ana Alvim da CETESB, para cálculo do $\mathrm{M}$ e $\mathrm{Q}$ de Hendrickson (1978). Compara taxocenoses a partir de matriz biológica de presença e ausência de espécies

Observações: - para a notação numérica substituiu-se em todo o texto a vírgula por ponto.

- para a notação da unidade litro, utilizou-se 1 ao invés de $L$. 


\subsection{1. ÍNDICE DE PERSISTÊNCIA DAS ESPÉCIES}

Elaborou-se um método tentativo, denominado Índice de Persistência das Espécies (IPE), utilizando-se a porcentagem média de pares positivos de ocorrência das espécies, dentro de cada conjunto amostral.

A persistência média das espécies é utilizada como indicador do grau de estabilidade de cada componente da comunidade fitoplanctônica no ecossistema. Este valor foi calculado a partir da matriz binária, de presença e ausência das espécies. $O$ número de coincidências positivas (táxon comum a duas amostras) foi calculado através do mesmo procedimento utilizado para o teste de Hendrickson (1978), ou seja, análise combinatória, da seguinte forma:

$$
\begin{array}{rl}
C P={ }^{j} \Sigma_{i=1} & R i(R i-1) / 2 \\
\text { onde } \quad & C P=\text { número de coincidências positivas; } \\
& R_{i}=\text { soma das ocorrências da espécie }\left(R_{i}=\Sigma_{j=1} Y_{i j}\right) ; \\
j & =\text { número de coletas ou amostras. }
\end{array}
$$

Se todas as espécies houvessem ocorrido em todas as amostras, $\mathrm{CP}_{\max }$, o número de espécies multiplicado pelo número máximo possível de coincidências positivas para cada espécie corresponderia a cem porcento, num determinado lote de dados. $\mathrm{O}$ valor encontrado corresponderia portanto, a uma porcentagem daquele total, que dividido pelo número de espécies fornece a porcentagem média de coincidências positivas dentro de cada lote de dados considerado. Por exemplo: dado um determinado conjunto amostral, expresso por uma matriz

\begin{tabular}{|c|c|c|c|c|}
\hline$a b c d e f g h i j$ & $\mathbf{R i}$ & $\mathrm{Ri}(\mathrm{Ri}-1) / 2$ & $\mathbf{R}_{\max }$ & $R_{\max }\left(R_{\max }-1\right) / 2$ \\
\hline 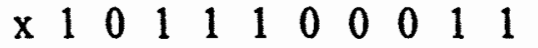 & 6 & 15 & 10 & 45 \\
\hline $\begin{array}{llllllllllll}\text { y } & 1 & 1 & 1 & 1 & 1 & 1 & 1 & 1 & 1 & 1\end{array}$ & 10 & 45 & 10 & 45 \\
\hline $\begin{array}{llllllllllll}z & 1 & 0 & 1 & 0 & 1 & 0 & 1 & 0 & 1 & 0\end{array}$ & 5 & 10 & 10 & 45 \\
\hline
\end{tabular}
binária de presença/ausência, com 3 espécies ( $x$, y e z) e 10 amostras (a-j), onde a presença recebe valor 1 e a ausência valor 0 , calcula-se o número de coincidências positivas e o número máximo possivel de coincidências positivas das espécies:

IPE é o índice de persistência média das espécies do conjunto amostral considerado; CP é o número de ocorrências positivas encontrado; $\mathrm{Cp}_{\max }$ é o número máximo possível de ocorrências positivas; St é o número total de espécies encontrado no conjunto amostral;

$$
\begin{gathered}
\mathrm{IPE}=\left[(70.100) .135^{-1}\right] 3^{-1}=17.28 \% \\
\mathrm{IPE}=17.28 \%
\end{gathered}
$$




\section{RESULTADOS}

\subsection{ASPECTOS CLIMATOLÓGICOS}

Nas Tabelas 1, 2 e 3 (do Anexo) estão expressos os dados dos parâmetros climatológicos. A Figura 3 mostra os pontos de coleta. A figura 4 mostra os diagramas climáticos dos anos de 1991 e 1992 e a Figura 5 representa o balanço hídrico, na bacia de Guarapiranga durante o período de estudo.

A radiação solar está expressa em Langley.dia-1 que corresponde a calorias por centímetro quadrado por dia. Variou nas datas de coleta entre $263 \mathrm{Ly}^{-d_{i a}-1}$ (J5 a J7) e 491

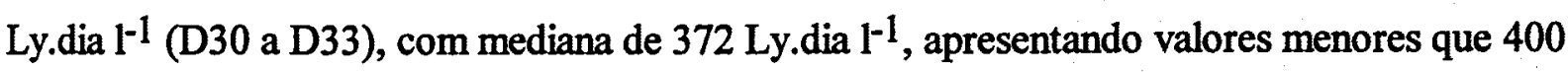
Ly.dia $^{-1}$ entre MA2 e O20; maiores entre $\mathrm{O} 21$ e F41 e após este período valores menores que $400 \mathrm{Ly}$.dia $\mathrm{1}^{-1}$ até o final das amostragens. A mediana de radiação solar foi maior na época de chuvas (434 Ly.dia $\mathrm{I}^{-1}$ ) que na seca (300 Ly.dia $\mathrm{l}^{-1}$ ). A radiação solar no ponto 1 correlacionou-se com a pluviosidade ( $\mathrm{r} s=0.72 \mathrm{P}=0$ ), excedente hídrico ( $\mathrm{rs}=0.55 \mathrm{P}=0$ ), temperatura da água ( $\mathrm{rs}=0.73 \mathrm{P}=0)$, dureza ( $\mathrm{rs}=0.59 \mathrm{P}=0.0007)$, teores de potássio ( $\mathrm{rs}=0.55$ $\mathrm{P}=0.0001$ ), sódio ( $\mathrm{rs}=0.65 \mathrm{P}=0$ ) e de zinco ( $\mathrm{rs}=-0.50 \mathrm{P}=0.0002$ ). No ponto 4 com temperatura da água ( $\mathrm{rs}=0.60 \mathrm{P}=0$ ), transparência ( $\mathrm{rs}=-0.53 \mathrm{P}=0.0001$ ), dureza ( $\mathrm{rs}=0.59$ $\mathrm{P}=0.0007$ ), teores de cácio ( $\mathrm{rs}=0.50 \mathrm{P}=0.0002$ ) e de magnésio ( $\mathrm{rs}=0.50 \mathrm{P}=0.0002$ ). Observação: embora várias das correlações estatisticamente significativas não tenham significado ecológico ou sanitário evidente, neste capítulo optou-se por relatar todas as encontradas, pois correlações espúrias muitas vezes refletem relações indiretas, podendo indicar padrões não evidenciados através de outras análises.

A insolação mensal variou entre 123.0 horas.mes $^{-1}$ em julho de 1992 e 208.2 horas.mes ${ }^{-1}$ em maio de 1991. A insolação diária das datas de coleta variou entre zero horas.dia ${ }^{-1}$ (S20, O22, JA36 e AB48) e 10.6 horas.dia $^{-1}$ (F39), com mediana de 6.4 horas.dia1. Em ambos os pontos não apresentou correlaçð̃es com os demais parâmetros ambientais nos niveis considerados.

$O$ vento predominante durante os meses do período de estudo foi o nordeste (NE). Os ventos de maior velocidade média mensal foram ENE, WNW e NE. A maior velocidade média mensal foi registrada em janeiro de 1992 (ENE=11.9 $\mathrm{km} \cdot \mathrm{h}^{-1}$ ) e a menor em junho de 1992 $\left(\mathrm{NE}=5.4 \mathrm{~km}^{-1} \mathrm{~h}^{-1}\right)$. Nas datas de coleta os ventos predominantes foram WNW, SSE, NE e NW. A maior velocidade média foi de $13.8 \mathrm{~km} \cdot \mathrm{h}^{-1}$ (WNW) em J6 e a menor de $3.4 \mathrm{~km} \cdot \mathrm{h}^{-1}$ (ENE) em J37. Não houve variação na velocidade dos ventos entre os períodos de chuva e seca 
(mediana de $6.30 \mathrm{~km} . \mathrm{h}$, para os dois períodos). A velocidade dos ventos não se correlacionou com os demais parâmetros nos níveis considerados.

A análise dos índices pluviométricos indica que o estudo iniciou-se durante o período de seca de 1991 MA2 que prolongou-se até a última semana de agosto AG16, com mínima mensal de 25 mm.mes ${ }^{-1}$ em julho de 1991 (JL8 a ЛL12). O período de chuvas iniciou-se em setembro de 1991, S17, e prolongou-se até março de 1992 MR44, com uma "estiagem" temporária de $83 \mathrm{~mm}^{-m^{-1}}$ em novembro, (N26 a N29), configurando um periodo de chuvas moderadas. Na primeira semana de abril de 1992, AB45, iniciou-se o segundo período de seca, que prolongou-se até o final das amostragens, JL58, com mínima mensal para o período de 8 mm.mes ${ }^{-1}$ em junho de 1992 (J54 e J57). As chuvas mais intensas, acima de $150 \mathrm{~mm}^{\mathrm{m}} \mathrm{ss}^{-1}$ ocorreram entre dezembro de 1991 D30, e março de 1992 MR44, com máxima mensal para o período de $256 \mathrm{~mm}^{-m^{-1}}{ }^{-1} \mathrm{em}$ março de 1992 (MR42 a MR44). A pluviosidade diária variou entre 0 e $31.4 \mathrm{~mm}$.dia-1, com mediana de $0 \mathrm{~mm} \cdot \mathrm{dia}^{-1}$ entre as datas de coleta. Correlacionouse no ponto $1 \mathrm{com}$ a temperatura da água ( $\mathrm{rs}=0.67 \mathrm{P}=0)$, dureza ( $\mathrm{rs}=0.58 \mathrm{P}=0.0008)$, teores de sódio ( $\mathrm{rs}=0.51 \mathrm{P}=0.0002$ ). No ponto 4 com temperatura da água ( $\mathrm{rs}=0.60 \mathrm{P}=0$ ), transparência ( $\mathrm{rs}=-0.60 \mathrm{P}=0)$, dureza $(\mathrm{rs}=0.61 \mathrm{P}=0.0004)$, teor de sólidos totais em suspensão ( $\mathrm{rs}=-0.53$ $\mathrm{P}=0.0012)$, cálcio $(\mathrm{rs}=0.53 \mathrm{P}=0.0001)$ e magnésio $(\mathrm{r}=0.57 \mathrm{P}=0)$.

O balanço hídrico mostra que houve deficiência hídrica do solo nas duas primeiras campanhas (MA2 e MA3), com retirada de água do solo em MA3, reposição entre $\mathrm{J} 5$ e J7, novamente retirada entre $J L 8$ e $J 10$, deficiência entre $J L 10$ e AG16, iniciando-se a reposição na S17. Em S20 começa a haver excedente hídrico no solo e escoamento básico. $O$ excedente ocorre até 025 . De N26 a N29 há um decréscimo da pluviosidade que passa de 106 para 83 mm, mas ainda há escoamento básico. $\mathrm{O}$ aumento da intensidade das chuvas de D30 a MR44 é responsável pelos elevados excedentes hídricos e embora houvesse retirada de $\mathrm{AB} 45$ até $\mathrm{AB} 47$ e a deficiência hídrica se iniciasse novamente em A47 permanecendo até o final do estudo, ainda havia escoamento básico que persistiu até MA53. A deficiência hídrica do solo correlacionou-se com a pluviosidade ( $\mathrm{rs}=-0.64 \mathrm{P}=0$ ), excedente hídrico ( $\mathrm{rs}=-0.60 \mathrm{P}=0$ ) e radiação solar (rs $=-0.50 \mathrm{P}=0.0002$ ).

O nível da água na represa, representado pela elevação apresentou variação em torno de apenas $1 \mathrm{~m}$, sendo de $736 \mathrm{~m}$ no início do estudo até $\mathrm{JL} 11$, de $735 \mathrm{~m}$ até 022 , de $736 \mathrm{~m}$ até 024, novamente de $735 \mathrm{~m}$ até MR44, flutuando mais no periodo subseqüente, apresentando: 736m em AB47, MA50 e MA51, 735 em MR45, AB46, AB48, AB49, MA53 a J57 e 734 em JL58, sempre acima do mínimo operacional para captação (723 m). A mediana foi de $735.28 \mathrm{~m}$. 
Portanto, a elevação foi mais influenciada, durante o período de estudo, pela operação hidráulica do sistema do que pela intensidade pluviométrica, o que é confirmado pela ausência de correlação significativa com a pluviosidade diária e negativa com a pluviosidade mensal (rs= - $0.45 \mathrm{P}=0.0008$ ) e pelo maior volume de água da represa durante o período de seca. $\mathrm{A}$ elevação correlacionou-se no ponto 1 com o teor de cloro ( $\mathrm{rs}=-0.50 \mathrm{P}=0.0002$ ), alumínio $(\mathrm{rs}=0.61 \mathrm{P}=0)$, ferro ( $\mathrm{rs}=0.61 \mathrm{P}=0$ ) e sódio ( $\mathrm{rs}=-0.62 \mathrm{P}=0$ ). No ponto 4 com profundidade $(\mathrm{rs}=0.58 \mathrm{P}=0$ ), teor de cloro $(\mathrm{rs}=-0.68 \mathrm{P}=0$ ) e de sódio $(\mathrm{rs}=-0.69 \mathrm{P}=0)$. $\mathrm{O}$ volume total de água apresentou as mesmas correlações que a elevação, pois são diretamente proporcionais e portanto foi descartado como variável ambiental, por ser redundante. Estas correlações mostram que a elevação contribuiu para aportes de alumínio e ferro, das áreas marginais inundadas próximas do ponto 4 , mas o acúmulo de maior volume de água causou diminuição das concentrações de sódio e cloro.

As entradas naturais dos principais afluentes foram mais elevadas nos períodos de maior pluviosidade, com medianas de $9.75 \mathrm{~m}^{3} . \mathrm{s}^{-1}$ nas chuvas e de $6.30 \mathrm{~m}^{3} . \mathrm{s}^{-1}$ na seca. Este valor também não se correlacionou com a elevação.

A captação de água para abastecimento foi mais elevada no período das chuvas com mediana de $13.05 \mathrm{~m}^{3} . \mathrm{s}^{-1}$ do que no período da seca, com mediana de $12.60 \mathrm{~m}^{3} . \mathrm{s}^{-1}$. Durante todo o período a captação de água coincidiu com o efluente total da represa, ou seja, não houve perdas de água para o canal para regularizar as vazões durante o período de estudo. Correlacionou-se com a vazão efluente total $(\mathrm{rs}=0.99 \mathrm{P}=0)$.

O tempo de retenção calculado pelas medianas de volume e vazão efluente do período de estudo foi estimado em aproximadamente 139 dias. Desta forma houve condições para uma renovação completa da água durante este estudo.

A aplicação de sulfato de cobre, realizada apenas no ponto 1, ocorreu em MA2, MA4, AG14 a AG15, 021 a O24, N29, D32 a MA50, tendo sido mais constante nos períodos de chuvas em que apresentou mediana de $1400 \mathrm{~kg}$.dia ${ }^{-1}$. Correlacionou-se com temperatura da água ( $\mathrm{rs}=0.51 \mathrm{P}=0.0002)$, dureza ( $\mathrm{rs}=0.64 \mathrm{P}=0.0002)$ e teores de cálcio $(\mathrm{rs}=0.53 \mathrm{P}=0.0001)$.

Apesar da vazão afluente ter apresentado mediana inferior à efluente $(9.0$ e 12.9 respectivamente), a represa não perdeu água, como mostram os dados de elevação e volume. Esta água deve ter sido reposta pelas entradas de afluentes menores, ou entradas submersas, bem como das águas percoladas. 


\subsection{QUALIDADE ABIÓTICA DA ÁGUA}

As Tabelas 4 e 5 mostram resultados das análises fisicas e químicas, respectivamente para os pontos 1 e 4. A Tabela 6 mostra os resultados do teste de correlação entre as variáveis abióticas. Na Tabela 34 estão expressas as medianas dos parâmetros considerados, no conjunto de dados de cada ponto, em cada período sazonal e de aplicação de algicida.

A temperatura da água variou entre $17.0(\mathrm{JL} 11)$ e $26.5^{\circ} \mathrm{C}(\mathrm{F} 40)$ no ponto 1 e entre 13.0 (JL58) e $27.0^{\circ} \mathrm{C}$ (F40) no ponto 4 , com mediana maior no ponto $4\left(22.5^{\circ} \mathrm{C}\right.$ ), devido ao horário das coletas. Em ambos os pontos a amplitude de variação foi relativamente pequena. $\mathrm{A}$ temperatura da água, no ponto 1 , correlacionou-se com a radiação solar ( $\mathrm{rs}=0.73 \mathrm{P}=0$ ), pluviosidade ( $\mathrm{rs}=0.67 \mathrm{P}=0$ ), excedente hídrico ( $\mathrm{rs}=0.57 \mathrm{P}=0$ ), temperatura do ar ( $\mathrm{rs}=0.69$ $\mathrm{P}=0$ ), $\mathrm{pH} \quad(\mathrm{rs}=0.97 \mathrm{P}=0.0077$ ), demanda bioquímica de oxigênio ( $\mathrm{rs}=0.50 \mathrm{P}=0.0022$ ), alcalinidade ( $\mathrm{rs}=0.98 \mathrm{P}=0.0089$ ), dureza ( $\mathrm{rs}=0.54 \mathrm{P}=0.0018$ ), teores de sulfato ( $\mathrm{rs}=0.54$ $\mathrm{P}=0.0001$ ), cálcio ( $\mathrm{rs}=0.60 \mathrm{P}=0)$, potássio $(\mathrm{rs}=0.74 \mathrm{P}=0$ ) e com o teor de sulfato de cobre aplicado no dia da coleta ( $\mathrm{rs}=0.51 \mathrm{P}=0.0002)$. No ponto 4 correlacionou-se com a radiação solar ( $\mathrm{rs}=0.60 \mathrm{P}=0$ ), pluviosidade ( $\mathrm{rs}=0.60 \mathrm{P}=0$ ), excedente hídrico ( $\mathrm{rs}=0.54 \mathrm{P}=0.0001$ ), escoamento básico ( $\mathrm{rs}=0.54 \mathrm{P}=0.0001$ ), teores de nitrato ( $\mathrm{rs}=-0.56 \mathrm{P}=0.0001$ ), cálcio $(\mathrm{r} s=0.65 \mathrm{P}=0)$ e potássio ( $\mathrm{rs}=0.65 \mathrm{P}=0$ ). As correlações apresentadas refletem o padrão climático normal para a região, de período chuvoso-quente com aportes de nutrientes da bacia e periodo seco-frio.

A profundidade variou entre 5.93 e $14.00 \mathrm{~m}$ no ponto 1 e entre 6.00 e $10.50 \mathrm{~m}$ no ponto 4 , com mediana maior no ponto $1(11.00 \mathrm{~m})$. Esta grande variação decorre da localização da medição, que variou e algumas vezes pode ter sido tomada nos canais dos rios originais. No ponto 1 não se correlacionou com os outros parâmetros ambientais, no nivel considerado, e no ponto 4 correlacionou-se com a elevação e volume $(\mathrm{rs}=0.58 \mathrm{P}=0$ ).

A transparência, medida através da profundidade de extinção do Disco de Secchi variou entre 1.00 e $3.00 \mathrm{~m}$ no ponto 1 e entre 1.00 e $2.40 \mathrm{~m}$ no ponto 4 , com mediana maior no ponto $1(2.00 \mathrm{~m})$. Correlacionou-se com a turbidez $(\mathrm{rs}=-0.53 \mathrm{P}=0.0001)$, alcalinidade ( $\mathrm{rs}=$ - $0.60 \mathrm{P}=0$ ), teores de cálcio ( $\mathrm{rs}=-0.54 \mathrm{P}=0.0001$ ), potássio ( $\mathrm{rs}=-0.53 \mathrm{P}=0.0001$ ) e sulfatação do dia anterior ( $r s=-0.54 \mathrm{P}=0.0001$ ), no ponto 1 . No ponto 4 correlacionou-se com a radiação solar $(r s=-0.52 \mathrm{P}=0.0001)$, pluviosidade $(\mathrm{rs}=-0.57 \mathrm{P}=0$ ), pluviosidade de 24 horas ( $r s=-0.63 \mathrm{P}=0$ ), de 72 horas ( $\mathrm{rs}=-0.55 \mathrm{P}=0$ ) e com o excedente hídrico ( $\mathrm{rs}=-0.53$ $\mathrm{P}=0.0001$ ). As correlações negativas apresentadas demonstram que as maiores transparências 
foram verificadas nos períodos de seca. A mediana maior no ponto 1 retrata um dos efeitos do sulfato de cobre, atestado pela correlação negativa com a sulfatação do dia anterior.

A cor variou entre 10 e $40 \mathrm{mg} . \mathrm{l}^{-1} \mathrm{Pt}$ no ponto 1 e entre 20 e $70 \mathrm{mg} . \mathrm{l}^{-1} \mathrm{Pt}$ no ponto 4 , com mediana superior no ponto $4\left(40 \mathrm{mg} . \mathrm{l}^{-1} \mathrm{Pt}\right.$ ), enquanto a turbidez variou entre 0.8 e 2.2 UNT no ponto 1 e entre 1.1 e 7.1 UNT no ponto 4 , com mediana maior no ponto 4 ( 2.3 UNT). A cor não apresentou correlações com os demais parâmetros nos niveis considerados. A turbidez correlacionou-se com a transparência, alcalinidade ( $\mathrm{rs}=0.50 \mathrm{P}=0.0006)$ e ao teor de sulfato de cobre aplicado no dia anterior à coleta ( $\mathrm{rs}=0.57 \mathrm{P}=0)$, no ponto 1 . No ponto 4 correlacionou-se com o teor de alumínio ( $\mathrm{rs}=0.63 \mathrm{P}=0$ ). A amplitude de variação destes parâmetros foi considerável e as correlações apresentadas mostram que a turbidez elevada esteve mais associada aos efeitos dos períodos de chuvas.

A condutividade variou entre 32 e $100 \mu$ S.cm no ponto 1 e entre 33 e $72 \mu$ S.cm no ponto 4 com mediana maior no ponto $1\left(57 \mu \mathrm{S} . \mathrm{cm}^{2}\right)$. Correlacionou-se no ponto 1 com alcalinidade ( $\mathrm{rs}=0.60 \mathrm{P}=0$ ), cálcio ( $\mathrm{rs}=0.54 \mathrm{P}=0.0001$ ), ferro ( $\mathrm{rs}=-0.55 \mathrm{P}=0.0001$ ) e $\mathrm{pH}$ ( $r s=0.50 \mathrm{P}=0.0002$ ). No ponto 4 correlacionou-se com alcalinidade ( $\mathrm{rs}=0.66 \mathrm{P}=0$ ), ferro ( $\mathrm{rs}=$ $0.64 \mathrm{P}=0)$, potássio $(\mathrm{rs}=0.58 \mathrm{P}=0)$ e $\mathrm{pH}(\mathrm{rs}=0.61 \mathrm{P}=0)$. Estas correlações mostram que a condutividade mais elevada esteve associada aos efeitos da pluviosidade mais intensa. A máxima e a mediana mais elevadas no ponto 1 indicam a possibilidade de maiores acúmulos de nutrientes e também expressa a liberação mais intensa decorrente das mortandades de algas e outros organismos do plâncton, causada pelas aplicações de sulfato de cobre.

O pH variou entre 6.1 e 8.6 no ponto 1 e entre 6.3 e 8.1 no ponto 4 , com mediana maior no ponto 1 (7.18). Correlacionou-se com a condutividade nos dois pontos e com a temperatura da água no ponto 1 , conforme mencionado e portanto sua elevação associou-se mais aos períodos de chuvas.

O oxigênio dissolvido variou entre 5.33 e $8.63 \mathrm{mg} . \mathrm{l}^{-1}$ no ponto 1 e entre 4.22 e 8.87 mg. $1^{-1}$ no ponto 4 , com mediana superior no ponto $4\left(7.33 \mathrm{mg} . \mathrm{l}^{-1}\right)$. No ponto 4 correlacionouse negativamente com a pluviosidade das 72 horas anteriores ( $\mathrm{rs}=-0.50 \mathrm{P}=0.0003$ ). $\mathrm{A}$ demanda bioquímica de oxigênio variou entre 0 e $4.29 \mathrm{mg} .1^{-1}$ no ponto 1 , correlacionandose com a temperatura da água ( $\mathrm{rs}=0.50 \mathrm{P}=0.0022$ ) e no ponto 4 variou entre 0 e $6.40 \mathrm{mg} . \mathrm{l}^{-1}$, com mediana maior no ponto $4\left(1.21 \mathrm{mg} . \mathrm{l}^{-1}\right)$, não se correlacionando com as outras variáveis ambientais no nível considerado. As correlações apresentadas indicam maior consumo de oxigênio da água durante os períodos de maior pluviosidade e decomposição. Este parâmetro é dependente da fotossíntese e da respiração, processos que sofreram menor impacto no ponto 
4, onde além de não haver aplicação de sulfato de cobre, as condições de oxigenação atmosférica foram melhores.

A alcalinidade variou entre 6.7 e $38.7 \mathrm{mg}^{-1} \mathrm{de}^{-1} \mathrm{CaCO}_{3}$ no ponto 1 e entre 7.2 e 25.7

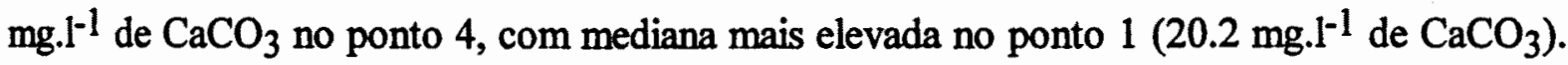
Correlacionou-se, no ponto 1 , com a temperatura da água, transparência, cor, turbidez e condutividade, conforme relatado, e com teores de sulfato ( $\mathrm{rs}=0.51 \mathrm{P}=0.0005$ ), cálcio ( $\mathrm{rs}=0.77$ $\mathrm{P}=0$ ), potássio $(\mathrm{rs}=0.65 \mathrm{P}=0$ ) e zinco $(\mathrm{rs}=0.62 \mathrm{P}=0)$. No ponto 4 , correlacionou-se com condutividade, conforme relatado, e com os teores de potássio ( $\mathrm{rs}=0.51 \mathrm{P}=0.0006$ ) e de zinco $(\mathrm{rs}=0.57 \mathrm{P}=0.0002)$. As correlações indicam que a alcalinidade mostrou relação com os períodos de chuvas.

A dureza variou entre 17.1 e $174.5 \mathrm{mg} \cdot \mathrm{l}^{-1}$ de $\mathrm{CaCO}_{3}$ no ponto 1 e entre 14.5 e 154.0 mg. $\mathrm{l}^{-1}$ de $\mathrm{CaCO}_{3}$ no ponto 4 , com mediana maior no ponto 1 (31.2 mg. $\left.\mathrm{l}^{-1} \mathrm{CaCO}_{3}\right)$. Correlacionou-se no ponto 1 com a temperatura da água, conforme relatado, e com a radiação solar ( $\mathrm{rs}=0.59 \mathrm{P}=0.0007$ ), pluviosidade ( $\mathrm{rs}=0.58 \mathrm{P}=0.0008$ ), teores de cobre ( $\mathrm{rs}=0.51$ $\mathrm{P}=0.0033$ ), potássio ( $\mathrm{rs}=0.60 \mathrm{P}=0.0005$ ), sódio ( $\mathrm{rs}=0.63 \mathrm{P}=0.0003$ ) e teor de sulfato de cobre aplicado no dia de coleta ( $\mathrm{rs}=0.64 \mathrm{P}=0.0002$ ). No ponto 4 correlacionou-se com radiação solar ( $\mathrm{rs}=0.59 \mathrm{P}=0.0007$ ), pluviosidade ( $\mathrm{rs}=0.61 \mathrm{P}=0.0004)$, excedente hídrico ( $\mathrm{rs}=0.53 \mathrm{P}=0.0025) \mathrm{e}$ teores de cálcio ( $\mathrm{rs}=0.52 \mathrm{P}=0.0031$ ). Estas correlações demonstram que a dureza esteve mais elevada no período de chuvas.

$O$ teor de sólidos totais em suspensão variou entre 33 e $155 \mathrm{mg} . \mathrm{l}^{-1}$ no ponto le entre 10 e $280 \mathrm{mg} \cdot \mathrm{l}^{-1}$ no ponto 4 , com mediana maior no ponto $1\left(50 \mathrm{mg} \cdot \mathrm{l}^{-1}\right)$. No ponto 1 não se correlacionou com os outros parâmetros ambientais analisados. No ponto 4 correlacionou-se com a pluviosidade ( $\mathrm{rs}=-0.53 \mathrm{P}=0.0012$ ). Como a aplicação de sulfato de cobre foi mais intensa no período de chuvas, a ausência de correlações no ponto 1 pode ser conseqüência da aplicação do sulfato de cobre, que favorece a sedimentação das partículas em suspensão.

$O$ fósforo solúvel reativo variou entre $<1.63$ e $19.57 \mu \mathrm{g} . \mathrm{l}^{-1}$ no ponto 1 e entre $<1.63 \mathrm{e}$ $14.67 \mu \mathrm{g} . \mathrm{l}^{-1}$ no ponto 4 , apresentando mediana mais elevada no ponto $4\left(4.89 \mu \mathrm{g} . \mathrm{l}^{-1}\right)$. $\mathrm{O}$ fosfato total variou entre $<1.63$ e $34.24 \mu \mathrm{g} . \mathrm{l}^{-1}$ no ponto $1 \mathrm{e}$ entre $<1.63$ e $37.5 \mu \mathrm{g} . \mathrm{l}^{-1}$ no ponto $4 \mathrm{com}$ mediana mais elevada no ponto $4\left(17.12 \mu \mathrm{g} \cdot \mathrm{l}^{-1}\right)$. Não se correlacionaram com outros parâmetros ambientais no nível considerado.

0 amônio variou entre $<0.20$ e $0.70 \mathrm{mg} . \mathrm{l}^{-1}$ no ponto 1 e entre $<0.20$ e $2.60 \mathrm{mg} . \mathrm{l}^{-1}$ no ponto 4 , com ambas as medianas iguais a $<0.20 \mathrm{mg} . \mathrm{l}^{-1}$. Correlacionou-se no ponto 1 , apenas com manganês ( $\mathrm{rs}=0.54 \mathrm{P}=0.0001$ ). 
O nitrato variou entre 0.2 e $1.0 \mathrm{mg} . \mathrm{l}^{-1}$ no ponto 1 e entre 0.1 e $1.7 \mathrm{mg} .1^{-1}$ no ponto 4 , com mediana maior no ponto $1\left(0.4 \mathrm{mg} \cdot \mathrm{l}^{-1}\right)$. Correlacionou-se com escoamento básico (rs= $0.65 \mathrm{P}=0$ ) no ponto 1 . No ponto 4 correlacionou-se com escoamento básico ( $\mathrm{rs}=-0.58 \mathrm{P}=0$ ) e negativamente com temperatura da água, conforme mencionado. Portanto, esteve disponível em maior quantidade durante o período seco-frio.

O sulfato variou entre 2.3 e $14.7 \mathrm{mg} .1^{-1}$ no ponto 1 e entre 2.6 e $6.2 \mathrm{mg} . \mathrm{l}^{-1}$ no ponto 4 , com mediana maior no ponto $1\left(4.6 \mathrm{mg} \cdot \mathrm{l}^{-1}\right)$. Correlacionou-se com temperatura da água $\mathrm{e}$ alcalinidade, conforme mencionado, com os teores de cálcio ( $\mathrm{rs}=0.67 \mathrm{P}=0$ ), potássio ( $\mathrm{rs}=0.69$ $\mathrm{P}=0$ ), magnésio ( $\mathrm{rs}=0.63 \mathrm{P}=0$ ) e sódio ( $\mathrm{rs}=0.59 \mathrm{P}=0$ ) no ponto 1 . No ponto 4 correlacionou-se com os teores de sódio ( $\mathrm{rs}=0.50 \mathrm{P}=0.0003$ ).

O cloro variou entre 2.4 e $8.0 \mathrm{mg} . \mathrm{l}^{-1}$ no ponto 1 e entre 4.0 e $13.8 \mathrm{mg} .1^{-1}$ no ponto 4 , com mediana mais elevada no ponto $1\left(6.5 \mathrm{mg}^{-1}\right)$. Correlacionou-se com volume e elevação $(\mathrm{rs}=-0.50 \mathrm{P}=0)$ e teores de sódio $(\mathrm{rs}=0.82 \mathrm{P}=0)$ no ponto 1 e com volume e elevação ( $\mathrm{rs}=$ $0.68 \mathrm{P}=0$ ), teores de sódio ( $\mathrm{rs}=0.91 \mathrm{P}=0$ ) e de magnésio $(\mathrm{rs}=0.68 \mathrm{P}=0$ ) no ponto 4 . Portanto sofreu diluição no período em que a represa apresentou maior retenção de água, concentrandose nas épocas em que as águas estiveram mais baixas.

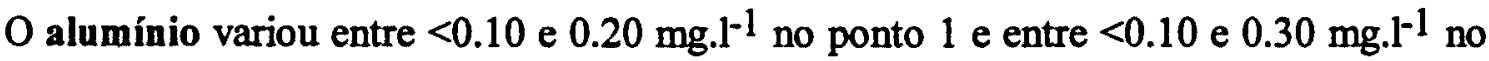
ponto 4 , com mediana maior no ponto $4\left(0.1 \mathrm{mg} \cdot \mathrm{l}^{-1}\right)$. Correlacionou-se com elevação e volume ( $r s=0.61 \mathrm{P}=0$ ) e com os teores de ferro ( $\mathrm{rs}=0.61 \mathrm{P}=0$ ) no ponto 1 . No ponto 4 com os teores de ferro ( $\mathrm{rs}=0.75 \mathrm{P}=0$ ) e com a turbidez, conforme mencionado. A elevação, volume, teores de alumínio e ferro tiveram aumentos simultâneos e podem estar indicando aportes dos solos expostos das margens da represa. $O$ aumento concomitante da turbidez no ponto 4 , onde as áreas de solo exposto eram maiores, confirma estes ingressos.

O cálcio variou entre 2.8 e $7.4 \mathrm{mg} .1^{-1}$ no ponto 1 e entre 4.1 e $10.1 \mathrm{mg} .1^{-1}$ no ponto 4 , com mediana mais elevada no ponto $1\left(6.1 \mathrm{mg} . \mathrm{l}^{-1}\right)$. No ponto 1 , correlacionou-se com temperatura da água, transparência, condutividade, alcalinidade e teor de sulfato, conforme mencionado, e com ferro ( $\mathrm{rs}=-0.54 \mathrm{P}=0.0001$ ), potássio ( $\mathrm{rs}=0.87 \mathrm{P}=0$ ), magnésio ( $\mathrm{rs}=0.69$ $\mathrm{P}=0$ ) e com o teor de sulfato de cobre aplicado nos dias anteriores às coletas ( $\mathrm{rs}=0.54$ $\mathrm{P}=0.0001$ ) e no dia da coleta ( $\mathrm{rs}=0.53 \mathrm{P}=0.0001$ ). No ponto 4 , correlacionou-se com a temperatura da água e a dureza, conforme mencionado e com a radiação solar ( $\mathrm{r} s=0.50$ $\mathrm{P}=0.0002$ ), pluviosidade ( $\mathrm{rs}=0.53 \mathrm{P}=0.0001$ ), teores de sódio ( $\mathrm{rs}=0.55 \mathrm{P}=0.0001$ ), magnésio $(\mathrm{rs}=0.80 \mathrm{P}=0$ ) e potássio $(\mathrm{rs}=0.87 \mathrm{P}=0$ ). Portanto esteve disponivel em maior quantidade nos periodos de temperaturas mais elevadas. 
$\mathrm{O}$ potássio variou entre 0.70 e $3.40 \mathrm{mg} . \mathrm{l}^{-1}$ no ponto 1 e entre 1.80 e $3.10 \mathrm{mg} . \mathrm{l}^{-1}$ no ponto 4 , com mediana mais elevada no ponto $1\left(2.50 \mathrm{mg} \cdot \mathrm{l}^{-1}\right)$. Correlacionou-se com temperatura da água, transparência, alcalinidade, dureza, sulfato, cálcio, ferro ( $\mathrm{rs}=-0.64 \mathrm{P}=0$ ), conforme relatado e com a radiação solar ( $\mathrm{rs}=0.55 \mathrm{P}=0.0001$ ), teores de magnésio ( $\mathrm{rs}=0.64$ $\mathrm{P}=0$ ) e sódio ( $\mathrm{rs}=0.62 \mathrm{P}=0$ ) no ponto 1 . No ponto 4 correlacionou-se com temperatura da água, condutividade, alcalinidade, cálcio, ferro ( $\mathrm{rs}=-0.59 \mathrm{P}=0$ ), sódio ( $\mathrm{rs}=0.55 \mathrm{P}=0.0001) \mathrm{e}$ magnésio ( $\mathrm{rs}=0.63 \mathrm{P}=0$ ). Portanto, também esteve disponivel em maior quantidade nos períodos de temperaturas mais elevadas.

O magnésio variou entre 0.8 e $1.8 \mathrm{mg} . \mathrm{l}^{-1}$ no ponto 1 e entre 1.1 e $2.5 \mathrm{mg} . \mathrm{l}^{-1}$ no ponto 4 , apresentando mediana mais elevada no ponto $1\left(1.6 \mathrm{mg} . \mathrm{l}^{-1}\right)$. Correlacionou-se com sulfato, cálcio, conforme relatado e com os teores de sódio ( $\mathrm{rs}=0.51 \mathrm{P}=0.0002$ ) no ponto 1 e com cloro, cálcio, potássio conforme relatado e com a pluviosidade ( $\mathrm{rs}=0.57 \mathrm{P}=0$ ), radiação solar $(\mathrm{rs}=0.50 \mathrm{P}=0.0002)$ e os teores de sódio $(\mathrm{rs}=0.71 \mathrm{P}=0)$ no ponto 4 .

$\mathrm{O}$ manganês variou entre $<0.02$ e $0.06 \mathrm{mg} . \mathrm{l}^{-1}$ no ponto 1 e no ponto 4 entre $<0.02 \mathrm{e}$ $0.10 \mathrm{mg} \cdot \mathrm{l}^{-1}$, com ambas as medianas menores que o valor de detecção do método utilizado.

O sódio variou entre 1.9 e $6.4 \mathrm{mg} . \mathrm{l}^{-1}$ no ponto 1 e entre 3.5 e $9.4 \mathrm{mg} . \mathrm{l}^{-1}$ no ponto 4 , com mediana superior no ponto $1\left(5.5 \mathrm{mg} . \mathrm{l}^{-1}\right)$. Correlacionou-se com a dureza, sulfato, cloro, magnésio conforme mencionado e com os teores de ferro ( $\mathrm{rs}=-0.54 \mathrm{P}=0.0001$ ), sódio ( $\mathrm{rs}=$ $0.54 \mathrm{P}=0.0001$ ), radiação solar ( $\mathrm{rs}=0.65 \mathrm{P}=0$ ), pluviosidade ( $\mathrm{rs}=0.51 \mathrm{P}=0.0002$ ), elevação ( $\mathrm{rs}=$ - $0.62 \mathrm{P}=0$ ) e volume ( $\mathrm{rs}=-0.63 \mathrm{P}=0$ ) no ponto 1 . No ponto 4 correlacionou-se com a condutividade, teores de cálcio, cloro, potássio, magnésio e sulfato conforme mencionado, com elevação e volume $(r s=-0.69 \mathrm{P}=0)$ e ferro ( $\mathrm{rs}=-0.56 \mathrm{P}=0.0001)$.

$O$ silício variou entre 0.60 e $2.20 \mathrm{mg} .1^{-1}$ no ponto 1 e entre 0.80 e $2.80 \mathrm{mg} .1^{-1}$ no ponto 4 , onde apresentou mediana mais elevada $\left(1.90 \mathrm{mg} . \mathrm{l}^{-1}\right)$. Não se correlacionou com os outros parâmetros no nível considerado, exceto com os teores de cobre no ponto 1 ( $\mathrm{rs}=0.55$ $\mathrm{P}=0.0210$ ). Esta correlação pode estar indicando que as diatomáceas tenham sido sensíveis às aplicações do sulfato de cobre, declinando quando os teores de cobre foram mais elevados e deixando de aproveitar o silício.

O cobre variou entre $<0.02$ e $0.09 \mathrm{mg} . \mathrm{l}^{-1}$ no ponto 1 , com mediana de $0.04 \mathrm{mg} . \mathrm{l}^{-1} \mathrm{e}$ no ponto 4 permaneceu abaixo do limite de detecção do método utilizado, durante todo o período de estudo. Correlacionou-se no ponto 1 com a dureza e os teores de silício, conforme relatado.

$O$ ferro variou entre $<0.02$ e $0.40 \mathrm{mg} . \mathrm{l}^{-1}$ no ponto 1 e entre $<0.02$ e $0.70 \mathrm{mg} . \mathrm{l}^{-1}$ no ponto 4 , com mediana superior no ponto $4\left(0.20 \mathrm{mg} \cdot \mathrm{l}^{-1}\right)$. Correlacionou-se com 
condutividade, alumínio, cálcio, sódio e potássio conforme mencionado, com volume e elevação ( $\mathrm{rs}=0.61 \mathrm{P}=0$ ), conforme mencionado, no ponto 1. Correlacionou-se com condutividade, teores de alumínio, potássio e sódio, conforme mencionado, no ponto 4 .

O zinco variou entre $<0.02$ e $0.20 \mathrm{mg} . \mathrm{l}^{-1}$, no ponto 1 , e entre $<0.02$ e $0.10 \mathrm{mg} . \mathrm{l}^{-1}$, no

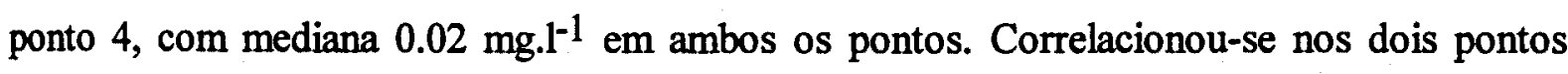
com alcalinidade, conforme mencionado e no ponto 1 , com a radiação solar ( $r s=-0.53$ $\mathrm{P}=0.0001$ ).

Boro, bário, cádmio, cromo, chumbo e níquel estiveram sempre abaixo do nível de deteç̧ão do método utilizado. 


\subsection{COMUNIDADE FITOPLANCTÔNICA DA REPRESA DE GUARAPIRANGA}

\subsubsection{COMPOSIÇÃO}

A comunidade fitoplanctônica da represa de Guarapiranga apresentou-se constituída por 240 táxons (espécies, variedades e formas), distribuídos em 97 gêneros, pertencentes a 8 classes taxonômicas (14 Cyanophyceae, 106 Chlorophyceae, 41 Zygnemaphyceae, 19 Euglenophyceae, 26 Bacillariophyceae, 14 Chrysophyceae, 9 Cryptophyceae e 11 Dinophyceae), conforme relacionado a seguir. Além disto, também foram consideradas como unidades taxonômicas: as 3 diferentes fases do ciclo de vida da espécie Chlamydomonas cf gloeophila e 2 dimensões diferenciadas, constituindo dois tipos de Synedra ulna.

\section{QUADRO 1 - COMPOSIÇÃO FLORÍSTICA}

Espécie exclusiva de cada ponto: *

\section{PONTO 1}

\section{CYANOPHYCEAE - CHROOCOCCALES}

1. APHDE Aphanocapsa cf. delicatissima W. \& G.S. West *

2. APHEC Aphanocapsa elachista W. \& G. S. West var. conferta W. \& G.S.West

3. APHEL Aphanothece elabens (Brébisson) Elenkin *

4. APHEP Aphanocapsa elachista W. \& G. S. West var. planctonica G.M.Smith

5. CRCMI Chroococcus cf. minor (Kuetzing) Naegeli

6. CRCMU Chroococcus ef. minutus (Kuetzing) Naegeli

7. CYAHA Cyanarcus hamiformis Pascher

8. GLOS1 Gloeocapsa sp.1*

9. SYNEL Synechoccocus elongatus Naegeli

10. SYNSE Synechocystis septentrionalis Skuja

TOTAL: 10 táxons: 6 identificados nos níveis específicos ou infraespecíficos, 3 a confirmar e 1 no nível genérico.

\section{CYANOPHYCEAE - HORMOGONALES}
1. ANAS1
Anabaenopsis sp. $1^{*}$
2. OSCSA
Oscillatoria sancta Kuetzing *
3. OSCSU
Oscillatoria subtilissima Kuetzing
4. PSECA Pseudanabaena catenata Lauterberborni

TOTAL: 4 táxons: 3 no nivel específico e 1 no nível genérico.

Total de Cyanophyceae: 14 táxons: 10 identificados nos níveis específicos ou infraespecificos, 3 a confirmar e 2 no nível genérico.

Táxons comuns aos dois pontos de coleta: 9

Táxons exclusivos do ponto 1: 5

\section{CHLOROPHYCEAE - CHLOROCOCCALES}

1. ANKBR Ankistrodesmus bribaianus (Reinsch)Korsikov *

2. ANKFU Ankistrodesmus fusiformis Corda

3. ANKGR Ankistrodesmus gracilis (Reinsch) Korsikov. *

4. BOTNE Botryococcus neglectus (W. et G.S.West) Komárek

5. CLCS07 Chlorococcales sp. $7 \mathrm{col}$.

6. CLCS13 Chlorococcales sp.13 col. *

7. CLCS14 Chlorococcales sp. 14 col.*

8. CLCS5 Chlorococcales sp.5 unic. * 
9. CLOLO Closteriopsis longissima (Lemmermarn) Lermermam var. longissima Lemmermam*

10. CLOMI Chlorella cf. minutissima Fott \& Novák.

11. CLOSA Chlorella cf. sacharophila (Krieger) Migula *

12. CLOVI Chlorella vulgaris Beijerink var. viridis Chodat

13. CLOVU Chlorella vulgaris Beijerink var. vulgaris Beijerink

14. CLUS7 Chlorococcales sp.7 unic. *

15. COECA Coelastrum cambricum Archer

16. COEHI Coenochloris hindakii Komárek

17. COEMI Coelastrum microporum Naegeli var. microporum Naegeli*

18. COEPR Coelastrum proboscideum Bohlin *

19. COERE Coelastrum reticulatum (Dangeard) Senn

20. CRUCR Crucigeniella crucifera (Wolle) Komárek

21. CRUTE Crucigenia tetrapedia (Kirchnner) W. \& G.S. West

22. DICAN Dictyosphaerium anomalum Korsikov

23. DICCH Dictyosphaerium chlorelloides (Naumann) Komárek \& Perman *

24. DICEH Dictyosphaerium ehrenberghianum Naegeli

25. DICEL Dictyosphaerium elegans Bachmann.

26. DICPU Dictyosphaerium pulchellum Wood var. pulchellum Wood

27. DISSP. Dispora speciosa Korsikov *

28. ELAFA Elakatothrix gelifacta (Chodat) Hindák

29. ELAGE Elakatothrix gelatinosa Wille

30. EUTFO Eutetramorus fotii (Hindák) Komárek

31. EUTNY Eutetramorus cf. nygaardii Komárek

32. FRADR Franceia droescherii (Lemmermann) G.M. Smith

33. FRAPO Franceia polychaeta (Sirs) Korsikov*

34. GEMIN Geminella interrupta (Turpin) Lagerheim. Syn. Dactylothece braunii Lagerheim

35. GLOAM . Gloeocystis ampla (Kuetzing) Rabenhorst *

36. GLOBA Gloeocystis cf. bannergattensis Iyengary *

37. GLORU Gloeocystis rupestris (Lyngbie) Rabenhorst *

38. GLOVE Gloeocystis vesiculosa Naegeli

39. GOLPA Golenkinia paucispina W. \& G.S. West

40. GOLRA Golenkinia radiata Chodat

41. KIRLU Kirchneriella lunaris (Kirchner) Moebius

42. KIROB Kirchneriella obesa (W.West) Schmidle *

43. KIRPS Kirchneriella cf. pseudoaperta Komárek *

44. MICPU Micractinium pusillum Fresenius

45. MONAR Monoraphidium arcuatum (Korsikov) Hindák

46. MONCA Monoraphidium caribeum Hindák

47. MONCO Monoraphidium contortum (Thurpin) Komarkova-Legnerová

48. MONCV Monoraphidium convolutum (Corda) Komarkova-Legnerová

49. MONMI Monoraphidium cf. minutum (Naegeli.) Komarkova-Legnerová *

50. MONSE Monoraphidium setiforme (Nygaard) Komarkova-Legnerová

51. OOCLA Oocystis lacustris Chodat

52. OOCNA Oocystis cf. natans (Lemmermann) Lemmermann

53. OOCNO Oocystis cf. nodulosa W. \& G.S. West *

54. OOCPU Oocystis pusilla Hansgirg

55. PACKO Pachycladella komarekii (Fott \& Novak) Reymond *

56. PALTE Palmelochaete tenerrima Korsikov

57. QUALA Quadrigula lacustris (Chodat) G.M. Smith

58. SCEAC Scenedesmus acuminatus (Lagerheim) Chodat

59. SCEAR Scenedesmus arcuatus (Lemmermann) Lemmermann

60. SCEBC Scenedesmus bicaudatus (Hansgirg) Chodat

61. SCEBJ Scenedesmus bijugus (Turpin) Kuetzing

62. SCEDA Scenedesmus dactylococcoides Chodat

63. SCEDE Scenedesmus denticulatus Langerheimii 
64. SCEJA Scenedesmus javanensis Chodat

65. SCEOP Scenedesmus opoliensis P.Richt *

66. SCEOV Scenedesmus ovalternus Chodat *

67. SCEQU Scenedesmus quadricauda (Turpin) Brébisson

68. SCERM Scenedesmus cf.. armatus Chodat *

69. SP.HPL Sphaerocystis cf. planctonica (Korsikov) Bourrelly *

70. SP.HSC Sphaerocystis schroeterii Chodat

71. TETLA Tetrallanthos langerheimii Teiling *

72. TREEL Treubaria elegans Hortobágy

73. TRESE Treubaria setigera (Archer) G.M. Smith

74. WESBO Westella botryoides (W.West) De-Wildemann

TOTAL: 74 táxons: 60 identificados nos níveis específicos ou infraespecíficos, 9 a confirmar e 5 no nivel de ordem.

Táxons comuns aos dois pontos de coleta: 48

Táxons exclusivos do ponto 1:26

\section{CHLOROPHYCEAE - OEDOGONIALES}

1. ZOED1 Zigoto Oedogoniales sp.1

2. ZOED2 Zigoto Oedogoniales sp.2

3. ZOED3 Zigoto Oedogoniales sp. 3 *

TOTAL: 3 táxons identificados no nível de ordem.

Táxons comuns aos dois pontos de coleta: 2

Táxons exclusivos do ponto $1: 1$

\section{CHLOROPHYCEAE - VOLVOCALES}

1. CLAG1 Chlamydomonas cf. gloeophila Skuja fasel

2. CLAG2 Chlamydomonas cf. gloeophila Skuja fase2

3. CLAGC Chlamydomonas cf. gloeophila Skuja col.

4. CLAGL Chlamydomonas cf. globosa Snow

5. CLAGR Chlamydomonas cf. gracilis Snow

6. CLAPR Chlamydomonas cf. proteus Pringsheim

7. CLAS1 Chlamydomonas sp.1

8. CLASU Chlamydomonas cf. subcaudata Wille

9. EUDEL Eudorina elegans Ehrenberg *

10. VOLC1 Volvocales sp.1 col.

11. VOUS1 Volvocales sp.1 uni.

TOTAL: 11 táxons: 1 identificado no nível específico, , 7 a confirmar, 1 no nível genérico e 2 no de ordem.

Táxons comuns aos dois pontos de coleta: 10

Táxons exclusivos do ponto 1: 1

Total de Chlorophyceae: 88 táxons

Táxons comuns aos dois pontos de coleta: 60

Táxons exclusivos do ponto 1: 28

\section{ZYGNEMAPHYCEAE - ZYGNEMATALES}

1. ACTS1

2. ACTS2

3. ACTWO

4. CLOS1

5. $\cos 12$

6. $\cos 15$

7. $\cos 16$

8. $\cos 18$
Actinotaenium sp. 1 *

Actinotaenium sp. 2 *

Actinotaenium cf. wollei (W. \& G.S. West) Teiling

Closterium sp. $1^{*}$

Cosmarium sp.12*

Cosmarium sp.15

Cosmarium sp.16*

Cosmarium sp.18* 


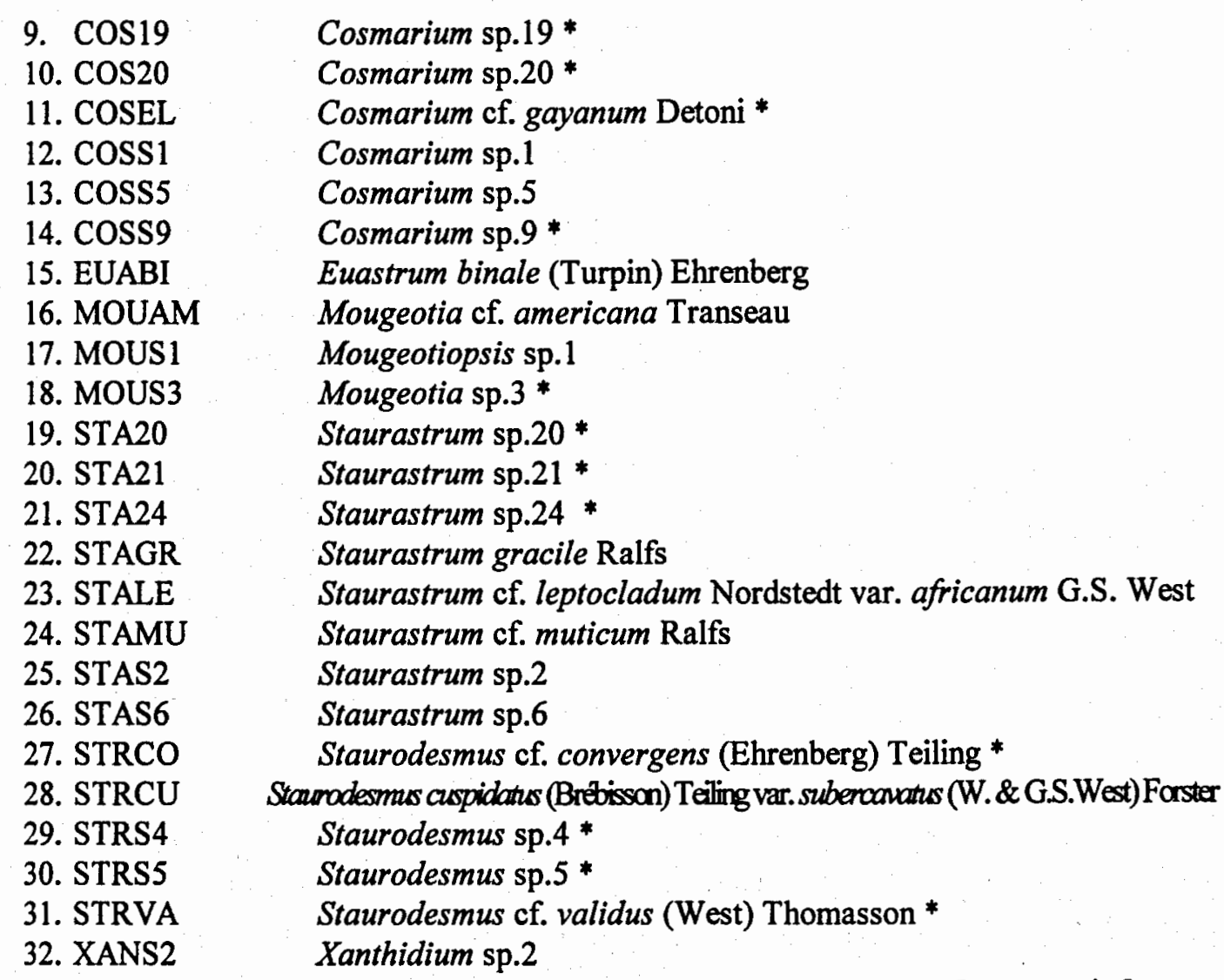

TOTAL: 32 táxons: 3 identificados nos niveis específicos ou infraespecíficos, 7 a confirmar e 22 no nivel genérico

Táxons comuns aos dois pontos de coleta: 14

Táxons exclusivos do ponto 1: 18

Total de espécies identificadas no ponto 1: 182, considerando-se 183 unidades taxonômicas.

\section{EUGLENOPHYCEAE - EUGLENALES}
1. EUGAC
Euglena acus Ehrenberg var. acus Ehrenberg
2. EUGDE
3. EUGPA
4. LEPTE
5. STROF
6. TRACE
7. TRAOB
8. TRAS4
9. TRAS5
10. TRATY
11. TRAVO
Euglena cf. deses Ehrenberg *
Euglena estágio palmeloide *
Lepocynclis texta (Dujardin)Lemmermann var. richiona (Corrad)Huber-Pestaberi
12. TRAVP
Strombomonas cf. fluviatilis (Lemmermann) Deflandre *
Trachelomonas cf. cervicula Stokes
Trachelomonas cf. oblonga Lemmermann
Trachelomonas sp.4*
Trachelomonas $\mathrm{sp.5*}$
Trachelomonas cf. tympanum Pascher *
Trachelomonas volvocina Ehrenberg var. derephora Conrad

TOTAL: 12 táxons: 4 identificados nos níveis específicos ou infraespecíficos, 5 a confirmar e 3 no nível genérico

táxons comuns aos dois pontos de coleta: 6

táxons exclusivos do ponto $1: 6$

\section{BACILLARIOPHYCEAE - CENTRALES}

1. AULAN Aulacoseira granulata (Ehrenberg) Ralfs var. angustissima $\mathrm{O}$. Mueller

2. AULCU Aulacoseina gramulata (Ehrenberg) Ralfs var. angustissima OMuele f cumata Grnnov

3. AULGR Aulacoseira granulata (Ehrenberg) Ralfs 
4. CYCME Cyclotella meneghiniana Kuetzing

5. CYCOC Cyclotella cf. ocellata Pantockse *

6. RHIEIR Rhizosolenia eiriensis H.L. Smith var. morsa W. \& G.S. West

7. RHILO Rhizosolenia longiseta Zacharias

8. RHISP.1 Rhizosolenia sp.1

9. STEDUB Stephanodiscus dubius (Fricke) Hustedt

TOTAL: 9 táxons: 7 identificados nos níveis específicos ou infraespecíficos, 1 a confirmar e 1no nivel genérico.

Táxons comuns aos dois pontos de coleta: 8

Táxons exclusivos do ponto $1: 1$

\section{BACILLARIOPHYCEAE - PENNALES}

1. AMPS1 Amphora sp. $1^{*}$

2. ASTFO Asterionella formosa Hasall

3. CALAM Caloneis amphisbaena (Bory) Cleve

4. DIAS3 Diatomacea sp.3*

5. EUNS4 Eunotia sp.4*

6. NAVS1 Navicula sp. 1 *

7. SYNMI Synedra minuscula Grunov

8. SYNU1 Synedra ulna (Nitzsch) t.1

9. SYNU2 Synedra ulna (Nitzsch) t.2

TOTAL: 8 táxons: 4 identificados nos níveis específicos ou infraespecíficos, 3 no nível genérico, 1 no de sub-classe. Synedra ulna foi dividida em dois táxons, devido a constância das respectivas dimensões.

Táxons comuns aos dois pontos de coleta: 4

Táxons exclusivos do ponto 1: 4

Total de Bacillariophyceae: 17 táxons

Táxons comuns aos dois pontos de coleta: 12

Táxons exclusivos do ponto $1: 5$

\section{CHRYSOPHYCEAE - OCHROMONADALES}

1. DINBA Dinobryon bavaricum Imhoff var. medium (Lemmermann) Krieger

2. DINDI Dinobryon divergens Imhoff var. angulatum (Seligo) Brunnthaler

3. DINSE Dinobryon sertularia Ehrenberg

4. MALAP Mallomonas apochromatica Conrad

5. MALCA Mallomonas cf. caudata Iwanoff

6. MALMA Mallomonas cf. majorensis Skuja *

7. MALPA Mallomonas cf. pallida Conrad

8. MALRH Mallomonas cf. rhopaloides Conrad *

9. MALTE Mallomonas cf. tenuis Conrad

10. MALTO Mallomonas tonsurata Teiling

11. SYNUV Synura uvella Ehrenberg

TOTAL: 11 táxons: 6 identificados nos níveis específicos ou infraespecíficos e 5 a confirmar.

Táxons comuns aos dois pontos de coleta: 9

Táxons exclusivos do ponto 1: 2

\section{CRYPTOPHYCEAE - CRYPTOMONADALES}

1. CHIAC Chilomonas cf. acuta Schiller

2. CHIMI Chilomonas cf. minuta (Skuja) *

3. CROBR Chroomonas cf. breviciliata Nyigaard

4. CRYBR Cryptomonas cf. brasiliensis Castro, Bicudo \& Bicudo

5. CRYER Cryptomonas cf. erosa Ehrenberg 
6. CRYTE Cryptomonas cf. tenuis Pascher

7. SENCO Sennia cf. communata Pascher emend. Skuja

TOTAL: 7 táxons: 7 a confirmar.

Táxons comuns aos dois pontos de coleta: 6

Táxons exclusivos do ponto 1: 1

\section{DINOPHYCEAE - PERIDINIALES}

1. GYMEU Gymnodinium cf. eurytopum Skuja

TOTAL: 1 táxon: 1 a confirmar

táxons comuns aos dois pontos de coleta: 1

\section{PONTO 4}

\section{CYANOPHYCEAE - CHROOCOCCALES}

1. APHEC Aphanocapsa elachista W. \& G. S. West var. conferta W. \& G.S.West

2. APHEP Aphanocapsa elachista W. \& G. S. West var. planctonica G.M.Smith

3. CRCMI Chroococcus cf. minor (Kuetzing) Naegeli

4. CRCMU Chroococcus cf. minutus (Kuetzing) Naegeli

5. CYAHA Cyanarcus hamiformis Pascher

6. SYNEL Synechoccocus elongatus Naegeli

7. SYNSE Synechocystis septentrionalis Skuja

TOTAL: 7 táxons: 5 identificados nos níveis específicos ou infraespecíficos e 2 a confirmar.

Táxons comuns aos dois pontos de coleta: 7

\section{CYANOPHYCEAE - HORMOGONALES}

\section{OSCSU Oscillatoria subtilissima Kuetzing}

2. PSECA Pseudanabaena catenata Lauterborni

TOTAL: 2 táxons: 2 identificados nos níveis especificos.

Táxons comuns aos dois pontos de coleta: 2

Total de Cyanophyceae: 9 táxons: 7 identificados nos níveis específicos ou infraespecíficos e 2 a confirmar.

Táxons comuns aos dois pontos de coleta: 9

\section{CHLOROPHYCEAE - CHLOROCOCCALES}

1. ANKFU Ankistrodesmus fusiformis Corda

2. BOTNE Botryococcus neglectus (W \& G.S. West) Komárek

3. CHLSE Chlorophyceae séssil *

4. CLC07 Chlorococcales sp.7 col.

5. CLC10 Chlorococcales sp.10 col. *

6. CLC11 Chlorococcales sp.11 col. *

7. CLC12 Chlorococcales sp.12 col. *

8. CLCHU Chlorococcum cf. humicola (Naegeli) Rabenhorst *

9. CLCSP. Chlorococcum cf. sphagni Dangeard

10. CLOMI Chlorella cf. minutissima Fott \& Novák.

11. CLOVI Chlorella vulgaris Beijerink var. viridis Chodat

12. CLOVU Chlorella vulgaris Beijerink var. vulgaris Beijerink

13. COECA Coelastrum cambricum Archer

14. COEHI Coenochloris hindakii Komárek

15. COEPS Coelastrum pseudomicroporum Korsikov *

16. COERE Coelastrum reticulatum (Dangeard) Senn

17. CRUCR Crucigeniella crucifera (Wolle) Komárek 
18. CRUTE Crucigenia tetrapedia (Kirchner) W. \& G.S. West

19. DICAN Dictyosphaerium anomalum Korsikov

20. DICEH Dictyosphaerium ehrenberghianum Naegeli

21. DICEL Dictyosphaerium elegans Bachmann.

22. DICPU Dictyosphaerium pulchellum Wood var. pulchellum Wood

23. ELAFA Elakatotrix gelifacta (Chodat) Hindák

24. ELAGE Elakatotrix gelatinosa Wille

25. EUTFO Eutetramorus fotii (Hindák) Komárek

26. EUTNY Eutetramorus cf. nygaardii Komárek

27. FRADR Franceia droescherii (Lemmermann) G.M. Smith

28. GEMIN Geminella interrupta (Turpin) Lagerheim. Syn. Dactylothece braunii Lagerheim.

29. GLKPA Golenkiniopsis cf. parvula (Voronichin) Korsikov *

30. GLOVE Gloeocystis vesiculosa Naegeli

31. GOLPA Golenkinia paucispina W. \& G.S. West

32. GOLRA Golenkinia radiata Chodat

33. KIRLU Kirchneriella lunaris (Kirchner) Moebius

34. MICPU Micractinium pusillum Fresenius

35. MONAR Monoraphidium arcuatum (Korsikov) Hindák

36. MONCA Monoraphidium caribeum Hindák

37. MONCO Monoraphidium contortum (Thurpin) Komarkova-Legnerová

38. MONCV Monoraphidium convolutum (Corda) Komarkova-Legnerová

39. MONSE Monoraphidium setiforme (Nygaard) Komarkova-Legnerová

40. MONTO Monoraphidium cf. tortile (W. \& G.S. West) Komarkova-Legnerová

41. OOCLA Oocystis lacustris Chodat

42. OOCNA Oocystis cf. natans (Lemmermann) Lemmermann

43. OOCPU Oocystis pusilla Hansgirg

44. OOCRO . Oocystis cf. rhomboidea Fott *

45. PALTE Palmelochaete tenerrima Korsikov

46. PEDTE Pediastrum tetras (Ehrenberg) Ralfs *

47. QUALA Quadrigula lacustris (Chodat) G.M. Smith

48. SCEAC Scenedesmus acuminatus (Lagerheim) Chodat *

49. SCECU Scenedesmus acutus Meyen

50. SCEAR Scenedesmus arcuatus (Lemmermann) Lemmermann

51. SCEBC Scenedesmus bicaudatus (Hansgirg) Chodat

52. SCEBJ Scenedesmus bijugus (Turpin) Kuetzing

53. SCEDA Scenedesmus dactylococcoides Chodat

54. SCEDE Scenedesmus denticulatus Lagerheim

55. SCEJA Scenedesmus javanensis Chodat

56. SCEQM Scenedesmus quadricauda (Turpin) Brébisson var. maximus W. \& G.S. West *

57. SCEQU Scenedesmus quadricauda (Turpin) Brébisson

58. SCESP. Scenedesmus cf. spinosus Hortobágy *

59. SP.HSC Sphaerocystis schroeterii Chodat

60. TETMI Tetraedron minimum (A.Braun) Hansgirg *

61. TETMM Tetraedron minimum (A.Braun) Hansgirg var. minimum A.Braun *

62. TETTR Tetraedron cf. triangulares Korsikov *

63. TETVI Tetraedron cf. victorieae Woloszinska *

64. TREEL Treubaria elegans Hortobágy

65. TRESC Treubaria schmidlei (Schroeder) Fott \& Kovácik *

66. TRESE Treubaria setigera (Archer) G.M. Smith

67. WESBO Westella botryoides (W.West) De-Wildemann

68. WESS4 Westella sp.4

69. WESS3 Westella sp.3*

TOTAL: 69 táxons: 50 identificados nos níveis específicos ou infraespecíficos, 11 a confirmar, 2 no nível genérico, 4 no nível de ordem e 1 classe. 
Táxons comuns aos dois pontos de coleta: 48

Táxons exclusivos do ponto 4: 19

\section{CHLOROPHYCEAE - OEDOGONIALES}

1. ZOED1 Zigoto Oedogoniales sp.1

2. ZOED2 Zigoto Oedogoniales sp.2

TOTAL: 2 táxons identificados no nível de ordem.

Táxons comuns aos dois pontos de coleta: 2

Táxons exclusivos do ponto 4: 0

\section{CHLOROPHYCEAE - VOLVOCALES}

1. CLAG1 Chlamydomonas cf. gloeophila Skuja fase 1

2. CLAG2 Chlamydomonas cf. gloeophila Skuja fase 2

3. CLAGC Chlamydomonas cf. gloeophila Skuja col.

4. CLAGL Chlamydomonas ef. globosa Snow

5. CLAGR Chlamydomonas cf. gracilis Snow

6. CLAPR Chlamydomonas cf. proteus Pringsheim

7. CLAS1 Chlamydomonas sp.1

8. CLASU Chlamydomonas cf. subcaudata Wille

9. VOLC1 Volvocales sp.1 col.

10. VOUS1 Volvocales sp.1 uni.

TOTAL: 8 táxons: 5 a confirmar, 1 no nível genérico e 2 no nível de ordem.

Táxons comuns aos dois pontos de coleta: 10

Táxons exclusivos do ponto 4: 0

Total de Chlorophyceae: 81 táxons.

Táxons comuns aos dois pontos de coleta: 60

Táxons exclusivos do ponto 4: 21

\section{ZYGNEMAPHYCEAE - ZYGNEMATALES}

\section{ACTS3 Actinotaenium sp. $3^{*}$}

2. ACTWO Actinotaenium cf. wollei (W. \& G.S.West) Teiling

3. $\operatorname{Cos} 10$ Cosmarium sp.10*

4. $\operatorname{Cos} 15$ Cosmarium sp.15

5. COSS1 Cosmarium sp.1

6. Coss5 Cosmarium sp.5

7. COSS7 Cosmarium sp.7*

8. DESM1 Desmidium sp.1 *

9. DESU1 Desmidiaceae unic sp. 1 *

10. EUABI Euastrum binale (Turpin) Ehrenberg

11. EUAS1 Euastrum sp.1*

12. MOUAM Mougeotia cf. americanc Transeau

13. MOUS1 Mougeotiopsis sp.1

14. STA16 Staurastrum sp.16*

15. STAGR Staurastrum gracile Ralfs

16. STALE Staurastrum cf. leptocladum Nordstedt var. africanum G.S.West

17. STAMU Staurastrum cf. muticum Brébisson

18. STAS2 Staurastrum sp.2

19. STAS6 Staurastrum sp.6

20. STASA Staurastrum sagitarium Nordstedt f africanum Nordstedt *

21. STRSP. Staurodesmus sp.encerianus (Maskell) Teiling *

22. STRCU Strourodesmus cuspidatus (Brebisson) Teling var. suberconatus(W.\& G.S.West)Forster

23. XANS2 Xanthidium sp.2 
TOTAL: 23 táxons: 6 identificados nos níveis específicos ou infraespecíficos, 3 a confirmar, 13 no nível genérico e 1 no de familia.

Táxons comuns aos dois pontos de coleta: 14

Táxons exclusivos do ponto 4: 9

Total de espécies identificadas no ponto 4: 175, considerando-se 178 unidades taxonômicas.

\section{EUGLENOPHYCEAE - COLACIALES}

1. COLSI Colacium sideropus Skuja *

TOTAL: 1 táxon identificado no nível específico.

Táxons exclusivos do ponto 4: 1

\section{EUGLENOPHYCEAE - EUGLENALES}

1. EUGAA Euglena acus Ehrenberg var. acus Ehrenberg

2. EUGHA Euglena cf. haematodes (Ehrenberg) Lemmermann *

3. EUGOX Euglena cf. oxyurus Schmarda *

4. LEPTE Lepocinclis texta (Dujardin) Lommermannvar. richiona (Corrad)Huber-Pestalozi

5. PHAAC Phacus acuminatus Stokes ssp. americana *

6. PHAGL Phacus cf. glaber (Deflandre) Pochman *

7. PHALO Phacus longicauda (Ehrenberg) Dujardin var. longicauda (Ehrenberg) Dujardin *

8. TRACE Trachelomonas cf. cervicula Stokes

9. TRAOB Trachelomonas cf. oblonga Lemmermann

10. TRASI Trachelomonas cf. similis Stokes var. similis Stokes *

11. TRAVO Trachelomonas volvocina Ehrenberg var. derephora Conrad

12. TRAVP Trachelomonas volvocinopsis Swirenko var. volvocinopsis Swirenko

TOTAL: 12 táxons: 6 identificados nos niveis específicos ou infraespecíficos e 6 a confirmar.

Táxons comuns aos dois pontos de coleta: 6

Táxons exclusivos do ponto 4: 6

Total de Euglenophyceae: 13 táxons: 7 identificados nos níveis específicos ou infraespecíficos e 6 a confirmar.

Táxons comuns aos dois pontos de coleta: 6

Táxons exclusivos do ponto 4: 7

\section{BACILLARIOPHYCEAE - CENTRALES}

1. AULAN Aulacoseira granulata (Ehrenberg) Ralfs var. angustissima O.Mueller

2. AULCU Aulacoseira gromulata (Ehrenberg) Rals var. angrstissima $O$.Mueler $\mathrm{f}$ cumata Grunov

3. AULGR Aulacoseira granulata (Ehrenberg) Ralfs

4. AULSP. Aulacoseina gramulata (Ehrenberg) Ralfs var. angrstissima OMueler f spiralis Habitusbid*

5. CYCGL Cyclotella cf. glomerata Bachmann *

6. CYCME Cyclotella meneghiniana Kuetzing

7. CYCPS Cyclotella cf. pseudostelligera Hustedt *

8. RHIEIR Rhizosolenia eiriensis H.L. Smith var. morsa W. \& G.S. West

9. RHILO Rhizosolenia longiseta Zacharias

10. RHISP.1 Rhizosolenia sp.1

11. STEDUB Stephanodiscus dubius (Fricke) Hustedt

TOTAL: 11 táxons: 8 identificados nos niveis específicos ou infraespecíficos, 2 a confirmar e 1 no nivel genérico

Táxons comuns aos dois pontos de coleta: 8

Táxons exclusivos do ponto $4: 3$

\section{BACILLARIOPHYCEAE - PENNALES}
1. ASTFO
Asterionella formosa Hasall 
2. CALAM Caloneis amphisbaena (Bory) Cleve

3. CYMS1 Cymbella sp. $1^{*}$

4. DIAS4 Diatomacea sp. 4 *

5. EUNS1 Eunotia sp. $1^{*}$

6. GOMS1 Gomphonema sp.1 *

7. SURS2 Surirella sp.2*

8. SYNMI Synedra minuscula Grunov

9. SYNU1 Synedra ulna (Nitzsch) t.1

10. SYNU2 Synedra ulna (Nitzsch) t.2

TOTAL: 9 táxons: 4 identificados nos níveis específicos ou infraespecíficos, 4 no nívelgenérico e 1sub-classe. Synedra ulna foi dividida em dois táxons, devido a constância das respectivas dimensões.

Táxons comuns aos dois pontos de coleta: 4

Táxons exclusivos do ponto 4: 5

Total de Bacillariophyceae: 20 táxons

Táxons comuns aos dois pontos de coleta: 12

Táxons exclusivos do ponto 4: 8

\section{CHRYSOPHYCEAE - OCHROMONADALES}

1. DINBA Dinobryon bavaricum Imhoff var. medium (Lemmermann) Krieger

2. DINDI Dinobryon divergens Imhoff var. angulatum (Seligo) Brunthaler

3. DINSE Dinobryon sertularia Ehrenberg

4. MAAL Mallomonas cf. allorgei (Doflein) Conrad *

5. MALAP Mallomonas apochromatica Conrad

6. MALAC Mallomonas cf. acaroides Perty *

7. MALCA Mallomonas cf. caudata Iwanoff

8. MALFU Mallomonas cf. fusiformis Werm *

9. MALPA Mallomonas cf. pallida Conrad

10. MALTE Mallomonas cf. tenuis Conrad

11. MALTO Mallomonas tonsurata Teiling

12. SYNUV Synura uvella Ehrenberg

TOTAL: 12 táxons: 6 identificados nos níveis específicos ou infraespecíficos e 6 a confirmar.

Táxons comuns aos dois pontos de coleta: 9

Táxons exclusivos do ponto 4: 3

\section{CRYPTOPHYCEAE - CRYPTOMONADALES}

1. CHIAC Chilomonas cf. acuta Schiller

2. CROBR Chroomonas cf. breviciliata Nyigaard

3. CROPU Chroomonas cf. pulex Pascher *

4. CRYBR Cryptomonas cf. brasiliensis Castro, Bicudo \& Bicudo

5. CRYER Cryptomonas cf. erosa Ehrenberg

6. CRYTE Cryptomonas cf. tenuis Pascher

7. RHOLA Rhodomonas cf. lacustris Pascher et Ruttner *

8. SENCO Sennia cf. communata Pascher emend. Skuja

TOTAL: 8 táxons: 8 a confirmar.

Táxons comuns aos dois pontos de coleta: 6

Táxons exclusivos do ponto $4: 2$

\section{DINOPHYCEAE - PERIDINIALES}

1. GYMBO Gymnodinium cf. bogoriense Klebs *

2. GYMCO Gymnodinium cf. coronatum Woloszinska *

3. GYMEU Gymnodinium cf. eurytopum Skuja 
4. GYMFU Gymnodinium fuscum (Ehrenberg) Stein *

5. GYMHE Gymnodinium cf. helveticum Penard *

6. HEMS1 Hemidinium sp. * $^{*}$

7. HEMS2 Hemidinium $\mathrm{sp} .2 *$

8. HEMS3 Hemidinium sp.3*

9. PERS1 Peridinium sp. ${ }^{*}$

10. PERS2 Peridinium sp. ${ }^{*}$

11. PERS3 Peridinium sp. 3 *

TOTAL: 11 táxons: 1 identificado nos níveis específicos ou infraespecíficos, 4 a confirmar e 6 no nível genérico

Táxon comum aos dois pontos de coleta: 1

Táxons exclusivos do ponto 4: 10

No ponto 1 a comunidade fitoplanctônica constituiu-se de 183 , e no ponto 4 de 178 táxons. No total foram registrados 240 táxons distribuídos em 81 gêneros identificados, sendo os gêneros não identificados: 13 de cloroficea, 2 de bacilarioficea e 1 de zignemaficea.

Dentre os 240 táxons, 107 foram identificados nos niveis específicos e/ou infraespecíficos. Houve espécies (50) que foram identificadas através de números, devido à dificuldade de observação de características necessárias à sua identificação ou por não haver sido encontradas descrições correspondentes na literatura disponível. Outras espécies (68) que não conferiram exatamente com as descrições, mas apresentavam forma semelhante, necessitam de confirmação e foram assinaladas com cf.. Algumas algas apresentaram características diferenciadas, indicando a possibilidade de ocorrência de alterações induzidas pelo ambiente, como por exemplo, Rhizosolenia sp.1 alguns espécimes de Scenedesmus sp., Staurastrum cf. gracile e de Chlamydomonas cf. gloeophila. A espécie Synedra ulna foi separada em dois tipos devido à constância de duas determinadas dimensões o que leva a supor uma atuação ambiental diferenciada. Chlamydomonas cf. gloeophila apresentou três formas ou fases: unicelular esférica, unicelular elipsóide e colonial ou palmelóide.

As cloroficeas apresentaram o maior número de táxons nos dois pontos de coleta. Ocorreram 74 táxons de clorococales no ponto 1 e 69 no ponto 4, representando respectivamente 38 e $39 \%$ dos totais de cada ponto de coleta. As volvocales foram tratadas a parte, devido à presença de flagelos o que lhes confere comportamento diferenciado. Nos dois pontos zignemaficea foi a segunda classe mais importante em termos de número de táxons apresentando 32 no ponto 1 e 23 no ponto 4, respectivamente 17 e $13 \%$ dos totais. Dos 240 táxons encontrados 65 foram exclusivos do ponto 1 e 60 do ponto $4 ; 115$ táxons foram comuns aos dois pontos.

As Tabelas 35 e 36 mostram que a mediana do número de táxons no ponto 1 foi maior no período da seca (27) que nas chuvas (22). O número de táxons no ponto 1 , foi aumentando 
do início para o final das amostragens: primeira seca (19), chuvas moderadas (17), chuvas intensas (26) e segunda seca (29), conforme mostram as respectivas medianas. No ponto 4 , a mediana do número de táxons foi maior no período de chuvas (20) que no da seca (18) e também aumentou do início para o final das amostragens: primeira seca (13), chuvas moderadas (16), chuvas intensas (24) e segunda seca (26).

\subsubsection{FREQÜÊNCIA DE OCORRÊNCIA}

No ponto 1 (Tabela 7) registrou-se 119 táxons, com freqüência inferior a $10 \%$ das amostras, ou seja, entre 1 e 5 coletas, que foram consideradas espécies raras, constituindo $63 \%$ do total das espécies; 36 táxons ocorreram em menos que $25 \%$ e mais que $10 \%$ das coletas e foram consideradas pouco freqüentes, perfazendo $20 \%$ do total das espécies; 18 ocorreram com frequiência superior a $25 \%$ e inferior ou igual a $50 \%$ das amostras e foram considerados moderadamente freqüentes, perfazendo $10 \%$ do total das espécies; 9 alcançaram frequiência maior que $50 \%$ e equivalente ou menor que $75 \%$ das coletas, sendo considerados freqüentes, perfazendo $5 \%$ do total das espécies e 1 ocorreu com freqüência entre 76 e $90 \%$ das coletas sendo considerado muito freqüente, perfazendo menos que $1 \%$ do total das espécies. Nenhum táxon ocorreu entre 90 e $100 \%$ das coletas no ponto 1 .

Os dez táxons mais freqüentes nas coletas, no ponto 1, foram: Synedra cf. minuscula (47 coletas), Scenedesmus bicaudatus (42), Scenedesmus bijugus (38), Synedra ulna t.1 ((37), Chlorella vulgaris var. vulgaris (36), Mougeotia cf. americana (32), Crucigenia tetrapedia (7), Treubaria setigera (31), Chlorella vulgaris var. viridis (30) e Monoraphidium arcuatum (29).

No ponto 4 (Tabela 8) registrou-se 121 táxons com freqüência inferior a $10 \%$ das coletas, perfazendo $68 \%$ do total; 37 táxons ocorreram com freqüência entre 25 e $10 \%$ das coletas, perfazendo $21 \%$ do total das espécies; 11 táxons ocorreram com freqüência entre $26 \mathrm{e}$ $50 \%$ das coletas, perfazendo $6 \%$ do total das espécies e 9 táxons ocorreram entre 51 e $75 \%$ das coletas perfazendo $5 \%$ do total das espécies. Neste ponto não ocorreram espécies com frequiência superior a $75 \%$ das coletas.

Os dez táxons mais freqüentes nas coletas do ponto 4 foram: Chlamydomonas cf. gloeophila fase 1 (42 coletas) Scenedesmus bijugus (42), Cryptomonas cf. brasiliensis (41), Rhizosolenia eiriense (34), Scenedesmus bicaudatus (34), Crucigenia tetrapedia (33), Synedra cf. minuscula (31). Chlamydomonas cf. gloeophila fase 2 (30), Chlorella vulgaris var. viridis (29) e Cryptomonas cf. tenuis (27). 


\subsubsection{CARACTERÍSTICAS MORFOLÓGICAS FUNCIONAIS OU ESTRATÉGLAS} ADAPTATIVAS.

\subsubsection{DIMENSÃO DOS ORGANISMOS - ANÁLISE DA VARIAÇÃO ENTRE AS ESPÉCIES}

A maior dimensão linear (MDL ou GALD), no ponto 1 (Tabela 7), variou entre $2.6 \mu \mathrm{m}$ (Chlorella cf. minutissima, Synechococcus elongatus e Cosmarium sp.12) e $202.8 \mu \mathrm{m}$ (Synedra ulna t.2). No ponto 4 (Tabela 8), variou entre $2.6 \mu \mathrm{m}$ (Chlorella cf. minutissima e Synechococcus elongatus) e $202.8 \mu \mathrm{m}$ (Synedra ulna t.2).

No ponto 1 ocorreram 128 táxons (70\%) de organismos nanoplanctônicos (1-20 $\mu \mathrm{m}), 54$ táxons $(30 \%)$ de microplanctônicos $(>20-200 \mu \mathrm{m})$ e 1 táxon (menos que $1 \%$ ) macroplanctônico $(>200 \mu \mathrm{m})$, segundo a maior dimensão linear. No ponto 4 ocorreram 119 táxons (67\%) de organismos nanoplanctônicos, 58 táxons (33\%) de microplanctônicos e 1 táxon (menos que 1\%) macroplanctônico.

O biovolume variou no ponto 1 , entre $0.28 \mu \mathrm{m}^{3}$ (Anabaenopsis sp1) e $25252.00 \mu \mathrm{m}^{3}$ (Volvocales colonial sp1) e, no ponto 4 , entre $2.30 \mu \mathrm{m}^{3}$ (Synechochoccus elongatus) e $45213.00 \mu^{3}$ (Peridinium sp3).

Quanto às classes de biovolume o ponto 1 apresentou a Classe $1\left(1-100 \mu \mathrm{m}^{3}\right)$ constituída por 45 táxons (25\%); a Classe $2\left(>100-1000 \mu \mathrm{m}^{3}\right)$ por $88(48 \%)$; a Classe 3 $\left(>1000-10000 \mu \mathrm{m}^{3}\right)$ por $37(20 \%)$; a Classe $4\left(>10000 \mu \mathrm{m}^{3}\right)$ por 13 táxons (7\%). No ponto 4 ocorreram 45 táxons (25\%) na Classe 1; 82 (46\%) na Classe 2; 33 (19\%) na Classe 3 e 18 na Classe $4(10 \%)$. A distribuição quanto às porcentagens de táxons por classe de tamanho foi semelhante nos dois pontos, com predominância da Classe 2, seguida pelas Classes 1,3 e 4 . No ponto 4, destaca-se um maior número de espécies da Classe 4. Estes organismos de maiores dimensర̃es, tiveram aparentemente melhores condições de manter-se na superfície, devido a maior turbulência da água, neste ponto.

No ponto 1, a maior contribuição para o nanoplâncton foi de clorococales (54 táxons) e zignemaficeas (23), o mesmo ocorrendo para o microplâncton (23 e 9 respectivamente). A única macroplanctônica pertence as penales. $O$ ponto 4 , mostrou igual ocorrência para 0 nanoplâncton (51 clorococales e 16 zignemaficeas), acrescendo penales junto a zignemafíceas como as maiores contribuiçōes para o microplâncton (20 clorococales, 7 zignemáficeas e 7 penales).

No ponto 1 a maior contribuição para a Classe 1, foi de clorococales (17 táxons), seguida por cianoficeas (9); na Classe 2, de clorococales (31) seguida por zignemaficeas (22); 
na Classe 3, de clorococales (20) seguida por euglenoficeas (6); na Classe 4, de clorococales (9) seguida por cianoficeas (3). No ponto 4 , para a Classe 1 , a maior contribuição foi de clorococales (19), seguida por cianoficeas (7); na Classe 2, de clorococales (28) seguidas por zignemaficeas (12) e crisofíceas (11); na Classe 3, de clorococales (15) seguidas por zignemaficeas (6); na Classe 4, de clorococales (9) seguidas por dinoficeas (4). Conclui-se que as clorococales distribuíram-se por todo o espectro de dimensões, sendo bem representadas em todos os componentes.

\subsubsection{DIMENSÃO DOS ORGANISMOS - ANÁLISE DA VARIAÇÃO TEMPORAL}

Considerando-se a distribuição de tamanho, observa-se que os dois pontos apresentaram dominância de organismos nanoplanctônicos (Tabelas 14 a 21 e Figuras 6 e 7). No ponto 1 o nanoplâncton representou $83 \%$, o microplâncton $17 \%$ e o macroplâncton menos que $1 \%$ do total geral da densidade populacional (em células). A distribuição em GALD por espécie apresentou equivalência seca:chuva $\mathrm{em}$ ambos os pontos de coleta. $\mathrm{O}$ nanoplâncton apresentou em geral maior densidade no periodo de seca, em ambos os pontos de coleta. No ponto $1 \mathrm{o}$ microplâncton foi dominante nas coletas: MA2, MA3, J4, JL12, AG13, AG14, AG15, AG16, $\mathrm{S} 18, \mathrm{~S} 20, \mathrm{O} 21, \mathrm{O} 22, \mathrm{JA} 34, \mathrm{JA} 35$, J55, J56, e J57, apresentando maior densidade nas chuvas, em ambos os pontos. Nas demais coletas o nanoplâncton foi dominante. O macroplâncton ocorreu apenas nas coletas MA3 a J6, JL8, AG13, AG14, J55 e J56, ou seja, apenas no inverno. No ponto 4 , o nanoplâncton alcançou $73 \%$, o microplâncton $27 \%$ e o macroplâncton menos que $1 \%$, do total geral de densidade. $O$ microplâncton foi dominante apenas nas coletas MA2, S19 e O22, nas demais coletas o nanoplâncton foi dominante. O macroplâncton ocorreu nas coletas MA2, MA3, JL12, AG16, N28, D30, D32, JA34, F40, MR42, MR43, AB46, AB48 e MA50.

Quanto à distribuição em classes de biovolume, expresso em $\mu \mathrm{m}^{3} / \mathrm{ml}$, no ponto 1 houve dominância da Classe 4, com 44\%; seguida pela Classe 2, com 28\%; pela Classe 3, com 18\%; pela Classe 1 , com $10 \%$ do total geral em biovolume. Neste ponto, a Classe 4 apresentou maiores biovolumes nas chuvas, enquanto as outras classes tiveram maior biovolume durante a seca. No ponto 4, a Classe 3 dominou representando 43\%; seguida pela Classe 2 com 29\%; pela Classe 4 com $22 \%$ e pela Classe 1 com $6 \%$ do total geral em biovolume. As Classes 2 e 3 , neste ponto, atingiram maiores biovolumes na época das chuvas, enquanto a Classe 1 , no período de seca. A Classe 4 não apresentou variação considerável entre seca e chuva neste ponto. 


\subsubsection{ANÁLISE DA MOTILIDADE}

No ponto 1, quanto à capacidade de movimento próprio (Tabelas 15 e 17 ), 97\% das algas expresso em densidade (de células), não apresentaram capacidade de movimento próprio e $3 \%$ apresentaram. No ponto 4 (Tabelas 19 e 21 ) $84 \%$ das algas, não apresentaram capacidade de movimento próprio considerando-se o valor expresso em densidade (de células) e $16 \%$ apresentaram. Não houve variação sazonal significativa nos dois pontos, apenas uma tendência geral de maiores valores de densidade numérica durante o periodo das chuvas. No ponto 1 , quanto ao movimento, $90 \%$ das algas, expresso em biovolume, não apresentaram capacidade de movimento próprio e $10 \%$ apresentaram. No ponto $4,70 \%$ das algas não apresentaram capacidade de movimento próprio, quando expresso em biovolume e $30 \%$ apresentaram, observando-se a mesma tendência sazonal relatada para capacidade de movimento em densidade numérica.

\subsubsection{ANÁLISE DA FORMA}

No ponto 1 (Tabelas 15 e 17), ocorreram as formas: unicelulares $40 \%$, cenobiais ou coloniais $32 \%$ e filamentosas $28 \%$, em porcentagem da densidade total de células. Quanto à forma, em biovolume, obteve-se o seguinte resultado: $18 \%$ foram unicelulares, $68 \%$ cenobiais ou coloniais e $14 \%$ filamentosas. Neste ponto a densidade de cenobiais/coloniais foi mais elevada nas chuvas, indicando taxa de crescimento mais elevada neste periodo. A densidade de unicelulares foi a única mais elevada da seca, considerada a densidade de células, pois cenobiais e filamentosas atingiram maiores valores durante as chuvas. Porém, considerando-se densidade de organismos, as formas cenobiais/colôniais também passam a apresentar seus maiores valores no periodo de seca, ou seja, as coloniais/cenobiais de seca eram constituidas por organismos menores, em maior número e as de chuva por organismos maiores, em menor número. As filamentosas atingiram maiores densidades durante as chuvas.

Quanto ao biovolume total, o de cenobiais/coloniais e unicelulares foi mais elevado na seca e o de filamentosas nas chuvas. Entretanto, não foram observadas diferenças significativas nas dimensões intra-específicas de coloniais/cenobiais, decorrentes de variaç̃̃es ambientais.

No ponto 4 (Tabelas 19 e 21), ocorreram as seguintes formas em porcentagem da densidade total (de células): $53 \%$ unicelulares; $33 \%$ cenobiais ou coloniais e $14 \%$ filamentosas. Quanto à forma, em biovolume, ocorreram neste ponto: $34 \%$ unicelulares, $52 \%$ cenobiais ou coloniais e $14 \%$ filamentosas. A densidade de cenobiais/coloniais e de filamentosas foi mais elevada no período das chuvas e a de unicelulares na seca, conservando-se o mesmo comportamento se considerarmos densidade de organismos, mas o padrão altera-se quanto ao 
biovolume, pois as unicelulares atingiram valores mais elevados de biomassa durante as chuvas. Deve-se observar que as altas densidades de unicelulares de grande porte, encontradas neste ponto, contribuiram bastante para esta diferença, p. ex. Gymnodinium fuscum e Peridinium sp.3.

\subsubsection{ANÁlise dO ENVOLTÓRIO OU PAREDE CELULAR}

No ponto 1, quanto ao envoltório ou parede celular (Tabela 15), 90\% das algas, expresso em densidade de células, não apresentaram envoltório rígido e $10 \%$ apresentou. No ponto 4 (Tabela 17), 83\%, expresso em densidade de células, não apresentaram envoltório rígido e $17 \%$ apresentaram. Quanto ao envoltório ou parede celular, expresso em biovolume (Tabela 19), $85 \%$ das algas no ponto 1 , não apresentaram envoltório rigido e $15 \%$ apresentaram. No ponto 4 (Tabela 21), 79\%, expresso em biovolume, não apresentaram envoltório rígido e $21 \%$ apresentaram. Em ambos os pontos, tanto em densidade de células como em biovolume, as algas providas de envoltório rigido apresentaram maiores valores durante o período da seca $\mathrm{e}$ as desprovidas apresentaram maiores valores no período das chuvas.

\subsubsection{DENSIDADE, BIOÁREA, BIOVOLUME E DOMINÂNCIA}

\subsubsection{TOTAL GERAL}

Os resultados relatados a seguir estão expressos nas Tabelas 7 e 8.0 ponto 1 apresentou soma total geral de 1304821 células, ou seja, 2.38 vezes a do ponto 4 , cujo total geral foi de 548719 células. Entretanto, considerando-se a soma total geral de espécimes, no ponto 1, ocorreram 1206329 organismos, ou seja, 2.51 vêzes o valor encontrado no ponto 4, de 479771 organismos.

$\mathrm{Na}$ somatória de densidade, em células por mililitro abrangendo todas as coletas, predominaram com valores iguais ou superiores a $5 \%$ do total geral no ponto 1, Mougeotia cf. americana, que atingiu $17.14 \%$ do total geral, Chlorella cf. minutissima, com $15.86 \%$, Scenedesmus bijugus, com $12.06 \%$, Chlorella vulgaris var. vulgaris, com $5.95 \%$ e Dictyosphaerium ehrenberghianum, com $5.06 \%$. No ponto 4 , Chlorella cf. minutissima com $15.23 \%$, Mougeotia cf. americana com $7.01 \%$ e Dictyosphaerium ehrenberghianum com $6.34 \%$.

Na somatória de densidade por táxon, em organismos por mililitro, abrangendo todas as coletas, predominaram com valores iguais ou superiores a $5 \%$ do total geral, no ponto 1 , Mougeotia cf. americana, com $18.54 \%$, Chlorella cf. minutissima, com $17.15 \%$, Scenedesmus bijugus, com $13.04 \%$, Oscillatoria subtilissima, com $8.90 \%$, Chlorella vulgaris var. vulgaris, 
com 6.44\%. Dictyosphaerium ehrenberghianum passa ao valor de $0.58 \%$. No ponto 4 , predominaram Chlorella minutissima com $17.42 \%$, Scenedesmus bijugus com $9.30 \%$ e Mougeotia cf. americana com $8.02 \%$ e Dictyosphaerium ehrenberghianum passou a $0.77 \%$, sendo substituida entre as superiores, por Scenedesmus bijugus. Pode-se considerar que esta forma de contagem não expressa bem o potencial reprodutivo das unidades fitoplanctônicas, uma vez que não valorizou a importância, em densidade, das colônias de Dictyosphaerium ehremberghianum, uma das espécies que atingiram densidades de floração das águas, nos dois pontos de coleta.

A bioárea total geral, em unidade padrão de área, no ponto 1 foi de 211662 , portanto 1.5 vezes maior que no ponto 4 , onde atingiu o valor de 141310 . No ponto 1 , atingiram valor igual ou superior a 5\% do total geral: Mougeotia cf. americana 12.50\%, Dictyosphaerium ehrenberghianum 10.35\%, Scenedesmus bijugus 10.05\%, Rhizosolenia eiriensis $6.34 \%$ e Scenedesmus bicaudatus 5.08\%. No ponto 4, Scenedesmus bijugus $10.67 \%$, Rhizosolenia eiriensis 9.96\%, Dictyosphaerium ehrenberghiamum 8.17\%, Synedra ulna t2 6.74\%, Gymnodinium fuscum $5.94 \%$, Aulacoseira granulata 5,48\% e Dictyosphaerium elegans $5.42 \%$.

O biovolume total geral, expresso em micrômetros cúbicos, no ponto 1 , foi de 349484956 , logo, 1.14 vezes maior que no ponto 4, onde apresentou o valor de 306284332. Atingiram valores iguais ou superiores a $5 \%$ do total geral, no ponto 1: Dictyosphaerium ehrenberghianum $21.73 \%$, Dictyosphaerium pulchellum $9.51 \%$, Scenedesmus bijugus $6.33 \%$, Mougeotia cf. americana $6.18 \%$ e Aulacoseira granulata $5.08 \%$; e no ponto 4 Dictyosphaerium ehrenberghianum 13.07\%, Gymnodinium fuscum 12.11\% Aulacoseira granulata 9.54\%, Dictyosphaerium elegans $8.67 \%$ e Scenedesmus bijugus 5.12\%.

Os resultados relatados demonstram a importância das espécies mencionadas para o contexto geral deste estudo, permitindo considerá-las como indicadoras da qualidade do ambiente. Estes resultados também mostram que no ponto 1 houve condições mais propícias ao desenvolvimento do fitoplâncton, tanto em densidade como em biomassa.

As correlacões entre as caracteristicas das espécies dos pontos 1 e 4 estão expressas na Tabela 9 e os resultados serão utilizados durante a discussão.

\subsubsection{VARIAÇÃO TEMPORAL}

As Tabelas 10 a 21 e as Figuras 8 a 11 mostram os resultados relatados a seguir.

No ponto 1, a densidade total, expressa em células por mililitro, variou entre 944 , em JL11 e 122607, em AB49. A bioárea total, expressa em unidade padrão de área por mililitro, variou entre 167, em JL11 e 9684, em F39. O biovolume total, expresso em micrômetros 
cúbicos por mililitro, variou entre 275678 , em $J 11$ e 32093281 , em N28. Portanto, os menores valores coincidiram em JL11, no inverno, seca, simultâneos com um período de maior transparência (Tabela 10).

No ponto 4, a densidade total por amostra, em células por mililitro, variou entre 628 , em 023 e 35421, em JL58. A bioárea total, expressa em unidade padrão de área por mililitro, variou entre 273 , em JL9 e 7243 , em D30. O biovolume total, expresso em micrômetros cúbicos por mililitro, variou entre 588514, em JL10 e 24170468, em D30 (Tabela 12).

Quanto a densidade, seis táxons foram dominantes no ponto 1, apresentando valores iguais ou superiores a $50 \%$ do total da amostra: Dinobryon divergens (64\% - S18), Dictyosphaerium ehrenberghianum (72\% - N27, 52\% em N29 e 81\% - D32), Mougeotia cf. americana (65\% - JA37, 69\% - F38, 66\% - F39), Chlorella vulgaris var. vulgaris (61\% F40), Dictyosphaerium pulchellum (70\% - N28) e Synedra cf. minuscula (51\% - J7). A dominância esteve distribuída entre espécies de bacilariofícea - penales, crisoficea, clorofícea e zignemaficea e foi mais freqüente nas coletas das chuvas (Tabela 29).

No ponto 4 quanto a densidade, três táxons foram dominantes apresentando valores iguais ou superiores a $50 \%$ - do total da amostra: Rhizosolenia eiriensis (52\% - MA2), Mougeotia cf. americana (76\% - JA37) e Botryococcus neglectus (51\% - AB45). A dominância em densidade neste ponto, esteve então distribuída entre bacilarioficea - penales, zignemaficea e cloroficea e foi mais freqüente durante a seca (Tabela 31 ).

Quanto à bioárea, dez táxons foram dominantes no ponto 1: Aphanocapsa elachista var. conferta (52\% - D33), Aulacoseira granulata (52\% - O21), Chlamydomonas cf. gloeophila fase 2 (51\% - S17), Dictyosphaerium ehrenberghianum (50\% - N26; 75\% - N27; 54\% - D30; 56\% - D31, 85\% - D32), Dictyosphaerium pulchellum (71\% - N28), Dinobryon divergens (86\% - S18), Mougeotia cf. americana (61\% - MA53), Synedra ulna t1 (52\% - JA34) e Volvocales colonial sp1 (62\% - J10). A dominância em bioárea esteve neste ponto, distribuída entre cloroficea, bacilarioficea, cianoficea e crisoficea e foi mais freqüente durante as chuvas.

No ponto 4, quanto a bioárea, foram dominantes nove táxons: Aulacpseira granulata (50\% - JL9; 57\% - JL11), Botryococcus neglectus (65\% - AB45), Dictyosphaerium ehrenberghianum (50\% - N28), Dictyosphaerium elegans (50\% - D30), Mougeotia cf. americana (54\% - JA37), Peridinium sp3 (68\% - O23), Rhizosolenia eiriensis (61\% - MA2; $56 \%$ - J4; 55\% - S20; 50\% - J57)), Scenedesmus bijugus (52\% - MA51) e Synedra ulna t2 (54\% - JL12; 68\% - MR42). Portanto, a dominância em bioárea esteve distribuída entre cloroficea, bacilarioficea, zignemaficea e dinoficea e foi mais freqüente durante a seca. 
Quanto ao biovolume foram dominantes dez táxons no ponto 1: Aulacoseira granulata (56\% - JL12; 61\% - S20; 70\% - O21), Dictyosphaerium ehrenberghianum (67\% - O24; 50\% $\mathrm{O} 25 ; 79 \%-\mathrm{N} 26 ; 79 \%-\mathrm{N} 27 ; 58 \%-\mathrm{D} 30 ; 73 \%-\mathrm{D} 31 ; 94 \%-\mathrm{D} 32 ; 55 \%$ - JA34), Dictyosphaerium pulchellum (64\% - N28; 68\% - JL58), Scenedesmus bijugus (68\% - MA53), Dinobryon divergens (79\% - S18), Aphanocapsa elachista var. conferta (57\% - D33), Chlamydomonas cf. gloeophila fase 2 (84\% - S17), Volvocales colonial sp1 (50\% - Л8; 88\% - JL10), Mougeotia cf. americana (51\% - JA37; 51\% - F41) e Mougeotiopsis sp1 (64\% JA35). A dominância em biovolume esteve distribuida portanto, entre cloroficea, bacilarioficea

- centrales, crisoficea, cianoficea e zignemaficea e foi mais freqüente durante as chuvas (Tabelas 30 e 35).

No ponto 4, quanto ao biovolume foram dominantes oito táxons: Aulacoseira granulata (64\% - JL9; 75\% - JL11; 55\% - AG15; 71\% - S17; 56\% - S19; 77\% - O22; 66\% - AB49; 62\% - J54), Botryococcus neglectus (84\% - AB45), Dictyosphaerium ehrenberghianum (53\% 024; 60\% - N28), Dictyosphaerium elegans (52\% - D30; 54\% - D31), Gymnodinium fuscum (70\% - F39; 52\% - F40; 73\% - MR44; 68\% - AB46), Peridinium sp3 (97\% - O23), Chlamydomonas gloeophila fase $2(59 \%$ - S18) e Volvocales colonial sp1 (81\% - O25). Resultando numa dominância em biovolume distribuida entre clorofícea, bacilarioficea e dinoficea e foi mais freqüente durante as chuvas (Tabelas 32 e 36).

A Tabela 33, expressa os valores das espécies que destacaram-se pela alta freqüência de ocorrência e/ou pela dominância e abundância em organismos, bioárea ou biovolume por mililitro.

\subsubsection{RIQUEZA, DIVERSIDADE, UNIFORMIDADE E TAXAS DE ALTERAÇÃO DA COMUNIDADE}

As Tabelas 10 a 13 expressam os resultados mencionados a seguir, também representados nas Figuras 8 e 9 .

A riqueza, quanto ao número de táxons (S), variou entre 8, em $J 11$ e 46, em J54, no ponto 1 , com mediana de 24 . No ponto 4 , entre 7 , em S17 e 30 , em N28, MA51, MA53 e JL58, com mediana de 19.

A diversidade ( $\left.\mathbf{H}^{\prime}\right)$ máxima do ponto 1 , considerando-se densidade de organismos foi de 4.28 bits.ml ${ }^{-1}$ na AG16 e a mínima de 1.3 bits. $\mathrm{ml}^{-1}$ na D32, com mediana de 3.06. No ponto 4 a máxima diversidade em densidade de organismos foi de 4.04 bits. $\mathrm{ml}^{-1}$ na JA34 e a mínima de 1.76 bits. $\mathrm{ml}^{-1}$ na JA37, com mediana de 3.25 bits. $\mathrm{ml}^{-1}$. O ponto 4 apresentou mediana de diversidade superior a do ponto 1 , apesar da mediana do número de táxons haver sido maior 
no ponto 1 (24), que no ponto 4 (19), devido à maior uniformidade neste ponto (valor mediano 0.80), que no ponto 1 (mediana de 0.70). A mediana da diversidade do ponto 1 foi mais elevada no periodo de seca (3.29) que no de chuvas (2.77), mas no ponto 4 , não apresentou diferença entre o período de seca e o das chuvas ( 3.25 e 3.24 bits.ml $^{-1}$ ). A máxima diversidade considerando-se bioárea no ponto 1, foi de 4.19 bits.ml ${ }^{-1}$ em AG16 e a mínima de 0.96 bits. $\mathrm{ml}^{-1} \mathrm{em} \mathrm{S18}$, com mediana de 2.85 bits. $\mathrm{ml}^{-1}$. No ponto 4 a máxima foi de 3.82 bits. $\mathrm{ml}^{-1}$

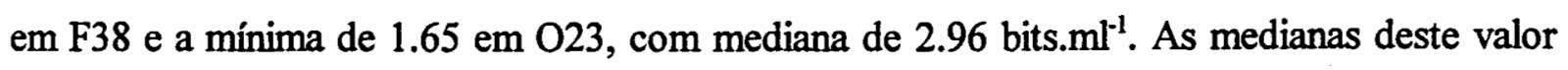

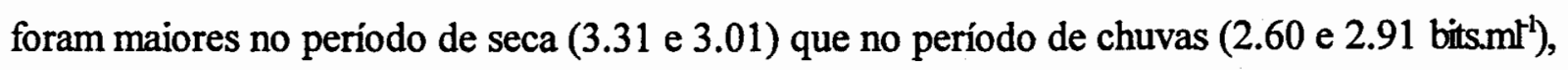
nos dois pontos, respectivamente. A máxima diversidade em biovolume no ponto 1 , foi de 3.89 bits.ml ${ }^{-1}$ em J6 e a mínima de 0.49 bits. $\mathrm{ml}^{-1}$ em D32, com mediana 2.74 bits. $\mathrm{ml}^{-1}$. No ponto 4 a

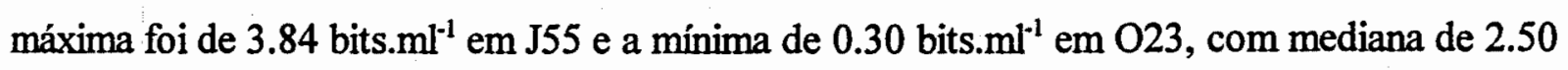
bits.ml ${ }^{-1}$. As medianas deste valor foram mais elevadas no período de seca (3.29 e 3.16) que

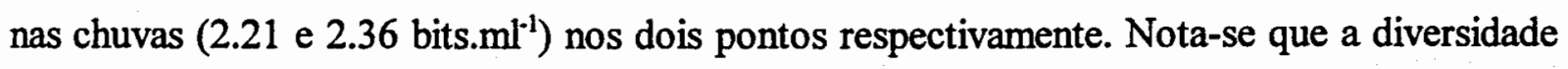
decresce se calculada em organismos, bioárea e biovolume, conservando-se mais elevada no periodo de seca, para as três formas de cálculo. As medianas de diversidade do ponto 1 foram maiores que as do ponto 4 , exceto para densidade de células.

A uniformidade em organismos no ponto 1 , variou entre 0.90 de $\mathrm{J} 9$ a $\mathrm{JL} 12$ e 0.30 em D32, com mediana de 0.70 . No ponto 4 variou entre 1.00 em $\mathrm{O} 23$ e $0.30 \mathrm{em} \mathrm{JA37}$, com mediana de 0.80. A uniformidade em organismos foi muito semelhante entre seca e chuva nos dois pontos. A uniformidade em bioárea, no ponto 1 , variou entre $0.90 \pi 11$ e $0.20 \mathrm{em} \mathrm{S18,} \mathrm{com} \mathrm{mediana}$ de 0.60 . No ponto 4 , variou entre $0.96 \mathrm{em} J \mathrm{~L} 8$ e $0.48 \mathrm{em} \mathrm{MR42,} \mathrm{com} \mathrm{mediana} \mathrm{de} 0.69$. A uniformidade em bioárea foi mais elevada no periodo de seca que nas chuvas, especialmente no ponto 1 com 0.70 na seca, para 0.55 nas chuvas, enquanto no ponto 4 apresentou 0.74 na seca, para 0.68 nas chuvas. A uniformidade em biovolume, variou entre 0.84 em J11 e AG19 e 0.14 em D32, com mediana de 0.63 . No ponto 4 variou entre $0.87 \mathrm{em} \mathrm{J} 7$ e $0.10 \mathrm{em} \mathrm{O} 23$, com mediana de 0.63. A uniformidade em biovolume foi mais elevada na seca (0.69), que nas chuvas $(0.55$ e 0.57$)$, nos dois pontos respectivamente. As medianas de uniformidade, do ponto 4 , foram mais elevadas que as do ponto 1 , exceto para biovolume em que foram iguais.

A taxa de alteração da comunidade, expressa em densidade de células, variou entre 0.324 (relativa à diferença entre D32 e D33) e 0.035 (relativa à diferença entre F38 e F39), no ponto 1 , com mediana de 0.140 . No ponto 4 , variou entre 0.361 (relativa à diferença entre $\mathrm{N} 25 \mathrm{e}$ N26) e 0.037 (relativa à diferença entre M51 e M53), com mediana de 0.176. A taxa de alteração da comunidade, expressa em bioárea, variou entre 0.322 (relativa à diferença entre D32 e D33) e 0.050 (relativa à diferença entre M51 e M53), com mediana de 0.150 no ponto 
1. Esta taxa variou entre 0.370 (relativa à diferença entre 025 e N26) e 0.041 (relativa à diferença entre M51 e M53), com mediana de 0.201 , no ponto 4. A taxa de alteração da comunidade, expressa em biovolume, variou entre 0.283 (relativa à diferença entre $\mathrm{O} 23$ e $\mathrm{O} 24$ ) e 0.052 (relativa à diferença entre N26 e N27), com mediana de 0.190 no ponto 1 e entre 0.377 (relativa à diferença entre 024 e 025 ) e 0.050 (relativa à diferença entre J57 e J158) no ponto 4, com mediana de 0.221 . Em ambos os pontos as taxas de alteração da densidade de células e da bioárea foram mais elevadas durante as chuvas, mas a alteração do biovolume foi semelhante nos dois períodos, apresentando-se inclusive, um pouco mais elevada no período seco do que no período das chuvas, no ponto 1 .

\subsubsection{RELAÇÕES ENTRE O FITOPLÂNCTON E A QUALIDADE ABIÓTICA DA ÁGUA}

As Tabelas 22 a 25 expressam os resultados do teste de correlação entre as variáveis abióticas e as do fitoplâncton.

A densidade em número de células correlacionou-se no ponto 1 , com: temperatura da água $(\mathrm{rs}=0.56 \mathrm{P}=0)$, transparência ( $\mathrm{rs}=-0.61 \mathrm{P}=0)$, condutividade ( $\mathrm{rs}=0.52 \mathrm{P}=0.0001$ ), alcalinidade ( $\mathrm{rs}=0.74 \mathrm{P}=0$ ), teores de cálcio $(\mathrm{rs}=0.65 \mathrm{P}=0)$ e potássio $(\mathrm{rs}=0.64 \mathrm{P}=0)$. No ponto 4, correlacionou-se com: temperatura da água ( $\mathrm{rs}=0.52 \mathrm{P}=0.0001$ ), condutividade ( $\mathrm{rs}=0.64$ $\mathrm{P}=0$ ), $\mathrm{pH}(\mathrm{rs}=0.63 \mathrm{P}=0$ ), alcalinidade ( $\mathrm{rs}=0.62 \mathrm{P}=0$ ), teores de alumínio ( $\mathrm{rs}=-0.52 \mathrm{P}=0.0002$ ), ferro ( $\mathrm{rs}=-0.51 \mathrm{P}=0.0002$ ), potássio ( $\mathrm{rs}=0.52 \mathrm{P}=0.0002$ ). A sulfatação apresentou correlações positivas com a densidade, porém abaixo do limite considerado ( $\mathrm{rs}=0.46$, com a aplicação do dia anterior e $\mathrm{rs}=0.36 \mathrm{com}$ a do dia da coleta). Estes resultados mostram que as densidades elevadas ocorreram nos períodos de temperatura e mineralização mais elevadas, conforme atestam a condutividade $\mathrm{e}$ os teores de nutrientes. No ponto 1 indicam que as densidades elevadas podem ter sido responsáveis pela diminuição da transparência da água. A elevação dos teores de alumínio e ferro no ponto 4 foi simultânea à queda no número de células, indicando que sob estas condições pode ter ocorrido restrição à capacidade de desenvolvimento das algas.

A densidade em organismos correlacionou-se, no ponto 1 , com a transparência ( $r s=$ $0.56 \mathrm{P}=0$ ), alcalinidade ( $\mathrm{rs}=0.73 \mathrm{P}=0$ ), teores de cálcio ( $\mathrm{rs}=0.62 \mathrm{P}=0$ ), cobre ( $\mathrm{rs}=0.53$ $\mathrm{P}=0.0001$ ) e potássio ( $\mathrm{rs}=0.54 \mathrm{P}=0.0001$ ). No ponto 4 , com a condutividade ( $\mathrm{rs}=0.63 \mathrm{P}=0$ ), $\mathrm{pH}(\mathrm{rs}=0.61 \mathrm{P}=0)$, alcalinidade ( $\mathrm{rs}=0.67 \mathrm{P}=0$ ) e teores de alumínio ( $\mathrm{rs}=-0.54 \mathrm{P}=0.0001$ ). Os resultados da contagem por organismos diferem quanto às relações apresentadas pela contagem por número de células, por não mostrarem a relação com a temperatura; no ponto 1 
com a condutividade e no ponto 4 com alcalinidade, alumínio, ferro e potássio. No ponto 1 , entretanto, mostram a correlação positiva significativa com os teores de cobre, associado à aplicação de sulfato de cobre, mais intensas quando as densidades foram mais elevadas.

A bioárea do ponto 1 correlacionou-se com: temperatura da água ( $\mathrm{rs}=0.50 \mathrm{P}=0.0002$ ), alcalinidade ( $\mathrm{rs}=0.58 \mathrm{P}=0.0001$ ) e teores de potássio ( $\mathrm{rs}=0.55 \mathrm{P}=0.0001$ ). No ponto 4 , com: $\mathrm{pH}(\mathrm{rs}=0.51 \mathrm{P}=0.0002)$, alcalinidade ( $\mathrm{rs}=0.56 \mathrm{P}=0.0002$ ). $\mathrm{O}$ maior número de correlações apresentadas pela bioárea no ponto 1 devem decorrer do fato das aplicações de sulfato de cobre serem relativas a esta unidade de medida, provocando indiretamente alterações ambientais, enquanto no ponto 4 esta medida não tem a mesma importância.

$\mathrm{O}$ biovolume no ponto 1 correlacionou-se apenas com os teores de potássio ( $\mathrm{rs}=0.50$ $\mathrm{P}=0.0002$ ). No ponto 4 , com a radiação solar ( $\mathrm{rs}=0.51 \mathrm{P}=0.0002)$, temperatura da água $(\mathrm{rs}=0.51 \mathrm{P}=0.0002)$, condutividade ( $\mathrm{rs}=0.54 \mathrm{P}=0.0001), \mathrm{pH}(\mathrm{rs}=0.57 \mathrm{P}=0)$ e teores de potássio $(\mathrm{rs}=0.54 \mathrm{P}=0.0001)$. $\mathrm{O}$ menor número de correlações apresentadas no ponto 1 , evidencia os efeitos das aplicações de sulfato de cobre.

A riqueza correlacionou-se no ponto 1 , com alcalinidade ( $r s=0.63 \mathrm{P}=0$ ) e com os teores de cálcio ( $\mathrm{rs}=0.50 \mathrm{P}=0.0002$ ) e no ponto 4 , com temperatura da água ( $\mathrm{rs}=0.56 \mathrm{P}=0$ ), condutividade ( $\mathrm{rs}=0.54 \mathrm{P}=0.0001), \mathrm{pH}(\mathrm{rs}=0.52 \mathrm{P}=0.0001$ ), alcalinidade ( $\mathrm{rs}=0.73 \mathrm{P}=0) \mathrm{e}$ teores de potássio ( $\mathrm{rs}=0.50 \mathrm{P}=0.0003$ ).

A diversidade, em densidade de células, não apresentou correlações no nível considerado com os parâmetros físicos e químicos estudados nos dois pontos. A diversidade, em bioárea, correlacionou-se com a radiação solar ( $\mathrm{rs}=-0.54 \mathrm{P}=0.0001)$ e teores de sódio ( $\mathrm{rs}=$ $-0.52 \mathrm{P}=0.0001$ ), no ponto 1 . No ponto 4 não apresentou correlaçð̃es nos niveis considerados, o mesmo ocorrendo para a diversidade em biovolume em ambos os pontos.

A uniformidade, em densidade de células, correlacionou-se no ponto 1, com: temperatura da água ( $\mathrm{rs}=-0.71 \mathrm{P}=0$ ) e com o teor de potássio $(\mathrm{rs}=-0.66 \mathrm{P}=0$ ). No ponto 4 , correlacionou-se com temperatura da água $(\mathrm{rs}=-0.54 \mathrm{P}=0.0001)$, com a condutividade ( $\mathrm{rs}=$ $0.50 \mathrm{P}=0.0002$ ) e alcalinidade ( $\mathrm{r}=-0.51 \mathrm{P}=0.0004$ ). A uniformidade, em bioárea, correlacionou-se, no ponto 1 , com a radiação solar $(\mathrm{rs}=-0.53 \mathrm{P}=0.0001)$, pluviosidade $(\mathrm{rs}=$ $0.50 \mathrm{P}=0.0002$ ), elevação e volume ( $\mathrm{rs}=0.53 \mathrm{P}=0.0001$ ), temperatura da água ( $\mathrm{r}=-0.55$ $\mathrm{P}=0.0001$ ), teores de potássio $(\mathrm{rs}=-0.50 \mathrm{P}=0.0003)$ e de sódio $(\mathrm{rs}=-0.58 \mathrm{P}=0)$. No período de seca, para garantir o abastecimento há um maior controle da retirada de água, resultando na contenção de um maior volume, o que explica haver menor pluviosidade, simultânea aos valores maiores de elevação e volume. No ponto 4 , não ocorreram correlações significativas no nível considerado. A uniformidade em biovolume não apresentou correlações com os 
parâmetros físicos e químicos nos níveis considerados em ambos os pontos de coleta. As uniformidades da bioárea e da densidade comportaram-se de forma semelhante, ambas indicando que temperaturas mais baixas, maior diluição devido ao aumento do nível e do volume da água, decorrentes da contenção de água durante o inverno, associam-se aos menores teores de nutrientes, favorecendo a uniformidade da distribuição do número de espécimes nas espécies presentes.

A taxa de alteração da comunidade aplicada a densidade de células no ponto 1 , não correlacionou-se significativamente nos níveis considerados com os parâmetros físicos $\mathrm{e}$ químicos. No ponto 4 correlacionou-se com o teor de alumínio ( $\mathrm{rs}=0.51 \mathrm{P}=0.0003$ ). Esta correlação indica que teores elevados de alumínio podem ter causado alterações na densidade das algas no ponto 4 , onde este metal apresentou teores mais elevados. $O$ índice de alteração da comunidade aplicado aos valores de bioárea e de biovolume, não apresentou correlações significativas com os parâmetros físicos e químicos, nos níveis considerados.

Os parâmetros utilizados como indicadores da forma de vida e as estratégias adaptativas utilizadas pelo fitoplâncton, por serem inter-dependentes das variáveis que expressam a densidade e a biomassa total da comunidade, mostraram-se geralmente redundantes com o padrão geral de comportamento destas últimas, sendo comentados a seguir.

A densidade do nanofitoplâncton, correlacionou-se no ponto 1 com a temperatura da água $(\mathrm{rs}=0.65 \mathrm{P}=0$ ), transparência ( $\mathrm{rs}=-0.63 \mathrm{P}=0$ ), alcalinidade ( $\mathrm{rs}=0.66 \mathrm{P}=0$ ), teores de sulfato ( $\mathrm{rs}=0.54 \mathrm{P}=0.0001$ ), cálcio $(\mathrm{rs}=0.67 \mathrm{P}=0$ ) e potássio ( $\mathrm{rs}=0.69 \mathrm{P}=0)$. No ponto 4 , com a temperatura da água ( $\mathrm{rs}=0.55 \mathrm{P}=0)$, condutividade ( $\mathrm{rs}=0.64 \mathrm{P}=0), \mathrm{pH}(\mathrm{rs}=0.62 \mathrm{P}=0)$, alcalinidade ( $\mathrm{rs}=0.58 \mathrm{P}=0$ ) e teores de alumínio ( $\mathrm{rs}=-0.50 \mathrm{P}=0$ ). As densidades de micro e macrofitoplâncton não apresentaram correlações nos níveis considerados, em ambos os pontos.

A Classe 1 de biovolume correlacionou-se, no ponto 1 , com a transparência (rs $=-0.59$ $\mathrm{P}=0$ ), alcalinidade ( $\mathrm{rs}=0.65 \mathrm{P}=0$ ), teores de cálcio ( $\mathrm{rs}=0.59 \mathrm{P}=0$ ), cobre ( $\mathrm{rs}=0.61 \mathrm{P}=0$ ), potássio ( $\mathrm{rs}=0.50 \mathrm{P}=0.0002$ ) e com o teor de sulfato de cobre aplicado no dia anterior à coleta $(\mathrm{rs}=0.51 \mathrm{P}=0.0002$ ). No ponto 4 , com a condutividade ( $\mathrm{rs}=0.59 \mathrm{P}=0)$ e $\mathrm{pH}(\mathrm{rs}=0.56 \mathrm{P}=0)$.

A Classe 2 de biovolume no ponto 1, correlacionou-se com a deficiência hídrica do solo $(\mathrm{rs}=0.56 \mathrm{P}=0)$ e com a alcalinidade ( $\mathrm{rs}=0.51 \mathrm{P}=0.0002$ ). No ponto 4 , com a deficiência hídrica do solo ( $\mathrm{rs}=0.54 \mathrm{P}=0.0001$ ), $\mathrm{pH}(\mathrm{rs}=0.51 \mathrm{P}=0.0002)$ e alcalinidade ( $\mathrm{rs}=0.51 \mathrm{P}=0.0002)$. Esta Classe, portanto, teve seu desenvolvimento favorecido nos períodos de seca.

As Classes 3 e 4 não apresentaram correlações com os parâmetros físicos e químicos nos níveis considerados, em ambos os pontos. 
O desenvolvimento das algas da Classe 1 , ou seja, daquelas com biovolume menor ou igual a $100 \mu \mathrm{m}^{3}$ foi favorecido nos períodos em que o teor de nutrientes foi elevado, mostrando no ponto 1 correlação positiva com os teores de cobre, provavelmente decorrente das aplicações de sulfato de cobre quando as densidades de algas como Chlorella vulgaris atingiram valores elevados. Para a Classe 2, cujo desenvolvimento foi favorecido durante os períodos de seca mais intensa, destacaram-se espécies do gênero Scenedesmus.

Quanto à motilidade, a densidade em número de células, das algas sem motilidade, no ponto 1 , correlacionou-se com a temperatura da água ( $\mathrm{rs}=0.59 \mathrm{P}=0)$, transparência ( $\mathrm{rs}=-0.64$ $\mathrm{P}=0$ ), condutividade ( $\mathrm{rs}=0.52 \mathrm{P}=0.0001$ ), alcalinidade ( $\mathrm{rs}=0.72 \mathrm{P}=0)$ e teores de sulfato $(\mathrm{rs}=0.53 \mathrm{P}=0.0001)$, cálcio $(\mathrm{rs}=0.69 \mathrm{P}=0)$ e potássio $(\mathrm{rs}=0.67 \mathrm{P}=0)$. No ponto 4 , com a temperatura da água ( $\mathrm{rs}=0.50 \mathrm{P}=0.0002)$, condutividade $(\mathrm{rs}=0.54 \mathrm{P}=0.0001)$, alcalinidade $(\mathrm{rs}=0.59 \mathrm{P}=0)$, sulfato $(\mathrm{rs}=0.55 \mathrm{P}=0.0001)$, cálcio ( $\mathrm{rs}=0.63 \mathrm{P}=0)$, ferro $(\mathrm{rs}=0.50 \mathrm{P}=0.0002) \mathrm{e}$ potássio ( $\mathrm{rs}=0.68 \mathrm{P}=0$ ). No ponto 1 , o biovolume dos organismos sem motilidade correlacionou-se com a temperatura da água ( $\mathrm{rs}=0.55 \mathrm{P}=0$ ), teores de potássio $(\mathrm{rs}=0.60 \mathrm{P}=0) \mathrm{e}$ no ponto 4 com os teores de potássio ( $\mathrm{rs}=0.53 \mathrm{P}=0.0001$ ). A densidade e o biovolume dos organismos com movimento próprio em ambos os pontos, não apresentaram correlações nos níveis considerados. Estes resultados mostram que os organismos desprovidos de motilidade tiveram seu desenvolvimento favorecido quando temperatura e teor de nutrientes foram mais elevados.

Quanto ao envoltório celular, as densidades e biovolumes de organismos com envoltório rígido no ponto 1 , e sem envoltório rígido no ponto 4 , não apresentaram correlações nos níveis considerados. No ponto 1 , a densidade de organismos sem envoltório rígido, correlacionou-se com a temperatura da água $(\mathrm{rs}=0.63 \mathrm{P}=0)$, transparência ( $\mathrm{rs}=-0.65$ $\mathrm{P}=0$ ), condutividade ( $\mathrm{rs}=0.57 \mathrm{P}=0$ ), alcalinidade ( $\mathrm{r}=0.70 \mathrm{P}=0)$ e teores de sulfato ( $\mathrm{rs}=0.56$ $\mathrm{P}=0$ ), cálcio ( $\mathrm{rs}=0.69 \mathrm{P}=0$ ) e potássio $(\mathrm{rs}=0.71 \mathrm{P}=0)$. No ponto 4 , a densidade de organismos com envoltório rígido correlacionou-se com a condutividade ( $\mathrm{rs}=0.62 \mathrm{P}=0), \mathrm{pH}(\mathrm{rs}=0.55 \mathrm{P}=0)$, alcalinidade ( $\mathrm{rs}=0.60 \mathrm{P}=0$ ), teores de alumínio ( $\mathrm{rs}=-0.55 \mathrm{P}=0$ ) e de ferro ( $\mathrm{rs}=-0.51$ $\mathrm{P}=0.0001$ ). $\mathrm{O}$ biovolume dos não rígidos no ponto 1 , correlacionou-se com a temperatura da água $(\mathrm{rs}=0.60 \mathrm{P}=0)$ e teores de sulfato $(\mathrm{rs}=0.55 \mathrm{P}=0.0001)$ e potássio ( $\mathrm{rs}=0.63 \mathrm{P}=0)$. No ponto 4 , o biovolume dos rígidos, correlacionou-se com a temperatura da água ( $\mathrm{rs}=0.50$ $\mathrm{P}=0.0001)$, condutividade $(\mathrm{rs}=0.56 \mathrm{P}=0), \mathrm{pH}(\mathrm{rs}=0.52 \mathrm{P}=0.0001)$ e teores de cálcio ( $\mathrm{rs}=0.50$ $\mathrm{P}=0.0002$ ) e potássio ( $\mathrm{rs}=0.54 \mathrm{P}=0.0001$ ). A porcentagem do total geral de organismos providos de envoltório rígido foi maior no ponto 4 . No ponto 1 os organismos sem envoltório rígido atingiram $90 \%$ da densidade de células, mostrando correlações semelhantes às 
encontradas pelo total de organismos, tanto em densidade como em biovolume. Entretanto, destacam-se as correlações apresentadas pelos organismos dotados de envoltório rígido no ponto 4 , mostrando que seu desenvolvimento foi favorecido pelo aumento da condutividade $\mathrm{e}$ alcalinidade, mas desfavorecido pela elevação dos teores de alumínio e ferro. Seu biovolume eleva-se nos períodos de pluviosidade e teores de nutrientes elevados (condutividade, cálcio e potássio).

Quanto a forma, a densidade de colônias ou cenóbios correlacionou-se, no ponto 1, com alcalinidade ( $\mathrm{rs}=0.50 \mathrm{P}=0.0002$ ) e com os teores de potássio ( $\mathrm{rs}=0.55 \mathrm{P}=0$ ) e no ponto 4 , com a condutividade ( $\mathrm{rs}=0.50 \mathrm{P}=0.0002$ ). As maiores densidades de colônias ou cenóbios foram registradas para Dictyosphaerium e Scenedesmus. A densidade de filamentosas, no ponto 1, correlacionou-se com transparência ( $\mathrm{rs}=-0.55 \mathrm{P}=0$ ), condutividade ( $\mathrm{rs}=0.50 \mathrm{P}=0.0002$ ), alcalinidade ( $\mathrm{rs}=0.66 \mathrm{P}=0$ ) e teores de sulfato ( $\mathrm{rs}=0.50 \mathrm{P}=0.0002$ ), cálcio ( $\mathrm{rs}=0.64 \mathrm{P}=0$ ), cobre $(\mathrm{rs}=0.60 \mathrm{P}=0)$ e potássio $(\mathrm{rs}=0.59 \mathrm{P}=0$ ) e no ponto 4 , com condutividade ( $\mathrm{rs}=0.52 \mathrm{P}=0.0001$ ) e alcalinidade ( $\mathrm{rs}=0.53 \mathrm{P}=0.0001$ ). A maior densidade de filamentosas foi de algas do gênero Mougeotia, que atingiu quantidade suficiente para diminuir a transparência da água, tendo apresentado maior densidade no período das chuvas. A densidade de unicelulares, correlacionou-se, no ponto 1 , com a transparência ( $\mathrm{rs}=-0.55 \mathrm{P}=0$ ), alcalinidade ( $\mathrm{rs}=0.69 \mathrm{P}=0$ ) e teores de cálcio ( $\mathrm{rs}=0.53 \mathrm{P}=0.0001$ ), cobre ( $\mathrm{rs}=0.53 \mathrm{P}=0.0001$ ) e zinco ( $\mathrm{rs}=0.55 \mathrm{P}=0.0001$ ). No ponto 4 , com a condutividade ( $\mathrm{rs}=0.55 \mathrm{P}=0), \mathrm{pH}(\mathrm{rs}=0.50 \mathrm{P}=0.0002)$, alcalinidade $(\mathrm{rs}=0.62 \mathrm{P}=0)$ e teor de alumínio ( $\mathrm{rs}=-0.55 \mathrm{P}=0)$.

Os biovolumes de colônias ou cenóbios em ambos os pontos, de unicelulares no ponto 1 , e de filamentosas no ponto 4 , não apresentaram correlações com os parâmetros abióticos nos níveis considerados. $\mathrm{O}$ biovolume de filamentosas no ponto 1 , correlacionou-se positivamente com o teor de cobre ( $\mathrm{rs}=0.53 \mathrm{P}=0.0001$ ). O maior biovolume de filamentosas foi de Mougeotia cf. americana, simultâneo aos maiores teores de cobre. A extensão do período em que esta floração persistiu, mesmo a despeito da aplicação do algicida e esta correlação positiva com o teor de cobre podem estar indicando tolerância desta alga ao algicida aplicado ou seu favorecimento na competição com espécies sensiveis ao tratamento.

No ponto 1 , o biovolume de clorococales correlacionou-se com a temperatura da água $(\mathrm{rs}=0.57 \mathrm{P}=0$ ) e com os teores de sulfato ( $\mathrm{rs}=0.57 \mathrm{P}=0$ ), cálcio ( $\mathrm{rs}=0.50 \mathrm{P}=0.0002$ ) e potássio $(\mathrm{rs}=0.64 \mathrm{P}=0)$. $\mathrm{O}$ maior biovolume atingido pelas clorococales ocorreu no período de chuvas, com altas densidades de Dictyosphaerium.

$\mathrm{O}$ biovolume de volvocales correlacionou-se com alcalinidade ( $\mathrm{rs}=-0.51 \mathrm{P}=0.0002$ ), no ponto 1 . 
O biovolume de zignemafíceas correlacionou-se no ponto 1 , com a temperatura da água ( $\mathrm{rs}=0.56 \mathrm{P}=0)$, transparência $(\mathrm{rs}=-0.55 \mathrm{P}=0)$, alcalinidade ( $\mathrm{rs}=0.61 \mathrm{P}=0)$, teores de cálcio $(\mathrm{rs}=0.61 \mathrm{P}=0)$, cobre $(\mathrm{rs}=0.55 \mathrm{P}=0)$, potássio $(\mathrm{rs}=0.54 \mathrm{P}=0.0001)$ e com sulfatação do dia anterior à coleta $(\mathrm{rs}=0.53 \mathrm{P}=0.0001)$.

No ponto 4, o biovolume de cianofíceas correlacionou-se com alcalinidade ( $r s=0.51$ $\mathrm{P}=0.0002$ ) e com o teor de cálcio ( $\mathrm{rs}=0.53 \mathrm{P}=0.0001$ ), possivelmente indicando a importância dos sais de ácido carbônico como fonte de carbono para estas algas, uma vez que a alcalinidade corresponde ao teor de sais de ácido carbônico, sob a forma de bicarbonatos solúveis, geralmente bicarbonato de cálcio, o mesmo podendo ser mencionado para as zignemaficeas do ponto 1 .

$\mathrm{O}$ biovolume de dinofíceas, correlacionou-se com a dureza ( $\mathrm{rs}=0.54 \mathrm{P}=0.0002$ ) e o de zignemafíceas com a alcalinidade ( $\mathrm{rs}=0.53 \mathrm{P}=0.0001$ ), no ponto 4 .

\subsubsection{SAZONALIDADE}

As Tabelas 29 e 30 expressam as variações temporais de densidade e biovolume das espécies do ponto 1 e as Tabelas $32 \mathrm{e} 32$, as do ponto 4 . Os resultados descritos a seguir estão expressos nas Figuras 18 e 19 que resumem a dinâmica temporal da comunidade fitoplanctônica e suas principais forçantes. Nas Tabelas 34 a 36 mostra-se os valores das medianas dos parâmetros analisados, através das quais foram elaborados quadros-resumo de cada período sazonal (Figuras 12 e 13).

Em relação aos fatores climáticos, balanço hídrico, operação da represa, qualidade da água e comunidade fitoplanctônica, considerando-se as medianas para cada período, delimitaram-se neste estudo quatro períodos mais marcantes:

\section{Primeiro período de seca (MA2 a AG16):}

Este período mostrou valores mais elevados para insolação, velocidade do vento, elevação e volume. Estiveram relativamente elevados os valores de pluviosidade imediata, ou seja das 24 horas nos dias de coleta, vazão afluente natural dos tributários mais importantes e captação de água para abastecimento. Ocorreu deficiência hídrica do solo em 9 das 15 coletas e os valores mais baixos para excedente hídrico, pluviosidade acumulada de 72 e 168 horas, vazão afluente recalcada, evapotranspiração, temperatura do ar e aplicação de algicida.

Quanto a qualidade da água, o ponto 1 apresentou os mais elevados valores para profundidade, transparência, cor, oxigênio dissolvido, teor de nitrato, alumínio e silício; valores relativamente elevados de cálcio e zinco e os menores valores de temperatura da água, turbidêz, condutividade, $\mathrm{pH}$, demanda bioquímica de oxigênio, alcalinidade, dureza, fósforo 
turbidêz, condutividade, $\mathrm{pH}$, demanda bioquímica de oxigênio, alcalinidade, dureza, fósforo solúvel reativo, fósforo total, amônio, sulfato, cloro, cobre, potássio, magnésio e sódio. $O$ conteúdo iônico total foi mais baixo que nos demais períodos.

O fitoplâncton do ponto 1 , mostrou os maiores valores de uniformidade, expressa em número de organismos, bioárea e biovolume, valores relativamente elevados de diversidade $\mathrm{e}$ de alteração da comunidade e o menor valor de biovolume.

As freqüências mais elevadas em número de organismos no periodo, foram atingidas por bacilarioficeas, clorococales e criptoficeas e em biovolume por bacilarioficeas, volvocales e zignemaficeas. Estiveram entre as três espécies mais freqüentes em densidade: Asterionella formosa, Synedra minuscula, Rhizosolenia eiriensis, Scenedesmus bijugus, Chlorella cf. minutissima e Chlamydomonas cf. gloeophila t2. Em biovolume: Aphanocapsa elachista, Rhizosolenia eiriensis, Chlamydomonas cf. gloeophila colonial e t2, Xanthidium sp2, Volvocales sp1 colonial, zigoto de Oedogoniales sp1, Asterionella formosa e Aulacoseira granulata. Este periodo de águas claras, quando ocorreram teores elevados de silício (indicando a possibilidade de haver maiores teores de sílica reativa), temperaturas mais baixas $\mathrm{e}$ a maior transparência, favoreceu o desenvolvimento de diatomáceas.

O ponto 4, quanto a qualidade da água, mostrou os valores de mediana mais elevados para profundidade da água, transparência, oxigênio dissolvido, fósforo total, alumínio, ferro e silício, valores relativamente elevados de turbidez, cloro, magnésio e zinco e os menores valores de temperatura da água, cor, condutividade, $\mathrm{pH}$, alcalinidade, dureza, sólidos totais em suspensão, amônio, cálcio, potássio, manganês e sódio.

O fitoplâncton do ponto 4 , mostrou os maiores valores de uniformidade em número de organismos, bioárea e biovolume, como no ponto 1 , e os menores valores de densidade em organismos, bioárea, biovolume, GALD, SGALD, e número de táxons.

As freqüências relativas mais elevadas, em número de organismos foram de bacilarioficeas, criptoficeas, volvocales e clorococales e em biovolume de bacilarioficeas, volvocales, clorococales, euglenoficeas e zignemaficeas. Estiveram entre as três espécies mais freqüentes, por coleta, em densidade: Rhizosolenia eiriensis, Cryptomonas cf. brasiliensis, Synedra minuscula, Cryptomonas cf. tenuis, Aulacoseira granulata, Chlamydomonas cf. gloeophila $\mathrm{t}$, Chlorella vulgaris e Scenedesmus bicaudatus. Em biovolume: Sphaerocystis schroeterii, zigoto de Oedogoniales, Rhizosolenia eiriensis, Euglena acus, Staurodesmus cuspidatum, Scenedesmus bijugus, Aulacoseira granulata, Chlamydomonas cf. gloeophila $\mathrm{t} 2$ e Botryococcus neglectus. Neste ponto, as diatomáceas também foram favorecidas neste periodo, mas destacaram-se as criptoficeas pelo maior desenvolvimento. 


\section{Período de chuvas moderadas (SE17 a N29):}

Este período apresentou o valor mais elevado de captação de água para abastecimento e valores relativamente elevados de radiação solar, vento, excedente hídrico, pluviosidade imediata e acumulada de 72 e de 168 horas e evapotranspiração, verificou-se os menores valores de mediana a insolação, deficiência hídrica do solo, escoamento básico, vazão afluente recalcada, volume e aplicação de sulfato de cobre.

0 ponto 1 , quanto a qualidade da água, apresentou os valores de mediana mais elevados para cor, demanda bioquímica de oxigênio, nitrato, cloro, alumínio e sódio; valores relativamente elevados de dureza, sólidos totais em suspensão, fósforo solúvel reativo, cálcio, cobre e ferro e os menores valores de profundidade, turbidez, amônio, magnésio e zinco.

0 ponto 1 , apresentou os maiores valores de mediana para os índices de alteração da comunidade em número de organismos, bioárea e biovolume, valores relativamente elevados de uniformidade em número de organismos e bioárea e os menores valores de densidade em organismos, bioárea, GALD, SGALD, número de táxons, diversidade de bioárea e de biovolume bem como da uniformidade do biovolume.

As freqüências relativas mais elevadas em número de organismos foram de bacilarioficeas, clorococales, volvocales, crisoficeas, zignemaficeas e criptoficeas e em biovolume de clorococales, bacilarioficeas, volvocales e crisoficeas. Estiveram entre as três espécies mais frequientes em cada coleta, quanto a densidade: Chlamydomonas cf. gloeophila t2, Dinobryon divergens, Rhizosolenia eiriensis, Asterionella formosa, Aulacoseira granulata, Chlorella vulgaris, Mougeotia cf. americana, Sennia communata, Dictyosphaerium ehrenberghianum e Dictyosphaerium pulchellum. Em biovolume: Chlamydomonas cf. gloeophila t2, Dinobryon divergens, Aulacoseira granulata, Asterionella formosa, Scenedesmus bicaudatus, Dictyosphaerium ehrenberghianum e Dictyosphaerium pulchellum.

0 ponto 4 , quanto a qualidade da água, mostrou os maiores valores de mediana para cor, turbidez, nitrato, sulfato, cloro, alumínio e sódio, valores relativamente elevados de oxigênio dissolvido, dureza, fósforo solúvel reativo, ferro, potássio, magnésio e silício e os menores valores de demanda bioquímica de oxigênio, fósforo total, amônio, manganês e zinco.

O fitoplâncton, no ponto 4, apresentou os maiores valores de mediana para os índices de alteração da comunidade em organismos, bioárea e biovolume, valores relativamente elevados de uniformidade de número de organismos e de bioárea e os menores valores de densidade em organismos e bioárea, GALD, SGALD, número de táxons, diversidade de densidade de organismos e bioárea, bem como da uniformidade do biovolume.

As frequiências relativas, para número de organismos, foi mais elevada entre as 
clorococales, criptoficeas, crisoficeas, volvocales e bacilarioficeas e para biovolume de clorococales, bacilarioficeas, volvocales, dinoficeas e euglenoficeas. Das três espécies mais freqüentes em cada coleta, destacaram-se quanto a densidade: Cryptomonas cf. brasiliensis, Chlamydomonas cf. gloeophila t1 e t2, Dinobryon sertularia, Rhizosolenia eiriensis, Aulacoseira granulata, Dictyosphaerium ehrenberghianum. Em biovolume: Aulacoseira granulata, Chlamydomonas cf. gloeophila t2, Peridinium sp3, Dictyosphaerium ehrenberghianum, Volvocales sp1 e Gymnodinium fuscum.

\section{Período de chuvas intensas (D30 a MR44):}

Este período apresentou os valores mais elevados de mediana para radiação solar, excedente hídrico, escoamento básico, pluviosidade imediata e acumulada de 72 e 168 horas, vazão afluente natural, evapotranspiração e quantidade de sulfato de cobre aplicado no ponto 1; estiveram relativamente elevados, os valores de insolação e velocidade do vento; ocorreram os menores valores para deficiência hídrica do solo, vazão afluente recalcada e elevação.

0 ponto 1 , quanto à qualidade da água mostrou os maiores valores de mediana para temperatura da água, cor, dureza, sulfato, cálcio, cobre, potássio e magnésio; ocorreram valores relativamente elevados de transparência, turbidez, condutividade, $\mathrm{pH}$, alcalinidade, fósforo total, cloro, sódio, e silício; observaram-se os menores valores de oxigênio dissolvido, sólidos totais em suspensão, fósforo solúvel reativo, amônio, nitrato, alumínio, ferro, e zinco.

$\mathrm{O}$ ponto 1 , mostrou os maiores valores de mediana de biovolume, diversidade do número de organismos e da bioárea; ocorreram valores relativamente elevados de densidade em número de organismos e bioárea, GALD, SGALD e número de táxons e os menores valores de diversidade e uniformidade do número de organismos, uniformidade da bioárea e índices de alteração da comunidade, em bioárea e biovolume.

As freqüências relativas mais elevadas, quanto à densidade em organismos, foram de zignemaficeas, clorococales, bacilarioficeas e cianoficeas e quanto ao biovolume de zignemaficeas, clorococales, bacilarioficeas e cianoficeas. Estiveram entre as três espécies mais frequientes em densidade, nas coletas: Dictyosphaerium ehrenberghianum, Aphanocapsa elachista, Synedra ulna t1, Mougeotiopsis sp1, Mougeotia cf. americana, Chlorella vulgaris e Chlorella cf. minutissima. Em biovolume: Dictyosphaerium ehrenberghianum, Aphanocapsa elachista, Mougeotiopsis sp1, Mougeotia cf. americana, Gloeocystis bannergatensis e Aulacoseira granulata.

O ponto 4, quanto a qualidade da água apresentou os valores de mediana mais elevados para temperatura da água, cor, demanda bioquímica de oxigênio, dureza, cloro, alumínio, cálcio, potássio, magnésio, manganês e sódio; valores relativamente elevados de turbidez, 
condutividade, $\mathrm{pH}$, alcalinidade, sólidos totais em suspensão, sulfato, silício e zinco e os menores valores de profundidade, transparência, oxigênio dissolvido, amônio, nitrato e ferro.

$\mathrm{O}$ fitoplâncton do ponto 4 , apresentou os maiores valores de mediana de biovolume $\mathrm{e}$ das diversidades, expressa em relação ao número de células e de bioárea; ocorreram valores relativamente elevados de densidade de organismos e de bioárea, GALD, SGALD e número de táxons, diversidade de biovolume, uniformidade de bioárea e de biovolume, dos índices de alteração da comunidade, em densidade e bioárea e os menores valores de mediana de uniformidade da densidade e do indice de alteração do biovolume da comunidade.

As frequiências relativas mais elevadas, em número de células, ocorreram para clorococales, zignemaficeas, criptoficeas e cianoficeas e em biovolume, para clorococales, dinoficeas e bacilarioficeas. Das três espécies mais freqüentes em cada coleta, destacaram-se quanto a densidade: Dictyosphaerium elegans, Dictyosphaerium ehrenberghianum, Mougeotiopsis sp1, Mougeotia cf. americana, Synechococcus elongatus, Cryptomonas cf. brasiliensis, Cryptomonas cf. tenuis, Chlorella cf. minutissima e Chlorella vulgaris. Em biovolume: Dictyosphaerium elegans, Dictyosphaerium ehrenberghianum, Synedra ulna t2, Aulacoseira granulata, Peridinium sp1, Gymnodinium fuscum e Chlorella vulgaris.

\section{Segundo período de seca (AB45 a JL58):}

Este período apresentou os valores de mediana mais elevados para deficiência hídrica do solo e vazão afluente recalcada, valores relativamente elevados do nível da água, volume $\mathrm{e}$ temperatura do ar e os menores valores de mediana para radiação solar, velocidade do vento,excedente hídrico, pluviosidade imediata e acumulada de 72 horas, vazão afluente natural e captação de água para abastecimento.

0 ponto 1, quanto a qualidade da água mostrou os valores de mediana mais elevados, para turbidez, condutividade, $\mathrm{pH}$, alcalinidade, sólidos totais em suspensão, fósforo solúvel reativo, amônio, cálcio e zinco, valores relativamente elevados de temperatura da água, profundidade, cor, demanda bioquímica de oxigênio, nitrato, sulfato, cobre, potássio e magnésio e os menores valores de alumínio e silício.

Ocorreram os maiores valores de mediana de densidade e de bioárea, GALD, SGALD, número de táxons, diversidade em densidade, bioárea e biovolume; valores relativamente altos de uniformidade em densidade, bioárea e biovolume e os menores valores de alteração da densidade da comunidade.

As freqüências relativas mais elevadas, em número de organismos, foram encontradas entre as clorococales, cianoficeas, bacilarioficeas e zignemaficeas e em biovolume entre as clorococales, bacilarioficeas e volvocales. Estiveram entre as três espécies mais frequientes em 
cada coleta, quanto a densidade: Mougeotia cf. americana, Chlorella cf. minutissima, Oscillatoria subtilissima, Scenedesmus bijugus e Rhizosolenia eiriensis. Em biovolume: Volvocales spl colonial, Scenedesmus bijugus, Aulacoseira granulata, Scenedesmus bicaudatus, Rhizosolenia eiriensis e Dictyosphaerium pulchellum.

0 ponto 4 , quanto à qualidade da água, mostrou os valores de mediana mais elevados para condutividade, $\mathrm{pH}$, alcalinidade, sólidos totais em suspensão, fósforo solúvel reativo, amônio, potássio, manganês e zinco; mostrou valores relativamente mais elevados de temperatura da água, profundidade, transparência, cor, demanda bioquímica de oxigênio, fósforo total, nitrato, cálcio, magnésio e sódio e os menores valores de sulfato, cloro, alumínio, ferro e silício.

Ocorreram os maiores valores de mediana de densidade, bioárea, GALD, SGALD, número de táxons e da diversidade do biovolume; ocorreram valores relativamente elevados de biovolume, diversidade da densidade e da bioárea e os menores valores de uniformidade da densidade e da bioárea e alteração da densidade e da bioárea.

As freqüências relativas, mais elevadas, para número de células foram de clorococales, volvocales e bacilarioficeas e em biovolume foram de clorococales, dinoficeas, bacilarioficeas, euglenoficeas e cianoficeas.

Estiveram entre as espécies mais freqüentes em cada coleta, quanto a densidade: Botryococcus neglectus, Chlorella cf. minutissima, Chlorella vulgaris, Chlamydomonas cf. globosa e Aulacoseira granulata. Em biovolume: Botryococcus neglectus, Gymnodinium fuscum, Scenedesmus bijugus, Phacus longicauda, Aulacoseira granulata, Rhizosolenia eiriensis e Aphanocapsa elachista.

\subsubsection{ANÁLISE DOS COMPONENTES PRINCIPAIS}

Após comparação com os resultados da análise canônica, optou-se pela aplicação da análise de componentes principais que proporcionou resultados mais significativos, com os eixos fatoriais 1 e 2 apresentando maiores valores de explicação para as relações entre as variáveis ambientais.

Para reduzir a possibilidade de erros na interpretação do comportamento das variáveis biológicas utilizou-se o biovolume da comunidade fitoplanctônica como variável ambiental representativa do comportamento do fitoplâncton, integrando-se estes resultados aos resultados da análise das dominâncias de espécies na comunidade, nas figuras apresentadas. Os resultados numéricos da análise de componentes principais estão expressos nas Tabelas $26 \mathrm{e}$ 27 , respectivamente para os pontos 1 e 4 . As figuras 14 a 17 mostram a representação gráfica 
destes resultados.

Os dois primeiros componentes foram responsáveis por 79 e $67 \%$ da explicação dos eixos fatoriais dos respectivos pontos 1 e 4 .

Para formação dos eixos no ponto 1, associaram-se:

- no lado positivo do eixo 1: deficiência hídrica do solo (638), oxigênio dissolvido (14), nitrato (11), sólidos totais em suspensão (10) e as coletas de maio, junho, julho e agosto, ou seja, de outono e inverno, abrangendo 4 coletas do primeiro periodo de seca, 11 do segundo periodo de seca e 1 do período de chuvas intensas AG13, quando já se iniciava a transição para o segundo período de seca.

- no lado negativo do eixo 1: pluviosidade (-372), cor (-32) e coletas de setembro, outubro, novembro, dezembro, janeiro, fevereiro e março, abrangendo 2 coletas do primeiro periodo de seca - coletas em que houve um pequeno aumento da pluviosidade, 7 coletas do período de chuvas moderadas, 14 do período de chuva intensas e 2 do segundo período de seca, as mais próximas das chuvas intensas, quando a água ainda mantinha características do período anterior.

- o lado positivo do eixo 2: insolação (235), fósforo total (88), transparência (48), teores de silício (27), ferro (24), alumínio (11), profundidade da água (10), bem como coletas de maio, junho, julho, setembro e outubro abrangendo 8 coletas do primeiro período de seca e 3 do periodo de chuvas moderadas, representando portanto a fase inicial da transição de seca para chuvas.

- no lado negativo do eixo 2: biovolume algáceo (-595), sulfatação (-196), dureza (-77), radiação solar (-68), temperatura da água $(-51)$, alcalinidade $(-48)$, teor de sulfato $(-46)$, demanda bioquímica de oxigênio (-43), teor de potássio $(-38)$, condutividade $(-32)$, teores de sódio (-32), cálcio (-29), cloro (-27), fósforo solúvel reativo $(-20)$, turbidez $(-18)$, $\mathrm{pH}(-16)$, velocidade dos ventos $(-16)$, teores de amônio $(-11)$, magnésio $(-9)$, cobre $(-3)$ e coletas de novembro e dezembro, sendo 3 coletas do período de chuvas moderadas e 1 do período de seca (N27 - 22646 um $^{3} .1^{-1} ; \mathrm{N} 28$ - 32093 um $^{3} .1^{1-1}$; N29 - 23166 um $^{3} .1^{-1} ;$ D33 - 26054 um $^{3} .1^{-1}$ ), ou seja, as coletas que apresentaram os valores mais elevados de biovolume algáceo.

Para formação dos eixos no ponto 4, associaram-se:

- no lado positivo do eixo 1: deficiência hídrica do solo (622), sólidos totais em suspensão (104), fósforo solúvel reativo (50), oxigênio dissolvido (19), teores de zinco (3), manganês (1) e coletas de abril, maio, junho, julho e agosto, abrangendo 5 coletas do primeiro período de seca e 11 do segundo período de seca e portanto representou a seca.

- no lado negativo do eixo 1: pluviosidade $(-361)$, turbidez $(-55)$, cor $(-53)$ e coletas de 
setembro, outubro, dezembro, janeiro, fevereiro, março e abril, sendo 1 coleta do primeiro período de seca, do momento em que houve um pequeno aumento da pluviosidade, de 55 para $66 \mathrm{~mm}$; 6 coletas do período de chuvas moderadas; 13 coletas do período de chuvas intensas; 2 do segundo período de seca, mostrando um lapso de uma a três semanas, entre a alteração ambiental alóctone e a resposta na qualidade da água, quando o ambiente ainda mantinha características do período anterior, também observado no ponto 1 .

- no lado positivo do eixo 2: insolação (169), fósforo total (142), ferro (38), transparência (35), silício (24), amônio (17), nitrato (7) e coletas de maio, junho, julho, setembro e outubro, sendo 9 do primeiro periodo de seca e 3 coletas de chuvas moderadas, portanto, representando o período de transição entre a seca e as chuvas moderadas.

- no lado negativo do eixo 2: biovolume (-636), demanda bioquimica de oxigênio (-91), dureza (-84), radiação solar (-69), condutividade (-55), temperatura da água (-43), alcalinidade $(-45)$, teores de cálcio $(-37)$, sódio $(-33)$, cloro $(-28)$, potássio $(-26)$, sulfato $(-24), \mathrm{pH}(-17)$, magnésio $(-17)$, velocidade dos ventos $(-14)$ e coletas de novembro, dezembro e fevereiro, abrangendo 4 coletas do período de chuvas moderadas e 2 de chuvas intensas (N26 - 12396 $\mathrm{um}^{3} \mathrm{l}^{-1}, \mathrm{~N} 27-20496 \mathrm{um}^{3} . \mathrm{l}^{-1}, \mathrm{~N} 28-16650 \mathrm{um}^{3} \cdot \mathrm{l}^{-1}, \mathrm{~N} 29-20229 \mathrm{um}^{3} \cdot \mathrm{l}^{-1}, \mathrm{D} 30-24170 \mathrm{um}^{3} . \mathrm{l}^{-1}$ e F40 - $16159 \mathrm{um}^{3} \cdot \mathrm{l}^{-1}$ ), ou seja, as coletas que atingiram os maiores biovolumes algáceos durante as chuvas. As únicas coletas dentre as demais que apresentaram biovolume superior a 10000 um $^{3} . \mathrm{l}^{-1}$ foram AB48 e AB49 durante a seca, com biovolumes elevados de Phacus longicauda e Aulacoseira granulata respectivamente.

A análise dos componentes principais no ponto 1, mostra que em maio de 1991, MA2, prevaleciam condições de seca, com ocorrência da situação ambiental mais próxima da configurada pela deficiência hídrica do solo, com elevação da insolação, profundidade, transparência e teores de nitrato. O desenvolvimento de diatomáceas foi favorecido, representado tanto pelas expressivas densidades de Synedra cf. minuscula como pelo biovolume elevado de Rhizosolenia eiriensis e também da volvocales Chlamydomonas cf. gloeophila.

Nesta situação, é interessante notar que apesar da baixa pluviosidade, a profundidade atinge os maiores valores, indicando que a operação hidráulica para captação de água e não a pluviosidade, conforme seria esperado, é responsável pelo nível da água na represa.

Chlamydomonas cf. gloeophila continuou com valores expressivos de densidade e biovolume até $\mathrm{O} 22$, mas à partir de $\mathrm{JL10}$ é acompanhada por Asterionella formosa em densidade e biovolume e por Aulacoseira granulata em biovolume. Nestes períodos o teor de fósforo total e de silício, ferro e aluminio encontram-se mais elevados e as coletas S20 e S21, 
quando ocorreram chuvas mais elevadas, assemelham-se às coletas do período chuvoso.

A maior disponibilidade de fósforo total, ocorreu quando a densidade algácea atingia valores menos expressivos, no inverno e outono (setembro, outubro e fim de março).

Em O23 altera-se a situação de dominâncias, sem alterações ambientais perceptiveis exceto a aplicação de sulfato, com cloroficeas de porte reduzido atingindo as mais expressivas densidades (Chlorella vulgaris, Crucigeniella crucifera e Scenedesmus bijugus) e biovolumes (Scenedesmus bicaudatus, Chlorella vulgaris e Chlorella cf. minutissima).

Com a elevação da temperatura e o início das primeiras chuvas ocorrem grandes aportes de matéria orgânica e de nutrientes da bacia, aumentando os teores de fósforo solúvel reativo, amônio, a demanda bioquímica de oxigênio e a condutividade. Nesta fase conservou-se o mesmo padrão de dominância relatado para o período de seca mais intensa. $\mathrm{O}$ porte reduzido das espécies indica ambiente favorável ao desenvolvimento de espécies oportunistas, de volume reduzido e crescimento rápido, as r-estrategistas.

A elevação da temperatura, da radiação solar e dos índices pluviométricos aumentaram a disponibilidade de cálcio, potássio, sulfato, cloro, sódio, magnésio, acarretando aumento da dureza e permitindo o desenvolvimento simultâneo de densidade e biomassa fitoplanctônica elevadas, com dominância de Dictyosphaerium ehrenberghianum entre 024 e JA32, induzindo à aplicação de maiores concentrações de sulfato de cobre. Quando Dictyosphaerium ehrenberghianum entrou em senescência, havia grandes massas de gelatina com apenas algumas células vivas. A conseqüente disponibilidade dos nutrientes liberados por estas algas nas águas superficiais, induziu o desenvolvimento de Aphanocapsa elachista var. conferta, que ocorreu em alta densidade em D33.

As altas densidades e biovolumes do gênero Mougeotia entre JA35 e AB46 sugerem a ocorrência de distúrbios físicos ocasionados pela elevada pluviosidade e vento, mobilizando a coluna d'água com impacto suficiente para desgarrar e transportar estas algas do perifiton, das margens para a água aberta. A queda da pluviosidade e a diminuição de Mougeotia dão lugar novamente ao desenvolvimento de uma biomassa abundante de espécies planctônicas.

No final de abril, em AB47 e em todo o período de seca subseqüente, o teor de nutrientes manteve-se elevado. No auge da seca, quando a deficiência hídrica do solo foi mais expressiva, com a temperatura e a umidade do solo baixas (inibindo a degradação acelerada de materiais sólidos da bacia), a entrada de nutrientes restringiu-se às contribuiçðes dos tributários e dos esgotos, uma vez que a pluviosidade muito reduzida não permitiu aportes por carreamento ou percolação.

A análise da dominância mostrou que entre as clorococales, apresentaram os maiores 
totais de densidade Chlorella cf. minutissima, de espécies do gênero Scenedesmus e de biovolume a bacilarioficea Rhizosolenia eiriensis e as clorococales Scenedesmus bijugus e Dictyosphaerium pulchellum, sendo que JL58 apresentou densidade elevada de Oscillatoria subtilissima.

Quando se compara os dois periodos de seca observa-se o retorno às condições ambientais semelhantes (MA2 e MA50, 51 e 53; $\mathrm{AB} 13$ a 16 e AB47) mas a seca mais acentuada de 1992, desloca os resultados das coletas de junho e julho para a direção positiva do eixo fatorial 1, devido a deficiência hídrica do solo.

No ponto 1, as algas de biovolume mais expressivo, por espécie, foram Dictyosphaerium ehrenberghianum e Aphanocapsa elachista e a mais expressiva, na contribuição para o biovolume da represa, foi Dictyosphaerium ehrenberghianum.

As dominâncias iguais ou maiores que $80 \%$ entre até três espécies e as altas densidades estiveram mais concentradas nos períodos de maior disponibilidade de nutrientes, simultâneas às pluviosidades mais intensas, indicando altas contribuições, por carreamento da bacia de drenagem, decorrentes da exposição dos solos e conseqüências das outras atividades antrópicas que degradam o ecossistema desta bacia.

A análise dos dados do ponto 4 mostra que embora os fatores climáticos e a operação hidráulica tenham sido iguais, a ausência de aplicação de sulfato de cobre e as situações peculiares desta região da represa, onde a retenção hidráulica e a profundidade são menores, propiciaram uma configuração diferente do ponto 1 , quanto a alguns fatores abióticos. Neste ponto o amônio, fósforo solúvel reativo e fósforo total deslocam-se para o quadrante 1 do gráfico, que representa altos valores de insolação e menor biovolume. Amônio e fósforo solủvel reativo no ponto 1 posicionaram-se no quadrante 2 , próximo ao eixo fatorial 1 , com influência mais acentuada da produtividade algácea em biovolume, da sulfatação e da deficiência hídrica do solo. Fósforo total situou-se no quadrante 4, que abrangeu coletas do início das chuvas. A turbidez, deslocou-se para o quadrante 4, mostrando que neste ponto, onde nas proximidades houve desmatamento e uma área grande de solo foi exposta, o início das chuvas em setembro e outubro induziu aportes expressivos, responsáveis pelo aumento da turbidez e dos teores de silício, ferro e alumínio para a água.

As diferenças mencionadas somam-se e favorecem diferenças expressivas entre as comunidades fitoplanctônicas dos dois pontos estudados.

Em maio de 1991, MA2, ainda prevalecendo as condições de seca, observa-se um período de maior densidade e biovolume de Rhizosolenia eiriensis que perdura até $\mathrm{J} 7$, com a 
maior parte destas campanhas posicionadas no quadrante 4, onde estão expressos os valores mais elevados de silício. Em L8 Chlamydomonas cf. gloeophila supera Rhizosolenia atingindo mais elevada densidade e biovolume. Esta densidade mais expressiva é compartilhada por Cryptomonas cf. brasiliensis e perdura até AG14. Em AG15 é superada temporariamente por Scenedesmus bijugus, voltando a ocorrer entre AG16 a S18, mas Chlamydomonas cf. gloeophila manteve-se elevada quanto ao biovolume até AG13. As algas flageladas foram portanto, favorecidas nos periodos em que as temperaturas foram mais baixas, coincidentes com a maior transparência, ou seja, no período de águas claras, que também favoreceram o desenvolvimento das penales, conforme mencionado anteriormente.

Entre S19 e O25 Chlamydomonas cf. gloeophila passa a compartilhar a prevalência em densidade com Rhizosolenia eiriensis e Aulacoseira granulata, o mesmo ocorrendo para o biovolume entre AG14 e O22. A única exceção foi O23 em que a uniformidade foi igual a 1.0, ou seja, todos os táxons apresentaram igual densidade na amostra. Em O23 o maior biovolume foi de Peridinium sp3. Em 024 e $\mathrm{O} 25$ o maior biovolume foi de Chlamydomonas cf. gloeophila.

De N26 a JA32, na transição para o periodo de alta pluviosidade, Dictyosphaerium ehrenberghianum e Dictyosphaerium elegans atingiram as maiores densidades das amostras, o mesmo ocorrendo para o biovolume, que neste caso permanece até JA35. De D33 a JA35 as densidades mais elevadas estiveram entre Dictyosphaerium ehrenberghianum e Mougeotia cf. americana. Em JA36 Cryptomonas cf. brasiliensis é a espécie de maior densidade e Aulacoseira granulata a de maior biovolume. Mougeotia cf. americana mostra a mais elevada densidade de JA37 a J38 e em JA37 prevalece em biovolume, simultaneamente com Peridinium sp1. O desenvolvimento mais expressivo da densidade de espécies de pequeno porte ocorre entre F39 até JL58, com Chlorella cf. minutissima e Chlorella vulgaris. Quanto ao biovolume, de F38 a J54 Gymnodinium fuscum e Scenedesmus bijugus e entre J55 e ЛL58 quando a seca já está no auge, Rhizosolenia eiriensis e Aulacoseira granulata prevalecem.

No ponto 4 observou-se aproximadamente o mesmo padrão, mas devido às condições de maior movimento da massa d'água, menor tempo de retenção e ausência da sulfatação, as espécies envolvidas na dominância em biovolume diferiram e os intervalos de alteração tạmbém foram menores. Esta queda nos intervalos de alteração parecem refletir a movimentação da água, uma vez que o ponto 4 situa-se num compartimento de comportamento mais fluvial que lacustre. 


\subsubsection{TESTE DE HENDRICKSON}

Este teste permite avaliar qualitativamente, tanto a homogeneidade do número de espécies, como a existência de coincidências positivas de espécies, dentro de um conjunto de dados e desta forma localizar rupturas da estrutura específica da(s) comunidade(s), determinadas por alterações ambientais (antropogênicas ou não). A determinação de fatores promotores de alteração das comunidades é extremamente importante em estudos sanitários e ecológicos, provendo informação útil para subsidiar o manejo ambiental.

Os resultados do teste de Hendrickson, expressos na Tabela 28, mostraram que os conjuntos de dados totais do fitoplâncton, de ambos os pontos, apresentaram heterogeneidade no número de espécies e mais que uma taxocenose envolvida, considerando-se o período total de estudo.

Procedeu-se então à separação em lotes de dados de forma a identificar o grupo sistemático e o período em que a comunidade apresentou homogeneidade no número de espécies e apenas uma taxocenose.

Os critérios de separação adotados não permitiram remover a heterogeneidade das clorococales em nenhum periodo no ponto 1 , bem como a de centrales (durante os períodos de chuvas moderadas e da segunda seca), penales (durante os dois periodos de seca).

Da mesma forma, no ponto 4 as clorococales (durante os periodos de chuva e na segunda seca), volvocales (durante as chuvas moderadas e a segunda seca), euglenoficeas (durante o segundo período de seca) e zignemaficeas (durante o primeiro periodo de seca), mantiveram a heterogeneidade.

Estes resultados indicam a existência de forçantes da alteração destes grupos de algas, alheias à sazonalidade.

A heterogeneidade das criptoficeas e zignemaficeas do ponto 1 foi removida eliminandose as coletas em que houve aplicação de algicida, indicando que para estes grupos de algas, a aplicação do sulfato de cobre funcionou como a principal forçante de modificações, promovendo alterações, tanto no número, quanto na composição de espécies. A situação descrita é resumida a seguir. 
QUADRO 2 - RESUMO DOS RESULTADOS DO TESTE DE HENDRICKSON (1978), APLICADOS À COMUNIDADE FITOPLANCTÔNICA DA REPRESA DE GUARAPIRANGA, 1991-92.

Ponto 1 (P1); Ponto 4 (P4); conjunto total dos dados de cada ponto (T); periodo da primeira seca (S1); período de chuvas moderadas (CM); período de chuvas intensas (CI); periodo da segunda seca (S2); centrales (CEN); penales (PEN); clorococales e cedogoniales (CHL); volvocales (VOL); crisoficeas (CHR); criptoficeas (CRY); dinoficeas (DIN); euglenoficeas (EUG); cianoficeas (CYA); zignemaficeas (ZYG), periodo sem aplicação de sulfato de cobre (SS); período com aplicação de sulfato de cobre (CS); caso em que houve homogeneidade no número de táxons e apenas uma taxocenose para o conjunto de dados $(\mathrm{X})$; caso em que não houve coincidências positivas de espécies para o conjunto de dados analisados (SP).

\begin{tabular}{|c|c|c|c|c|c|c|c|c|c|c|c|c|}
\hline P1 & & & & & & & & & & & & \\
\hline & $\mathrm{T}$ & S1 & $\mathrm{CM}$ & $\mathrm{CI}$ & S2 & SS & CS & $\mathrm{T}$ & S1 & $\mathrm{CM}$ & CI & S2 \\
\hline CEN & & $X$ & & $\mathrm{X}$ & & & & & X & $\mathbf{X}$ & $\underset{Y}{X}$ & \\
\hline PEN & & & $X$ & $\mathrm{X}$ & & & & $X$ & $\mathrm{X}$ & & $X$ & $\mathrm{X}$ \\
\hline CHL & & & & & & & & & $\mathrm{X}$ & & & \\
\hline VOL & $\mathrm{X}$ & $\mathrm{X}$ & $\mathrm{X}$ & $\mathrm{X}$ & X & $\mathrm{X}$ & $\mathrm{X}$ & & $X$ & & $X$ & \\
\hline CHR & & $X$ & $X$ & $X$ & $X$ & & $x$ & $\mathrm{X}$ & $\mathrm{X}$ & $\mathrm{X}$ & $\mathrm{X}$ & $X$ \\
\hline CRY & & $\mathrm{X}$ & $\mathrm{X}$ & & & $\mathrm{X}$ & & $\mathrm{X}$ & $\mathrm{X}$ & $\mathrm{X}$ & $\mathrm{X}$ & $X$ \\
\hline $\mathrm{DNN}$ & $X$ & $\mathrm{X}$ & $\mathrm{X}$ & $\mathbf{X}$ & $X$ & $\mathrm{X}$ & $X$ & & SP & $\mathrm{X}$ & $\mathrm{X}$ & $\mathrm{X}$ \\
\hline EUG & $\mathrm{X}$ & $\mathrm{X}$ & $\mathrm{X}$ & $\mathrm{X}$ & $\mathrm{X}$ & $\mathrm{X}$ & $\mathrm{X}$ & $X$ & $\mathrm{X}$ & SP & $\mathrm{X}$ & \\
\hline CYA & & $\mathrm{X}$ & $\mathrm{X}$ & $\mathrm{X}$ & $\mathrm{X}$ & & & & $X$ & $\mathrm{X}$ & $\mathrm{X}$ & $\mathrm{X}$ \\
\hline ZYG & & & $\mathrm{X}$ & $\mathrm{x}$ & $\mathrm{X}$ & $X$ & & & & SP & $\mathrm{X}$ & $\mathrm{X}$ \\
\hline
\end{tabular}

\subsubsection{0. ÍNDICE DE PERSISTÊNCIA DAS ESPÉCIES:}

$O$ indice de persistência das espécies foi elaborado para avaliar a capacidade da comunidade total e dos grupos de algas que a constituem de sobreviverem às alterações ambientais. Está sendo proposto neste momento e sua validade será testada com os dados aqui obtidos.

A análise dos resultados da aplicação para o conjunto total de dados de cada ponto de coleta, mostrou que o ponto 1 apresentou valor mais elevado que o ponto 4 , ao contrário do esperado devido às aplicações de sulfato de cobre, pois em 25 coletas o algicida havia sido aplicado no dia anterior e em 28 dos 56 dias foi aplicado no dia da coleta. Entretanto, a maior profundidade da coluna, o maior tempo de residência da água e a própria capacidade das espécies existentes no ponto 1 para tolerar este algicida, podem ter favorecido estes resultados.

Em ambos os pontos a persistência média relativa apresentou-se mais elevada durante 0 período de seca, especialmente durante a segunda seca (1992), porém, enquanto no ponto $4 \mathrm{o}$ indice de persistência elevou-se gradativamente nos períodos sazonais sucessivos, no ponto 1 houve uma queda do valor durante as chuvas moderadas, mostrando uma alteração acentuada 
na composição de espécies, com desaparecimento de várias das espécies, anteriormente persistentes durante o primeiro periodo de seca (1991). A mediana da riqueza cai apenas de 19 para 17 táxons.coleta ${ }^{-1}$, entre estes dois periodos, mostrando que não houve queda acentuada no número de espécies, mas sim sua substituição: algumas desaparecem, mas outras as substituem. As chuvas moderadas provocaram o primeiro impacto do carreamento de material da bacia e promoveram grande alteração na qualidade da água, evidenciada pelos mais elevados valores de cor, demanda bioquímica de oxigênio, nitrato, cloro, alumínio e sódio, mas também pelos elevados teores de fósforo solúvel reativo, cálcio, cobre e ferro. Portanto, durante este periodo a disponibilidade de nutrientes aumentou e também elevaram-se o teor de matéria orgânica e as taxas de decomposição, atestadas pela demanda de oxigênio. Esta alteração ambiental exerceu uma pressão seletiva capaz de promover o desaparecimento de algumas espécies e dar lugar a outras mais capacitadas a sobreviverem nas novas condições.

A aplicação do sulfato de cobre foi mais assídua entre dezembro de 1991 e maio de 1992, ou seja, no final do verão, no outono e início do inverno. O índice de persistência aplicado às coletas dos periodos em que não houve controle algáceo, mostrou-se mais baixo do que quando houve aplicação do algicida. É evidente, e confirmado pelos dados analisados que este controle foi sempre mais intenso nos períodos de maior desenvolvimento algáceo e que sua eficiência deve ser muito restrita, em vista do potencial de crescimento algáceo, conforme atesta a freqüência destas aplicações. Logo, a forçante inicialmente predominante sobre o desenvolvimento algáceo é a sazonalidade e suas conseqüências, tais como a sua interação com o uso e ocupação antrópica da bacia, promovendo a magnificação dos efeitos das chuvas na qualidade da água.

Estes fatores explicam o valor mais baixo do índice de persistência das espécies durante os períodos sem sulfatação (e portanto de menor desenvolvimento algáceo) em relação ao período com aplicação do algicida, quando as chuvas foram intensas e o desenvolvimento algáceo foi mais favorecido ainda, elevando os valores destes resultados. As ocorrências de florações prolongadas deste período, também contribuíram para elevar o valor deste índice.

Dentre os grupos analisados no ponto 1 , penales mostrou o maior valor de persistência durante o ciclo inteiro, seguida por volvocales. Estes grupos também mostraram-se os de valores elevados durante os dois períodos de seca, confirmando seu sucesso simultâneo durante a seca, evidenciado anteriormente na análise da sazonalidade. Os menores valores dos resultados deste indicador ocorreram para o conjunto das espécies de crisofíceas, dinoficea (representada apenas por uma espécie), zignemaficeas e cianoficeas, mostrando menor capacidade de persistência destes grupos, nas condições ambientais existentes no ponto 1 . No 
ponto 4 as criptoficeas e as volvocales destacaram-se por valores mais elevados de persistência das espécies, tanto no período pleno como em cada período sazonal, mostrando a capacidade elevada de suas espécies em permanecerem neste ambiente a despeito das alterações ambientais. As aplicações de sulfato de cobre foram simultâneas às quedas expressivas na persistência média relativa das criptoficeas e das centrales, mas também com a queda mais amena de crisoficeas, euglenoficeas e volvocales. Os valores deste índice foram acentuadamente mais elevados para as cloroficeas, quando o algicida estava sendo aplicado do que nos periodos em que não estava; estas algas parecem beneficiar-se da ausência de competidores por recursos, mas os indices também foram mais elevados para cianoficeas, dinoficeas, penales e zignemaficeas, pois as aplicações são realizadas nas fases em que ocorreram maiores riquezas específicas. Talvez o acompanhamento mais assíduo que a amostragem semanal, dos efeitos do sulfato de cobre, possa responder a esta dúvida. Os resultados obtidos estão relatados no Quadro a seguir.

\section{QUADRO 3 - ÍNDICE DE PERSISTÊNCIA DAS ESPÉCIES OU PERSISTÊNCIA MÉDIA RELATIVA DAS ESPÉCIES, APLICADO À COMUNIDADE FITOPLANCTÔNICA DA REPRESA DE GUARAPIRANGA, 1991-92.}

Ponto 1 (Pl); Ponto 4 (P4); conjunto total dos dados de cada ponto (T); período de seca (S); período de chuvas (C);primeiro periodo de seca (S1), período de chuvas moderadas (CM); periodo de chuvas intensas (CI); periodo da segunda seca (S2); centrales (CEN); penales (PEN); clorococales e oedogoniales (CHL); volvocales (VOL); crisoficeas (CHR); criptoficeas (CRY); dinoficeas (DIN); euglenoficeas (EUG); cianoficeas (CYA); zignemaficeas (ZYG), período sem aplicação de sulfato de cobre (SS); período com aplicação de sulfato de cobre (CS); periodo de chuvas intensas, com aplicação de sulfato de cobre (CSCI).

RESULTADOS DO PONTO 1. (\%)

\begin{tabular}{|c|c|c|c|c|c|c|c|c|c|c|}
\hline & $\mathbf{T}$ & $\mathbf{S}$ & C & 51 & $\mathrm{CM}$ & $\mathrm{CI}$ & $\mathbf{S 2}$ & SS & $\mathrm{CS}$ & $\mathrm{CSCI}$ \\
\hline$T$ & 4.02 & 4.78 & 3.52 & 3.65 & 2.37 & 5.42 & 8.32 & 3.60 & 4.86 & 5.93 \\
\hline CEN & 2.80 & 4.41 & 4.41 & 6.14 & 4.70 & 0.42 & 4.42 & 5.44 & 1.00 & 0.43 \\
\hline CHL & 5.20 & 6.11 & 4.57 & 3.28 & 2.81 & 7.14 & 12.37 & 0.44 & 6.89 & 8.23 \\
\hline CHR & 0.61 & 0.94 & 0.34 & 1.04 & 0.82 & 0.09 & 1.05 & 1.32 & 0.19 & 0.12 \\
\hline CRY & 4.42 & 5.44 & 3.36 & 6.12 & 5.31 & 2.04 & 4.21 & 8.99 & 1.74 & 2.75 \\
\hline CYA & 1.80 & 2.12 & 1.97 & 0.07 & 0.92 & 3.74 & 8.52 & 1.04 & 2.70 & 3.48 \\
\hline $\mathrm{DN}$ & 0.97 & 0 & 2.65 & 0 & 0.30 & 0.77 & 0 & 0 & 265 & 3.85 \\
\hline EUG & 2.09 & 1.92 & 2.09 & 1.90 & 0.64 & 3.81 & 1.92 & 2.62 & 1.70 & 3.10 \\
\hline VOL & 5.46 & 7.29 & 3.90 & 10.48 & 4.66 & 3.12 & 8.86 & 6.16 & 4.67 & 15.50 \\
\hline PEN & 13.21 & 15.76 & 11.17 & 16.72 & 5.27 & 19.37 & 15.81 & 10.93 & 15.84 & 3.85 \\
\hline ZIG & 1.34 & 1.30 & 1.62 & 0.51 & 0.28 & 3.57 & 3.37 & 0.67 & 2.53 & 4.13 \\
\hline
\end{tabular}


QUADRO 3 (cont.) - ÍNDICE DE PERSISTÊNCIA DAS ESPÉCIES OU PERSISTÊNCIA MÉDIA RELATIVA DAS ESPÉCIES, APLICADO À COMUNIDADE FITOPLANCTÔNICA DA REPRESA DE GUARAPIRANGA, 1991-92.

Ponto 1 (P1); Ponto 4 (P4); conjunto total dos dados de cada ponto (T); período de seca (S); período de chuvas (C);primeiro período de seca (S1), período de chuvas moderadas (CM); periodo de chuvas intensas (CI); período da segunda seca (S2); centrales (CEN); penales (PEN); clorococales e oedogoniales (CHL); volvocales (VOL); crisoficeas (CHR); criptoficeas (CRY); dinoficeas (DIN); euglenoficeas (EUG); cianoficeas (CYA); zignemaficeas (ZYG), período sem aplicação de sulfato de cobre (SS); periodo com aplicação de sulfato de cobre (CS); período de chuvas intensas, com aplicação de sulfato de cobre (CSCI).

RESULTADOS DO PONTO 4. (\%)

\begin{tabular}{llllllll}
\hline & $\mathrm{T}$ & $\mathrm{S}$ & $\mathrm{C}$ & $\mathrm{S} 1$ & $\mathrm{CM}$ & $\mathrm{CI}$ & $\mathrm{S} 2$ \\
\hline T & 3.39 & 3.57 & 3.55 & 2.34 & 2.92 & 4.93 & 6.26 \\
CEN & 5.76 & 5.77 & 5.65 & 3.72 & 8.51 & 4.42 & 9.44 \\
CHL & 3.64 & 4.52 & 3.29 & 2.48 & 2.18 & 4.80 & 9.14 \\
CHR & 1.03 & 1.46 & 1.10 & 0.79 & 1.92 & 0.87 & 9.67 \\
CRY & 9.97 & 10.05 & 9.62 & 9.05 & 9.13 & 10.71 & 12.18 \\
CYA & 2.59 & 1.41 & 4.67 & 0.11 & 0.43 & 12.59 & 5.13 \\
DIN & 0.74 & 0.14 & 1.85 & 0 & 0.47 & 3.64 & 0.70 \\
EUG & 0.72 & 0.81 & 0.53 & 0.15 & 0 & 1.32 & 1.58 \\
VOL & 9.31 & 6.93 & 11.83 & 5.52 & 12.56 & 11.05 & 9.23 \\
PEN & 4.03 & 4.15 & 3.70 & 5.05 & 3.97 & 4.48 & 3.08 \\
ZIG & 0.65 & 0.76 & 0.81 & 0.41 & 0 & 2.86 & 1.51 \\
\hline
\end{tabular}




\section{DISCUSSĀO}

As represas são ambientes com características intermediárias entre as dos lagos e rios. Lagos são sistemas caracterizados por um ciclo fechado de matéria, impulsionado por um fluxo aberto de energia (Margalef, 1992), enquanto os reservatórios têm o ciclo de matéria, dependente de seu período de retenção. $O$ período de retenção controla a exportação de matéria, conservando o fluxo de energia aberto.

Entre as características peculiares aos reservatórios podem ser citadas: a taxa de renovação da água mais lenta que a dos rios; a organização espacial, especialmente a área de superficie exposta, influindo nos movimentos horizontais da água, que aliados à taxa de renovação, induzem processos de mistura ou estratificação da água, capazes de interferir na disposição e na qualidade dos organismos presentes; o equilibrio entre as entradas e saídas alterando a profundidade e em diferentes graus os estratos, tornando a produção primária menos dependente da ressurgência dos elementos nutritivos acumulados no sedimento. Nesses ambientes ocorre a magnificação dos efeitos naturais e das atividades antrópicas desenvolvidas na bacia de drenagem, tanto pela somatória da informação adquirida ao longo do percurso de cada contribuinte, como pelo acúmulo de material ao longo do tempo, de acordo com seu período de retenção e a dinâmica de sedimentação (Margalef, 1983).

Esses ecossistemas artificiais, tornam-se assim, depositários de todos os processos desenvolvidos nas bacias de drenagens de seus tributários, além daqueles de sua própria bacia. 0 funcionamento de cada sub-bacia também se reflete na formação de gradientes horizontais $\mathrm{e}$ verticais de nutrientes, de matéria orgânica e de substâncias poluentes, bem como na estratificação térmica, na turbulência, no transporte de sedimento, na interação água-sedimento e na estrutura, composição e diversidade das comunidades biológicas (Tundisi, 1984 e 1985).

$\mathrm{Na}$ descrição da área de estudo verificou-se o declínio da qualidade da água da represa de Guarapiranga, decorrente dos usos e ocupações antrópicas de sua bacia de drenagem.

A eutrofização e o teor de sólidos em suspensão são os maiores problemas desta represa segundo vários autores (Beyruth e col., no prelo). Desde 1988 a capacidade de assimilação dos impactos decorrentes dos aportes de poluentes tem sido considerada insuficiente, podendo inviabilizar seu uso para abastecimento através dos métodos convencionais de tratamento (SEMA, 1988). A intensa eutrofização tem acarretado o desenvolvimento excessivo da comunidade fitoplanctônica, com prejuízos para a operação de tratamento, inclusive para a qualidade do produto final, a água para abastecimento. 
A floração de Anabaena solitaria associada ao surto de gastrenterite na população humana de usuários de suas águas (Beyruth e col., 1992) acentua as preocupações de ordem sanitária e configura risco à saúde pública. Esta deterioração na qualidade da água tem como consequiência a ampliação do risco das florações de cianofíceas potencialmente tóxicas tornarem-se recorrentes (Skulberg e col. 1984).

O estudo da seqüência temporal das espécies, relacionado às alterações das variáveis ambientais pode prover informação para a elaboração de previsões sobre as seqüências de dominância na comunidade fitoplanctônica. A escassez de conhecimento básico torna urgente sua geração, imprescindível para subsidiar as medidas de manejo necessárias para melhorar o aproveitamento do sistema, tornando-se parte indispensável do estudo de represas destinadas ao abastecimento, onde a flora planctônica tem importância em saúde pública.

Os objetivos de estudo orientam a escolha dos métodos, que devem responder de forma satisfatória à necessidades propostas de conhecimento. Para atender aos objetivos propostos para o estudo da comunidade fitoplanctônica, foram analisados os fatores ambientais, procedeu-se à verificação da adequação dos métodos utilizados, estudou-se as interações entre a comunidade fitoplanctônica e o meio abiótico e aplicou-se métodos pertinentes de estudo das variações espaciais e temporais da comunidade fitoplanctônica, investigando-se os fatores que promovem alterações no seu desenvolvimento. Os resultados foram discutidos através da abordagem ecológica, utilizando-se conceitos e hipóteses da teoria ecológica e sob o aspecto do saneamento, com ênfase na saúde pública. Esta avaliação prestou-se para subsidiar algumas propostas de manejo adequadas a este ambiente. 


\subsection{QUALIDADE AMBIENTAL ABIÓTICA}

A estrutura morfológica da bacia de drenagem da represa de Guarapiranga, com relevo atenuado e a pequena profundidade da água, favorecem a ação eólica, que somada ao movimento gerado pelo fluxo dos contribuintes e rios formadores tornam a mistura e a oxigenação mais eficientes, ampliando o potencial de autodepuração. Esta movimentação da água facilita a exposição dos organismos fitoplanctônicos à luz e aos nutrientes, contribuindo para a alta produção primária planctônica na água aberta.

Ventos de velocidade inferior a $4 \mathrm{~m} . \mathrm{s}^{-1}$ não são suficientes para romper gradientes preexistentes com densidade de até $0.02 \mathrm{~kg} \cdot \mathrm{m}^{-4}$ a $1 \mathrm{~m}$, ou prevenir o desenvolvimento algáceo sob condições favoráveis de irradiância, permitindo, assim, a estabilidade da estratificação da coluna d'água (Reynolds, 1993). Como a maior velocidade média do vento encontrada neste estudo corresponde a $3.83 \mathrm{~m} . \mathrm{s}^{-1}$, haveria potencial para estabilização dos gradientes horizontais e de densidade, em relação aos ventos, em todo o período de estudo. Porém, quando se observa a velocidade máxima do vento (Tabela 3), o único valor inferior a $4 \mathrm{~m} . \mathrm{s}^{-1}$ ocorreu em J5 $\left(3{\left.\mathrm{~m} . \mathrm{s}^{-1}\right)}^{-1}\right.$ mostrando haver condição propícia à ruptura dos gradientes em todo $\mathrm{o}$ período das demais coletas. A afirmação de Reynolds (1993), refere-se a condições de clima temperado, presumindo-se que sob as temperaturas mais altas subtropicais a ocorrência de condições favoráveis à estabilidade prolongada seja menos freqüente.

Esta represa além da estrutura morfológica favorável, conta ainda com atividades náuticas que constituem outro fator favorável a mistura da coluna d'água (Branco e Rocha, 1977). Beyruth e col. (dados inéditos) não encontraram estratificação térmica acentuada, sendo que as diferenças em geral situaram-se na faixa de décimos de grau centígrado, que de acordo com Wright (1936), podem ser rapidamente desfeitas.

Em relação ao movimento da água é também importante considerar o tempo de residência nas regiões estudadas da represa. O estudo realizado por Occhipinti (1973) mostrou que o tempo de residência da água tende a prolongar-se de montante para jusante, na represa de Guarapiranga. Este autor relata que próximo à barragem, na área onde situou-se o ponto 1 , o tempo de residência da água varia entre 11 a 83 dias e na região onde situou-se o ponto 4 , de zero a 27 dias e portanto, comporta-se mais como um ambiente lótico que ó ponto 1 , especialmente nos períodos em que o reservatório atinge seus menores niveis devido à captação de água para abastecimento, correspondente neste estudo, aos períodos de afluências mais intensas ocasionadas pela pluviosidade mais elevada. As diluições específicas, têm, por 
definição e experiência, comportamento inverso ao do tempo de residência, segundo Occhipinti (1973), o que foi confirmado pelos totais iônicos e pela condutividade encontrados nos dois pontos de coleta. A mistura vertical tem profunda influência na organização espacial das comunidades aquáticas (Margalef, 1978), promovendo a homogeneização dos solutos e movimentando as algas ao longo do gradiente de luz.

A tendência para a seqüência de cátions e ânions, relatada por Wetzel (1983), para a América do Sul é de $\mathrm{Ca}>\mathrm{Na}>\mathrm{K}>\mathrm{Mg}$ e $\left[\mathrm{HCO}_{3}\right]^{-1}>\mathrm{Cl}^{-1}>\left[\mathrm{SO}^{2}\right]^{2}$ para um total de $31.00 \mathrm{mgl}^{1}$. Esta tendência é compatível com os resultados encontrados neste estudo, para os dois pontos de coleta; que reproduzem essa distribuição prevista para cátions e ânions, com um total de $33.42 \mathrm{mg} . \mathrm{I}^{-1}$ no ponto $1 \mathrm{e}$ de $30.40 \mathrm{mg} . \mathrm{I}^{-1}$ no ponto 4 . Os resultados obtidos diferem, entretanto, dos teores iônicos específicos reportados por Wetzel (1983), apresentando teores de $\left[\mathrm{HCO}_{3}\right]^{-1}$ muito inferiores; os de cálcio e sulfato geralmente inferiores; os de sódio e cloretos mais elevados e finalmente potássio e magnésio semelhantes. Os acréscimos de sódio e cloreto confirmam aportes de esgoto (Beyruth, 1989).

Maier e Takino (1985) encontraram a seguinte seqüência iônica para represas próximas a grandes centros urbanos do Estado de São Paulo: $\mathrm{Na}>\mathrm{Mg}>\mathrm{K}$ e baixos teores de cálcio. Para a represa de Guarapiranga, encontraram: $\left[\mathrm{HCO}_{3}\right]^{-1}>\mathrm{Cl}^{-1}>\left[\mathrm{SO}_{4}\right]^{2}$, durante as quatro estações do ano estudadas, e $\mathrm{Na}>\mathrm{Ca}>\mathrm{Mg}>\mathrm{K}$ em março, $\mathrm{Na}>\mathrm{Ca}>\mathrm{K}>\mathrm{Mg}$ em maio e agosto, e $\mathrm{Ca}>$ $\mathrm{K}>\mathrm{Na}>\mathrm{Mg}$ em novembro, sendo que a ordem $\left[\mathrm{HCO}_{3}\right]^{-1}>\mathrm{Cl}^{-1}>\left[\mathrm{SO}_{4}\right]^{2}$ manteve-se no estudo atual, porém os conteúdos de $\left[\mathrm{HCO}_{3}\right]^{-1}$ foram inferiores e os de $\mathrm{Cl}^{-1}$ e $\left[\mathrm{SO}_{4}\right]^{-2}$ mais elevados que os encontrados pelas autoras citadas. A ordem dos cátions modificou-se, com aumento da proporção de sódio e cálcio, que mantiveram-se superiores a potássio e magnésio em todas as estações do ano. $O$ conteúdo total de íons dominantes elevou-se. Estas diferenças refletem os aportes de origem antrópica, incluindo o de esgoto doméstico, mais acentuado nos últimos anos.

Comparando-se estes resultados com os obtidos por Beyruth e col. (no prelo), que realizaram estudos sazonais em 20 pontos da represa, verifica-se que os pontos 1 e 4 situam-se no compartimento de água aberta, cujo total de $33.10 \mathrm{mg} .1^{-1}$ foi o mais próximo da somatória das medianas dos íons dominantes do conjunto dos 20 pontos da represa $\left(33.70 \mathrm{mg} .1^{-1}\right)$. Estes dados indicam que os dois pontos estudados neste trabalho representam bem as condições da represa, uma vez que os teores iônicos constituem um dos principais determinantes da produção fitoplanctônica, tanto em qualidade quanto em quantidade. Este compartimento, quando comparado com os demais da represa, apresentou maior profundidade, transparência e 
menores valores de turbidez, teores de amônio, alumínio e manganês (Beyruth e col, no prelo). No estudo mencionado os autores relatam também, que a seca de 1991 mostrou-se menos intensa que a de 1992. Em julho de 91, no pico da seca, a pluviosidade foi de 24.7 mm.dia ${ }^{-1}$ com média anual de $159.9 \mathrm{~mm}^{-d_{i a}{ }^{-1}}$. No pico da seca, em junho de 92 , a pluviosidade foi de $8.2 \mathrm{~mm}^{-1 i a}{ }^{-1}$ e a média anual de $125.5 \mathrm{~mm}^{-1 i a}{ }^{-1}$. A seca mais acentuada de 1992 propiciou maior concentração das substâncias na água e em conseqüência densidades maiores do fitoplâncton.

A condutividade foi em geral mais elevada no ponto 1, o mesmo ocorrendo para oxigênio dissolvido, alcalinidade, dureza e conteúdo iônico total. A maior condutividade neste ponto decorre da maior concentração de nutrientes nesta área da represa, onde o periodo de retenção e a profundidade são maiores, o escoamento é superficial, houve ingresso das águas muito ricas em nutrientes do córrego de Itupu, Guavirutuba, do rio Embu-mirim e dos córregos Rio Bonito e Rio das Pedras. Além disto, os processos de liberação de nutrientes pelos organismos são mais acentuados devido ao constante combate às algas.

Entre os 20 pontos estudados por Beyruth e col. (no prelo), apenas o ponto 1, o mais próximo à captação para abastecimento, mostrou quantidades significativas de cobre na água.

Os valores mais elevados de alcalinidade e $\mathrm{pH}$ no ponto 1 são consequêência da mais alta densidade de fitoplâncton, no entanto a taxa mais elevada de fotossíntese, que propiciou estes resultados, não foi suficiente para elevar a produção de oxigênio a valores superiores aos detectados no ponto 4. A alcalinidade da água corresponde a seu teor de sais de ácido carbônico. A disponibilidade freqüente de carbonatos insolúveis nas águas naturais e o papel desempenhado pelo gás carbônico no metabolismo dos vegetais aquáticos indicam a importância destes sais como fonte de carbono, sob a forma de bicarbonatos solúveis, freqüentemente de bicarbonato de cálcio (Dussart, 1966).

Os teores de oxigênio estiveram sempre acima de $4.0 \mathrm{mg} . \mathrm{I}^{-1}$ e portanto, dentro dos limites considerados na legislação (CONAMA-20, 1986), como favoráveis ao desenvolvimento da vida aquática.

Os processos de decomposição biológica, expressos pelos valores da demanda bioquímica de oxigênio foram favorecidos no ponto 4 , devido à ausência de sulfatação, que também é responsável pela diminuição do número de organismos decompositores, bactérias e fungos, devido à sua toxicidade (Damato e col., 1989). A cor, turbidez e metais pesados também apresentaram valores mais elevados no ponto 4, durante todas as estações, o que 
resulta da exposição do solo nas áreas mais próximas a este ponto. Entretanto a lise celular das algas pelo efeito do sulfato de cobre aplicado, pode promover a liberação simultânea de grandes quantidades de nutrientes e matéria orgânica na coluna d'água no ponto 1 .

A análise sazonal mostra que no ponto 1 , a menor concentração ocorreu no primeiro período de seca, tanto para o conteúdo iônico total como para a condutividade, sendo que o primeiro elevou-se no início das chuvas, decaiu durante as chuvas intensas por diluição e consumo, elevando-se novamente até o final das coletas, alcançando o maior valor no segundo período de seca. Entretanto, no ponto 4, houve diluição durante as chuvas. Esta diferença mostra a influência da urbanização na região da bacia que contribui mais diretamente para os aportes recebidos pelo ponto 1 .

No ponto 4 o conteúdo iônico total foi elevado no início das coletas, decaindo do início para o final das chuvas e as maiores concentrações foram encontradas, em ambos os pontos, no segundo período de seca. Os valores de fósforo e de condutividade acompanharam esta seqüência, da qual pode-se concluir que durante o segundo periodo de seca houve maior disponibilidade de nutrientes, devido à concentração. Neste ponto a maior diluição, expressa pelo teor iônico total mais baixo, ocorreu no período de chuvas intensas e não foi simultânea à menor condutividade, registrada no primeiro período de seca, quando as temperaturas mais baixas foram menos propícias à mineralização. Os teores totais dos metais: ferro, manganês, alumínio, zinco e cobre, estiveram mais elevados no ponto 4 , exceto no segundo período de seca, quando apresentaram-se semelhantes em ambos os pontos.

O teor de sólidos totais em suspensão expressou a somatória de sólidos orgânicos e inorgânicos refletindo tanto os efeitos do desenvolvimento intenso da biomassa, quanto os aportes da bacia. Os resultados mostraram transparências mais elevadas nos períodos de seca, em ambos os pontos. A ausência de correlação entre transparência e pluviosidade no ponto $1 \mathrm{e}$ as correlações negativas entre pluviosidade e transparência ou sólidos totais em suspensão no ponto 4 , mostram que no ponto 1 a sulfatação e portanto a biomassa, influíram na transparência enquanto no ponto 4, a pluviosidade foi o fator mais importante nesta determinação. As correlações negativas entre transparência e pluviosidade e entre transparência e turbidez verificadas no ponto 4 , decorrem do carreamento de material da bacia para a represa, nos periodos de maior intensidade pluviométrica.

A dureza e a alcalinidade estiveram em geral mais elevadas nos periodos de maior intensidade pluviométrica, quando as temperaturas foram mais elevadas. 
O grande número de correlações positivas, apresentadas pela maior parte dos nutrientes, com a pluviosidade, temperatura ou com parâmetros que atingiram valores mais expressivos nos mesmos períodos, demonstram a importância dos eventos climáticos para a qualidade da água. $\mathrm{O}$ periodo de chuvas favoreceu a disponibilidade de nutrientes para os consumidores primários, indicando a importância daqueles eventos também para a produtividade algácea. Representaram exceções o nitrato especialmente no ponto 4, o alumínio e o ferro. $O$ aluminio e o ferro apresentaram correlações que indicam entradas em conseqüência da elevação da cota da represa e portanto de aportes do solo exposto da bacia de drenagem, por desmatamentos, refletindo a importância da influência antrópica na qualidade da água, tanto pela degradação da bacia como pela operação da represa. A correlação entre a turbidez e os teores de alumínio, no ponto 4 , resulta possivelmente, do desmatamento das margens e da conseqüente exposição do solo na região próxima a este ponto, que havia sido associada anteriormente a ingressos de aluminio por Beyruth e col. (no prelo). A disponibilidade de nitrato foi maior nos períodos de temperaturas mais baixas, devido ao menor potencial de atividade biológica.

No ponto 1 o maior teor de nutrientes, a menor taxa de fluxo e o maior volume de água, favorecendo uma maior estabilidade, permitiriam teoricamente, um desenvolvimento algáceo quantitativo e qualitativo mais acentuado que no ponto 4 . Em contrapartida, a aplicação de sulfato de cobre e as saídas da água captada, deveriam constituir-se em fatores de inibição, impedindo que a comunidade fitoplanctônica atingisse uma estabilidade mais prolongada, entretanto a resultante destas condições proporcionou o desenvolvimento mais acentuado no ponto 1 .

Beyruth e col. (no prelo) consideram que houve um decréscimo acentuado da qualidade da água desde o estudo de Maier e Takino (1985) até este período, permitindo concluir que atualmente os teores iônicos desta represa refletem mais o uso e ocupação do solo, do que os padrões iônicos naturais decorrentes da conformação geológica da bacia de drenagem. 


\subsection{COMUNIDADE FITOPLANCTÔNICA}

Os estudos da comunidade fitoplanctônica são indispensáveis em avaliações dos ambientes aquáticos, pois estes organismos são o primeiro elo com 0 ambiente abiótico, constituindo-se na principal porta de entrada da matéria e da energia, através da produção primária, na cadeia trófica das regiões de água aberta. Esta é a comunidade-base da cadeia alimentar e portanto a produtividade dos elos seguintes depende da sua biomassa, bem como de outras alterações que essa comunidade impõe ao ambiente.

$\mathrm{O}$ estudo do fitoplâncton tem importância intrínseca sob os aspectos ecológicos e de saneamento. Sob o aspecto ecológico Sommer (1989) afirma que muitas das abordagens clássicas da teoria ecológica podem ser desenvolvidas através de pesquisas ambientais e experimentais mais facilmente nas comunidades fitoplanctônicas que nas demais comunidades:

1. amostras representativas podem ser obtidas sem dificuldades; estimativas de abundância, biomassa e produtividade são mais confiáveis que em qualquer outra comunidade, a despeito da propriedade do plâncton de formar "nuvens";

2. o cultivo de muitas das espécies é relativamente fácil. Devido às dimensões corpóreas reduzidas, ao reduzido tempo de geração e às altas taxas de crescimento, as necessidades de tempo e espaço para realizar experimentos são bastante modestas, possibilitando o uso de populações com milhões de individuos, o que exclui a indesejável influência da variabilidade inter-individual;

3. a velocidade do crescimento populacional permite a produção de sequiências sucessionais dentro de uma só estação sazonal, que contém tantos estágios quanto as sucessões da vegetação terrestre perfazem no curso de séculos.

Estes fatores facultam observações diretas, reproduziveis, enquanto os ecologistas da vegetação terrestre têm que basear-se em evidências indiretas, provenientes de estudos paleoecológicos, ou têm que assumir artificialmente que a vegetação de diferentes locais representa diferentes estágios da mesma seqüência. Além das afirmações de Sommer (1991) é importante considerar que a comunidade fitoplanctônica exibe sobre os estudos de outras comunidade aquáticas microscópicas, a vantagem de apresentar uma imensa diversidade morfológica o que as diferencia da maioria das bactérias e permite distinguir os grupos taxonômicos e as várias estratégias adaptativas através da observação microscópica direta, não havendo necessidade de realizar avaliações fisiológicas para identificação das espécies, como se faz para identificar as bactérias. Além disto também apresenta geralmente riqueza especifica e densidades populacionais mais elevadas que a comunidade zooplanctônica, possibilitanto um maior conteúdo de informação por volume de água amostrado. 


\subsubsection{METODOLOGIAS DE AVALIAÇÕES QUANTITATIVAS}

As dificuldades de elaboração de normas técnicas que atendam a grande maioria dos objetivos dos estudos do fitoplâncton aplicados ao saneamento, tornam oportuna a discussão da metodologia comumente utilizada.

Os métodos de avaliação quantitativa utilizados neste trabalho, tanto para densidade (densidade de células e de organismos), como para biomassa (bioárea e biovolume) mostraram que a densidade de organismos é útil na determinação do biovolume, mas não apresentou significado próprio especial, uma vez que subestimou a importância das algas que atingiram densidades populacionais elevadas, como foi o caso das espécies encontradas de Dictyosphaerium e de Aphanocapsa. Nesta depreciação perdeu-se informação sobre uma das características fundamentais para avaliações sanitárias, que é a noção sobre a capacidade reprodutiva ou de geração de novas células e indivíduos de cada espécie. As algas não têm necessidade de produzirem tecidos de sustentação, sendo que todas as células vegetativas podem contribuir para a produtividade líquida (Reynolds, 1987), desta forma, o número de células informa sobre a capacidade de multiplicação de cada espécie. A contagem considerando número de células, provê maior conteúdo de informação por si, especialmente quando não se avalia o biovolume. A correlação entre os resultados destes dois métodos estimativos da densidade mostrou-se baixa ( $\mathrm{rs}=0.22 \mathrm{P}=0.0022$ para o ponto 1 e rs $=0.19$ e $\mathrm{P}=0.0140$ para o ponto 4) e portanto elas não podem ser consideradas alternativas, mas complementares.

A avaliação quantitativa da biomassa em unidade padrão de área por mililitro (utilizada pelos órgãos de controle ambiental em São Paulo), correspondente a $400 \mu \mathrm{m}^{2} \cdot \mathrm{ml}^{-1}$ mostrou elevada correlação com a estimativa do biovolume ( $\mathrm{rs}=0.85 \mathrm{P}=0$ no ponto $1 \mathrm{e} \mathrm{rs}=0.86 \mathrm{P}=0$ no ponto 4). A estimativa da bioárea envolve menor tempo de trabalho de microscopia, uma vez que pode ser efetuada simultaneamente às determinações das densidades. Porém não é comparável com os dados da literatura produzida em outras instituições nacionais ou internacionais, além de envolver erros na estimativa da biomassa. Sugere-se então, que para os principais corpos d'água estudados por aquelas instituições, sejam levantados e armazenados dados de biovolume por espécie, formando-se bancos de dados atualizados com freqüência adequada, que possibilitariam gerar informação de melhor qualidade com menor periodo de análise.

Outro fato a considerar na escolha do método de contagem é a relação a ser preservada durante a comparação entre amostras. Os objetivos deste trabalho de cunho sanitário e ecológico levaram à necessidade de comparar as amostras quanto a diversidades e riquezas de 
espécies, atributos muito importantes em estudos de impactos ambientais (Hellawell, 1989). Desta forma houve-se por bem comparar o fitoplâncton de amostras de igual volume de água da represa, mantendo-se igual procedimento de análise para todas as amostras, independente das suas densidades. Esta forma de quantificar, embora trabalhosa, permite comparar riquezas e diversidades das amostras (Margalef, 1983 e Eloranta, 1993) e também permite preservar a relação entre quantidade de algas e volume de água, muito importante em estudos de represas destinadas ao abastecimento, embora possa subestimar o biovolume das espécies mais raras.

\subsubsection{COMPOSIÇÃO FLORÍSTICA}

O controle algáceo efetuado através da aplicação do sulfato de cobre na represa de Guarapiranga, dificulta tecer considerações sobre aspectos biogeográficos quanto à sua composição florística. Porém, apesar deste controle, a composição da ficoflora mostrou elevada complexidade quanto a riqueza, com mais de 170 espécies presentes nos dois pontos de amostragem, das quais 30 a 46 chegaram a ocorrer numa única amostra, conforme expresso novamente a seguir, para facilitar a visualização:

\section{QUADRO DA COMPOSIÇÃO FLORÍSTICA DA REPRESA DE GUARAPIRANGA, 1991-92.}

Número de táxons de cianoficeas (CYA); cloroficeas (CHL); euglenoficeas (EUG); bacilarioficeas (BAC); crisoficeas (CHR); criptoficeas (CRY); dinoficeas (DIN); zignemaficeas (ZYG) e total (T), máxima (máx); mínima (mín); média (méd) e total (tot).

P1 (56 semanas) P4 (56 semanas)

\begin{tabular}{lllllllll}
\hline & máx & mín & méd & tot & máx & mín & méd & tot \\
\hline CYA & 5 & 0 & 1 & 14 & 4 & 0 & 1 & 9 \\
CHL & 28 & 3 & 13 & 88 & 19 & 2 & 10 & 81 \\
EUG & 3 & 0 & 1 & 12 & 3 & 0 & 1 & 13 \\
BAC & 6 & 0 & 3 & 17 & 8 & 0 & 3 & 20 \\
CHR & 3 & 0 & 1 & 11 & 3 & 0 & 1 & 12 \\
CRY & 3 & 0 & 1 & 7 & 3 & 0 & 2 & 8 \\
DIN & 0 & 0 & 1 & 1 & 3 & 0 & 1 & 11 \\
ZYG & 6 & 0 & 2 & 32 & 6 & 0 & 1 & 23 \\
T & 46 & 8 & 23 & 183 & 30 & 7 & 19 & 177 \\
\hline
\end{tabular}


Wetzel (1983) chama a atenção para o número elevado de clorococales nos lagos em processo de eutrofização. Estas algas também são citadas por Thunmark (1949, apud Coesel, 1983) como abundantes em ambientes eutróficos. A riqueza mais elevada de clorococales na comunidade fitoplanctônica de ambientes aquáticos lênticos, eutrofizados, do Estado de São Paulo também é observada nos trabalhos de Xavier e col. (1985), Lemos e col. (1993), Beyruth e Pereira (1994), entre outros.

As zignemaficeas, entretanto, mostram maior riqueza em ambientes oligotróficos (Coesel, 1983). Verificou-se ocorrência de riqueza elevada destas algas na Guarapiranga, nos periodos de chuvas intensas, havendo indícios da possibilidade de algumas das espécies serem provenientes do perifiton das margens ou dos bancos de macrófitas existentes nas entradas dos tributários. Coesel, no trabalho citado, relata que as desmídias podem ser trazidas destes habitats originais para o plâncton, nele persistindo, porém sem reproduzir-se.

A amplitude entre o número máximo e mínimo de riqueza específica das amostras é grande, quando comparado com outros lagos tropicais e sub-tropicais: Lago Lanao max. $=51$, min.=36; Lago Monte Alegre $\max .=61$, mín.=37.; Lago Los Matadores $\max .=59$, mín. $=25$, 1980, Lago Naivasha máx.=71, mín.=37, (Lewis, 1978a, Silva, em prep, Garcia de Emiliani, Kalff e Watson, 1986, respectivamente, apud Huszar, 1994), demonstrando a instabilidade do ecossistema de Guarapiranga. O Lago Batata mostrou amplitude maior: máx. $=49$, mín. $=0$, por tratar-se de um lago impactado por rejeitos de bauxita e sujeito a grandes flutuações de nível, segundo Huszar (1994), que conclui em seu estudo sobre os aspectos biogeográficos da composição florística de lagos tropicais, que as comparações realizadas ressaltam a necessidade de ampliar este conhecimento

Este trabalho vem demonstrar a necessidade de estender estes estudos para represas, incluindo avaliações da variação da composição florística face às variáveis ambientais e impactos a que estes ambientes estejam submetidos.

As dúvidas relatadas por Payne (1986) sobre haver ou não tendência de aumento da diversidade do fitoplâncton com a proximidade do Equador e sobre a possibilidade de generalizar as conclusões de Lewis (1978a), de haver menor riqueza de espécies fitoplanctônicas nos ambientes tropicais que nos temperados, somente poderão ser comprovadas através da ampliação destes estudos. 


\subsubsection{ESTRATÉGIAS ADAPTATIVAS E AS SEQÜÊNCIA DE DOMINÂNCIAS}

A luz, os nutrientes e outros fatores abióticos (temperatura, elementos-traço, substâncias tóxicas) e fatores bióticos (micróbios heterótrofos, patógenos, parasitas, herbívoros e indiretamente seus predadores) influem na composição específica do fitoplâncton. As interações e alterações simultâneas de tantas variáveis, tornam dificil realizar previsões de dominâncias no nível das espécies, porém as respostas da comunidade a um determinado conjunto de condições ambientais, podem ser previsiveis com elevado nível de probabilidade, quando as espécies são agrupadas por caracteristicas morfológicas e fisiológicas semelhantes (Reynolds, 1987). A taxa de incremento das algas, relacionada à quantidade de nutrientes disponiveis e de luz é limitada pela probabilidade de serem desviadas para fora da zoṇa fótica ou de serem ingeridas por animais. As diferentes estratégias que permitem a sobrevivência podem ser previstas de acordo com a organização geral do ecossistema e devem ser consideradas em termos probabilísticos (Margalef, 1978).

Estratégias adaptativas são definidas por Reynolds (1988) como características morfológicas, fisiológicas, reprodutivas e comportamentais, que evoluiram entre as espécies e populações, sendo melhor sucedidas em determinadas condições ambientais do que as demais estratégias.

Lewis (1978c) relata que a distribuição das espécies no Lago Lanao mostrou relação com a turbulência da água e a morfologia e motilidade dos organismos.

A movimentação da água controla as comunidades planctônicas, porém o uso dos nutrientes, o crescimento, a herbivoria e a sedimentação distinguem a eficiência de sobrevivência das algas e suas formas de vida. Estes organismos, sendo em geral autotróficos, tem crescimento dependente da disponibilidade de luz, gás carbônico e nutrientes, cujo aproveitamento eficiente e simultâneo, requer sua permanência em suspensão na coluna d'água. Isto pode ser conseguido através de sua incorporação passiva às correntes ou através de mecanismos de redução da densidade excessiva; do aumento da razão superficie por volume corpóreo; da existência de estruturas ou forma corpórea que ampliem a resistência por atrito com a água circundante, ou da ocorrência de motilidade, que propicia renovação do meio e portanto dos nutrientes ao redor das células (Reynolds, 1993).

As características consideradas como estratégias adaptativas neste estudo foram tamanho, forma, motilidade e rigidez do envoltório celular dos organismos.

A maior parte dos componentes celulares apresenta densidade maior que a da água e apenas os lipídeos, que raramente contribuem com mais que dez porcento do peso seco da célula, apresentam densidade inferior (Reynolds, 1993). As células do fitoplâncton são 
normalmente mais densas que a água e tendem a afundar. A única exceção, de acúmulo de lipídeos suficiente para sustentar a flutuação, foi registrada para Botryococcus braunii (Reynolds, 1993). A presença de vacúolos gasosos também aumenta a capacidade de flutuação, como é o caso para algumas cianoficeas. Estas estratégias não demonstraram importância nas espécies bem representadas deste trabalho.

A secreção de mucilagem pode reduzir a taxa de sedimentação, mas é compensada pelo aumento do tamanho. Segundo Reynolds (1993) a mucilagem é constituída por uma rede de polissacarideos hidrófilos, capazes de conter grande quantidade de água, cuja densidade não sustentaria flutuação positiva por ser muito próxima à da água. Entretanto a mucilagem provê uma certa redução da densidade e pode servir para impedir a herbivoria, além de proteger contra as alterações imediatas do ambiente, garantindo uma reserva provisória de nutrientes. $\mathrm{Na}$ represa de Guarapiranga as algas com envoltório gelatinoso atingiram elevadas densidades e biovolumes.

Alta razão superficie corpórea por volume, facilita a absorção de nutrientes e sua difusão intracelular. Em ambientes ricos em nutrientes, as células pequenas com alta razão de área superficial por volume, podem multiplicar-se mais rapidamente que as células maiores (Margalef, 1978). A razão superficie por volume decresce com o aumento das dimensões celulares e uma forma de evitar a perda da superficie relativa é o distanciamento da forma esférica.

O tamanho reduzido é vantajoso por permitir suspensão prolongada, mas o aumento das dimensões não é necessariamente contraproducente. $O$ aumento da área superficial pela distorção da forma (desenvolvimento de colonias ou de estruturas elaboradas), evidencia a existência de outras pressões de seleção natural, atuantes sobre a forma e o tamanho dos organismos fitoplanctônicos. Maior dimensão seria vantajosa para aumentar a resistência contra a herbivoria, ampliar a eficiência tanto dos processos fotossintéticos (pelo aumento da distribuição dos pigmentos fotossintéticos, mais eficiente sob condições de redução da luminosidade), como do aproveitamento hidrodinâmico. A herbivoria é exercida principalmente por cladóceros, calanóides e rotíferos, que são organismos filtradores. Muitas espécies do zooplâncton apresentam preferências alimentares definidas, mas a seletividade é altamente dependente do tamanho das partículas alimentares, sendo que a maioria dos rotíferos restringese a partículas com a maior dimensão linear (MDL ou GALD) menor que $15 \mu \mathrm{m}$. Alguns cladóceros podem ingerir partículas cujo eixo principal é maior que $60 \mu \mathrm{m}$, no caso de filamentos flexíveis de pequeno diâmetro (Reynolds, 1993). Geralmente, a literatura sobre o fitoplâncton, não considera a herbivoria pela fauna ictíca, cuja maioria das fases jovens é 
planctófaga. Carmichael (1992) considera que a fauna ictiica pode ser bastante eficiente no consumo de algumas cianoficeas como Microcystis.

A presença de flagelos pode contribuir tanto para a motilidade (Reynolds, 1993), como para renovar a água ao redor do organismo, facilitando o contato com os nutrientes, por romper gradientes ao redor da célula (Wetzel, 1983). Nas águas naturais sempre existe um gradiente luminoso e se houver estratificação térmica, pode haver gradientes de nutrientes, ambos podendo ser explorados pelas algas dotadas de motilidade. Os estudos atuais sobre os recursos limitantes tem dado mais atenção à micro-heterogeneidade da distribuição dos nutrientes na água (Sommer, 1988b). Margalef (1978) afirma que a motilidade relativa à água circundante é vantajosa inclusive em ambientes homogêneos, pois permite aos organismos escaparem das zonas com depleção de nutrientes, renovando a água ao seu redor. A quemotaxia, um campo ainda inexplorado de pesquisa quanto à nutrição, talvez possa prover informações muito úteis sobre a sobrevivência das algas em ambientes pobres em nutrientes (Sommer, 1988b).

Wetzel (1983) relata que Gymnodinium pode mover-se com velocidade de até um metro por hora, elevando-se na coluna d'água, à tarde, e afundando quando há aumento da intensidade luminosa. Segundo Reynolds (1993), a velocidade de organismos do fitoplâncton situa-se na ordem de 0.1 a $1.0 \mathrm{~mm} . \mathrm{s}^{-1}$, incapacitando-os a superarem correntes ou turbulência com velocidades uma a duas ordens de grandeza superiores a estes valores. Entretanto o mesmo autor afirma que esta motilidade pode ter importância nos movimentos verticais, mais eficientes em camadas não turbulentas. As espécies adaptadas a vicejar e persistir sob baixas concentrações de nutrientes, em geral devem estar adaptadas a baixa turbulência, o que requer alguma motilidade, segundo Margalef (1978).

Considerou-se motilidade apenas para os organismos flagelados, entretanto, há relatos de motilidade própria para outros grupos de algas.

A presença de vacúolos gasosos é um importante mecanismo para a flutuação das cianoficeas que os produzem (Reynolds, 1993). Na represa de Guarapiranga, entre as espécies de cianofíceas importantes, tanto em densidade como em biovolume, esta característica não chegou a assumir papel importante. As cianoficeas que se destacaram foram as formas coloniais com envoltório mucilaginoso como as espécies encontradas do gênero Aphanocapsa. Em Oscillatoria subtilissima não foi possível verificar a presença de vacúolos gasosos. Entretanto verificou-se a ocorrência de exemplares de Anabaena solitaria apresentando vacúolos gasosos bem evidenciados, nas amostras obtidas através de filtração, utilizadas apenas para a identificação das espécies, o que leva a supor que esta espécie estivesse presente 
em densidades significativas nos estratos inferiores da coluna d'água.

Drum e Hopkins (1965) relatam que cianoficeas ejetam materiais extracelulares e algumas desmídias podem secretar mucilagem a partir de um poro apical, ambos os processos resultando em locomoção sem cílios, flagelos ou estruturas análogas para impelirem os organismos através da água.

Nas diatomáceas parece haver regulação fisiológica permitindo manterem-se em suspensão, pois células mortas têm maior taxa de sedimentação, segundo Reynolds (1993). Bourrelly (1981) menciona como espetacular, o deslocamento da diatomácea Cylindrotheca na água e Pickett-Heaps e col. (1991, apud Cohn e Disparti, 1994) relatam movimentos lentos na água, para diatomáceas arafideas. A necessidade de secreção de mucilagem durante o movimento é considerada uma das razões para explicar porque a motilidade, em geral, restringe-se às diatomáceas arafideas. O contato entre rafe e substrato, mesmo com partículas em suspensão na água, seria necessário para motilidade. O movimento das diatomáceas aumenta a oportunidade de absorver nutrientes por processos de conveç̧ão, assegurando a continuidade da renovação da camada de água em contato com a célula (Boney, 1975). Se as diatomáceas arafideas podem ou não utilizar o mesmo mecanismo de locomoção no substrato (produzindo correntes através da rafe) quando estão em água aberta, renovando assim a água ao seu redor, ainda é uma incógnita, mas, supondo que sim esta habilidade seria muito útil em ambientes com limitação de nutrientes.

Nos ambientes com baixos teores de nutrientes, a motilidade mesmo quando lenta, facilita a renovação da água em contato com a célula e em conseqüência, a nutrição. Quanto mais efetiva ou rápida a locomoção, maior seu custo energético e portanto a motilidade rápida seria útil apenas em ambientes com heterogeneidade espacial significativa, quanto aos teores de nutrientes. Nos organismos flagelados, segundo o próprio Boney (1975), haveria um dispêndio apreciável de energia se a ação do flagelo fosse a única forma de manter-se em suspensão, havendo também o auxilio de gotículas de óleos e outras substâncias menos densas que a água circundante.

Ambientes mais turbulentos geralmente associam-se a ingressos elevados de nutrientes e portanto, a motilidade própria torna-se dispensável, pois requer um custo energético melhor aproveitado para crescimento e reprodução.

O estado fisiológico das células influi na velocidade de sedimentação, pois células mortas ou senescentes de diatomáceas sedimentam de três a cinco vezes mais rapidamente que as células viáveis (Reynolds, 1993) e segundo o mesmo autor, Margalef (1957) afirma que a viscosidade do meio adjacente pode ser alterada por variações nas cargas elétricas produzidas 
na parede celular.

Projeções e irregularidades da superficie celular, distorções da forma esférica e formas mais elaboradas podem reduzir de duas a cinco vezes a taxa de sedimentação. A sedimentação passiva é considerada eficiente na absorção de nutrientes pois resulta na troca contínua da água em contato com as células (Margalef, 1978).

A forma pode dificultar herbivoria e também favorecer a permanência em suspensão: organismos filamentosos podem preservar alta razão superficie por volume e ao mesmo tempo dificultar a predação. Colônias ou cenóbios maiores, com envoltório gelatinoso, também dificultam a predação (Sommer, 1988b).

Formas mais elaboradas podem aumentar a eficiência da distribuição dos pigmentos fotossintéticos na célula. A atenuação da forma cilíndrica permite aumento de até dez vezes no volume, sem alterar a taxa de sedimentação (Reynolds, 1993). As formas atenuadas foram bem representadas neste estudo, especialmente pelas diatomáceas e algumas cloroficeas como Monorapidium. As formas elaboradas também podem permitir uma melhor orientação da célula em relação a correntezas e quanto mais entranhada na correnteza, maior pode ser o tempo de permanência da célula em suspensão.

Na represa de Guarapiranga as densidades de organismos dotados de ornamentação elaborada, capazes de aumentarem a razão mencionada ou a resistência à sedimentação por atrito com a água, não foram significativas. Houve predominio de formas menores, esféricas ou alongadas na maior parte do período estudado.

A presença de envoltório rígido parece atender a outros princípios seletivos. As vantagens relacionadas à presença de frústulas silicosas foram associadas ao aproveitamento da luz, permitindo a sobrevivência em ambientes com elevada turbidez, onde a exposição à luz destes organismos mais pesados é favorecida e à proteção contra choques mecânicos, associados a ambientes de turbulência e turbidez mineral elevadas, provendo também proteção para sobrevivência nas zonas mais próximas ao substrato sólido do fundo. Outras vantagens que poderiam ocorrer seriam maior proteção contra predação ou contra digestão, aumento da área superficial e a facilidade de sedimentação, que possibilita renovação do meio circundante.

Um último fator a considerar é a habilidade das espécies sobreviverem a períodos de condições ambientais desfavoráveis, mantendo o inóculo potencial, capaz de explorar o retorno das condições mais favoráveis, o que constitui outro importante aspecto da estratégia das algas planctônicas. $O$ consumo luxuriante de nutrientes, a formação de cistos de resistência, o aumento da taxa de sedimentação, as migrações verticais, podem constituir as estratégias de manutenção da viabilidade dos inóculos para resistirem às condições desfavoráveis (Reynolds, 1988). 
O estudo das estratégias adaptativas relaciona-se ao da seqüência das espécies, pois as alterações ambientais ou o próprio desenvolvimento da comunidade são determinantes na definição das estratégias favorecidas nas novas condições, imediatas às alterações ambientais (alogênicas) ou geradas pelo desenvolvimento da própria comunidade (autogênicas).

Quanto aos efeitos das alterações promovidas por distúrbios ambientais não catastróficos, podem ser consideradas duas possibilidades relacionadas à freqüência e intensidade dos distúrbios (Reynolds, 1993):

mudança - quando um distúrbio severo ou prolongado ocorre num estágio sucessional inicial podendo levar ao inicio de um novo processo de sucessão;

reversão - quando um distúrbio leve ou breve ocorre em estágios sucessionais tardios e apenas suspende temporariamente $o$ andamento do processo, de forma que muito da informação remanescente será utilizada para retornar a uma sucessão similar.

Margalef (1958 apud Sommer, 1981) delineou um padrão geral para a sucessão do fitoplâncton iniciando-se com espécies de ciclo de vida curto, alta taxa reprodutiva e biovolume reduzido, seguidas por espécies de tamanho médio com taxa de crescimento intermediária e finalmente por espécies grandes, de crescimento lento com elevada habilidade competitiva, freqüentemente com necessidades de micro-nutrientes orgânicos (aloauxotróficas). Esta é uma seqüência de r-para K-estrategista, possível em lagos com tempo de retenção elevado e estratificação térmica estável e portanto não esperada para a represa de Guarapiranga. As espécies r-estrategistas são favorecidas em ambientes ricos em nutrientes, submetidos a alterações constantes e as espécies K-estrategistas em ambientes estáveis, pobres em nutrientes livres. $O$ conceito original baseou-se na equação logística do crescimento, $r$ sendo a taxa intrínseca de crescimento e $\mathrm{K}$ o limite superior da curva de crescimento, ou a capacidade de carga do ambiente para as espécies de interesse. Tornou-se usual referir-se a espécies favorecidas pela seleção $\mathrm{r}$, como r-estrategistas e as favorecidas pela seleção $\mathrm{K}$, como K-estrategistas (Sommer, 1981).

Para definir as estratégias das espécies do fitoplâncton em relação ao grau de estresse por limitação de nutrientes e em relação a frequiência de distúrbios, Reynolds propõe a aplicação da terminologia de Grime (1979, apud Reynolds, 1988), fazendo a analogia desta terminologia, com a utilizada por Margalef, definindo as espécies como C-estrategistas ou competidoras, S-estrategistas ou estresse tolerantes e R-estrategistas ou ruderais, relacionando-as às características ambientais, conforme expresso no esquema a seguir. 


\section{ESQUEMA DAS CARACTERÍSTICAS MORFOMÉTRICAS E FISIOLÓGICAS DAS ESPÉCIES E AMBIENTE PARA AS ESTRATÉGIAS C-, R-, S (Reynolds, 1988).}

CARACTERÍSTICAS DAS ESPÉCIES: atuação; tamanho; área superficial por volume: $S^{-1} V^{-1}\left(\mu m^{-1}\right)$; máxima dimensão linear - GALD $(\mu \mathrm{m})$; biovolume BVL $\left(\mu \mathrm{m}^{3}\right)$; motilidade; eficiência fotossintética [umoles $\mathrm{C}$ (mg.Chlo. a) $\mathrm{m}^{-1} \cdot \mathrm{mol}$ fớton) $\left.)^{-1} \cdot \mathrm{m}^{2}\right]$; área projetada $\mathrm{Kc}\left[\mathrm{m}^{2}(\mathrm{mg} \text { Chlo a) })^{-1}\right]$; taxa de crescimento máximo $\left(20^{\circ} \mathrm{C}\right), \mathrm{r}_{\operatorname{mx}}{ }^{\left.-\mathrm{d}^{-1}\right]}$; taxa de absorção cetular do fösforo, relativa a $r_{\max }^{\prime}\left(\mu \mathrm{M} .10^{9}\right.$ cetula-1. $\left.d^{-1}\right]$; sensibilidade térmica de $\mathrm{r}, \mathrm{Q}_{10}$; dose limiar de exposição (DLE) à intensidade de saturação de luz $\left[\mathrm{h} \mathrm{d}^{-1}\right]$; taxa de sedimentação mínima [m.d. $\left.\mathrm{d}^{-1}\right]$; suscetibilidade à herbivoria; aproveitamento de recursos; atividade metabólica; reprodução; perdas por sedimentação.

CARACTERISTICAS AMBIENTAIS: temperatura; luz; vento; turbulência; nutrientes.
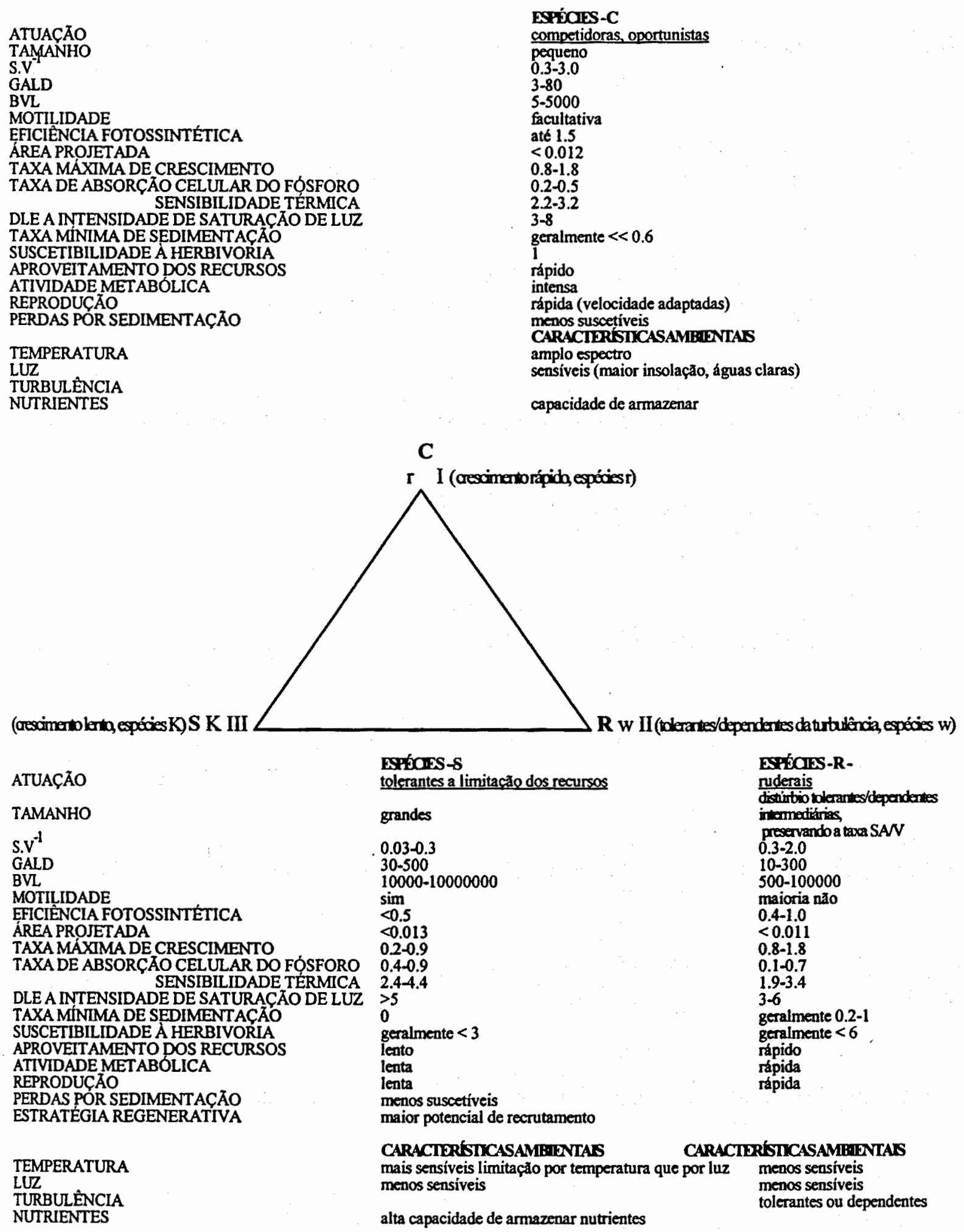
A evolução do fitoplâncton deve estar relacionada, de forma muito importante à maneira de exploração das várias possibilidades disponiveis. Diferentes espécies podem atingir taxas semelhantes de sobrevivência, combinando diferentes estratégias, ainda que de acordo com a teoria ecológica clássica, as estratégias devessem ser predominantemente divergentes. Margalef (1978) argumenta que as estratégias são impostas de uma forma considerável pelas propriedades fisicas do ambiente. Os mecanismos de seleção natural fazem com que a estratégia predominante entre as algas seja o reflexo da dinâmica do ambiente em que vivem.

O estudo da comunidade fitoplanctônica é enriquecido pela discussão das estratégias adaptativas, quando se pretende gerar informações que permitam realizar previsões (Reynolds, 1987). As estratégias adaptativas das algas do fitoplâncton de Guarapiranga virão a ser discutidas em relação à distribuição espacial (horizontal) e à temporal sazonal, nos próximos itens deste trabalho.

\subsubsection{CARACTERÍSTICAS DA COMUNIDADE FITOPLANCTÔNICA}

Ravera (1983) afirma que estrutura e biomassa da comunidade fitoplanctônica expressam melhor o estado trófico de um corpo d'água do que os elos posteriores da cadeia trófica, que são dependentes do fitoplâncton e indiretamente, dos teores de nutrientes disponiveis.

Em ambos os pontos houve uma tendência de aumento da densidade de outubro de 1991 em diante. $O$ biovolume aumenta muito em novembro e dezembro e mantém menor amplitude de variação após este período do que nos períodos anteriores a novembro. Estes resultados mostram as respostas da comunidade fitoplanctônica aos acréscimos de nutrientes relacionados ao início e continuidade do período das chuvas.

A tendência para a riqueza das espécies foi de apresentar maior amplitude de variação até novembro e daí em diante aumentar de valor e/ou reduzir a amplitude de variação. A uniformidade no ponto 1 teve grande amplitude de variação até dezembro, aumentando e se estabilizando a partir de então. No ponto 4 foi mais elevada até outubro quando a amplitude de variação aumentou, decresceu em novembro e elevou-se novamente a partir de janeiro.

As taxas de alteração são mais estáveis e elevadas até o final de setembro e a partir deste mês aumentam a amplitude de variação, que atinge maiores dimensões durante as alternâncias de dominância entre as florações, em ambos os pontos. Em geral atingiram valores mais elevados no ponto 4 . O aumento da taxa de alteração indica que uma nova espécie ou um novo grupo de espécies está em ascensão, encaminhando-se para a dominância. Quanto menor for a tendência para dominância, menor será amplitude de variação destas taxas (Reynolds, 1993), 
indicando ambiente mais estável quanto à ocorrência de distúrbios. Quedas destas taxas e valores mais baixos refletem uma comunidade mais conservativa. Em sucessões autogênicas seria esperado teoricamente que as alterações da comunidade fossem mais graduais, sem rupturas abruptas.

É interessante observar que há alguns casos de diferenças entre os resultados quanto às taxas de alteração aplicadas para biovolume em relação as de densidade: isto ocorre em AG15, N26, N27, D33 no ponto 1 e AG15, D33, F41 no ponto 4, casos em que os picos da taxa de biovolume foram inversos, menores que os de densidade; neste caso a alteração da densidade aumentou simultaneamente ao decréscimo na alteração do biovolume (biovolume mais conservativo que a densidade). Ocorreu o inverso em JA34 e MR42 no ponto 1 e em AG14, JA34 e MR42 no ponto 4, quando o pico da taxa de biovolume foi maior, mostrando que as alterações da comunidade quanto ao biovolume nem sempre correspondem as de densidade. Isto confirma a afirmação de Reynolds (1993) de que a densidade não é suficiente para avaliar as alterações da comunidade, pois as células diferem muito quanto às dimensões e contribuem de formas diferentes para a comunidade como um todo.

Quanto a distribuição do biovolume nas classes de tamanho, observou-se que a contribuição do macroplâncton foi inexpressiva em ambos os pontos. No ponto 1 a contribuição do microplâncton apresentou amplitude de variação elevada entre maio e outubro e de janeiro (J34) em diante; foi mais expressiva entre novembro N26 e dezembro D33, durante as florações de Dictyosphaerium ehrenberghianum e Aphanocapsa elachista. Portanto sua contribuição foi mais acentuada nos períodos de chuva, indicando dependência da elevação dos teores de nutrientes, temperatura, pluviosidade e turbulência. A contribuição do microplâncton foi mais expressiva no ponto 4 do que no ponto 1 e sua contribuição foi muito elevada durante novembro e dezembro. $O$ efeito mais acentuado da chegada do verão no Hemisfério Norte, que em maior ou menor extensão parece ser semelhante em latitudes mais baixas, é que a elevação da temperatura promove o aumento relativo das taxas de assimilação de todas as algas, especialmente das espécies maiores, com baixa razão superficie por volume. O potencial para o crescimento é ampliado e pode ser efetivo não apenas quanto ao aumento da biomassa total, mas também quanto ao aumento do número das espécies competidoras (Reynolds, 1993).

O nanoplâncton mostrou aumento a partir de janeiro, culminando em F39 com elevados biovolumes de Scenedesmus bijugus. Espécies dos gêneros Scenedesmus e Chlorella mantiveram o biovolume do nanoplâncton elevado até junho de 1992. O nanoplâncton neste ponto, apresentou uma tendência geral para aumento nos mesmos períodos que no ponto 1 . As 
espécies mencionadas apresentam baixa razão superficie por volume e alta taxa de crescimento, podendo aproveitar com eficiência, as condições existentes no período: elevados teores de nutrientes, menor potencial de circulação da massa d'água e temperaturas amenas.

As maiores diversidades para o Hemisfério Norte geralmente ocorrem nos períodos de mistura e crescimento ( 2.8 a 3.7 ); os menores valores ocorrem no verão com as populações mais segregadas (1.9 a 4.4) e os valores mínimos em áreas contaminadas (1.4 a 1.9) (Willén,1976 apud Margalef, 1983).

$\mathrm{Na}$ Guarapiranga as maiores diversidades para o ponto 1 ocorreram durante o segundo período de seca, ou seja, com baixo potencial de mistura e também com menor intensidade de sulfatação, logo o fator modificador do padrão esperado para o comportamento da diversidade pode ter sido a sulfatação. Entretanto, maiores diversidades de biovolume ocorreram também para o ponto 4, no segundo período de seca.

As maiores diversidades de densidade e bioárea coincidiram com o período de chuvas intensas, de maior mistura, neste caso confirmando o relato de Margalef (1983), e presumindose que as diversidades reportadas por este autor, tenham sido calculadas a partir de dados de densidade, como é mais comum, então os resultados encontrados neste estudo confirmam o relato de Margalef para diversidade máxima da comunidade do ponto 4 , mas não para a do ponto 1 , sujeita as alterações pela sulfatação.

Os resultados de diversidade do ponto 1, quanto a densidade (mínima de 1.30 e máxima de 4.20 bits.ml ${ }^{-1}$ ), comparados aos reportados por Margalef (1983) mostram respectivamente valor semelhante ao de áreas contaminadas e valor semelhante ao de períodos de populações mais segregadas, o primeiro ocorrendo no verão, quando as aplicações de algicida foram mais frequientes e o valor máximo ocorrendo no final do inverno, início das chuvas moderadas. No ponto 4 a diversidade da densidade variou entre 1.76 e 4.04 , parecendo mais relacionada (inversamente) à intensidade pluviométrica nas coletas imediatamente anteriores.

Comparou-se a seguir os resultados de densidade e bioárea reportados por outros autores, para represas do Estado de São Paulo e os encontrados no estudo atual, apesar das possíveis diferenças nos métodos de análise e das diferenças de períodos.

Esta comparação, ainda que superficial, permite situar a produtividade fitoplanctônica em relação a de outras represas de São Paulo e indica que a produtividade de Guarapiranga, durante este estudo, foi bastante elevada em relação aos valores relatados para as demais represas. 


\begin{tabular}{|c|c|c|c|c|}
\hline \multicolumn{5}{|c|}{ DADOS DO FITOPLÂNCTON DE REPRESAS DO ESTADO DE SĀO PAULO } \\
\hline Autor(es) (data de publicação) & \multicolumn{2}{|c|}{ represa (data de obtenção) } & $\begin{array}{l}\text { DENSIDADE } \\
\text { org.ml }^{-1}\end{array}$ & $\begin{array}{l}\text { BIOÁREA } \\
\text { upa.ml }{ }^{-1}\end{array}$ \\
\hline \multirow[t]{2}{*}{ Rocha e Branco (1986) } & Barra Bonita & $(1975-76)$ & 1024 & 2757 \\
\hline & $\begin{array}{l}\text { Barirí } \\
\text { Promissão } \\
\text { Ibitinga } \\
\text { Ilha Solteira } \\
\text { Jupiá } \\
\text { Salto Grande } \\
\text { Jurumirim } \\
\text { Euclides da C } \\
\text { Caconde } \\
\text { Limoeiro }\end{array}$ & $\begin{array}{l}\text { (idem) } \\
\text { (idem) } \\
\text { (idem) } \\
\text { (idem) } \\
\text { (idem) } \\
\text { (idem) } \\
\text { (idem) } \\
\text { nha (idem) } \\
\text { (idem) } \\
\text { (idem) }\end{array}$ & $\begin{array}{l}3130 \\
5700 \\
383 \\
302 \\
443 \\
195 \\
284 \\
1576 \\
1010 \\
1088\end{array}$ & $\begin{array}{l}3709 \\
32347 \\
1200 \\
152 \\
65 \\
120 \\
157 \\
27 \\
204 \\
24\end{array}$ \\
\hline CETESB (1992) & \multicolumn{3}{|c|}{ Guarapiranga $(1991-92)$} & \\
\hline Lemos e col.(1993) & Sumaré & $\begin{array}{l}\text { P1 } \\
(1988-91)\end{array}$ & 3411 & 1996 \\
\hline Lemos e col.(1993) & \multicolumn{2}{|c|}{$\begin{array}{l}\text { Fase inicial da represa } \\
\text { Fase de eutrofização } \\
\text { Fase c/ aplic. } \mathrm{CuSO}_{4}\end{array}$} & $\begin{array}{l}8000 \\
18232 \\
17646\end{array}$ & $\begin{array}{l}2600 \\
5443 \\
3593\end{array}$ \\
\hline \multirow[t]{2}{*}{ Beyruth (trabalho atual) } & \multicolumn{3}{|c|}{ Guarapiranga (1991-92) } & \\
\hline & $\begin{array}{l}\mathrm{P} 1 \\
\mathrm{P} 4\end{array}$ & & $\begin{array}{l}23300 \\
9799\end{array}$ & $\begin{array}{l}3780 \\
2523\end{array}$ \\
\hline
\end{tabular}

Os valores verificados pela CETESB (1992), para Guarapiranga, abrangem dados obtidos entre outubro de 1991 e fevereiro de 1992, um período menor que o deste estudo.

As densidades da Guarapiranga apresentaram valores maiores, comparáveis apenas aos registrados na represa de Sumaré. A bioárea atingiu valores mais próximos aos registrados em Barra Bonita, Barirí, Ibitinga, da bacia do rio Tietê, e Sumaré, que são represas eutrofizadas. É interessante notar que os dados da fase inicial não eutrofizada da represa de Sumaré, assemelham-se aos encontrados no ponto 4 e os dados da fases de eutrofização e sulfatação aos do ponto 1, da Guarapiranga.

Tundisi e col. (1988) classificam as represas de Barra Bonita, Bariri e Ibitinga como mesotróficas em relação aos conteúdos de fosfato; em eutróficas quanto à transparência e teores de clorofila $a$, em hipereutróficas quanto à condutividade, baseados em dados sazonais obtidos entre 1983 e 1984. Tundisi e col. (1991) relatam elevada produtividade primária em julho de 1989, nestas mesmas represas. Caleffi e col. (1994) baseando-se em dados sazonais da represa de Guarapiranga obtidos entre 1991 e 1992, classificam o ponto 1 do estudo atual, de meso a eutrófico quanto à transparência (devido as aplicações de sulfato de cobre) e eutrófico quanto aos teores de fósforo. O ponto 4 , com variação entre oligo e eutrófico, quanto à 
transparência e em eutrófico, quanto aos teores de fósforo. Portanto, a semelhança das densidades e bioáreas entre Guarapiranga e as demais represas mencionadas, da Bacia do Tietê devem estar refletindo o estado trófico destas águas.

Os dados de Guarapiranga são mais recentes que os das demais bacias do Tietê. Seria interessante avaliar, simultaneamente, durante ao menos um ciclo anual, o conjunto das represas do Alto Tietê quanto às relações entre os níveis tróficos e as comunidades algáceas, para saber se Barra Bonita, Bariri e Ibitinga espelhariam a previsão mais pessimista do futuro de Guarapiranga, quanto à qualidade ambiental.

\subsubsection{DISTRIBUIÇÃO ESPACIAL}

A heterogeneidade espacial da comunidade fitoplanctônica reflete a dos fatores ambientais, bem como as diferentes estratégias adaptativas apresentadas pelas espécies. A incidência do padrão de distribuição do fitoplâncton é previsível se considerados o tamanho da bacia, o comportamento vertical das espécies dominantes e a história imediata da ação dos ventos (Reynolds, 1993). Lewis (1978c) enfatiza a necessidade de comparar a distribuição individual das espécies, afirmando que este aspecto da variabilidade espacial é importante para a compreensão da estrutura da comunidade e dos processos de sucessão.

A represa de Guarapiranga tem condições excelentes para a formação de gradientes térmicos e químicos horizontais, por apresentar heterogeneidade da qualidade da água de seus contribuintes. Os afluentes mais ricos em nutrientes e contaminantes desaguam nas áreas mais próximas à barragem, de influência direta para o ponto 1 , que também apresenta maior uso $\mathrm{e}$ ocupação antrópica do solo, maior urbanização, baias mais fechadas, relevo mais acentuado, menor potencial de circulação por ação eólica, propiciando a ocorrência de ambientes de águas mais lênticas com grande potencial para produtividade primária. A própria diferença do tempo de retenção dos diferentes compartimentos, conforme Occhipinti (1973), produz variabilidade espacial horizontal. Nos compartimentos de água aberta, onde situam-se os pontos estudados, a circulação e a exposição aos ventos é mais intensa, mas os dois pontos estão sujeitos às influências das áreas marginais e/ou de montante havendo potencial para apresentarem comunidades diferentes. Os dados obtidos neste estudo permitem, tecer algumas considerações sobre a distribuição horizontal na água superficial da represa de Guarapiranga, uma vez que mostraram diferenças espaciais significativas quanto ao ambiente e à comunidade fitoplanctônica.

A maior parte das espécies registradas foi comum aos dois pontos. Ocorreram 65 táxons exclusivos do ponto 1 e 60 do ponto 4 , não havendo diferença significativa na riqueza exclusiva de cada ponto. 
Wetzel (1983) relata que em lagos de dimensões reduzidas ou moderadas, as variações horizontais na produtividade são relativamente pequenas, menores que $10 \%$, mas que as variações horizontais tornam-se mais significativas em lagos muito pequenos, bem como em lagos extremamente grandes, nas proximidades da zona litoral, ou quando a complexidade da bacia aumenta.

$\mathrm{Na}$ represa de Guarapiranga considerando-se a soma de todos os espécimes quantificados, as diferenças entre os pontos foram significativas. $O$ ponto 4 apresentou um total geral correspondente a apenas $42 \%$ do total geral do ponto 1 . Em termos de biovolume, entretanto, o total para o ponto 4 corresponde a $88 \%$ do total do ponto 1 , mostrando que a biomassa total foi mais conservativa que o número de espécimes total.

A comparação entre os valores de mediana dos dois pontos de coleta mostra que o ponto 1 apresentou valores superiores aos do ponto 4 , quanto a densidade, bioárea, biovolume e riqueza. Nos dois pontos as densidades apresentaram grandes flutuações entre as coletas, com maior amplitude de variação no ponto 1 . O desenvolvimento maior da comunidade algácea, mostra que este ambiente apresentou maior estabilidade que o ponto 4 , e indica que a taxa de renovação dos nutrientes na água superficial pode ter sido mais elevada no ponto 1 , principalmente devido às aplicações de sulfato de cobre.

Espécies que podem ser litorâneas ou do perifiton como Synedra ulna $\mathrm{t} 2$ (devido às dimensões celulares) e Mougeotia cf. americana (por motivos relacionados mais adiante), que atingiram elevadas densidades e biovolumes no ponto 1 , mostram que as contribuições da flora bentônica e das áreas marginais podem ser importantes para a água aberta desta região da represa.

Quanto aos grupos sistemáticos, o ponto 1 apresentou maiores valores que o ponto 4 , para riqueza, densidade e biovolume de penales, clorococales e zignemaficeas e maior biovolume de cianoficeas e euglenoficeas. Entre as penales, destacaram-se as espécies Asterionella formosa e Synedra ulna, que ocorreram com valores elevados nos períodos de inverno; entre as clorococales espécies dos gêneros Chlorella, Dictyosphaerium e Scenedesmus, entre as cianoficeas, os biovolumes mais expressivos foram de espécies de Aphanocapsa. As clorococales e cianoficeas apresentaram valores mais elevados, nos periodos de maior disponibilidade de nutrientes. Entre as euglenoficeas relacionadas à disponibilidade de matéria orgânica (Dia e Reynaud, 1982), destacaram-se espécies de Trachelomonas.

Entre as zignemaficeas, destacaram-se espécies de Mougeotia, e segundo Wetzel (1983), é comum encontrar algas bentônicas, o que parece ter sido o caso de Mougeotia, misturadas a formas planctônicas após turbulências irregulares causadas por tempestades. 
Vários fatores indicam Mougeotia cf. americana como espécie litorânea, apesar de sua descrição (Transeau, 1951), não incluir dados sobre o ambiente. Esta espécie foi encontrada associada aos bancos de macrófitas vasculares, em amostras coletadas no dia 31.07.91, JL12, na entrada do rio Embu-mirim na represa de Guarapiranga; Sládecková e Sládecek (1963) descrevendo as características do perifiton verdadeiro, afirmam que são organismos que permanecem fixos, possuindo adaptações para a vida séssil e só se desgarram da margem, aparecendo no plâncton em densidades elevadas, quando os movimentos da água são mais intensos (o que ocorreu neste trabalho) e relatam a ocorrência do gênero Mougeotia como perifiton verdadeiro das represas que estudaram; espécies deste gênero, mesmo as de menor diâmetro celular, têm sido encontradas no perifiton, tanto firme como frouxamente aderidas ao substrato em corpos d'água da cidade de São Paulo e da bacia do rio Paraná (com. pessoal da Dra. Denise Bicudo); este gênero é geralmente relacionado como proveniente de regiões litorâneas, sendo que em 39 resumos de trabalhos relacionados no ASFA (1988 a 1995), sobre este gênero, dos 15 que se referem a hábito de vida, todos relatam este gênero como litorâneo, descrevendo-o como perifitico, bentônico, metafitico ou epilitico. $O$ único trabalho que as relata no fitoplâncton é o de Sommer (1991), porém trata-se de experimentos de laboratório, realizados com inóculos algáceos provenientes de lagos, sem descrição destes ambientes e da origem da espécie mencionada (Mougeotia thilespora) no corpo d'água onde foram obtidos os inóculos, tampouco se esta alga multiplicou-se aderida às paredes do recipiente, ou livre, na água durante os experimentos.

Considerando-se a contribuição em porcentagem de cada estratégia, para cada ponto, o ponto 1 apresentou valores mais elevados que o ponto 4, para densidade e biovolume de organismos sem motilidade, densidade e biovolume de organismos sem envoltório rígido; densidade e biovolume das Classes 1 e 4 . A porcentagem de contribuição, da densidade de nanoplâncton e do microplâncton, foi igual nos dois pontos, mas para o biovolume, apenas a de nanoplâncton foi mais elevada no ponto 1 que no 4 ; a densidade e biovolume das cenobiais/coloniais, também foi maior no ponto 1. A taxa de circulação foi em geral suficiente no ponto 1 , para favorecer a exposição dos organismos aos nutrientes e à luz, não havendo necessidade de motilidade própria na maior parte do período. A rápida ciclagem e renovação dos nutrientes na água superficial, decorrente das elevadas mortandades causadas pelo sulfato de cobre, favoreceram as cloroficeas, cianoficeas e/ou organismos oportunistas, com características de r-estrategistas. Nos periodos de elevada disponibilidade de nutrientes as formas cenobiais/coloniais maiores também foram favorecidas neste ponto.

O ponto 4 apresentou valores mais elevados que o ponto 1, para diversidade, 
uniformidade e alteração da comunidade. Quanto aos grupos sistemáticos, foram maiores neste ponto riqueza, densidade e biovolume de centrales, dinoficeas e crisoficeas; a densidade e o biovolume das volvocales e criptoficeas. As condições ambientais do ponto 4, com maior fluxo horizontal, favoreceram o desenvolvimento das centrales, especialmente Rhizosolenia e espécies de Aulacoseira, estas últimas citadas por Gasse (1986) e por Hörnström (1981) como próprias de ambientes lóticos, eutróficos e de águas com elevada turbidez, desenvolvendo-se melhor em águas mais rasas, com baixa transparência. A dominância de diatomáceas filamentosas ou com células maiores, com frústula fortemente silicificada, está associada à disponibilidade de silício e às águas turbulentas, onde é comum atingirem altas densidades. A turbulência possibilita sua exposição alternada à luz, na superficie e aos nutrientes mais concentrados, nas camadas inferiores. Segundo Esteves (1988) as diatomáceas têm crescimento máximo, em intensidade luminosa baixa e elevada disponibilidade de nutrientes.

As algas flageladas, representadas por volvocales (especialmente de espécies coloniais, ou do gênero Chlamydomonas); dinoficeas (espécies de Gymnodinium e de Peridinium); crisoficeas (espécies de Dinobryon e de Mallomonas); criptoficeas (espécies de Criptomonas); foram favorecidas no ponto $4 \mathrm{em}$ que a menor transparência pode tornar esta estratégia adaptativa importante, permitindo aos organismos situarem-se em posições favoráveis ao longo dos gradientes de temperatura, luz e nutrientes.

Pollingher (1988) afirma que nas regiões sub-tropicais a luz fica disponivel durante todo o ano; a sucessão sazonal é influenciada por ventos e chuvas, e que devido aos efeitos da turbulência sobre a taxa de divisão de Peridinium, o sucesso de seu desenvolvimento é diretamente correlacionado com a época e duração do período de mistura; sendo que este gênero ocorreu em maior número no final do período de mistura no lago Kinneret. Relata ainda que a distribuição espacial dos dinoflagelados resulta da interação de três diferentes componentes: migração circadiana vertical, mistura turbulenta resultante de alto estresse por ventos e deslocamento da água.

As diferenças entre os dois pontos em relação às dominâncias, foram especialmente marcantes no caso de Gymnodinium fuscum, que ocorreu em maiores densidades e biovolumes no ponto 4, em período simultâneo ao de dominância por Mougeotia cf. americana no ponto 1.

Espécies de dinoficeas podem formar cistos de resistência, que permanecem no fundo até que as condições ambientais favoreçam seu ingresso sob a forma vegetativa, para a coluna d'água (Pollingher, 1988). No caso, as condições favoráveis ao desenvolvimento de Gymnodinium fuscum parecem estar relacionadas ao aumento da turbulência devido às intempéries (vento e pluviosidade elevados). 
Quanto às estratégias adaptativas, o ponto 4 apresentou maior porcentual de contribuição que o ponto 1 , para densidade e biovolume de organismos com motilidade, com envoltório rígido, densidade das Classes 2 e 3, de algas filamentosas e unicelulares bem como do biovolume de organismos da Classe 3 e do microplâncton.

A maior turbidez e teor de metais indicam que os aportes inorgânicos, favoreceram o desenvolvimento de organismos dotados de envoltório rígido, no ponto 4 . Beyruth e Lemos (1993) e Beyruth (1994a), estudando ambientes muito degradados por mineração de areia, com valores elevados de turbidez e teor de sólidos inorgânicos em suspensão, dificultando a exposição à luz e favorecendo choques e atrito com partículas inorgânicas, encontraram dominância expressiva de organismos flagelados com envoltório rigido, geralmente dinoficeas (espécies de Peridinium) e euglenoficeas (Trachelomonas). Estas observações sugerem que estes ambientes selecionam as espécies dotadas destas características adaptativas, uma vez que a motilidade possibilita alcançar iluminação adequada e que o envoltório rígido pode conferir alguma proteção contra choques mecânicos e atrito.

As espécies oportunistas, r-estrategistas, tiveram seu desenvolvimento favorecido em porcentagem total de espécies, tanto no ponto 1 , como no ponto 4 , indicando que independente do período, esta estratégia é muito bem sucedida nesta represa.

Segundo Sommer (1981), um ciclo de vida curto, alta taxa reprodutiva e biovolume reduzido, que são características das espécies r-estrategistas, favorecem o sucesso em ambientes ricos em nutrientes, submetidos a alterações constantes.

Entretanto não foram encontradas entre as dominantes, espécies com as características da estratégia $\mathrm{K}$, ou seja, elevado biovolume, baixas taxas reprodutivas e de assimilação de nutrientes. Dictyosphaerium ehrenberghianum, a espécie que atingiu o maior biovolume nesta represa, parece ter taxa reprodutiva acelerada, conforme inferido pela velocidade de seu desenvolvimento durante este estudo. Entretanto não foram encontrados dados sobre a velocidade de crescimento desta espécie, na literatura disponivel. $O$ mesmo pode-se afirmar a respeito de Aphanocapsa elachista, que também mostrou biovolumes expressivos. Portanto, as espécies que atingiram biovolume individual elevado eram coloniais, com volume celular reduzido e taxa reprodutiva aparentemente acelerada, não obedecendo aos critérios estritos da definição desta estratégia, porém, considerando estas estratégias como extremos de um gradiente, conforme Margalef (1958 apud Sommer, 1981), estas duas espécies seriam as que mostraram estratégia mais próxima da K-seleção.

O espectro de diversidade é função da taxa de reprodução, da difusão e da locomoção ativa em relação à turbulência das águas; turbulência intensa propicia maior mistura das 
populações; a diversidade está inversamente correlacionada com a densidade total de células em conseqüência da transitoriedade e dinamismo das populações muito densas, próprias de águas eutróficas (Margalef, 1983). No ponto 1, houve correlação negativa entre a diversidade do biovolume e o biovolume ( $\mathrm{rs}=-0.32 \mathrm{P}=0.0164$ ) como seria esperado, já que as espécies responsáveis por florações apresentaram biovolume elevado, mas para a densidade de organismos, bem como para densidade e biovolume no ponto 4 , as correlações com as diversidades não foram significativas.

A diversidade, segundo Margalef (1983), geralmente mostra correlações positivas com temperatura e concentração de nutrientes e correlações negativas com a extensão superficial, (provavelmente devido a menor possibilidade de mistura com as zonas do litoral, o que não é o caso da Guarapiranga). A diversidade tende a aumentar com a eutrofia moderada. A únicas correlações significativas (ambas negativas) da diversidade ocorreram no ponto 1, entre diversidade de bioárea e radiação solar, possivelmente devido à seleção das espécies quanto a área corpórea exposta à luz nos períodos de intensa radiação e com os teores de sódio, que possivelmente favoreceram apenas as espécies resistentes ao seu aumento.

\subsubsection{SAZONALIDADE}

As variações temporais na escala de mistura e difusão desestabilizam qualquer equilíbrio em andamento nos sistemas aquáticos, por alterarem as interações entre os processos físicos, químicos e biológicos, selecionando respostas alternativas das espécies (Reynolds, 1987).

Os parâmetros que definem a estrutura da comunidade responderam sazonalmente da mesma forma em ambos os pontos, com exceção do número de táxons, que no ponto 1 , atingiu maior valor de mediana no período da seca e no ponto 4 , durante as chuvas. Como a aplicação de sulfato de cobre foi mais intensa durante as chuvas, os níveis específicos de sensibilidade à presença do sulfato de cobre podem ter sido responsáveis por esta diferença.

As correlações apresentadas entre os parâmetros da comunidade fitoplanctônica e as variáveis ambientais expressam um padrão geral de maiores densidades e biovolumes nas chuvas, menores densidades e biovolumes na seca e aumento das densidades do início para o final das amostragens. A disponibilidade de nutrientes e a circulação, mais elevadas nos períodos das chuvas, propiciaram o desenvolvimento acelerado do fitoplâncton. As maiores densidades ocorreram sob temperatura, condutividade, alcalinidade e teores de potássio relativamente elevados em ambos os pontos. $\mathrm{O}$ mesmo ocorreu em relação aos biovolumes no ponto 4 , porém, para o ponto 1 , as aplicações de sulfato de cobre, conforme mencionado anteriormente, alteraram o comportamento da comunidade e o biovolume apresentou 
correlação positiva apenas com os teores de potássio.

A temperatura da água, condutividade e alcalinidade, apresentaram valores mais elevados durante o período de chuvas e correlacionaram-se com um maior número de parâmetros biológicos dependentes da densidade ou do biovolume.

As clorococales apresentaram as mais elevadas densidades, número de táxons e poucas correlações com os parâmetros ambientais. A grande variedade de estratégias adaptativas entre suas espécies, permite que estas se substituam, aproveitando os vários nichos expressos pelos gradientes ambientais ao longo de um ciclo anual completo, diminuindo a probabilidade de ocorrência de um maior número de correlações significativas entre este grupo de algas e as variáveis ambientais. Além disto as condições de eutrofia aliadas à uma alta taxa de circulação da massa d'água favoreceram a coexistência de espécies de requisitos ambientais semelhantes, contribuindo para estes resultados. Beyruth e col. (1993b) também encontraram clorococales em densidades elevadas e verificaram a coexistência de várias espécies de um mesmo gênero, num lago raso, eutrofizado e com alta taxa de circulação no Parque Ibirapuera, SP.

O primeiro período de seca (MA2 a AG16) caracterizou-se pelos menores valores de biovolume, com elevada uniformidade. $\mathrm{O}$ teor de nutrientes é determinante da produtividade algácea e de forma geral, foi menor neste período. Luz e temperatura determinam as taxas metabólicas, influindo na utilização dos nutrientes, sendo portanto fatores decisivos na distribuição sazonal do fitoplâncton. A insolação neste período foi mais elevada e segundo Lund (1965) a excessiva intensidade luminosa restringe o desenvolvimento de muitos vegetais por inibir a fotossíntese, e pode ter contribuído para o menor biovolume das algas nas águas superficiais, onde a exposição à luz é maior. Durante este período os dois pontos apresentaram maiores valores de transparência, favorecendo ainda mais a exposição das algas à luz. Os teores de nutrientes e as temperaturas mais baixas devem ter contribuído para as baixas densidades do fitoplâncton.

Outro fator a considerar é a renovação da água. A maior elevação, volume e o baixo teor iônico total, indicam diluição pelos aportes mais elevados e menos ricos dos tributários neste periodo. Os teores mais elevados de silício em ambos os pontos e de ferro especialmente no ponto 4, indicam ingressos dos solos expostos das margens devido à elevação da cota da represa. As temperaturas mais baixas deste período e os teores elevados de silício favoreceram o desenvolvimento de diatomáceas, que segundo Lund (1965) são freqüentes em águas claras e frias. O sucesso das volvocales, nos dois pontos, e o de criptoficeas no ponto 4, pode estar relacionado a sua capacidade de movimento, uma vez que as temperaturas e os conteúdos iônicos foram mais baixos e a insolação mais elevada. Entretanto, as volvocales são 
indicadoras de níveis sapróbicos e tróficos elevados (Ruts, 1983) e Chlamydomonas, que destacou-se entre seus gêneros, em ambos os pontos neste período, é freqüente em ambientes polúdos (Palmer, 1957). Rosén (1981) relata que Cryptomonas, gênero que ocorreu com densidades expressivas no ponto 4 , é comum no plâncton e que criptoficeas, como um todo, parecem ser euritróficas, sendo que seu desenvolvimento massivo foi observado em lagos com descarga de esgotos municipais e/ou em águas servidas de indústria de madeira, ricas em nutrientes e matéria orgânica.

É interessante observar que as clorococales destacaram-se em densidade no ponto 1 , sendo sobrepujadas por bacilarioficeas, quanto ao biovolume. No ponto 4 estas algas apresentaram as densidades e biovolumes mais expressivos, acompanhadas de perto pelas bacilarioficeas, quanto ao biovolume. As bacilarioficeas atingiram seu auge neste periodo. Dia e Reynaud (1982) afirmam que estas algas são características de águas claras e bem iluminadas, aparentemente contradizendo Esteves (1988). Entretanto, certas centrales como Aulacoseira granulata têm sido encontradas em rios do Estado de São Paulo, em que a movimentação da água é intensa e a turbidez muito elevada, enquanto algumas penales como por exemplo algumas espécies dos gêneros Pinnullaria, Synedra e Surirella parecem "preferir" águas mais claras e iluminadas (Mussarra e col., no prelo e Beyruth, dados inéditos).

Keating (1978) afirma haver correlação inversa entre o sucesso de cianoficeas de inverno e os niveis de sucesso das bacilarioficeas na primavera, indicando que as algas azuis liberam substâncias que inibem o desenvolvimento das diatomáceas em fases subseqüentes. Desta forma, a restrição de florações de cianoficeas em períodos prévios, devido ao controle algáceo, também pode ter contribuído para o sucesso de bacilarioficeas, nas condições favoráveis ao seu desenvolvimento, que ocorreram neste período.

A associação entre penales e flageladas parece ser comum no inverno, nos períodos de menor densidade algácea, conforme verificado pelos resultados da análise das espécies dominantes, integrada a de componentes principais. Quanto às flageladas, este fato pode relacionar-se com a capacidade destas algas propiciarem a renovação da água ao seu redor, o que favoreceria a absorção de nutrientes, nos períodos em que sua escassez limita o desenvolvimento algáceo. As penadas mais expressivas em densidade foram aquelas que possuem rafe verdadeira. Partículas sólidas em suspensão poderiam ter servido como apoio, favorecendo sua presença na água superficial. Outros fatores que favoreceriam a subsistência em ambiente oligotrófico, seriam a capacidade de armazenamento de nutrientes, o transporte devido à operação hidráulica ou ingresso dos tributários e ação eólica.

Nestes períodos de temperatura mais baixa, a transparência foi mais elevada. Foram 
periodos de águas claras, que também favoreceram a ocorrência de densidades mais elevadas de organismos zooplanctônicos, conforme relatado por Caleffi (1994).

Segundo Jassby e Goldman (1974) as quedas da produtividade podem decorrer de herbivoria, sedimentação, transporte vertical ou horizontal, advecção lateral ou motilidade, e morte celular. Indícios de herbivoria poderiam ser percebidos comparando-se as densidades de herbivoros do zooplâncton com a densidade algácea dos períodos sazonais simultâneos ao estudo mencionado, realizado por Caleffi (1994). Neste período a densidade de zooplâncton, segundo esta autora, mostrou valores mais elevados em ambos os pontos ( $>5$ org. $\left.\mathrm{m}^{-3}\right)$ apesar de que no ponto 1 , o zooplâncton mostrou, no geral, densidade reduzida com predomínio de rotíferos, possivelmente pelos efeitos da aplicação do sulfato de cobre. No ponto 4 , aquela autora registrou as maiores densidades de cladóceros.

Sob o ponto de vista da forma dos organismos fitoplanctônicos em relação à herbivoria, deve-se considerar que menores dimensões, ausência de massa gelatinosa e envoltório não rígido facilitam o aproveitamento do fitoplâncton como alimento pelo zooplâncton, especialmente para espécies de cladóceros que costumam ter maior eficiência no espectro de tamanho do nanofitoplâncton (Sommer, 1988a). Neste período ocorreram densidades elevadas de Scenedesmus bijugus, Chlorella cf. minutissima e biovolumes elevados de Chlamydomonas cf. gloeophila no ponto 1 . Ocorreram valores elevados de densidade de Cryptomonas cf. brasiliensis, Synedra cf. minuscula, Cryptomonas cf. tenuis, Chlamydomonas cf. gloeophila t2, Chlorella cf.. vulgaris var. vulgaris e Scenedesmus bicaudatus e de biovolume de Scenedesmus bijugus e Chlamydomonas cf. gloeophila no ponto 4 , sendo que todas estas espécies são nanoplanctônicas e podem ser utilizadas como alimento pelo zooplâncton.

Sommer (1988a) relata que Synedra minuscula esteve entre as algas melhor aproveitadas pelo zooplâncton em seu experimento. Synedra cf. minuscula ocorreu em densidades elevadas de MA2 até J6, no ponto 4. Portanto, neste período houve condições favoráveis à herbivoria, especialmente neste ponto. $O$ periodo de águas claras nesta represa, poderia corresponder à altas taxas de herbivoria, desde que outros fatores como a sulfatação, não estivessem atuando. Entretanto, as densidades do zooplâncton foram muito baixas para explicar o decréscimo da densidade do fitoplâncton.

Além da herbivoria, o transporte horizontal também pode ter contribuído para a baixa produtividade mencionada, por apresentar-se bastante significativo nesta represa (tempo de renovação menor que um ano) e potencialmente foi facilitado durante este período em que a captação de água para abastecimento esteve relativamente elevada, conforme mencionado.

Os indices de alteração da comunidade mostraram-se menos flutuantes até outubro de 
1991, em 023 no ponto 1 e em $\mathrm{O} 22$ no ponto 4. Destas coletas em diante passaram a flutuar mais, com maior amplitude de variação. A fase de águas claras correspondeu à maior estabilidade destes indices.

As algas mais expressivas quanto à dominância neste periodo seriam, segundo a classificação de Reynolds (1988), as S-estrategistas ou tolerantes à limitação de nutrientes: Chlamydomonas cf. gloeophila e Cryptomonas cf. brasiliensis, que embora não correspondam à K-estratégia, apresentam motilidade. Quanto as bacilarioficeas, só poderiam ser consideradas S-estrategistas se possuíssem algum mecanismo que permitisse superar a deficiência de nutrientes, conforme mencionado anteriormente.

Durante o período de chuvas moderadas (S17 a N29) a comunidade fitoplanctônica caracterizou-se pelas elevadas taxas de alteração da densidade, bioárea e biovolume, pela elevação do biovolume total e pelo declínio da riqueza de espécies. Chlamydomonas, Dinobryon, Rhizosolenia, Aulacoseira e Dictyosphaerium destacaram-se por densidades e biovolumes elevados em ambos os pontos. Neste periodo centrales, criptoficeas, volvocales e penales destacaram-se pela elevada persistência nos dois pontos de amostragem.

$\mathrm{O}$ início das chuvas propiciou maior alteração das comunidades, por modificar substancialmente características do ecossistema, importantes para esta comunidade: aumento significativo dos aportes de materiais orgânicos e/ou em diversos graus de mineralização ingressando da bacia para a água, elevações da cor, demanda bioquímica de oxigênio, condutividade, alcalinidade, dureza, teor de fosfato, sulfato, potássio, sódio e cloro e diminuição da transparência, incremento dos movimentos da água, entre outros, propiciando tanto as maiores alterações na comunidade fitoplanctônica como as menores densidades. A densidade de zooplâncton ainda esteve elevada no ponto 1, podendo ter contribuído para estas densidades mais baixas. A elevação dos teores de sódio e cloro indicam que o aporte de esgotos também aumentou. Os aportes de silício, ferro e alumínio, do solo exposto da bacia de drenagem, foram favorecidos pelas primeiras chuvas (Beyruth e col., no prelo).

A análise dos componentes principais, como será visto adiante, evidenciou que a maior disponibilidade de fósforo total, ocorreu quando a densidade algácea atingia valores menos expressivos, no outono e inverno (setembro, outubro e final de março). Portanto, em vista desta disponibilidade, outros fatores limitaram a taxa de crescimento algáceo nestes períodos. As correlações negativas da densidade com os teores de alumínio, nos dois pontos e com o teor de ferro no ponto 1 podem ser consideradas para estas fases, como possíveis fatores restritivos.

Destacaram-se as coletas S19, no ponto 1, pela elevada densidade de Dinobryon 
sertularia ( $18 \%$ do total) e S18 no ponto 4 pela elevada densidade de Dinobryon divergens (64\% do total).

Entre os grupos de algas destacaram-se clorococales, bacilarioficeas e volvocales pelas densidades e biovolumes mais elevados; apenas por densidades mais elevadas destacaram-se as crisoficeas e as criptoficeas. No ponto 1 destacaram-se a densidade elevada de zignemaficeas, bem como o biovolume de crisoficeas e no ponto 4 destacaram-se os biovolumes de dinoficeas e euglenoficeas.

Nota-se que clorococales passam a ser o principal grupo nos dois pontos, sendo sobrepujadas por bacilarioficeas apenas no ponto 1, quanto a densidade. Wetzel (1983) chama a atenção para o número elevado de clorococales nos lagos em processo de eutrofização. Estas algas também são citadas por Thunmark (1945, apud Coesel, 1983) e por Beyruth e col. (1993) como abundantes em ambientes eutróficos. Sua elevação neste período deve-se principalmente às altas taxas reprodutivas, expressas pelos aumentos rápidos das densidades de Dictyosphaerium ehrenberghianum, que esteve entre as três espécies de maior freqüência entre $\mathrm{O} 24$ e JA34 no ponto 1 e entre N26 e JA36 no ponto 4, configurando floração. Esta espécie e espécies de Aphanocapsa, foram as algas de biovolume mais expressivo do ponto $1 \mathrm{e}$ a mais expressiva, na contribuição para o biovolume da represa foi Dictyosphaerium ehrenberghianum.

A elevação da densidade de zignemaficeas no ponto 1 , deve-se principalmente a Mougeotia cf. americana que apresentou densidades expressivas apenas em outubro (O24 $44 \%$ e 025 - 5\%). Entre N26 e N29 ocorreu uma estiagem temporária, com queda nos índices pluviométricos. O desaparecimento simultâneo desta alga com a queda dos índices pluviométricos, indica sua proveniência do litoral e durante a estiagem, não poderia ser removida do perifiton, pois o movimento da água tendeu a decrescer. Esta estiagem temporária caracteriza-se como um distúrbio breve, entre fases de maior pluviosidade. $\mathrm{O}$ retorno desta espécie à água aberta a partir de D33 coincide com o início das chuvas intensas, o que mostra a influência marcante das chuvas na mobilização da massa d'água, tão intensa, que poderia ser capaz não apenas de trazer estas algas, como também de promover acréscimos consideráveis de materiais do fundo e das margens para a coluna d'água. Este período de chuvas com a estiagem intermediária caracterizam uma fase de reversão, pois a informação remanescente, constituída pelos inóculos de Mougeotia é utilizada para retornar ao estado anterior da seqüência que culminará com sua dominância em períodos subseqüentes.

Entre as volvocales, Chlamydomonas continua se destacando, como no periodo anterior. As crisoficeas foram melhor representadas pelas espécies citadas de Dinobryon. Rosén 
(1981) considera que este grupo indica oligotrofia pois até aquela época não se havia encontrado espécies pronunciadamente eutróficas. Este autor afirma que Dinobryon "prefere" lagos pobres em nutrientes, com águas claras. Nestas coletas o fósforo diminuiu. Wetzel (1983) em sua classificação quanto às características tróficas relata a presença de Dinobryon em lagos oligotróficos ou mais produtivos, durante fases de redução de nutrientes, relatando fagotrofia neste grupo, que pode ter contribuído para as altas densidades do início das chuvas, quando houve maior disponibilidade de matéria orgânica.

As criptoficeas, conforme mencionado para o periodo anterior, desenvolvem-se bem em ambientes ricos em nutrientes e matéria orgânica.

No ponto 4, o sucesso das dinoficeas, melhor representadas por Peridinium e Gymnodinium pode ter decorrido da sua capacidade de movimento, permitindo superar a deficiência de luminosidade deste periodo. Conforme mencionado anteriormente Wetzel (1983) relata que Gymnodinium pode mover-se com velocidade de até um metro por hora, elevando-se na coluna d'água à tarde e afundando quando há aumento da intensidade luminosa. Lieberman e col. (1994) também relatam ciclos diuturnos de migração vertical, relacionado ao melhor aproveitamento de recursos, para Gymnodinium bogoriense de represas de Israel. Sommer (1988b) relata migrações diuturnas verticais com amplitude máxima registrada em metros, de 10 para Peridinium cinctum; 8 para Peridinium aciculiferum; 5 para Peridinium penardii e de 5.5 para Gymnodinium uberrimum, 2.5 para Gymnodinium lacustre. Esta escala de dimensão é compatível e pode ser importante em relação a profundidade da água de Guarapiranga.

As euglenoficeas são comuns em comunidades planctônicas de lagos ricos a moderados em substâncias húmicas, sendo notoriamente favorecidas por aportes de esgoto, podendo desenvolver-se então, em quantidades consideráveis (Rosén, 1981), e como foi visto, os teores de sódio e cloro elevaram-se, indicando aportes de esgoto. Dia e Reynaud (1982) e Esteves (1988) relacionam a proporção destas algas com a disponibilidade de matéria orgânica. Branco (1986) relata fagotrofia em espécies deste grupo.

Bacilarioficeas predominam no início do periodo mas no final inicia-se a floração de Dictyosphaerium ehrenberghianum nos dois pontos. Para o sucesso de Dictyosphaerium, neste período no ponto 1 , pode ter contribuído o fato desse gênero possuir dimensões maiores, com massa e fios de gelatina, dificultando sua apreensão pelos herbívoros do zooplâncton. Sommer (1988a) afirma que espécies gelatinosas são consideradas refratárias à herbivoria por causa das dimensões ou quando de menor tamanho, o envoltório gelatinoso torna-as resistentes à digestão e estas espécies podem até mesmo aproveitar-se do enriquecimento em 
nutrientes, durante a passagem pelo trato digestivo do animal.

Há indícios de decréscimo na diversidade, no período de rápido crescimento do fitoplâncton (Margalef, 1983), o que ocorreu na Guarapiranga para diversidade de densidade e de biovolume, que apresentaram os menores valores durante o início das chuvas nas fases em que o crescimento foi intenso.

Neste período houve transição entre deficiência de nutrientes e aportes decorrentes do inicio das chuvas. As espécies dominantes tenderiam a apresentar desde a S-estratégia no início do periodo, até a R-estratégia já para o final do período, de acordo com a classificação de Reynolds (1988). Gymnodinium e Peridinium representariam esta última, enquanto as espécies do primeiro período de seca que ainda estavam presentes no início deste período, seriam as melhores representantes da S-estratégia.

No período das chuvas intensas (D30 a MR44), a comunidade fitoplanctônica caracterizou-se por maiores valores de biovolume, diversidade de densidade e bioárea, menores valores da uniformidade da densidade e de alteração do biovolume. Houve elevação da densidade, bioárea, biovolume, riqueza e diversidade nos dois pontos, exceto da diversidade da densidade no ponto 4 . Os índices de alteração declinaram.

Neste período de radiação solar e temperaturas mais elevadas, houve grandes aportes de água devido às máximas de excedente hídrico, escoamento básico e afluxos dos tributários. Houve valores mais elevados de cálcio, potássio e magnésio e aumento da cor e da dureza.

As menores alterações do biovolume, ocorreram durante este periodo nos dois pontos, o mesmo ocorrendo para as alterações da bioárea no ponto 1. A maior circulação que propicia melhores condições de exposição à luz e aos nutrientes, bem como rápida reposição dos mesmos nas águas superficiais (possibilitando menor custo energético com estratégias adaptativas especiais), permitiram que o biovolume apresentasse um padrão mais conservativo durante as chuvas intensas.

Neste período de chuvas intensas o teor iônico total foi menor, possivelmente pela diluição devido à intensidade das chuvas, mas mais provavelmente por consumo pela floração de Dictyosphaerium iniciada no período anterior e que continuou (até JA34 e JA36, respectivamente) nos dois pontos. Sua senescência foi simultânea à elevação da densidade e biovolume da cianoficea Aphanocapsa (D33, no ponto 1 e D30, D34 no ponto 4), e de Synechoccocus elongatus em densidade (JA3, no ponto 1, e JA34, JA35 e JA36, no ponto 4). No ponto 4, ocorreu densidade elevada de Oscillatoria subtilissima, também neste período (JA34). Estas esporádicas elevações de cianoficeas, mostram a capacidade destas algas de aproveitarem rapidamente os nutrientes liberados na água superficial durante a senescência de 
grandes massas de clorococales. Posteriormente, ocorreu a floração de Mougeotia cf. americana no ponto 1, onde iniciou-se em JA36 e no ponto $4 \mathrm{em} \mathrm{JA37}$, sendo que neste ponto dividiu a dominância com Cryptomonas.

No ponto 4, o biovolume das unicelulares correlacionou-se com a demanda bioquímica de oxigênio. $O$ biovolume mais elevado entre as espécies unicelulares neste ponto foi de dinoficeas - Peridinium, Hemidinium ou Gymnodinium. Neste ponto Gymnodinium fuscum aumenta em densidade e biovolume, atingindo valores expressivos neste período, com a floração de Peridinium sp3 e a de Gymnodinium fuscum.

Houve algumas respostas diferenciadas entre as comunidades dos pontos 1 e 4 quanto às estratégias adaptativas favorecidas no periodo de chuvas. No ponto 1 , a permanência de grandes quantidades de Mougeotia cf. americana na água aberta teria sido favorecida pela diminuição de competidores planctônicos, eliminados pela sulfatação. No ponto 4 durante o mesmo período, ocorreram altos valores de densidade e biomassa de Gymnodinium fuscum, organismo flagelado dotado de motilidade, capaz de superar o gradiente desfavorável de iluminação decorrente da cor elevada e da presença de Mougeotia e que pode ter sido favorecido (por recrutamento) pela turbulência mais elevada.

Destacaram-se por densidades e biovolumes elevados, configurando florações, as clorococales representadas por Dictyosphaerium, as cianoficeas por Aphanocapsa e as zignemaficeas por Mougeotia. Segundo Lund (1965) a disponibilidade de luz e temperatura elevada determinam altas taxas de fotossíntese e de utilização dos nutrientes e até mesmo sua eventual exaustão. Nestas condições o desenvolvimento de organismos de taxa reprodutiva mais acelerada é favorecido, especialmente o de cloroficeas e cianoficeas, melhores competidoras nestas condições ambientais. Lund (1965) relata que estas algas tem suas máximas de crescimento no período do ano em que os dias são mais longos.

A taxa de circulação da massa d'água também foi mais elevada neste período e Margalef (1983) afirma haver uma tendência a valores de diversidade mais elevados nos períodos de maior mistura em lagos eutróficos. A represa de Guarapiranga apresentou em geral, elevação das diversidades neste período.

De forma geral, as condições ambientais do periodo total de chuvas com maiores aportes de materiais, inclusive de nutrientes da bacia de drenagem, as maiores temperaturas e radiação solar favorecendo taxas metabólicas e fotossintéticas mais elevadas, permitiram o desenvolvimento abundante de organismos com taxa reprodutiva mais acelerada, sem estruturas adaptativas elaboradas, e em geral de pequeno porte. $\mathrm{A}$ alta densidade de pequenos organismos refletiu-se no aumento do biovolume total nestes períodos. No ponto 4 , durante as 
chuvas o comportamento das variáveis em geral foi semelhante ao do ponto 1 , sendo que as diferenças decorrem tanto das condições particulares deste ponto, com fluxo mais rápido e menor aporte de nutrientes, como devido à ausência de sulfatação, que no ponto 1 foi mais intensa neste periodo.

Neste periodo de elevada turbulência a estratégia favorecida, segundo os critérios de Reynolds (1988) foi a R-estratégia, com dominância de formas ruderais, tolerantes ou dependentes de distúrbios: Mougeotia cf. americana e Gymnodinium fuscum constituiriam seus melhores exemplos. Dictyosphaerium ehrenberghianum teria um comportamento entre C-estrategista e R-estrategista. Ocorreu durante periodos de disponibilidade mais elevada de nutrientes, mas sua manutenção na água superficial dependeria de turbulência moderada, enquanto nas fases de turbulência mais acentuada esta espécie declina. Aphanocapsa elachista mostrou-se uma competidora mais eficiente C-estrategista, só alcançando densidades elevadas quando houve alta disponibilidade de nutrientes.

No segundo periodo de seca (AB45 a JL58), a comunidade fitoplanctônica caracterizou-se pelos maiores valores de densidade, bioárea, GALD, SGALD, riqueza e das diversidades no ponto 1 e apenas da diversidade do biovolume no ponto 4 .

A deficiência hídrica contribuiu para a elevação da condutividade, alcalinidade, sólidos em suspensão, teores de fosfato, amônio, zinco e conteúdo iônico total, que foram os mais elevados. Os teores de aluminio e silício foram os menores registrados.

A temperatura declinou mas a mediana foi igual ou superior a $22^{\circ} \mathrm{C}$, portanto maior que no primeiro período de seca, propiciando melhores condições para o desenvolvimento algáceo. As diatomáceas geralmente são as algas mais favorecidas pelas menores temperaturas de inverno, mas como as temperaturas ainda não haviam declinado consideravelmente, apenas Rhizosolenia destaca-se em ambos os pontos e Aulacoseira no ponto 4.

As alterações da densidade do ponto 1 , e as da densidade e bioárea do ponto 4 , foram menores durante o segundo período de seca. Neste período a maior concentração de nutrientes mineralizados, atestada pela elevada condutividade, aliou-se aos elevados teores de sólidos em suspensão. A floração de Mougeotia cf. americana, ainda se manteve até AB46, no ponto 1, e até $\mathrm{F} 38$, no ponto 4. A partir de então, nas condições mencionadas, passam a dominar espécies de dimensões reduzidas como Scenedesmus spp e Chlorella spp, espécies oportunistas $\mathrm{r}$ estrategistas. A substituição de Mougeotia por estas espécies foi gradativa, sem drásticas alterações nas densidades totais.

Os teores elevados de fosfato e amônio indicam que os aportes de esgoto foram importantes neste período e o mais elevado conteúdo iônico mostra que houve concentração 
devido à seca. Neste período apesar da alta taxa reprodutiva expressa pelas elevadas densidades, o biovolume foi inferior ao das chuvas intensas, pelo predomínio de organismos de pequeno porte.

No auge da seca, a deficiência hídrica mais acentuada foi simultânea a inibição dos processos de mineralização, pelas baixas taxas metabólicas decorrentes das baixas temperaturas. A entrada de nutrientes restringiu-se aos aportes dos tributários e dos esgotos, conforme considerado anteriormente, pois a pluviosidade reduzida impedia outras entradas, como percolação ou carreamento. Mancuso (1992) relata lançamentos elevados de esgoto, baseando-se em dados de 1988, que desde então, tenderam a aumentar, pelo aumento da urbanização da bacia, contribuíndo para esta situação.

Entre as cianoficeas houve aumentos expressivos da densidade de Oscillatoria subtilissima entre AB47 e MA51 e em J57 e JL58, no ponto 1 e no ponto 4, em AB46, AB48, e MA51. Verificou-se também o aumento do biovolume de Aphanocapsa, em J56 e J57, no ponto 1 e em J58, no ponto 4, provavelmente favorecida pelo aumento do teor de nutrientes na água, liberados durante a senescência de Mougeotia. A elevação da densidade de Oscillatoria subtilissima, de Synecoccocus elongatus e de Pseudoanabaena catenata, não se refletiu na expressividade do biovolume das cianoficeas, pois estas espécies tem biovolume reduzido. A alta densidade de Oscillatoria subtilissima foi simultânea à elevação da densidade e biovolume de espécies dos gêneros Chlorella e Scenedesmus, configurando-se assim um período de elevada reciclagem biológica, com alto dinamismo da comunidade e rápida substituição das espécies. As alterações foram mais qualitativas que quantitativas e as modificações da comunidade foram gradativas, impedindo que os índices para taxa de alteração, se elevassem muito de uma vez.

Margalef (1983) afirma que não se observa muita regularidade na distribuição dos valores de diversidade, exceto uma tendência a valores mais elevados nos períodos de mistura em lagos eutróficos. $\mathrm{Na}$ Guarapiranga os maiores valores foram registrados no segundo periodo de seca, ou seja, de menor circulação e maior concentração.

No ponto 1 , a riqueza de táxons, índices de alteração da comunidade, diversidade e uniformidade foram mais elevados no período da seca. Apesar da elevação da taxa de alteração, a comunidade não teve favorecimentos acentuados de determinadas espécies em detrimento de outras, indicando que em geral as alterações da comunidade foram mais equilibradas nestes períodos. $O$ ponto 4 mostrou-se diferente do ponto 1 durante a seca, especialmente pelas taxas mais baixas de alteração do biovolume, pelas mais elevadas densidades de zignemaficeas e biovolume de dinoficeas e por apresentar maiores valores de 
biovolume apenas na Classe 1.

Observa-se grande diferença na estrutura da comunidade entre J57 e JL58, devidas provavelmente à queda abrupta da temperatura entre estas coletas.

No início do periodo ainda dominavam as R-estrategistas do período anterior. A partir de $\mathrm{AB} 46$ no ponto 1 e de JA38 no ponto 4, este período favoreceu a presença de espécies menores, de crescimento rápido que segundo o critério de Reynolds (1988), seriam Cestrategistas, competidoras, oportunistas.

\subsubsection{SAZONALIDADE DO FITOPLÂNCTON E TEORIAS ECOLÓGICAS}

A afirmativa de Dobzhanski "nada em biologia tem sentido, exceto à luz da evolução", é verdadeira tanto para a ecologia como para qualquer outro campo da biologia (Deshmukh, 1986). A ecologia estuda sistemas heterogêneos, complexos formados por vários níveis, o que acarreta problemas durante a definição das entidades, no teste das hipóteses, na operacionalização ou clarificação dos conceitos e na concordância sobre a suficiência das explicações (Loehle, 1988).

Pressupondo-se que ecologia e evolução partem das mesmas premissas básicas e devem ser consistentes, já que ecologia é a ação da evolução (Harris, 1986), é necessário rever alguns conceitos que direcionaram as teorias atualmente mais aceitas sobre a dinâmica do fitoplâncton.

A ecologia do fitoplâncton fundamentou-se durante muitos anos no conceito de que os fatores físicos controlam a dinâmica da comunidade, determinando os padrões de alteração. Temperatura, turbulência e estratificação têm sido consideradas determinantes da composição das espécies e dos padrões de sazonalidade tanto das espécies como da biomassa.

Segundo Harris (1986), em meados da década de 70 estudiosos da ecologia do plâncton começaram a considerar as interações bióticas, dando origem aos conceitos de controle através das interações entre as comunidades.

Estas linhas de pensamento evoluiram para a teoria da competição pelos recursos (hipótese razão-recurso), ou seja, a disponibilidade de recursos (nutrientes, luz, temperatura) em que as relações entre eles seriam os principais fatores de controle (Tilman, 1985, Tilman e col., 1982) e para o conceito de cascata trófica, no qual cada nível trófico atua sobre o seguinte e a estrutura da cadeia trófica é controlada pelos predadores do topo da cadeia alimentar (Carpenter e col. 1985, segundo Harris, 1986). 
As idéias que fundamentam as explicações na importância das interações bióticas, essencialmente darwinianas, são conceitos de equilibrio, uma vez que os controles sobre o crescimento da população, competição e coevolução das comunidades são dependentes da densidade (Harris, 1986). Já aquelas que fundamentam o controle das populações nos fatores físicos, constituem conceitos de não equilibrio, por considerarem que o controle das populações é exercido por eventos climáticos ou catastróficos e que a estrutura da comunidade não é determinada exclusivamente pela competição.

O conceito de equilibrio impõe as seguintes premissas: o sistema está em equilibrio, ao menos parte dos recursos é limitante, o ambiente está totalmente ocupado pelas espécies e, portanto, não há lapsos temporários na seleção que favoreçam respostas ótimas às condições; o ótimo teórico é sempre atingivel e é sempre o mesmo em qualquer momento e o histórico da população não exerce efeitos na situação atual.

Em contraposição, o conceito de não equilibrio pressupõe flutuações no ambiente fisico e biótico acarretando mortalidade independente da densidade, ausência de competição e de limitação de recursos; o ambiente não está saturado por espécies, as espécies têm diferentes taxas de crescimento e, portanto, uma determinada periodicidade de distúrbio vai afetar diferentes espécies de diferentes maneiras. $O$ ótimo adaptativo altera-se com o tempo e os efeitos dos componentes históricos são fortes. As comunidades são sistemas abertos e então a exclusão ou extinção das espécies constituem eventos locais, para a população local. Neste sentido a hipótese do distúrbio intermediário baseia-se no mecanismo evolutivo pontuado, que assume ausência de competição contínua devido a flutuações ambientais que rompem o equilíbrio com freqüência suficiente para permitir a coexistência das espécies.

As teorias de equilíbrio e de não equilibrio podem ser consideradas como os dois extremos de um espectro ecológico (Harris, 1986). Num mesmo ambiente é possível que os dois casos ocorram em períodos diferentes ou apresentem graus diferentes de eficiência para os diferentes níveis, tais como espécies, populações ou comunidades. Os organismos diferem em tamanho, forma, motilidade e nas suas capacidades adaptativas, podendo perceber o mesmo ambiente através de vias diferentes.

Em ambientes ou períodos estáveis, como resultado de altas taxas de crescimento, a população aumenta até o nível em que a exclusão competitiva torna-se importante. Em ambientes ou periodos instáveis ou desfavoráveis ao crescimento as taxas de crescimento podem ser reduzidas e a população tornar-se limitada pelos fatores ambientais. 
Levins (1979, apud Harris, 1986) afirma que em ambientes instáveis as próprias flutuações podem tornar-se recursos e sua caracterização é tão importante quanto a determinação dos recursos disponíveis. Observa ainda que a prática de definir o ambiente e os organismos, separadamente, é objetável e sugere que uma abordagem mais útil seria considerar a mútua dependência entre organismos e ambiente. Aquele autor considera que em ambientes onde as flutuações são a norma é possível evitar competição através da exploração da variabilidade temporal de um recurso, de forma diferente do utilizado pelas demais espécies.

A teoria do não equilíbrio assume que as alterações ambientais ocorrem com freqüência suficiente para romper o curso da exclusão competitiva, considerando o tempo como componente, diferindo assim da teoria do equilíbrio. Neste contexto o tempo é determinado como o período ou taxa de crescimento. Hutchinson (1961) iniciou a formulação deste conceito aplicando-o ao fitoplâncton, afirmando que a diversidade do fitoplâncton resulta da falha constante em atingir o equilíbrio, devido às alterações relevantes dos fatores externos. Este conceito evoluiu para a hipótese do distúrbio intermediário de Connel (1978, apud Sommer e col., 1993). Desta forma reduções periódicas da população resultantes de alterações ambientais, evitam que a população alcance densidades tão elevadas, que possam gerar competição acirrada, resultando na exclusão de espécies.

Basicamente existe uma incoerência entre as linhas de pensamento que fundamentam o controle da comunidade nas interações biológicas. A linha que considera a competição como única fonte de controle marcante, contrapõe-se à teoria de sucessão ecológica que afirma que as espécies interagem com o ambiente e com as demais espécies, propiciando a alteração dos nichos existentes, ou a criação de novos nichos tornando o ambiente favorável ao desenvolvimento de outras espécies. Neste caso a competição não seria a única forma de interação biótica importante na seleção das espécies e na alteração da comunidade, mesmo considerando os demais preceitos da teoria do equilibrio.

No contexto evolutivo espera-se que os organismos capazes de direcionar a maior proporção da energia adquirida para produtos finais úteis (crescimento e reprodução) sejam os mais capacitados a sobreviver (Townsend e Calow, 1981). No nível das comunidades, se o processo de evolução se baseasse indefinidamente, apenas na exclusão competitiva sem que novos recursos fossem criados pelas próprias comunidades biológicas e compartilhados pelas mesmas, o custo energético para o sistema seria muito maior, o que estaria em desacordo com os preceitos de economia de energia, bastante evidentes nas comunidades biológicas. 
Considerando-se o tempo expresso pelo número possível de gerações das algas, é possível testar algumas hipóteses ecológicas que consideram fenômenos imediatos de resposta e interação com o ambiente.

Um ambiente tão sujeito a alterações, como a represa de Guarapiranga, dificilmente sustentaria a possibilidade de sucessões ecológicas autogênicas nas comunidades planctônicas. Partindo-se desta premissa, seria esperado que distúrbios ambientais explicassem de forma mais adequada as alterações da comunidade fitoplanctônica.

Neste estudo sobre a represa de Guarapiranga verificou-se a marcante influência tanto dos fatores fisicos, como químicos, relacionados à disponibilidade de nutrientes e também das ações antrópicas. Estes fatores foram suficientes para explicar os eventos mais importantes que ocorreram na comunidade fitoplanctônica durante $o$ período. Portanto o estudo da disponibilidade de recursos também pode contribuir para o conhecimento e por isso a discussão sobre a sazonalidade do fitoplâncton será realizada à luz das teorias ecológicas do equilibrio (hipótese razão-recurso) e do não equilibrio (hipótese do distúrbio intermediário).

As fases de estabilidade poderiam ser apontadas pelos índices de alteração da comunidade. Na Guarapiranga estes índices mostraram-se mais elevados ou menos flutuantes até outubro de 1991, em O23, no ponto 1 e em 022 no ponto 4. Destas coletas em diante passaram a flutuar mais, com maior amplitude de variação. A fase de águas claras correspondeu à maior estabilidade destes índices, conforme mencionado anteriormente.

Nos dois pontos a variação dos índices de alteração da comunidade em densidade, bioárea e biovolume foi em geral simultânea, mas houve discrepâncias, correspondentes no ponto 1: em N26 à transição de uma fase instável quanto à dominância para a fase de dominância de Dictyosphaerium; D33 transição da dominância de Dictyosphaerium para Aphanocapsa; D34 volta à dominância de Dictyosphaerium; D41 transição da dominância de Chlorella e Dictyosphaerium para Mougeotia; M42 transição de dominância de Mougeotia para Chlorella e Scenedesmus. No ponto 4, as inversões corresponderam: em D33 à transição de dominância de Dictyosphaerium para Mougeotia; D34 de Mougeotia para Dictyosphaerium; D40 de Gymnodinium para Chlorella; F42 de Chlorella para Synedra e Gymnodinium.

Na represa de Guarapiranga há indícios de que a degradação da qualidade da água ocorrida nas últimas décadas, tenha exercido um efeito controlador no topo da cadeia trófica, pois segundo relatos de pescadores, a qualidade do pescado alterou-se de peixes maiores, com 
valor comercial e desportivo, para dominância de peixes de pequeno porte e valor comercial inexpressivo. Os indícios existentes de herbivoria foram discutidos no item sobre distribuição sazonal. Entretanto uma avaliação mais profunda dos efeitos da herbivoria ou de "cascata trófica", demandariam a realização de experimentos controlados ou um profundo conhecimento da história das comunidades na represa, tornando necessários estudos abrangentes e prolongados sobre todos os níveis da cadeia trófica.

\subsection{TEORIA DO EQUILÍBRIO - HIPÓTESE RAZÃO RECURSO}

Competição por recursos não parece ter sido a principal causa das alterações na comunidade, exceto nos períodos em que Mougeotia ou Dictyosphaerium atingiram altas densidades, pois diminuindo a incidência luminosa podem ter causado a limitação deste recurso para os estratos inferiores da coluna d'água. $O$ fósforo também pode ter sido limitante nos períodos em que seus teores estiveram muito reduzidos, contudo, seu rápido aproveitamento pela biomassa fitoplanctônica induz a que tão logo torne-se disponível, seja imediatamente aproveitado por outros organismos.

A decomposição, nos ambientes aquáticos é mais rápida que no ambiente terrestre. A matéria orgânica produzida na zona fótica é decomposta e re-fotossintetizada duas ou três vezes antes de atingir o hipolímnio (Ohle, 1956 apud Saunders, 1976). Margalef (1983) relata que grande parte da decomposição da biomassa planctônica ocorre na própria coluna d'água e em lagos profundos os corpos das algas e de outros organismos mortos não chegam a atingir o fundo, sendo reciclados na própria coluna d'água. Ohle (1962, apud Golterman, 1976) estimou, através de experimentos com coletores de detritos, que a mineralização no epilímnio, pode atingir valores superiores a $90 \%$ da produção primária. A autólise é responsável por 20 a $30 \%$ de perda da biomassa de algas (Saunders, 1976). As células das algas têm ciclo de vida curto e seus constituintes ciclam rapidamente. Durante a lise celular os nutrientes são liberados, mas são imediatamente reabsorvidos pelas células vivas e em decorrência, geralmente não é possivel demonstrar aumento das concentrações de nutrientes dissolvidos. Esta hipótese explica porque os nutrientes não se exaurem completamente em poucos dias, através dos processos fotossintéticos (Golterman, 1976).

O zooplâncton pode chegar a remover $300 \%$ por dia da matéria orgânica de um determinado volume de água (Haney, 1973 apud Saunders, 1976), sendo que a digestão e absorção de alimento pelo zooplâncton pode ser muito rápida, chegando a valores de 20 a 35 minutos para Simocephalus sp. e 7 minutos para Eurycercus sp. (Berrie, 1976).

A reciclagem na própria coluna d'água pode ser extremamente rápida e os teores de 
fósforo dificilmente indicam, por si, o grau de trofia da água, além disto, muitas espécies de algas são capazes de armazenar este nutriente em suas células, especialmente as cianoficeas, diatomáceas e cloroficeas (Kohler e Labus, 1983). O resultado disto é que não é comum encontrar-se correlação entre teores de fósforo na água e densidade do fitoplâncton.

Kilham (1971, apud Tilman e col. 1982) demonstrou através de experimentos que com o declínio da razão Si:P a sucessão prevista para a comunidade estudada seria de Synedra $\rightarrow$ Asterionella $\rightarrow$ Fragillaria $\rightarrow$ Diatoma $\rightarrow$ Stephanodiscus e também que a necessidade de Melosira quanto aos silicatos seria maior que a apresentada por Asterionella.

Aplicando-se o teste de correlação de Spearman entre as razões de Si por P (utilizandose o valor de silício total, uma vez que não se dispõe dos valores de silicatos reativos) e os biovolumes das algas mais expressivas, encontrou-se correlações não significativas para todas as diatomáceas do ponto 1 , indicando que tal relação não foi limitante para estas algas durante 0 período total de estudo. No ponto 4 Aulacoseira granulata e Rhizosolenia eiriensis apresentaram correlações significativas negativas ( $r s=0.29 \mathrm{P}=0.03$ e $\mathrm{rs}=-0.26 \mathrm{P}=0.05$, respectivamente) com a razão Si:P, indicando que o silício pode ter sido o fator limitante para estas espécies neste ponto.

A taxa $\mathrm{N}: \mathrm{P}\left(\left[\mathrm{NH}_{4}\right]^{+1}+\left[\mathrm{NO}_{3}\right]^{-1}: \mathrm{PT}\right)$ no ponto 1 mostrou correlação negativa com Mougeotia cf. americana (rs $=-0.29 \mathrm{P}=0.03$ ) e no ponto 4 com Chlamydomonas cf. gloeophila ( $\mathrm{rs}=0.28 \mathrm{P}=0.04$ ), Coelastrum reticulatum ( $\mathrm{rs}=0.30 \mathrm{P}=0.03$ ) e negativas com Scenedesmus bijugus ( $\mathrm{rs}=-0.28 \mathrm{P}=0.04$ ), Staurodesmus cuspidatus ( $\mathrm{rs}=-0.32 \mathrm{P}=0.02$ ) e volvocales colonial $\mathrm{sp} 1$ ( $\mathrm{rs}=-0.30 \mathrm{P}=0.03$ ), porém, sempre abaixo dos níveis considerados.

A correlação apresentada por Mougeotia cf. americana, no ponto 1 , pode resultar da necessidade desta alga de teores mais elevados de fósforo, além disto podem ter sombreado a água dos estratos inferiores, inibindo o crescimento de outras espécies e assim, suas altas densidades coincidiram com teores de fósforo mais elevados. Entretanto, como a relação utilizada envolveu o teor de fósforo total, também há a possibilidade do fósforo estar incorporado à biomassa algácea, pois os valores de fósforo solúvel reativo não foram muito expressivos no mesmo período.

Coelastrum reticulatum tem sido encontrada em florações de pequenos tanques de alvenaria com peixes ornamentais e altos teores de nitrogênio (Beyruth, dados inéditos). Chlamydomonas é um gênero de algas abundante em lagoas de estabilização com altos teores de nitrogênio (Branco, 1980). Scenedesmus bijugus, Staurodesmus cuspidatus e volvocales coloniais sp1, mostraram maior dependência de teores mais elevados de fösforo, em relação a nitrogênio, no ponto 4 . No ponto 1 , as alterações decorrentes da sulfatação prejudicam as interpretações. 
A importância de cada nutriente na razão-recurso só é definitivamente estabelecida, através de experimentos cujos resultados nem sempre podem ser extrapolados para as situações de campo, em que as múltiplas variáveis interagem durante todo o tempo. A sulfatação constituiu um dos maiores problemas para esta análise, pois interfere diretamente sobre a densidade. Alia-se a isto o fato do ambiente estudado estar sujeito a outras alterações constantes, prejudicando estudos baseados na análise das respostas da comunidade às diferentes taxas de recursos, por sobrepujarem seus efeitos. Em decorrência destes fatos esta abordagem teórica não pode ser melhor desenvolvida e acrescentou menor quantidade de informação a este estudo, mas poderá ser ampliada com estes mesmos dados, detalhando-se o estudo das relações entre os recursos, separando-se os dados em lotes, pois como foi visto, a comunidade parece ter reagido em menor ou maior grau às limitações dos recursos, de acordo com as interações entre os mesmos, especificas de cada fase do ciclo sazonal.

Por outro lado, a qualidade da informação obtida a partir de dados ambientais de curto prazo, é discutível por basear-se apenas em resultados de correlações ou gráficos, sendo dificil a aplicação de outras formas de tratamento. Conforme afirma Cox (1993) o estabelecimento de uma correlação não prova a causa de um fenômeno e uma explicação não confere validade a uma causa, pois as variáveis ambientais estão sujeitas a inúmeras influências e podem interagir. As correlações entre duas variáveis de um mesmo lote de dados apenas indicam causas possiveis e as explicações originadas constituem-se em hipóteses, necessitando da confirmação experimental e de outras formas de análise de dados ambientais, como por exemplo, através da comparação entre dados temporais de longo prazo que permitam a análise de vários ciclos hidrológicos e/ou dados de várias regiões no mesmo corpo d'água.

A importância seletiva das razões entre nutrientes controlando o crescimento do fitoplâncton e até mesmo promovendo a exclusão competitiva deve ser questionada, segundo Reynolds (1992). Este autor afirma que ainda que as necessidades de nitrogênio, fósforo e carbono sejam universais entre as algas do fitoplâncton, as formas disponiveis e as quantidades ótimas diferem e portanto poderia haver tantas espécies coexistindo, quantos fossem os recursos potencialmente limitantes. A exaustão de um nutriente essencial impede a divisão celular e portanto a razão entre os nutrientes passa a não ser relevante, mas sim o valor absoluto de cada nutriente. Há algas que conseguem armazenar nutrientes e para as quais a razão entre os nutrientes disponíveis na água passa a não ser tão importante. Por fim, em ambientes enriquecidos, com reciclagem rápida, a tendência é de não haver exaustão dos nutrientes e do controle ou limitação do crescimento algáceo serem promovidos por outros fatores, na maior parte do tempo. 


\subsection{TEORLA DO NÃO EQUIĹBRIO - HIPÓTESE DO DISTƯRBIO INTERMEDIÁRIO}

A Hipótese do Distúrbio Intermediário (HDI) aplicada ao fitoplâncton deve basear-se em escalas de amostragem próximas ao tempo de geração das algas (semanais ou bissemanais), com amostragens muito regulares, durante muitos anos ou em curtos intervalos de amostragem durante alguns anos (Sommer e col., 1993). No Brasil, poucos corpos d'água foram estudados durante vários anos consecutivos.

Da represa de Guarapiranga, há levantamentos realizados pela SABESP, mas infelizmente não estão disponíveis para estudo. Já os dados da CETESB atêm-se a períodos de florações, a alguns estudos que prolongaram-se por alguns meses e a estudos regulares de parâmetros físicos, químicos e bacteriológicos apenas na área próxima à captação e nas baías dos rios Embu-mirim e Embu-guaçu e portanto não são comparáveis com este estudo.

Decidiu-se então utilizar apenas os dados levantados nesta pesquisa, aplicando-se as orientações de Sommer e col. (1993), no intuito de ampliar o conhecimento sobre a comunidade de algas nesta represa.

De acordo com a HDI e com o princípio da exclusão competitiva de espécies, qualquer evento que interrompa o direcionamento para uma exclusão eventual é considerado distúrbio. Geralmente os distúrbios seriam reconhecidos pelo decréscimo da biomassa fitoplanctônica e provavelmente pelo aumento na disponibilidade de recursos.

Como indicadores de distúrbios Sommer e col. (1993) também aconselham a utilização de alterações na profundidade da mistura e eventos como o vento e o resfriamento. Estes pesquisadores afirmam que para lagos não estratificados, como é o caso de Guarapiranga, a identificação dos distúrbios é mais problemática e que alterações de algumas variáveis ambientais como a transparência e a turbidez, e de variáveis biológicas, como a contribuição de espécies não planctônicas, por exemplo, podem indicar distúrbios físicos.

Nos periodos com maior pluviosidade o aporte de algas relacionadas ao perifiton, como Mougeotia cf. americana, Mougeotiopsis spl e zigotos de Oedogoniales, para a água aberta, foi maior, mostrando a alta taxa de mistura da água. A pluviosidade associada ao regime eólico, induz à ocorrência de um distúrbio fisico, importante a ser considerado no estudo da estrutura deste ambiente, produzindo alterações mais efetivas e duradouras que a sulfatação.

Para identificar uma fase de equilíbrio Sommer e col. (1993) aconselham, na prática, que se verifique períodos em que: uma, duas ou três espécies contribuíram com $80 \%$ ou mais da biomassa total da amostra; sua existência ou coexistência persistiu por tempo suficiente, ou seja, mais que uma ou duas semanas; durante este periodo a biomassa não decresceu significativamente. 
Atendidos estes requisitos esta fase pode ser considerada de equilibrio.

Considerando-se como períodos de estabilidade aqueles em que pelo menos duas coletas consecutivas apresentassem as três espécies mais representativas, atingindo biovolume igual ou superior a $80 \%$ da amostra, ambos os pontos apresentaram 17 coletas obedecendo a este critério. Portanto, em $30 \%$ das coletas haveria condições de estabilidade da comunidade, segundo o conceito de Sommer e col. (1993).

De acordo com os critérios mencionados foi possível distinguir, no ponto 1 , as seguintes fases:

1. fase inicial entre MA2 e $\mathrm{LL} 10$, de instabilidade, indicada por quedas significativas da biomassa, com aplicação de sulfato de cobre entre MA2 e J4.

2. fase de equilibrio (senso Sommer e col., 1993) com quatro coletas consecutivas, JL11 a AG14 sem queda de biomassa, tendo Chlamydomonas cf. gloeophila, Asterionella formosa e Aulacoseira granulata contribuindo para os $80 \%$ da biomassa total das amostras, interrompida entre AG15 e S18 por instabilidade relacionada a quedas significativas da biomassa associada à sulfatação - em AG14 e AG15 foi aplicado sulfato neste ponto. Houve retomada das condições de equilíbrio, com as mesmas espécies prevalecendo entre S19 e 021. De AG16 a S20 não foi aplicado sulfato de cobre, portanto a comunidade recuperou suas características anteriores de dominância, decorridas três semanas à partir da aplicação.

3. fase de instabilidade entre $\mathrm{O} 22$ e 024 , com queda significativa na biomassa, por efeito da aplicação de sulfato entre $\mathrm{O} 21$ e $\mathrm{O} 24$ e com variação na dominância.

4. fase de equilibrio, com quatro coletas entre $\mathrm{N} 25$ e N28, sem quedas expressivas na biomassa, sem aplicação de sulfato, com Dictyosphaerium prevalecendo, interrompida em N29 e D30 por queda da biomassa associada à aplicação de sulfato um dia antes da N29, e novamente a retomada das condições de equilibrio anteriores entre D31 e D33 com Aphanocapsa. Em D30 e D31 não foi aplicado sulfato de cobre, mas de D33 a MA50 a sulfatação foi constante e elevada.

5. fase de instabilidade entre JA34 e JA36, com variação nas espécies predominantes, com aplicação de sulfato entre D33 e JA35, embora sem quedas significativas da biomassa.

6. fase de equilibrio entre JA37 e F40, com Mougeotia cf. americana prevalecendo, sem quedas na biomassa, embora a aplicação de sulfato iniciada em D32, tenha sido mantida até MA50.

7. fase de instabilidade, com alterações significativas da biomassa e variação nas espécies predominantes à partir de F41 e conforme mencionado, com aplicação de sulfato até MA50.

No ponto 4 , não houve caso de equilibrio, pois embora tenham ocorrido periodos de 
estabilidade quanto à biomassa, nestas oportunidades, as espécies predominantes não permaneceram as mesmas ou não atingiram porcentagens de dominâncias compativeis.

Desta análise conclui-se que no ponto 1 , a aplicação de sulfato de cobre interrompe fases de equilibrio e quando não é muito prolongada, tão logo se encerre, o equilibrio anterior é retomado, com aumento da biomassa e predominância das mesmas espécies, portanto a aplicação de sulfato comportou-se como um distúrbio não drástico e contribuiu para a ocorrência de processos de reversão. No ponto 4 , devido às condições instáveis, promovidas pelo fluxo horizontal mais intenso, não houve oportunidade para ocorrências prolongadas de equilibrio na comunidade. Esta suposição poderia ser confirmada através de avaliações da intensidade e direção do fluxo, nesta região, que não foram possíveis durante este estudo.

Esta análise demonstrou maior eficiência que a baseada na competição por recursos, fornecendo mais informação e explicações de interesse prático para este estudo.

\subsubsection{HOMOGENEIDADE DO NƯMERO DE ESPÉCIES E DA TAXOCENOSE}

A comunidade fitoplanctônica apresentou heterogeneidade quanto ao número de táxons e mais que uma taxocenose envolvida, como seria de esperar para o conjunto total de dados de cada ponto de coleta. Na busca de identificar os grupos de algas ou os períodos em que as condições ambientais permitiram que a comunidade estabelecida fossem homogênea quanto ao número de táxons e houvesse apenas uma taxocenose envolvida, os dados ambientais foram separados em lotes, utilizando-se como critério de separação os fatores mais marcantes: sazonalidade e aplicação de sulfato de cobre. Quanto à comunidade fitoplanctônica separou-se as espécies de algas nos grupos taxonômicos.

Para o ponto 1 eliminando-se as coletas em que houve aplicação de sulfato de cobre, foi possível remover a heterogeneidade das criptoficeas, o mesmo ocorrendo para zignemaficeas indicando que o fator que mais influiu na alteração das comunidades destas algas foi a sulfatação.

O critério adotado para separação dos dados, baseado na pluviometria e na sulfatação não foi suficiente para indicar ocorrência de homogeneidade para as clorococales em nenhum período no ponto 1 , bem como a de centrales (durante os períodos de chuvas moderadas e da segunda seca), penales (durante os dois períodos de seca) e no ponto 4 a de clorococales (durante os períodos de chuva e na segunda seca), volvocales (durante as chuvas moderadas e a segunda seca), euglenoficeas (durante o segundo período de seca) e zignemafíceas (durante o primeiro período de seca).

Uma comunidade de clorococales tão rica em espécies, diversificada em estratégias 
adaptativas, capacitada a superar gradientes temporais de condições ambientais inóspitas através de alterações rápidas da comunidade, como a da Guarapiranga, torna difícil a identificação de períodos de homogeneidade, pois pode responder a fatores mais específicos do que aqueles que restringem o desenvolvimento de comunidades menos ricas. A aplicação deste teste ao fitoplâncton de um lago marginal ao rio Embu-mirim nesta mesma bacia hidrográfica, mostrou que a comunidade de cloroficeas tornava-se homogênea pela remoção dos dados das comunidades de pontos que continham macrófitas, Beyruth (1989), exemplificando alteração da comunidade decorrente dos efeitos da presença de outras comunidades. Pelos motivos expostos neste ambiente, as clorococales não podem ser tratadas como um grupo sistemático constituído por um conjunto de espécies de requisitos ambientais semelhantes.

Os demais grupos, ao menos em dois periodos sazonais, mostraram comunidades homogêneas em relação ao número de espécies e à taxocenose presente, indicando que a sazonalidade teve realmente um efeito pronunciado na comunidade algácea.

As heterogeneidades remanescentes devem-se portanto, aos fatores que não a sazonalidade ou a sulfatação e demandam outros critérios de análise para sua investigação, devendo tornar-se objeto de investigação futura.

\subsubsection{ESTABILIDADE DA COMUNIDADE}

Segundo Margalef (1991), uma população ou comunidade é estável desde que flutue pouco, dentro de limites próximos. Estabilidade é portanto uma característica descritiva das populações.

Um ecossistema estável mantém os níveis de produção e de biomassa, ainda que para isto, a proporção das diferentes espécies que o formam tenha que se alterar continuamente. A estabilidade como sinônimo de persistência complementa a diversidade pois proporciona uma medida da "organização" do sistema.

De acordo com a capacidade do ambiente em manter-se estável, os sistemas podem ser classificados em lábeis (adaptáveis) e conservativos (persistentes). Os ecossistemas com maior energia, onde a relação produção por biomassa é mais alta, em geral são mais flutuantes ou adaptáveis e menos persistentes de acordo com Margalef (1991). Quanto mais freqüentes as flutuações na estabilidade, menor a oportunidade das espécies desenvolverem populações limitadas por recursos, interagirem com outras espécies ou para a comunidade atingir alguma condição estável de equilibrio. Apenas quando a freqüência de alteração da estabilidade aproxima-se ou é menor que o tempo de geração das algas (em lagos de águas tépidas durante a circulação e com ciclos diuturnos de re-estratificação), a composição de espécies se 
acomoda, mais do que responde aos ciclos de mistura (Reynolds, 1987).

Pimm (1984, apud Payne, 1986) afirma que dois aspectos importantes da estabilidade a serem considerados são a resiliência e a persistência do sistema. Resiliência pode ser definida como a taxa com que as alterações ambientais são absorvidas pela comunidade e o equilibrio original é recuperado. A persistência é o tempo em que uma variável permanece, antes que seja alterada para um novo valor.

A curto prazo, as espécies fitoplanctônicas são pouco persistentes devido ao ciclo de vida curto e a comunidade responde a alterações ambientais não catastróficas e de curta duração, pela alteração na composição e abundância das espécies. Em regiões tropicais, as espécies podem ser menos persistentes que em regiões temperadas, pois as alterações ambientais podem ser mais freqüentes durante o ano, e muitas vezes menos previsíveis. A longo prazo entretanto, as perturbações no fitoplâncton são consideradas cíclicas, de tal forma que não necessariamente impliquem em alterações irreversiveis (Payne, 1986). Para Guarapiranga, se as alterações sofridas pelo ecossistema nas últimas décadas não houvessem sido drásticas, seria esperado que durante a repetição do ciclo sazonal, algumas características da comunidade se repetissem.

Indícios de resiliência, a um prazo mais longo poderiam ser obtidos comparando-se a variação sazonal das espécies dominantes relatadas por Kleerekoper (1939), Rocha (1984), Xavier e col. (1985) e Pereira (1987). O trabalho de Pereira (1987) foi realizado até o nível de gênero, o mesmo ocorrendo com o efetuado por Rocha (1984). Dadas as dificuldades relatadas por Kleerekoper, sobre a determinação das espécies existentes naquela época e que em parte perduram até hoje, esta comparação fica muito prejudicada. Constata-se, mais uma vez, a necessidade de estudos taxonômicos dos corpos d'água do Estado de São Paulo, uma vez que mesmo para Guarapiranga, uma das represas mais importantes para a cidade de São Paulo, não havia até este trabalho, estudos taxonômicos da flora algácea até o nível de espécies.

A represa de Guarapiranga sofreu alterações profundas devido aos impactos antrópicos a que tem sido submetida desde o estudo efetuado por Kleerekoper (1939), que podem ser constatadas através da alteração de sua comunidade fitoplanctônica

No conjunto de espécies identificadas até este nivel no estudo atual e que também foram relatadas por Kleerekoper estão: Eudorina elegans, Dinobryon sertularia, Dinobryon divergens, Closteriopsis longissima, Kirchneriella lunaris, Scenedesmus bijugus, Golenkinia paucispina e Coelastrum cambricum. Kleerekoper (1939) relata que Peridinium willei dominou durante os dois anos de suas observações, no periodo entre novembro e março e 
Dinobryon sertularia entre maio e junho. Neste estudo também observou-se domínio de Dinobryon porém apenas em setembro.

No trabalho de Xavier e col. (1985) não foram registradas as espécies encontradas no estudo atual, pois a maior parte da pesquisa foi realizada até o nível de gênero; estes autores relatam maiores densidades em março e novembro (20035 e $1008 \mathrm{em}$ org. $\left.\mathrm{I}^{-1}\right)$ e as menores em junho e agosto (384 e 314 em org. $1^{-1}$ ), com dominância de Anabaena em março, Melosira e Mougeotia em junho, Anabaena, Peridinium e Melosira em agosto e Rhizosolenia, Melosira e Anabaena em novembro. No estudo atual, Anabaena não atingiu dominância e os períodos de dominâncias dos demais gêneros mencionados, não corresponderam aos deste estudo.

Estas comparações, embora utilizando dados obtidos através de metodologia e periodicidade diferentes, mostram que as condições também foram diferentes das encontradas atualmente, provavelmente devido à crescente eutrofização e alteração da qualidade da água, não sendo perceptíveis semelhanças acentuadas nos padrões de recorrência da dominância.

Alguns indícios atuais de resiliência a curto prazo, neste ecossistema, puderam ser identificados através do retorno à comunidade amostrada, de espécies de Rhizosolenia, Chlorella e Scenedesmus que foram registradas no início e no final do ciclo deste estudo, no rol das espécies mais expressivas; embora o período total tenha sido muito reduzido para uma análise mais aprofundada. Outro indício foi a semelhança mencionada, encontrada para o comportamento das variáveis ambientais verificadas pelos resultados da análise de componentes principais, entre coletas das secas de 1991 e 1992, em ambos os pontos.

$O$ índice de persistência que está sendo proposto embora não obedeça a definição estrita de persistência do sistema: "a persistência é o tempo em que uma variável permanece antes que seja alterada para um novo valor" (Pimm, 1984 apud Payne, 1986), trata da persistência das espécies no sistema durante um período determinado de estudo. Sua elaboração surgiu da necessidade de verificar qual grupo de algas conseguiria sobreviver durante um maior periodo às forçantes de alterações ambientais atuantes nesta represa. Esta informação mostra-se importante pois, supondo-se por exemplo que as cianoficeas fossem as algas mais persistentes nesta represa, o risco da utilização destas águas para abastecimento, seriam maiores; além disto o custo do tratamento pode aumentar com a persistência de qualquer grupo problemático para o tratamento de água para abastecimento. Esta análise é possivel, pois as algas têm ciclo de vida curto, permitindo a avaliação da persistência das espécies em tempo hábil. Para outros grupos vegetais, ou mesmo animais de ciclo de vida mais longo, isto seria possível apenas através de outros tipos de registros, como fósseis ou evidências espaciais, conforme mencionado anteriormente. Os dados deste trabalho permitem este tipo de análise pois, a 
identificação taxonômica foi realizada até o nível de espécie e as coletas tiveram freqüência compatível permitindo o acompanhamento da maior parte das alterações da comunidade que ocorreram durante o ciclo sazonal estudado.

Quanto à persistência das espécies no conjunto amostral total do ponto 1 , penales, volvocales, clorococales e criptoficeas mostraram comunidades mais conservativas nas 56 coletas, acima do valor médio total, enquanto crisoficeas, dinoficeas e zignemaficeas mostraram as menores porcentagens médias por espécie na comunidade.

No ponto 4, criptoficeas, centrales, volvocales, penales e clorococales mostraram porcentagens superiores ao valor médio total quanto à capacidade de conservarem suas espécies no ecossistema, durante o período total de estudo. As zignemaficeas, euglenoficeas, dinoficeas e crisoficeas representaram as porcentagens inferiores.

A maior persistência de criptoficeas em ambos os pontos pode estar associada ao favorecimento de espécies oportunistas, r-estrategistas neste ecossistema. Para a persistência das clorococales também vale a explicação apresentada para as r-estrategistas pois grande parte das espécies apresenta esta estratégia na maior parte do tempo, além disto as espécies dos gêneros Chlorella, Crucigenia, Dictyosphaerium e Scenedesmus mostraram elevada frequiência de ocorrência. As volvocales, por sua motilidade, tem persistência favorecida em ambientes com menor transparência, sendo que penales também podem ter sua persistência sustentada por aportes de indivíduos do perifiton, especialmente durante chuvas intensas. As centrales são favorecidas em ambientes com elevada turbulência, conforme mencionado anteriormente.

A persistência das espécies no ponto 1, foi maior durante o período de seca, periodo este em que a aplicação do sulfato de cobre foi reduzida. Foi maior ainda durante o período de aplicação de sulfato e mesmo durante o período em que as aplicações se intensificaram, uma vez que durante as chuvas intensas esteve mais elevada que a média total deste ponto. Estes resultados indicam que as espécies presentes eram resistentes ao sulfato de cobre e/ou a eficiência da sulfatação pode ter sido obstada pela diluição. Além disto, algas provenientes do perifiton poderiam ter sido recrutadas ou permanecido por mais tempo na água aberta, devido a indução de sua mobilização pelos efeitos da elevada intensidade pluviométrica. A persistência média das espécies diminuiu no início das chuvas e foi aumentando até o final das coletas. No ponto 4, foi semelhante entre chuvas e seca, aumentando do início para o final das amostragens.

Entre os grupos sistemáticos considerados no ponto 1, penales destacou-se pelas elevadas porcentagens de persistência que só foram reduzidas durante as chuvas, moderadas e 
intensas com aplicação de sulfato de cobre. Apresentaram as mais elevadas porcentagens de ocorrência, no ponto 1: Synedra cf. minuscula (84\%) e Synedra ulna t1 (66\%).

No ponto 4 , destacaram-se as criptoficeas por sua elevada capacidade de persistência no sistema, apresentando elevada porcentagem de ocorrência: Cryptomonas cf. brasiliensis (73\%) e Cryptomonas cf. tenuis (48\%), e volvocales, especialmente durante as chuvas, das quais destacaram-se: Chlamydomonas cf. gloeophila $\mathrm{t} 1$ (75\%) e Chlamydomonas cf. gloeophila t2 $(54 \%)$.

$\mathrm{O}$ indice de persistência proposto considera apenas a presença da espécie, porém segundo Padisák (1992) e Pollingher e col. (1988 apud Sommer 1993), mesmo a escassez extrema quanto a densidade, não previne as espécies de tornarem-se dominantes. A elevada persistência de diatomáceas no ponto 1 indica que a obstrução de filtros por estas algas é um risco constante, pois suas densidades podem elevar-se para níveis prejudiciais tão logo as condições favoreçam seu desenvolvimento, o que já tem ocorrido no inverno em anos anteriores, conforme mencionado no capítulo Introdução.

Cianoficeas apresentaram alta porcentagem de persistência, no ponto 4 , nos períodos de chuvas intensas destacando-se a espécie Synechococcus elongatus pela elevada porcentagem de ocorrência (32\%).

Várias espécies de clorococales apresentaram porcentagem de ocorrência elevada, superior a 50\% das coletas, assim como a zignemaficea Mougeotia cf. americana para o ponto 1 e a bacilarioficea Rhizosolenia eiriensis para ambos os pontos. Clorococales e zignemaficeas, por apresentarem maior número de táxons, apresentaram persistência média relativa pouco elevada, devido aos cálculos para persistência basearem-se no conjunto de cada grupo sistemático.

Análises processadas sobre a persistência das espécies fitoplanctônicas considerando presença-ausência das espécies, não foram encontradas na literatura consultada e desta forma a discussão atém-se apenas aos resultados encontrados, indicando a necessidade de aprofundar este tipo de abordagem em investigações futuras. O trabalho de Padisák (1992) também mostra a preocupação de determinar a persistência do inóculo, mas trata-se de um cálculo que envolve avaliações quantitativas, e por isso mais trabalhosas. Aquela autora chega a conclusão de que a simples presença da espécie já seria suficiente para determinar a persistência do inóculo. Este método tentativo acrescenta informação, podendo ser testado quanto à sua utilidade, especialmente nos estudos sobre ambientes impactados e/ou sujeitos à controle algáceo. 


\subsection{ANÁLISE INTEGRADA: COMPONENTES PRINCIPAIS (VARIÁVEIS AMBIENTAIS) E ESPÉCIES MAIS REPRESENTATIVAS DA COMUNIDADE FITOPLANCTÔNICA}

A configuração expressa através da análise dos componentes principais mostrou que os fatores climáticos, de operação da represa e sua biomassa fitoplanctônica orientaram as relações entre os fatores ambientais estudados. Para os dois pontos de coleta o primeiro componente representou o gradiente entre os períodos de seca (concentração) e chuvas (diluição, ou maiores aportes de material e energia) e o segundo componente representou o gradiente entre a baixa (águas claras) e a alta produtividade primária.

A análise dos componentes principais, evidencia relações anteriormente verificadas na análise sazonal e das correlações, mas acrescenta à discussão, a conclusão de que em ecossistemas aquáticos submetidos à degradação, por aportes orgânicos e inorgânicos da bacia de drenagem, a contraposição chuva e seca adquire importância especial, magnificando a degradação dos ambientes terrestres e seus efeitos para os aquáticos.

Comparando-se a delimitação de períodos sazonais com os resultados da análise multivariada integrados aos das espécie que atingiram valores mais expressivos de frequiência relativa, observa-se novamente que em alguns períodos a alteração da dominância ocorreu entre uma e duas semanas após a alteração climatológica mais expressiva, indicando que a comunidade, conserva suas características anteriores por algum tempo antes que a resposta às alterações ambientais, geradas pelas alterações climáticas possam ser detectadas. Esta informação sobre o comportamento do fitoplâncton e da qualidade da água é interessante para subsidiar medidas de manejo ambiental e pode ser utilizada para prevenir alterações de crescimento indesejáveis. As respostas dinâmicas das espécies individuais são aparentemente relacionadas às suas caracteristicas morfológicas e funcionais, enquanto as respostas da comunidade tendem a ser tardias, dependendo do estabelecimento das dominâncias pelas espécies selecionadas (Reynolds, 1987). 


\subsection{ASPECTOS SANITÁRIOS}

A investigação das condições sanitárias dos ecossistemas aquáticos é de suma importância, pois as águas são o reduto final dos produtos dos processos desenvolvidos nas suas bacias hidrográficas, quer sejam de origem antrópica ou não. Estes produtos alteram tanto a qualidade de vida dentro do ecossistema aquático, interferindo em sua capacidade biogênica, quanto os usos da água pelos seres terrestres, inclusive o homem.

Represas de abastecimento, merecem atenção especial quanto aos aspectos sanitários, por terem a qualidade de suas águas imediatamente vinculada à qualidade de vida dos usuários.

\subsubsection{QUALIDADE ABIÓTICA DA ÁGUA}

A qualidade da água da represa de Guarapiranga mostra os efeitos da eutrofização acelerada, que já havia iniciado em 1934, quando Kleerekoper (1936) realizou seu estudo e teve um grande aumento nestas últimas décadas.

No ponto 1 , a aplicação de sulfato de cobre além de restringir o desenvolvimento algáceo, restringe os organismos decompositores como bactérias e fungos (Damato e col. 1989).

Existe atualmente um impasse quanto às medidas de recuperação da bacia, pois se os esgotos forem desviados para tratamento e o produto posteriormente for descartado para corpos d'água de outras bacias hidrográficas, grandes volumes de água deixarão de retornar à esta represa, diminuindo sua capacidade como manancial.

Reverter o quadro de urbanização atual é praticamente inviável, não havendo local nem meios para deslocar e reassentar a população humana já estabelecida na bacia.

Assim o convívio com as condições atuais deve perdurar enquanto não forem aplicadas tecnologias de reabilitação abrangendo a exportação ou remoção eficiente de nutrientes, tanto dos esgotos gerados, como das águas da própria represa.

Outro problema a ser considerado além da eutrofização são os altos teores de ferro, alumínio e cobre na água que segundo CETESB (1992), também ocorre nos sedimentos. Os metais como o cobre, alumínio e ferro têm influência negativa sobre o desenvolvimento algáceo, mas também para outros organismos e teores elevados são objetáveis por causarem danos aos ecossistemas aquáticos e também à saúde humana (Damato e col. 1989).

O cobre é um micronutriente necessário às algas, sendo inclusive utilizado para produzir meios de cultura. A estabilidade do cobre na água depende da dureza, alcalinidade, conteúdo de matéria orgânica e silte na fração coloidal, que determinam a velocidade de sedimentação 
(Riemer e Toth, 1970). Em doses elevadas geralmente sob a forma de sulfato de cobre, é utilizado como algicida, segundo Mackenthun e Ingram (1967).

O ferro é indispensável à vida vegetal (Dussart, 1966). Em águas naturais geralmente ocorre sob a forma de suspensões coloidais parcialmente adsorvidas a partículas vivas, por exemplo Trachelomonas; ou inertes do seston. Algumas cianoficeas produzem siderocromos ferro-específicos e sua abundância pode determinar competições interespecíficas pelas fontes disponiveis de ferro. Segundo Reynolds (1993) também é utilizado como ingrediente para meios de cultura algácea.

Não se conhece a necessidade das algas quanto ao alumínio, segundo Lund (1965). Porém o ferro e o alumínio participam de eventos de complexação e trocas com o fósforo do sedimento dos lagos, especialmente no hipolímnio anóxico, segundo Reynolds (1993).

As concentrações de cobre neste estudo mostraram-se superiores aos recomendados pela legislação (0.02 mg. $\left.\mathrm{l}^{-1}\right)$ para águas das classes de água 1 e 2 (CONAMA-20/86): no ponto 1 , em 41 das 56 coletas ( $73 \%$ ) e no ponto 4 , em 37 coletas ( $66 \%$ do período de estudo) com teor máximo de $0.09 \mathrm{mg} \cdot \mathrm{l}^{-1}$.

Os teores de alumínio recomendados pela legislação (CONAMA-20/86) de $0.10 \mathrm{mg} . \mathrm{l}^{-1}$ para águas das classes 1 e 2, foram ultrapassados, no ponto 1 em 15 coletas (27\% do período estudado) e no ponto 4 em 6 coletas (11\%), com máximo de $0.3 \mathrm{mg}^{-1}{ }^{1}$ registrado no ponto 4 em JA36, na época das chuvas. Beyruth e col (no prelo) encontraram teores mais elevados na primavera e verão quando a pluviosidade foi elevada e o metal pode ter sido carreado da bacia de drenagem, especialmente do solo exposto de áreas recém-desmatadas próximas ao ponto 4 . Entretanto não é possível descartar a hipótese da existência de outras fontes, sendo necessário pesquisar esta possibilidade.

O tratamento convencional da água para abastecimento em São Paulo, não remove o excesso de alumínio e este metal também é utilizado para coagulação durante o tratamento da água. Segundo Martyn e col. (1989) há 40 a 50\% de probabilidade de que a concentração deste metal aumente acima das concentrações originais durante o tratamento da água.

Concentrações elevadas de alumínio na água ingerida ou injetada durante diálise tem sido relacionadas à ocorrência do mal de Alzheimer e à encefalopatia por diálise em seres humanos, segundo Miller e col. (1984) e Martyn e col. (1989), devendo ser evitadas, conforme mencionado anteriormente. Deposições de alumínio e manganês têm sido encontradas durante autópsias, no córtex cerebral de vítimas do mal de Alzheimer e outras demências precoces, segundo os mesmos autores e Cooke e Gould (1991). Estes últimos, em sua revisão sobre os efeitos do alumínio, relatam que este metal parece não ser necessário para sustentar a vida e 
que sua neurotoxicidade foi claramente demonstrada para animais. Estes autores consideram que a exposição a este metal é incrementada pelo uso de utensílios de alumínio, principalmente para cozimento de alimentos ácidos, ou em embalagens de alimentos ou bebidas, que sob certas condições podem contribuir para sua ingestão (recipientes danificados ou em que o metal mantenha contato direto com o conteúdo, especialmente de refrigerantes e outras bebidas ou alimentos contendo p.ex. ácido fosfórico); que a exposição ao alumínio, através do contato com o ar contaminado, pode ser maior em áreas urbanizadas ou industrializadas; há aumento da mobilização do alumínio, do solo para o ambiente aquático, com a acidificação e que o alumínio é utilizado comercialmente para melhorar a aparência de certos alimentos. Portanto, estes acréscimos de contato, incrementados por hábitos recentes da população humana, indicam a importância de evitar-se a exposição a este metal.

$\mathrm{Na}$ Guarapiranga os efeitos da degradação ambiental, incluem o risco de que grandes aportes de alumínio e manganês do solo exposto da bacia de drenagem alcancem a água, tornando-a imprópria para o consumo. $\mathrm{O}$ desenvolvimento de doenças crônicas neurológicas demenciais em seres humanos, implica em custos sociais e econômicos elevadíssimos para os sistemas públicos de saúde. A ocorrência destes metais em doses elevadas nas águas de abastecimento deve portanto ser evitada, impedindo-se o seu lançamento nas águas ou seu carreamento do solo exposto da bacia. A cobertura com vegetação das áreas expostas deve ser uma das prioridades mais urgentes de qualquer programa de reabilitação da qualidade ambiental de represas de abastecimento.

Os teores de ferro, recomendados pela legislação (CONAMA-20/86), de $0.30 \mathrm{mg}^{-1}{ }^{-1}$ para águas das classes 1 e 2 foram ultrapassados no ponto 1 , em 14 coletas e no ponto 4, em 3 coletas, com máximo 0.70 mg.l-1, registrado no ponto 4 em MA2, na época da seca.

Segundo Klapper (1991), o ferro e o manganês, os metais mais comuns nas águas naturais, atuam como agentes combinatórios para o fósforo, sendo que o ferro ferroso (divalente) é importante por sua toxicidade para peixes.

Havendo grande quantidade de ferro e manganês nos sedimentos, se o ambiente tornarse anaeróbico - situação freqüente em ocasiões de grandes colapsos algáceos - estes metais são liberados dos sedimentos para a água e com eles o fósforo e os metais pesados que a ele possam estar combinados, pois muitos metais traço, alguns tóxicos, são adsorvidos pelo hidróxido de ferro e com ele co-precipitam.

Estas ressurgências acrescentam fósforo novamente à água, em grandes quantidades de uma só vez o que pode ser uma das explicações para a reincidência de florações algáceas, nos ambientes eutrofizados. 


\subsubsection{ESPÉCIES INDICADORAS DA QUALIDADE AMBIENTAL}

Geralmente as avaliações ambientais tem por objetivo preservar a qualidade de vida, sendo assim, os melhores indicadores da saúde dos ecossistemas são os próprios seres vivos.

De acordo com o conceito convencional de indicador biológico, a alta porcentagem de uma espécie num determinado ambiente, correlaciona-se aos fatores ambientais que mais favorecem seu desenvolvimento.

As espécies de algas variam quanto à sensibilidade aos fatores ambientais abióticos e bióticos $\mathrm{e}$ as mais resistentes às alterações ambientais particulares (causadas tanto por alterações naturais, como pelas atividades antrópicas) podem ter seu desenvolvimento favorecido. Estas espécies podem ser utilizadas como indicadoras da qualidade da água (Rocha, 1992).

A necessidade de efetuar ou complementar avaliações da qualidade dos ambientes aquáticos levou a elaboração de sistemas que utilizam indicadores biológicos de poluição dos ambientes aquáticos, destinados a subsidiar ações de controle e manejo ambiental.

Vários autores (Patrick, 1953; Edwards e col. 1972; Brook, 1950; Nygaard, 1949; Thunmark, 1945; UNESCO/EH, 1978 apud Rocha, 1992) e Sládecek (1973); Van Dam e col. 1994), entre outros, desenvolveram sistemas de indicadores biológicos, com maior ou menor grau de detalhamento, utilizando diferentes niveis taxonômicos (classes, ordens, gêneros, espécies), como indicadores do estado trófico, sapróbico ou da qualidade ambiental. Estes sistemas podem ser criticados à exaustão, porém tratam-se de ferramentas necessárias, que necessitam de aprimoramento e atualização constantes. Sua importância reside na utilização da biota na avaliação qualitativa e quantitativa do ambiente, baseando-se em dados ambientais e experimentais de diversos autores.

Os distúrbios ambientais não são essecialmente deletérios, pois as perturbações freqüentemente são essenciais para a manutenção do vigor e da saúde dos ecossistemas. Entretanto vários ecossistemas têm sofrido deterioração severa, como resultado direto ou como produto das atividades humanas (Rapport, 1992).

As avaliações sanitárias servem para subsidiar ações de manejo e recuperação ambiental destinadas a beneficiar e proteger a qualidade de vida, de forma a garantir a continuidade dos recursos naturais, bem como sua exploração para manutenção das atividades antrópicas. Nos países em desenvolvimento, estas avaliações passaram recentemente a ser objeto de exigência da legislação e têm como características principais a limitação dos recursos financeiros e prazos de análise extremamente restritos. Geralmente baseiam-se em levantamentos superficiais da qualidade ambiental, pois é comum não haver dados prévios sobre os ambientes a serem 
avaliados. Considerando-se estas restrições, nas análises exploratórias é necessária a utilização de todas as informações relevantes e os métodos de análise disponíveis devem ser conciliados, na intenção de obter um conhecimento mais amplo.

A avaliação sanitária deve produzir o diagnóstico da saúde do ambiente, determinar os possiveis problemas e suas causas e prescrever o tratamento, para tentar recompor a estrutura física, química e biológica do ambiente (Rapport, 1992). Como na medicina, a ênfase deve ser dada à prevenção dos distúrbios graves à saúde dos ecossistemas, especialmente devido às limitações de compreensão científica, às impossibilidades técnicas e ao elevado custo econômico, bem como ao tempo dispendido que envolvem a recuperação ou reabilitação dos ambientes aquáticos já degradados, quando possíveis. Além disto, deve-se considerar a importância destas avaliações serem realizadas de forma objetiva, através de metodologia científica e de proverem valores de julgamento, ou seja indicadores mensuráveis confiáveis e respostas reprodutíveis.

Os principios da otimização em ecologia, independente da elegância do aparato matemático, não são capazes de compensar premissas simplistas acerca dos processos evolutivos, dos comportamentos humanos e dos ecossistemas (Rapport, 1992).

As sindromes que afligem os ecossistemas aquáticos envolvem os seguintes sintomas: alteração na estrutura da comunidade biótica, favorecendo formas menores; redução na diversidade de espécies; aumento da dominância por espécies r-selecionadas; aumento da dominância por espécies exóticas; diminuição da extensão da cadeia trófica; redução da produtividade primária e secundária; aumento da prevalência de doenças; redução da estabilidade das populações; perda de espécies sensiveis; aumento da circulação ambiental dos contaminantes; perda de nutrientes (Rapport, 1992). Este autor comenta o progresso na identificação de componentes sensiveis do ecossistema, afirmando que ecossistemas aquáticos estudados em larga escala, como os Grandes Lagos nos Estados Unidos, mostraram que a presença de certas espécies sugere o estado geral de saúde e inversamente sua ausência sugere a degradação do ecossistema. Este autor ressalta que a abordagem de espécie como indicador tem a vantagem de reduzir a lentidão da deteç̧ão da resposta global do ecosistema ao distúrbio, dando atenção às respostas mais rápidas das espécies.

A definição de saúde de um ecossistema engloba a redução do risco e aumento da probabilidade de sobrevivência, que implica em estabilidade ou habilidade do ecosistema atingir um ponto de equilibrio e de contrabalançar distúrbios. Um ecossistema saudável deve ter alto nivel de biodiversidade, produtividade e habitabilidade (IUCN/UNEP/WWF, 1990 apud Chapman, 1992), deve permitir a existência de habitats e fluxo de energia e matéria 
adequados para sustentar biocenoses apropriadas para a eco-região particular (Ross, 1992 apud Chapman, 1992).

Chapman (1992) propõe os seguintes enfoques genéricos para determinar a saúde dos ecosistemas: a presença, ausência ou condições das múltiplas espécies; a persistência do habitat e a continuidade normal da sucessão. Em nenhum caso os resultados destas medições podem ser reduzidos a um único número pois a incerteza e variabilidade inerentes, tanto nos ecossistemas como nos métodos de mensuração requerem uma ampla gama de valores.

Para proteger a saúde dos ecossistemas é necessário compreender a resposta, adaptação e recuperação do ecossistema e os componentes chave do ecossistema em face dos distúrbios que incluem os impactos antropogênicos (Chapman, 1992).

A distribuição das espécies no ambiente reflete aspectos da variação da qualidade ambiental e esta caracteristica é explorada no conceito dos indicadores biológicos.

As algas são muito importantes como indicadores do estado trófico, sendo a melhor opção para estudos de enriquecimento nas águas abertas, por serem a comunidade que melhor expressa estes acréscimos, além disto, sua tolerância à poluição orgânica está bem documentada na literatura (Patrick, 1954; Fjerdingstad, 1964, 1965; Palmer, 1969 apud Hellaweil, 1989). Porém não são tão eficientes como indicadores de poluição por pesticidas e metais pesados. Ao lado dos macroinvertebrados, as algas constituem o grupo mais utilizado como indicadores biológicos das condições ambientais dos ambientes aquáticos.

No nível de individuos e populações, muitos organismos apresentam respostas anatômicas $\mathrm{e}$ fisiológicas às condições ambientais. No nivel da estrutura da comunidade poucos métodos de rotina de monitoramento utilizam critérios de presença ou ausência de espécies individuais, a maior parte utiliza a composição da comunidade e provê bases comparativas entre ambiente não alterado e alterado. A forma típica da curva log-normal da estrutura da comunidade apresenta um achatamento indicando redução na abundância de algumas espécies sensiveis e raras, bem como uma extensão da curva que representa um aumento do número de algumas poucas espécies insensiveis que passam a dominar a comunidade. As modificações estruturais geralmente são acompanhadas por alterações funcionais (Hellawell, 1989).

Há ainda os indicadores bioacumulativos, que podem magnificar em suas células, elementos nutritivos ou poluentes que estejam em doses sub-letais na água.

As características de um indicador biológico ideal, segundo Hellawell (1989), são: ser prontamente identificável, pois incertezas taxonômicas podem causar confusões na interpretação dos dados; ser amostrado facilmente para análises quantitativas; apresentar 
distribuição cosmopolita, pois a ausência de espécies com exigências ambientais muito específicas e/ou de distribuição geográfica limitada pode não estar associada com poluição; estar associado a abundância de dados de auto-ecologia, muito úteis na análise de resultados $\mathrm{e}$ no mapeamento da área poluída; ter importância econômica como recurso ou como problema; acumular prontamente poluentes, especialmente os que refletem os níveis ambientais, facilitando a compreensão da sua distribuição em relação aos níveis de poluição; ser facilmente cultivado em laboratório permitindo estudos experimentais que possam ser relacionados às observações ambientais; apresentarem baixa variabilidade, tanto genética como quanto ao seu papel na comunidade biológica.

A maior parte das condições relatadas, que não têm a ver diretamente com contaminação também foram mencionadas quando se indicou a comunidade fitoplanctônica como ideal para estudos ecológicos, conforme Sommer (1989), mostrando que ecologia e saneamento têm mais em comum do que se supõe a primeira vista, e que a abordagem sanitária acentua ou acresce o enfoque antropocêntrico aos estudos de ecologia.

A análise da distribuição das espécies que ocorreram em alta porcentagem, durante algum tempo, permite comparar os dados obtidos com os de outros estudos, inclusive experimentais, provendo maior confiabilidade nas hipóteses explicativas aventadas durante os estudos baseados em dados obtidos no ambiente.

A seguir são apresentadas as espécies encontradas que se destacaram como dominantes, abundantes ou pela elevada freqüência de ocorrência durante este estudo e as citações literárias que informam sobre as características do gênero ou espécies, bem como seu valor sanitário nas classificações ou sistemas destinados a utilizá-las como indicadores do estado trófico, saprobidade ou da qualidade ambiental. Ainda que algumas destas classificações sejam extremamente simplistas, foram assim mesmo consideradas devido a escassez de informação específica na literatura.

\section{- Aulacoseira}

Segundo Gasse (1986), diferentes autores em trabalhos recentes, comentam sobre as variedades da espécie Aulacoseira granulata concluindo que não se pode distinguir entre esta espécie, a variedade angustissima Müller e a var. angustissima f. curvata (Grünwald) Hustedt. Estes diferentes "tipos morfológicos", previamente elevados ao status de variedades, têm sido entretanto, contados separadamente para detectar quaisquer possíveis diferenças na sua distribuição ecológica. Este autor afirma que a espécie é considerada alcalófila, com pH ótimo entre 7.8 e 8.2, mas também é comum em águas neutras a fracamente ácidas. No estudo feito por Gasse (1986), na África, a espécie foi encontrada em águas carbonato-bicarbonato, não 
parecendo mostrar qualquer preferência catiônica. Foi encontrada como espécie não comum, ou rara em condições fortemente alcalinas. A variedade angustissima, segundo Gasse, tem seu crescimento ótimo em lagos rasos, tolerando águas com turbidez muito elevada. A condição ótima parece ser condutividade média de 500 a 1200 uS.cm ${ }^{-1}, \mathrm{pH}$ ao redor de 8-8.5, alcalinidade de cerca de 7-10 meq..$^{-1}$ e águas ricas em sódio. A forma curvata não parece diferir da variedade angustissima quanto à ecologia.

Hórnström (1981) considera A. granulata e a var. angustissima como indicadoras de ambientes eutróficos. Van Dam e col. (1994) tratam Aulacoseira granulata, Aulacoseira granulata f. curvata e var. angustissima, com idêntica classificação como indicadores ecológicos: alcalófila; águas doces a salobras $\left(\mathrm{Cl}^{-1}\left(\mathrm{mg}^{-1}\right)\right.$ entre 500 e 1000 ; salinidade entre 0.9 a $1.8 \%$; autotrófica assimilando nitrogênio e tolerando elevadas concentrações de compostos orgânicos ligados ao nitrogênio; requerimento moderado quanto ao oxigênio (acima de $50 \%$ da saturação); quanto à saprobidade é considerada $\beta$-mesosapróbia [águas de Classe II, 70-80\% saturação de oxigênio; $\mathrm{DBO}_{5} 20\left(\mathrm{mg.1}^{-1}\right)=2-4$ ]; eutróficas; nunca ou raramente ocorrendo no exterior de corpos d'água.

Marins (1981, apud Esteves, 1988) relata que esta espécie aumenta sua proporção na superficie da água por ação eólica e com calmaria tende a permanecer no sedimento da represa do Lobo.

Na lista de Palmer (1969) dos 60 gêneros mais tolerantes à poluição orgânica é o 13은 com 51 pontos. A espécie granulata é a 38ㅇ da lista de 80 espécies mais tolerantes. Branco (1986) relata que este gênero é freqüentemente citado por obstruir filtros, podendo produzir odor de gerânios ou terra na água, sendo muito sensivel ao sulfato de cobre e muito resistente ao cloro. Segundo Mackenthun e Ingram (1967) produz odor de gerânio quando em quantidade moderada e de mofo quando abundante. $\mathrm{Na}$ lista de organismos indicadores de saprobidade de Sládecek (1973) esta espécie indica ambiente $\beta$-mesosapróbio.

Espécies encontradas neste estudo: Aulacoseira granulata var.. angustissima e var.. angustissima f. curvata. Na Guarapiranga atingiu valores mais elevados durante o período de seca, com temperaturas mais baixas ou em declínio, valores reduzidos de alcalinidade, condutividade, dureza e conteúdo iônico total. Entretanto também atingiu valores elevados durante o segundo período de seca em que a velocidade dos ventos foi mais reduzida, a alcalinidade mais alta e os teores iônicos relativamente mais elevados. A redução da temperatura, nos dois períodos, parecem ter sido o fator determinante mais efetivo. 


\section{- Asterionella}

Reynolds (1993) afirma que Asterionella formosa é comum em lagos meso a eutróficos devido à sua alta eficiência fotossintética sob baixa irradiância, e relata que Lund, 1978, encontrou altas densidades desta espécie quando os dois meses anteriores haviam sido relativamente secos.

Reynolds (1993), relata que a associação desta espécie com Stephanodiscus é própria de lagos mais produtivos da América do Norte e Europa. Dussart (1966) relata a elevada capacidade desta alga em remover fósforo da água, mesmo quando este nutriente encontra-se em proporções muito baixas ( $\left.1 \mathrm{mg} \cdot \mathrm{m}^{-3}\right)$.

Wetzel (1983) afirma que esta espécie prolifera em lagos eutróficos usualmente alcalinos.

Asterionella formosa, segundo Margalef (1969) é indicadora de cobre, mas também foi registrada em ambientes com elevados teores de cromo, cádmio e zinco. Segundo Margalef (1983) esta alga é favorecida pela turbulência. Beyruth e Pereira (1994), relataram altas densidades desta espécie no inverno, durante a seca, após dois meses de seca, na represa Billings, conforme havia sido relatado por Lund (1978 apud Reynolds, 1993).

É o $51_{-}^{\circ}$ da lista de gêneros de Palmer, com 17 pontos. Segundo Branco (1986) este gênero interfere com a floculação durante o tratamento, podendo persistir em sistemas de distribuição, sendo muito sensivel ao sulfato de cobre e ao cloro. Produz odor de gerânio e especiarias quando em quantidade moderada e de peixe quando abundante, segundo Mackenthun e Ingram (1967). A espécie encontrada indica ambiente oligo a $\beta$-mesosapróbio (Sládecek, 1973).

Espécie encontrada neste estudo: Asterionella formosa. Seu desenvolvimento na Guarapiranga foi mais intenso durante os períodos de seca ou chuvas moderadas, com temperatura mais baixas. Foi mais abundante nos períodos de maior velocidade dos ventos, confirmando a relação com a turbulência reportada por Margalef (1983).

\section{- Botryococcus}

Este gênero segundo Branco (1986) é de águas superficiais, podendo ocorrer em grande número em represas de abastecimento público. São sensiveis ao sulfato de cobre.

Segundo Esteves (1988) é um gênero capaz de aumentar sua capacidade de flutuação formando gotículas de óleo na mucilagem que envolve a colônia, conferindo coloração amarelada à água. Tundisi e Hino (1981) relatam a presença deste gênero em ambiente oligotrófico.

Espécies encontradas neste estudo: Botryococcus neglectus. 


\section{- Chlamydomonas.}

Segundo Margalef (1983), muitas espécies são genuinamente planctônicas e algumas podem desenvolver-se no escuro, se houver fonte orgânica de carbono, havendo muitas formas heterotróficas.

Este gênero foi encontrado na represa de Guarapiranga por Rocha (1984) e Pereira (1987). Segundo Esteves (1988) as populações de inverno são dominadas por espécies pequenas. Este gênero segundo Lund (1965) abrange espécies que sobrevivem em águas com pH abaixo de 4.

Segundo Sakaguchi e col. (1981 apud Gadd, 1988) observou-se acúmulo de molibdênio e urânio por espécies deste gênero.

O gênero atinge 115 pontos, sendo o $3_{-}^{\circ}$ na classificação de Palmer (1969). Segundo Branco (1986) indicam águas eutróficas, não dispensam a presença de certos compostos orgânicos, suportando perfeitamente ambientes ricos em matéria orgânica em decomposição ou altamente mineralizados. São freqüentes em lagoas de estabilização, servindo para caracterizar as fases ou condições do tratamento nestes sistemas devido às suas exigências tróficas. São resistentes aos algicidas: sulfato de cobre, ao DNQ, ZDD e ao CMU e sensíveis ao DAC e às rosaminas. Produzem odor de mofo ou de grama quando em quantidades moderadas e quando abundantes, odor séptico ou de peixe e sabor adocicado (Mackenthun e Ingram, 1967).

Espécies encontradas neste estudo: Chlamydomonas cf. gloeophila, Chlamydomonas cf. globosa, Chlamydomonas cf. gracilis, Chlamydomonas cf. proteus, Chlamydomonas cf. subcaudata. A espécie gloeophila na forma colonial (ou palmelóide) atingiu biomassa expressiva, durante o primeiro período de seca e sob a forma unicelular durante as chuvas moderadas.

\section{- Chlorella}

Segundo Prescott (1962), o gênero Chlorella é citado em ambientes ricos em compostos orgânicos e salinidade elevada. Palmer (1969) afirma que este é um dos dez gêneros mais freqüentes em águas com elevada concentração de matéria orgânica. Pereira (1987) cita a ocorrência deste gênero na represa de Guarapiranga. Lund (1965) afirma que algumas espécies suportam pH 4. Margalef (1983) afirma que espécies deste gênero são encontradas em lagos europeus e norte-americanos em ambientes mesotróficos de água pouco mineralizada. Somashekar (1984) afirma que Chlorella vulgaris é uma espécie freqüente em ambientes polissapróbios. 
Segundo Butler e col., 1980 (apud Gadd, 1988) Chlorella vulgaris acumula cobre e ouro e pode acumular cádmio e outros metais, inclusive urânio, por bioadsorção na parede celular, sendo que o gênero possui espécies capazes de acumular mercúrio, manganês, molibdênio e urânio. Estes autores afirmam que há linhagens resistentes de Chlorella vulgaris cuja tolerância ao cobre deve-se a mecanismos ativos de exclusão celular. Segundo Galloway e Krauss (1963 apud Esteves, 1988), este gênero pode absorver polifosfatos de cadeias longas.

É o $5_{-}^{\circ}$ da lista de gêneros de Palmer (1969) com 103 pontos. Chlorella vulgaris é a $11^{\mathrm{a}}$ espécie com 29 pontos. Segundo Branco (1986) estas algas desenvolvem-se bem em ambientes com poluição orgânica ou com elevados teores de sais minerais, sendo freqüentes em lagoas de estabilização. São sensiveis ao cloro, $\mathrm{CuSO}_{4}, \mathrm{DAC}$ e Rosinamina-acetato. São resistentes aos demais algicidas. Podem obstruir filtros. Quando em grande quantidade, produzem odor de mofo segundo Mackenthun e Ingram (1967). Chlorella vulgaris indica poli a $\alpha$ mesosaprobidade (Sládecek, 1973).

Espécies encontradas neste estudo: Chlorella cf. minutissima, Chlorella vulgaris var. viridis e Chlorella vulgaris var. vulgaris. Trata-se de um gênero com características de restrategista, oportunista, de pequeno porte e reprodução rápida. Ocorreu em periodos de elevada demanda bioquímica de oxigênio, ou seja com saprobidade mais elevada.

\section{- Coelastrum}

É o $41_{-}^{\circ}$ gênero da lista de Palmer (1969), com 24 pontos. Coelastrum microporum é a $60^{\mathrm{a}}$ espécie com 14 pontos. Coelastrum microporum indica $\beta$-mesosaprobidade (Sladecék, 1973).

Espécies encontradas neste estudo: Coelastrum reticulatum, Coelastrum cambricum, Coelastrum pseudomicroporum, Coelastrum proboscideum, Coelastrum microporum.

\section{- Crucigenia}

Rosén (1981), após analisar 442 lagos suecos, concluiu que Crucigenia tetrapedia é característica de lagos eutróficos. É o $60_{-}^{\circ}$ gênero da lista de Palmer (1969), com 14 pontos. Segundo Branco (1986) são algas de superficie resistentes ao sulfato de cobre. A espécie encontrada indica zona oligo a $\beta$-mesosapróbia (Sládecek, 1973).

Espécie encontrada neste estudo: Crucigenia tetrapedia

\section{- Cryptomonas}

Telzer, 1972, e Rodhe, 1955, citados por Esteves (1988) afirmam que populações de inverno são dominandas por espécies pequenas. Rosén (1981), relata que este gênero é 
totalmente eutrófico e seu desenvolvimento foi observado em águas com descargas de esgotos municipais e industriais ricas em nutrientes e matéria orgânica.

Na classificação de Palmer este gênero atinge 23ㅇ. lugar, com 36 pontos. Branco (1986) afirma que este gênero vive em águas ácidas e/ou mineralizadas por esgotos oxidados, não havendo dados sobre sua resistência ao sulfato de cobre. Produz odor de violetas e sabor adocicado (Mackenthun e Ingram, 1967).

Espécies encontradas neste estudo: Cryptomonas cf. brasiliensis e Cryptomonas cf. tenuis

\section{- Dictyosphaerium}

Segundo Prescott (1962) este gênero indica baixos teores de cálcio e nitrogênio na água. Entretanto Brook (1965) encontrou este gênero em lagos enriquecidos com nutrientes e Rosén (1981) afirma que Dictyosphaerium ehrenberghianum e Dictyosphaerium pulchellum são freqüentes em lagos eutróficos (média de fósforo total de $20 \mu \mathrm{g} .1^{-1}$ e condutividade média de $80 \mu{\mathrm{S} . \mathrm{cm}^{-1}}^{-1}$ ). Este gênero foi encontrado na Guarapiranga por Rocha (1984) e Pereira (1987).

Whitton (apud CETESB, 1992) relata aumento no rio Tâmisa devido à eutrofização. Margalef (1983) afirma este gênero é muito comum e que os restos das membranas persistem formando cordões que podem obstruir filtros, aumentando com a eutrofização e podendo derivar durante o dia. Dictyosphaerium pulchellum é freqüente em águas ricas em nitrogênio e cálcio, sendo uma espécie mesosapróbia, segundo Margalef (1983). Tundisi e Hino (1981) relatam a presença deste gênero em águas oligotróficas.

Este gênero é o 58 - da classificação de Palmer (1969), atingindo 14 pontos. Dictyosphaerium pulchellum é a 73 ${ }^{\mathrm{a}}$ espécie da lista de Palmer, com 11 pontos. Segundo Branco (1986), este gênero além de obstruir filtros produz odor de capim e quando em densidades elevadas, odor de peixe, sendo resistente ao sulfato de cobre e sensível ao cloro. Produz odor de grama ou nastúrcio, quando em quantidades moderadas e de peixe quando abundante (Mackenthun e Ingram, 1967).

Espécies encontradas neste estudo: Dictyosphaerium ehrenberghianum. Dictyosphaerium pulchellum Dictyosphaerium elegans. Durante as análises microscópicas ficou evidente que no período de senescência, os restos de gelatina das colônias permaneciam na água superficial preservando sua forma inicial, mesmo com poucas células vivas e que apenas $45 \%$ do biovolume encontrado era de células vivas durante as coletas de D30 a D33 no ponto $1 \mathrm{e}$ em $\mathrm{D} 33$ no ponto 4 . Isso indica que os nutrientes liberados mantiveram-se disponiveis na coluna d'água, podendo então serem rapidamente consumidos por espécies oportunistas, antes que houvesse tempo para sedimentação. Este fator deve ter contribuído 
para o sucesso imediato da cianoficea Aphanocapsa elachista, que entrou em floração imediatamente. Outro fator a observar é a alta densidade simultânea de mais do que uma espécie deste gênero, tanto no ponto 1 como no 4.

\section{- Dinobryon.}

Espécies deste gênero, segundo Margalef (1983) são de temporada, formando cistos durante a entressafra, que afundam e repousam no sedimento aguardando condições de temperatura favoráveis à germinação. Podem ser dominantes no fitoplâncton de água doce e produzir odor de peixe estragado durante muitos verões, como foi o caso do Lago Michigan (Bold e Wine, 1985). Wetzel (1983) relata a presença de vacúolos alimentares, indicando ingestão fagotrófica. Segundo Rosén (1981) Dinobryon divergens ocorreu em lagos com altos níveis de nutrientes (média de fósforo total igual a $12 \mu \mathrm{g} .1^{-1}$ ). Kleerekoper (1990) relata que este gênero é comum em represas do Estado de São Paulo, às vêzes ocorrendo em grande número, mas que não tem efeito sobre o oxigênio dissolvido na água, tendo fraca ação fotossintética e portanto seu valor como planta autotrófica é pequeno. Aquele autor encontrou Dinobryon sertularia na represa de Santo Amaro, antigo nome da Guarapiranga, em elevadas densidades entre maio e junho dos anos 30 .

Segundo Branco (1986) este é um dos gêneros mais nocivos à qualidade da água, devendo ser combatido mesmo quando em números relativamente baixos, inferiores a 1000 org. $\mathrm{cm}^{-3}$, pois é um dos principais causadores de odor. Produz odor de violeta quando em quantidade moderada e de peixe quando abundante (Mackenthun e Ingram, 1967).

Espécies encontradas neste estudo: Dinobryon divergens, Dinobryon bavaricum, Dinobryon sertularia. Neste estudo tal gênero ocorreu em altas densidades em setembro, alcançando $64 \%$ da densidade do ponto 1 em S18 e $18 \%$ da densidade do ponto 4 em S19.

\section{- Geminella}

Segundo diversos autores, conforme relata Margalef (1969) Geminella interrupta é oligossapróbia.

Espécie encontrada neste estudo: Geminella interrupta.

\section{- Gymnodinium}

Segundo Esteves (1988), este gênero apresenta populações de inverno dominadas por espécies pequenas. Algumas espécies deste gênero (Gymnodinium brevis e outras), são citadas como responsáveis por ardência nos olhos, tosses fortes e ardência no trato respiratório, segundo Mackenthun e Ingram (1967). Beyruth (dados inéditos) encontrou elevada densidade deste gênero num lago em Bertioga, litoral sul de São Paulo, em que banhistas, especialmente 
crianças guaranís, apresentavam lesões cutâneas e febre após banharem-se em suas águas, algumas tendo sido hospitalizadas.

Espécies encontradas neste estudo: Gymnodinium fuscum.

- Mougeotia.

Este gênero, segundo Branco (1986) pode causar obstrução de filtros durante o tratamento da água não havendo dados sobre sua sensibilidade a algicidas. $O$ gênero tem sido citado em diversos trabalhos sobre elevação de teores de alumínio relacionado a acidificação de corpos d'água. Havens e Heath (1990) relatam sua proliferação nas paredes de mesocosmos representativos da situação que ocorre no litoral de lagos acidificados. Stokes (1986 apud Havens e Heath, 1990) relata o desenvolvimento acentuado destas algas em ambientes acidificados e sugere que este aumento deve-se à habilidade destas algas utilizarem com eficiência o gás carbônico livre, em concentrações limitantes para outras algas além de tolerarem níveis elevados de alumínio. Mougeotia viridis desenvolveu-se mais rapidamente quando em meio ácido contendo alumínio (50 $\mu \mathrm{g}, \mathrm{l}^{1}$ de $\mathrm{Al}$ e $\left.\mathrm{pH} 4.5\right)$, que em meio ácido ( $\mathrm{pH}$ 4.5).

Espécies encontradas neste estudo: Mougeotia cf. americana, Mougeotia sp1. Quanto a Mougeotia cf. americana sua alta incidência, confirma a mistura d'água por ação dos ventos e navegação, uma vez que esta espécie é séssil e deveria ser encontrada em altas densidades, apenas nas proximidades das margens, se não houvesse intensa movimentação da água. Quando Mougeotia cf. americana foi dominante o $\mathrm{pH}$ variou entre 6.64 e 8.10 no ponto $1 \mathrm{e}$ entre 6.70 e 8.10 no ponto 4 , enquanto o alumínio apresentou valores entre $<0.10$ e $0.30 \mathrm{mg} .1^{-1}$ no ponto 1 e entre $<0.10$ e $0.10 \mathrm{mg} \cdot \mathrm{l}^{-1}$ no ponto 4 .

\section{- Oocystis}

É o 35﹎. gênero da classificação de Palmer (1969), com 28 pontos.

Espécies encontradas neste estudo: Oocystis pusilla, Oocystis cf. lacustris, Oocystis cf. natans, Oocystis cf. nodulosa.

\section{- Oscillatoria}

Esteves (1988) relata que este gênero vive em águas profundas de lagos, na ausência de luz, por serem mixotróficas, assimilando compostos orgânicos. São potenciais formadores de florações, apresentando vacúolos gasosos que thes confere a possibilidade de migrar na coluna d'água, havendo espécies capazes de armazenamento luxuriante de fosfato. Podem ocorrer em águas com alta salinidade. Somashekar (1984), encontrou alta densidade deste gênero em águas de elevada poluição. 
É o 2º̂nero da lista de Palmer (1969) com 161 pontos. Este gênero, segundo Branco (1986) é causador de florações, podendo desenvolver-se nas paredes dos reservatórios, sendo muito citado por obstruir filtros. Algumas espécies de Oscillatoria podem causar a corrosão de estruturas de concreto e metais segundo relatam os trabalhos de Oborn e Higgison, 1954, e de Myers, 1947 (apud Mackenthun e Ingram, 1967). Produz odor de grama quando em quantidade moderada ou de mofo e especiarias quando abundante, segundo Mackenthun e Ingram (1967). O desenvolvimento intenso de cianoficeas é sempre visto como problemático, pelo potencial de toxicidade, especialmente em corpos d'água destinados ao abastecimento e este é um dos gêneros mais citados pela capacidade de produzir toxinas (Falconer, 1991).

Espécies encontradas neste estudo: Oscillatoria subtilissima.

\section{- Pseudoanabaena}

Pseudoanabaena catenata, segundo Margalef (1969) é saprobionte na classificação de Fjerdingstad.

Espécies encontradas neste estudo: Pseudoanabaena catenata

\section{- Rhizosolenia}

Segundo Van Dam e col. (1994), quanto ao pH, Rhizosolenia eiriensis var. morsa é circumneutra, de água doce, autotrófica. Assimila nitrogênio, tolera concentrações muito reduzidas de compostos orgânicos ligados a nitrogênio, requer elevadas concentrações de oxigênio, próximas a $100 \%$ da saturação; é oligosapróbio [vive em águas de classe I e I-II, $>85 \%$ OS, $\mathrm{DBO}_{5} 20\left(\mathrm{mg}^{-1} \mathrm{-}^{-1}\right)<2$ ], quanto ao estado trófico é considerada mesotrófica e quanto à umidade, nunca ou raramente ocorre no exterior de corpos d'água.

Segundo Branco (1986), não há dados sobre sua sensibilidade a algicidas.

Espécies encontradas neste estudo: Rhizosolenia eiriensis var. morsa. Neste estudo esta espécie apresentou correlação negativa com os teores de aplicação de sulfato de cobre, sugerindo a necessidade de testes experimentais, que confirmem sua sensibilidade ao algicida.

\section{- Scenedesmus}

Prescott (1962) afirma que é um gênero muito utilizado em culturas destinadas a estudos de genética e para avaliar respostas a várias substâncias químicas, sendo também utilizado para produção de antibióticos.

Segundo Brook (1965) Scenedesmus bijugatus ocorreu em águas com alta salinidade. Golterman (1975, apud Payne, 1986)) demonstrou que populações de Scenedesmus podem remover muito fosfato da argila dos sedimentos em suspensão (no rio Kainji, Uganda), 
chegando a $10 \%$ do limite da fração, tanto quanto poderia ser removido artificialmente, utilizando-se agentes quelantes.

Segundo Weers e Zaret (1975, apud Payne, 1986), houve diminuição deste gênero em compartimentos enriquecidos artificialmente com Ceriodaphnia cornuta e Diaptomus gatunensis (calanóide).

Sakaguchi e col. (1981 apud Gadd, 1988) observaram acúmulo de molibdênio e urânio por este gênero e espécies que acumulam cádmio. Segundo Esteves (1988), absorvem $\left[\mathrm{HCO}_{3}\right]^{-1}$ preferencialmente e $\mathrm{CO}_{2}$ livre em menor quantidade. Beyruth (1994a) encontrou floração da espécie Scenedesmus quadricauda no verão, num lago que recebe descargas de efluentes de industrias, com teores elevados de metais pesados, especialmente zinco.

É o $4_{-}^{o}$ gênero da classificação de Palmer (1969), com 112 pontos. Scenedesmus quadricauda é a quarta espécie com 41 pontos na lista de espécies, Scenedesmus acuminatus com 12 pontos, Scenedesmus opoliensis com 7, Scenedesmus armatus com 4 e Scenedesmus bijugus com 3. Segundo Branco (1962) este gênero desenvolve-se em águas ricas em sais minerais, é freqüente em águas poluidas e lagoas de estabilização e resistente ao sulfato de cobre. Produz odor de grama quando abundante, segundo Mackenthun e Ingram (1967).

Espécies encontradas neste estudo: Scenedesmus bicaudatus, Scenedesmus bijugus, Scenedesmus acuminatus, Scenedesmus arcuatus, Scenedesmus dactylococcoides, Scenedesmus denticulatus, Scenedesmus javanensis, Scenedesmus opoliensis, Scenedesmus ovalternus, Scenedesmus quadricauda, Scenedesmus cf. armatus.

\section{- Staurastrum}

Produz odor de grama quando abundantes, segundo Mackenthun e Ingram (1967).

Espécies encontradas neste estudo: Staurastrum gracile

\section{- Synechococcus}

Gadd (1988) relata que este gênero é capaz de acumulação passiva de manganês, cobalto, zinco, prata, selênio, césio, mercúrio, e que Synechococcus elongatus foi capaz de remover urânio da água. Este gênero pode sintetizar grandes quantidades de um polímero intracelular capaz de ligar-se ao níquel.

Espécies encontradas neste estudo: Synechococcus elongatus

\section{- Synedra}

Archibald (1983, apud Gasse, 1986), não distingue entre variedades de Synedra ulna descritas por Hustedt, considerando-as inseridas numa ampla gama de variações, possuindo 
ligações intermediárias entre as formas. As observações de Gasse, em amostras do Leste da África, sustentam esta opinião.

Smith (1985) relata que são encontradas numa ampla variedade de ambientes e que as espécies de água doce são geralmente sésseis, crescendo sobre pedras e madeira em água corrente. Em lagos também são encontradas no plâncton. Esteves (1988) afirma que as populações de inverno são dominadas por espécies pequenas. Este gênero foi encontrado na represa de Guarapiranga por Rocha (1984) e Pereira (1987). Segundo Hörnström (1981), ocorrem em ambientes eutróficos.

Gasse (1986) relata que esta espécie é de ampla distribuição na África, mas em seu estudo nunca atingiu altas porcentagens. Ocorreu no perifiton de lagos e rios, usualmente como epífita, também havendo sido encontrada no plâncton. Este gênero é geralmente mencionado como alcalinófilo, oligohalófilo indiferente, eutrófico e com espécies euritérmicas (oligo a mesotérmicas). Chlonoky (1968 apud Gasse, 1986), estabeleceu que seu pH ótimo está ao redor de 7.8. Lowe (1974, apud Gasse, 1986), afirma que não é possivel utilizar esta espécie como indicadora ecológica devido à sua ampla distribuição ecológica. Entretanto Gasse (1986) afirma que em seu estudo, esta espécie mostrou-se claramente favorecida por ambientes de água doce, baixas condutividade e alcalinidade, desenvolvendo-se otimamente em águas do tipo carbonato-bicarbonato, parecendo ser indiferente à razão catiônica.

Cox (1993) relata resultados de experimentos e afirma que Synedra ulna mostrou resposta positiva tanto à luz como à temperatura, podendo desenvolver-se bem em água aberta não sombreada.

É o $9_{-}^{\circ}$ gênero da lista de Palmer (1969) com 58 pontos. Synedra ulna é a $7^{\mathrm{a}}$ espécie da lista de espécies com 33 pontos. Segundo Branco (1986), causam odor de capim ou grama quando em pequeno número e de terra ou mofo quando em maior número. Produzem odor $\mathrm{e}$ sabor de dificil remoção. A ação do cloro sobre as substâncias produtoras de odor levam à formação de clorofenóis e consequente produção de odor de medicamento. Podem obstruir filtros e são sensiveis ao sulfato de cobre e ao cloro. Produz odor de grama quando em quantidade moderada e de mofo quando abundante (Mackenthun e Ingram, 1967).

Espécies encontradas neste estudo: Synedra cf. minuscula, Synedra ulna.

\section{- Trachelomonas}

Segundo Margalef (1969) estas algas tem carapaça formada quase exclusivamente por hidróxido de ferro e manganês, sendo indicadoras de precipitação destes metais.

É o 26- gênero da classificação de Palmer (1969), com 34 pontos e Trachelomonas volvocina é a $72^{\mathrm{a}}$ espécie com 11 pontos. 
Espécies encontradas neste estudo: Trachelomonas volvocina, Trachelomonas volvocinopsis.

As espécies a seguir também se destacaram neste trabalho, mas não foram encontradas referências sobre suas características ecológicas ou sanitárias.

- Aphanocapsa. Espécie encontrada neste estudo: Aphanocapsa elachista.

- Crucigeniella. Espécie encontrada neste estudo: Crucigeniella crucifera

- Eutetramorus. Espécies encontradas neste estudo: Eutetramorus fotii e Eutetramorus cf. nyigaard.

- Monoraphidium. Espécies encontradas neste estudo: Monoraphidium arcuatum, Monoraphidium caribeum, Monoraphidium contortum, Monoraphidium convolutum, Monoraphidium setiforme, Monoraphidium cf. minutum.

- Palmelochaete Espécie encontrada neste estudo: Palmelochaete tenerrima

- Peridinium. Espécies encontradas neste estudo: Peridinium sp1, Peridinium sp2, Peridinium sp3.

- Sennia. Espécie encontrada neste estudo: Sennia cf. communata.

- Staurodesmus. Espécies encontradas neste estudo: Staurodesmus cuspidatus

- Treubaria. Espécie encontrada neste estudo: Treubaria setigera

- Xanthidium. Espécie encontrada neste estudo: Xanthidium sp2

Imagens fotográficas de algumas das espécies desta lista encontram-se na Figura 22.

A falta de informação disponível na literatura ecológica ou sanitária a respeito destas últimas espécies e mesmo alguns gêneros mencionados, impedem comparações, mostrando a importância de estudos taxonômicos que relacionem as espécies às condições ambientais, bem como a de estudos experimentais à respeito de seus requisitos. Embora o uso das classificações sanitárias seja criticável por sua imprecisão, devido às dificuldades de identificação das espécies fitoplanctônicas e da escassez de conhecimento sobre sua biologia, parece ser viável neste contexto, utilizar os métodos destas classificações (Beyruth, 1989).

No caso da Guarapiranga o primeiro fator a ser considerado como determinante de altas porcentagens das espécies é a eutrofização. Dos gêneros encontrados, alguns bem representados podem apresentar armazenamento luxuriante de fósforo. Muitos são citados por remover metais. Vários são relatados na literatura como resistentes ao sulfato de cobre, mas na maior parte dos casos tratam-se de gêneros e espécies cosmopolitas, de ampla distribuição em águas do Estado de São Paulo, não caracterizando uma comunidade resistente, por ter sido 
selecionada ao longo das últimas décadas. Estas informações podem ser utilizadas para manejo visando a remoção e o aproveitamento da biomassa algácea desta represa.

A maioria das espécies encontradas neste trabalho, que também estão relacionadas na lista do sistema de Sládecek (1973), apresentou saprobidade própria de zona $\beta$-mesosapróbia, ou seja seriam algas de zonas de poluição moderada. Estas zonas $\beta$-mesosapróbias em geral mostram na curva diária do teor de oxigênio, flutuações dependentes da atividade dos organismos, apresentando-se geralmente supersaturadas de oxigênio durante o dia, com deficiência de oxigênio durante a noite. Em relação a estrutura trófica indicam um ambiente com razão produtores/consumidores/decompositores balanceada, um aumento relativo da abundância de decompositores e compativel com os consumidores existentes; comunidades de organismos ricas em individuos e espécies, com biomassa e bioatividade elevadas. Esta classificação, como águas de moderada poluição, está de acordo com a classificação de Tümpling (1968 apud Sládecek, 1973) para qualidade da água relacionada a utilização na Classe II: águas com carga moderada de poluição e elevada capacidade de autodepuração. Sua utilização para abastecimento público é geralmente satisfatória quando sua qualidade é próxima dos limites superiores da Classe, porém, com custos elevados de tratamento. Pode ser utilizada para pesca e recreação, incluindo balneabilidade. Estas águas também podem ser utilizadas para atividades industriais. Para estas águas Tümpling (1968, 1969 apud Sládecek, 1973) relata níveis de oxigênio dissolvido superiores a $4 \mathrm{mg} \cdot \mathrm{l}^{-1}$, demanda bioquímica de oxigênio inferior a $8 \mathrm{mg} \cdot \mathrm{l}^{-1}$, ín amônio com teores inferiores a $4 \mathrm{mg} \cdot \mathrm{I}^{-1}$, nível de saprobidade $\beta$ mesosapróbia, índice sapróbico menor que 2.5 , valores menores que $10^{5}$ para bactérias psicrofilicas e menores que $10^{3}$ para bactérias coliformes.

$\mathrm{O}$ uso de sistemas biológicos indicadores implica num conhecimento abrangente sobre as espécies da eco-região estudada, sua taxonomia, biologia, distribuição geográfica, relações com outras espécies, com o meio abiótico, com os poluentes, sazonalidade, etc., que envolvem estudos amplos (geograficamente) e extensivos (ao longo de períodos prolongados), o que só é possível com investimentos elevados em pesquisa e com a participação conjunta de equipes multidisciplinares, envolvendo profissionais qualificados. Este quadro até o momento foi possivel apenas em países ricos e/ou com sistemas de educação e saúde aprimorados, onde houve investimento político para viabilização de pesquisas científicas. $\mathrm{O}$ Brasil, além da enorme extensão territorial, que já aumenta os custos das pesquisas científicas, está longe desta situação, tanto em termos econômicos, como de educação e saúde, o que é causa e conseqüência do descaso das autoridades governamentais, uma vez que resultados positivos de 
pesquisas demoram mais que um ciclo político de 4 anos, e dificilmente fornecem beneficios políticos a curto prazo, apesar dos elevados lucros que possam retornar ao país a longo ou médio prazo. Desta forma os estudos ambientais, têm que basear-se em métodos e sistemas desenvolvidos em paises mais desenvolvidos, cujo conjunto das espécies não abrange o total de espécies encontradas nas águas continentais brasileiras. A enorme biodiversidade natural de diversas eco-regiões deste pais-continente e a degradação ambiental mais recente, ampliam o campo de estudos. Sistemas elaborados para áreas mais restritas e/ou com menor biodiversidade, dificilmente seriam totalmente compatíveis.

O sistema de Sládecek (1973), talvez o mais completo, recente e amplamente divulgado, pode ser utilizado com ressalvas, se considerados os fatores mencionados, pois como em Guarapiranga, outras experiências (comunic. pessoal de técnicos da CETESB) demonstraram que muitas das espécies encontradas em corpos d'água do Estado de São Paulo não estão incluídas naquele sistema, inviabilizando seu uso pleno, ou seja a sua utilização para definir o índice sapróbico de um corpo d'água (índice sapróbico é a somatória dos valores relativos a saprobidade, atribuidos a cada espécie, a partir do conhecimento prévio do comportamento de cada espécie).

Constituem as mais graves restrições ao uso de indicadores biológicos:

a) a utilização de niveis taxonômicos pouco informativos, pois diferentes espécies de um mesmo gênero, ordem ou classe podem apresentar diferentes niveis de sensibilidade às variações ambientais;

b) as incertezas e dificuldades taxonômicas que causam confusões nas interpretações dos resultados das avaliações ambientais;

c) o fato de muitas espécies relacionadas pelos autores destes sistemas biológicos serem de distribuição geográfica restrita, dificultando a aplicação de tais índices para outras regiões;

d) a escassez de dados de auto-ecologia, mesmo das espécies de distribuição ampla, cosmopolitas;

e) o fato de haver redução de uma grande quantidade de informação a um único número (nos sistemas de indicadores), incorrendo num simplismo ingênuo que pode comprometer a qualidade das conclusões e gerar graves conseqüências se utilizado indiscriminadamente para basear ações de manejo ambiental

Estas características também se contrapõe às condições determinantes de um bom indicador, relacionadas por Hellawell (1989).

Avaliações ambientais (estado trófico, nivel sapróbico, potencial biogênico, etc.), devido aos múltiplos fatores que integram os ecossistemas aquáticos continentais, devem utilizar o 
maior número possível de instrumentos de medida e de conhecimento disponível. Devem integrar o maior número possível de informaç̋̃es, com o maior detalhamento possível, abrangendo as características das espécies, dos vários níveis taxonômicos, características estruturais e funcionais das comunidades, do ecossistema e dos ecossistemas intervenientes $\mathrm{e}$ sobre todas as relações mútuas, permitindo delinear um quadro amplo da situação ambiental, para dar suficiente consistência e para consolidar as conclusões que direcionarão as medidas de manejo e controle ambiental.

As ações antrópicas sobre o ambiente, geradoras potenciais de impactos imediatos e futuros devem basear-se nos fundamentos mais consistentes existentes. Devem ser consideradas todas as experiências disponíveis adquiridas anteriormente, mantendo-se sempre a maior margem de segurança possível. Deve-se ter sempre em vista que o conhecimento na área ambiental ainda é muito precário e o desenvolvimento científico e tecnológico não são suficientes, nem mesmo os únicos envolvidos no processo para garantir a preservação dos recursos naturais. A importância econômica da preservação da qualidade ambiental deve ser sempre abordada, por ser talvez o argumento mais eficiente na preservação dos recursos naturais.

\subsubsection{ALGAS POTENCIALMENTE PREJUDICIAIS AOS USOS DA ÁGUA}

\subsubsection{CIANOFÍCEAS}

Durante as últimas décadas tornou-se evidente que os teores de nitrogênio e fỏsforo determinam o crescimento do fitoplâncton dos lagos. Desde o início do século (Naumann, 1919, 1932 e Thienemann, 1925 apud Smith, 1990) já consideravam estes nutrientes como determinantes da fertilidade desses ambientes.

Alguns casos de ređuções simultâneas da produção do fitoplâncton e dos teores de nitrato tem sido relatadas na literatura para lagos e reservatórios tropicais (Moss, 1969; Lewis, 1974; Talling e Rzoska, 1967 apud Henry, 1990); para lagos subtropicais (Canfield, 1983; Baker e col., 1985 apud Smith, 1990); para lagos da Amazônia brasileira (Rai e Hiel, 1981; Zaret e col., 1981; Henry e col., 1985 apud Henry, 1990). Entretanto, Henry (1990) afirma que a hipótese da limitação por nitrogênio ser mais importante que a limitação por fósforo nos ambientes tropicais, não tem recebido muitas confirmações, mencionando trabalhos em que houve limitação por fósforo tanto em lagos naturais não impactados por atividades antrópicas (Melack e col., 1982; Kalff, 1983; Henry e Tundisi, 1986; Henry e col., 1987 e 1989 apud Henry, 1990) como em ambientes submetidos a impactos antrópicos como a represa de Barra Bonita (Henry, 1986; Henry e Simão, 1988 apud Henry 1990). 
$O$ ingresso de fósforo e o tempo de renovação da água tornaram-se o centro da interpretação dos problemas de eutrofização nos últimos anos (Schindler, 1978).

A eutrofização é tipicamente acompanhada por decréscimo na razão NT:PT (Shapiro, 1981 apud Smith, 1990), ou seja acresce fósforo. O declínio da razão N:P favorece a substituição de cloroficeas por cianoficeas (Rhee, 1978; Rhee e Gotham, 1980 apud Reynolds, 1987). A razão limitante durante a fase de crescimento e a ocorrência de dominâncias de cianoficeas podem ser previsíveis a partir do conhecimento sobre as as necessidades das algas quanto às razões-nutrientes mas na maior parte dos caso estas razões são também conseqüêências e não apenas determinantes dos eventos, segundo Reynolds (1992).

$\mathrm{O}$ enriquecimento das águas causa aumento da biomassa e exerce efeitos marcantes na periodicidade (Marshall, 1987 apud Smith, 1990): altera a composição, estrutura e tamanho e diversidade das espécies, aumenta a variância da biomassa fitoplanctônica, altera o padrão de sucessão e um dos seus efeitos mais notáveis é o aumento da freqüência e intensidade das florações de cianoficeas durante o verão. A biomassa relativa destas algas tende a aumentar com a eutrofização, tanto em lagos temperados como em lagos tropicais (Smith, 1990).

A floração intensiva de algas tem-se tornado freqüente em lagos e reservatórios de todo o mundo como resultado dos ingressos de nutrientes através dos esgotos domésticos, carreamento de áreas agrícolas e drenagem urbana (Smith, 1990).

As cianoficeas são eficientes no aproveitamento da luz por possuírem pigmentos acessórios, as ficobilinas que as capacitam a aproveitar luz numa ampla faixa do espectro visivel (Carmichael, 1992) e por aumentarem a clorofila celular (Zevenboon e Mur, 1986 apud Shapiro, 1990). Apresentam baixa demanda de energia podendo manter-se sob baixas irradiâncias (Van Liere e Mur, 1979 apud Shapiro, 1990).

A flutuação das cianoficeas que possuem vacúolos gasosos permite o aproveitamento da luminosidade na superficie da coluna d'água; maior eficiência tanto na obtenção de gás carbônico como na competição por promover o sombreamento para as demais algas, aproveitando-se dos nutrientes liberados pelas mesmas.

Estas algas distribuem-se por um amplo espectro de temperaturas, nas quais podem manter taxas de crescimento elevadas (Ganf e Oliver, 1982 apud Shapiro, 1990), porém segundo Carmichael (1992) águas com temperaturas abaixo de $20^{\circ} \mathrm{C}$ desfavorecem o desenvolvimento massivo dos gêneros mais comuns. As baixas taxas de crescimento sob temperaturas mais baixas indicam a necessidade de um tempo de retenção mais longo para o aumento da população durante o inverno. 
São eficientes na absorção do fósforo, apresentando baixa constante de saturação média para sua absorção e muitas delas são capazes de fixar nitrogênio molecular, na ausência de nitrato e amônia (Horne e Commins, 1987 apud Shapiro, 1990). São mais eficientes que as clorofíceas no aproveitamento de baixas concentrações de carbono. Podem produzir sideróforos, absorvendo ferro com eficiência, geralmente não exigem fontes exógenas de vitaminas. As florações de cianoficeas são freqüentemente observadas quando os nutrientes excedem a demanda do fitoplâncton - ambientes eutróficos e hipereutróficos - e baixa taxa N:P favorece cianoficeas (10 a16 N:1 P) sobre a maioria das outras algas (16 a $23 \mathrm{~N}: 1 \mathrm{P}$ ) e em condições oligotróficas o fosfato é considerado o melhor indicador da abundância de cianoficeas (Carmichael, 1992). Porém, como a maioria das florações tóxicas ocorrem em condições de excesso de nutrientes então a razão N:P torna-se de utilidade mínima para predizer a ocorrência destas florações (Pearson, 1990 apud Carmichael, 1992).

Em ambientes rasos e com alta taxa de mistura o aumento da biomassa em resposta a carga de nutrientes pode causar limitação de luz. Sob estas condições a seqüência de dominância vai de fitoplâncton eucariótico para cianofíceas fixadoras de nitrogênio e finalmente para cianoficeas não fixadoras de nitrogênio (Klemmer, 1991), portanto a limitação de luz pode ser uma das condições para as florações de cianoficeas. A presença de turbidez inorgânica na coluna d'água pode causar redução de até $10 \%$ da biomassa algácea do que a esperada pelas concentrações de fỏsforo total, pois além de reduzir a disponibilidade de luz o fósforo pode estar agregado ou ligado a partículas (Smith, 1990).

As populações densas de fitoplâncton abaixam o teor de gás carbônico e aumentam o pH e em muitos lagos as cianoficeas são dominantes apenas nos períodos em que o $\mathrm{pH}$ é elevado (Jackson, 1964 apud Shapiro, 1990). Isto sugere que as cianoficeas podem tirar vantagem destas condições. Lagos nos quais o pH não aumenta significativamente no verão (oligotróficos ou com outras fontes de gás carbônico, além da atmosfera - decomposição no substrato, decomposição orgânica) geralmente não apresentam predominância de cianoficeas. As cloroficeas e as diatomáceas são favorecidas por valores mais baixos de $\mathrm{pH}$ e mais elevados de gás carbônico (Shapiro, 1990).

Muitas espécies de cianoficeas são refratárias a herbivoria por serem impalatáveis devido ao tamanho e forma ou por produzirem substâncias que os herbivoros parecem evitar (Shapiro, 1990).

São condições para ocorrência de floração de cianoficeas: população pré-existente (inóculo), grande número de organismos com vacủolos gasosos permitindo sua manutenção nas camadas mais iluminadas, baixa turbulência e intensidade de ventos, insolação, temperatura 
e teor de nutrientes elevados, além de pH entre 6 e 9 (Gonzales de Infante, 1988). Em alguns lagos as cianoficeas ingressam no plâncton por flutuação de indivíduos e colônias provenientes da interface com o sedimento, onde puderam permanecer no início do verão (Reynolds, 1984).

As florações de cianoficeas desempenham papel importante na sequiência anual de florações em lagos eutróficos e também nas alterações das sucessões de longo prazo e a alteração da dominância, que ocorre quando um lago "envelhece" e passa de oligo, para meso, para eutrófico, sendo que a alelopatia oferece explicação para a principal característica deletéria da eutrofização acelerada, que é o rapido aumento das cianoficeas (Keating, 1978). Esta autora verificou correlação negativa, consistente, entre populações de cianofíceas de inverno e florações de diatomáceas na primavera, indicando que sob condições aparentemente favoráveis, a habilidade endógena de diatomáceas desenvolverem florações na primavera, é limitada pela ocorrência das florações no inverno. Através de resultados experimentais, esta autora demonstrou haver produção de substâncias inibidoras do crescimento de diatomáceas, por espécies de Anabaena, sendo que Asterionella formosa mostrou-se mais resistente aos efeitos inibitórios das cianoficeas, que outras diatomáceas testadas.

Também, quanto ao significado ecológico das florações, existem outras duas hipóteses interessantes:

- as florações de algas não palatáveis servem como tampão, contra as variações no conteúdo de nutrientes disponíveis na água (Phillips, 1974 apud Briand e McCauley, 1978);

- as florações constituem mecanismo de proteção contra herbivoria. As cianoficeas não são prontamente digeriveis por peixes que não possuam celulase, pois sua digestão exigiria pH baixo. Os ciclídeos têm $\mathrm{pH}$ gástrico variando entre 2 a menor que 2 , permitindo a ruptura celular e por isso adaptam-se bem em represas e tanques (Gonzales de Infante, 1988).

Segundo Carmichael (1992) as cianoficeas ou cianobactérias constituem a maior fonte de toxinas produzidas naturalmente - biotoxinas - na superficie de mananciais de água doce. Essas cianotoxinas produzem envenenamentos intermitentes e repetidos de animais em várias regiões do planeta.

Abundância de cianoficeas pode indicar eutrofia e a possibilidade de produção de toxinas (Beyruth e col., 1992). Nesse estudo encontrou-se alta frequiência relativa destas algas nos períodos finais de dominância de cloroficeas, conforme mencionado anteriormente.

Como as florações de cianoficeas comumente resultam de processos de eutrofização, as florações tóxicas tendem a aumentar de tamanho e duração e é possivel, segundo Carmichael (1992), que seres humanos sejam expostos, no futuro próximo, a teores de toxinas capazes de causar toxicidade aguda, especialmente nas regiões tropicais e sub-tropicais onde $o$ 
crescimento destas algas é favorecido durante todo o ano pelas condições climáticas (Beyruth e col, 1992).

Os danos mais comuns à saúde, resultantes de florações de cianobactérias em represas de abastecimento são desordens gastrointestinais e hepáticas, registradas nos EUA, leste da África e Austrália segundo Carmichael (1992) e no Brasil, em São Paulo segundo Beyruth e col. (1992), além disto também registrou-se hepatoenterites, alergias da pele e vias respiratórias, promoção de tumores, efeitos neurotóxicos, lesões hepáticas, renais, pulmonares, das glândulas adrenais, intestinais e hemorragias.

Falconer (1991) relata estudos realizados nos EUA e África, que mostraram claras evidências de injúria aguda ao figado e/ou hepatoenterites, em seres humanos, causada por ingestão de água contaminada por cianoficeas/cianobactérias tóxicas. $O$ gênero causador mais freqüente destas injúrias é Microcystis, ainda que linhagens de Anabaena, Cylindrospermopsis, Nodullaria e Oscillatoria, tenham sido causa da morte de animais domésticos. Segundo relato de Beyruth e col. (1992), uma floração de Anabaena cf. solitaria foi associada a distúrbios gastrointestinais e hepáticos na população abastecida pelas águas da Guarapiranga em 1991, constituindo o primeiro caso registrado na literatura científica de ocorrência de danos à saúde pública por cianobactérias em águas paulistas.

Rocha e Branco (1986) afirmam que as águas eutrofizadas das represas do Estado de São Paulo parecem apresentar grandes concentrações de cianoficeas em julho (inverno) e em dezembro (verão), não havendo estudos sistemáticos destas distribuições temporais. Este padrão foi seguido para as máximas de densidade e do biovolume do fitoplâncton de Guarapiranga, durante este estudo, pois as cianoficeas foram especialmente importantes nos periodos de inverno (MA2, J5, J56 e J57) e esporadicamente no início das chuvas intensas (D33).

Zagatto (1995) realizou um trabalho de avaliação ecotoxicológica na represa de Guarapiranga, em fevereiro, abril e junho de 1994. Em junho de 1993 este autor relata que já havia encontrado toxicidade aguda para Ceriodaphnia dubia, com 100\% de mortalidade após 24 e 48 horas de exposição dos animais a água bruta da represa, contendo $0.08 \mathrm{mg} . \mathrm{l}^{-1}$ de cobre. Nas proximidades da barragem (onde localizou-se o ponto 1 desta tese) encontrou toxicidade em fevereiro e abril de 1994, com 100\% de mortalidade para microcrustáceos, com valores de cobre variando entre 0.13 e $0.08 \mathrm{mg}^{-1}$. $\mathrm{Na}$ água bruta Zagatto identificou as seguintes espécies de cianoficeas: Chroococcus sp, Pseudoanabaena galeata, Oscillatoria quadripunctulata*, Oscillatoria amphibia*, Oscillatoria planctonica, Oscillatoria limnetica*, Oscillatoria redekei, Oscillatoria $\mathrm{sp}$, Synechococcus $\mathrm{sp}$, Phormidium $\mathrm{sp}^{*}$, Microcystis 
incerta*, Microcystis aeruginosa. Todas as algas marcadas com asterístico na última frase apresentaram toxicidade para ratos e a toxicidade mais efetiva, ou seja, a menor dose que causou efeito tóxico foi registrada para Microcystis aeruginosa.

Um caso de mortalidade de dezenas de pessoas foi registrado em Caruarú, Ceará, 1996. Estas pessoas eram pacientes de um hospital e haviam sido submetidas à diálise na qual se utilizou água proveniente de uma represa com floração de Microcystis, havendo suspeita, segundo notícias divulgadas por toda a imprensa escrita e falada, destas mortes haverem sido causadas por microcistinas, toxinas encontradas em Microcystis aeruginosa. As microcistinas causam lise celular e degeneração hepática (Falconer, 1989), os sintomas são: fraqueza, diarréias, estremidades frias e hepatomegalia (Carmichael, 1992). Embora ainda não haja confirmação oficial ou trabalhos científicos sobre as causas desta mortalidade, talvez este seja o melhor momento para alertar as autoridades e a população em geral, para os riscos da ignorância acerca dos recursos naturais dos quais dependemos para sobreviver. Este caso alerta também para os riscos de utilizar águas contaminadas para servir as populações humanas que já estejam com sua saúde comprometida.

Porém tão importante quanto os efeitos destes surtos, seria considerar o potencial de injúria à saúde decorrente da ingestão contínua de águas contaminadas com baixos teores de toxinas algáceas.

Como há tendência destas florações serem recorrentes em águas eutrofizadas de represas tropicais e sub-tropicais, algumas populações humanas correm $o$ risco de ingerir continuamente estas toxinas. Os efeitos de ingestões contínuas ainda não estão bem determinados devido a inviabilidade de realizar testes com populações humanas, entretanto há correlação entre o número de casos de câncer e o uso da água proveniente de mananciais superficiais lênticos com florações de cianoficeas na China, relatados por Carmichael (1992). Em ratos a toxicidade crônica por ingestão repetida promove tumores, induz crescimento de papilomas dérmicos após sua indução com carcinogênicos, estimulando o desenvolvimento de câncer, segundo o mesmo autor. Efeitos teratogênicos devidos a administração oral contínua de extratos de Microcystis foram demonstrados em ratos de ambos os sexos, sendo que a prole apresentou danos no hipocampo e volume cerebral menor do que o normal (Carmichael, 1992).

A sulfatação constitui uma medida paliativa emergencial. Segundo Falconer (1989) os tratamentos convencionais não removem as toxinas e a aplicação de sulfato de cobre provocando a lise das células algáceas, libera de uma só vez todo o conteúdo de toxinas, produzidas pelas algas, para a água. $\mathrm{O}$ carvão ativado mostrou-se efetivo, prático e viável 
economicamente para remoção das toxinas, necessitando, entretanto, de adequação de propostas de engenharia que facilitem a implantação deste método nas instalações das estações de tratamento de água existentes. $\mathrm{Na}$ Austrália as autoridades responsáveis pelo abastecimento de água, aplicam sulfato de cobre antes da formação de florações de cianobactérias, na concentração de 0.2 a 1.0 ppm, com base nas contagens de 100 a 1000 células por mililitro de água. Nos locais onde se tem acesso ao carvão ativado, o tratamento da água está sendo modificado para incluir a adsorção das toxinas (Carmichael, 1992).

Dentre as cianoficeas encontradas na Guarapiranga durante este estudo, Carmichael e col. (1972) citam Synechocystis sp como produtora de toxina semelhante a anatoxina-C.

Estes resultados demonstram a necessidade de impedir as florações tóxicas e mostram que o controle algáceo efetuado na represa, utilizando sulfato de cobre não é satisfatório, havendo urgência na aplicação de métodos mais eficientes e menos arriscados.

\subsubsection{INDICADORES PRÉVIOS DO DESENVOLVIMENTO EXCESSIVO DO FITOPLÂNCTON E DAS CIANOFÍCEAS}

É interessante observar que na represa de Guarapiranga, decorrem aproximadamente duas semanas entre a alteração promovida por aumento da intensidade pluviométrica e o nivel perceptível de produtividade primária intensa ou das alterações da qualidade da água.

Uma vez que haja disponibilidade de nutrientes, a qual evolui na mesma proporção do aumento anterior da biomassa fitoplanctônica, a eficiência do controle algáceo teoricamente tende a decair. As algas, após a morte em altas taxas de uma só vez, seja por sulfatação ou por causas naturais, liberam grandes quantidades de nutrientes para a coluna d'água, que tornam-se disponíveis para outras espécies. O controle da biomassa sendo efetuado logo no início das chuvas e portanto prevenindo seu aumento, pode ser uma forma de diminuir a disponibilidade dos nutrientes na coluna d'água, permitindo que haja tempo para remoção por diluição, decantação ou transporte horizontal. A sulfatação efetuada na represa não seguiu este critério no período estudado.

Portanto, seria interessante realizar o monitoramento destas mesmas variáveis durante o controle efetuado segundo o critério proposto, para avaliar sua eficiência.

Se a origem de Mougeotia foi litorânea, sua floração poderia ter sido evitada detectandose os bancos de crescimento em tempo, aplicando-se sulfato de cobre para o controle de Dictyosphaerium simultaneamente à aplicações nos bancos de macroalgas, evitando que as populações de Mougeotia se desgarrassem das margens pela ação das ondas e correntes 
produzidas nos periodos de maior intensidade pluviométrica e viessem a ocupar a água aberta, sem competidores devido à recente sulfatação.

As densidades e biovolumes mais expressivos de cianoficeas foram registradas nos períodos de senescência de altos biovolumes de florações de cloroficeas e de zignemaficeas: a senescência de Dictyosphaerium, devida a aplicações maciças de sulfato de cobre, foi seguida pela elevação de cianoficeas como Aphanocapsa elachista var planctonica e Aphanocapsa elachista var conferta - em D33; a de Scenedesmus bijugus - por Aphanocapsa elachista var conferta em J56 e em J57 e Oscillatoria subtilissima em J57 e em JL58 e Pseudoanabaena catenata em J57 e a da zignemaficea Mougeotia cf. americana - por Oscillatoria subtilissima entre $\mathrm{AB} 47$ e MA51.

Sob condições de densidade e biovolume prévios mais baixos, não atingindo valores de florações em J5, o biovolume expressivo de Aphanocapsa delicatissima foi simultâneo ao decréscimo da biomassa de cloroficeas e em J8 houve alta contribuição de Synechococcus elongatus para a densidade, concomitante com o início de um decréscimo acentuado das cloroficeas em geral, embora não houvesse aplicação de sulfato de cobre.

Quanto à coleta inicial MA2 que mostrou biovolume expressivo de Aphanocapsa elachista var planctonica, por não haver conhecimento anterior, não há condições de análise.

Estes resultados mostraram o que nesta comunidade seria o caso mais próximo e evidente encontrado, de alteração dependente de eventos em que a biomassa fitoplanctônica influiu acentuadamente, ainda que por motivos alógenos.

Os indícios prévios mais significativos da taxa acelerada do crescimento e/ou aumento do biovolume de cianoficeas, encontrados na represa foram:

a) a elevação da pluviosidade, que promove aportes por carreamento e/ou percolação da bacia de drenagem, aumentando a concentração e disponibilidade de nutrientes na água;

b) a concentração de nutrientes, principalmente nos períodos de seca mais intensa;

c) o aumento significativo da biomassa algácea, especialmente de clorococales, acarretando aumento da disponibilidade durante seu declínio e manutenção dos nutrientes na coluna d'água, além de diminuir a incidência luminosa para os estratos inferiores;

d) o incremento dos fatores que promovem a mobilização da massa d'água (chuvas, vento, etc.), promovendo ressurgências de nutrientes e o ingresso de algas do perifiton, para a água aberta.

Surgem então algumas questões: porque não houve maiores densidades de cianoficeas durante o período de estudo? No ponto 4 , a ausência de estabilidade decorre possivelmente da maior mobilização da massa d'água. Mas no ponto 1 a sulfatação intensiva nos períodos 
propícios ao seu desenvolvimento teria sido o principal fator limitante? A floração de Aphanocapsa elachista demonstrou que não. A mobilização da água nos períodos de maior disponibilidade de nutrientes impediu a estabilidade da coluna que segundo Reynolds (1984) é uma das condições para as florações. Outros fatores a considerar seriam condições favoráveis quanto ao $\mathrm{pH}$ e ao gás carbônico. As florações de cianoficeas foram em geral simultâneas aos períodos de queda de gás carbônico, aumento de $\mathrm{pH}$, ocorreram logo após florações de cloroficeas ou zignemaficeas e portanto iniciaram-se em fases de menor luminosidade, a sulfatação liberando grandes quantidades de nutrientes, inclusive de nitrogênio favoreceram as cianoficeas não fixadoras deste gás (Figuras 20 e 21). A sulfatação também inibe a decomposição e a queda consequiente do $\mathrm{pH}$.

Havia inóculo da espécie Aphanocapsa elachista. Apesar da existência de outras espécies de cianoficeas, esta em especial apresentou-se mais eficiente nestas condições e destacou-se das outras espécies de cianoficeas, que em outros momentos atingiram densidades elevadas como Oscillatoria subtilissima e Pseudoanabaena catenata no ponto $1 \mathrm{e}$ Oscillatoria subtilissima e Synechococcus elongatus no ponto 4, por apresentar biovolume mais expressivo.

As ocorrências de florações de cianoficeas nesta represa obedeceram estritamente a todas as condições relatadas na literatura citada.

\subsubsection{ALGAS POTENCIALMENTE PREJUdICIAIS AO TRATAMENTO DA ÁGUA PARA ABASTECIMENTO}

Dentre as três espécies que atingiram elevados valores de densidade relativa em cada coleta e podem representar ônus ao processo de tratamento pela obstrução de filtros, ocorreram os seguintes gêneros:

\begin{tabular}{|ll|}
\hline QUADRO DOS GÊNEROS POTENCIALMENTE CAUSADORES DE ÔNUS AO \\
TRATAMENTO, REGISTRADOS NA REPRESA DE GUARAPIRANGA - 1991-92 \\
Ponto 1 \\
Bacilariophyceae & Synedra, Rhizosolenia, Aulacoseira, Asterionella \\
Chrysophyceae & Dinobryon \\
Euglenophyceae & Trachelomonas \\
Chlorophyceae & Dictyosphaerium, Chlamydomonas (cf. gloeophila) \\
Zygnemaphyceae & Mougeotia, Mougeotiopsis \\
\hline
\end{tabular}




\begin{tabular}{|ll|}
\hline Ponto 4 & \\
Bacilariophyceae & Synedra, Rhizosolenia, Aulacoseira, Asterionella \\
Chrysophyceae & Mallomonas \\
Dinophyceae & Peridinium sp3, Gymnodinium (fuscum) \\
Euglenophyceae & Trachelomonas \\
Chlorophyceae & Chlamydomonas (cf. gloeophila), Botryococcus, Dictyosphaerium \\
Zygnemaphyceae & zigoto de Oedogoniales \\
\hline
\end{tabular}

A obstrução de filtros demanda maior consumo de água tratada para sua lavagem, causando lentidão no tratamento. A capacidade de obstruir filtros é maior com altas densidades de organismos com: envoltório celular rígido (diatomáceas, dinoficeas como Peridinium sp.3 e euglenoficeas como Trachelomonas volvocina); estrutura filamentosa (zignemaficeas Mougeotia cf. americana e diatomáceas filamentosas Aulacoseira granulata); fios de gelatina (cloroficeas como Dictyosphaerium ehrenberghianum); massas de gelatina (como Chlamydomonas cf gloeophila e volvocales coloniais) maior porte (Gymnodinium fuscum, Synedra ulna, Rhizosolenia eiriensis).

A biomassa algácea é considerada problemática à partir de 2000 UPA.ml $^{-1}$ (Branco, 1986), valor atingido no ponto 1 nas seguintes coletas: MA2 a J6, AG13, AG14, AG16, S18, $\mathrm{O} 24$, N26 em diante, portanto, em 41 coletas, perfazendo $73 \%$ das coletas. No ponto 4 atingiu 2000 UPA.ml $^{-1}$ nas coletas: MA2, J6, AG14, S19, N26 a D32, JA34, JA35, JA37, F39, F40, MR42, AB45, AB47 a J56 e JL58, portanto em 28 coletas perfazendo 50\% das coletas, com equivalência de coletas de seca e chuva.

Alta densidade e biomassa totais de algas também causam os mesmos problemas. Valores de biovolume superiores a $5000 \mathrm{um}^{3} \cdot 10^{-3}$ ocorreram no ponto 1 nas coletas: J5, S18, 021, O24, N26 a D33, JA36, F38 a F41, AB47, AB49 a MA51 e JL58. No ponto 4 nas coletas: O25 a D33, JA35, JA37, F39, F40, MR42 a MR43, AB45, AB48 a AB49, MA51 a J54, J56 e JL58.

O número de coletas do período seco e chuvoso em valores de densidade numérica de org.ml ${ }^{-1}$ superiores a 10000 foi semelhante (ponto 1 seca=19; chuva=18; ponto 4 seca=11, chuva=12) o mesmo ocorrendo para bioárea (ponto 1 seca=23, chuva=21; ponto 4 seca=11, chuva=13), mas quanto ao biovolume os valores superiores a $5000 \mathrm{um}^{3} \cdot 10^{-3}$ foram mais comuns no periodo das chuvas (ponto 1 seca=6, chuva=16; ponto 4 seca=8, chuva=15), portanto o período das chuvas favoreceu a ocorrência de biovolumes mais elevados, mais 
problemáticos ao tratamento (entupimento de filtros, esgotamento da capacidade dos filtros de carvão ativado, etc.).

Segundo Klapper (1991) partículas inferiores a $2 \mathrm{~mm}$, que é o diâmetro usual empregado em muitos sistemas de filtração rápida, não são retidas pela filtração e sua remoção depende da adição de coagulantes como o sulfato de aluminio e o cloreto férrico.

Florações também exigem o emprego de coagulantes (Klapper, 1991). Algumas substâncias de origem algácea agem como inibidores da floculação, causando o aumento da concentração necessária de coagulantes e portanto o aumento de metais adicionados à água durante o tratamento da água já filtrada. A remoção do cloro, ocasionada por estas substâncias, agrava o problema de desinfecção da rede de distribuição da água e os locais não atingidos pela desinfecção ficam expostos à reinfecção e contaminação por animais herbívoros do zooplâncton, protozoários, bactérias e outros, que se alimentam nos filmes biológicos aderidos às paredes das tubulações. Algas capazes de uitrapassar os filtros, podem desenvolver-se nestes filmes e também servir de alimento aos herbívoros.

Symons e col. (1981, apud Klapper, 1991), demonstraram experimentalmente a relação entre a poluição orgânica e a formação de trihalometanos cancerígenos, após cloração de uma ampla gama de suspensões algáceas. Durante este processo formam-se também outros compostos organoclorados prejudiciais à saúde, como o clorofórmio.

No levantamento das espécies indicadoras realizado observa-se grande quantidade de algas com potencial para produzir odor e sabor na água. Uma das principais objeções ao uso da água da represa de Guarapiranga durante o período de estudo foi seu forte odor, geralmente de terra ou mofo, perceptível mesmo com cloração elevada.

\subsubsection{CONTROLE ALGÁCEO}

Mackenthun e Ingram (1967) afirmam que, desde 1904 até o presente, o sulfato de cobre tem sido o produto químico mais utilizado no controle algáceo, podendo-se estender esta afirmação até a década atual. A despeito de seu uso intensivo há restrições, pois concentrações elevadas podem causar envenenamento de peixes e outros organismos aquáticos, pode haver acúmulo nos sedimentos sob a forma de compostos insolúveis devido ao uso extensivo e além disto o produto é corrosivo, danificando pinturas e equipamentos (Damato e col., 1989).

$O$ cobre inibe a taxa de fotossíntese e de respiração celular e desta forma a divisão celular das algas.

O controle da densidade algácea durante o período de estudo foi efetuado pela SABESP através da aplicação de sulfato de cobre nas regiões próximas à captação, córrego Itupu, 
Guavirutuva, rio Bonito e rio São José, locais em que geralmente ocorrem as densidades mais elevadas. Segundo Caleffi (1994), dados fornecidos pela Coordenadoria de Recursos Hídricos e Proteção Ambiental da SABESP reportam que no ano de 1991 foram aplicadas 51,6 toneladas de sulfato de cobre e de janeiro a agosto de 1992, 96,6 toneladas já haviam sido aplicadas na represa de Guarapiranga, para controle das altas densidades algáceas, dado alarmante, mas comparável aos da CETESB (1983) para o período de 1981 a 1983, mencionados na introdução deste trabalho (1.5 toneladas em 1981, 123 toneladas em $1982 \mathrm{e}$ 63 toneladas no primeiro trimestre de 1983). O ano de 1982 foi um marco neste histórico, pois foi o ano em que as florações de cianoficeas passaram a ser recorrentes nesta represa.

Kleerekoper (1939) relata altas densidades algáceas na região da baía do rio Itupu, atribuindo-as aos ingressos de esgoto das residências e áreas construídas às margens da represa, que já ocorriam desde aquela época. $O$ ponto 1 deste estudo, por ser o mais próximo da captação recebe sulfatação com maior constância e freqüência de aplicação. O ponto 4 por situar-se à montante das áreas de maiores aportes de esgoto e também a montante da área sulfatada, não sofreu aplicações do sulfato de cobre durante este estudo.

Caleffi (1994) observou que na região próxima à captação, onde se aplica grandes quantidades de sulfato de cobre, a comunidade zooplanctônica apresentou densidades menores e maior frequêencia relativa de rotíferos, além de porcentagens inexpressivas de cladóceros e copépodos calanóides.

As aplicações de sulfato de cobre são eficientes na eliminação das algas da superficie e dependendo da qualidade da água podem ser mais ou menos eficientes ao longo da coluna d'água (Damato e col. 1989). Além da toxicidade, a decomposição destas algas eleva o consumo de oxigênio e a disponibilidade de nutrientes e matéria orgânica em toda a coluna e no sedimento, diminuindo a capacidade de autodepuração do sistema, alterando também desta forma a qualidade do ambiente para toda a fauna aquática, especialmente para os organismos mais exigentes quanto aos teores de oxigênio dissolvido.

A aplicação do sulfato de cobre tem sido intensiva e extensiva na represa de Guarapiranga, durante as últimas décadas. As espécies poderiam ter sido selecionadas, por sua resistência a este algicida e desta forma a grande maioria das espécies atualmente encontradas apresentariam então, esta característica. Entretanto, isto pode não corresponder.a realidade, pois trata-se de um ambiente que recebe aportes constantes de águas, contém algas de áreas não sulfatadas e tem baixo tempo de retenção, além do fato de que o período necessário à reprodução pode ser menor que o intervalo de aplicação do algicida. Como a captação é feita 
em profundidade, uma parte considerável de cobre pode ser removida como material precipitado, através do revolvimento do sedimento (CETESB, 1992).

Do conjunto de espécies encontradas, 118 foram comuns aos dois os pontos, ou seja, $66 \%$ das algas do ponto 4 , que não recebia sulfatação, também ocorriam no ponto 1 . Este valor não é tão baixo, considerando-se que os dois pontos apresentavam diferenças de fluxo, profundidade, estabilidade da coluna, etc., porém também não é conclusivo, havendo necessidade de maior informação.

A influência da sulfatação sobre o biovolume das espécies dominantes pode ser constatada pelos resultados das correlações entre os teores de aplicação de sulfato no dia anterior e no dia da coleta. Entre as espécies dominantes e abundantes apenas Rhizosolenia eiriensis apresentou correlação negativa de seu biovolume com as sulfatações ( $r s=-0.27$ $\mathrm{P}=0.0440$ com a do dia anterior e $\mathrm{rs}=-0.32 \mathrm{P}=0.0186$ do dia da coleta), indicando a necessidade de estudos experimentais para testar sua sensibilidade ao sulfato de cobre. Geminella interrupta ( $\mathrm{rs}=0.39 \mathrm{P}=0.037$ dia anterior e $\mathrm{rs}=0.50 \mathrm{P}=0.0002$ do dia), Mougeotia cf. americana ( $\mathrm{rs}=0.55 \mathrm{P}=0$ dia anterior e $\mathrm{rs}=0.54 \mathrm{P}=0.0001$ do dia), Scenedesmus bijugus ( $\mathrm{rs}=0.52 \mathrm{P}=0.0001$ dia anterior e $\mathrm{rs}=0.37 \mathrm{P}=0.0058 \mathrm{do} \mathrm{dia}$ ) e Synedra ulna $\mathrm{t} 1$ ( $\mathrm{rs}=0.45$ $\mathrm{P}=0.0001$ dia anterior e $\mathrm{rs}=0.41 \mathrm{P}=0.0025$ do dia) apresentaram correlação positiva com as sulfatações do dia anterior e do dia da coleta, podendo ser consideradas resistentes.

Mougeotia cf. americana, por ter apresentado valores de biovolume superiores durante as chuvas intensas e por ser possivelmente espécie do perifiton, pode ter tido sua biomassa rapidamente reposta na massa d'água devido às intempéries deste periodo, mas os exemplares examinados apresentavam-se com excelente aspecto, parecendo pouco provável que estivessem sofrendo danos à sua integridade devido ao algicida.

Chlorella vulgaris var viridis ( $\mathrm{rs}=0.28 \mathrm{P}=0.0353$ do dia da coleta), Scenedesmus bicaudatus ( $\mathrm{rs}=0.30 \mathrm{P}=0.0250$ do dia), Scenedesmus bijugus ( $\mathrm{rs}=0.37 \mathrm{P}=0.058$ dia) e Synedra minuscula ( $\mathrm{rs}=0.31 \mathrm{P}=0.0200$ do dia) apresentaram correlações posistivas com as aplicações de sulfato do dia anterior. As demais espécies dominantes, abundantes ou muito freqüentes nas amostras do ponto 1 não apresentaram correlação significativa com os teores de sulfato de cobre aplicado, podendo ser consideradas indiferentes ou tolerantes.

Branco (1986) relata, conforme já mencionado, a resistência de Scenedesmus ao sulfato de cobre, mas afirma que Synedra é um gênero sensível e portanto sua ocorrência nestes periodos pode decorrer de características particulares das espécies encontradas ou destas espécies serem bentônicas, com acesso facilitado para água aberta nos períodos de maior mistura como ocorreu com Mougeotia. 


\section{SUBSÍDIOS E MEDIDAS PARA REABILITAÇÃO DA QUALIDADE AMBIENTAL}

O tempo de residência da água na represa de Guarapiranga sendo menor que um ano, aliado à seu alto potencial de autodepuração indicam que a qualidade de suas águas pode tornar-se excelente tão logo sejam eliminadas as causas da poluição, entretanto, a maior parte da poluição que recebe é consumida pelos usuários da água em menos de um ano!

A necessidade de melhorar a qualidade da água, diminuindo a eutrofização e o aporte de metais pesados é urgente, visto que quase a totalidade de sua água é utilizada para consumo humano. Os teores de alumínio devem ser imediatamente diminuidos em suas águas, pois podem contribuir para a ocorrência de doenças neurológicas crônicas nos usuários da água, com elevados custos sociais e financeiros. As florações de algas potencialmente tóxicas, devem ser impedidas pela restrição das condições favoráveis ao seu desenvolvimento, dentre as quais a única passivel de controle através do manejo é a eutrofização.

O processo de tratamento da água deve garantir a deteç̧ão e a remoção de toxinas através de técnicas já existentes como aplicação de carvão ativado, ou de técnicas alternativas a serem pesquisadas - ou garantir o impedimento da distribuição da água contaminada.

O estudo das represas de abastecimento precisa tornar-se prioritário através do aumento de investimento em pesquisa científica, geração de tecnologia e da promoção de parcerias entre os órgãos capacitados a estes estudos.

A represa de Guarapiranga por sua importância no abastecimento e pelos problemas relacionados à sua eutrofização, pode servir de modelo para aplicação de medidas de recuperação e reabilitação da qualidade ambiental, que poderão posteriormente ser aplicados a outros corpos d'água em situação semeihante.

A principal dificuldade para implantar medidas de recuperação, relaciona-se à sensibilização política e social para os problemas decorrentes da degradação, aliada ao descaso com o ambiente.

No desenvolvimento da teoria econômica, água, ar, solo, vegetais e animais de boa qualidade tem sido tratados tradicionalmente como inexauriveis e, portanto, sem valor (CGLRM, 1991). Atualmente considera-se que estes recursos são exauriveis e sua qualidade pode ser prejudicada, a despeito dos avanços tecnológicos. A concep̧̧ão de que estes elementos devem ser tratados como capital ambiental, vem substituir a noção anterior, tornando importante a incorporação do capital ambiental aos instrumentos econômicos existentes, que direcionam o controle ambiental, p.ex. análises de impacto ambiental, análises de custo-benefício e análises de decisão. Estes esforços somente serão bem sucedidos se os estudos forem baseados na premissa de que o homem é parte do ambiente. A abordagem 
monetária persiste, pois provê meios de medir elementos díspares do ambiente e da economia, de forma a integrá-los. Neste contexto, o CGLRM (1991), deixando de lado considerações sobre recreação, estética e outros usos da água, atendo-se apenas ao uso para consumo humano, considera como indicadores potenciais da resposta do usuário à degradação ambiental:

a. em termos quantitativos: a reserva, a captação e a estimativa de renovação da água;

b. em termos qualitativos: os custos de tratamento, violações dos padrões químicos e bacteriológicos, restrições ao consumo, relatos de moléstias agudas e da satisfação dos usuários por receber um produto de qualidade e pela percepção de um ambiente saudável;

c. em termos de avaliação de custos: a disposição de pagar e compensar pelo dano ao ambiente, avaliações do bem estar humano e dos valores sociais;

d. em termos de manejo: os custos do tratamento da água e da manutenção e operação do manancial e portanto o custo do produto ao consumidor;

e. em termos de saúde humana: os custos médicos e a perda humana potencial.

Aconselhando considerar-se estes fatores nos niveis da saúde humana tanto da comunidade abastecida como dos habitantes da área da bacia hidrográfica.

No caso de Guarapiranga, as falhas no abastecimento, o aumento do custo de tratamento, 0 descontentamento da população abastecida, os relatos de distúrbios agudos da saúde provocados pelo consumo da água, servem para confirmar que apesar do pouco conhecimento formal sobre estes dados, estes indicadores são úteis e podem ser utilizados para sensibilizar a população e os órgãos governamentais responsáveis, para a necessidade de medidas mais efetivas de controle ambiental nesta bacia.

Não se pretende esgotar o quadro de medidas necessárias à reabilitação e nos textos do Programa de Saneamento Ambiental da Represa de Guarapiranga (PARA SALVAR..., 1992) e em COBRAPE (1991, 1994a, 1994b, 1995) esta discussão é extensiva e outras medidas também são propostas. Porém, durante este estudo, algumas peculiaridades do sistema e da situação chamaram muito a atenção, tornando esta contribuição indispensável por basear-se no estudo de campo da realidade atual da represa e mesmo incorrendo no pecado da redundância, a importância deste manancial e a urgência da situação permitem este procedimento.

Os resultados deste estudo mostraram que num contexto de longo prazo, como medida profilática à melhoria da qualidade da água, é indispensável a redução drástica dos aportes de nutrientes e minerais contaminantes originários da bacia de drenagem, o que pode ser feito através das seguintes ações:

1. reflorestar as áreas em que o solo está exposto e impedir novos desmatamentos, 
através da criação de parques, p.ex.;

2. tratar os esgotos produzidos na bacia através de processos primários, secundários e terciários, mantendo a água remanescente na própria bacia;

3. impedir o assentamento de novas populações e o crescimento das áreas urbanas na bacia, através do incentivo à atividades econômicas não impactantes, com ocupação extensiva de grandes áreas e oferta de poucos empregos, evitando novas ocupações urbanas;

4. impedir as atividades impactantes de mineração, que segundo Beyruth (1994b) contribuem para a eutrofização e aportes de sólidos, diminuindo a capacidade de retenção de água, pelo rápido assoreamento;

5. remover o lixo produzido na bacia e impedir a importação de residuos sólidos provenientes de outras áreas - como é o caso do produto da dragagem da represa Billings, decorrentes da instalação de lixões ou depósitos clandestinos na bacia de Guarapiranga, que também se constitui num problema muito grave, segundo Beyruth (1994b);

6. criar áreas de contenção de impacto, através do reflorestamento, entre a represa, seus tributários e as terras utilizadas da bacia;

7. criar ou exercer dispositivos legais que obriguem as indústrias a captarem água a jusante de seus lançamentos, nos corpos d'água desta bacia, quando estes lançamentos forem permitidos;

8. proteger especialmente as áreas de inundação dos tributários e remover as populações já instaladas na bacia de captação, pois estas áreas constituem zonas de contenção de nutrientes e minerais, tendo alta capacidade de depuração e assimilação (Beyruth, 1989, 1994b), além disto sua ocupação promove problemas sociais graves e ônus para o Estado, por estarem sujeitas a enchentes;

9. como a contribuição da população humana autóctone para a degradação desta bacia é considerável, qualquer iniciativa para conter a degradação deve considerar como prioridade o envolvimento da população, através de programas intensivos e extensivos de educação ambiental.

Como medidas de médio prazo (um a dois anos) sugere-se gerar e/ou testar intensivamente até encontrar soluções e implantar tecnologias que promovam:

1. a remoção de nutrientes e contaminantes;

2. a remoção e o aproveitamento econômico da biomassa algácea;

3. a deteç̧ão mais eficiente dos problemas de toxicidade;

4. o aproveitamento econômico da biomassa de organismos que possam servir como alimento; 
5. melhoria no sistema de operação da represa quanto à contenção do desenvolvimento da biomassa algácea;

6. melhoria no sistema de tratamento da água;

A SABESP realiza amostragens rotineiras na represa de Guarapiranga, há aproximadamente 40 anos, mas os dados obtidos não tiveram o tratamento merecido por falta de tempo e de especialistas nas diversas áreas de conhecimento, especialmente na área de saneamento ambiental, a qual encontra-se atualmente, praticamente em extinção, com baixa produtividade e capacitação científica e tecnológica em todo o país. O conhecimento do histórico da área e das séries históricas de dados ambientais podem mostrar padrões de comportamento dificeis de detectar através de dados de apenas um ciclo hidrológico. Estes fatos indicam que seria útil a implantação de um centro ou núcleo de estudos sobre represas de abastecimento do Estado de São Paulo, envolvendo SABESP, CETESB, Institutos de Pesquisa e Universidades, para num esforço conjunto efetuar em parceria, o acompanhamento da obtenção e análise de dados, realizando avaliações em maior profundidade, que poderiam fornecer informação científica e suprir a necessidade de conhecimento para a criação de tecnologia, nas áreas necessárias para o manejo destes ambientes.

Como medidas de curto prazo:

1. promover ações de sensibilização política e social através de programas de educação e de informação da comunidade;

2. melhorar o manejo, utilizando critérios mais eficientes, baseados no conhecimento adquirido;

3. ampliar o conhecimento sobre os aportes dos tributários e o comportamento das áreas de entrada dos tributários;

4. ampliar o conhecimento sobre as áreas marginais e o desenvolvimento do perifiton;

5. ampliar o conhecimento sobre a dinâmica trófica e de sedimentação/ressurgência deste ambiente;

6. realizar parcerias entre SABESP e instituições de pesquisa, aproveitando melhor os recursos do Estado, visando o aprimoramento tanto do sistema de obtenção de informação como dos critérios de manejo. 


\section{UTILIZAÇÃO E APROVEITAMENTO ECONÔMICO DA BIOMASSA ALGÁCEA}

Num contexto mais simples e prático a remoção da biomassa algácea e seu aproveitamento podem ser efetuados através de:

- aproveitamento da biomassa fitoplanctônica como alimento para o zooplâncton e peixes, especialmente os de interesse esportivo, comercial e ou social; caso em que há necessidade da verificação prévia do potencial de bioacumulação de metais pesados e outros poluentes;

- instalação de tanques-rede com espécies de peixes planctófagas, autóctones ou já existentes na represa, também demandando verificação prévia do potencial de bioacumulação de metais pesados e outros poluentes;

- instalação de suportes para desenvolvimento de perifiton e aproveitamento comercial para produção de ração para zooplâncton e outros organismos, bem como de material a ser utilizado na descontaminação de efluentes com teores elevados de metais pesados;

Apenas o controle das cianoficeas já teria uma função econômica apreciável, mas o controle biológico das populações de cianoficeas pode constituir uma forma a mais de aproveitamento econômico se envolver o cultivo de zooplâncton e de peixes planctívoros. Bactérias e cianófagos poderiam ser utilizados para o controle das cianoficeas mas o risco potencial do manejo com estes microorganismos desaconselha o uso destes métodos.

Carmichael (1992) relata suas observações na China sobre o decréscimo das populações de cianobactérias, com elevada taxa de remoção nas criações das seguintes espécies de peixes: Hypophthalmichthys molitrix, Ctenopharyngodon idellus, Aristichthys nobilis, Tilapia nilotica (Oreochromis niloticus) e Tilapia mossambica. Na Guarapiranga existem as espécies Oreochromis niloticus e Tilapia rendalli (Zagatto, 1995).

Os peixes parecem não serem afetados pelo consumo de algas tóxicas e quando removem grandes colônias de Microcystis de tanques de aquicultura ou mesmo de lagos de tamanho significante, deixam espécies de pequenas algas unicelulares e flageladas, as quais constituem melhores fontes de alimento para o zooplâncton (Carmichael, 1992). Tem-se observado o colapso de populações de cianoficeas como resultado de herbivoria pelo ciliado Nassula (Canter e col., 1990 apud Carmichael, 1992) e no Japão tem-se utilizado rotífera e oligoqueta para controlar florações de Microcystis. Entretanto Microcystis, Nodularia e Anabaena apresentam efeitos danosos para Daphnia e Diaptomus (Demott e col., 1991 apud Carmichael, 1992).

Num contexto mais elaborado, de tecnologias mais sofisticadas e portanto mais dispendiosas, poderia ser estudada a viabilidade de utilizar-se os princípios de autodepuração, 
aplicados a corpos d'água ou a canais de contenção artificiais, construídos em cotas mais elevadas à volta da represa, que pudessem reter nutrientes, utilizando-se o mesmo princípio das lagoas de estabilização, conforme aconselhado por Straskraba (comunic. pessoal) e posteriormente proposto por Lemos e col. (1993) para a represa de Sumaré.

Vários tipos de sistemas utilizam microorganismos vivos para descontaminação de esgoto e águas servidas, em locais onde a concentração de metais, encontra-se abaixo do nível em que a toxicidade se manifesta. Sistemas de tanques e meandros de água corrente contendo algas como Cladophora, Spirogyra, Rhizoclonium e cianoficeas como Oscillatoria tem sido utilizados para tratamento de efluentes de mineração mostrando redução de chumbo, zinco, cobre e manganês para niveis permitidos para o lançamento (Gale e Wixson, 1979, apud. Gadd, 1988). Outros sistemas de tratamento utilizando algas e bactérias mostraram remoção de urânio, selênio, cádmio e molibdênio de efluentes de mineração de urânio, através da passagem por três tanques consecutivos de algas, segundo Brierley e Brierley (1983 apud. Gadd, 1988)

Boyle (1984) também relata a bioconcentração de metais pesados por algas planctônicas e levanta a hipótese de que as algas são organismos que podem ser menos sensiveis aos contaminantes aquáticos, sendo muito importantes na mitigação de seus efeitos sobre os outros organismos, tanto por degradarem substâncias químicas orgânicas como por bioacumularem substâncias tóxicas em geral, diminuindo sua disponibilidade no ambiente aquático.

Zagatto (1995) realizou ensaios de acumulação de cobre com Oscillatoria quadripunctulata, Pseudoanabaena galeata e Microcystis aeruginosa provenientes da represa de Guarapiranga e de uma cepa tóxica de Microcystis aeruginosa (NPJB), submetidas as concentrações de $0.06 \mathrm{mg} .1^{-1}$ para Microcystis e de $0.33 \mathrm{mg} .1^{-1}$ para as demais (equivalente respectivamente a 0.25 e $1.18 \mathrm{mg} \cdot \mathrm{l}^{-1}$ de sulfato de cobre). Os resultados mostraram acumulação de cobre pelas algas, sendo que Oscillatoria quadripunctulata e Microcystis aeruginosa (NPJB) mostraram acumulação mais elevada, aproximadamente na ordem de 8000 e 10000 vezes. A avaliação do teor de cobre no fitoplâncton, zooplâncton e peixes da represa de Guarapiranga mostrou que a concentração no fitoplâncton era de três a sete vezes maior do que a encontrada no zooplâncton, com teores máximos no fitoplâncton de $6.6 \mathrm{mg} \cdot \mathrm{g}^{-1} \mathrm{e}$ de 1 mg. $g^{-1}$ no zooplâncton. Os dados obtidos para peixes mostram acúmulo maior nas vísceras que na musculatura, com valor médio de $0.9 \mathrm{mg} \cdot \mathrm{g}^{-1}$ na musculatura e $34 \mathrm{mg} . \mathrm{g}^{-1}$ nas visceras. A legislação para os teores de cobre no alimento estabelece $30 \mathrm{mg} \cdot \mathrm{kg}^{-1}$ como valor máximo permitido e portanto a carne dos peixes eviscerados, das diferentes espécies piscícolas da represa de Guarapiranga estava em conformidade com o limite preconizado na legislação, 
podendo ser consumida (Zagatto, 1995). Este autor ressalta que os teores de cobre mais elevados nas vísceras resultam da ingestão de matérias de origem orgânica sedimentar ou alimentar (fitoplâncton e zooplâncton), contaminadas pelo cobre.

Florações de algas, que podem ser provocadas pela presença de esgoto doméstico, podem prestar-se à biosorção de metais pesados. As algas também podem ser imobilizadas através de alginatos ou peletizadas como biomassa algácea morta, para biosorção de metais pesados. Estas tecnologias podem vir a ser necessárias e aceitas no futuro, ainda que atualmente seu uso tenha baixa prioridade política e industrial, tendo importância prioritária apenas como medida de proteção ambiental (Gadd, 1988). 


\section{CONCLUSÕES}

As principais forçantes sobre a qualidade da água da represa de Guarapiranga resultam dos efeitos dos fatores climáticos, da operação da represa e das conseqüências das atividades antrópicas desenvolvidas em sua bacia de drenagem. Estrutura, composição e alteração da comunidade fitoplanctônica estão, portanto, sujeitas aos efeitos conjuntos destas funções de força e da qualidade da água. Seus principais problemas atuais decorrem da eutrofização de suas águas decorrentes dos ingressos de esgotos domésticos lançados em suas águas.

Esta represa tem alta capacidade de depuração, devido ao seu elevado potencial oxidativo, favorecido por sua alta taxa de renovação e pela mistura das águas promovida pelos ventos, ondas, correntes e atividades náuticas.

A comunidade fitoplanctônica demonstrou os efeitos da eutrofização, através da alta produção em densidade e biomassa totais, bem como da alta densidade e biomassa de espécies indicadoras de águas eutróficas. Mesmo tratando-se de ambiente tão alterado e apesar do controle algáceo efetuado mostrou uma comunidade muito rica em espécies - 240 táxons, apresentando elevados valores de diversidade.

Os dois pontos de coleta estudados mostraram diferenças relacionadas às taxas de renovação da água, bem como às aplicações de sulfato de cobre efetuadas apenas no ponto 1 . Apesar da sulfatação o ponto 1 mostrou maior produtividade que o ponto 4. Aquele ponto, que é a estação de coleta mais próxima à barragem e captação de água para abastecimento, mostrou a influência da urbanização de suas margens, e o ponto 4 , que é a estação mais a montante, mostrou as influências de desmatamentos recentes.

Os efeitos da sulfatação foram marcantes na sequiência da dominância, mas relativamente pouco eficientes no controle algáceo geral e no controle das cianoficeas, favorecendo $o$ desenvolvimento de cloroficeas. Após a aplicação de sulfato de cobre ocorre a senescência de elevados biovolumes de cloroficeas, liberando nutrientes e favorecendo o desenvolvimento de cianoficeas, contrariando os objetivos da aplicação do algicida. As criptofíceas e zignemaficeas apresentaram maior influência da sulfatação na aiteração de suas comunidades e Rhizosolenia eiriensis mostrou-se sensivel ao sulfato de cobre.

A operação hidráulica altera o periodo de elevação (do nível da água) e desta forma influi na seqüência dos eventos sazonais.

A deficiência hidrica do solo, o escoamento e o excedente hídrico associados a variação da pluviosidade e da temperatura delimitaram periodos característicos: o primeiro período de seca em 1991, o periodo do início das chuvas ou das chuvas moderadas, o período das chuvas intensas e o segundo período de seca em 1992. Estas diferenças sazonais e as conseqüentes 
diferenças ambientais de cada período refletiram-se nas alterações da comunidade fitoplanctônica. A sazonalidade magnificada pelas contribuições e aportes da bacia, foi marcante influindo nas densidades, biomassa, dominâncias e na alteração da comunidade.

Clorococales destacou-se como o grupo que atingiu maiores densidades e biovolumes, apresentando elevada riqueza de espécies e grande diversidade de estratégias adaptativas. Zignemafíceas destacou-se por ser o segundo grupo com riqueza mais elevada.

Quanto ao total geral de espécimes quantificados no ponto 1 destacaram-se por elevada densidade (em número de células - ordem decrescente): Mougeotia cf. americana, Chlorella cf. minutissima, Scenedesmus bijugus, Chlorella vulgaris var. vulgaris e Dictyosphaerium ehrenberghianum. No ponto 4 destacaram-se Chlorella cf. minutissima, Mougeotia cf. americana e Dictyosphaerium ehrenberghianum.

Quanto ao total geral de espécimes quantificados no ponto 1 destacaram-se por elevado biovolume (ordem decrescente): Dictyosphaerium ehrenberghianum, Dictyosphaerium pulchellum, Scenedesmus bijugus, Mougeotia cf. americana e Aulacoseira granulata. No ponto 4 destacaram-se: Dictyosphaerium ehrenberghianum, Gymnodinium fuscum, Aulacoseira granulata, Dictyosphaerium elegans e Scenedesmus bijugus.

No ponto 1 destacaram-se por terem sido dominantes quanto a densidade: Dinobryon divergens, Dictyosphaerium ehrenberghianum, Dictyosphaerium pulchellum, Mougeotia of americana, Chlorella vulgaris var. vulgaris e Synedra cf. minuscula. No ponto 4 destacaramse por elevadas densidades Rhizosolenia eiriensis, Mougeotia cf. americana e Botryococcus neglectus.

Quanto ao biovolume destacaram-se por terem sido dominantes, no ponto 1: Aulacoseira granulata, Dictyosphaerium ehrenberghianum, Dictyosphaerium pulchellum, Scenedesmus bijugus, Dinobryon divergens, Aphanocapsa elachista, Chlamydomonas cf. gloeophila, volvocales colonial sp.1, Mougeotia cf. americana e Mougeotiopsis sp.1. No ponto 4 Aulacoseira granulata, Botryococcus neglectus, Dictyosphaerium ehrenberghianum, Dictyosphaerium elegans, Gymnodinium fuscum, Peridinium sp3, Chlamydomonas of gloeophila e volvocales colonial sp 1.

A densidade mais expressiva nesta represa, foi compartilhada por Mougeotia cf americana e Chlorella cf minutissima, no ponto 1 e Chlorella cf minutissima, no ponto 4.0 biovolume mais expressivo foi de Dictyosphaerium ehrenberghianum.

A espécie que mais se destacou nos dois pontos amostrados, quanto a densidade e biomassa foi Dictyosphaerium ehrenberghianum, apenas quanto a densidade destacaram-se 
Chlorella cf minutissima e apenas quanto ao biovolume destacou-se Aulacoseira granulata. No ponto 1, Scenedesmus bijugus, Chlorella cf vulgaris e Oscillatoria subtilissima apresentaram densidades muito elevadas; no ponto 4, Gymnodinium fuscum e Dictyosphaerium elegans destacaram-se por elevados biovolumes.

A produtividade foi mais elevada durante o período das chuvas, com florações consecutivas de clorococales, zignemaficeas, cianoficeas e clorococales, no ponto 1 e de clorococales, zignemaficeas, dinoficeas e clorococales, no ponto 4.

As maiores taxas de alteração da comunidade fitoplanctônica ocorreram nos períodos de chuvas, durante as alterações de dominâncias entre florações.

As estratégias adaptativas favorecidas nesta represa, foram as seguintes: formas unicelulares ou coloniais/cenobiais, de pequeno porte, sem motilidade e sem envoltório rígido, ou seja organismos r-estrategistas oportunistas, como seria de se esperar para um ambiente em constante alteração. Não foram observadas densidades ou biovolumes expressivos dos organismos que obedecessem aos preceitos estritos da estratégia $\mathrm{K}$, mas Dictyosphaerium ehrenberghianum e Aphanocapsa elachista poderiam ser consideradas as espécies com estratégia mais próxima a $\mathrm{K}$.

Na maior parte do periodo a seqüência de espécies apresentou alterações devidas a influências ambientais, entretanto foram identificados periodos de reversão, com retorno a seqüências anteriores aos distúrbios breves ou leves (estiagem temporária durante período de elevada pluviosidade, caracterizando distúrbio breve e aplicação de sulfato de cobre, caracterizando distúrbio leve).

Houve uma acentuada tendência à dominância por espécies tolerantes ou dependentes de distúrbios no verão, quando a pluviosidade foi mais intensa, com dominância de espécies ruderais ou R-estrategistas. A S-estratégia ou tolerância a estresse devido aos menores teores de nutrientes foi oportuna durante o período de seca de 1991, enquanto no período de seca de 1992 a C-estratégia ou estratégia das espécies competidoras, oportunistas, foi favorecida pelos elevados teores de nutrientes.

Quanto à distribuição nas Classes de tamanho o microplâncton foi mais expressivo durante o primeiro periodo de seca e o período seguinte de chuvas moderadas e o nanaplâncton predominou durante os dois períodos subseqüentes, no ponto 1 . No ponto 40 nanoplâncton predominou no período de seca de 1991 e foi sobrepujado pelo microplâncton nos períodos seguintes.

O período das águas claras favoreceu as algas flageladas. Durante o periodo de chuvas intensas os organismos flagelados tiveram seu desenvolvimento favorecido no ponto $4 \mathrm{e}$ as 
espécies coloniais ou filamentosas no ponto 1 .

Quanto a estabilidade do ecossistema, destacaram-se pela persistência no ponto 1 , penales, representada por Synedra ulna e no ponto 4 as criptoficeas representadas por espécies do gênero Cryptomonas e as volvocales representadas por Chlamydomonas cf. gloeophila.

Os indicadores prévios da ocorrência de florações e desenvolvimento expressivo de cianoficeas foram a disponibilidade de nutrientes, baixa intensidade luminosa promovida por sombreamento, temperaturas adequadas e as elevadas densidades fitoplanctônicas prévias, especialmente de clorococales. A sulfatação também influiu nestas ocorrências, pois, além de reduzir a competição e favorecer espécies oportunistas, alterou a seqüência de dominância, tomando disponíveis grandes quantidades de nutrientes de uma só vez na coluna d'água e podendo ter causado anoxia nos estratos próximos ao sedimento, acarretando também a liberação de fósforo para a coluna d'água.

Dentre os organismos que podem favorecer o melhoramento das condições ambientais encontrou-se espécies com capacidade de remoção e acúmulo luxuriante de fósforo ou de metais pesados; bem como de algas que podem servir de alimento para o zooplâncton e para fases planctófagas de peixes, podendo ser utilizadas em processos destinados à remoção de nutrientes.

Os métodos de análise aplicados mostraram-se muito úteis, destacando-se a análise integrada dos componentes principais à densidade e ao biovolume das espécies mais representativas.

A comparação entre os métodos de quantificação do fitoplâncton mostram a necessidade de utilizar uma medida mais precisa de biovolume nos estudos aplicados ao saneamento.

O método empregado para análise da persistência das espécies mostrou-se satisfatório, mas a avaliação do significado ecológico da persistência ficou prejudicada pela falta de informações comparáveis na literatura.

A análise das correlações, a análise sazonal baseada nos resultados do estudo do balanço hídrico e a análise da homogeneidade das taxocenoses foram complementares, tendo-se obtido informação em quantidade e qualidade suficientes para efetuar as avaliações propostas, mostrar a consistência das explicações aventadas e indicar alternativas mais adequadas de manejo.

A teoria ecológica que forneceu maior conteúdo de informação, dentre as teorias avaliadas para o estudo deste ambiente, foi a teoria do não equilibrio com a aplicação da hipótese do distúrbio intermediário.

A represa de Guarapiranga pode ser considerada um ambiente de alta transferência de matéria e energia por receber grandes aportes de nutrientes, ter uma produtividade biológica 
elevada e por renovar rapidamente grande parte de sua massa d'água, inclusive de sua biomassa planctônica, devido ao baixo tempo de retenção, exportando rapidamente o seu conteúdo para outros ecossistemas, caracterizando-se como um ambiente bastante instável, adaptável e favorável ao desenvolvimento de espécies oportunistas.

Essas características mostram um elevado potencial de autodepuração mas também mostram que esse potencial não está sendo suficiente para garantir a qualidade da água. Qualquer melhoramento no nível sanitário desta bacia hidrográfica se refletirá rapidamente na qualidade da água para o abastecimento e portanto na qualidade de vida de todos os usuários destas águas.

$\mathrm{O}$ reflorestamento e a preservação das florestas remanescentes; o impedimento da expansão da área urbana e da mineração; o incentivo à atividades econômicas não impactantes; o tratamento primário, secundário e terciário dos esgotos gerados na bacia; a conversão dos materiais em biomassa utilizável e exportável, são medidas indispensáveis para melhoria do ambiente e amplo aproveitamento dos seus recursos.

Pesquisas científicas essenciais para a geração de tecnologias adequadas podem ser viabilizadas através de parcerias entre os diversos órgãos públicos e empresas privadas gerando a estrutura necessária para o aproveitamento mais eficiente, tanto do recurso natural, como dos recursos econômicos do Estado. 


\section{REFERÊNCIAS BIBLIOGRÁFICAS}

APHA, AWWA,WPCF. Standard methods for examination of water and wastewater. Washington. 16th ed. APHA, AWWA,WPCF. 1985.

ASFA. Aquatic Sciences \& Fisheries Abstracts. Cambridge Scientific Abstracts/United Nations Agencies. Compact Disk. SP-160-012. ERL Compliant. 1988-1995. 1995.

BERRIE, A.D. Chap.XIV. Detritus, micro-organisms and animals in freshwater. p. 323-338. In.: Anderson, M.J. \& MacFadyen, A. The role of terrestrial and aquatic organisms in decomposition. Processes 17th. Symposium of the British Ecological Society. Blackwell Sci. Publ. London. 1976.

BEYRUTH, Z. Estudo ecológico sanitário de um lago marginal ao rio Embu-mirim Itapecerica da Serra, São Paulo e ensaio sobre a possibilidade de utilização da macrófita aquática Eichhornia crassipes (Mart.) Solms como indicadora de poluição. São Paulo, 1989. [Dissertação de mestrado. Dep. Ecologia Geral - Instituto de Biociências - USP].

BEYRUTH, Z. SANT'ANNA, C.L., AZEVEDO, M.T.P., CARVALHO, M.C. \& PEREIRA, H.A.S.L. Toxic algae in freshwaters of São Paulo State. p.53-64. In: CORDEIROMARINO, M., AZEVEDO, M.T.P., SANT'ANNA, C.L., TOMITA, N.Y. \& PLASTINO, E.M., 1992. Algae and Environment: a general approach. SBFic/CETESB. 1992.

BEYRUTH, Z. Aspectos do fitoplâncton de lagos submetidos a impactos antrópicos. X Congresso da Sociedade Botânica de São Paulo, 04 a 10 de setembro de 1994. Resumos, Santos, Gráfica da UniSantos, 1994a. p.35(-1.6).

BEYRUTH, Z. Avaliação do impacto decorrente de atividade de portos de areia para o rio Embu-mirim. Relatório. Brasília.. CNPq. Processo número 80.4531/90-0. 1994b.

BEYRUTH, Z., \& LEMOS, M.M.G. Características do fitoplâncton de lagos marginais ao rio Paraíba do Sul, S. Paulo, originadas por extração de areia 6a. Reunião Brasileira de Fitoplâncton.Tramandai/Imbé, R.S. 01 a 05 de março de 1993. Resumos. Tramandai/Imbé, SBFic, 1993a. p.73. 
BEYRUTH, Z., MENEZES, L.B., SANT'ANNA, C.L. \& AZEVEDO, M.T. Fitoplâncton do lago do Parque Ibirapuera, São Paulo, SP. VI Reunião Brasileira de Ficologia. 01 a 05 de março de 1993. Resumos, Tramandaí-Imbé, R.S. SBFic, 1993b. p.68.

BEYRUTH, Z. \& PEREIRA, H.A.S.L. Ecology and sanitary aspects of the phytoplankton of Rio Grande supply reservoir - Billings System, S.Paulo, Brazil. ASLO \& PSA, 1994, Joint Meeting. Miami, 1994. Abstracts. ASLO \& PSA, 1994. p-a7.

BEYRUTH, Z. CALEFFI, S., ZANARDI, E. CARDOSO, E. \& ROCHA, A.A. Water Quality of Guarapiranga Reservoir 1991-92. SP, Brazil. Verh. Internat. Verein Limnol., XXVI. [no prelo].

BOLD, H.C. \& WINE, M.J. Introduction to the algae. New Jersey. Prentice-Hall International Inc. p. 1985.

BONEY, A.D. Phytoplankton. The Institute of Biology. Studies in Biology, n.52. Edward Arnolds Publ. 1975.

BOYLE, T.P. The effect of environmental contaminants on aquatic algae. p.237-256. In.: Shubert, L.E. (Ed.). Algae as ecological indicators. London. Acad. Press Inc. 1984.

BRANCO, S. M. \& ROCHA, A.A. Poluição, proteção e usos múltiplos de represas. São Paulo, CETESB/Ed. Edgard Blücher. 1977.

BRANCO, S.M. Controle preventivo e corretivo de algas em águas de abastecimento. Rev. DAE-SABESP, 23(45):61-75. 1962.

BRANCO, S.M. Hidrobiologia Aplicada à Engenharia Sanitária - Água. São Paulo. CETESB.ASCETESB. p. 1986.

BRIAND, F. \& McCAULEY, E. Cybernetics mechanisms in lake plankton systems: how to control undesirable algae. Nature, 273:228-230. 1978.

BROOK, A.J. Planktonic algae as indicators of lake types, with special reference to the Desmidiaceae. Limnol. \& Oceanogr., 10:403-411. 1965. 
CGLRM (Council of Great Lakes Research Managers). A proposed framework for developing indicators of ecosystem health for the Great Lakes region. Report. Report to the International Joint Comission. United States and Canada. 1991.

CALEFFI, S. A represa de Guarapiranga: estudo da comunidade zooplanctônica e aspectos da eutrofização. São Paulo, 1994. [Dissertação de mestrado. Dep. Saúde Ambiental Faculdade de Saúde Pública-USP].

CALEFFI, S. ZANARDI, E. \& BEYRUTH, Z. Trophic state of Guarapiranga reservoir in 1991-92. Verh. Internat. Verein. Limnol. 25:1306-1310. 1994.

CARDOSO, E \& BEYRUTH, Z. Estudo sobre as contribuições do ribeirão de Itaquaciara e de um lago marginal para o rio Embu-mirim. II. Aspectos da qualidade da água. In: III

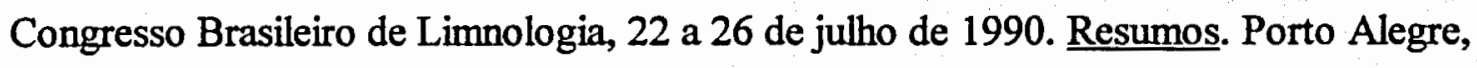
R.S., SBL, 1990. p.75.

CARMICHAEL, W.W. Status report on planktonic cyanobacteria (Blue-green algae) and their toxins. Report. Cincinnatti. EPA/600/r-92/079. EMSL.ORD.USEPA. 1992.

CARMICHAEL, W.W., JONES, C.L.A., MAHMOOD, N.A., \& THEISS, W.C. Algal toxins and water-based diseases. Critical Rev. in Environ Contr., 15(3):275-313. 1972.

CARVALHO, B.A. Desenho Geométrico. Ao Livro Técnico S.A. Rio de Janeiro. p. 1970.

CETESB. Controle das Fontes de Poluição Localizadas nas Áreas de Proteção de Mananciais. Congresso Brasileiro de Engenharia Sanitária e Ambiental de Camboriú (SC), 1983. Resumos. Camboriú, ABES, 1983. 12p.

CETESB. Avaliação da qualidade das águas para consumo humano no Estado de São Paulo 1990. São Paulo, CETESB. Relatório Técnico. 1991.

CETESB. Eutrofização e contaminação por metais no reservatório do Guarapiranga - Dados preliminares. São Paulo, CETESB. Relatório Técnico. 1992.

CETESB. Avaliação ecotoxicológica do reservatório do Guarapiranga, SP, com ênfase ao problema de algas tóxicas e algicidas. Projeto: 15.13.00. Recuperação da Bacia do Guarapiranga. São Paulo, CETESB. Relatório Técnico. 1995. 
CHAPMAN, P.M. Ecosystem health synthesis. Can we get there from here? Jour. of Aquatic Ecosystem Health. 1:69-79, 1992.

CHAVES, C.M. Caracterização ecológica da autodepuração de lagos do Parque Zoológico de São Paulo. São Paulo, 1978. [Dissertação de mestrado - Dep. Saúde Ambiental Faculdade de Saúde Pública - USP].

COBRAPE. Programa de saneamento ambiental em áreas metropolitanas - bacia do Guarapiranga. Relatório.(Publ. Secretaria de Estado do Governo de São Paulo). 1991.

COBRAPE. Relatório consolidado dos estudos complementares relacionados à qualidade da água. Análises e proposições. Relatório.UGP/COBRAPE, novembro, 1994a.

COBRAPE. Ações diretamente relacionadas à qualidade da água. Relatório de andamento para avaliação de meio termo do Programa de Saneamento Ambiental da Bacia do Guarapiranga. Relatório. UGP/COBRAPE, dezembro 1994b.

COBRAPE. Cargas poluidoras na bacia do córrego Guavirutuba. Relatório parcial das atividades. Apresentação de resultados e diretrizes para discussão. Projeto Guarapiranga, Programa de Saneamento Ambiental da Bacia do Guarapiranga. Relatório. UGP/SABESP/CETESB/PMSP, dezembro 1995.

COESEL, P.F.M. The significance of desmids as indicators of the trophic status of freshwater. Schweiz. Z. Hydrol 45 (2):388-393. 1983.

COHN, S.A. \& DISPARTI, N.C. Environmental factors influencing diatom cell motility. Jour. of Phycol., 30:818-828. 1994.

CONAMA-20/86. Resolução do Conselho Nacional do Meio Ambiente n.003 (05.06.84). Conselho Nacional do Meio Ambiente, Ministério do Desenvolvimento Urbano e Meio Ambiente. Publ. CETESB - Diário Oficial da União - Executivo. 30 jul. 1987. p.11-22.

COOKE, K \& GOULD, M.H. The health effects of Aluminum - a review. Jour. Roy. Soc. Health, 111:163-168.

COX, E.J. Freshwater diatom ecology: developing an experimental approach as an aid to interpreting field data. Hydrobiol. 269/270:447-452. 1993. 
DAMATO, M. BEYRUTH, Z., MUCCI, J.L.N., ALVARENGA, C.D. \& ROCHA, A.A. O sulfato de cobre como agente tóxico. Rev. Ambiente, $\underline{3}(1): 26-31.1989$.

DARLEY, W.M. Algal biology: a physiological approach Basic Microbiology, vol 9. Blackwell Scientific Publications. Oxford. 1982.

DESHMUKH, I. Ecology and evolution. In: Ecology and tropical biology. Blackwell., C.6, p.143-175.1986.

DIA, A. \& REYNAUD, P.A. Le phytoplancton du Lac de Guiers: approche qualitative et quantitative. Cah. O.R.S.T.R.O.M Sér. Biol., 45:35-47. 1982.

DRURY, H.W. \& NISBET, I.C.T. Succession. Jour. Arnold Arboretum, 52(3):331-366.

DRUM, R.W. \& HOPKINS, J.T. Diatom locomotion: an explanation. Protoplasma, 62(1):1-33.

DUSSART, B. Limnologie. L'étude des eaux continentales. Ed. Gauthier-Villars, Paris. 1966.

ELORANTA, P. Diversity and succession of the phytoplankton in a small lake over a two-year period. Hydrobiol., 249:25-32. 1993.

ESTEVES, F.A. Fundamentos de limnologia Ed. Interciência/FINEP. 1988.

FALCONER, I.R. Effects on human health of some toxic cyanobacteria (Blue-green algae) in reservoirs, lakes, and rivers. Toxic. Assess., 4:175-184. 1989.

FALCONER, I.R. Tumor promotion and liver injury caused by oral consumption of cyanobacteria. Environmental Toxicol. and Wat. Qual., 6:177-184. 1991.

GADD, G. Accumulation of metals by microorganisms and algae. In.: Rehm, H.-J. Biotechnology - a comprehensive treatise. vol. 6b. Special Microbial Processes. V.H.C. Verlagsgesellschaft:13.1. Chap. 13.p.401-433. 1988.

GASSE, F. East African Diatoms: taxonomy, ecological distribution. Bibliotheca Diatomologica. J. Cramer Ed., Berlin. 1986. 
GOLTERMAN, H.L. Chap. I. Zonation in stratifying lakes.p.3-22. In.: Anderson, M.J. \& MacFadyen, A. (Eds.). The role of terrestrial and aquatic organisms in decomposition. Processes 17th. Symposium of the British Ecological Society. Blackwell Sci. Publ. London. 1976.

GOLTERMAN, H.L., CLYMO, R.S. \& OHNSTAD, M.A.M. Methods for physical and chemical analysis of freshwater. IBP Handbook 8, 2th ed. Blackwell Scientific Publ., Oxford. 1978.

GONZALES DE INFANTE, I. El plancton de las aguas continentales. Secretaria General de la Organización de los Estados Americanos. Programa Regional de Desarrollo Científico y Tecnologico. Washington. 1988.

GORHAM, P.R. Toxic algae as a public health hazard. Jour. AWWA, $\underline{56}$ (11):1481-1488. 1964.

GORHIAM, P.R.Toxic waterblooms of blue-green algae. In: Biological Problems of Water Pollution. Third Seminar US Public Health Service Bulletin. 999 WP 25. Cincinnatti. Ohio. p:37-44. 1965.

HAMMMER, U.T. Toxic blue-green algae in Saskatchevan. Canad. Vet. Jour., $\underline{9}(10): 221-229$. 1968.

HARRIS, G.P. Phytoplankton Ecology, Structure, Function and Fluctuation Chapman and Hall, New York. 1986.

HASLE, G.P. 1978. The inverted-microscope method. p.88-96. In: Sournia, A. 1978. Phytoplankton manual. UNESCO. 337p.

HAVENS K.E. \& HEATH, R.T. Phytoplankton succession during acidification with and without increasing Aluminum levels. Environ. Poll., 68:129-145.1990.

HELLAWELL, J.M. Biological indicators of freshwater pollution and environmental management. Elsevier Science Publ. Ltda. 1989.

HELOU, L.C. \& SILVA, L.G. Estudo de operação do reservatório de Guarapiranga. Versão I. In: Congresso Brasileiro de Engenharia Sanitária e Ambiental, XIV . 20 a 25 set de 1987 Salvador, ABES. 1987. 
HELOU, L.C. \& SILVA, L.G. Estudo de operação do reservatório de Guarapiranga. Rev. DAE, SABESP. 48(151), p.29-47.1988.

HENDRICKSON JR., J.A. Statistical analysis of the presence absence data in water pollution assessment: quantitative and statistical analysis. In.: K.L. Dickson, J. Cairns Jr. and R.J. Livingston (Eds.). Biological data in water pollution assessment: quantitative and statistical analysis. ASTM STP. p. 113-124. 1978.

HENRY, R. Amônia ou fosfato como agente estimulador do crescimento do fitoplâncton na represa de Jurumirim (Rio Paranapanema, SP). Rev. Brasil. Biol., 50(4):883-892.

HÖRNSTRÖM, E. Trophic characterization of lakes by means of qualitative phytoplankton analysis. Limnol. (Berlin), 13(2):249-261. 1981.

HUSZAR, V.L.M. Fitoplâncton de um lago amazônico impactado por rejeito de bauxita (Lago Batata, Pará, Brasil): Estrutura da comunidade, flutuações espaciais e temporais. São Carlos, 1994. [Tese de doutorado em Ciências Biológicas e Saúde. Centro de Ciências Biológicas e da Saúde - UFSCar.].

HUTCHINSON, G.E. The paradox of the plankton. Amer. Natur., 95(882):137-143. 1961.

IBGE. Censo de 1980. IBGE. Imprensa Oficial do Estado de São Paulo. 1989.

JASSBY, A.D. \& GOLDMAN, C.R. Loss rates from a lake phytoplankton community. Limnol. \& Oceanogr. 19(4):618-627. 1974.

KEATING, K.I. Blue-green algal inhibition of diatom growth: transition from mesotrophic to eutrophic community structure. Science, 199:971-973. 1978.

KLAPPER, $\mathrm{H}$. The control of eutrophication in inland waters. Ellis Horwood in Water and Wastewater Technology. Ed. Horwood Ltd. Publ. 1991.

KLEEREKOPER, H. Estudo limnológico da represa de Santo Amaro em São Paulo. Bol. FPSL-USP, v.7, Botânica, n.2:13-151. 1939.

KLEEREKOPER, H. Introdução ao estudo da limnologia Segunda edição (Fac-simile). Ed. da Universidade Federal do Rio Grande do Sul. 1990. 
KLEMER, A.R. Effects of nutritional status on cyanobacterial buoyancy, blooms, and dominance, with special reference to inorganic carbon. Can. J. Bot. 69:1133-1138.

KOHLER, A. \& LABUS, B.C. Eutrophication processes of pollution of freshwater ecosystems including waste water. p.:413-464. In: Lange, O.L., Nobel, P.S., Osmand, C.B., Ziegler, H. (Eds.). Ecosystems Processes: Mineral Cycling, Productivity and Man's Influence. Physiological Plant Ecology, VI. Encyclopedie of Plant Physiology, New Series. v. 12D. Spring-Verlag. Berlin. 1983.

LEGENDRE, L. \& LEGENDRE, P. Numerical Ecology. Developments in Environmental Modelling, 3. Elsevier Scientific Publishing Company. New York. 1983.

LEMOS, M.M.G., BEYRUTH, Z. \& CARVALHO, M.C. Aspectos do fitoplâncton da represa nova do Horto de Sumaré, SP, 1988/91. Rev. DAE -SABESP, 174:1-9. 1993.

LEWIS JR, W.M. Spatial distribution of the phytoplankton in a tropical lake (Lake Lanao, Philippines). Int. Revue ges. Hydrobiol. 63(5):619-635. 1978c.

LEWIS JR., W.M. \& RIEHL, W. Phytoplankton composition and morphology in lake Valencia, Venezuela. Int. Revue ges. Hydrobiol., 67(3):297-322. 1982.

LEWIS JR., W.M. A compositional, phytogeographical and elementary structural analysis of the phytoplankton in a tropical lake: Lake Lanao, Philippines. Jour.Ecol., ㅁ:213-226. 1978a.

LEWIS JR., W.M. Analysis of succession in a tropical phytoplankton community and a new measure of succession rate. Amer. Natur., 112 (984):401-414. $1978 \mathrm{~b}$.

LIEBERMAN, O.S., SHILO, M. \& RIJN, J.V. The physiological ecology of freshwater dinoflagellate bloom population: vertical migration, nitrogen limitation, and nutrient uptake kinetics. Jour. of Phycol., $\underline{30: 964-971 . ~} 1994$.

LOBO E. \& LEIGHTON, G. Estructuras comunitarias de las fitocenosis planctonicas de los sistemas de desembocaduras de rios y esteros de la Zona Central de Chile. $\underline{\text { Rev. Biol. }}$ Mar. Valparaiso, 22(1):1-29. 1986.

LOEHLE, C. Philosophical tools: potential contributions to ecology. Oikos, 51:97-104. 1988. 
LUND, J.W.G. The ecology of freshwater phytoplankton. Biol. Rev. 40:231-293. 1965.

MACKENTHUN, K.M. \& INGRAM, W.M. Biological associated problems in freshwater environments: their identification, investigation and control USDI-FWPCA. US Government Printing Office. 1967.

MAIER, M.H. \& TAKINO, M. Limnologia de reservatórios do sudeste do Estado de São Paulo, Brasil. V. Tipificação através de fatores abióticos e clorofila $a$. B. Inst. Pesca, São Paulo, 12(1):103-122. 1985.

MAIER, M.H. Limnologia de reservatórios do sudeste do Estado de São Paulo, Brasil. II. Circulação e estratificação da água. B. Inst. Pesca, São Paulo, 12(1):11-43. 1985.

MANCUSO, P.S.C. Reuso da água e sua possibilidade na Região Metropolitana de São Paulo. São Paulo, 1992. [Tese de Doutorado. Dep. Saúde Ambiental - Faculdade de Saúde Pública USP].

MARGALEF, R. El concepto de polución en limnologia y sus indicadores biologicos. In.: Simposium sobre polución de las aguas, Alicante, novembre, 1968. Ponencia, $\underline{7}$, sep. de Documento de investigación hidrológica, Supl. Cient. Rev. Água, Barcelona (7):104132. 1969.

MARGALEF, R. Life-forms of phytoplankton as survival alternatives in an instable environment. Oceanol. Acta.,1(4):493-509. 1978.

MARGALEF, R. Limnologia. Ed. Omega. Barcelona. 1983.

MARGALEF, R. Ecologia. Ed. Omega. Barcelona. 1991.

MARGALEF, R. Ecologia. Série Manuales Prácticos. Ed. Planeta. Barcelona. 1992.

MARTYN, C.N., OSMOND, C., EDWARDS, J.A., BARKER, D.J.P., HARRIS, E.C. \& LACEY, R.F. Geographical relation between Alzheimer's disease and Aluminum in drinking water. Lancet, 14:59-62. 1989.

MELCHOR, A., SILVEIRA, A., LOPEZ, G.M. \& ARAÚJO, R. Preservação de mananciais para abastecimento - Guarapiranga, um modelo de preservação. Rev. DAE - SABESP, $\underline{35}: 14-25.1974$. 
MILLER, R.G., KOPFLER, F.C., KELTY, K.C., STOBER, J.A. \& ULMER, N.S. The occcurrence of Aluminum in drinking water. Jour. AWWA. n.: 84-91. 1984.

MUSSARRA, M.L.; MONTEIRO JR., A.J.; BEYRUTH, Z.; SENDACZ, S.; NOVELLI, J.L. \& VIANA, N.C. Limnological characterization of lentic and lotic habitats of the Upper Paraná River System prior to the inundation of Porto Primavera Reservoir. Verh. Internat. Verein Limnol., XXVI. [no prelo].

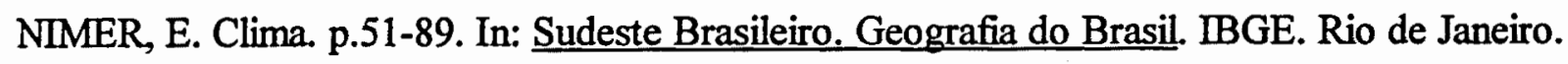
1977.

OCCHIPINTI, A.G. Modelo de qualidade da água do reservatório de Guarapiranga. In: VII Congresso Brasileiro de Engenharia Sanitária, Salvador, ABES. 1973.

ODUM, E.P. Fundamentos de Ecologia Fundação Calouste Gulbekian. Lisboa. 1971.

OLSON, T.A. Toxic plankton. Wat. \& Sew. Wor. 13(2):75-77. 1952.

PADISÁK, J. Seasonal succession of phytoplankton in a shallow lake (Balaton, Hungary) - a dinamic approach to ecological memory, its possible role and mechanisms. Jour. Ecol., 80:217-230. 1992.

PALMER, C.M. A composite rating of algae tolerating organic pollution. Jour. Phycol., 5(1):78-82. 1969.

PALMER, C.M. Algae as biological indicators of water pollution. In: $\underline{\text { Seminar of Biological }}$ Problems - Water Pollution. Ohio, 1957. Biol. Wat. Poll. p.60-69.

PALMER, C.M. Algas e suprimento de água na área de São Paulo. Rev. DAE - SABESP, 21:11-15. 1960.

PARA SALVAR O MANANCIAL. Revista DAE - SABESP, 22(164):8-17.1992.

PAYNE, A.I. The ecology of tropical lakes and rivers. John Wiley \& Sons. New York. 1986.

PEREIRA, H.A.S.L. Aspectos ecológicos sanitários e o fitoplâncton de represas da Área Metropolitana de São Paulo utilizadas como mananciais. Relatório. São Paulo. Apresentado ao Conselho do Departamento de Saúde Ambiental, Dep. Saúde Ambiental - Faculdade de Saúde Pública - USP, São Paulo. 1987. 
POLLINGHER, U. Chap. IV. Freshwater armored dinoflagellates: growth, reproduction, strategies, and population dynamic. p.134-174. In.: Sandgren, C. D. (Ed.). Growth and Reproductive strategies of freshwater phytoplankton. Cambridge University Press. 1988.

PRESCOTT, G.W. Algae of Western Great Lakes Area. W.M.C. Brown Comp. Publ. Dubuque. 1962.

RAPPORT, D.J. Evaluating ecosystem health. Jour. of Aquat. Ecosystem Health, 1:15-24. 1992.

RAVERA, O. Assessment of the trophic state of a water body. Annls. Limnol., 19(3):229-234. 1983.

REYNOLDS, C.S. Phytoplankton periodicity: interactions of form, function and environmental variability. Fresh. Biol, 14:111-142. 1984.

REYNOLDS, C.S. Chap. XIV. Community organization in the freshwater plankton. p.297325. In.: Gee, J.H.R. \& Giller, P.S. (Eds.). Organizations of communities: past and present. The 27th Symposium of the British Ecological Society. Aberrystwith, 1986. Backwell Scientific Publ. Oxford, 1987.

REYNOLDS, C.S. Chap. X. Functional morphology and the adaptative strategies of freshwater phytoplankton. p. 388-433. In.: Sandgren, C. D. (Ed.). Growth and Reproductive strategies of freshwater phytoplankton. Cambridge University Press. 1988.

REYNOLDS, C.S. Eutrophication and the management of planktonic algae: what Vollenweider couldn't tell us. p.4-29. In.: Sutcliffe, D.W. \& Jones, G.J. Eutrophication: research and application to water supply. Publ. by Freshwater Biological Association. London, 1992.

REYNOLDS, C.S. The ecology of freshwater phytoplankton. Cambridge Studies in Ecology, Cambridge University Press. 1993.

RIEMER, D.N. \& TOTH, S.J. Adsortion of copper by clay minerals, humic and bottom muds. Jour. AWWA, 62(3):195-197. 1970. 
ROCHA, A.A. \& BRANCO, S.M. A eutrofização e suas implicações na ciclagem de nutrientes. Acta Limnol. Brasil 1:201-242. 1986.

ROCHA, A.A. A limnologia, os aspectos ecológico-sanitários e a macrofauna bentônica da represa do Guarapiranga na Região Metropolitana de São Paulo. São Paulo, 1984. [Tese de doutoramento. Dep. Zoologia - Instituto de Biociências - USP].

ROCHA, A.A. Algae as biological indicators of water pollution. p.34-52. In: Cordeiro-Marino, M., Azevedo, M.T.P., Sant'Anna, C.L., Tomita, N.Y. e Plastino, E.M. (Eds.). Algae and Environment: a general approach. SBFic/CETESB. 1992.

ROSÉN, G. Phytoplankton indicators and their relations to certain chemical and physical factors. Limnol. (Berlin), 13(2):263-290. 1981.

RUTS, M. Desmids as biological indicators of water quality in two nature reserves of Campine (Belgium). Bibl. Jb. Dodon., 51:243-253. 1983.

SANTOS, C.L., SOUZA, M.P. \& MANCUSO, P.C.S. Plano de controle sanitário da qualidade da água bruta na RMSP, programa preliminar de monitoramento. Relatório. São Paulo. Apresentado no curso de Saneamento Ambiental - Dep. Saúde Ambiental Faculdade de Saúde Pública - USP. 1985.

SANTOS, L.E. \& SANTO PAULO, M. Limnologia de reservatórios do Sudeste do Estado de São Paulo. I. Climatologia. Bol. Inst. Pesca, 12(1):1-10. 1985.

SAUNDERS, G.W. Decomposition in freshwater. p.341-373. In.: Anderson, M.J. \& MacFadyen, A. The role of terrestrial and aquatic organisms in decomposition. Processes 17th. Symposium of the British Ecological Society. Blackwell Sci. Publ. London. 1976.

SCHINDLER, D.N. Factors regulating production and standing crop in the world's freshwaters. Limnol. \& Oceanogr., 83(3):478-486, 1978.

SEMA. Recuperação ambiental na bacia do Guarapiranga. Imprensa Oficial do Estado de São Paulo. 1988.

SHAPIRO, J. Blue-green algae: why they become dominant. Science, 179:382-384. 1973. 
SHAPIRO, J. Current beliefs regarding dominance by blue-greens: the case for the importance of $\mathrm{CO}_{2}$ and $\mathrm{pH}$. Verh. Internat. Verein. Limnol., 24:38-54. 1990.

SIEGEL, S. Estatística não paramétrica. Mc Graw Hill Inc. São Paulo. 1975.

SILVA, R.J.C., BRASIL, A.L. \& SILVA, A.C.C. Guaracabí - Plano de um novo sistema sul de abastecimento de água da Grande São Paulo. Rev. DAE - SABESP, 46(146):236246. 1986.

SKULBERG, O.M.; CODD, G.A. \& CARMICHAEL, W.W. Toxic blue-green algal blooms in Europe: a growing problem. Ambio, 13:244-247. 1984.

SLÁDECKOVÁ, A. \& SLÁDECEK, V. Periphyton as indicator of the reservoir water quality. I. True-periphyton. Scientific Papers from Institute of Chemical Technology, Prague. Techn. of Water, Z(1):507-561. 1963.

SLÁDECEK, V. System of water quality from biological point of view. Arch. Hydrobiol., 7:1218. 1973.

SMITH, G.M. Cryptogamic Botany. I. Algae and Fungi. Tata McGraw-Hill Publishing Company Ltda, New Delhi, v. I. 2a Ed..New Delhi. 1985.

SMITH, V.H. Phytoplankton responses to eutrophication in inland waters. p.231-249. In.: Akatsuka, I. (Ed.). Introduction to Applied Phycology. STP Academic Publ. The Hague. The Netherlands. 1990.

SOMASHEKAR, R.K. Phytoplankton constituents as indicators of water quality: a study of the river Cauvery. Intern. J. Environ. Stud., 23:209-215. 1984.

SOMMER, U. Phytoplankton succession in microcosm experiments under simultaneous grazing pressure and resource limitation. Limnol. \& Oceanogr. 33(5):1037-1054. 1988a.

SOMMER, U. Some size relationships in phytoflagellate motility. Hydrobiol., 161:125-131. $1988 \mathrm{~b}$.

SOMMER, $\mathrm{U}$. The role of $\mathrm{r}$ and $\mathrm{K}$ selection in succession of phytoplankton in lake Constance. A..Oecol., Oecol. Gener., 2(4):327-343. 1981. 
SOMMER, U. Chap. I. Toward a darwinian ecology of plankton. p. 1-8. In.: Sommer, U. (Ed.) Plankton ecology. Succession in plankton communities. Spring-Verlag, Berlin. 1989.

SOMMER, U. Convergent succession of phytoplankton in microcosms with different inoculum

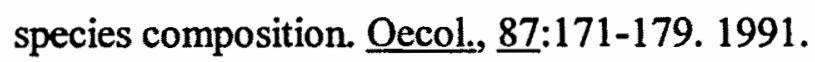

SOMMER, U., PADISÁK, J., REYNOLDS, C.S. E JUHÁSZ-NAGY, P. Hutchinson's heritage: the diversity-disturbance relationship in phytoplankton. Hydrobiol., 249:1-7. 1993.

SOURNIA, A. Phytoplankton manual. UNESCO. 1978.

TER BRAAK, C.J. F. Chap. V. Ordination. In: Jongman, R.H.G., Ter Braak, C.J.F. e Van Tongeren, O.F.R. (Eds.). Data analysis in community and landscape ecology. Pudoc, Wageningen. 1987.

TER BRAAK, C.J.F. CANOCO - a Fortran program for canonical correspondance analysis, principal component analysis and redundancy analysis. Ver.2.1. Report. Agriculture; Mathematics Group. Technical Report: LWA 88-02. 1988.

TER BRAAK, C.J.F. Canonical correspondance analysis: a new eigenvector technique for multivariate direct gradient analysis. Ecol. $\underline{67(5): 1167-1179.1986 .}$

THORNTON, K. W., KIMMEL, B.L. \& PAYNE, F.E. Reservoir Limnology: Ecological Perspectives. John Wiley \& Sons, Inc. New York. 1990.

TILMAN, D. KILHAM, S.S. \& KILHAM, P. Phytoplankton community ecology: the role of limiting nutrients. Ann. Rev. Ecol. Syst., 13:349-72. 1982.

TILMAN, D. The resource ratio hypothesis of plant succession. Amer. Natur., 125(6):827852. 1985.

TOWSEND, C.R. \& CALOW, P. Eds. Chap. II. Bioenergetic options and phylogeny. p.20-45. In: Physiological ecology: an evolutionary approach to resource use. Blackwell. 1981.

TRANSEAU, E.N. The Zygnemataceae. Columbus Ed. The Ohio State University Press. p.1327. 1951. 
TUBELIS, A. E NASCIMENTO, F.J.L. Meteorologia descritiva: fundamentos e aplicações brasileiras. ed. Nobel. 1988.

TUNDISI, J.G. \& HINO, K. List of species and growth seasons of phytoplankton from Lobo (Broa) Reservoir. Rev. Bras. Biol., 41:63-68. 1981.

TUNDISI, J.G. Estratificação hidráulica em reservatórios e suas conseqüências ecológicas. Ciênc. Cult., $\underline{36}(9): 1498-1504.1984$.

TUNDISI, J.G. Represas artificiais: perspectivas para o controle e manejo da qualidade da água para usos múltiplos. In: VI Simpósio Brasileiro de Hidrologia e Recursos Hídricos. Anais. São Paulo. 1985.

TUNDISI, J.G., MATSUMURA-TUNDISI, T. CALIJURI, M.C. \& NOVO, E.M.L. Comparative limnology of five reservoirs in the Middle Tietê River, S. Paulo State. Verh. Internat. Verein. Limnol., 24:1489-1496. 1991.

TUNDISI, J.G., MATSUMURA-TUNDISI, T. HENRY, R. ROCHA, O. \& HINO, K. Comparação do estado trófico de 23 reservatórios do Estado de São Paulo: eutrofização e manejo. In: TUNDISI, J.G. (Ed.). Limnologia e manejo de represas. Série Monografias em Limnologia v.I (1):165-204. 1988.

VAN DAM, H., MERTENS, A. \& SINKELDAM, J. A coded checklist and ecological indicator values of freshwater diatoms from Netherlands. Netherl. Jour. Aqua. Ecol., 20(1):117-133. 1994.

VOLLENWEIDER, R.A. (Ed.). A manual on methods for measuring primary production in aquatic environments. 2. ed. IBP Programe - handbook n. 12. Blackwell Scientific Publications. Oxford. 1974

WETZEL R.G. \& LIKENS, G.E. Limnological analyses. Second Edition. Springer-Verlag Ed. New York. 1991.

WETZEL, R.,G. Limnology. Saunders College Publ.. 1983. 
WETZEL, R.G. Chap. IX. Reservoir Ecosystems: conclusions and speculations. p. 227-238. In: Thornton, K.W., Kimmel, B.L. e Payne, F.E. (Eds.). Reservoir Limnology: ecological perspectives. Wiley Insterscience Publ. John Wiley \& Sons Inc. New York. 1990.

WRIGHT, S. Limnologia das águas de São Paulo. Archiv. do Inst. Biol., 7(7):65-73. 1936.

XAVIER, M.B., MONTEIRO-JÚNIOR, A.J. \& FUJIARA, P. Limnologia de reservatórios do sudeste do Estado de São Paulo, Brasil. VII. Fitoplâncton. Bol. I. Pesca, São Paulo, 12(1):145-186. 1985 .

ZAGATTO, P.A. Evaluation écotoxicologique du reservoir Guarapiranga, SP-Brésil, en relation avec le probléme des algues toxiques et des algicides. Metz, 1995. [Tese de doutoramento. Université de Metz, Centre des Sciences de l'Environement.]

ZAR, J.H. Biostatistical analysis. Prentice-Hall Inc. London. 1974. 
A NEXO-TABELAS E FIGURAS 
TABELA 1 - OPERAÇAO HIDRAULICA DO SISTEMA DE GUARAPIRANGA, MEDIDA PRÓXIMO AO PONTO 1. REPRESA DE GUARAPIRANGA 1991-92.

Identificação da coleta (ID), variação no intervalo de coletas em dias (INT); precipitação em mm nas 24 horas (P24), 72 horas (P72), 168 horas (P168) anteriores as coletas; vazåo média $\mathrm{em} \mathrm{m}^{3} \cdot \mathrm{s}^{-1}$; afluente natural (ANA), recalcada (ARE), total (AT); vazão média $\mathrm{em} \mathrm{m}^{3} \cdot \mathrm{s}^{-1}$ : efluente canal do rio Pinheiros (EC), abastecimento (EAB), total (ET); elevação ou nível da água em m (ELE) e volume em $\mathrm{m}^{3} \cdot 10^{3}$ (VOL).

\begin{tabular}{|c|c|c|c|c|c|c|c|c|c|c|c|c|}
\hline ID & INT. & P24 & P72 & P168 & ANA & ARE & AT & EC & EAB & ET & ELE & VOL \\
\hline MA2 & 7 & 0.0 & 0.0 & 5.8 & 9.3 & 0.0 & 9.3 & 0.0 & 13.0 & 13.0 & 735.93 & 175024 \\
\hline MA3 & 7 & 0.0 & 0.0 & 0.0 & 9.6 & 0.0 & 9.6 & 0.0 & 13.2 & 13.2 & 735.84 & 172182 \\
\hline MA4 & 7 & 0.0 & 0.0 & 0.0 & 6.5 & 0.0 & 6.5 & 0.0 & 13.6 & 13.6 & 735.72 & 168437 \\
\hline JS & 7 & 0.0 & 0.0 & 1.6 & 12.9 & 0.0 & 12.9 & 0.0 & 12.9 & 12.9 & 735.67 & 166892 \\
\hline$J 6$ & 7 & 0.0 & 0.0 & 0.0 & 6.3 & 0.0 & 6.3 & 0.0 & 13.4 & 13.4 & 735.57 & 163829 \\
\hline 57 & 7 & 0.0 & 22.4 & 49.8 & 23.9 & 0.0 & 23.9 & 0.0 & 13.2 & 13.2 & 735.71 & 168127 \\
\hline ЛL8 & 7 & 0.0 & 0.0 & 8.0 & 9.4 & 0.0 & 9.4 & 0.0 & 13.0 & 13.0 & 735.73 & 168747 \\
\hline JL9 & 7 & 8.0 & 0.0 & 0.0 & 6.1 & 0.0 & 6.1 & 0.0 & 13.3 & 13.3 & 735.64 & 165970 \\
\hline JL10 & 7 & 0.0 & 0.0 & 18.8 & 10.4 & 1.4 & 11.8 & 0.0 & 11.8 & 11.8 & 735.63 & 165663 \\
\hline JL11 & 7 & 0.0 & 0.0 & 0.0 & 4.3 & 1.3 & 5.6 & 0.0 & 12.6 & 12.6 & 735.54 & 162918 \\
\hline ЛL12 & 7 & 0.0 & 0.0 & 0.0 & 4.8 & 1.4 & 6.2 & 0.0 & 13.1 & 13.1 & 735.43 & 159602 \\
\hline AG13 & 7 & 11.0 & 2.2 & 4.2 & 15.9 & 0.7 & 16.6 & 0.0 & 13.2 & 13.2 & 735.35 & 157218 \\
\hline AG14 & 7 & 0.0 & 0.0 & 34.2 & 9.3 & 0.7 & 10.0 & 0.0 & 13.4 & 13.4 & 735.36 & 157515 \\
\hline AG15 & 5 & 0.0 & 0.0 & 0.0 & 5.0 & 1.0 & 6.0 & 0.0 & 12.8 & 12.8 & 735.28 & 155151 \\
\hline AG16 & 9 & 0.0 & 0.0 & 0.0 & 6.1 & 0.3 & 6.4 & 0.0 & 13.1 & 13.1 & 735.09 & 149630 \\
\hline S17 & 7 & 0.0 & 2.2 & 2.2 & 8.0 & 1.3 & 9.3 & 0.0 & 12.6 & 12.6 & 734.96 & 145927 \\
\hline S18 & 7 & 0.0 & 0.0 & 0.0 & 0.2 & 0.0 & 0.2 & 0.0 & 0.2 & 0.2 & 734.83 & 142278 \\
\hline S19 & 7 & 5.4 & 0.0 & 0.0 & 3.6 & 0.0 & 3.6 & 0.0 & 13.1 & 13.1 & 734.65 & 137314 \\
\hline $\mathrm{S} 20$ & 7 & 7.8 & 4.0 & 16.8 & 7.8 & 1.4 & 9.2 & 0.0 & 12.4 & 12.4 & 734.55 & 134600 \\
\hline 021 & 7 & 3.4 & 54.6 & 65.2 & 37.0 & 1.7 & 38.7 & 0.0 & 13.3 & 13.3 & 734.74 & 139784 \\
\hline 022 & 7 & 31.4 & 51.6 & 101.0 & 43.7 & 3.4 & 47.1 & 0.0 & 13.0 & 13.0 & 735.37 & 157812 \\
\hline 023 & 7 & 1.0 & 0.0 & 35.6 & 9.7 & 0.0 & 9.7 & 0.0 & 13.2 & 13.2 & 735.63 & 165663 \\
\hline $\mathrm{O} 24$ & 7 & 0.0 & 0.0 & 1.0 & 6.2 & 0.0 & 6.2 & 0.0 & 13.3 & 13.3 & 735.53 & 162614 \\
\hline 025 & 7 & 0.0 & 0.0 & 1.0 & 2.9 & 0.0 & 2.9 & 0.0 & 13.3 & 13.3 & 735.38 & 158110 \\
\hline N26 & 5 & 3.6 & 14.0 & 15.0 & 12.6 & 0.0 & 12.6 & 0.0 & 12.6 & 12.6 & 735.35 & 157218 \\
\hline $\mathrm{N} 27$ & 9 & 0.0 & 74.6 & 83.6 & 9.8 & 0.0 & 9.8 & 0.0 & 13.3 & 13.3 & 735.30 & 155740 \\
\hline $\mathrm{N} 28$ & 7 & 0.0 & 0.2 & 9.2 & 3.1 & 0.0 & 3.1 & 0.0 & 13.3 & 13.3 & 735.22 & 153394 \\
\hline N29 & 7 & 0.0 & 0.0 & 0.0 & 6.7 & 0.0 & 6.7 & 0.0 & 13.3 & 13.3 & 735.03 & 147913 \\
\hline D30 & 7 & 0.0 & 6.2 & 12.3 & 3.3 & 0.0 & 3.3 & 0.0 & 13.0 & 13.0 & 734.88 & 143675 \\
\hline D31 & 7 & 0.0 & 18.4 & 52.8 & 3.0 & 0.0 & 3.0 & 0.0 & 12.7 & 12.7 & 734.83 & 142000 \\
\hline D32 & 7 & 0.4 & 2.0 & 2.0 & 16.3 & 0.0 & 16.3 & 0.0 & 13.0 & 13.0 & 734.88 & 143675 \\
\hline D33 & 5 & 1.0 & 24.4 & 60.4 & 9.6 & 0.0 & 9.6 & 0.0 & 12.0 & 12.8 & 734.93 & 145080 \\
\hline JA34 & 16 & 0.0 & 9.4 & 38.4 & 13.3 & 0.0 & 13.3 & 0.0 & 13.3 & 13.3 & 734.84 & 142557 \\
\hline JA35 & 7 & 0.0 & 7.4 & 40.8 & 15.8 & 0.0 & 15.8 & 0.0 & 12.6 & 12.6 & 734.87 & 143395 \\
\hline JA36 & 7 & 4.4 & 1.0 & 6.0 & 12.4 & 0.0 & 12.4 & 0.0 & 12.4 & 12.4 & 734.86 & 143116 \\
\hline JA37 & 7 & 9.4 & 0.0 & 4.4 & 10.1 & 0.0 & 10.1 & 0.0 & 13.3 & 13.3 & 734.81 & 141722 \\
\hline F38 & 5 & 0.0 & 1.0 & 14.2 & 6.7 & 0.0 & 6.7 & 0.0 & 13.1 & 13.1 & 734.72 & 139233 \\
\hline F39 & 9 & 0.0 & 0.0 & 31.0 & 19.7 & 0.0 & 19.7 & 0.0 & 13.3 & 13.3 & 734.88 & 143675 \\
\hline F40 & 9 & 0.0 & 3.3 & 11.3 & 3.8 & 0.0 & 3.8 & 0.0 & 13.3 & 13.3 & 734.71 & 138958 \\
\hline F41 & 6 & 8.8 & 74.8 & 76.8 & 25.2 & 0.0 & 25.2 & 0.0 & 12.3 & 12.3 & 734.82 & 142000 \\
\hline MR42 & 14 & 0.0 & 31.6 & 39.1 & 12.8 & 0.0 & 12.8 & 0.0 & 12.8 & 12.8 & 735.16 & 151649 \\
\hline MR43 & 7 & 14.6 & 24.2 & 24.2 & 23.5 & 0.0 & 23.5 & 0.0 & 13.4 & 13.4 & 735.16 & 151649 \\
\hline MR44 & 7 & 0.0 & 19.6 & 34.2 & 19.5 & 0.0 & 19.5 & 0.0 & 12.7 & 12.7 & 735.26 & 154564 \\
\hline AB45 & 7 & 0.0 & 35.0 & 132.2 & 30.6 & 0.0 & 30.6 & 0.0 & 12.8 & 12.8 & 735.65 & 166277 \\
\hline AB46 & 7 & 0.0 & 0.0 & 0.0 & 8.3 & 0.0 & 8.3 & 0.0 & 11.8 & 11.8 & 735.64 & 165970 \\
\hline AB47 & 6 & 0.0 & 0.2 & 0.8 & 8.0 & 0.0 & 8.0 & 0.0 & 11.5 & 11.5 & 735.56 & 163525 \\
\hline AB48 & 7 & 0.0 & 3.2 & 3.2 & 5.6 & 0.0 & 5.6 & 0.0 & 12.6 & 12.6 & 735.44 & 159902 \\
\hline AB49 & 7 & 14.8 & 0.8 & 2.2 & 7.6 & 1.4 & 9.0 & 0.0 & 12.4 & 12.4 & 735.34 & 156922 \\
\hline MA50 & 7 & 0.0 & 23.0 & 49.8 & 20.4 & 1.6 & 22.0 & 0.0 & 11.5 & 11.5 & 735.54 & 162918 \\
\hline MA51 & 6 & 6.0 & 0.0 & 0.0 & 5.5 & 0.0 & 5.5 & 0.0 & 12.5 & 12.5 & 735.52 & 162312 \\
\hline MA53 & 7 & 0.0 & 0.0 & 11.4 & 0.4 & 1.3 & 1.7 & 0.0 & 12.0 & 12.0 & 735.39 & 158407 \\
\hline J54 & 7 & 0.0 & 0.0 & 0.0 & 4.5 & 1.3 & 5.8 & 0.0 & 12.6 & 12.6 & 735.27 & 154857 \\
\hline J55 & 7 & 0.0 & 0.0 & 0.0 & 3.9 & 1.3 & 5.2 & 0.0 & 11.9 & 11.9 & 735.13 & 150782 \\
\hline J56 & 7 & 0.0 & 0.0 & 0.0 & 5.4 & 0.0 & 5.4 & 0.0 & 11.9 & 11.9 & 734.98 & 146493 \\
\hline J57 & 7 & 0.0 & 0.0 & 0.0 & 5.4 & 0.3 & 5.7 & 0.0 & 12.2 & 12.2 & 734.82 & 142000 \\
\hline JL58 & 27 & 0.0 & 0.0 & 2.0 & 4.7 & 0.9 & 5.6 & 0.0 & 11.7 & 11.7 & 734.35 & 128739 \\
\hline
\end{tabular}

DADOS CEDIDOS PELA ELETROPAULO - ELETRICIDADE DE SÃO PAULO S.A. RELATIVOS AO CONTEÚDO DE 24 HORAS. 
TABELA 2 - BALANÇO HÍDRICO REPRESA DE GUARAPIRANGA, 1991-92.

Identificação da coleta (ID); pluviosidade média mensal em mm (P); deficiência hídrica do solo em mm (DEF), excedente hídrico em mm (EXC) e escoamento básico em mm (ESC).

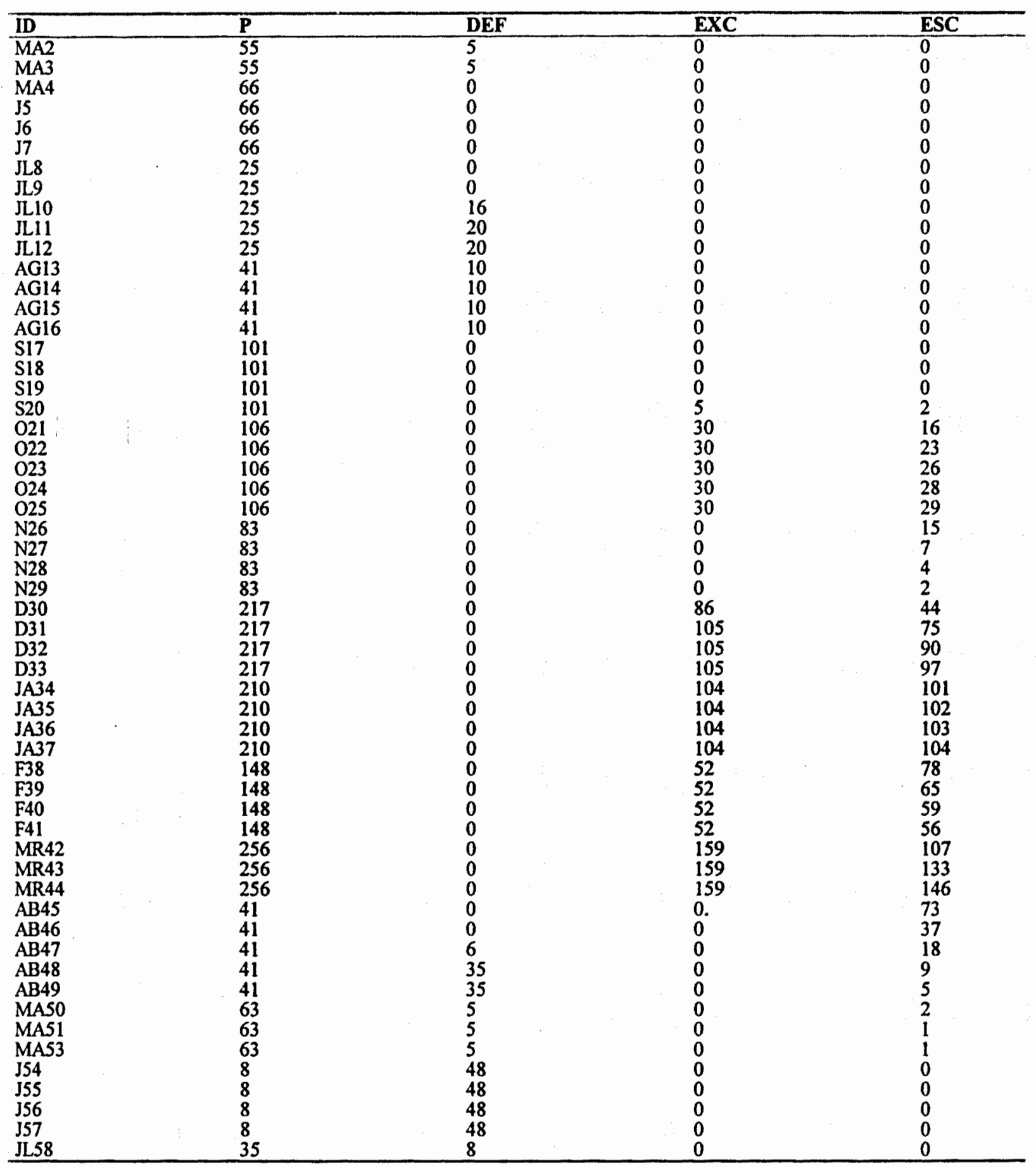

PARA 100 MM de CAPACIDAdE de ARMAZENAMENTO. CALCULAdo A PARTIR dE DADOS dE PLUVIOMETRIA OBTIDOS PELA. ELETROPAULO S.A. E DADOS DA ESTAÇÃO METEOROLÓGICA DO IAG-USP (THORNTWATTE, 1949, IN: TUBELIS \& NASCIMENTO, 1988). 
TABELA 3 - VARIAÇĀo DOS PARÂMETROS METEOROLÓGICOS E DO CONTROLE DAS ALGAS NA REPRESA DE GUARAPIRANGA, 1991-92.

Identificação da coleta (ID); direção dos ventos (DV); velocidade média dos ventos em $\mathrm{m} . \mathrm{s}^{-1}$ (VEN);insolação diária em horas.dia ${ }^{-1}$ (INS); radiação solar média mensal em Ly.dia ${ }^{-1}$ (RAD).Aplicações de sulfato de cobre em $1000 \mathrm{~kg} \cdot \mathrm{dia}^{-1}$ : do dia anterior a coleta (SA) e do dia da coleta (S), no ponto 1.

\begin{tabular}{|c|c|c|c|c|c|c|c|}
\hline ID & DV & & VEN & INS & RAD & $\mathbf{S A}$ & $S$ \\
\hline MA2 & $\mathrm{NW}$ & & 2.8 & 9.0 & 337 & 2.00 & 2.00 \\
\hline $\mathrm{MA3}$ & NNE & & 1.3 & 9.3 & 337 & 2.00 & 0.00 \\
\hline MA4 & NNE & & 1.9 & 9.2 & 337 & 0.50 & 2.00 \\
\hline $\mathrm{J} 5$ & $\mathrm{SE}$ & & 1.1 & 6.2 & 263 & 0.00 & 0.00 \\
\hline J6 & WNW & & 3.8 & 3.0 & 263 & 0.00 & 0.00 \\
\hline J7 & $\mathrm{NE}$ & & 1.9 & 5.5 & 263 & 0.00 & 0.00 \\
\hline JL8 & WNW & & 1.5 & 8.8 & 300 & 0.00 & 0.00 \\
\hline JL9 & NW & & 1.9 & 9.1 & 300 & 0.00 & 0.00 \\
\hline JL10 & ENE & & 1.5 & 5.8 & 300 & 0.00 & 0.00 \\
\hline JL11 & WNW & & 1.1 & 8.8 & 300 & 0.00 & 0.00 \\
\hline $\mathrm{JL} 12$ & NNE & & 1.9 & 8.8 & 300 & 0.00 & 0.00 \\
\hline AG13 & SE & & 1.9 & 5.8 & 340 & 0.00 & 0.00 \\
\hline AGl4 & ESE & & 1.9 & 6.9 & 340 & 0.00 & 1.50 \\
\hline AG15 & ENE/NE & & 2.3 & 8.9 & 340 & 1.50 & 1.50 \\
\hline AGI6 & SSE & & 1.7 & 8.0 & 340 & 0.00 & 0.00 \\
\hline S17 & NE & & 2.1 & 8.3 & 368 & 0.00 & 0.00 \\
\hline S18 & SSE & & 1.2 & 7.5 & 368 & 0.00 & 0.00 \\
\hline S19 & $\mathrm{NW}$ & & 2.3 & 7.0 & 368 & 0.00 & 0.00 \\
\hline $\mathbf{S} 20$ & ESE & & 1.8 & 0.0 & 368 & 0.00 & 0.00 \\
\hline 021 & ENE & & 1.7 & 0.1 & 417 & 0.00 & 2.00 \\
\hline 022 & NNE & & 1.8 & 0.0 & 417 & 3.00 & 1.50 \\
\hline 023 & SE & & 1.5 & 9.0 & 417 & 2.00 & 1.35 \\
\hline 024 & ENE & & 1.7 & 9.4 & 417 & 2.00 & 2.00 \\
\hline 025 & $\mathrm{SE}$ & & 1.6 & 7.4 & 417 & 0.00 & 0.00 \\
\hline N26 & SE/ESE & & 2.1 & 3.4 & 480 & 0.00 & 0.00 \\
\hline N27 & SSE & & 1.7 & 4.9 & 480 & 0.00 & 0.00 \\
\hline N28 & SSE & & 1.9 & 2.5 & 480 & 0.00 & 0.00 \\
\hline N29 & $S E$ & & 2.1 & 0.2 & 480 & 2.00 & 2.00 \\
\hline D30 & NE & & 1.9 & 10.0 & 491 & 0.00 & 0.00 \\
\hline D31 & WNW & & 2.5 & 7.3 & 491 & 0.00 & 0.00 \\
\hline D32 & WNW & & 1.8 & 3.7 & 491 & 0.00 & 2.00 \\
\hline D33 & NW & & 2.2 & 0.3 & 491 & 2.00 & 2.00 \\
\hline JA34 & ESE & & 1.7 & 7.7 & 434 & 2.00 & 2.00 \\
\hline JA35 & SSW & & 1.5 & 5.7 & 434 & 2.00 & 2.00 \\
\hline JA36 & SSW & & 1.3 & 0.0 & 434 & 2.00 & 1.25 \\
\hline JA37 & ENE & & 0.9 & 6.5 & 434 & 0.00 & 3.00 \\
\hline F38 & NE/ENE & & 2.5 & 5.9 & 457 & 1.20 & 1.20 \\
\hline F39 & $\mathrm{NE}$ & & 1.8 & 10.6 & 457 & 3.00 & 2.30 \\
\hline $\mathrm{F} 40$ & NNW & & 1.3 & 9.6 & 457 & 0.00 & 1.50 \\
\hline F41 & WNW & & 2.0 & 5.6 & 457 & 3.00 & 1.00 \\
\hline MR42 & WNW & & 1.1 & 7.1 & 386 & 1.15 & 2.00 \\
\hline MR43 & NW & & 1.5 & 1.9 & 386 & 3.00 & 3.00 \\
\hline MR44 & NW & & 2.0 & 6.3 & 386 & 2.00 & 1.50 \\
\hline $\mathrm{AB} 45$ & SSE & & 1.4 & 8.7 & 372 & 3.00 & 3.00 \\
\hline $\mathrm{AB} 46$ & ESE & & 1.7 & 0.3 & 372 & 3.00 & 3.00 \\
\hline $\mathrm{AB} 47$ & WNW & & 2.1 & 9.4 & 372 & 3.00 & 3.00 \\
\hline AB48 & SSE/ESE & & 1.0 & 0.0 & 372 & 3.00 & 3.00 \\
\hline AB49 & NW & & 3.4 & 5.2 & 372 & 3.00 & 2.00 \\
\hline MA50 & SSE & & 1.4 & 4.4 & 268 & 2.00 & 2.00 \\
\hline MA5I & WNW & & 1.1 & 6.0 & 268 & 3.00 & 0.00 \\
\hline MA53 & NNE & & 2.8 & 9.2 & 268 & 0.00 & 0.00 \\
\hline J54 & WNW & & 1.5 & 7.5 & 270 & 0.00 & 0.00 \\
\hline $\mathrm{J} 55$ & SSE & & 1.1 & 1.2 & 270 & 0.00 & 0.00 \\
\hline J56 & $\mathrm{NE}$ & & 1.8 & 8.1 & 270 & 0.00 & 0.00 \\
\hline J57 & $\mathrm{NE}$ & & 1.3 & 5.5 & 270 & 0.00 & 0.00 \\
\hline JL58 & NNE/SSE & & 2.0 & 5.9 & 298 & 0.00 & 0.00 \\
\hline
\end{tabular}

DADOS OBTIDOS NO IAG-USP E SABESP. 
TABELA 4 - VARIAÇĀO TEMPORAL DAS VARIÁVEIS FÍSICAS E QUIMICAS. REPRESA DE GUARAPIRANGA 1991-92. PONTO 1: ÁREA DA CAPTAÇÃO DE ÁGUA PARA ABASTECIMENTO. Identificação da coleta (ID); temperatura do ar (TAR), da água em ${ }^{\circ} \mathrm{C}$ (TAG); profundidade em m (PROF); transparência ao disco de Secchi em m (SEC); cor em mg. $1^{-1} \mathrm{Pt}$ (COR); turbidez em UTN (TUR); condutividade em $\mu$ S. $\mathrm{cm}^{2-1}$ (CON); $\mathrm{pH}$ (pH);oxigênio dissolvido em mg.l $\mathrm{l}^{-1}(\mathrm{OD})$; demanda bioquímica de oxigênio em mg. ${ }^{-1}$ (DBO); alcalinidade em mg. $\mathrm{l}^{-1} \mathrm{CaCO}_{3}$ (ALC); dureza em mg. $1^{-1} \mathrm{CaCO}_{3}$ (DUR) e teores de sólidos totais em suspensão (SOT) em mg. ${ }^{-1}$.

\begin{tabular}{|c|c|c|c|c|c|c|c|c|c|c|c|c|c|}
\hline ID & TAR & TAG & PROF & SEC & COR & TUR & $\mathrm{CON}$ & pH & OD & DBO & ALC & DUR & SOT \\
\hline$\overline{\mathrm{MA} 2}$ & - & - & 10.5 & 2.50 & 35 & 1.7 & 32 & 6.60 & 7.86 & 4.29 & - & - & - \\
\hline $\mathrm{MA3}$ & 20.0 & 21.0 & 12.3 & 1.63 & 30 & 1.45 & 45 & 6.50 & 8.60 & 1.86 & - & - & - \\
\hline MA4 & 21.5 & 20.5 & 12.0 & 2.13 & 30 & 1.4 & 52 & 6.50 & 7.62 & 1.14 & - & - & - \\
\hline J5 & 17.7 & 19.2 & 11.8 & 1.92 & 20 & 1.4 & 47 & 6.50 & 6.50 & 0.00 & 19.0 & - & - \\
\hline J6 & 21.5 & 19.0 & 13.0 & 2.25 & 30 & 1.2 & 45 & 6.60 & 7.13 & 1.17 & 19.4 & - & - \\
\hline $\mathrm{J} 7$ & 20.0 & 19.0 & 14.0 & 1.27 & 20 & 1.2 & 43 & 6.52 & 6.58 & 0.16 & - & 21.7 & - \\
\hline 几8 & 20.0 & 17.8 & 11.9 & 2.52 & 25 & 1.2 & 52 & 6.65 & 7.59 & 0.74 & 13.3 & 19.9 & - \\
\hline 几9 & 18.0 & 17.9 & 12.1 & 3.00 & 15 & 1 & 52 & 7.75 & 7.63 & 1.17 & 20.5 & 20.7 & - \\
\hline Лlo & 16.0 & 17.2 & 9.3 & 3.00 & 20 & 1 & 49 & 6.10 & 7.63 & 1.04 & 15.5 & 20.3 & - \\
\hline $\mathrm{JLI1}$ & 9.0 & 17.0 & 11.5 & 2.00 & 25 & 1.7 & 54 & 6.37 & 6.77 & 1.10 & - & - & - \\
\hline Лl2 & 15.0 & 17.8 & 11.8 & 2.00 & 25 & 1.4 & 57 & 6.92 & 6.97 & 1.00 & 14.2 & 19.5 & - \\
\hline AGI3 & 17.0 & 17.0 & 12.7 & 2.28 & 20 & 1.2 & 52 & 7.15 & 8.15 & 1.12 & 6.7 & 44.0 & - \\
\hline AG14 & 19.0 & 18.2 & 6.5 & 2.49 & 20 & 1.1 & 50 & 7.75 & 7.12 & 0.34 & 16.7 & 45.0 & - \\
\hline AGIS & 23.0 & 18.5 & 11.8 & 2.50 & 15 & 1 & 51 & 6.93 & 8.00 & 1.01 & 15.8 & - & - \\
\hline AGI6 & 17.1 & 20.1 & 11.2 & 2.40 & 25 & 0.9 & 57 & 7.38 & 8.36 & 1.01 & 15.8 & 29.4 & - \\
\hline S17 & 15.0 & 19.2 & 7.0 & 2.46 & 35 & 1 & 51 & 6.91 & 7.15 & 0.31 & 16.6 & - & 95 \\
\hline S18 & 17.2 & 19.8 & 7.4 & 3.00 & 25 & 0.9 & 57 & 6.95 & 7.07 & 0.00 & 17.4 & 17.1 & 85 \\
\hline S19 & 22.5 & 21.5 & 11.2 & 3.00 & 20 & 0.8 & 58 & 7.30 & 8.49 & 1.59 & 17.9 & 29.3 & 117 \\
\hline $\mathbf{S 2 0}$ & 16.5 & 19.5 & 8.5 & 2.00 & 35 & 1.4 & 47 & 7.08 & 7.47 & 0.73 & 19.7 & 30.4 & 50 \\
\hline 021 & 17,20 & 20.0 & 10.8 & 2.00 & 30 & 1.2 & 56 & 7.06 & 6.74 & 0.00 & 17.2 & 44.6 & 45 \\
\hline 022 & 16.0 & 18.1 & 5.9 & 2.00 & 20 & 12 & 48 & 6.72 & 7.25 & 0.91 & 16.8 & 45.3 & 40 \\
\hline 023 & 24.5 & 21.0 & 12.0 & 2.00 & 10 & 2 & 57 & $\longrightarrow$ & 8.35 & 1.49 & 18 & 48.5 & 41 \\
\hline 024 & 23.0 & 22.5 & 7.8 & 1.60 & 25 & 1.4 & 56 & 7.18 & 8.43 & 1.63 & 18.1 & 49.4 & 155 \\
\hline 025 & 22.5 & 25.0 & 11.4 & 2.00 & 25 & 1.2 & 60 & 7.35 & 7.67 & 1.27 & 19.5 & 41.9 & 40 \\
\hline N26 & 23.1 & 22.0 & 10.6 & 2.00 & 25 & 1 & 58 & 7.44 & 8.16 & 1.52 & 19.1 & 53.3 & 51 \\
\hline N27 & 20.9 & 24.0 & 9.0 & 2.00 & 25 & 12 & 59 & 7.80 & 8.16 & 1.52 & 18.6 & 31.9 & 51 \\
\hline N28 & 18.5 & 25.2 & 11.0 & 2.00 & 25 & 12 & 53 & 8.55 & 8.19 & 2.58 & 18.1 & 33.8 & 51 \\
\hline N29 & 21.0 & 24.5 & 11.0 & 2.00 & 15 & 1.7 & 56 & 6.99 & 7.21 & 2.27 & 18.6 & 35.3 & 49 \\
\hline D30 & 20.5 & 24.0 & 10.8 & 2.00 & 25 & 0.9 & 58 & 7.08 & 7.03 & 1.42 & 19.2 & 37.0 & 43 \\
\hline D31 & 24.0 & 24.0 & 10.8 & 2.00 & 25 & $i$ & 58 & 7.17 & 6.28 & 0.83 & 20.2 & - & 54 \\
\hline D32 & 21.5 & 24.6 & 11.0 & 2.00 & 30 & 1.5 & 58 & 7.02 & 6.06 & 0.90 & 20.7 & . & - \\
\hline D33 & 22.5 & 24.8 & 10.8 & 2.00 & 20 & 13 & 52 & 6.96 & 6.28 & 2.13 & 20.7 & - & 45 \\
\hline $\mathrm{JA34}$ & 23.0 & 26.2 & 11.4 & 2.00 & 25 & 13 & 56 & 7.23 & 6.85 & 1.60 & 20.7 & - & 49 \\
\hline JA35 & 24.0 & 25.5 & 10.8 & 2.00 & 30 & 1.4 & 58 & 7.09 & 6.17 & 0.32 & 20.7 & 36.0 & - \\
\hline JA36 & 22.0 & 24.0 & 11.0 & 2.00 & 15 & 1.5 & 58 & 7.80 & 7.11 & 0.68 & 23.7 & 174.5 & - \\
\hline JA37 & 28.0 & 26.0 & 11.2 & 2.00 & 35 & 12 & 67 & 8.10 & 8.08 & 2.22 & 21.2 & 58.2 & 47 \\
\hline F38 & 28.0 & 25.0 & 10.8 & 2.00 & 40 & 2 & 68 & 6.70 & 5.35 & 1.80 & 19.7 & 46.0 & 78 \\
\hline F39 & 23.5 & 25.0 & 11.5 & 2.00 & 25 & 1.5 & 53 & 7.40 & 7.36 & 1.02 & 20.2 & 57.6 & 48 \\
\hline F40 & 29.5 & 26.5 & 8.1 & 1.55 & 20 & 1.1 & 67 & 7.60 & 8.15 & 2.11 & 20.2 & - & 50 \\
\hline $\mathrm{F} 41$ & 32.5 & 26.5 & 11.3 & 1.26 & 20 & 1.1 & 52 & 7.23 & 7.25 & 1.21 & 38.7 & - & 51 \\
\hline MR42 & 26.0 & 24.0 & 12.0 & 1.00 & 15 & 1.4 & 70 & 7.50 & 7.06 & 1.32 & 22.2 & - & 48 \\
\hline MR43 & 24.2 & 24.5 & 10.5 & 1.20 & 30 & 1.5 & 69 & 7.10 & 5.84 & 0.98 & 33.3 & - & 48 \\
\hline MR44 & 23.5 & 24.5 & 7.0 & 1.45 & 30 & 1.5 & 72 & 7.03 & 5.33 & 0.78 & 23.2 & - & 38 \\
\hline $\mathrm{AB} 45$ & 21.0 & 24.0 & 11.1 & 1.00 & 25 & 1.7 & 72 & 7.21 & 6.16 & 1.45 & 22.2 & - & 53 \\
\hline $\mathrm{AB} 46$ & 22.0 & 22.8 & 9.5 & 1.68 & 20 & 1.3 & 61 & 7.19 & 6.27 & - & 24.2 & - & 72 \\
\hline AB47 & 22.5 & 24.0 & 12.3 & 1.25 & 25 & 1.6 & 50 & 7.19 & 6.18 & - & 23.2 & - & 97 \\
\hline AB48 & 22.5 & 22.2 & 10.4 & 1.20 & 20 & 1.6 & 76 & 7.52 & 6.70 & 0.22 & 24.1 & - & 66 \\
\hline $\mathrm{AB} 49$ & 23.0 & 22.0 & 11.7 & 1.32 & 25 & 1.7 & 58 & 7.61 & 7.96 & 1.31 & 24.6 & - & 65 \\
\hline MASO & 22.5 & 22.0 & 10.0 & 1.40 & 25 & 1.4 & 60 & 7.67 & 7.92 & 1.38 & 24.6 & - & 44 \\
\hline MAS1 & 22.2 & 22.2 & 11.3 & 1.60 & 20 & 2.2 & 67 & 7.27 & 7.14 & 1.37 & 24.6 & 26.4 & 33 \\
\hline MAS3 & 21.5 & 21.0 & 11.5 & 1.60 & 30 & 1.6 & 100 & 7.20 & 7.22 & 1.44 & 24.1 & 92.7 & 43 \\
\hline 154 & 27.5 & 21.0 & 11.6 & 3.00 & 20 & 12 & 62 & 7.79 & - & - & 23.1 & 29.8 & 55 \\
\hline 155 & 27.0 & 21.0 & 10.0 & 3.00 & 10 & 1.2 & 70 & 7.36 & 7.31 & 1.16 & 23.6 & 30.4 & 62 \\
\hline JS6 & 19.5 & 19.0 & 11.5 & 2.50 & - & - & - & 7.49 & - & - & 22.6 & - & - \\
\hline 357 & 22.0 & 19.0 & 10.0 & 2.16 & 20 & 1.2 & 70 & 7.18 & 7.56 & 1.43 & 23.1 & 29.4 & 63 \\
\hline JL58 & 18.0 & 17.0 & 10.0 & 1.42 & 25 & 1.5 & 62 & 7.20 & 8.63 & 1.02 & 30.3 & 24.7 & 48 \\
\hline
\end{tabular}

$\mathrm{B}, \mathrm{Ba}, \mathrm{Cd}, \mathrm{Cr}, \mathrm{Pb}$ e $\mathrm{Ni}$ constantes ou abaixo do nivel de detecaga do método utilizado. 
TABELA 4 (continuação) - VARIAÇÃO TEMPORAL DAS VARIÁVEIS FÍSICAS E QUíMICAS. REPRESA DE GUARAPIRANGA 1991-92, PONTO 1. CAPTAÇĀO.

Identificação da coleta (ID); teores em $\mu \mathrm{g} . \mathrm{l}^{-1}$ de: fósforo solúvel reativo (PO, ${ }^{-3}$; fósforo total (PT). Teores em mg. $\mathrm{I}^{-1}$ : amônio $\left(\mathrm{NH}_{4}{ }^{4}\right)$; nitrato $\left(\mathrm{NO}_{3}\right)$; sulfato $\left(\mathrm{SO}_{4}{ }^{-2}\right)$; cloro $(\mathrm{Cl})$; alumínio $(\mathrm{Al})$; cálcio $(\mathrm{Ca})$; cobre $(\mathrm{Cu})$; ferro $(\mathrm{Fe})$; potássio $(\mathrm{K})$; magnésio $(\mathrm{Mg})$; manganês $(\mathrm{Mn})$; sódio $(\mathrm{Na})$; silício (Si) e zinco $(\mathrm{Zn})$.

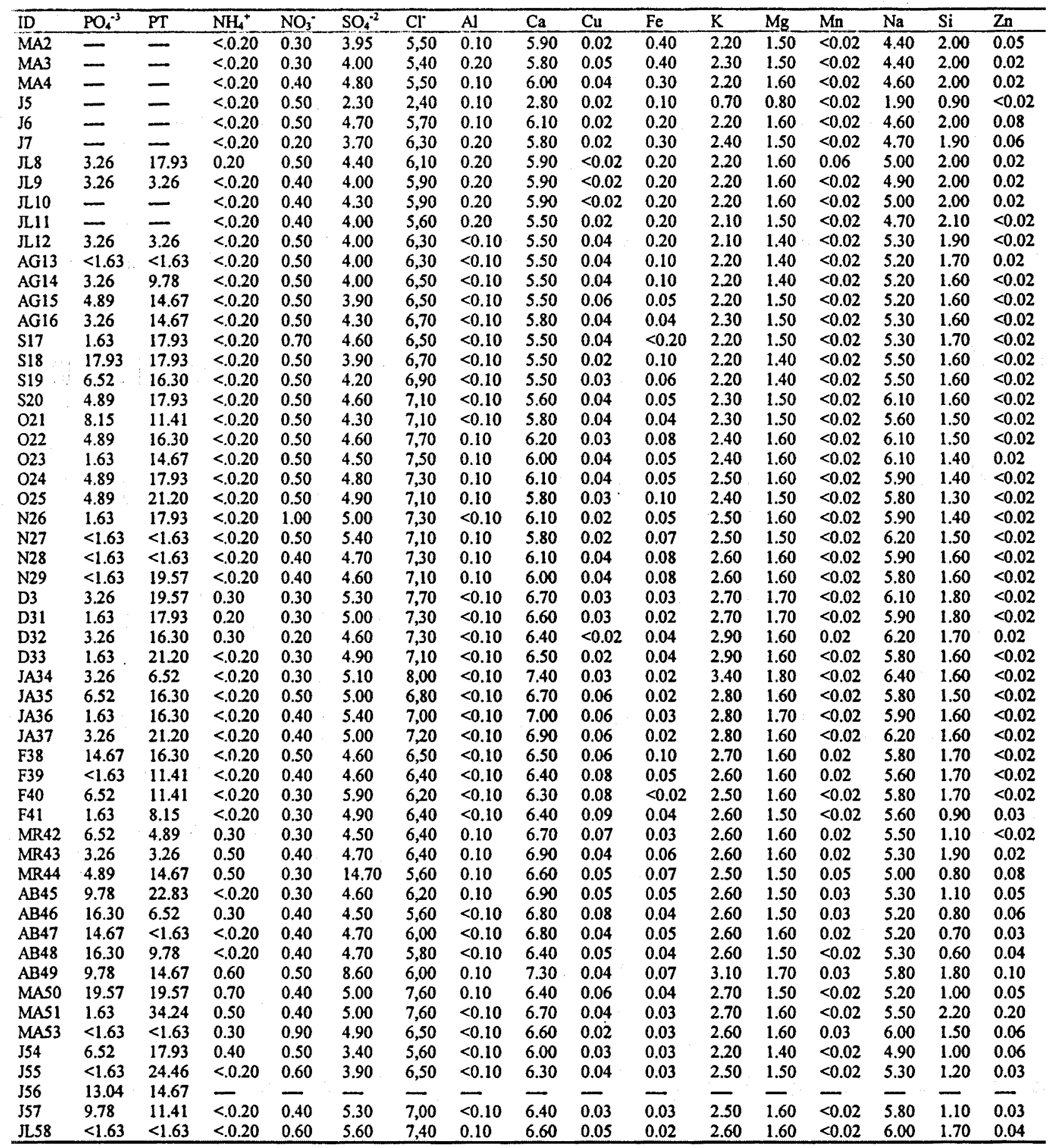

$\mathrm{B}, \mathrm{Ba}, \mathrm{Cd}, \mathrm{Cr}, \mathrm{Pb}$ e Ni constantes ou abaixo do nível de detecção do método utilizado.

--- Dados ausentes 
TABELA 5 - VARIAÇĀO TEMPORAL DAS VARIÁVEIS FÍSICAS E QUÍMICAS. REPRESA DE GUARAPIRANGA 1991-92. PONTO 4 - ÁREA PRÓXIMA DA ILHA DOS EUCALIPTOS.

Identificação da coleta (ID); temperatura em ${ }^{\circ} \mathrm{C}$ do ar (TAR), da água (TAG); profundidade em m (PROF); transparência ao disco de Secchi em m (SEC); cor em mg.1 $1^{-1} \mathrm{Pt}$ (COR); turbidez em UTN (TUR); condutividade em $\mu$ S.cm ${ }^{2-1}(\mathrm{CON})$; $\mathrm{pH}(\mathrm{pH})$;oxigênio dissolvido em mg. $\mathrm{l}^{-1}$ (OD); demanda bioquímica de oxigênio em mg. $\mathrm{l}^{-1}(\mathrm{DBO})$; alcalinidade em mg. $1^{-1} \mathrm{CaCO}_{3}$ (ALC); dureza em mg.l $\mathrm{l}^{-1} \mathrm{CaCO}_{3}$ (DUR) e teores de sólidos totais em suspensão (SOT) em mg. $\mathrm{I}^{-1}$.

\begin{tabular}{|c|c|c|c|c|c|c|c|c|c|c|c|c|c|}
\hline ID & TAR & TAG & PROF & SEC & COR & TUR & COND & pH & OD & DBO & ALC & DUR & SOT \\
\hline MA2 & - & - & 9.80 & 1.70 & 45 & 3.2 & 38 & 6.60 & 8.71 & 4.40 & - & - & - \\
\hline MA3 & 19.3 & 21.0 & 8.00 & 1.50 & 40 & 2.8 & 42 & 6.50 & 7.80 & 1.60 & - & - & - \\
\hline MA4 & 19.5 & 20.5 & 8.00 & 1.75 & 40 & 3.4 & 44 & 6.70 & 7.31 & 1.37 & - & - & - \\
\hline J5 & 18.2 & 19.8 & 8.04 & 1.54 & 40 & 2.6 & 44 & 6.30 & 7.45 & 1.15 & - & 19.0 & $\ldots$ \\
\hline J6 & 16.5 & 19.5 & 8.49 & 1.37 & 40 & 2.4 & 33 & 6.70 & 7.10 & 0.98 & - & 17.9 & - \\
\hline J7 & 23.0 & 20.5 & 8.85 & 2.00 & 40 & 1.5 & 39 & 6.38 & 5.83 & 0.00 & - & 20.2 & - \\
\hline JL8 & 23.0 & 18.5 & 8.38 & 2.00 & 30 & 3.0 & 47 & 6.61 & 7.88 & 0.29 & 12.1 & 17.6 & - \\
\hline JL9 & 24.0 & 18.2 & 8.16 & 2.00 & 30 & 2.6 & 48 & 7.15 & 7.33 & 0.90 & 16.4 & 16.8 & - \\
\hline JL10 & 19.0 & 16.0 & 8.10 & 2.00 & 20 & 1.7 & 51 & 6.60 & 7.33 & 0.74 & 14.7 & 18.7 & - \\
\hline JL11 & 20.0 & 18.5 & 8.00 & 2.00 & 39 & 2.3 & 51 & 6.76 & 8.08 & 1.19 & 一 & - & - \\
\hline JL12 & 22.0 & 18.5 & 8.22 & 2.00 & 35 & 2.3 & 54 & 7.08 & 7.89 & 1.15 & 12.7 & 17.7 & - \\
\hline AGl3 & 19.0 & 18.0 & 8.00 & 2.00 & 25 & 1.4 & 51 & 7.26 & 8.23 & 1.28 & 7.2 & 44.0 & - \\
\hline AGl4 & 19.5 & 17.7 & 8.06 & 2.00 & 20 & 1.7 & 52 & 7.12 & 7.62 & 2.13 & 15.8 & 40.6 & - \\
\hline AG15 & 22.0 & 18.5 & 7.63 & 2.00 & 30 & 2.3 & 50 & 6.98 & 5.69 & 0.94 & 15.4 & - & - \\
\hline AG16 & 23.8 & 20.0 & 9.48 & 2.40 & 30 & 2.1 & 44 & 6.86 & 7.50 & 0.46 & 15.4 & 20.4 & 80 \\
\hline S17 & 18.2 & 18.2 & 7.86 & 1.42 & 25 & 3.7 & 51 & 6.52 & 6.19 & 0.64 & 16.6 & - & 96 \\
\hline S18 & 20.5 & 19.2 & 7.00 & 1.60 & 30 & 2.2 & 54 & 7.27 & 7.34 & 0.81 & 16.1 & 14.5 & 20 \\
\hline S19 & 22.5 & 20.5 & 7.00 & 2.00 & 25 & 1.5 & 59 & 6.85 & 7.76 & 1.59 & 16.1 & 28.7 & 10 \\
\hline $\mathbf{S} 20$ & 15.5 & 19.2 & 7.32 & 1.63 & 35 & 2.5 & 49 & 6.86 & 6.87 & 0.78 & 18.8 & 26.8 & 35 \\
\hline 021 & 19.2 & 19.2 & 7.17 & 1.20 & 55 & 4.5 & 51 & 6.72 & 6.09 & 0.00 & 19.1 & 39.4 & 19 \\
\hline $\mathrm{O} 22$ & 16.2 & 18.2 & 7.80 & 1.37 & 55 & 6.2 & 54 & 6.72 & 7.10 & 0.76 & 16.8 & 44.0 & 55 \\
\hline 023 & 27.2 & 22.8 & 7.75 & 1.50 & 30 & 7.1 & 54 & - & 8.13 & 1.43 & 17.5 & 44.1 & 52 \\
\hline O24 & 23.0 & 22.5 & 7.76 & 1.60 & 55 & 4.6 & 53 & 6.89 & 7.70 & 1.27 & 16.3 & 49.4 & 35 \\
\hline 025 & 25.0 & 23.0 & 7.50 & 1.35 & 40 & 3.0 & 52 & 7.20 & 7.41 & 0.69 & 16.3 & 36.8 & 38 \\
\hline N26 & 22.0 & 21.0 & 7.75 & 1.18 & 70 & 5.0 & 51 & 7.06 & 6.40 & 6.40 & 15.9 & 22.0 & 50 \\
\hline N27 & 24.1 & 22.8 & 8.00 & 1.50 & 55 & 2.3 & 57 & 7.15 & 7.77 & 1.28 & 16.8 & 31.7 & 48 \\
\hline N28 & 21.2 & 23.5 & 8.25 & 2.00 & 45 & 1.8 & 49 & 7.43 & 7.89 & 2.43 & 16.8 & 36.8 & 49 \\
\hline N29 & 21.2 & 25.2 & 7.80 & 1.55 & 25 & 1.7 & 58 & 7.23 & 7.59 & 1.91 & 18.1 & 35.8 & 20 \\
\hline D30 & 21.5 & 23.0 & 7.37 & 1.50 & 40 & 1.5 & 59 & 6.73 & 5.01 & 0.45 & 19.7 & 35.5 & 40 \\
\hline D31 & 25.0 & 24.8 & 9.88 & 1.48 & 45 & 2.5 & 57 & 7.11 & 6.69 & 0.86 & 18.2 & - & 34 \\
\hline D32 & 25.0 & 26.2 & 8.39 & 1.50 & 40 & 2.5 & 58 & 7.11 & 6.54 & 1.08 & 19.7 & - & - \\
\hline D33 & 22.5 & 25.5 & 7.90 & 1.00 & 40 & 1.1 & 55 & 6.98 & 6.60 & 1.44 & 19.7 & - & 47 \\
\hline JA34 & 23.2 & 25.0 & 7.15 & 1.50 & 55 & 1.8 & 49 & 6.64 & 4.22 & 1.47 & 20.7 & - & 50 \\
\hline JA35 & 25.0 & 26.0 & 7.00 & 1.00 & 40 & 2.3 & 60 & 7.13 & 6.97 & 0.07 & 20.7 & 31.6 & - \\
\hline JA36 & 21.5 & 23.5 & 6.50 & 1.00 & 50 & 5.5 & 49 & 6.90 & 6.15 & 0.62 & 18.2 & 154.0 & - \\
\hline JA37 & 31.0 & 26.8 & 7.00 & 1.50 & 45 & 2.4 & 67 & 8.10 & 8.12 & 1.89 & 21.9 & 54.4 & 49 \\
\hline F38 & 21.5 & 25.0 & 7.20 & 1.00 & 55 & 4.5 & 49 & 6.70 & 6.28 & 2.05 & 17.2 & 39.8 & 79 \\
\hline F39 & 25.0 & 25.0 & 7.50 & 1.50 & 40 & 2.3 & 52 & 7.40 & 7.32 & 1.43 & 19.2 & 52.6 & 46 \\
\hline F40 & 31.5 & 27.0 & 6.00 & 1.40 & 25 & 1.7 & 68 & 7.70 & 8.75 & 3.17 & 19.2 & - & 50 \\
\hline F41 & 29.0 & 25.8 & 7.45 & 1.00 & 45 & 3.0 & 62 & 6.74 & 5.13 & 0.90 & 15.2 & - & 48 \\
\hline MR42 & 27.0 & 26.0 & 10.50 & 1.40 & 20 & 2.0 & 67 & 7.82 & 8.15 & 1.66 & 20.2 & - & 49 \\
\hline MR43 & 31.5 & 25.5 & 8.34 & 1.33 & 35 & 2.3 & 62 & 7.10 & 6.90 & 1.25 & 22.2 & - & 25 \\
\hline MR44 & 27.0 & 25.0 & 7.80 & 1.20 & 35 & 2.4 & 66 & 6.92 & 6.43 & 1.25 & 20.7 & - & 35 \\
\hline $\mathrm{AB} 45$ & 25.0 & 25.0 & 8.70 & 1.00 & 40 & 3.4 & 69 & 6.96 & 5.65 & 1.30 & 22.2 & - & 57 \\
\hline AB46 & 21.0 & 23.8 & 7.80 & 1.60 & 45 & 3.7 & 53 & 7.14 & 5.80 & - & 22.0 & - & 63 \\
\hline AB47 & 23.0 & - & 7.13 & 1.40 & 40 & 2.4 & 58 & 7.19 & 7.33 & - & 20.5 & - & 56 \\
\hline $\mathrm{AB} 48$ & 24.2 & 23.0 & 8.30 & 1.20 & 40 & 1.2 & 60 & 7.29 & 7.25 & 1.50 & 22.6 & - & 280 \\
\hline AB49 & 27.0 & 22.5 & 7.68 & 1.35 & 35 & 2.0 & 59 & 7.14 & 6.34 & 0.87 & 25.7 & - & 76 \\
\hline MA50 & 21.5 & 23.3 & 8.00 & 1.35 & 40 & 1.5 & 60 & 7.16 & 7.01 & 1.23 & 22.1 & - & 45 \\
\hline MA51 & 22.5 & 22.5 & 8.50 & 2.00 & 20 & 1.4 & 60 & 7.28 & 7.68 & 1.68 & 22.1 & 19.4 & 86 \\
\hline MA53 & 22.0 & 22.0 & 8.00 & 1.60 & 30 & 1.7 & 72 & 7.20 & 7.92 & 1.80 & 21.6 & 29.3 & 48 \\
\hline J54 & 27.5 & 21.0 & 7.84 & 1.80 & 40 & 1.7 & 62 & 7.28 & - & - & 21.6 & 27.2 & 63 \\
\hline J55 & 22.0 & 20.0 & 9.00 & 1.85 & 20 & 1.6 & 65 & 7.52 & 7.30 & 1.11 & 21.8 & 28.8 & 79 \\
\hline J56 & 22.5 & 21.0 & 7.50 & 2.31 & - & - & - & 7.47 & - & - & 22.1 & - & - \\
\hline J57 & 20.0 & 25.0 & 7.46 & 2.33 & 35 & 1.2 & 70 & 6.89 & 8.87 & 0.89 & 24.6 & 27.9 & 71 \\
\hline ЛL58 & 26.0 & 13.0 & 7.00 & 1.40 & 20 & 2.5 & 69 & 7.50 & 8.63 & 1.10 & 23.7 & 23.2 & 53 \\
\hline
\end{tabular}

$\mathrm{B}, \mathrm{Ba}, \mathrm{Cd}, \mathrm{Cr}, \mathrm{Pb}$ e Ni constantes ou abaixo do nível de detecção do método utilizado. 
TABELA 5 (continuação) - VARIAÇÃO TEMPORAL DAS VARIÁVEIS FÍSICAS E QUÍMICAS DA REPRESA DE GUARAPIRANGA 1991-92. PONTO 4-ÁREA PRÓXIMA DA ILHA DOS EUCALIPTOS.

Identificação das coletas (ID); teores em $\mu \mathrm{g} .1^{-1}$ : fósforo solúvel reativo $\left(\mathrm{PO}_{4}{ }^{-}\right)$; fósforo total (PT). Teores em mg. ${ }^{-1}$ : amônio $\left(\mathrm{NH}_{4}\right)$; nitrato $\left(\mathrm{NO}_{3}\right)$; sulfato $\left(\mathrm{SO}_{4}{ }^{2}\right)$; cloro (Cl); alumínio (Al); cálcio (Ca); cobre (Cu); ferro $(\mathrm{Fe})$; potássio $(\mathrm{K})$; magnésio $(\mathrm{Mg})$; manganês $(\mathrm{Mn})$; sódio $(\mathrm{Na})$; silício $(\mathrm{Si})$ e zinco $(\mathrm{Zn})$.

\begin{tabular}{|c|c|c|c|c|c|c|c|c|c|c|c|c|c|c|c|c|}
\hline ID & $\mathrm{PO}_{4}{ }^{3}$ & PT & $\mathrm{NH}_{4}^{+}$ & $\mathrm{NO}_{3}^{-}$ & $\mathrm{SO}_{4}^{2}$ & a & Al & $\mathrm{Ca}$ & $\mathrm{Cu}$ & $\mathrm{Fe}$ & $\mathbf{K}$ & $\mathbf{M g}$ & Mn & $\mathrm{Na}$ & $\mathbf{S i}$ & Zn \\
\hline MA2 & - & - & $<0.2$ & 0.20 & 3.60 & 4.90 & 0.20 & 4.90 & $<0.0$ & 0.70 & 2.10 & 1.30 & $<0.0$ & 3.80 & 2.10 & 0.02 \\
\hline & & & & & 4.00 & 4.90 & 0.20 & 4.90 & $<0.0$ & 0.60 & 2.00 & 1.30 & $<0.0$ & 4.00 & 2.00 & 0.02 \\
\hline MA4 & - & - & 0.40 & 0.30 & 4.50 & 4.90 & 0.10 & 5.10 & $<0.0$ & 0.40 & 2.00 & 1.40 & 0.02 & 4.20 & 2.10 & 0.05 \\
\hline J5 & - & - & $<0.2$ & 0.30 & 4.60 & 5.10 & 0.10 & 5.30 & $<0.0$ & 0.50 & 2.20 & 1.40 & $<0.0$ & 4.20 & 2.10 & 0.02 \\
\hline 36 & - & - & $<0.2$ & 0.30 & 4.50 & 5.30 & 0.10 & 5.40 & $<0.0$ & 0.40 & 2.10 & 1.40 & $<0.0$ & 4.60 & 2.00 & 0.02 \\
\hline $\mathrm{J7}$ & & - & $<0.2$ & 0.30 & 3.70 & 5.30 & 0.20 & 5.20 & $<0.0$ & 0.40 & 2.10 & 1.40 & $<0.0$ & 4.40 & 2.00 & 0.02 \\
\hline JL8 & 6.52 & 19.5 & $<0.2$ & 0.30 & 3.70 & 5.50 & 0.20 & 4.90 & $<0.0$ & 0.50 & 2.00 & 1.30 & 0.02 & 4.10 & 2.20 & 0.02 \\
\hline Л 9 & 1.63 & 21.2 & 2.60 & 0.30 & 3.60 & 5.70 & 0.20 & 4.80 & $<0.0$ & 0.50 & 2.00 & 1.30 & $<0.0$ & 4.10 & 2.10 & 0.02 \\
\hline JL10 & - & - & $<0.2$ & 0.40 & 4.40 & 5.70 & 0.10 & 5.40 & $<0.0$ & 0.30 & 2.20 & 1.40 & $<0.0$ & 4.80 & 2.00 & $<0.0$ \\
\hline JL11 & - & - & $<0.2$ & 0.30 & 4.00 & 5.90 & 0.10 & 5.10 & $<0.0$ & 0.30 & 2.10 & 1.40 & $<0.0$ & 4.40 & 1.90 & 0.02 \\
\hline $\mathrm{JL} 12$ & 3.26 & 21.2 & 0.80 & 0.40 & 3.70 & 6.10 & 0.10 & 5.20 & $<0.0$ & 0.20 & 2.10 & 1.40 & $<0.0$ & 4.80 & 1.90 & $<0.0$ \\
\hline AGl & $<1.6$ & $<1.6$ & $<0.2$ & 0.40 & 4.10 & 6.10 & 0.10 & 5.30 & $<0.0$ & 0.20 & 2.10 & 1.40 & $<0.0$ & 4.80 & 2.00 & $<0.0$ \\
\hline AGI & 14.6 & 34.2 & $<0.2$ & 0.50 & 4.40 & 6.10 & 0.10 & 5.50 & $<0.0$ & 0.20 & 2.20 & 1.40 & $<0.0$ & 5.00 & 1.90 & $<0.0$ \\
\hline $\mathrm{AGl}$ & 6.99 & 13.0 & $<0.2$ & 0.40 & 4.00 & 5.70 & 0.10 & 5.20 & $<0.0$ & 0.20 & 2.10 & 1.40 & $<0.0$ & 4.80 & 2.00 & $<0.0$ \\
\hline $\mathrm{AGl}$ & 3.26 & 16.3 & $<0.2$ & 0.30 & 3.70 & 6.10 & 0.10 & 4.50 & $<0.0$ & 0.30 & 1.90 & 1.30 & $<0.0$ & 4.40 & 2.00 & $<0.0$ \\
\hline $\mathrm{S} 17$ & 3.26 & 26.0 & $<0.2$ & 0.60 & 5.30 & 6.50 & $<0.1$ & 5.20 & $<0.0$ & $<0.0$ & 2.20 & 1.50 & $<0.0$ & 5.30 & 2.10 & $<0.0$ \\
\hline S18 & 4.89 & 14.6 & $<0.2$ & 0.40 & 3.40 & 6.10 & 0.10 & 5.00 & $<0.0$ & 0.20 & 2.10 & 1.40 & $<0.0$ & 5.00 & 1.90 & $<0.0$ \\
\hline S19 & 4.89 & 14.6 & $<0.2$ & 0.50 & 4.10 & 6.30 & 0.10 & 5.20 & $<0.0$ & 0.20 & 2.10 & 1.40 & $<0.0$ & 5.10 & 1.80 & $<0.0$ \\
\hline S20 & 4.89 & 11.4 & $<0.2$ & 0.50 & 5.00 & 7.00 & 0.10 & 5.80 & $<0.0$ & 0.20 & 2.30 & 1.50 & $<0.0$ & 5.50 & 2.00 & $<0.0$ \\
\hline 021 & 11.4 & 21.2 & $<0.2$ & 0.50 & 4.20 & 6.70 & 0.20 & 5.40 & $<0.0$ & 0.20 & 2.20 & 1.50 & $<0.0$ & 5.50 & 1.80 & $<0.0$ \\
\hline 022 & 4.89 & 21.2 & 0.30 & 0.50 & 4.50 & 7.00 & 0.20 & 6.20 & $<0.0$ & 0.10 & 2.40 & 1.60 & $<0.0$ & 5.50 & 1.60 & $<0.0$ \\
\hline $\mathrm{O} 23$ & 4.89 & 9.78 & $<0.2$ & 0.40 & 4.20 & 6.30 & 0.20 & 5.40 & $<0.0$ & 0.20 & 2.40 & 1.40 & $<0.0$ & 5.10 & 1.50 & $<0.0$ \\
\hline 024 & 6.52 & 19.5 & $<0.2$ & 0.40 & 4.90 & 6.30 & 0.20 & 5.40 & $<0.0$ & 0.30 & 2.40 & 1.50 & $<0.0$ & 5.00 & 1.80 & $<0.0$ \\
\hline 025 & 9.78 & 16.3 & $<0.2$ & 0.40 & 3.40 & 5.90 & 0.20 & 5.00 & $<0.0$ & 0.20 & 2.20 & 1.30 & $<0.0$ & 5.00 & 1.50 & 0.02 \\
\hline N26 & $<1.6$ & $<1.6$ & $<0.2$ & 0.40 & 4.50 & 6.10 & 0.20 & 5.20 & $<0.0$ & 0.40 & 2.20 & 1.40 & 0.02 & 4. & 1.80 & $<0.0$ \\
\hline N27 & $<1.6$ & 13.0 & 0.20 & 0.40 & 6.20 & 6.10 & 0.10 & 5.50 & $<0.0$ & 0.20 & 2.30 & 1.40 & $<0.0$ & 5. & 50 & $<0.0$ \\
\hline N28 & 6.52 & 3.26 & $<0.2$ & 0.30 & 4.50 & 6.10 & 0.10 & 5.70 & $<0.0$ & 0.20 & 2.30 & 1.50 & $<0.0$ & 5.00 & 1.70 & $<0.0$ \\
\hline N29 & $<1.6$ & $<1.6$ & $<0.2$ & 0.30 & 5.80 & 7.90 & 0.10 & 10.1 & $<0.0$ & 0.20 & 3.10 & 2.50 & 0.03 & 6. & 2.80 & 0.07 \\
\hline D30 & $<1.6$ & 16.3 & $<0.2$ & 0.20 & 4.40 & 6.50 & $<0.1$ & 6.20 & $<0.0$ & 0.08 & 2.40 & 1.50 & 0.05 & 5.30 & 1.80 & $<0.0$ \\
\hline D31 & 6.52 & 17.9 & $<0.2$ & 0.20 & 3.50 & 6.30 & 0.10 & 6.30 & $<0.0$ & 0.1 & 2. & 1.60 & 0.02 & & 1.90 & 0.02 \\
\hline D32 & 4.89 & 17.9 & $<0.2$ & 0.20 & 4.40 & 6.30 & 0.10 & & $<0.0$ & 0.10 & 2. & 1.50 & 0.02 & 5.50 & 1.80 & $<0.0$ \\
\hline D33 & 6.52 & 27.7 & $<0.2$ & 0.20 & 3.90 & 6.30 & 0.10 & 6.30 & $<0.0$ & 0.10 & 2.40 & 1.50 & 0.02 & 5.10 & 1.80 & $<0.0$ \\
\hline $\mathrm{JA} 34$ & 3.26 & 17.9 & 0.20 & 0.40 & 4.22 & 6.70 & $<0$ & 7. & $<0.0$ & 0.07 & 2.70 & 1.70 & 0.07 & 5.50 & 1.80 & 0.02 \\
\hline $\mathrm{JA} 3$ & 3.26 & 19.5 & $<0.2$ & 0.40 & 4.10 & 6.50 & 0.10 & 6. & $<0.0$ & 0.10 & 2.50 & 1.60 & $<0.0$ & & 1.70 & 0.02 \\
\hline JA36 & 1.63 & 14.6 & $<0.2$ & 0.2 & 4.10 & 6.10 & 0.30 & 6.00 & $<0.0$ & 0.50 & 2.20 & 1.50 & 0.03 & 4.60 & 2.20 & 0.02 \\
\hline $\mathrm{JA} 37$ & 3.26 & 16.3 & $<0.2$ & 0.30 & 4.20 & 6.50 & 0.20 & 7.00 & $<0.0$ & 0.40 & 2. & & 0.02 & & 2.00 & 0.05 \\
\hline F38 & 6.52 & 22.8 & 0.30 & 0.2 & 3.80 & 5.70 & 0.20 & 5.50 & $<0.0$ & 0.30 & 2.20 & 1.4 & 0.04 & 4.70 & 1.80 & 0.02 \\
\hline F39 & 6.52 & 17.9 & $<0.2$ & 0.2 & & 5.70 & 0.10 & 5.50 & $<0.0$ & 0. & 2.3 & & 0.02 & & 1.80 & $<0.0$ \\
\hline $\mathrm{F} 40$ & $<1.6$ & 8.15 & 0.40 & 0.2 & 4.80 & 6.10 & $<0$ & 5. & $<0.0$ & 0.10 & 2.50 & 1.4 & $<0.0$ & 4.9 & 1.80 & $<0.0$ \\
\hline F4 & $<1.6$ & 4.89 & 0.40 & 0.20 & 3.70 & 5.90 & 0.10 & 5.90 & $<0.0$ & 0.10 & 2.40 & 1.40 & 0.02 & 4.90 & 1.50 & 0.04 \\
\hline MF & $<1.6$ & $<1.6$ & & & & & & & & & & & & & & \\
\hline & 6.52 & 6.52 & 0.30 & 0.10 & 3.50 & 5.70 & 0.10 & 6.00 & $<0.0$ & 0.20 & 2.40 & 1.40 & $<0.0$ & 4.60 & 2.10 & 0.05 \\
\hline M & 6.52 & 13.0 & 0.40 & & 3.10 & 5.20 & & & $<0.0$ & 0.2 & 2 & 1.40 & 0.03 & & 1.10 & 0.02 \\
\hline$A B$ & 14.6 & 6.52 & 0.40 & 0.2 & 3.80 & 5.60 & 0.10 & & $<0.0$ & 0.1 & 2 & & 0.03 & & 1.90 & $<0.0$ \\
\hline$A B$ & 13.0 & 17.9 & 0.30 & 0.2 & 3.30 & 4.90 & 0.2 & & $<0.0$ & 0.4 & 2.2 & 1.30 & 0.10 & & 2.10 & 0.02 \\
\hline$A B$ & 9.78 & 21.2 & 0.20 & 0.2 & & 4.00 & $<0.1$ & & $<0.0$ & 0.1 & 1. & 1.10 & $<0.0$ & & 0.80 & 0.10 \\
\hline $\mathrm{AB}$ & 8.15 & 29.3 & 0.80 & 0.3 & 4.40 & 5.40 & $<0.1$ & 5.7 & $<0.0$ & 0.0 & 2.7 & 1.40 & 0.02 & 4.50 & 0.80 & 0.04 \\
\hline & 3.26 & 19.5 & 0.30 & 0.2 & 4.40 & 5.00 & $<0.1$ & & $<0.0$ & 0. & & & 0.02 & & 0.90 & 0.03 \\
\hline & 9.78 & 9.78 & 0.60 & 1.7 & 5.00 & 5.40 & $<0.1$ & 5.8 & $<0.0$ & 0.1 & 2. & 1.40 & 0.02 & 4.50 & 2.10 & 0.10 \\
\hline & $<1.6$ & 21 & $<0.2$ & 0.3 & 3.80 & 5.00 & $<0.1$ & 5.80 & $<0.0$ & 0.10 & & & $<0.0$ & 4.80 & 2.10 & 0.03 \\
\hline & 4.89 & 14. & - & - & - & $\ldots$ & - & & - & & & & & & & \\
\hline & $<1$. & 17. & $<0$. & & 2.60 & & 0.10 & & $<0.0$ & 0.4 & & & $<0.0$ & 4.00 & 1.30 & 0.10 \\
\hline & 1.63 & 37.5 & 0.9 & & 3.7 & & & & $<0.0$ & 0. & & 1. & $<0.0$ & 5.00 & 1.50 & 0.03 \\
\hline & 9.78 & 13.0 & - & - & - & - & $\ldots$ & & - & & & & & & & \\
\hline & 9.78 & 17.9 & $<0.2$ & 0.30 & 5.30 & 6.70 & $<0.1$ & 6.00 & $<0.0$ & $0.0^{\circ}$ & & 1.5 & $<0.0$ & 5.20 & 1.20 & 0.03 \\
\hline & 9.78 & & & & 5.00 & 13.8 & & 4.50 & $<0.0$ & 0.04 & & & $<0.0$ & 9.40 & 2.00 & 0.08 \\
\hline
\end{tabular}

$\mathrm{B}, \mathrm{Ba}, \mathrm{Cd}, \mathrm{Cr}, \mathrm{Pb}$ e $\mathrm{Ni}$ constantes ou abaixo do nível de detecção do método utilizado.

-.-- Dados ausentes. 
TABELA 6 - CORRELAÇŌES ENTRE AS VARIÁVEIS AMBIENTAIS ABIÓTICAS DURANTE O PERIODO DE ESTUDO, TESTE DE SPEARMAN (SIEGEL, 1975); NÍVEL CONSIDERADO: $P>=0.050$. REPRESA DE GUARAPIRANGA - PONTOS 1 E 4 , 1991-92.

Temperatura da água (TAG); profundidade (PROF); transparência ao disco de Secchi (SEC); cor (COR);turbidez (TUR); condutividade (CON); $\mathrm{pH}(\mathrm{pH})$; oxigênio dissolvido (OD); demanda bioquímica de oxigênio (DBO); alcalinidade (ALC); dureza (DUR); sólidos totais em suspensão (SOT); fósforo solúvel reativo $\left(\mathrm{PO}_{4}{ }^{-3}\right)$; fósforo total (PT); amônio $\left(\mathrm{NH}_{4}{ }^{+}\right)$; nitrato $\left(\mathrm{NO}_{3}{ }^{-}\right)$; sulfato $\left(\mathrm{SO}_{4}{ }^{-2}\right)$; cloro $(\mathrm{Cl})$; aluminio (Al); cálcio $(\mathrm{Ca})$; cobre $(\mathrm{Cu})$; ferro $(\mathrm{Fe})$; potássio $(\mathrm{K})$; magnésio $(\mathrm{Mg})$; manganês $(\mathrm{Mn})$; sódio $(\mathrm{Na})$; silício (Si); zinco $(\mathrm{Zn})$; Ponto 1 (P1) $\rightarrow$ Ponto $4 \downarrow$ (P4).

\begin{tabular}{|c|c|c|c|c|c|c|c|c|c|c|c|c|}
\hline TAG & $\begin{array}{l}\mathrm{N}=55 \\
\mathrm{TAG} \\
\mathrm{X} \\
\mathrm{X}\end{array}$ & $\begin{array}{l}56 \\
\text { PROF } \\
\mathrm{N} \\
\mathrm{X}\end{array}$ & $\begin{array}{l}56 \\
\text { SEC } \\
-0.49 \\
0.00\end{array}$ & $\begin{array}{l}55 \\
\mathrm{COR} \\
\mathrm{N}\end{array}$ & $\begin{array}{l}55 \\
\text { TUR } \\
N\end{array}$ & $\begin{array}{l}55 \\
\text { CON } \\
0.41 \\
0.00\end{array}$ & $\begin{array}{l}55 \\
\mathrm{pH} \\
0.97 \\
0.01\end{array}$ & $\begin{array}{l}54 \\
O D \\
N\end{array}$ & $\begin{array}{l}52 \\
\text { DBO } \\
0.50 \\
0.00\end{array}$ & $\begin{array}{l}49 \\
\text { ALC } \\
0.98 \\
0.01\end{array}$ & $\begin{array}{l}34 \\
\text { DUR } \\
0.54 \\
0.00\end{array}$ & $\begin{array}{l}37 \\
\text { SOT } \\
\mathrm{N}\end{array}$ \\
\hline PROF & $\mathrm{N}$ & $\mathrm{X}$ & $N$ & $\mathrm{~N}$ & $N$ & $\mathrm{~N}$ & $\mathrm{~N}$ & $N$ & $\mathrm{~N}$ & $\mathrm{~N}$ & $\mathrm{~N}$ & $\mathrm{~N}$ \\
\hline SEC & $\begin{array}{l}-0.49 \\
0.00\end{array}$ & $\begin{array}{l}0.28 \\
0.04\end{array}$ & $\begin{array}{l}\mathrm{X} \\
\mathrm{X}\end{array}$ & $\mathrm{N}$ & $\begin{array}{l}-0.53 \\
0.00\end{array}$ & $\begin{array}{l}-0.33 \\
0.01\end{array}$ & $\mathrm{~N}$ & $\begin{array}{l}0.28 \\
0.04\end{array}$ & $\mathrm{~N}$ & $\begin{array}{l}-0.60 \\
0.00\end{array}$ & $\mathrm{~N}$ & $\mathrm{~N}$ \\
\hline $\mathrm{COR}$ & $\begin{array}{l}0.34 \\
0.02\end{array}$ & $\mathrm{~N}$ & $\begin{array}{l}-0.44 \\
0.00\end{array}$ & $\begin{array}{l}X \\
X\end{array}$ & $\mathrm{~N}$ & $\mathrm{~N}$ & $\begin{array}{l}-0.27 \\
0.05\end{array}$ & $\mathrm{~N}$ & $\mathrm{~N}$ & $\mathrm{~N}$ & $\mathbf{N}$ & $\mathrm{N}$ \\
\hline TUR & $\mathrm{N}$ & $N$ & $\begin{array}{l}-0.35 \\
0.01\end{array}$ & $\begin{array}{l}0.46 \\
0.00\end{array}$ & $\begin{array}{l}X \\
X\end{array}$ & $N$ & $\mathrm{~N}$ & $\begin{array}{l}-0.28 \\
0.04\end{array}$ & $\mathrm{~N}$ & $\begin{array}{l}0.50 \\
0.00\end{array}$ & $\mathrm{~N}$ & $\mathrm{~N}$ \\
\hline CON & $\begin{array}{l}0.46 \\
0.00\end{array}$ & $N$ & $\begin{array}{l}-0.28 \\
0.04\end{array}$ & $\mathrm{~N}$ & $\begin{array}{l}-0.34 \\
0.01\end{array}$ & $\begin{array}{l}\mathrm{X} \\
\mathrm{X}\end{array}$ & $\begin{array}{l}0.50 \\
0.00\end{array}$ & $\mathrm{~N}$ & $\mathrm{~N}$ & $\begin{array}{l}0.60 \\
0.00\end{array}$ & $\mathrm{~N}$ & $\mathbf{N}$ \\
\hline $\mathrm{pH}$ & $\begin{array}{l}0.28 \\
0.04\end{array}$ & $N$ & $\mathrm{~N}$ & $N$ & $\begin{array}{l}-0.36 \\
0.01\end{array}$ & $\begin{array}{l}0.61 \\
0.00\end{array}$ & $\begin{array}{l}\mathrm{X} \\
\mathrm{X}\end{array}$ & $\begin{array}{l}0.30 \\
0.03\end{array}$ & $\mathrm{~N}$ & $\begin{array}{l}0.39 \\
0.01\end{array}$ & $\begin{array}{l}0.45 \\
0.01\end{array}$ & $\mathrm{~N}$ \\
\hline$O D$ & $\mathrm{~N}$ & $N$ & $\begin{array}{l}0.46 \\
0.00\end{array}$ & $\begin{array}{l}-0.40 \\
0.00\end{array}$ & $N$ & $\mathrm{~N}$ & $\begin{array}{l}0.34 \\
0.01\end{array}$ & $\begin{array}{l}\mathrm{X} \\
\mathrm{X}\end{array}$ & $\begin{array}{l}0.44 \\
0.00\end{array}$ & $\begin{array}{l}-0.30 \\
0.04\end{array}$ & $\mathrm{~N}$ & $\mathrm{~N}$ \\
\hline DBO & $\begin{array}{l}0.33 \\
0.02\end{array}$ & $N$ & $\mathrm{~N}$ & $\mathrm{~N}$ & $N$ & $\mathrm{~N}$ & $\begin{array}{l}0.34 \\
0.02\end{array}$ & $\begin{array}{l}0.40 \\
0.00\end{array}$ & $\begin{array}{l}\mathrm{X} \\
\mathrm{X}\end{array}$ & $\mathrm{N}$ & $N$ & $N$ \\
\hline ALC & $\begin{array}{l}0.43 \\
0.00\end{array}$ & $\mathrm{~N}$ & $\mathrm{~N}$ & $\mathrm{~N}$ & $N$ & $\begin{array}{l}0.66 \\
0.00\end{array}$ & $\begin{array}{l}0.39 \\
0.01\end{array}$ & $\mathrm{~N}$ & $\mathrm{~N}$ & $\begin{array}{l}X \\
X\end{array}$ & $\mathrm{~N}$ & $N$ \\
\hline DUR & $\begin{array}{l}0.48 \\
0.01\end{array}$ & $\begin{array}{l}-0.43 \\
0.01\end{array}$ & $\begin{array}{l}-0.42 \\
0.02\end{array}$ & $\begin{array}{l}0.37 \\
0.04\end{array}$ & $N$ & $\mathrm{~N}$ & $\mathrm{~N}$ & $\mathrm{~N}$ & $\mathbf{N}$ & $\mathrm{N}$ & $\begin{array}{l}X \\
X\end{array}$ & $N$ \\
\hline SOT & $\mathrm{N}$ & $\mathrm{N}$ & $\mathrm{N}$ & $\mathrm{N}$ & $N$ & $\mathrm{~N}$ & $\mathbf{N}$ & $N$ & $\mathrm{~N}$ & $\begin{array}{l}0.33 \\
0.04\end{array}$ & $N$ & $\underset{X}{X}$ \\
\hline $\mathrm{PO}_{4}$ & $\mathrm{~N}$ & $\mathrm{~N}$ & $\mathrm{~N}$ & $\mathrm{~N}$ & $\mathrm{~N}$ & $\mathrm{~N}$ & $\mathrm{~N}$ & $\mathbf{N}$ & $\mathrm{N}$ & $\mathrm{N}$ & $N$ & $\begin{array}{l}0.34 \\
0.04\end{array}$ \\
\hline PT & $\begin{array}{l}-0.32 \\
0.03\end{array}$ & $N$ & $\mathrm{~N}$ & $\mathbf{N}$ & $\mathbf{N}$ & $\mathrm{N}$ & $\mathbf{N}$ & $\mathrm{N}$ & $\mathrm{N}$ & $\mathrm{N}$ & $\mathrm{N}$ & $\mathbf{N}$ \\
\hline $\mathrm{NH}_{4}$ & $\mathrm{~N}$ & $\mathbf{N}$ & $\begin{array}{l}-0.28 \\
0.04\end{array}$ & $\mathbf{N}$ & $N$ & $\begin{array}{l}0.33 \\
0.02\end{array}$ & $\mathrm{~N}$ & $\mathrm{~N}$ & $\mathbf{N}$ & $\begin{array}{l}0.31 \\
0.04\end{array}$ & $\mathrm{~N}$ & $\mathbf{N}$ \\
\hline $\mathrm{NO}_{3}$ & $\begin{array}{l}-0.56 \\
0.00\end{array}$ & $\mathrm{~N}$ & $\mathrm{~N}$ & $\mathrm{~N}$ & $N$ & $\mathrm{~N}$ & $N$ & $N$ & $N$ & $\begin{array}{l}-0.34 \\
0.02\end{array}$ & $\mathrm{~N}$ & $\mathrm{~N}$ \\
\hline $\mathrm{SO}_{4}$ & $\mathrm{~N}$ & $\mathrm{~N}$ & $\mathbf{N}$ & $\mathrm{N}$ & $\mathrm{N}$ & $\mathrm{N}$ & $\mathbf{N}$ & $\mathrm{N}$ & $\mathrm{N}$ & $\mathrm{N}$ & $N$ & $N$ \\
\hline $\mathrm{Cl}$ & $\mathrm{N}$ & $\begin{array}{l}-0.40 \\
0.00\end{array}$ & $\mathrm{~N}$ & $\mathrm{~N}$ & $\mathrm{~N}$ & $\mathrm{~N}$ & $\mathrm{~N}$ & $N$ & $N$ & $\mathrm{~N}$ & $\begin{array}{l}0.40 \\
0.02\end{array}$ & $\mathbf{N}$ \\
\hline Al & $\mathrm{N}$ & $\mathrm{N}$ & $\mathrm{N}$ & $\begin{array}{l}0.43 \\
0.00\end{array}$ & $\begin{array}{l}0.63 \\
0.00\end{array}$ & $\begin{array}{l}-0.49 \\
0.00\end{array}$ & $\mathrm{~N}$ & $\mathrm{~N}$ & $\mathbf{N}$ & $\begin{array}{l}-0.45 \\
0.00\end{array}$ & $\mathrm{~N}$ & $\begin{array}{l}-0.33 \\
0.05\end{array}$ \\
\hline $\mathrm{Ca}$ & $\begin{array}{l}0.65 \\
0.00\end{array}$ & $\mathrm{~N}$ & $\begin{array}{l}-0.38 \\
0.01\end{array}$ & $\mathrm{~N}$ & $\mathrm{~N}$ & $\begin{array}{l}0.42 \\
0.00\end{array}$ & $\mathrm{~N}$ & $\mathrm{~N}$ & $\mathrm{~N}$ & $\begin{array}{l}0.41 \\
0.01\end{array}$ & $\begin{array}{l}0.52 \\
0.00\end{array}$ & $\mathrm{~N}$ \\
\hline $\mathrm{Cu}$ & $\mathrm{N}$ & $N$ & $\mathrm{~N}$ & $\mathrm{~N}$ & $\mathrm{~N}$ & $\mathrm{~N}$ & $\mathrm{~N}$ & $\mathrm{~N}$ & $N$ & $\mathrm{~N}$ & $\mathrm{~N}$ & $N$ \\
\hline $\mathrm{Fe}$ & $\mathrm{N}$ & $\mathrm{N}$ & $\mathrm{N}$ & $\mathrm{N}$ & $\begin{array}{l}0.36 \\
0.01\end{array}$ & $\begin{array}{l}-0.64 \\
0.00\end{array}$ & $\begin{array}{l}-0.30 \\
0.03\end{array}$ & $\mathbf{N}$ & $\mathrm{N}$ & $\begin{array}{l}-0.47 \\
0.00\end{array}$ & $N$ & $\mathbf{N}$ \\
\hline $\mathrm{K}$ & $\begin{array}{l}0.65 \\
0.00\end{array}$ & $\mathrm{~N}$ & $\begin{array}{l}-0.41 \\
0.00\end{array}$ & $\mathrm{~N}$ & $\mathrm{~N}$ & $\begin{array}{l}0.58 \\
0.00\end{array}$ & $\mathrm{~N}$ & $\mathrm{~N}$ & $\mathrm{~N}$ & $\begin{array}{l}0.51 \\
0.00\end{array}$ & $\begin{array}{l}0.48 \\
0.01\end{array}$ & $\mathbf{N}$ \\
\hline $\mathrm{Mg}$ & $\begin{array}{l}0.36 \\
0.01\end{array}$ & $\mathrm{~N}$ & $\mathrm{~N}$ & $\mathrm{~N}$ & $\mathrm{~N}$ & $\mathrm{~N}$ & $\mathrm{~N}$ & $\mathrm{~N}$ & $\mathrm{~N}$ & $\mathrm{~N}$ & $\begin{array}{l}0.49 \\
0.01\end{array}$ & $\mathrm{~N}$ \\
\hline $\mathrm{Mn}$ & $\mathrm{N}$ & $\mathrm{N}$ & $N$ & $N$ & $\mathrm{~N}$ & $\mathrm{~N}$ & $\mathrm{~N}$ & $N$ & $\mathrm{~N}$ & $\mathbf{N}$ & $\mathbf{N}$ & $\mathrm{N}$ \\
\hline $\mathrm{Na}$ & $\mathrm{N}$ & $\begin{array}{l}-0.37 \\
0.01\end{array}$ & $\mathrm{~N}$ & $\mathrm{~N}$ & $\mathrm{~N}$ & $\begin{array}{l}0.32 \\
0.02\end{array}$ & $\mathrm{~N}$ & $N$ & $\mathbf{N}$ & $\mathrm{N}$ & $\begin{array}{l}0.38 \\
0.03\end{array}$ & $\begin{array}{l}-0.34 \\
0.04\end{array}$ \\
\hline Si & $\begin{array}{l}-0.28 \\
0.05\end{array}$ & $\begin{array}{l}0.27 \\
0.05\end{array}$ & $\begin{array}{l}0.27 \\
0.05\end{array}$ & $\mathbf{N}$ & $\mathrm{N}$ & $\begin{array}{l}-0.44 \\
0.00\end{array}$ & $\mathrm{~N}$ & $\mathrm{~N}$ & $\mathrm{~N}$ & $\mathrm{~N}$ & $\mathrm{~N}$ & $\mathrm{~N}$ \\
\hline $\mathrm{Zn}$ & $\mathrm{N}$ & $\mathrm{N}$ & $\mathrm{N}$ & $N$ & $N$ & $\begin{array}{l}0.28 \\
0.04\end{array}$ & $N$ & $N$ & $N$ & $\begin{array}{l}0.56 \\
0.00\end{array}$ & $N$ & $\mathrm{~N}$ \\
\hline
\end{tabular}


TABELA 6 - CORRELAÇÕ̃S ENTRE AS VARIÁVEIS AMBIENTAIS ABIÓTICAS DURANTE O PERIODO DE ESTUDO. TESTE DE SPEARMAN (SIEGEL, 1975), NIVEL CONSIDERADO: P> $=0.050$. REPRESA DE GUARAPIRANGA - PONTOS 1 E 4 , 1991-92.

Temperatura da água (TAG); profundidade (PROF); transparência ao disco de Secchi (SEC); cor (COR);turbidez (TUR); condutividade (CON); $\mathrm{pH}(\mathrm{pH})$; oxigênio dissolvido (OD); dernanda bioquímica de oxigênio (DBO); alcalinidade (ALC); dureza (DUR); teores de sólidos totais em suspensão (SOT); fósforo solúvel reativo $\left(\mathrm{PO}_{4}^{-3}\right)$; fósforo total (PT); amônio $\left(\mathrm{NH}_{4}\right)$; nitrato $\left(\mathrm{NO}_{3}\right)^{-}$; sulfato $\left(\mathrm{SO}_{4}^{-2}\right)$; cloro $\left(\mathrm{Cl}^{-}\right)$; alumínio $(\mathrm{Al})$; cálcio $(\mathrm{Ca})$; cobre $(\mathrm{Cu})$; ferro $(\mathrm{Fe})$; potássio $(\mathrm{K})$; magnésio $(\mathrm{Mg})$; manganês (Mn); sódio (Na); silício (Si) e zinco (Zn); Ponto $1 \rightarrow$ (P 1); Ponto $4 \downarrow$ (P 4).

\begin{tabular}{|c|c|c|c|c|c|c|c|c|c|c|c|c|c|c|c|c|}
\hline & $\mathrm{N}=48$ & 48 & 55 & 55 & 55 & 55 & 55 & 55 & 55 & 55 & 55 & 55 & 55 & 55 & 55 & 55 \\
\hline & PO4 & PT & NH4 & NO3 & SO4 & $\mathrm{Cl}$ & $\mathrm{Al}$ & $\mathrm{Ca}$ & $\mathrm{Cu}$ & $\mathrm{Fe}$ & K & $\mathrm{Mg}$ & $M n$ & $\mathrm{Na}$ & $\mathrm{Si}$ & $\mathrm{Zn}$ \\
\hline \multirow[t]{2}{*}{ TAG } & $\mathrm{N}$ & $\mathrm{N}$ & $\mathrm{N}$ & -0.45 & 0.54 & $\mathrm{~N}$ & -0.27 & 0.60 & 0.40 & -0.42 & 0.74 & 0.36 & $\mathrm{~N}$ & 0.46 & -0.30 & $\mathrm{~N}$ \\
\hline & & & & 0.00 & 0.00 & & 0.05 & 0.00 & 0.00 & 0.00 & 0.00 & 0.01 & & 0.00 & 0.03 & \\
\hline \multirow[t]{2}{*}{ PRO } & $\mathrm{N}$ & $\mathrm{N}$ & $\mathrm{N}$ & $\mathrm{N}$ & -0.28 & -0.32 & $\mathrm{~N}$ & $\mathrm{~N}$ & $\mathrm{~N}$ & 0.29 & $\mathrm{~N}$ & $\mathrm{~N}$ & $N$ & -0.32 & $\mathrm{~N}$ & $\mathrm{~N}$ \\
\hline & & & & & 0.04 & 0.02 & & & & 0.03 & & & & 0.02 & & \\
\hline \multirow[t]{2}{*}{ SEC } & $\mathrm{N}$ & $\mathrm{N}$ & -0.31 & 0.36 & -0.44 & $\mathrm{~N}$ & $\mathrm{~N}$ & -0.54 & -0.44 & $\mathrm{~N}$ & -0.53 & $\mathbf{N}$ & -0.38 & $N$ & 0.30 & $N$ \\
\hline & & & 0.02 & 0.01 & 0.00 & & & 0.00 & 0.00 & & 0.00 & & 0.01 & & 0.03 & \\
\hline COR & $\mathrm{N}$ & $N$ & $\mathrm{~N}$ & $N$ & $\begin{array}{l}0.23 \\
0.03\end{array}$ & $\mathrm{~N}$ & $\mathrm{~N}$ & $\mathrm{~N}$ & $\mathrm{~N}$ & $\mathrm{~N}$ & $\mathrm{~N}$ & $N$ & $\mathrm{~N}$ & $N$ & $N$ & $N$ \\
\hline TUR & $\mathrm{N}$ & $\mathrm{N}$ & $\mathrm{N}$ & $\mathrm{N}$ & $\mathrm{N}$ & $\mathrm{N}$ & $\mathrm{N}$ & 0.39 & $\mathrm{~N}$ & $\mathrm{~N}$ & 0.34 & $N$ & 0.43 & $N$ & $\mathrm{~N}$ & 0.36 \\
\hline \multirow[t]{2}{*}{ CON } & $\mathrm{N}$ & $\mathrm{N}$ & 0.44 & $\mathrm{~N}$ & 0.45 & $\mathrm{~N}$ & -0.27 & $\begin{array}{l}0.00 \\
0.54\end{array}$ & 0.32 & -0.55 & $\begin{array}{l}0.01 \\
0.49\end{array}$ & $\mathrm{~N}$ & $\begin{array}{l}0.00 \\
0.34\end{array}$ & 0.35 & -0.38 & $\begin{array}{l}0.01 \\
\mathrm{~N}\end{array}$ \\
\hline & & & 0.00 & & 0.00 & & 0.05 & 0.00 & 0.02 & 0.00 & 0.00 & & 0.01 & 0.01 & 0.01 & \\
\hline \multirow[t]{2}{*}{ pH } & $N$ & $\mathrm{~N}$ & $\mathrm{~N}$ & $\mathrm{~N}$ & 0.37 & 0.31 & -0.29 & 0.35 & 0.33 & -0.48 & 0.41 & $\mathrm{~N}$ & $\mathrm{~N}$ & 0.39 & -0.40 & $\mathrm{~N}$ \\
\hline & & & & & 0.01 & 0.26 & 0.03 & 0.01 & 0.02 & 0.00 & 0.00 & & & 0.00 & 0.00 & \\
\hline \multirow[t]{2}{*}{ OD } & -0.30 & $\mathrm{~N}$ & -0.27 & 0.34 & $\mathrm{~N}$ & $\mathrm{~N}$ & $\mathrm{~N}$ & -0.34 & $\mathrm{~N}$ & $\mathrm{~N}$ & $\mathrm{~N}$ & $\mathrm{~N}$ & -0.40 & $\mathrm{~N}$ & $\mathrm{~N}$ & $\mathrm{~N}$ \\
\hline & 0.04 & & 0.05 & 0.01 & & & & 0.01 & & & & & 0.00 & & & \\
\hline \multirow[t]{2}{*}{ DBO } & $N$ & $N$ & $N$ & $N$ & $\mathrm{~N}$ & $N$ & $N$ & $N$ & $N$ & $\mathrm{~N}$ & 0.30 & 0.30 & $\mathrm{~N}$ & $\mathrm{~N}$ & $\mathrm{~N}$ & $\mathrm{~N}$ \\
\hline & & & & & & & & & & & 0.04 & 0.03 & & & & \\
\hline \multirow[t]{2}{*}{ ALC } & $N$ & $N$ & 0.46 & -0.34 & 0.51 & $N$ & $\mathrm{~N}$ & 0.77 & 0.35 & -0.47 & 0.65 & $\mathbf{N}$ & 0.31 & $N$ & -0.32 & 0.62 \\
\hline & & & 0.00 & 0.02 & 0.00 & & & 0.00 & 0.02 & 0.00 & 0.00 & & 0.03 & & 0.03 & 0.00 \\
\hline \multirow[t]{2}{*}{ DUR } & $N$ & $N$ & $N$ & $N$ & 0.42 & 0.45 & -0.35 & 0.47 & 0.51 & -0.45 & 0.60 & 0.39 & $N$ & 0.63 & -0.34 & $N$ \\
\hline & & & & & 0.01 & 0.01 & 0.05 & 0.01 & 0.00 & 0.01 & 0.00 & 0.03 & & 0.00 & 0.05 & \\
\hline SOT & $\mathrm{N}$ & $\begin{array}{l}0.44 \\
0.01\end{array}$ & $N$ & $N$ & $N$ & $\begin{array}{l}-0.41 \\
0.01\end{array}$ & $\mathbf{N}$ & $N$ & $N$ & $N$ & $N$ & $N$ & $N$ & $\mathrm{~N}$ & $N$ & $\mathrm{~N}$ \\
\hline \multirow[t]{2}{*}{ P04 } & $\mathrm{X}$ & $\mathrm{N}$ & $\mathrm{N}$ & $\mathrm{N}$ & $\mathrm{N}$ & -0.30 & $\mathbf{N}$ & $\mathrm{N}$ & $\mathrm{N}$ & $\mathrm{N}$ & $\mathrm{N}$ & $\mathrm{N}$ & $\mathrm{N}$ & -0.31 & $N$ & $\mathrm{~N}$ \\
\hline & $\mathrm{X}$ & & & & & 0.04 & & & & & & & & 0.04 & & \\
\hline \multirow[t]{2}{*}{$\mathrm{PT}$} & $\mathrm{N}$ & $\mathrm{X}$ & $\mathbf{N}$ & $\mathbf{N}$ & $N$ & 0.31 & $N$ & $\mathrm{~N}$ & $\mathrm{~N}$ & $\mathbf{N}$ & $\mathrm{N}$ & $\mathrm{N}$ & $\mathrm{N}$ & $\mathrm{N}$ & $N$ & $\mathrm{~N}$ \\
\hline & & $\mathrm{X}$ & & & & 0.03 & & & & & & & & & & \\
\hline $\mathrm{NH} 4$ & $\mathrm{~N}$ & $\mathrm{~N}$ & $X$ & $\mathrm{~N}$ & $\mathrm{~N}$ & $\mathrm{~N}$ & $N$ & 0.44 & $\mathrm{~N}$ & $\mathrm{~N}$ & 0.35 & $N$ & 0.54 & $N$ & $\mathrm{~N}$ & 0.45 \\
\hline & & & $\mathrm{X}$ & & & & & 0.00 & & & 0.01 & & 0.00 & & & 0.00 \\
\hline NO3 & $\mathrm{N}$ & $\mathrm{N}$ & $\mathrm{N}$ & $\mathrm{X}$ & $\mathrm{N}$ & $\mathrm{N}$ & $\mathrm{N}$ & -0.38 & $N$ & $N$ & -0.37 & $\mathrm{~N}$ & $\mathrm{~N}$ & $N$ & $N$ & $\mathrm{~N}$ \\
\hline & & & & $\mathrm{X}$ & & & & 0.01 & & & 0.01 & & & & & \\
\hline SO4 & $\mathrm{N}$ & $\mathrm{N}$ & $\mathrm{N}$ & 0.39 & $\mathrm{X}$ & 0.42 & $\mathrm{~N}$ & 0.67 & $\mathrm{~N}$ & -0.49 & 0.69 & 0.63 & $\mathrm{~N}$ & 0.59 & $\mathrm{~N}$ & $\mathrm{~N}$ \\
\hline & & & & 0.01 & $\mathrm{X}$ & 0.00 & & 0.00 & & 0.00 & 0.00 & 0.00 & & 0.00 & & \\
\hline $\mathrm{Cl}$ & $\mathrm{N}$ & $\mathrm{N}$ & -0.30 & 0.40 & 0.48 & $\mathrm{X}$ & -0.29 & $\mathrm{~N}$ & $\mathrm{~N}$ & -0.47 & 0.49 & 0.38 & -0.29 & 0.82 & $N$ & -0.39 \\
\hline & & & 0.03 & 0.00 & 0.00 & $\mathrm{X}$ & 0.04 & & & 0.00 & 0.00 & 0.01 & 0.04 & 0.00 & & 0.00 \\
\hline $\mathrm{Al}$ & $\mathrm{N}$ & $N$ & $\mathbf{N}$ & $\mathrm{N}$ & $\mathbf{N}$ & $N$ & $X$ & $N$ & -0.28 & 0.61 & -0.28 & $\mathbf{N}$ & $N$ & -0.36 & 0.28 & $N$ \\
\hline & & & & & & & $X$ & & 0.04 & 0.00 & 0.04 & & & 0.01 & 0.04 & \\
\hline $\mathrm{Ca}$ & $\mathrm{N}$ & $N$ & $\mathrm{~N}$ & $N$ & 0.29 & 0.44 & $N$ & $\mathrm{X}$ & 0.36 & -0.54 & 0.87 & 0.69 & 0.47 & 0.40 & $N$ & 0.30 \\
\hline & & & & & 0.04 & 0.00 & & $X$ & 0.01 & 0.00 & 0.00 & 0.00 & 0.00 & 0.00 & & 0.03 \\
\hline $\mathrm{Cu}$ & $\mathrm{N}$ & $N$ & $\mathbf{N}$ & $\mathrm{N}$ & $\mathrm{N}$ & $\mathrm{N}$ & $\mathrm{N}$ & $\mathrm{N}$ & $X$ & -0.38 & 0.36 & $N$ & $N$ & $N$ & 0.55 & $N$ \\
\hline & & & & & & & & & $X$ & 0.01 & 0.01 & & & & 0.02 & \\
\hline $\mathrm{Fe}$ & $N$ & $N$ & $N$ & $N$ & $\mathrm{~N}$ & -0.43 & 0.75 & -0.48 & $\mathrm{~N}$ & $\mathrm{X}$ & -0.59 & -0.32 & $\mathrm{~N}$ & -0.54 & 0.37 & $\mathrm{~N}$ \\
\hline & & & & & & 0.00 & 0.00 & 0.00 & & $\mathrm{X}$ & 0.00 & 0.02 & & 0.00 & 0.01 & \\
\hline K & $N$ & $N$ & $\mathrm{~N}$ & $\mathrm{~N}$ & 0.36 & 0.44 & -0.34 & 0.86 & $\mathrm{~N}$ & -0.64 & $\mathrm{X}$ & 0.64 & 0.30 & 0.62 & $\mathrm{~N}$ & $\mathrm{~N}$ \\
\hline & & & & & 0.01 & 0.00 & 0.02 & 0.00 & & 0.00 & $\mathrm{X}$ & 0.00 & 0.03 & 0.00 & & \\
\hline $\mathrm{Mg}$ & $\mathrm{N}$ & $\mathrm{N}$ & $\mathrm{N}$ & $N$ & 0.47 & 0.68 & $\mathrm{~N}$ & 0.80 & $\mathrm{~N}$ & -0.36 & 0.63 & $X$ & $N$ & 0.51 & $\mathrm{~N}$ & $\mathrm{~N}$ \\
\hline & & & & & 0.00 & 0.00 & & 0.00 & & 0.01 & 0.00 & $\mathrm{X}$ & & 0.00 & & \\
\hline $\mathrm{Mn}$ & $N$ & $\mathrm{~N}$ & $N$ & $\mathrm{~N}$ & $\mathrm{~N}$ & $\mathrm{~N}$ & $\mathrm{~N}$ & $\mathrm{~N}$ & $\mathrm{~N}$ & $\mathrm{~N}$ & $\mathrm{~N}$ & $\mathrm{~N}$ & $X$ & $\mathrm{~N}$ & $N$ & 0.35 \\
\hline $\mathrm{Na}$ & $\mathrm{N}$ & $\mathrm{N}$ & $\mathrm{N}$ & 0.40 & 0.50 & 0.91 & $\mathrm{~N}$ & 0.55 & $\mathrm{~N}$ & -0.56 & 0.55 & 0.71 & $\mathrm{~N}$ & $X$ & $\mathrm{~N}$ & -0.39 \\
\hline & & & & 0.00 & 0.00 & 0.00 & & 0.00 & & 0.00 & 0.00 & 0.00 & & $X$ & & 0.00 \\
\hline $\mathrm{Si}$ & $N$ & $N$ & $\mathrm{~N}$ & $\mathrm{~N}$ & $\mathrm{~N}$ & $\mathrm{~N}$ & $N$ & $\mathrm{~N}$ & $\mathrm{~N}$ & 0.45 & -0.29 & $\mathrm{~N}$ & $N$ & $N$ & $X$ & $\mathrm{~N}$ \\
\hline & & & & & & & & & & 0.00 & 0.04 & & & & $\mathrm{X}$ & \\
\hline $\mathrm{Zn}$ & $N$ & $\mathrm{~N}$ & 0.33 & -0.30 & $\mathrm{~N}$ & -0.37 & $\mathrm{~N}$ & $N$ & $\mathrm{~N}$ & $\mathrm{~N}$ & $\mathrm{~N}$ & $\mathbf{N}$ & $N$ & -0.29 & $\mathrm{~N}$ & $X$ \\
\hline & & & 0.02 & 0.03 & & 0.01 & & & & & & & & 0.03 & & $\mathrm{X}$ \\
\hline
\end{tabular}


TABELA 6 - CORRELAÇÕES ENTRE AS VARIÁVEIS AMBIENTAIS ABIÓTICAS DURANTE O PERÍODO DE ESTUDO, TESTE DE SPEARMAN (SIEGEL, 1975). NIVEL CONSIDERADO: P $>0.050$. REPRESA DE GUARAPIRANGA - PONTOS 1 E 4, 1991-92.

Precipitação de 24 (P24); 72 (P72) e 168 horas (P168) anteriores às coletas; vazão afluente natural (ANA), recalcada (ARE) e total (AT); na vazão para abastecimento (EAB); elevação (ELE) e volume (VOL). Temperatura da água (TAG); profundidade (PROF); transparência ao disco de Secchi (SEC); cor (COR); turbidez (TUR); condutividade (CON); $\mathrm{pH}(\mathrm{pH})$; oxigênio dissolvido (OD); demanda bioquimica de oxigênio (DBO); alcalinidade (ALC); dureza (DUR); sólidos totais em suspensão (SOT); fósforo solúvel reativo (PO4 ${ }^{-3}$ ); fósforo total (PT) ; amônio ( $\left.\mathrm{NH}^{+}\right)$; nitrato $\left(\mathrm{NO}^{-}\right)$; sulfato $\left(\mathrm{SO}^{-2}\right)$; cloro $\left(\mathrm{Cl}^{-}\right)$; alumínio (Al); cálcio (Ca); cobre (Cu); ferro (Fe); potássio (K); magnésio (Mg); manganês $(\mathrm{Mn})$; sódio $(\mathrm{Na})$; silício (Si) e zinco $(\mathrm{Zn})$; Ponto 1 (P l).

\begin{tabular}{|c|c|c|c|c|c|c|c|c|c|c|}
\hline TAG & $\begin{array}{l}\mathrm{N}=56 \\
\mathrm{P} 24 \\
\mathrm{~N}\end{array}$ & $\begin{array}{l}56 \\
\text { P72 } \\
0.39 \\
0.00\end{array}$ & $\begin{array}{l}56 \\
\text { P168 } \\
0.34 \\
0.01\end{array}$ & $\begin{array}{l}56 \\
\text { ANA } \\
\mathrm{N}\end{array}$ & $\begin{array}{l}56 \\
\text { ARE } \\
N\end{array}$ & $\begin{array}{l}56 \\
\text { AT } \\
\mathrm{N}\end{array}$ & $\begin{array}{l}56 \\
\text { EAB } \\
N\end{array}$ & $\begin{array}{l}56 \\
\text { EFT } \\
N\end{array}$ & $\begin{array}{l}56 \\
\text { ELE } \\
-0.37 \\
0.01\end{array}$ & $\begin{array}{l}56 \\
\text { VOL } \\
-0.37 \\
0.01\end{array}$ \\
\hline PROF & $\mathrm{N}$ & $\mathrm{N}$ & $\begin{array}{l}-0.26 \\
0.05\end{array}$ & $\mathrm{~N}$ & $N$ & $\mathrm{~N}$ & $N$ & $N$ & $\begin{array}{l}0.38 \\
0.01\end{array}$ & $\begin{array}{l}0.38 \\
0.01\end{array}$ \\
\hline SEC & $\mathrm{N}$ & $\begin{array}{l}-0.49 \\
0.00\end{array}$ & $\begin{array}{l}-0.39 \\
0.00\end{array}$ & $N$ & $\mathrm{~N}$ & $\begin{array}{l}-0.30 \\
0.03\end{array}$ & $\mathrm{~N}$ & $\mathrm{~N}$ & $\mathrm{~N}$ & $\mathrm{~N}$ \\
\hline COR & $\mathrm{N}$ & $\mathbf{N}$ & $N$ & $\mathrm{~N}$ & $N$ & $\mathrm{~N}$ & $\mathrm{~N}$ & $N$ & $\mathrm{~N}$ & $N$ \\
\hline TUR & $N$ & $\mathrm{~N}$ & $\mathrm{~N}$ & $N$ & $\mathrm{~N}$ & $\mathrm{~N}$ & $N$ & $\mathrm{~N}$ & $N$ & $\mathrm{~N}$ \\
\hline $\mathrm{CON}$ & $\mathbf{N}$ & $\mathrm{N}$ & $\mathrm{N}$ & $N$ & $\mathrm{~N}$ & $N$ & $\mathbf{N}$ & $\mathrm{N}$ & $N$ & $\mathrm{~N}$ \\
\hline $\mathrm{pH}$ & $N$ & $\mathrm{~N}$ & $\mathrm{~N}$ & $N$ & $\mathrm{~N}$ & $N$ & $\mathrm{~N}$ & $\mathrm{~N}$ & $\begin{array}{l}-0.29 \\
0.04\end{array}$ & $\begin{array}{l}-0.29 \\
0.04\end{array}$ \\
\hline$O D$ & $\mathrm{~N}$ & $\begin{array}{l}-0.37 \\
0.01\end{array}$ & $\mathrm{~N}$ & $\mathrm{~N}$ & $\mathrm{~N}$ & $N$ & $\mathrm{~N}$ & $\mathrm{~N}$ & $\mathrm{~N}$ & $\mathrm{~N}$ \\
\hline DBO & $\mathrm{N}$ & $\mathrm{N}$ & $\mathrm{N}$ & $\mathrm{N}$ & $\mathrm{N}$ & $\mathrm{N}$ & $\mathrm{N}$ & $\mathrm{N}$ & $\mathrm{N}$ & $\mathrm{N}$ \\
\hline ALC & $\mathrm{N}$ & $\mathrm{N}$ & $N$ & $\mathrm{~N}$ & $\mathrm{~N}$ & $\mathrm{~N}$ & $\mathbf{N}$ & $\begin{array}{l}-0.44 \\
0.00\end{array}$ & $\mathrm{~N}$ & $\mathrm{~N}$ \\
\hline DUR & $\mathbf{N}$ & $\mathrm{N}$ & $\begin{array}{l}0.46 \\
0.01\end{array}$ & $\mathrm{~N}$ & $\mathrm{~N}$ & $\mathrm{~N}$ & $\mathbf{N}$ & $\mathrm{N}$ & $\mathrm{N}$ & $\mathrm{N}$ \\
\hline SOT & $\mathrm{N}$ & $\mathrm{N}$ & $\begin{array}{l}-0.41 \\
0.01\end{array}$ & $\mathrm{~N}$ & $\mathbf{N}$ & $\mathbf{N}$ & $\mathrm{N}$ & $\mathbf{N}$ & $\mathrm{N}$ & $\mathrm{N}$ \\
\hline PO4 & $N$ & $\mathrm{~N}$ & $\mathrm{~N}$ & $\mathrm{~N}$ & $\mathbf{N}$ & $\mathbf{N}$ & $\mathbf{N}$ & $\mathbf{N}$ & $\mathrm{N}$ & $\mathrm{N}$ \\
\hline PT & $\mathrm{N}$ & $N$ & $\mathrm{~N}$ & $\mathrm{~N}$ & $\mathrm{~N}$ & $\mathrm{~N}$ & $\mathbf{N}$ & $\mathbf{N}$ & $\mathrm{N}$ & $\mathrm{N}$ \\
\hline NH4 & $\mathrm{N}$ & $\mathrm{N}$ & $N$ & $\mathrm{~N}$ & $N$ & $N$ & $\mathbf{N}$ & $\mathbf{N}$ & $N$ & $\mathbf{N}$ \\
\hline $\mathrm{NO} 3$ & $\mathbf{N}$ & $\mathrm{N}$ & $\mathrm{N}$ & $\mathrm{N}$ & $\mathrm{N}$ & $\mathrm{N}$ & $\mathbf{N}$ & $\mathbf{N}$ & $\mathbf{N}$ & $\mathrm{N}$ \\
\hline $\mathrm{SO} 4$ & $\mathrm{~N}$ & $\begin{array}{l}0.38 \\
0.01\end{array}$ & $\begin{array}{l}0.31 \\
0.02\end{array}$ & $N$ & $\mathrm{~N}$ & $\mathrm{~N}$ & $\mathrm{~N}$ & $\mathrm{~N}$ & $\begin{array}{l}-0.36 \\
0.01\end{array}$ & $\begin{array}{l}-0.36 \\
0.01\end{array}$ \\
\hline $\mathrm{Cl}$ & $\mathrm{N}$ & $\mathrm{N}$ & $\begin{array}{l}0.31 \\
0.02\end{array}$ & $\mathrm{~N}$ & $\mathrm{~N}$ & $\mathrm{~N}$ & $N$ & $\mathrm{~N}$ & $\begin{array}{l}-0.50 \\
0.00\end{array}$ & $\begin{array}{l}-0.50 \\
0.00\end{array}$ \\
\hline $\mathrm{Al}$ & $\mathrm{N}$ & $\mathrm{N}$ & $\mathrm{N}$ & $\mathbf{N}$ & $\mathbf{N}$ & $\mathbf{N}$ & $\mathrm{N}$ & $\mathrm{N}$ & $\begin{array}{l}0.61 \\
0.00\end{array}$ & $\begin{array}{l}0.61 \\
0.00\end{array}$ \\
\hline $\mathrm{Ca}$ & $\mathrm{N}$ & $\begin{array}{l}0.33 \\
0.02\end{array}$ & $\begin{array}{l}0.29 \\
0.03\end{array}$ & $\mathbf{N}$ & $\mathbf{N}$ & $\mathrm{N}$ & $\mathrm{N}$ & $\mathrm{N}$ & $\mathbf{N}$ & $\mathrm{N}$ \\
\hline $\mathrm{Cu}$ & $\mathrm{N}$ & $\mathrm{N}$ & $\mathrm{N}$ & $\mathrm{N}$ & $\mathrm{N}$ & $\mathrm{N}$ & $N$ & $\mathrm{~N}$ & $\begin{array}{l}-0.29 \\
0.03\end{array}$ & $\begin{array}{l}-0.29 \\
0.04\end{array}$ \\
\hline $\mathrm{Fe}$ & $\mathrm{N}$ & $\mathbf{N}$ & $\mathrm{N}$ & $N$ & $\mathrm{~N}$ & $\mathbf{N}$ & $\mathrm{N}$ & $\begin{array}{l}0.34 \\
0.01\end{array}$ & $\begin{array}{l}0.61 \\
0.00\end{array}$ & $\begin{array}{l}0.61 \\
0.00\end{array}$ \\
\hline $\mathrm{K}$ & $\mathrm{N}$ & $\begin{array}{l}0.43 \\
0.00\end{array}$ & $\begin{array}{l}0.38 \\
0.00\end{array}$ & $\mathrm{~N}$ & $\mathrm{~N}$ & $\mathbf{N}$ & $\mathrm{N}$ & $\mathrm{N}$ & $\begin{array}{l}-0.39 \\
0.00\end{array}$ & $\begin{array}{l}-0.39 \\
0.00\end{array}$ \\
\hline $\mathrm{Mg}$ & $\mathrm{N}$ & $\mathbf{N}$ & $\mathrm{N}$ & $\mathbf{N}$ & $\mathrm{N}$ & $\mathrm{N}$ & $\mathbf{N}$ & $\mathrm{N}$ & $\mathrm{N}$ & $\mathrm{N}$ \\
\hline $\mathrm{Mn}$ & $\mathrm{N}$ & $\mathrm{N}$ & $N$ & $N$ & $\mathrm{~N}$ & $N$ & $\mathrm{~N}$ & $\mathrm{~N}$ & $\mathrm{~N}$ & $\mathrm{~N}$ \\
\hline $\mathrm{Na}$ & $\begin{array}{l}0.30 \\
0.03\end{array}$ & $\begin{array}{l}0.31 \\
0.02\end{array}$ & $\begin{array}{l}0.36 \\
0.01\end{array}$ & $\mathbf{N}$ & $\mathrm{N}$ & $\mathrm{N}$ & $\mathrm{N}$ & $N$ & $\begin{array}{l}-0.62 \\
0.00\end{array}$ & $\begin{array}{l}-0.62 \\
0.00\end{array}$ \\
\hline $\mathrm{Si}$ & $\mathrm{N}$ & $\mathrm{N}$ & $\mathrm{N}$ & $N$ & $\mathbf{N}$ & $N$ & $\mathbf{N}$ & $\begin{array}{l}0.32 \\
0.02\end{array}$ & $\mathrm{~N}$ & $\mathrm{~N}$ \\
\hline $\mathrm{Zn}$ & $\mathrm{N}$ & $\mathbf{N}$ & $\mathrm{N}$ & $\mathrm{N}$ & $\mathrm{N}$ & $\mathrm{N}$ & $\mathbf{N}$ & $\begin{array}{l}-0.34 \\
0.01\end{array}$ & $\begin{array}{l}0.44 \\
0.00\end{array}$ & $\begin{array}{l}0.44 \\
0.00\end{array}$ \\
\hline
\end{tabular}


TABELA 6 - CORRELAÇÕES ENTRE AS VARIÁVEIS AMBIENTAIS ABIÓTICAS DURANTE O PERÍODO DE ESTUDO, TESTE DE SPEARMAN (SIEGEL, 1975). NÍVEL CONSIDERADO: $P>=0.050$.

REPRESA DE GUARAPIRANGA - PONTOS 1 E 4, 1991-92.

Precipitação média mensal (P); excedente hídrico (EXC); escoamento básico (ESC); deficiência hídrica do solo (DEF); radiação solar (RAD); insolação (INS); velocidade dos ventos (VEN); aplicação de sulfato de cobre do dia anterior (SA) e do dia da coleta (S).Temperatura da água (TAG); profundidade (PROF); transparência ao disco de Secchi (SEC); cor (COR);turbidez (TUR);condutividade (CON); $\mathrm{pH}(\mathrm{pH})$; oxigênio dissolvido (OD); demanda bioquímica deoxigênio (DBO); alcalinidade (ALC); dureza (DUR); sólidos totais em suspensão (SOT); fósforo solúvel reativo (PO ${ }_{4}^{-3}$ ); fósforo total (PT); amônio $\left(\mathrm{NH}_{4}{ }^{+}\right)$; nitrato $\left(\mathrm{NO}_{3}{ }^{-}\right)$; sulfato $\left(\mathrm{SO}_{4}^{-2}\right)$; cloro $\left(\mathrm{Cl}^{-}\right)$; alumínio (Al); cálcio (Ca); cobre (Cu); ferro (Fe); potássio $(\mathrm{K})$; magnésio $(\mathrm{Mg})$; manganês $(\mathrm{Mn})$; sódio $(\mathrm{Na})$; silício $(\mathrm{Si})$; zinco $(\mathrm{Zn})$; Ponto 1 (P 1).

\begin{tabular}{|c|c|c|c|c|c|c|c|c|c|c|c|}
\hline PONTO 1 & $\begin{array}{l}\mathrm{N}=56 \\
\mathrm{P}\end{array}$ & $\begin{array}{l}56 \\
\text { ETP }\end{array}$ & $\begin{array}{l}56 \\
\text { EXC }\end{array}$ & $\begin{array}{l}56 \\
\text { ESC }\end{array}$ & $\begin{array}{l}56 \\
\text { DEF }\end{array}$ & $\begin{array}{l}56 \\
\text { RAD }\end{array}$ & $\begin{array}{l}56 \\
\text { INS }\end{array}$ & $\begin{array}{l}56 \\
\text { VEN }\end{array}$ & & $\begin{array}{l}56 \\
\text { SA }\end{array}$ & $\begin{array}{l}56 \\
S\end{array}$ \\
\hline TAG & 0.67 & $\mathrm{~N}$ & 0.57 & 0.47 & -0.37 & 0.73 & $\mathrm{~N}$ & $\mathrm{~N}$ & & 0.42 & 0.51 \\
\hline & 0.00 & & 0.00 & 0.00 & 0.01 & 0.00 & & & & 0.00 & 0.00 \\
\hline PROF & $\mathrm{N}$ & $\mathrm{N}$ & $\mathrm{N}$ & $\mathrm{N}$ & $\mathrm{N}$ & $\begin{array}{l}-0.29 \\
0.03\end{array}$ & $\begin{array}{l}0.35 \\
0.01\end{array}$ & $N$ & & $\mathrm{~N}$ & $\mathrm{~N}$ \\
\hline SEC & $\begin{array}{l}-0.30 \\
0.03\end{array}$ & $\mathrm{~N}$ & $\mathrm{~N}$ & $\begin{array}{l}-0.42 \\
0.00\end{array}$ & $\mathrm{~N}$ & $\mathrm{~N}$ & $\mathrm{~N}$ & $\mathrm{~N}$ & & $\begin{array}{l}-0.54 \\
0.00\end{array}$ & $\begin{array}{l}-0.45 \\
0.00\end{array}$ \\
\hline $\mathrm{COR}$ & $\mathrm{N}$ & $\mathrm{N}$ & $\mathrm{N}$ & $\mathrm{N}$ & $\mathrm{N}$ & $\mathrm{N}$ & $\mathrm{N}$ & $\mathrm{N}$ & & $\mathrm{N}$ & $\mathrm{N}$ \\
\hline TUR & $\mathrm{N}$ & $\mathrm{N}$ & $N$ & $\begin{array}{l}0.33 \\
0.01\end{array}$ & $\mathbf{N}$ & $\mathbf{N}$ & $N$ & $N$ & & $\begin{array}{l}0.57 \\
0.00\end{array}$ & $\begin{array}{l}0.44 \\
0.00\end{array}$ \\
\hline $\mathrm{CON}$ & $\mathrm{N}$ & $N$ & $N$ & $\mathrm{~N}$ & $\mathrm{~N}$ & $\mathrm{~N}$ & $N$ & $\begin{array}{l}-0.33 \\
0.01\end{array}$ & & $\mathrm{~N}$ & $\mathrm{~N}$ \\
\hline $\mathrm{pH}$ & $\mathbf{N}$ & $N$ & $N$ & $N$ & $\mathrm{~N}$ & $\mathrm{~N}$ & $\mathrm{~N}$ & $\mathrm{~N}$ & & $N$ & $\mathrm{~N}$ \\
\hline OD & $\begin{array}{l}-0.27 \\
0.05\end{array}$ & $\mathrm{~N}$ & $\begin{array}{l}-0.34 \\
0.01\end{array}$ & $\begin{array}{l}-0.45 \\
0.00\end{array}$ & $N$ & $\mathrm{~N}$ & $\mathrm{~N}$ & $N$ & & $\mathrm{~N}$ & $\begin{array}{c}-0.32 \\
0.02\end{array}$ \\
\hline DBO & $\mathrm{N}$ & $N$ & $\mathrm{~N}$ & $\mathrm{~N}$ & $\mathrm{~N}$ & $N$ & $N$ & $\mathrm{~N}$ & & $\mathrm{~N}$ & $\mathrm{~N}$ \\
\hline ALC & $\mathrm{N}$ & $\mathrm{N}$ & $\mathrm{N}$ & $\begin{array}{l}0.38 \\
0.01\end{array}$ & $\mathbf{N}$ & $\mathrm{N}$ & $\mathrm{N}$ & $N$ & $f$ & $\begin{array}{l}0.44 \\
0.00\end{array}$ & $\begin{array}{l}0.33 \\
0.01\end{array}$ \\
\hline DUR & $\begin{array}{l}0.58 \\
0.00\end{array}$ & $\mathrm{~N}$ & $\mathrm{~N}$ & $\mathrm{~N}$ & $N$ & $\begin{array}{l}0.59 \\
0.00\end{array}$ & $\mathrm{~N}$ & $\mathrm{~N}$ & & $\begin{array}{l}0.43 \\
0.01\end{array}$ & $\begin{array}{l}0.64 \\
0.00\end{array}$ \\
\hline $\mathrm{PO}_{4}$ & $\mathrm{~N}$ & $N$ & $\mathrm{~N}$ & $\mathrm{~N}$ & $\mathrm{~N}$ & $\mathrm{~N}$ & $\mathrm{~N}$ & $\mathbf{N}$ & & $\mathrm{N}$ & $\begin{array}{l}0.36 \\
0.01\end{array}$ \\
\hline PT & $N$ & $\mathbf{N}$ & $\mathrm{N}$ & $\mathrm{N}$ & $\mathrm{N}$ & $N$ & $\mathrm{~N}$ & $\mathrm{~N}$ & & $\mathbf{N}$ & $\mathrm{N}$ \\
\hline SOT & $\begin{array}{l}-0.38 \\
0.02\end{array}$ & $\mathrm{~N}$ & $N$ & $\mathbf{N}$ & $\mathbf{N}$ & $N$ & $\mathbf{N}$ & $N$ & & $\mathrm{~N}$ & $\mathrm{~N}$ \\
\hline $\mathrm{NH}_{4}$ & $\mathrm{~N}$ & $\mathrm{~N}$ & $\mathrm{~N}$ & $\mathrm{~N}$ & $\mathrm{~N}$ & $\mathbf{N}$ & $N$ & $\mathbf{N}$ & & $\mathrm{N}$ & $\mathrm{N}$ \\
\hline $\mathrm{NO}_{3}$ & $\begin{array}{l}-0.32 \\
0.02\end{array}$ & $N$ & $\begin{array}{l}-0.36 \\
0.01\end{array}$ & $\begin{array}{l}-0.65 \\
0.00\end{array}$ & $\mathbf{N}$ & $\mathrm{N}$ & $\mathbf{N}$ & $\mathrm{N}$ & & $\begin{array}{l}-0.32 \\
0.02\end{array}$ & $\begin{array}{l}-0.36 \\
0.01\end{array}$ \\
\hline $\mathrm{SO}_{4}$ & $\begin{array}{l}-0.41 \\
0.00\end{array}$ & $N$ & $\begin{array}{l}0.30 \\
0.03\end{array}$ & $\mathrm{~N}$ & $\mathrm{~N}$ & $\begin{array}{l}0.44 \\
0.00\end{array}$ & $\mathrm{~N}$ & $N$ & & $\mathrm{~N}$ & $\mathrm{~N}$ \\
\hline $\mathrm{Cl}$ & $\begin{array}{l}0.43 \\
0.00\end{array}$ & $\mathrm{~N}$ & $\mathrm{~N}$ & $\begin{array}{l}-0.35 \\
0.01\end{array}$ & $\mathrm{~N}$ & $\begin{array}{l}0.44 \\
0.00\end{array}$ & $\mathrm{~N}$ & $\mathrm{~N}$ & & $\mathrm{~N}$ & $\mathrm{~N}$ \\
\hline Al & $\mathrm{N}$ & $\mathrm{N}$ & $\mathbf{N}$ & $\mathrm{N}$ & $\begin{array}{l}-0.27 \\
0.04\end{array}$ & $\mathrm{~N}$ & $\mathbf{N}$ & $\mathrm{N}$ & & $\mathrm{N}$ & $\mathrm{N}$ \\
\hline $\mathrm{Ca}$ & $\begin{array}{l}0.33 \\
0.02\end{array}$ & $N$ & $\begin{array}{l}0.33 \\
0.02\end{array}$ & $\begin{array}{l}0.49 \\
0.00\end{array}$ & $\mathrm{~N}$ & $\begin{array}{l}0.34 \\
0.01\end{array}$ & $\mathrm{~N}$ & $\mathrm{~N}$ & & $\begin{array}{l}0.54 \\
0.00\end{array}$ & $\begin{array}{l}0.53 \\
0.00\end{array}$ \\
\hline $\mathrm{Cu}$ & $\mathrm{N}$ & $\mathrm{N}$ & $\mathrm{N}$ & $N$ & $\mathrm{~N}$ & $\mathrm{~N}$ & $\mathrm{~N}$ & $N$ & & $\begin{array}{l}0.49 \\
0.00\end{array}$ & $\begin{array}{l}0.48 \\
0.00\end{array}$ \\
\hline $\mathrm{Fe}$ & $\begin{array}{l}-0.30 \\
0.03\end{array}$ & $\mathrm{~N}$ & $\begin{array}{l}-0.28 \\
0.04\end{array}$ & $\mathrm{~N}$ & $N$ & $\begin{array}{l}-0.28 \\
0.04\end{array}$ & $\mathrm{~N}$ & $N$ & & $\mathrm{~N}$ & $\mathrm{~N}$ \\
\hline $\mathrm{K}$ & $\begin{array}{l}0.48 \\
0.00\end{array}$ & $\mathrm{~N}$ & $\begin{array}{l}0.37 \\
0.01\end{array}$ & $\begin{array}{l}0.34 \\
0.01\end{array}$ & $\mathrm{~N}$ & $\begin{array}{l}0.54 \\
0.00\end{array}$ & $\begin{array}{l}-0.27 \\
0.04\end{array}$ & $\mathbf{N}$ & & $\begin{array}{l}0.46 \\
0.00\end{array}$ & $\begin{array}{l}0.48 \\
0.00\end{array}$ \\
\hline $\mathrm{Mg}$ & $\begin{array}{l}0.36 \\
0.01\end{array}$ & $\mathrm{~N}$ & $\begin{array}{l}0.33 \\
0.02\end{array}$ & $\begin{array}{l}0.32 \\
0.02\end{array}$ & $\mathbf{N}$ & $\begin{array}{l}0.39 \\
0.00\end{array}$ & $\mathrm{~N}$ & $\mathbf{N}$ & & $\mathrm{N}$ & $\mathrm{N}$ \\
\hline $\mathrm{Mn}$ & $\mathrm{N}$ & $\mathrm{N}$ & $\mathrm{N}$ & $\begin{array}{l}0.34 \\
0.01\end{array}$ & $\mathbf{N}$ & $\mathrm{N}$ & $\mathrm{N}$ & $N$ & & $\begin{array}{l}0.31 \\
0.02\end{array}$ & $\begin{array}{l}0.35 \\
0.01\end{array}$ \\
\hline $\mathrm{Na}$ & $\begin{array}{l}0.51 \\
0.00\end{array}$ & $N$ & $\begin{array}{l}0.36 \\
0.00\end{array}$ & $\mathrm{~N}$ & $\mathrm{~N}$ & $\begin{array}{l}0.65 \\
0.00\end{array}$ & $N$ & $\mathrm{~N}$ & & $N$ & $\mathrm{~N}$ \\
\hline $\mathrm{Si}$ & $\mathrm{N}$ & $\mathrm{N}$ & $\mathrm{N}$ & $\mathrm{N}$ & $\mathrm{N}$ & $\mathrm{N}$ & $N$ & $N$ & & $\mathrm{~N}$ & $\begin{array}{l}-0.29 \\
0.03\end{array}$ \\
\hline $\mathrm{Zn}$ & $\begin{array}{l}-0.44 \\
0.00\end{array}$ & $N$ & $\begin{array}{l}-0.36 \\
0.01\end{array}$ & $\mathrm{~N}$ & $\begin{array}{l}0.42 \\
0.00\end{array}$ & $\begin{array}{l}-0.53 \\
0.00\end{array}$ & $\mathrm{~N}$ & $\mathrm{~N}$ & & $\begin{array}{l}0.27 \\
0.05\end{array}$ & $\mathrm{~N}$ \\
\hline
\end{tabular}


TABELA 6 - CORRELAÇÕES ENTRE AS VARIÁVEIS AMBIENTAIS ABIÓTICAS DURANTE O PERÍODO DE ESTUDO, TESTE DE SPEARMAN (SIEGEL, 1975). NÍVEL CONSIDERADO: $P>=0.050$. REPRESA DE GUARAPIRANGA - PONTOS 1 E 4, 1991-92.

Precipitação de 24 (P24); 72 (P72) e 168 horas (P168) anteriores às coletas; vazão afluente natural (ANA), recalcada (ARE) e total (AT); na vazão para abastecimento (EAB); elevação (ELE) e volume (VOL). Precipitação média mensal (P); excedente hídrico (EXC); escoamento básico (ESC); deficiência hídricado solo (DEF); radiaçăo solar (RAD); insolação (INS); velocidade dos ventos (VEN); aplicação de sulfato de cobre do dia anterior (SA) e do dia da coleta (S); ponto 1 (P1); ponto 4 (P4).

\begin{tabular}{|c|c|c|c|c|c|c|c|c|c|c|}
\hline $\mathrm{P} 1 \rightarrow$ & $\mathrm{N}=56$ & 56 & 56 & 56 & 56 & 56 & 56 & 56 & 56 & 56 \\
\hline P $4 \downarrow$ & P24 & P72 & P168 & ANA & ARE & $\mathrm{AT}$ & EAB & EFT & ELE & VOL \\
\hline \multirow[t]{2}{*}{ P24 } & $\mathrm{X}$ & 0.27 & $\mathrm{~N}$ & 0.34 & $N$ & 0.33 & $\mathrm{~N}$ & $\mathrm{~N}$ & $\mathrm{~N}$ & $\mathrm{~N}$ \\
\hline & $\mathrm{X}$ & 0.04 & & 0.01 & & 0.01 & & & & \\
\hline \multirow[t]{2}{*}{ P72 } & 0.27 & $\mathrm{X}$ & 0.79 & 0.55 & $\mathrm{~N}$ & 0.55 & $\mathrm{~N}$ & $\mathrm{~N}$ & $\mathrm{~N}$ & $\mathrm{~N}$ \\
\hline & 0.04 & $\mathrm{X}$ & 0.00 & 0.00 & & 0.00 & & & & \\
\hline \multirow[t]{2}{*}{ P168 } & $\mathrm{N}$ & 0.79 & $\mathrm{X}$ & 0.62 & $\mathrm{~N}$ & 0.62 & $\mathrm{~N}$ & $\mathrm{~N}$ & $\mathrm{~N}$ & $\mathrm{~N}$ \\
\hline & & 0.00 & $X$ & 0.00 & & 0.00 & & & & \\
\hline \multirow[t]{2}{*}{ ANA } & $\mathrm{N}$ & $\mathrm{N}$ & $\mathrm{N}$ & $\mathrm{X}$ & $\mathrm{N}$ & 0.99 & $\mathrm{~N}$ & $\mathrm{~N}$ & $\mathrm{~N}$ & $\mathrm{~N}$ \\
\hline & & & & $X$ & & 0.00 & & & & \\
\hline \multirow[t]{2}{*}{ ARE } & $\mathrm{N}$ & $\mathrm{N}$ & $\mathrm{N}$ & $\mathbf{N}$ & $\mathrm{X}$ & $\mathrm{N}$ & -0.29 & -0.30 & $\mathrm{~N}$ & $\mathrm{~N}$ \\
\hline & & & & & $X$ & & 0.03 & 0.02 & & \\
\hline \multirow[t]{2}{*}{ AFT } & 0.33 & 0.55 & 0.62 & $\mathrm{~N}$ & $N$ & $X$ & $\mathrm{~N}$ & $\mathrm{~N}$ & $\mathrm{~N}$ & $\mathrm{~N}$ \\
\hline & 0.01 & 0.00 & 0.00 & & & $X$ & & & & \\
\hline \multirow[t]{2}{*}{ EAB } & $\mathrm{N}$ & $\mathrm{N}$ & $N$ & $\mathbf{N}$ & $N$ & $\mathrm{~N}$ & $X$ & 0.99 & $N$ & $\mathrm{~N}$ \\
\hline & & & & & & & $X$ & 0.00 & & \\
\hline \multirow[t]{2}{*}{ EFT } & $N$ & $\mathrm{~N}$ & $\mathrm{~N}$ & $\mathrm{~N}$ & $\mathrm{~N}$ & $\mathrm{~N}$ & $\mathrm{~N}$ & $X$ & $N$ & $\mathrm{~N}$ \\
\hline & & & & & & & & $\mathrm{X}$ & & \\
\hline ELE & $\mathrm{N}$ & $N$ & $\mathrm{~N}$ & $\mathrm{~N}$ & $\mathrm{~N}$ & $\mathrm{~N}$ & $N$ & $N$ & $\begin{array}{l}X \\
X\end{array}$ & $\begin{array}{l}1.00 \\
0.00\end{array}$ \\
\hline \multirow[t]{2}{*}{ VOL } & $\mathbf{N}$ & $N$ & $\mathrm{~N}$ & $\mathbf{N}$ & $\mathrm{N}$ & $\mathrm{N}$ & $\mathrm{N}$ & $\mathrm{N}$ & 1.00 & $\mathrm{X}$ \\
\hline & & & & & & & & & 0.00 & $\mathrm{X}$ \\
\hline \multirow[t]{2}{*}{$\mathrm{P}$} & $N$ & 0.53 & 0.53 & $\mathrm{~N}$ & $\mathrm{~N}$ & 0.30 & $\mathrm{~N}$ & 0.33 & -0.45 & -0.46 \\
\hline & & 0.00 & 0.00 & & & 0.02 & & 0.02 & 0.00 & 0.00 \\
\hline ETP & $\mathrm{N}$ & $\mathrm{N}$ & $\mathrm{N}$ & $\mathrm{N}$ & $N$ & $N$ & $\mathrm{~N}$ & $\mathrm{~N}$ & $\mathrm{~N}$ & $\mathrm{~N}$ \\
\hline \multirow[t]{2}{*}{ EXC } & $N$ & 0.42 & 0.43 & $\mathrm{~N}$ & $N$ & 0.31 & $\mathrm{~N}$ & 0.28 & -0.44 & -0.44 \\
\hline & & 0.00 & 0.00 & & & 0.02 & & 0.04 & 0.00 & 0.00 \\
\hline \multirow[t]{2}{*}{ ESC } & $\mathbf{N}$ & $\mathrm{N}$ & 0.29 & $\mathrm{~N}$ & $\mathrm{~N}$ & 0.40 & $\mathrm{~N}$ & $\mathrm{~N}$ & $\mathrm{~N}$ & $\mathrm{~N}$ \\
\hline & & & 0.03 & & & 0.00 & & & & \\
\hline
\end{tabular}


TABELA 6 - CORRELAÇŌES ENTRE AS VARIÁVEIS AMBIENTAIS ABIÓTICAS DURANTE O PERIODO DE ESTUDO, TESTE DE SPEARMAN (SIEGEL, 1975). NÍVEL CONSIDERADO: P>=0.050. REPRESA DE GUARAPIRANGA - PONTOS 1 E 4, 1991-92.

Precipitação média mensal (P); excedente hídrico (EXC); escoamento básico (ESC); deficiència hídrica do solo (DEF); radiação solar (RAD); insolação (INS); velocidade dos ventos (VEN); aplicação de sulfato de cobre do dia anterior (SA) e do dia da coleta (S).Precipitação de 24 (P24); 72 (P72) e 168 horas (P168) anteriores às coletas; vazão afluente natural (ANA), recalcada (ARE) e total (AT); na vazão para abastecimento (EAB); elevação (ELE) e volume (VOL); ponto 1 (P1); ponto 4 (P4).

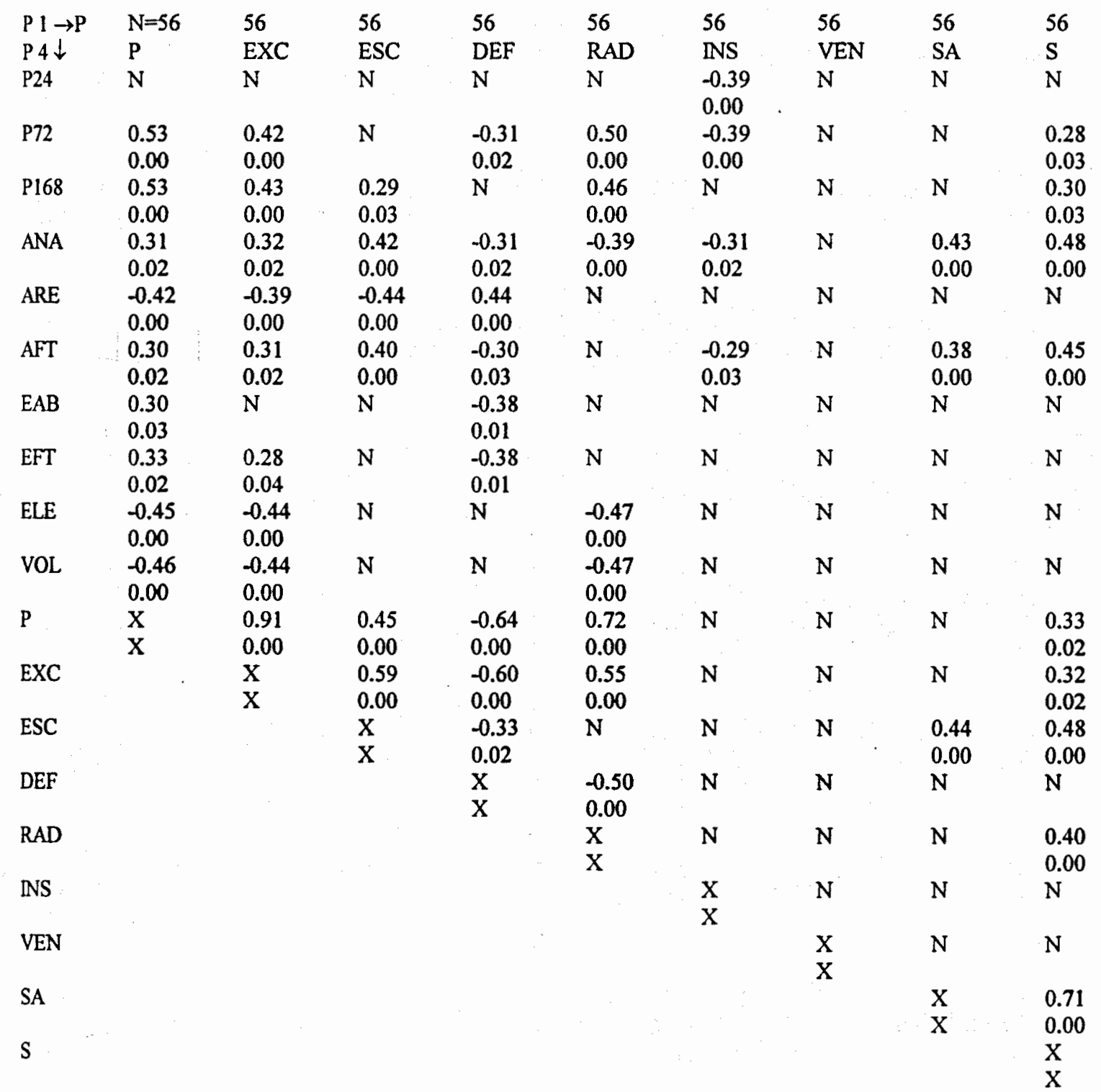


TABELA 7 - GUARAPIRANGA 1991-92. CARACTERÍSTICAS DAS ESPÉCIES DO PONTO 1.

Identificação da espécie (IDSP); número de ocorrências desta espécie (OC); gaid ou maior eixo linear em $\mu \mathrm{m}$ (G); sgald ou segundo maior eixo linear em $\mu \mathrm{m}$ (SG); unidade padrão de área em UPA (UPA); volume em $\mu \mathrm{m}^{3}$ (BVL); contribuição da espécie em porcentagem do total geral, para a densidade de células (\%DC); para a bioárea (\%UPA), para o biovolume (\%BVL) e para a densidade de organismos (\%DO).

\begin{tabular}{ll}
\multicolumn{3}{l}{ CYANOPHYCEAE } \\
IDSP & OC \\
ANAS1 & 1 \\
OSCSA & 1 \\
OSCSU & 8 \\
PSECA & 5 \\
\multicolumn{1}{l}{} \\
CYANOPHYCEAE \\
IDSP & OC \\
APHDE & 1 \\
APHEC & 3 \\
APHEL & 1 \\
APHEP & 5 \\
CRCMI & 15 \\
CRCMU & 8 \\
CYAHA & 1 \\
GLOSI & 1 \\
SYNEL & 20 \\
SYNSE & 6
\end{tabular}

\begin{tabular}{lll}
\multicolumn{3}{c}{ HORMOGONALES (4) } \\
G & SG & UPA \\
5.2 & 0.3 & 0.00 \\
5.2 & 2.6 & 0.03 \\
7.8 & 0.5 & 0.01 \\
5.2 & 1.3 & 0.02
\end{tabular}

$\begin{array}{lllll}\text { BVL } & \text { \%DC } & \text { \%UPA } & \text { \%VOL } & \text { \%DO } \\ 0.28 & 0.02 & 0.00 & 0.00 & 0.02 \\ 27.61 & 0.21 & 0.04 & 0.02 & 0.23 \\ 1.66 & 8.23 & 0.51 & 0.05 & 8.90 \\ 6.90 & 1.36 & 0.14 & 0.04 & 1.47\end{array}$

\section{CHLOROPHYCEAE}

CHROOCOCCALES (10)

$\begin{array}{lll}\text { G } & \text { SG } & \text { UPA } \\ \mathbf{4 6 . 5} & \mathbf{4 6 . 5} & 4.25 \\ 53.0 & 53.0 & 5.52 \\ 54.0 & 54.0 & 5.73 \\ 10.4 & 10.4 & 0.21 \\ 5.2 & 2.6 & 0.03 \\ 5.2 & 5.2 & 0.05 \\ 10.4 & 5.9 & 0.15 \\ 13.0 & 13.0 & 0.33 \\ 2.6 & 1.3 & 0.01 \\ 3.9 & 3.3 & 0.03\end{array}$

$\begin{array}{lllll}\text { BVL } & \text { \%DC } & \text { \%UPA } & \text { \%VOL } & \text { \%DO } \\ 52645.04 & 0.08 & 0.17 & 0.36 & 0.03 \\ 77951.81 & 1.04 & 2.12 & 4.45 & 0.27 \\ 82447.96 & 0.02 & 0.04 & 0.08 & 0.00 \\ 588.98 & 0.37 & 0.77 & 1.61 & 0.51 \\ 73.62 & 0.58 & 0.12 & 0.16 & 0.63 \\ 73.67 & 0.24 & 0.08 & 0.07 & 0.26 \\ 94.78 & 0.02 & 0.02 & 0.01 & 0.02 \\ 1150.35 & 0.01 & 0.01 & 0.03 & 0.01 \\ 2.30 & 0.81 & 0.04 & 0.01 & 0.88 \\ 15.28 & 0.22 & 0.04 & 0.01 & 0.23\end{array}$

IDSP

$\begin{array}{ll}\text { ANKBR } & 2 \\ \text { ANKFU } & 15\end{array}$

ANKGR 3

BOTNE 1

$\begin{array}{lll}\mathrm{CLC} 7 & 4 & 10\end{array}$

$\begin{array}{lll}\text { CLC14 } 1 & 1 & 10.4\end{array}$

$\begin{array}{ll}\text { CLOLO } & 1 \\ \text { CLOMI } & 24\end{array}$

CLOSA 3

CLOVI $\quad 30$

CLOVU $\quad 36$

CLUSS 2

CLUS7 2

COECA 2

$\begin{array}{ll}\text { COEHI } & 5 \\ \text { COEMI } & 2\end{array}$

$\begin{array}{ll}\text { COEMI } & 2 \\ \text { COEPR } & 2\end{array}$

COERE 14

CRUCR 13

CRUTE 31

DICAN

DICCH

DICEH 19

DICEL

DICPU

DISSP

ELAFA

ELAGE

EUTFO

EUTNY

FRADR 11

FRAPO 2

GEMIN 20

$\begin{array}{ll}\text { GLOAM } & 4 \\ \text { GLOBA } & 6\end{array}$

GLORU 2

GLOVE

\section{CHLOROCOCCALES (77)}

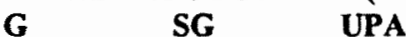

$\begin{array}{lll}44.2 & 2.6 & 3.84\end{array}$

$\begin{array}{lll}31.6 & 1.7 & 1.96\end{array}$

$\begin{array}{lll}26.0 & 2.6 & 1.33\end{array}$

$\begin{array}{lll}21.5 & 2.06\end{array}$

10.4
23.4

$\begin{array}{lll}0.4 & 10.4 & 0.21\end{array}$

$\begin{array}{lll}10.4 & 5.2 & 0.85\end{array}$

$2.6 \quad 2.6$

$\begin{array}{ll}6.5 & 2.6\end{array}$

$\begin{array}{ll}7.8 & 7.8\end{array}$

$5.2 \quad 5.2$

$5.2 \quad 2.6$

$5.2 \quad 4.6$

$32.4 \quad 32.4$

$54.0 \quad 54.0$

$65.0 \quad 65.0$

$18.0 \quad 18.0$

$21.6 \quad 21.6$

$10.4 \quad 5.2$

$5.2 \quad 5.2$

$37.8 \quad 37.8$

$54.0 \quad 54.0$

$52.0 \quad 52.0$

54.0

43.2

10.4

13.0

26.0

32.4

10.4

10.4

13.0

10.4

14.3

16.9

10.4

10.4

\section{0}

43.2

10.4

3.9

13.0

4.1

10.4

7.2

10.4

5.2

14.3

14.3

10.4

10.4
BVL

$2455.02 \%$ DC

258.11

81.68

17808.76

588.98

6708.82 0.07

588.98

460.14

9.20

143.79

248.47

73.62

73.62

73.62

17808.76

$82447.96 \quad 0.08$

$\begin{array}{ll}143793.31 & 0.02\end{array}$

$3053.63 \quad 0.01$

$\begin{array}{ll}5276.67 & 0.18\end{array}$

$140.61 \quad 0.25$

$\begin{array}{ll}70.30 & 0.45\end{array}$

$28279.65 \quad 0.04$

$82447.96 \quad 0.12$

$\begin{array}{ll}73622.18 & 5.06\end{array}$

$82447.96 \quad 0.42$

$\begin{array}{ll}42213.35 & 2.22\end{array}$

$281.22 \quad 0.06$

$131.82 \quad 0.04$

$\begin{array}{ll}1150.35 & 0.01\end{array}$

$3339.14 \quad 0.21$

$588.98 \quad 0.06$

588.98

1150.35

220.87

1531.11

9202.77

588.98

1150.35
0.13

0.01

0.70

0.07

0.08

0.01

0.06

$\begin{array}{lll}\text { \%UPA } & \text { \%VOL } & \text { \%DO } \\ 0.03 & 0.01 & 0.00 \\ 1.98 & 0.16 & 0.18 \\ 0.39 & 0.01 & 0.05 \\ 0.01 & 0.02 & 0.00 \\ 0.09 & 0.16 & 0.08 \\ 0.44 & 1.66 & 0.07 \\ 0.10 & 0.21 & 0.07 \\ 0.06 & 0.02 & 0.01 \\ 1.30 & 0.54 & 17.15 \\ 0.04 & 0.08 & 0.16 \\ 0.61 & 0.77 & 0.90 \\ 1.95 & 1.64 & 6.44 \\ 0.03 & 0.04 & 0.14 \\ 0.01 & 0.01 & 0.04 \\ 0.02 & 0.05 & 0.01 \\ 0.17 & 0.36 & 0.02 \\ 0.04 & 0.08 & 0.00 \\ 0.02 & 0.05 & 0.01 \\ 0.37 & 0.78 & 0.12 \\ 0.21 & 0.13 & 0.27 \\ 0.19 & 0.12 & 0.49 \\ 0.07 & 0.16 & 0.01 \\ 0.25 & 0.52 & 0.03 \\ 10.35 & 21.73 & 0.58 \\ 0.85 & 1.78 & 0.11 \\ 4.53 & 9.51 & 0.72 \\ 0.10 & 0.06 & 0.07 \\ 0.03 & 0.02 & 0.04 \\ 0.03 & 0.03 & 0.01 \\ 0.43 & 0.90 & 0.09 \\ 0.08 & 0.13 & 0.07 \\ 0.15 & 0.28 & 0.14 \\ 0.03 & 0.05 & 0.01 \\ 0.59 & 0.58 & 0.76 \\ 0.16 & 0.38 & 0.07 \\ 0.27 & 0.74 & 0.08 \\ 0.02 & 0.05 & 0.01 \\ 0.12 & 0.26 & 0.07\end{array}$




\begin{tabular}{|c|c|c|c|c|c|c|c|c|c|}
\hline \multicolumn{2}{|c|}{ CHLOROPHYCEAE } & \multicolumn{3}{|c|}{ CHLOROCOCCALES (77) } & \multirow[b]{2}{*}{ BVL } & \multirow[b]{2}{*}{$\% \mathrm{DC}$} & \multirow[b]{2}{*}{ \%UPA } & \multirow[b]{2}{*}{$\%$ VOL } & \multirow[b]{2}{*}{$\% \mathrm{DO}$} \\
\hline IDSP & OC & G & SG & UPA & & & & & \\
\hline GOLPA & 2 & 13.0 & 13.0 & 0.33 & 1150.35 & 0.02 & 0.04 & 0.08 & 0.02 \\
\hline GOLRA & 10 & 5.2 & 5.2 & 0.05 & 73.76 & 0.19 & 0.06 & 0.05 & 0.20 \\
\hline KIRLU & 4 & 15.6 & 15.6 & 0.48 & 1987.80 & 0.03 & 0.08 & 0.21 & 0.03 \\
\hline KIROB & 2 & 15.6 & 14.3 & 0.48 & 1987.80 & 0.02 & 0.05 & 0.13 & 0.02 \\
\hline KIRPS & 1 & 7.8 & 7.8 & 0.12 & 186.36 & 0.01 & 0.01 & 0.01 & 0.01 \\
\hline MICPU & 7 & 6.5 & 5.2 & 0.08 & 53.11 & 0.24 & 0.13 & 0.05 & 0.26 \\
\hline MONAR & 29 & 31.2 & 2.6 & 0.20 & 55.22 & 0.84 & 1.05 & 0.17 & 0.91 \\
\hline MONCA & 8 & 13.0 & 2.6 & 0.08 & 23.08 & 0.07 & 0.04 & 0.01 & 0.08 \\
\hline MONCO & 10 & 31.2 & 2.6 & 0.20 & 55.27 & 0.22 & 0.27 & 0.04 & 0.23 \\
\hline MONCV & 8 & 13.0 & 1.3 & 0.04 & 5.75 & 0.06 & 0.02 & 0.00 & 0.07 \\
\hline MONMI & 2 & 10.4 & 6.5 & 0.17 & 115.03 & 0.02 & 0.02 & 0.01 & 0.02 \\
\hline MONSE & 15 & 39.0 & 1.3 & 0.13 & 17.29 & 0.23 & 0.18 & 0.02 & 0.25 \\
\hline OOCLA & 3 & 10.7 & 7.8 & 0.21 & 641.43 & 0.02 & 0.03 & 0.06 & 0.03 \\
\hline OOCNA & 4 & 15.6 & 14.3 & 0.56 & 1987.80 & 0.03 & 0.10 & 0.22 & 0.03 \\
\hline OOCNO & 2 & 7.8 & 2.6 & 0.05 & 248.47 & 0.07 & 0.02 & 0.07 & 0.08 \\
\hline OOCPU & 20 & 7.8 & 5.2 & 0.10 & 248.93 & 0.48 & 0.30 & 0.44 & 0.51 \\
\hline PACKO & 1 & 5.2 & 5.2 & 0.07 & 42.47 & 0.01 & 0.01 & 0.00 & 0.01 \\
\hline PALTE & 7 & 13.0 & 9.1 & 0.30 & 106.19 & 0.47 & 0.86 & 0.19 & 0.51 \\
\hline QUALA & 3 & 15.6 & 13.0 & 0.51 & 127.42 & 0.03 & 0.09 & 0.01 & 0.03 \\
\hline SCEAC & 15 & 14.3 & 13.0 & 0.46 & 483.34 & 0.24 & 0.70 & 0.44 & 0.26 \\
\hline SCEAR & 11 & 13.0 & 13.0 & 0.33 & 1150.35 & 0.21 & 0.43 & 0.91 & 0.23 \\
\hline SCEBC & 42 & 13.0 & 10.4 & 0.34 & 351.52 & 2.44 & 5.08 & 3.20 & 2.64 \\
\hline SCEBJ & 38 & 10.4 & 5.2 & 0.14 & 140.61 & 12.06 & 10.05 & 6.33 & 13.04 \\
\hline SCEDA & 2 & 5.2 & 5.2 & 0.07 & 70.30 & 0.06 & 0.02 & 0.01 & 0.06 \\
\hline SCEDE & 16 & 14.3 & 9.1 & 0.33 & 338.34 & 0.24 & 0.49 & 0.31 & 0.26 \\
\hline SCEJA & 2 & 15.6 & 9.8 & 0.38 & 395.46 & 0.03 & 0.07 & 0.04 & 0.03 \\
\hline SCEOP & 3 & 16.9 & 13.0 & 0.55 & 571.22 & 0.02 & 0.07 & 0.04 & 0.02 \\
\hline SCEOV & 1 & 13.0 & 13.0 & 0.42 & 439.40 & 0.01 & 0.02 & 0.01 & 0.01 \\
\hline SCEQU & 25 & 10.4 & 7.8 & 0.20 & 210.91 & 0.41 & 0.52 & 0.33 & 0.45 \\
\hline SCERM & 1 & 10.4 & 5.2 & 0.14 & 140.61 & 0.02 & 0.02 & 0.01 & 0.03 \\
\hline SPHPL & 5 & 15.6 & 15.6 & 0.48 & 1987.80 & 0.03 & 0.09 & 0.22 & 0.03 \\
\hline SPHSC & 3 & 15.6 & 15.6 & 0.48 & 1987.80 & 0.07 & 0.21 & 0.54 & 0.08 \\
\hline TETLA & 1 & 26.0 & 5.2 & 0.34 & 351.52 & 0.01 & 0.01 & 0.01 & 0.01 \\
\hline TREEL & 4 & 31.2 & 2.6 & 0.20 & 18.41 & 0.04 & 0.05 & 0.00 & 0.04 \\
\hline TRESE & 31 & 18.2 & 5.2 & 0.24 & 42.95 & 0.99 & 1.44 & 0.16 & 1.07 \\
\hline WESBO & 6 & 10.4 & 10.4 & 0.27 & 589.76 & 0.05 & 0.09 & 0.11 & 0.06 \\
\hline CHLORC & HYCEAE & OED & JIALF & & & & & & \\
\hline IDSP & OC & G & SG & UPA & BVL & $\% D C$ & $\%$ UPA & \%VOL & $\% \mathrm{DO}$ \\
\hline ZOED1 & 6 & 18.2 & 18.2 & 0.65 & 3156.55 & 0.04 & 0.17 & 0.50 & 0.05 \\
\hline ZOED2 & 1 & 15.6 & 15.6 & 0.48 & 1987.80 & 0.01 & 0.02 & 0.04 & 0.01 \\
\hline ZOED3 & 2 & 26.0 & 20.8 & 1.35 & 9202.77 & 0.01 & 0.06 & 0.25 & 0.01 \\
\hline
\end{tabular}

\begin{tabular}{|c|c|c|c|c|c|c|c|c|c|}
\hline \multicolumn{2}{|c|}{ CHLOROPHYCEAE } & \multicolumn{3}{|c|}{ VOLVOCALES (11) } & \multirow[b]{2}{*}{ BVL } & \multirow[b]{2}{*}{$\% D C$} & \multirow[b]{2}{*}{ \%UPA } & \multirow[b]{2}{*}{$\%$ VOL } & \multirow[b]{2}{*}{$\%$ DO } \\
\hline IDSP & OC & G & SG & UPA & & & & & \\
\hline CLAG1 & 26 & 5.2 & 2.6 & 0.03 & 11.50 & 0.74 & 0.15 & 0.03 & 0.80 \\
\hline CLAG2 & 27 & 10.4 & 10.4 & 0.21 & 588.98 & 0.88 & 1.15 & 1.93 & 0.95 \\
\hline CLAGC & 3 & 22.1 & 22.1 & 0.96 & 5651.65 & 0.03 & 0.18 & 0.64 & 0.03 \\
\hline CLAGL & 8 & 5.2 & 5.2 & 0.05 & 73.62 & 0.43 & 0.14 & 0.12 & 0.47 \\
\hline CLAGR & 3 & 5.2 & 2.6 & 0.03 & 11.50 & 0.02 & 0.00 & 0.00 & 0.02 \\
\hline CLAPR & 4 & 10.4 & 5.2 & 0.14 & 92.03 & 0.08 & 0.07 & 0.03 & 0.08 \\
\hline CLAS1 & 18 & 5.2 & 2.6 & 0.03 & 73.62 & 0.36 & 0.08 & 0.10 & 0.39 \\
\hline CLASU & 1 & 7.8 & 2.6 & 0.05 & 248.47 & 0.02 & 0.01 & 0.02 & 0.03 \\
\hline EUDEL & 2 & 18.2 & 18.2 & 0.83 & 3156.55 & 0.01 & 0.06 & 0.14 & 0.01 \\
\hline VOLCI & 5 & 36.4 & 36.4 & 2.60 & 25252.41 & 0.05 & 0.77 & 4.55 & 0.05 \\
\hline VOUSI & 10 & 5.2 & 5.2 & 0.05 & 73.72 & 0.27 & 0.09 & 0.07 & 0.29 \\
\hline \multicolumn{10}{|c|}{ ZYGNEMAPHYCEAE ZYGNEMATALES (32) } \\
\hline IDSP & OC & $\mathbf{G}$ & SG & UPA & BVL & $\% D C$ & \%UPA & $\%$ VOL & $\% \mathrm{DO}$ \\
\hline ACTS1 & 7 & 26.0 & 15.6 & 1.01 & 637.11 & 0.08 & 0.49 & 0.19 & 0.08 \\
\hline ACTS2 & 2 & 15.6 & 13.1 & 0.51 & 321.01 & 0.02 & 0.08 & 0.03 & 0.03 \\
\hline ACTWO & 9 & 13.0 & 10.4 & 0.34 & 212.37 & 0.19 & 0.39 & 0.15 & 0.20 \\
\hline CLOS1 & 2 & 42.9 & 5.2 & 0.56 & 303.69 & 0.03 & 0.10 & 0.03 & 0.03 \\
\hline $\cos 12$ & 1 & 2.6 & 1.3 & 0.01 & 5.31 & 0.01 & 0.00 & 0.00 & 0.01 \\
\hline $\cos 15$ & 2 & 7.8 & 5.2 & 0.10 & 63.71 & 0.05 & 0.03 & 0.01 & 0.06 \\
\hline
\end{tabular}




\begin{tabular}{|c|c|c|c|c|c|c|c|c|c|}
\hline \multicolumn{10}{|c|}{ ZYGNEMAPHYCEAE } \\
\hline IDSP & OC & $\mathbf{G}$ & SG & UPA & BVL & $\% D C$ & \%UPA & \%VOL & $\%$ DO \\
\hline $\cos 16$ & 1 & 26.0 & 14.3 & 0.93 & 584.02 & 0.02 & 0.10 & 0.04 & 0.02 \\
\hline $\cos 18$ & 1 & 13.0 & 10.4 & 0.34 & 212.37 & 0.02 & 0.05 & 0.02 & 0.03 \\
\hline $\cos 19$ & 1 & 7.8 & 3.9 & 0.08 & 47.78 & 0.01 & 0.01 & 0.00 & 0.01 \\
\hline $\cos 20$ & 2 & 13.0 & 9.1 & 0.30 & 185.83 & 0.02 & 0.04 & 0.02 & 0.03 \\
\hline COSEL & 1 & 19.5 & 13.0 & 0.63 & 398.20 & 0.01 & 0.05 & 0.02 & 0.01 \\
\hline coss 1 & 2 & 11.7 & 9.1 & 0.27 & 167.24 & 0.09 & 0.15 & 0.06 & 0.10 \\
\hline Coss 5 & 6 & 14.3 & 11.5 & 0.41 & 258.32 & 0.11 & 0.29 & 0.11 & 0.12 \\
\hline $\operatorname{coss} 9$ & 1 & 15.6 & 15.6 & 0.61 & 382.27 & 0.01 & 0.05 & 0.02 & 0.01 \\
\hline EUABI & 3 & 15.6 & 15.6 & 0.61 & 382.27 & 0.02 & 0.07 & 0.03 & 0.02 \\
\hline MOUAM & 32 & 18.2 & 2.6 & 0.12 & 96.63 & 17.14 & 12.50 & 6.18 & 18.54 \\
\hline MOUS1 & 3 & 19.5 & 8.6 & 0.42 & 1143.28 & 0.42 & 1.08 & 1.77 & 0.45 \\
\hline MOUS3 & 1 & 13.0 & 2.6 & 0.08 & 69.02 & 0.01 & 0.00 & 0.00 & 0.01 \\
\hline STA20 & 1 & 52.0 & 18.2 & 2.37 & 1486.60 & 0.01 & 0.09 & 0.03 & 0.01 \\
\hline STA21 & 2 & 14.3 & 13.0 & 0.46 & 292.01 & 0.02 & 0.05 & 0.02 & 0.02 \\
\hline STA24 & 1 & 18.2 & 18.2 & 0.83 & 520.31 & 0.01 & 0.06 & 0.02 & 0.01 \\
\hline STAGR & 3 & 41.6 & 21.0 & 2.18 & 1372.25 & 0.04 & 0.57 & 0.22 & 0.05 \\
\hline STALE & 1 & 15.6 & 13.0 & 0.51 & 318.56 & 0.01 & 0.02 & 0.01 & 0.01 \\
\hline STAMU & 3 & 13.0 & 13.0 & 0.42 & 265.46 & 0.08 & 0.22 & 0.08 & 0.09 \\
\hline STAS2 & 2 & 19.5 & 19.5 & 0.95 & 597.30 & 0.01 & 0.07 & 0.03 & 0.01 \\
\hline STAS6 & 8 & 18.2 & 13.0 & 0.59 & 371.65 & 0.05 & 0.18 & 0.07 & 0.05 \\
\hline STRCO & 1 & 26.0 & 20.0 & 1.30 & 816.81 & 0.01 & 0.10 & 0.04 & 0.01 \\
\hline STRCU & 5 & 28.6 & 18.2 & 1.30 & 817.63 & 0.05 & 0.44 & 0.17 & 0.06 \\
\hline STRS4 & 1 & 18.2 & 15.6 & 0.71 & 445.98 & 0.01 & 0.03 & 0.01 & 0.01 \\
\hline STRS5 & 1 & 31.2 & 31.2 & 2.43 & 1529.08 & 0.01 & 0.09 & 0.03 & 0.01 \\
\hline STRVA & 1 & 15.6 & 15.6 & 0.61 & 382.27 & 0.01 & 0.05 & 0.02 & 0.01 \\
\hline XANS2 & 9 & 31.2 & 31.2 & 2.43 & 1529.08 & 0.09 & 1.40 & 0.53 & 0.10 \\
\hline EUGLEN & PHY & $\mathbf{E U}$ & NALES & & & & & & \\
\hline IDSP & OC & $\mathbf{G}$ & SG & UPA & BVL & $\% \mathbf{D C}$ & \%UPA & \%VOL & \%DO \\
\hline EUGAC & 3 & 20.8 & 6.5 & 0.34 & 266.02 & 0.02 & 0.05 & 0.02 & 0.03 \\
\hline EUGDE & 1 & 18.2 & 18.2 & 0.83 & 2367.41 & 0.01 & 0.03 & 0.05 & 0.01 \\
\hline EUGPA & 1 & 18.2 & 18.2 & 0.83 & 2367.41 & 0.01 & 0.03 & 0.05 & 0.01 \\
\hline LEPTE & 2 & 18.2 & 13.0 & 0.59 & 1092.83 & 0.03 & 0.11 & 0.12 & 0.03 \\
\hline STROF & 2 & 18.2 & 13.0 & 0.59 & 1092.83 & 0.02 & 0.07 & 0.07 & 0.02 \\
\hline TRACE & 1 & 7.8 & 7.8 & 0.12 & 248.47 & 0.02 & 0.02 & 0.02 & 0.03 \\
\hline TRAOB & 6 & 10.4 & 7.8 & 0.20 & 227.77 & 0.09 & 0.11 & 0.08 & 0.10 \\
\hline TRAS4 & 1 & 18.2 & 15.6 & 0.71 & 1656.50 & 0.01 & 0.03 & 0.04 & 0.01 \\
\hline TRAS5 & 2 & 20.8 & 10.4 & 0.54 & 736.22 & 0.02 & 0.06 & 0.05 & 0.02 \\
\hline TRATY & 1 & 7.8 & 7.8 & 0.12 & 248.47 & 0.06 & 0.04 & 0.06 & 0.07 \\
\hline TRAVO & 25 & 10.4 & 10.4 & 0.21 & 588.98 & 0.36 & 0.47 & 0.79 & 0.39 \\
\hline TRAVP & 12 & 13.0 & 13.0 & 0.33 & 1150.35 & 0.15 & 0.31 & 0.65 & 0.16 \\
\hline BACILLA & RIOPI & AE CE & ALES & & & & & & \\
\hline IDSP & OC & G & SG & UPA & BVL & $\% \mathrm{DC}$ & \%UPA & $\%$ VOL & $\% \mathrm{DO}$ \\
\hline AULAN & 2 & 31.2 & 5.2 & 0.41 & 662.60 & 0.09 & 0.23 & 0.22 & 0.10 \\
\hline AULCU & 3 & 31.2 & 5.2 & 0.41 & 662.60 & 0.07 & 0.18 & 0.18 & 0.08 \\
\hline AULGR & 9 & 39.0 & 15.6 & 1.52 & 7454.25 & 0.18 & 1.71 & 5.08 & 0.20 \\
\hline CYCME & 8 & 10.4 & 6.5 & 0.21 & 345.10 & 0.06 & 0.08 & 0.08 & 0.07 \\
\hline CYCOC & 1 & 10.4 & 5.2 & 0.21 & 220.87 & 0.01 & 0.01 & 0.00 & 0.01 \\
\hline RHIEI & 23 & 46.8 & 5.2 & 0.61 & 331.30 & 1.69 & 6.34 & 2.09 & 1.83 \\
\hline RHILO & 1 & 33.8 & 2.6 & 0.22 & 59.82 & 0.01 & 0.01 & 0.00 & 0.01 \\
\hline RHIS1 & 2 & 13.0 & 2.6 & 0.08 & 23.01 & 0.01 & 0.01 & 0.00 & 0.01 \\
\hline STEDU & 12 & 7.8 & 5.2 & 0.12 & 165.65 & 0.14 & 0.10 & 0.09 & 0.15 \\
\hline BACILLA & RIOPI & AE PEI & LES(9) & & & & & & \\
\hline IDSP & OC & $\mathbf{G}$ & SG & UPA & BVL & $\% \mathrm{DC}$ & \%UPA & \%VOL & $\%$ DO \\
\hline AMPS1 & 1 & 10.4 & 2.6 & 0.07 & 18.41 & 0.01 & 0.01 & 0.00 & 0.01 \\
\hline ASTFO & 10 & 31.2 & 5.2 & 0.41 & 662.60 & 0.54 & 1.35 & 1.34 & 0.59 \\
\hline CALAM & 3 & 33.8 & 5.2 & 0.44 & 239.27 & 0.03 & 0.08 & 0.03 & 0.03 \\
\hline DIAS3 & 1 & 26.0 & 7.8 & 0.51 & 414.12 & 0.01 & 0.02 & 0.01 & 0.01 \\
\hline EUNS4 & 1 & 26.0 & 2.6 & 0.17 & 46.01 & 0.13 & 0.13 & 0.02 & 0.14 \\
\hline NAVSI & 1 & 26.0 & 5.2 & 0.34 & 184.06 & 0.01 & 0.01 & 0.00 & 0.01 \\
\hline SYNMI & 47 & 18.2 & 2.6 & 0.12 & 32.21 & 3.77 & 2.75 & 0.45 & 4.08 \\
\hline SYNU1 & 37 & 65.0 & 2.6 & 0.42 & 115.03 & 1.66 & 4.32 & 0.71 & 1.80 \\
\hline SYNU2 & 9 & 202.8 & 5.2 & 2.64 & 1436.88 & 0.10 & 1.66 & 0.55 & 0.11 \\
\hline
\end{tabular}




\begin{tabular}{|c|c|c|c|c|c|c|c|c|c|}
\hline \multicolumn{2}{|c|}{ CHRYSOPHYCEAE } & \multicolumn{3}{|c|}{ OCHROMONADALES (11) } & \multirow[b]{2}{*}{ BVL } & \multirow[b]{2}{*}{$\% D C$} & \multirow[b]{2}{*}{ \%UPA } & \multirow[b]{2}{*}{ \%VOL } & \multirow[b]{2}{*}{$\%$ DO } \\
\hline IDSP & OC & G & SG & UPA & & & & & \\
\hline DINBA & 6 & 48.1 & 7.8 & 0.94 & 828.25 & 0.09 & 0.52 & 0.28 & 0.10 \\
\hline DINDI & 9 & 39.0 & 7.8 & 0.76 & 683.48 & 0.65 & 3.05 & 1.66 & 0.70 \\
\hline DINSE & 1 & 31.2 & 7.8 & 0.61 & 559.07 & 0.01 & 0.02 & 0.01 & 0.01 \\
\hline MALAP & 1 & 30.0 & 12.9 & 0.97 & 1614.91 & 0.00 & 0.01 & 0.01 & 0.00 \\
\hline MALCA & 2 & 15.6 & 5.2 & 0.20 & 128.84 & 0.01 & 0.02 & 0.01 & 0.01 \\
\hline MALMA & 1 & 13.0 & 7.8 & 0.25 & 269.18 & 0.01 & 0.01 & 0.01 & 0.01 \\
\hline MALPA & 1 & 13.0 & 5.2 & 0.17 & 110.43 & 0.01 & 0.01 & 0.00 & 0.01 \\
\hline MALRH & 1 & 13.0 & 5.2 & 0.17 & 110.43 & 0.01 & 0.01 & 0.00 & 0.01 \\
\hline MALTE & 2 & 13.0 & 6.5 & 0.21 & 179.74 & 0.02 & 0.03 & 0.02 & 0.03 \\
\hline MALTO & 9 & 13.0 & 7.8 & 0.25 & 269.18 & 0.07 & 0.12 & 0.07 & 0.08 \\
\hline SYNUV & 6 & 10.4 & 7.8 & 0.20 & 227.77 & 0.07 & 0.08 & 0.06 & 0.07 \\
\hline \multicolumn{2}{|c|}{ CRYPTOPHYCEAE } & \multicolumn{3}{|c|}{ CRYPTOMONADALES ( 7$)$} & & & & & \\
\hline IDSP & $\mathrm{OC}$ & G & SG & UPA & BVL & $\%$ DC & $\%$ UPA & $\%$ VOL & \%DO \\
\hline CHIAC & 2 & 13.0 & 7.8 & 0.25 & 269.18 & 0.02 & 0.03 & 0.02 & 0.02 \\
\hline CHIMI & 2 & 6.5 & 2.6 & 0.04 & 13.80 & 0.02 & 0.01 & 0.00 & 0.03 \\
\hline CROBR & 5 & 10.4 & 5.2 & 0.14 & 588.98 & 0.09 & 0.08 & 0.20 & 0.10 \\
\hline CRYBR & 25 & 10.4 & 5.2 & 0.14 & 92.21 & 0.34 & 0.28 & 0.12 & 0.37 \\
\hline CRYER & 2 & 13.0 & 5.2 & 0.17 & 110.43 & 0.02 & 0.02 & 0.01 & 0.02 \\
\hline CRYTE & 17 & 7.8 & 2.6 & 0.05 & 16.10 & 0.36 & 0.11 & 0.02 & 0.39 \\
\hline SENCO & 8 & 10.4 & 7.8 & 0.20 & 588.98 & 0.34 & 0.42 & 0.74 & 0.36 \\
\hline \multicolumn{2}{|c|}{ DINOPHYCEAE } & \multicolumn{3}{|c|}{ PERIDINIALES (1) } & & & & & \\
\hline IDSP & OC & G & SG & UPA & BVL & $\% \mathrm{DC}$ & $\%$ UPA & $\%$ VOL & $\% \mathrm{DO}$ \\
\hline GYMEU & 6 & 11.7 & 10.4 & 0.30 & 478.54 & 0.07 & 0.12 & 0.12 & 0.07 \\
\hline
\end{tabular}


TABELA 8 - GUARAPIRANGA 1991-92. CARACTERÍSTICAS DAS ESPÉCIES DO PONTO 4.

Identificação da espécie (IDSP); número de ocorrências desta espécie (OC); gald ou maior eixo linear em $\mu \mathrm{m}$ (G); sgald ou segundo maior eixo linear em $\mu \mathrm{m}$ (SG); unidade padrão de área em UPA (UPA); volume em $\mu \mathrm{m}^{3}$ (BVL); contribuição da espécie em porcentagem do total geral, para a densidade de células (\%DC); para a bioárea (\%UPA), para o biovolume (\%BVL) e para a densidade de organismos (\%DO).

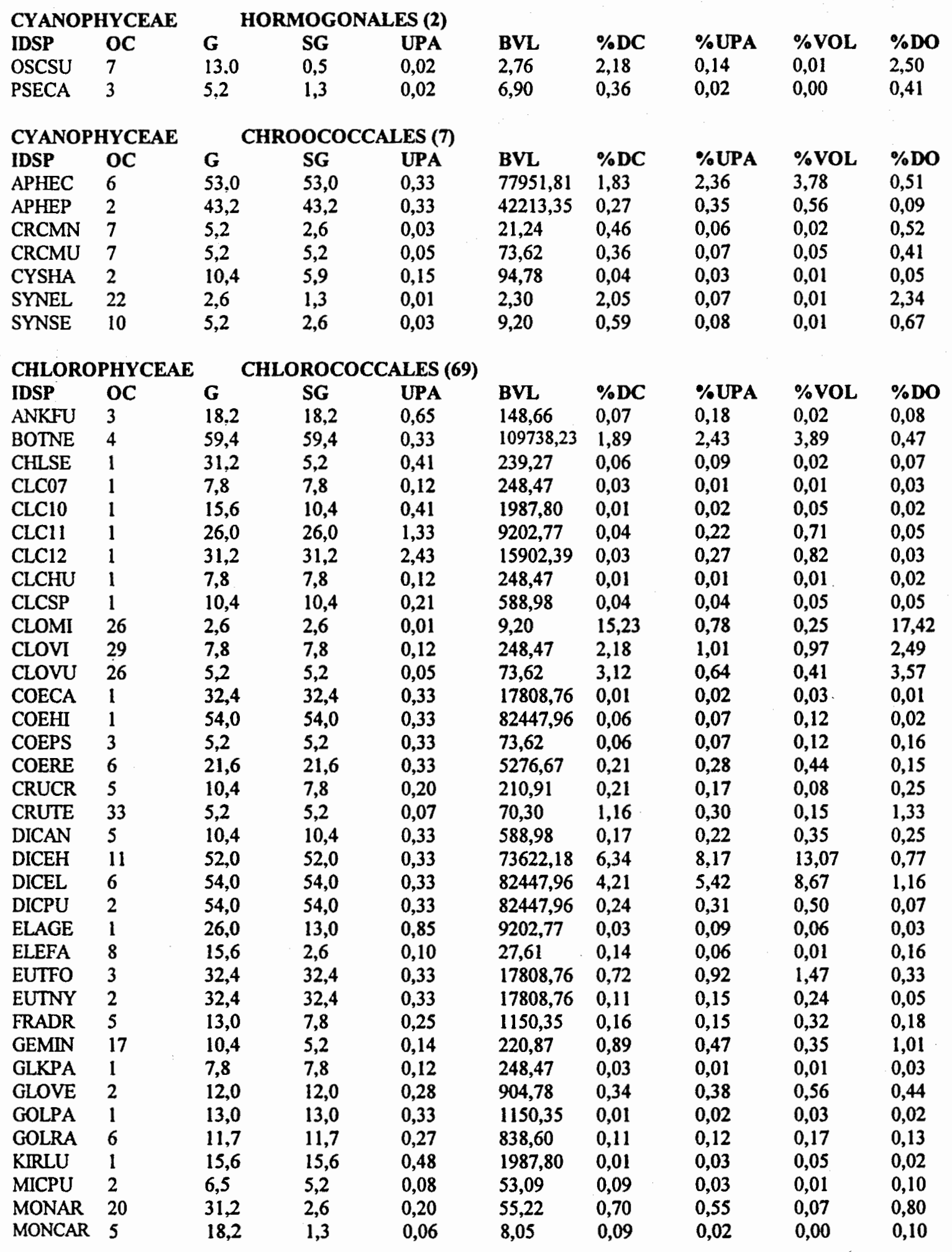




\begin{tabular}{|c|c|c|c|c|c|c|c|c|c|}
\hline CHLOR & PHY & & ROC & ALES ( & & & & & \\
\hline IDSP & OC & G & SG & UPA & BVL & $\% D C$ & $\%$ UPA & $\%$ VOL & $\% D O$ \\
\hline MONCT & 4 & 31,2 & 2,6 & 0,20 & 55,22 & 0,09 & 0,07 & 0,01 & 0,10 \\
\hline MONCV & 7 & 13,0 & 1,3 & 0,04 & 5,75 & 0,17 & 0,03 & 0,00 & 0,20 \\
\hline MONSE & 13 & 31,2 & 1,3 & 0,10 & 13,80 & 0,26 & 0,10 & 0,01 & 0,29 \\
\hline MONTO & 1 & 15,6 & 3,9 & 0,15 & 62,12 & 0,06 & 0.03 & 0,01 & 0,07 \\
\hline OOCLA & 2 & 7,8 & 5,2 & 0,10 & 248,47 & 0,09 & 0,30 & 0,04 & 0,10 \\
\hline OOCNA & 2 & 13,0 & 13,0 & 0,33 & 1150,35 & 0,03 & 0.04 & 0,06 & 0,03 \\
\hline OOCPU & 11 & 15,6 & 15,6 & 0,48 & 1987,80 & 0,76 & 0,05 & 2,70 & 0,87 \\
\hline OOCRO & 1 & 10,4 & 9,1 & 0,24 & 588,98 & 0,03 & 0,08 & 0,03 & 0,03 \\
\hline PALTE & 5 & 15,6 & 6,5 & 0,25 & 127,42 & 1,02 & 1,00 & 0,23 & 1,16 \\
\hline PEDTE & 3 & 15,6 & 15,6 & 0,48 & 127,42 & 0,04 & 0,08 & 0,01 & 0,05 \\
\hline QUALA & 1 & 39,0 & 18,2 & 1,77 & 3382,02 & 0,01 & 0,10 & 0,09 & 0,02 \\
\hline SCEAC & 6 & 18,2 & 13,0 & 0,59 & 615,16 & 0,14 & 0,33 & 0,16 & 0,16 \\
\hline SCEAR & 10 & 10,4 & 7,8 & 0,20 & 588,98 & 0,34 & 0,27 & 0,36 & 0,39 \\
\hline SCEBC & 34 & 13,0 & 10,4 & 0,34 & 351,52 & 2,23 & 2,93 & 1,41 & 2,55 \\
\hline SCEBJ & 42 & 13,0 & 10,4 & 0,34 & 351,52 & 8,13 & 10,67 & 5,12 & 9,30 \\
\hline SCECU & 1 & 13,0 & 10,4 & 0,34 & 351,52 & 0,03 & 0,04 & 0,02 & 0,03 \\
\hline SCEDA & 1 & 5,2 & 5,2 & 0,07 & 70,30 & 0,09 & 0,02 & 0,01 & 0,10 \\
\hline SCEDE & 10 & 11,7 & 10,4 & 0,30 & 316,37 & 0,26 & 0,30 & 0,15 & 0,29 \\
\hline SCEJA & 1 & 13,0 & 10,4 & 0,34 & 351,52 & 0,01 & 0,02 & 0,01 & 0,02 \\
\hline SCEQM & 1 & 28,6 & 20,8 & 1,47 & 1546,69 & 0,01 & 0,08 & 0,04 & 0,02 \\
\hline SCEQU & 12 & 13,0 & 10,4 & 0,34 & 351,52 & 0,23 & 0.30 & 0,14 & 0,26 \\
\hline SCESP & 1 & 7,8 & 5,2 & 0,10 & 105,46 & 0,01 & 0.01 & 0,00 & 0,02 \\
\hline SPHSC & 2 & 19,5 & 19,5 & 0,95 & 3882,42 & 0,09 & 0.32 & 0,60 & 0,10 \\
\hline TETMI & 1 & 10,4 & 10,4 & 0,27 & 281,22 & 0,01 & 0,02 & 0,01 & 0,02 \\
\hline TETMM & 1 & 9,1 & 9,1 & 0,21 & 215,31 & 0,01 & 0.01 & 0,01 & 0,02 \\
\hline TETTR & 1 & 5,2 & 5,2 & 0,03 & 70,30 & 0,01 & 0,00 & 0,00 & 0,02 \\
\hline TETVI & 1 & 26,0 & 26,0 & 0,85 & 1757,60 & 0,01 & 0,05 & 0,05 & 0,02 \\
\hline TREEL & 1 & 26,0 & 2,6 & 0,17 & 15,34 & 0,01 & 0,01 & 0,00 & 0,02 \\
\hline TRESC & 1 & 10,4 & 7,8 & 0,20 & 55,22 & 0,03 & 0,02 & 0,00 & 0,03 \\
\hline TRESE & 11 & 18,2 & 5,2 & 0,24 & 42,95 & 0,36 & 0,33 & 0,03 & 0,41 \\
\hline WESBO & 5 & 10,4 & 10,4 & 0,27 & 588,98 & 0,19 & 0,20 & 0,20 & 0,21 \\
\hline WESS3 & 1 & 5,2 & 5,2 & 0,07 & 73,62 & 0,04 & 0,01 & 0,01 & 0,05 \\
\hline WESS4 & 1 & 5,2 & 5,2 & 0,07 & 73,62 & 0,01 & 0,00 & 0,00 & 0,02 \\
\hline
\end{tabular}

CHLOROPHYCEAE OEDOGONIALES (2)

$\begin{array}{llllllllll}\text { IDSP } & \text { OC } & \text { G } & \text { SG } & \text { UPA } & \text { BVL } & \text { \%DC } & \text { \%UPA } & \text { \%VOL } & \text { \%DO } \\ \text { ZOED1 } & 10 & 18,2 & 18,2 & 0,65 & 3156,55 & 0,16 & 0,40 & 0,89 & 0,18 \\ \text { ZOED2 } & 1 & 13,0 & 13,0 & 0,33 & 1150,35 & 0,01 & 0,02 & 0,03 & 0,02\end{array}$

\begin{tabular}{|c|c|c|c|c|c|c|c|c|c|}
\hline \multicolumn{3}{|c|}{ CHLOROPHYCEAE } & \multicolumn{2}{|c|}{ VOLVOCALES (10) } & \multirow[b]{2}{*}{ BVL } & \multirow[b]{2}{*}{$\% D C$} & \multirow[b]{2}{*}{$\%$ UPA } & \multirow[b]{2}{*}{$\%$ VOL } & \multirow[b]{2}{*}{$\% \mathrm{DO}$} \\
\hline IDSP & OC & G & SG & UPA & & & & & \\
\hline CLAGI & 42 & 5,2 & 2,6 & 0,03 & 73,62 & 3,74 & 0,49 & 0,49 & 4,27 \\
\hline CLAG2 & 30 & 10,4 & 10,4 & 0,21 & 588,98 & 1,86 & 1,53 & 1,96 & 2,13 \\
\hline CLAGC & 1 & 22,1 & 22,1 & 0,96 & 5651,65 & 0,01 & 0,05 & 0,14 & 0,02 \\
\hline CLAGL & 14 & 5,2 & 5,2 & 0,05 & 73,62 & 1,67 & 0,35 & 0,22 & 1,92 \\
\hline CLAGR & 3 & 5,2 & 2,6 & 0,03 & 73,62 & 0,93 & 0,12 & 0,12 & 1,06 \\
\hline CLAPR & 1 & 10,4 & 5,2 & 0,14 & 588,98 & 0,01 & 0,01 & 0,02 & 0,02 \\
\hline CLASI & 6 & 5,2 & 2,6 & 0,03 & 73,62 & 0,17 & 0,02 & 0,02 & 0,20 \\
\hline CLASU & 4 & 7,8 & 2,6 & 0,05 & 248,47 & 0,29 & 0,06 & 0,13 & 0,33 \\
\hline VOLCl & 2 & 32,5 & 32,5 & 2,07 & 17974,16 & 0,07 & 0,58 & 2,30 & 0,08 \\
\hline VOUS1 & 7 & 5,2 & 5,2 & 0,05 & 73,62 & 0,19 & 0,04 & 0,02 & 0,21 \\
\hline \multicolumn{10}{|c|}{ ZYGNEMAPHYCEAE ZYGNEMATALES (23) } \\
\hline IDSP & OC & G & SG & UPA & BVL & $\%$ DC & \%UPA & \%VOL & $\%$ DO \\
\hline ACTS3 & 2 & 6,5 & 5,2 & 0,08 & 53,09 & 0,03 & 0,01 & 0,00 & 0,03 \\
\hline ACTWO & 1 & 13,0 & 10,4 & 0,34 & 212,37 & 0,01 & 0,02 & 0,01 & 0,02 \\
\hline $\cos 10$ & 2 & 7,8 & 6,5 & 0,13 & 79,64 & 0,04 & 0,02 & 0,01 & 0,05 \\
\hline $\cos 15$ & 1 & 7,8 & 7,8 & 0,15 & 95,57 & 0,06 & 0,03 & 0,01 & 0,07 \\
\hline
\end{tabular}




\begin{tabular}{|c|c|c|c|c|c|c|c|c|c|}
\hline \multicolumn{3}{|c|}{ ZYGNEMAPHYCEAE } & \multicolumn{2}{|c|}{ ZYGNEMATALES (23) } & \multirow[b]{2}{*}{ BVL } & \multirow[b]{2}{*}{$\% \mathrm{DC}$} & \multirow[b]{2}{*}{ \%UPA } & \multirow[b]{2}{*}{$\%$ VOL } & \multirow[b]{2}{*}{$\%$ DO } \\
\hline IDSP & OC & G & SG & UPA & & & & & \\
\hline $\operatorname{coss} 1$ & 5 & 15,6 & 13,0 & 0,51 & 318,56 & 0,10 & 0,20 & 0,06 & 0,11 \\
\hline Coss 5 & 2 & 15,6 & 13,0 & 0,51 & 318,56 & 0,04 & 0,08 & 0,02 & 0,05 \\
\hline $\operatorname{coss} 7$ & 2 & 13,0 & 9,1 & 0,30 & 185,83 & 0,03 & 0,03 & 0,01 & 0,03 \\
\hline DESMI & 1 & 23,4 & 23,4 & 1,37 & 10063,23 & 0,01 & 0,08 & 0,26 & 0,02 \\
\hline DESUI & 1 & 13,0 & 10,4 & 0,34 & 1104,33 & 0,01 & 0,02 & 0,03 & 0,02 \\
\hline EUABI & 3 & 13,0 & 13,0 & 0,42 & 265,46 & 0,06 & 0,09 & 0,03 & 0,07 \\
\hline EUASI & 1 & 13,0 & 13,0 & 0,42 & 265,46 & 0,01 & 0,02 & 0,01 & 0,02 \\
\hline MOTS1 & 2 & 16,9 & 5,2 & 0,22 & 358,91 & 0,73 & 0,62 & 0,47 & 0,83 \\
\hline MOUAM & 18 & 15,6 & 2,6 & 0,10 & 82,82 & 7,01 & 2,76 & 1,04 & 8,02 \\
\hline STA16 & 1 & 26,0 & 13,0 & 0,85 & 530,93 & 0,01 & 0,05 & 0,01 & 0,02 \\
\hline STAGR & 3 & 41,6 & 21,0 & 2,18 & 1372,25 & 0,04 & 0,36 & 0,11 & 0,05 \\
\hline STALE & 1 & 10,4 & 7,8 & 0,20 & 127,42 & 0,01 & 0,01 & 0,00 & 0,02 \\
\hline STAMU & 3 & 20,8 & 13,0 & 0,68 & 424,74 & 0,06 & 0,15 & 0,04 & 0,07 \\
\hline STAS2 & 1 & 19,5 & 19,5 & 0,95 & 597,30 & 0,01 & 0,05 & 0,02 & 0,02 \\
\hline STAS6 & 5 & 18,2 & 13,0 & 0,59 & 371,65 & 0,07 & 0,16 & 0,05 & 0,08 \\
\hline STASA & 1 & 44,2 & 18,2 & 2,01 & 1263,61 & 0,01 & 0,11 & 0,03 & 0,02 \\
\hline STRCU & 7 & 36,0 & 18,2 & 1,64 & 1029,19 & 0,20 & 1,27 & 0,37 & 0,23 \\
\hline STRSP & 1 & 18,2 & 13,0 & 0,59 & 2415,73 & 0,04 & 0,10 & 0,19 & 0,05 \\
\hline XANS2 & 7 & 31,2 & 31,2 & 2,43 & 1529,08 & 0,11 & 1,08 & 0,31 & 0,13 \\
\hline EUGLEN & PH & & CIAL & & & & & & \\
\hline IDSP & OC & G & SG & UPA & BVL & $\%$ DC & \%UPA & $\%$ VOL & $\% \mathrm{DO}$ \\
\hline COLSI & 1 & 22,1 & 10,4 & 0,57 & 773,03 & 0,06 & 0,13 & 0,08 & 0,07 \\
\hline EUGLEN & $\mathrm{PH}$ & & EUG & ALES (1 & & & & & \\
\hline IDSP & OC & G & SG & UPA & BVL & $\% D C$ & \%UPA & \%VOL & \%DO \\
\hline EUGAA & 3 & 39,0 & 12,0 & 1,17 & 1696,46 & 0,07 & 0,33 & 0,22 & 0,08 \\
\hline EUGHA & 1 & 18,2 & 5,2 & 0,24 & 147,24 & 0,01 & 0,01 & 0,00 & 0,02 \\
\hline EUGOX & 2 & 65,0 & 13,0 & 2,11 & 3163,45 & 0,04 & 0,35 & 0,24 & 0,05 \\
\hline LEPTE & 8 & 16,9 & 13,0 & 0,55 & 1035,31 & 0,17 & 0,37 & 0,32 & 0,20 \\
\hline PHAAC & 1 & 26,0 & 23,4 & 1,52 & 5404,33 & 0,01 & 0,08 & 0,14 & 0,02 \\
\hline PHAGL & 2 & 9,1 & 7,8 & 0,18 & 207,06 & 0,04 & 0,03 & 0,02 & 0,05 \\
\hline PHALO & 1 & 65,0 & 39,0 & 6,34 & 33647,64 & 0,03 & 0,70 & 1,73 & 0,03 \\
\hline TRACE & 1 & 10,4 & 10,4 & 0,21 & 588,98 & 0,03 & 0,02 & 0,03 & 0,03 \\
\hline TRAOB & 7 & 10,4 & 7,8 & 0,20 & 588,98 & 0,30 & 0,24 & 0,32 & 0,34 \\
\hline TRASI & 1 & 7,8 & 5,2 & 0,10 & 73,62 & 0,03 & 0,01 & 0,00 & 0,03 \\
\hline TRAVO & 11 & 7,8 & 7,8 & 0,12 & 248,47 & 0,54 & 0,25 & 0,24 & 0,62 \\
\hline TRAVP & 9 & 13,0 & 13,0 & 0,33 & 1150,35 & 0,21 & 0,28 & 0,44 & 0,25 \\
\hline BACILLA & RIOI & EAE C & RALE & & & & & & \\
\hline IDSP & OC & G & SG & UPA & BVL & $\%$ DC & \%UPA & \%VOL & \%DO \\
\hline AULAN & 4 & 31,2 & 5,2 & 0,41 & 662,60 & 0,73 & 1,15 & 0,87 & 0,83 \\
\hline AULCU & 2 & 31,2 & 5,2 & 0,41 & 662,60 & 0,09 & 0,14 & 0,10 & 0,10 \\
\hline AULGR & 20 & 29,9 & 12,0 & 0,90 & 3381,61 & 1,57 & 5,48 & 9,54 & 1,80 \\
\hline AULSP & 1 & 31,2 & 5,2 & 0,41 & 662,60 & 0,29 & 0,45 & 0,34 & 0,33 \\
\hline CYCGL & 1 & 7,8 & 7,8 & 0,12 & 372,71 & 0,03 & 0,01 & 0,02 & 0,03 \\
\hline CYCME & 17 & 10,4 & 7,8 & 0,21 & 496,95 & 0,33 & 0,27 & 0,29 & 0,38 \\
\hline CYCPS & 1 & 13,0 & 13,0 & 0,33 & 1725,52 & 0,01 & 0,02 & 0,04 & 0,02 \\
\hline RHIEI & 34 & 57,2 & 5,2 & 0,74 & 404,92 & 3,45 & 9,96 & 2,50 & 3,95 \\
\hline RHILO & 3 & 44,2 & 2,6 & 0,29 & 78,22 & 0,13 & 0,14 & 0,02 & 0,15 \\
\hline RHISI & 1 & 13,0 & 2,6 & 0,08 & 23,01 & 0,01 & 0,00 & 0,00 & 0,02 \\
\hline STEDU & 13 & 7,8 & 5,2 & 0,12 & 63,71 & 0,42 & 0,19 & 0,05 & 0,47 \\
\hline BACILLA & RIOI & EAE & ALES & & & & & & \\
\hline IDSP & OC & G & SG & UPA & BVL & $\% \mathrm{DC}$ & \%UPA & $\%$ VOL & \% DO \\
\hline ASTFO & 7 & 36,4 & 5,2 & 0,47 & 773,03 & 0,49 & 0,89 & 0,67 & 0,56 \\
\hline CALAM & 1 & 33,8 & 5,2 & 0,44 & 239,27 & 0,01 & 0,02 & 0,01 & 0,02 \\
\hline CYMSI & 1 & 33,8 & 10,4 & 0,88 & 957,09 & 0,01 & 0,05 & 0,02 & 0,02 \\
\hline
\end{tabular}


BACILLARIOPHYCEAE PENNALES (10)

$\begin{array}{llllllllll}\text { IDSP } & \text { OC } & \text { G } & \text { SG } & \text { UPA } & \text { BVL } & \text { \%DC } & \text { \%UPA } & \text { \%VOL } & \text { \%DO } \\ \text { DIAS4 } & 1 & 7,8 & 7,8 & 0,15 & 124,24 & \mathbf{0 , 0 3} & 0,02 & \mathbf{0 , 0 1} & 0,03 \\ \text { EUNS1 } & 1 & 39,0 & 2,6 & 0,25 & 69,02 & 0,04 & 0,04 & 0,01 & 0,05 \\ \text { GOMS1 } & 2 & 20,8 & 5,2 & 0,27 & 147,24 & 0,03 & 0,03 & 0,01 & 0,03 \\ \text { SURS2 } & 1 & 32,5 & 5,2 & 0,42 & 230,07 & 0,01 & 0,02 & 0,01 & 0,02 \\ \text { SYNMI } & 31 & 18,2 & 2,6 & 0,12 & 34,51 & 2,02 & 0,93 & 0,12 & 2,31 \\ \text { SYNU1 } & 8 & 65,0 & 2,6 & 0,42 & 115,03 & 0,23 & 0,38 & 0,05 & 0,26 \\ \text { SYNU2 } & 15 & 202,8 & 5,2 & 2,64 & 1435,63 & 0,66 & 6,74 & 1,69 & 0,75\end{array}$

CHRYSOPHYCEAE OCHROMONADALES (12)

$\begin{array}{llllllllll}\text { IDSP } & \text { OC } & \text { G } & \text { SG } & \text { UPA } & \text { BVL } & \text { \%DC } & \text { \%UPA } & \text { \%VOL } & \text { \%DO } \\ \text { DINBA } & 6 & 50,7 & \mathbf{7 , 8} & 0,99 & 869,66 & 0,39 & 1,48 & 0,60 & 0,44 \\ \text { DINDI } & 7 & 39,0 & 7,8 & 0,76 & 683,31 & 0,26 & 0,76 & 0,32 & 0,29 \\ \text { DINSE } & 4 & 23,4 & 7,8 & 0,46 & 434,83 & 0,26 & 0,46 & 0,20 & 0,29 \\ \text { MAAL } & 7 & 13,0 & 5,2 & 0,17 & 110,43 & 0,13 & 0,08 & 0,03 & 0,15 \\ \text { MALAC } & 1 & 10,4 & 7,8 & 0,20 & 227,77 & 0,03 & 0,02 & 0,01 & 0,03 \\ \text { MALAP } & 1 & 13,0 & 10,4 & 0,34 & 515,36 & 0,03 & 0,04 & 0,03 & 0,03 \\ \text { MALCA } & 2 & 10,4 & \mathbf{7 , 8} & 0,20 & 227,77 & 0,03 & 0,02 & 0,01 & 0,03 \\ \text { MALFU } & 1 & 18,2 & 10,4 & 0,47 & 662,60 & 0,04 & 0,08 & 0,05 & 0,05 \\ \text { MALPA } & 1 & 13,0 & 5,2 & 0,17 & 110,43 & 0,01 & 0,01 & 0,00 & 0,02 \\ \text { MALTE } & 3 & 10,4 & 5,2 & 0,14 & 92,03 & 0,07 & 0,04 & 0,01 & 0,08 \\ \text { MALTO } & 16 & 15,6 & \mathbf{7 , 8} & 0,30 & 310,59 & 0,30 & 0,36 & 0,17 & 0,34 \\ \text { SYRUV } & 3 & 10,4 & \mathbf{7 , 8} & 0,20 & 165,65 & 0,04 & 0,03 & 0,01 & 0,05\end{array}$

\begin{tabular}{llllllllll}
\multicolumn{1}{c}{ CRYPTOPHYCEAE } & \multicolumn{7}{c}{ CRYPTOMONADALES (8) } \\
IDSP & OC & G & SG & UPA & BVL & \%DC & \%UPA & \%VOL & \%DO \\
CHIAC & 1 & 13,0 & 7,8 & 0,25 & 269,18 & 0,16 & 0,15 & 0,08 & 0,18 \\
CROBR & 10 & 7,8 & 5,2 & 0,10 & 73,62 & 0,50 & 0,20 & 0,07 & 0,57 \\
CROPU & 1 & 5,2 & 5,2 & 0,05 & 55,22 & 0,03 & 0,01 & 0,00 & 0,03 \\
CRYBR & 41 & 13,0 & 7,8 & 0,25 & 269,18 & 2,66 & 2,62 & 1,28 & 3,04 \\
CRYER & 4 & 13,0 & 5,2 & 0,17 & 110,43 & 0,16 & 0,10 & 0,03 & 0,18 \\
CRYTE & 27 & 5,2 & 3,9 & 0,05 & 28,47 & 1,96 & 0,39 & 0,10 & 2,24 \\
RHOLA & 4 & 7,8 & 5,2 & 0,10 & 248,47 & 0,14 & 0,06 & 0,06 & 0,16 \\
SENCO & 1 & 10,4 & 7,8 & 0,20 & 588,98 & 0,03 & 0,02 & 0,03 & 0,03
\end{tabular}

\begin{tabular}{llllllllll} 
DINOPHYCEE & \multicolumn{9}{c}{ PERIDINLALES (11) } \\
IDSP & OC & G & SG & UPA & BVL & \%DC & \%UPA & \%VOL & \%DO \\
GYMBO & 6 & 10,4 & $\mathbf{7 , 8}$ & $\mathbf{0 , 2 0}$ & 227,77 & 0,11 & 0,09 & 0,05 & 0,13 \\
GYMCO & 1 & 13,0 & $\mathbf{7 , 8}$ & 0,25 & 269,18 & 0,01 & 0,01 & 0,01 & 0,02 \\
GYMEU & 7 & 20,8 & 5,2 & 0,27 & 165,65 & 0,16 & 0,17 & 0,05 & 0,18 \\
GYMFU & 13 & $\mathbf{4 4 , 2}$ & 31,2 & 3,45 & 15239,79 & 0,44 & 5,94 & 12,11 & 0,51 \\
GYMHE & 1 & 15,6 & 10,4 & 0,41 & 588,98 & 0,03 & 0,05 & 0,03 & 0,03 \\
HEMS1 & 1 & 13,0 & $\mathbf{7 , 8}$ & 0,25 & 1150,35 & 0,01 & 0,01 & 0,03 & 0,02 \\
HEMS2 & 1 & 28,6 & 18,2 & 1,30 & 12248,89 & 0,03 & 0,14 & 0,63 & 0,03 \\
HEMS3 & 1 & 20,8 & 20,8 & 1,08 & 4711,82 & 0,01 & 0,06 & 0,12 & 0,02 \\
PERS1 & 2 & 40,3 & 39,0 & 3,93 & 34269,97 & 0,04 & 0,66 & 2,64 & 0,05 \\
PERS2 & 5 & 18,2 & 13,0 & 0,65 & 3156,55 & 0,09 & 0,22 & 0,49 & 0,10 \\
PERS3 & 1 & 44,2 & 44,2 & 3,84 & 45213,22 & 0,01 & 0,21 & 1,16 & 0,02
\end{tabular}


TABELA 9 - CORRELAÇÕES ENTRE AS CARACTERÍSTICAS DAS ESPÉCIES DO PONTO 1 E DO PONTO 4 - REPRESA DE GUARAPIRANGA 1991-92

Densidade de células (DC); número de ocorrências (OC); gald ou maior dimensão linear (G); sgald ou segunda maior dimensão linear (SG); unidade padrão de área (UPA); volume (BVL) e densidade de organismos (DO). Ponto 1 (P1) e ponto 4 (P4); número de espécies (N).

$\begin{array}{llllllll} & \mathrm{Pl} \rightarrow \mathrm{N}=183 & & & & & \\ \mathrm{P} 4 \downarrow \mathrm{N}=178 & \mathrm{DC} & \mathrm{OC} & \mathrm{G} & \mathrm{SG} & \mathrm{UPA} & \mathrm{BVL} & \mathrm{DO} \\ \mathrm{DC} & \mathrm{X} & 0.8409 & -0.1834 & -0.2598 & -0.2766 & -0.2135 & 0.2271 \\ & \mathrm{X} & 0.0000 & 0.0134 & 0.0005 & 0.0002 & 0.0040 & 0.0022 \\ \text { OC } & 0.8785 & \mathrm{X} & \mathrm{N} & -0.2070 & -0.2119 & -0.1715 & 0.1491 \\ & 0.0000 & \mathrm{X} & & 0.0052 & 0.0042 & 0.0207 & 0.0442 \\ \mathrm{G} & \mathrm{N} & \mathrm{N} & \mathrm{X} & 0.4687 & 0.8590 & 0.617 & 0.1521 \\ & & & \mathrm{X} & 0.0000 & 0.0000 & 0.0000 & 0.0402 \\ \text { SG } & -0.2497 & -0.2489 & 0.4783 & \mathrm{X} & 0.7812 & 0.8401 & 0.2846 \\ & 0.0009 & 0.0009 & 0.0000 & \mathrm{X} & 0.0000 & 0.0000 & 0.0001 \\ \text { UPA } & -0.1875 & -0.1792 & 0.8147 & 0.7880 & \mathrm{X} & 0.8467 & 0.2762 \\ & 0.0126 & 0.0171 & 0.0000 & 0.0000 & \mathrm{X} & 0.0000 & 0.0002 \\ \text { BVL } & -0.1667 & -0.2056 & 0.6047 & 0.8440 & 0.8555 & \mathrm{X} & 0.3614 \\ & 0.0266 & 0.0062 & 0.0000 & 0.0000 & 0.0000 & \mathrm{X} & 0.0000 \\ \text { DO } & 0.1846 & \mathrm{~N} & 0.1674 & 0.3321 & 0.2205 & 0.2692 & \mathrm{X} \\ & 0.0140 & & 0.0260 & 0.0000 & 0.0034 & 0.0003 & \mathrm{X}\end{array}$


TABELA 10 - VARIAÇÃO TEMPORAL DAS CARACTERÍSTICAS DA COMUNIDADE FITOPLANCTÔNICA. REPRESA DE GUARAPIRANGA 1991-92: PONTO 1.

Identificação da coleta (ID); densidade em células. $\mathrm{ml}^{-1}$ (D); bioárea em UPA.ml-1 (BA); biovolume em $\mu \mathrm{m}^{3} \cdot \mathrm{ml}^{-1}$ (BV); maior dimensão linear - GALD. $\mathrm{l}^{-1}(\mathrm{G})$; número de táxons.amostra ${ }^{-1}(\mathrm{~S})$; diversidade em bits.ml $\mathrm{ml}^{-1}\left(\mathrm{H}^{\prime}\right)$; uniformidade $(U)$ e taxa de alteração da comunidade entre coletas sucessivas - soma das diferenças entre amostras consecutivas.dia ${ }^{-1}$ (TA).

\begin{tabular}{|c|c|c|c|c|c|c|c|c|c|c|c|c|c|c|}
\hline ID & D & $\mathbf{B A}$ & BV & $\mathbf{G}$ & $\mathbf{S}$ & H'D & H'BA & H'BV & UD & UBA & UBV & TAD & TABA & TABV \\
\hline MA2 & 16026 & 4543 & 4418 & 286 & 24 & 3.50 & 3.23 & 3.13 & 0.70 & 0.70 & 0.68 & $=$ & - & - \\
\hline $\mathrm{MA3}$ & 9976 & 4011 & 2900 & 176 & 22 & 3.19 & 2.85 & 3.34 & 0.70 & 0.60 & 0.75 & 0.116 & 0.166 & 0.208 \\
\hline MA4 & 6440 & 2557 & 3224 & 89 & 16 & 3.11 & 2.85 & 2.74 & 0.70 & 0.70 & 0.69 & 0.153 & 0.198 & 0.225 \\
\hline 15 & 14768 & 5142 & 6146 & 201 & 27 & 3.64 & 3.78 & 3.57 & 0.70 & 0.70 & 0.75 & 0.110 & 0.145 & 0.203 \\
\hline 16 & 10291 & 3070 & 2262 & 141 & 28 & 3.43 & 3.75 & 3.89 & 0.70 & 0.70 & 0.82 & 0.122 & 0.121 & 0.184 \\
\hline 17 & 9819 & 1998 & 1901 & 129 & 20 & 2.60 & 3.28 & 3.37 & 0.60 & 0.70 & 0.78 & 0.094 & 0.117 & 0.163 \\
\hline JL8 & 3379 & 1405 & 3959 & 63 & 16 & 3.07 & 3.33 & 2.08 & 0.70 & 0.80 & 0.52 & 0.128 & 0.199 & 0.269 \\
\hline ЛL9 & 1258 & 291 & 552 & 17 & 9 & 2.95 & 2.54 & 2.25 & 0.90 & 0.80 & 0.71 & 0.237 & 0.260 & 0.276 \\
\hline ЛL10 & 1573 & 665 & 4519 & 24 & 10 & 3.04 & 2.02 & 0.79 & 0.90 & 0.60 & 0.24 & 0.239 & 0.263 & 0.273 \\
\hline JL11 & 944 & 167 & 276 & 14 & 8 & 2.86 & 2.75 & 2.52 & 0.90 & 0.90 & 0.84 & 0.238 & 0.257 & 0.274 \\
\hline JL12 & 2595 & 759 & 2104 & 31 & 15 & 3.73 & 3.16 & 2.19 & 0.90 & 0.80 & 0.56 & 0.225 & 0.251 & 0.263 \\
\hline AGI3 & 8799 & 3006 & 3925 & 152 & 27 & 3.86 & 3.32 & 3.16 & 0.80 & 0.70 & 0.66 & 0.178 & 0.202 & 0.228 \\
\hline AGI4 & 5896 & 2262 & 3885 & 92 & 19 & 3.58 & 3.33 & 2.86 & 0.80 & 0.70 & 0.67 & 0.124 & 0.127 & 0.210 \\
\hline AG15 & 2435 & 661 & 1257 & 33 & 12 & 3.18 & 3.03 & 2.91 & 0.80 & 0.80 & 0.84 & 0.199 & 0.209 & 0.129 \\
\hline AGI 6 & 12727 & 2034 & 3147 & 171 & 30 & 4.28 & 4.19 & 3.85 & 0.80 & 0.80 & 0.79 & 0.124 & 0.119 & 0.182 \\
\hline $\mathrm{S} 17$ & 2044 & 358 & 607 & 27 & 13 & 3.01 & 2.45 & 1.10 & 0.80 & 0.60 & 0.31 & 0.194 & 0.211 & 0.207 \\
\hline S18 & 11702 & 6577 & 6477 & 311 & 16 & 2.16 & 0.96 & 1.30 & 0.50 & 0.20 & 0.33 & 0.215 & 0.271 & 0.258 \\
\hline S19 & 5423 & 1611 & 2494 & 79 & 21 & 3.69 & 3.19 & 3.00 & 0.80 & 0.70 & 0.68 & 0.190 & 0.190 & 0.209 \\
\hline $\mathrm{S} 20$ & 4008 & 1498 & 3844 & 54 & 17 & 3.62 & 2.81 & 1.99 & 0.80 & 0.60 & 0.49 & 0.168 & 0.192 & 0.244 \\
\hline 021 & 2515 & 1376 & 5014 & 36 & 11 & 3.20 & 2.20 & 1.57 & 0.90 & 0.60 & 0.45 & 0.129 & 0.108 & 0.073 \\
\hline 022 & 2593 & 897 & 1047 & 35 & 13 & 3.31 & 2.79 & 2.87 & 0.80 & 0.70 & 0.78 & 0.170 & 0.207 & 0.259 \\
\hline 023 & 4006 & 587 & 589 & 72 & 9 & 2.52 & 2.82 & 2.55 & 0.70 & 0.80 & 0.81 & 0.277 & 0.283 & 0.280 \\
\hline 024 & 12018 & 2405 & 6091 & 131 & 12 & 2.06 & 1.97 & 1.49 & 0.50 & 0.50 & 0.42 & 0.274 & 0.275 & 0.283 \\
\hline 025 & 4949 & 1197 & 3260 & 70 & 17 & 3.02 & 2.58 & 1.96 & 0.70 & 0.60 & 0.48 & 0.136 & 0.115 & 0.118 \\
\hline N26 & 11001 & 3205 & 7089 & 156 & 22 & 2.83 & 2.35 & 1.44 & 0.60 & 0.50 & 0.32 & 0.263 & 0.237 & 0.109 \\
\hline N27 & 21366 & 6837 & 22646 & 266 & 24 & 1.87 & 1.67 & 1.37 & 0.40 & 0.30 & 0.30 & 0.113 & 0.103 & 0.052 \\
\hline N28 & 25449 & 8372 & 32093 & 228 & 19 & 1.89 & 1.70 & 1.69 & 0.40 & 0.40 & 0.40 & 0.232 & 0.241 & 0.245 \\
\hline $\mathrm{N} 29$ & 15476 & 5685 & 23166 & 204 & 25 & 2.86 & 2.83 & 2.66 & 0.60 & 0.60 & 0.57 & 0.262 & 0.255 & 0.244 \\
\hline D30 & 10920 & 3118 & 10181 & 190 & 17 & 2.75 & 2.35 & 2.03 & 0.60 & 0.50 & 0.51 & 0.121 & 0.125 & 0.149 \\
\hline D31 & 13513 & 3255 & 8608 & 178 & 26 & 3.25 & 2.65 & 1.71 & 0.60 & 0.50 & 0.37 & 0.156 & 0.121 & 0.116 \\
\hline D32 & 9426 & 2981 & 9319 & 138 & 11 & 1.30 & 1.04 & 0.49 & 0.30 & 0.30 & 0.14 & 0.152 & 0.116 & 0.098 \\
\hline D33 & 27651 & 8237 & 26054 & 431 & 26 & 2.73 & 2.42 & 2.01 & 0.50 & 0.50 & 0.43 & 0.324 & 0.322 & 0.099 \\
\hline JA34 & 8879 & 2566 & 2640 & 144 & 20 & 3.38 & 2.62 & 2.54 & 0.70 & 0.60 & 0.59 & 0.103 & 0.103 & 0.226 \\
\hline JA35 & 10057 & 2852 & 4639 & 146 & 25 & 3.45 & 2.64 & 2.36 & 0.70 & 0.50 & 0.51 & 0.171 & 0.159 & 0.247 \\
\hline JA36 & 19875 & 4242 & 5293 & 255 & 35 & 3.63 & 3.93 & 3.80 & 0.70 & 0.70 & 0.74 & 0.211 & 0.244 & 0.246 \\
\hline JA37 & 26786 & 3447 & 3334 & 301 & 27 & 2.25 & 2.56 & 2.81 & 0.40 & 0.50 & 0.59 & 0.119 & 0.164 & 0.277 \\
\hline F38 & 39038 & 5212 & 7417 & 494 & 27 & 2.03 & 2.33 & 2.21 & 0.40 & 0.40 & 0.47 & 0.074 & 0.108 & 0.130 \\
\hline F39 & 72265 & 9684 & 11065 & 911 & 30 & 2.15 & 2.55 & 2.73 & 0.40 & 0.50 & 0.56 & 0.035 & 0.067 & 0.127 \\
\hline F40 & 81451 & 8094 & 12799 & 1417 & 25 & 2.00 & 2.78 & 2.21 & 0.40 & 0.60 & 0.48 & 0.160 & 0.136 & 0.256 \\
\hline F41 & 58522 & 5558 & 5217 & 1097 & 28 & 2.36 & 2.68 & 2.93 & 0.40 & 0.50 & 0.61 & 0.211 & 0.207 & 0.104 \\
\hline MR42 & 27967 & 2695 & 2028 & 753 & 20 & 2.49 & 3.23 & 3.28 & 0.50 & 0.70 & 0.77 & 0.060 & 0.076 & 0.150 \\
\hline MR43 & 36131 & 4709 & 3548 & 565 & 24 & 2.79 & 2.96 & 3.07 & 0.60 & 0.60 & 0.68 & 0.127 & 0.099 & 0.105 \\
\hline MR44 & 35425 & 5248 & 2959 & 733 & 32 & 3.50 & 3.44 & 3.68 & 0.70 & 0.60 & 0.74 & 0.091 & 0.112 & 0.109 \\
\hline $\mathrm{AB} 45$ & 25922 & 3712 & 4905 & 465 & 36 & 3.78 & 3.97 & 3.33 & 0.70 & 0.70 & 0.65 & 0.110 & 0.138 & 0.168 \\
\hline $\mathrm{AB} 46$ & 36445 & 4097 & 2954 & 991 & 29 & 3.10 & 3.61 & 3.48 & 0.60 & 0.70 & 0.72 & 0.146 & 0.130 & 0.216 \\
\hline $\mathrm{AB} 47$ & 40300 & 5267 & 7602 & 883 & 34 & 3.68 & 4.14 & 3.53 & 0.70 & 0.80 & 0.69 & 0.107 & 0.151 & 0.190 \\
\hline $\mathrm{AB} 48$ & 48311 & 4723 & 4616 & 1250 & 27 & 2.93 & 3.41 & 3.16 & 0.60 & 0.70 & 0.66 & 0.093 & 0.150 & 0.197 \\
\hline $\mathrm{AB} 49$ & 122607 & 8341 & 9222 & 3335 & 28 & 2.54 & 3.10 & 2.72 & 0.50 & 0.60 & 0.57 & 0.061 & 0.086 & 0.098 \\
\hline MASO & 75955 & 5893 & 5224 & 1881 & 28 & 2.76 & 3.40 & 3.12 & 0.50 & 0.70 & 0.65 & 0.075 & 0.096 & 0.131 \\
\hline MASI & 82004 & 7746 & 6432 & 1903 & 33 & 2.95 & 3.50 & 3.20 & 0.50 & 0.60 & 0.63 & 0.071 & 0.107 & 0.081 \\
\hline MA53 & 36368 & 3959 & 3667 & 823 & 22 & 2.35 & 2.52 & 2.10 & 0.50 & 0.50 & 0.47 & 0.059 & 0.050 & 0.107 \\
\hline 354 & 11930 & 2506 & 4075 & 210 & 46 & 3.87 & 3.53 & 3.34 & 0.70 & 0.60 & 0.62 & 0.166 & 0.192 & 0.224 \\
\hline J55 & 21453 & 5718 & 4765 & 435 & 38 & 4.14 & 3.68 & 3.88 & 0.70 & 0.70 & 0.74 & 0.151 & 0.189 & 0.173 \\
\hline J56 & 12099 & 3259 & 2808 & 209 & 26 & 3.81 & 3.00 & 3.59 & 0.80 & 0.60 & 0.76 & 0.140 & 0.125 & 0.139 \\
\hline 357 & 11314 & 2993 & 3637 & 213 & 24 & 3.84 & 3.02 & 3.57 & 0.80 & 0.60 & 0.78 & 0.136 & 0.115 & 0.154 \\
\hline JL58 & 72732 & 8375 & 15583 & 1527 & 28 & 3.38 & 3.30 & 1.96 & 0.70 & 0.60 & 0.41 & 0.041 & 0.060 & 0.063 \\
\hline
\end{tabular}


TABELA 11 - VARIAÇĀO TEMPORAL DA RIQUEZA DE ESPÉCIES DO FITOPLÂNCTON DA REPRESA DE GUARAPIRANGA 1991-92. PONTO 1.

Identificação da coleta (ID); número de espécies.coleta ${ }^{-1}$ : bacilarioficeas (SB); centrales (SC); penales (SP); clorococales (SCHC); volvocales (SVOL); cloroficeas (SCHL); crisoficeas (SCHR); cianoficeas (SCY); dinoficeas (SDI); euglenoficeas (SEU); zignemaficeas (SZY).

\begin{tabular}{|c|c|c|c|c|c|c|c|c|c|c|c|c|}
\hline ID & SB & SC & SP & SCHC & SVOL & SCHL & SCHR & SCR & SCY & SDI & SEU & SZY \\
\hline MA2 & 3 & 1 & 2 & 10 & 2 & 12 & 2 & 0 & 1 & 0 & 0 & 6 \\
\hline $\mathrm{MA3}$ & 3 & 1 & 2 & 11 & 2 & 13 & 0 & 1 & 1 & 0 & 1 & 3 \\
\hline MA4 & 3 & 1 & 2 & 8 & 3 & 11 & 0 & 0 & 0 & 0 & 1 & 1 \\
\hline 15 & 4 & 1 & 3 & 13 & 3 & 16 & 1 & 1 & 1 & 0 & 0 & 4 \\
\hline 16 & 5 & 1 & 4 & 11 & 2 & 13 & 2 & 1 & 1 & 0 & 2 & 4 \\
\hline 57 & 3 & 1 & 2 & 10 & 1 & 11 & 1 & 1 & 1 & 0 & 1 & 2 \\
\hline Л8 & 5 & 2 & 3 & 4 & 3 & 7 & 1 & 0 & 0 & 0 & 2 & 1 \\
\hline JL9 & 2 & 0 & 2 & 3 & 1 & 4 & 0 & 3 & 0 & 0 & 0 & 0 \\
\hline JL10 & 1 & 0 & 1 & 4 & 2 & 6 & 0 & 1 & 0 & 0 & 2 & 0 \\
\hline JL11 & 0 & 0 & 0 & 0 & 3 & 3 & 2 & 2 & 0 & 0 & 1 & 0 \\
\hline JL12 & 4 & 1 & 3 & 7 & 2 & 9 & 0 & 2 & 0 & 0 & 0 & 0 \\
\hline$A G 13$ & 6 & 2 & 4 & 12 & 4 & 16 & 2 & 1 & 0 & 0 & 1 & 1 \\
\hline AG14 & 6 & 2 & 4 & 4 & 2 & 6 & 0 & 3 & 0 & 1 & 2 & 1 \\
\hline AG15 & 3 & 1 & 2 & 5 & 2 & 7 & 0 & 0 & 1 & 0 & 1 & 0 \\
\hline AGI6 & 3 & 1 & 2 & 18 & 4 & 22 & 0 & 1 & 1 & 0 & 2 & 1 \\
\hline$\$ 17$ & 1 & 0 & 1 & 4 & 3 & 7 & 1 & 2 & 1 & 0 & 0 & 1 \\
\hline S18 & 3 & 2 & 1 & 8 & 2 & 10 & 1 & 2 & 0 & 0 & 0 & 0 \\
\hline S19 & 3 & 2 & 1 & 7 & 3 & 10 & 3 & 1 & 1 & 1 & 1 & 1 \\
\hline$\$ 20$ & 4 & 3 & 1 & 6 & 3 & 9 & 2 & 1 & 1 & 0 & 0 & 0 \\
\hline $\mathrm{O} 21$ & 3 & 2 & 1 & 5 & 2 & 7 & 0 & 0 & 1 & 0 & 0 & 0 \\
\hline $\mathrm{O} 22$ & 3 & 2 & $i$ & 5 & 1 & 6 & 1 & 1 & 1 & 0 & 1 & 0 \\
\hline $\mathrm{O} 23$ & 2 & 0 & 2 & 5 & 0 & 5 & 0 & 0 & 0 & 1 & 0 & 1 \\
\hline $\mathrm{O} 24$ & 1 & 0 & 1 & 6 & 1 & 7 & 1 & 1 & 0 & 0 & 1 & 1 \\
\hline 025 & 3 & 1 & 2 & 9 & 2 & 11 & 0 & 1 & 0 & 0 & 0 & 2 \\
\hline N26 & 2 & 1 & 1 & 14 & 3 & 17 & 0 & 2 & 1 & 0 & 0 & 0 \\
\hline N27 & 2 & 0 & 2 & 11 & 2 & 13 & 1 & 2 & 2 & 0 & 2 & 2 \\
\hline N28 & 2 & 0 & 2 & 10 & 2 & 12 & 0 & 1 & 2 & 0 & 1 & 1 \\
\hline N29 & 4 & 3 & 1 & 13 & 4 & 17 & 0 & 1 & 0 & 0 & 2 & 1 \\
\hline D30 & 3 & 1 & 2 & 8 & 0 & 8 & 0 & 1 & 1 & 0 & 3 & 1 \\
\hline D31 & 5 & 2 & 3 & 10 & 2 & 12 & 1 & 1 & 2 & 0 & 2 & 3 \\
\hline D32 & 1 & 0 & 1 & 5 & 0 & 5 & 1 & 1 & 0 & 0 & 1 & 2 \\
\hline D33 & 3 & 1 & 2 & 13 & 2 & 15 & 2 & 1 & 2 & 0 & 2 & 1 \\
\hline JA34 & 2 & 0 & 2 & 10 & 3 & 13 & 0 & 1 & 2 & 0 & 1 & 1 \\
\hline JA35 & 3 & 1 & 2 & 13 & 1 & 14 & 1 & 0 & 1 & 1 & 3 & 2 \\
\hline JA36 & 4 & 1 & 3 & 18 & 1 & 19 & 0 & 3 & 1 & $i$ & 3 & 4 \\
\hline JA37 & 4 & 1 & 3 & 16 & 1 & 17 & 0 & 3 & 1 & 0 & 0 & 2 \\
\hline F38 & 3 & 1 & 2 & 13 & 2 & 15 & 0 & 0 & 3 & 0 & 2 & 4 \\
\hline F39 & 2 & 0 & 2 & 19 & 1 & 20 & 0 & 0 & 2 & 1 & 0 & 5 \\
\hline F40 & 2 & 0 & 2 & 16 & 0 & 16 & 0 & 3 & 1 & 0 & 1 & 2 \\
\hline F41 & 2 & 0 & 2 & 16 & 1 & 17 & 1 & 1 & 0 & 0 & 3 & 4 \\
\hline MR42 & 2 & 0 & 2 & 11 & 3 & 14 & 0 & 0 & 1 & 0 & 1 & 2 \\
\hline MR43 & 2 & 0 & 2 & 15 & 0 & 15 & 0 & 0 & 4 & 0 & 0 & 3 \\
\hline MR44 & 2 & 0 & 2 & 19 & 2 & 21 & 1 & 0 & 3 & 0 & 0 & 5 \\
\hline $\mathrm{AB} 45$ & 3 & 1 & 2 & 18 & 4 & 22 & 0 & 2 & 4 & 0 & 1 & 4 \\
\hline $\mathrm{AB} 46$ & 2 & 0 & 2 & 17 & 2 & 19 & 0 & 0 & 3 & 0 & $i$ & 4 \\
\hline $\mathrm{AB} 47$ & 4 & 2 & 2 & 19 & 1 & 20 & 1 & 2 & 3 & 0 & 1 & 3 \\
\hline $\mathrm{AB} 48$ & 2 & 0 & 2 & 15 & 3 & 18 & 1 & 0 & 2 & 0 & 0 & 4 \\
\hline $\mathrm{AB} 49$ & 3 & 1 & 2 & 18 & 1 & 19 & 0 & 0 & 3 & 0 & 0 & 3 \\
\hline MASO & 3 & 0 & 3 & 14 & 2 & 16 & 1 & 0 & 3 & 0 & 1 & 4 \\
\hline MASI & 2 & 0 & 2 & 20 & 3 & 23 & 0 & 1 & 1 & 0 & 0 & 6 \\
\hline MAS3 & 3 & 1 & 2 & 13 & 2 & 15 & 0 & 1 & 1 & 0 & 0 & 2 \\
\hline J54 & 6 & 4 & 2 & 26 & 2 & 28 & 3 & 3 & 4 & 0 & 0 & 2 \\
\hline J55 & 6 & 3 & 3 & 20 & 2 & 22 & 1 & 2 & 2 & 0 & 3 & 2 \\
\hline J56 & 5 & 4 & 1 & 11 & 1 & 12 & 3 & 2 & 1 & 0 & 1 & 2 \\
\hline $\mathrm{J} 57$ & 4 & 4 & 0 & 12 & 0 & 12 & 0 & 1 & 3 & 0 & 2 & 2 \\
\hline JL58 & 4 & 2 & 2 & 13 & 1 & 14 & 1 & 0 & 5 & 0 & 1 & 3 \\
\hline
\end{tabular}

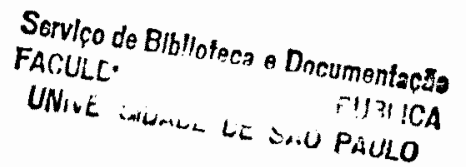


TABELA 12 - VARIAÇĀO TEMPORAL DAS CARACTERÍSTICAS DA COMUNIDADE FITOPLANCTÔNICA. REPRESA DE GUARAPIRANGA 1991-92: PONTO 4.

Identificação da coleta (ID); densidade em células. $\mathrm{ml}^{-1}$ (D); bioárea em UPA.ml ${ }^{-1}$ (BA); biovolume em $\mu \mathrm{m}^{3} \cdot \mathrm{ml}^{-1}$ (BV); maior dimensão linear - GALD. $\mathrm{l}^{-1}(\mathrm{G})$; número de táxons.amostra ${ }^{-1}$ (S); diversidade em bits.ml $\mathrm{l}^{-1}(\mathrm{H})$; uniformidade $(U)$ e taxa de alteração da comunidade entre coletas sucessivas - soma das diferenças entre amostras consecutivas.dia ${ }^{-1}$ (TA).

\begin{tabular}{|c|c|c|c|c|c|c|c|c|c|c|c|c|c|c|}
\hline ID & D & BA & BV & $\mathbf{G}$ & $\mathbf{S}$ & H'D & $\mathbf{H}^{\prime} \mathbf{B A}$ & H'BV & UD & LBA & UBV & TAD & TABA & TABV \\
\hline$\overline{M A 2}$ & 6519 & 4095 & 3722 & 273 & 14 & 2.48 & 2.09 & 2.16 & 0.60 & 0.55 & 0.57 & & & \\
\hline MA3 & 2278 & 1399 & 1202 & 69 & 15 & 3.27 & 3.04 & 3.20 & 0.80 & 0.78 & 0.82 & 0.194 & 0.163 & 0.204 \\
\hline MA4 & 2906 & 837 & 744 & 64 & 16 & 3.56 & 2.55 & 3.03 & 0.80 & 0.64 & 0.76 & 0.174 & 0.191 & 0.214 \\
\hline J5 & 3377 & 1112 & 922 & 72 & 13 & 3.24 & 2.90 & 2.88 & 0.80 & 0.78 & 0.78 & 0.162 & 0.130 & 0.173 \\
\hline J6 & 7697 & 3222 & 2884 & 212 & 25 & 3.90 & 3.50 & 3.66 & 0.80 & 0.75 & 0.79 & 0.094 & 0.146 & 0.181 \\
\hline 57 & 4477 & 1112 & 958 & 78 & 15 & 3.28 & 3.16 & 3.31 & 0.80 & 0.81 & 0.87 & 0.143 & 0.136 & 0.174 \\
\hline JL8 & 1728 & 349 & 691 & 17 & 9 & 2.83 & 3.03 & 2.61 & 0.80 & 0.96 & 0.82 & 0.209 & 0.191 & 0.224 \\
\hline JL9 & 1021 & 427 & 1249 & 17 & 9 & 3.03 & 2.34 & 1.72 & 0.90 & 0.74 & 0.54 & 0.177 & 0.177 & 0.196 \\
\hline JL10 & 1571 & 273 & 589 & 16 & 10 & 3.04 & 2.72 & 2.47 & 0.90 & 0.82 & 0.74 & 0.242 & 0.273 & 0.274 \\
\hline JL11 & 1335 & 494 & 1413 & 22 & 9 & 2.82 & 2.23 & 1.46 & 0.80 & 0.70 & 0.46 & 0.254 & 0.267 & 0.276 \\
\hline $\mathrm{JL12}$ & 1963 & 760 & 767 & 53 & 9 & 2.76 & 2.19 & 2.29 & 0.80 & 0.69 & 0.72 & 0.246 & 0.261 & 0.268 \\
\hline$A G 13$ & 6519 & 1660 & 3183 & 103 & 17 & 3.52 & 3.21 & 2.68 & 0.80 & 0.78 & 0.66 & 0.176 & 0.201 & 0.160 \\
\hline AG14 & 6519 & 2074 & 3663 & 133 & 18 & 3.77 & 3.33 & 3.02 & 0.90 & 0.80 & 0.72 & 0.172 & 0.150 & 0.261 \\
\hline AG15 & 1492 & 546 & 1442 & 26 & 13 & 3.54 & 2.74 & 2.05 & 0.90 & 0.74 & 0.55 & 0.276 & 0.268 & 0.135 \\
\hline AG16 & 1963 & 657 & 775 & 42 & 11 & 3.11 & 2.77 & 2.52 & 0.90 & 0.80 & 0.73 & 0.196 & 0.210 & 0.277 \\
\hline \$17 & 2278 & 865 & 2233 & 36 & 7 & 2.25 & 1.92 & 1.43 & 0.80 & 0.68 & 0.51 & 0.201 & 0.229 & 0.231 \\
\hline S18 & 3848 & 590 & 942 & 38 & 13 & 3.20 & 2.99 & 2.21 & 0.80 & 0.81 & 0.60 & 0.197 & 0.210 & 0.228 \\
\hline$\$ 19$ & 5812 & 2533 & 4744 & 139 & 15 & 3.38 & 2.69 & 2.24 & 0.80 & 0.69 & 0.57 & 0.183 & 0.230 & 0.242 \\
\hline S20 & 5027 & 1918 & 1836 & 128 & 12 & 3.03 & 2.26 & 2.55 & 0.80 & 0.63 & 0.71 & 0.171 & 0.183 & 0.236 \\
\hline 021 & 3063 & 1238 & 3561 & 55 & 16 & 3.53 & 3.07 & 2.69 & 0.80 & 0.77 & 0.67 & 0.195 & 0.229 & 0.255 \\
\hline $\mathrm{O} 22$ & 3220 & 1325 & 3110 & 75 & 16 & 3.63 & 2.65 & 1.55 & 0.90 & 0.66 & 0.39 & 0.165 & 0.146 & 0.134 \\
\hline 023 & 628 & 441 & 3679 & 15 & 8 & 3.00 & 1.65 & 0.30 & 1.00 & 0.55 & 0.10 & 0.216 & 0.234 & 0.281 \\
\hline $\mathrm{O} 24$ & 3142 & 1076 & 1529 & 62 & 13 & 3.38 & 2.85 & 2.42 & 0.90 & 0.77 & 0.65 & 0.200 & 0.224 & 0.278 \\
\hline 025 & 5498 & 1960 & 6943 & 98 & 18 & 3.53 & 2.56 & 1.21 & 0.80 & 0.61 & 0.29 & 0.218 & 0.233 & 0.377 \\
\hline N26 & 10446 & 3765 & 12396 & 149 & 16 & 2.65 & 2.74 & 2.47 & 0.60 & 0.68 & 0.62 & 0.361 & 0.370 & 0.216 \\
\hline N27 & 19871 & 5778 & 20496 & 241 & 19 & 2.50 & 2.36 & 2.22 & 0.50 & 0.56 & 0.53 & 0.107 & 0.100 & 0.124 \\
\hline N28 & 18221 & 5756 & 16650 & 266 & 30 & 3.22 & 2.96 & 2.29 & 0.60 & 0.60 & 0.47 & 0.122 & 0.097 & 0.111 \\
\hline N29 & 12488 & 5444 & 20229 & 176 & 23 & 3.04 & 2.78 & 2.44 & 0.60 & 0.61 & 0.54 & 0.097 & 0.139 & 0.149 \\
\hline D30 & 22777 & 7243 & 24170 & 315 & 19 & 2.49 & 2.36 & 2.07 & 0.50 & 0.56 & 0.49 & 0.194 & 0.224 & 0.231 \\
\hline D31 & 11153 & 2956 & 9245 & 139 & 20 & 3.10 & 2.53 & 2.09 & 0.70 & 0.59 & 0.48 & 0.144 & 0.121 & 0.114 \\
\hline D32 & 11231 & 3208 & 7474 & 183 & 24 & 3.21 & 3.18 & 2.62 & 0.70 & 0.69 & 0.57 & 0.199 & 0.201 & 0.271 \\
\hline D33 & 8011 & 1926 & 6093 & 111 & 22 & 3.36 & 3.14 & 2.79 & 0.70 & 0.70 & 0.63 & 0.286 & 0.272 & 0.075 \\
\hline JA34 & 10092 & 3318 & 3151 & 288 & 29 & 4.04 & 3.15 & 3.53 & 0.80 & 0.65 & 0.74 & 0.080 & 0.104 & 0.228 \\
\hline JA35 & 9896 & 2884 & 5854 & 140 & 29 & 3.95 & 3.62 & 3.18 & 0.80 & 0.75 & 0.65 & 0.208 & 0.213 & 0.194 \\
\hline JA36 & 3456 & 754 & 1540 & 40 & 16 & 3.51 & 3.27 & 3.01 & 0.80 & 0.82 & 0.75 & 0.229 & 0.266 & 0.276 \\
\hline JA37 & 24504 & 3479 & 7246 & 362 & 25 & 1.76 & 2.69 & 2.94 & 0.30 & 0.58 & 0.63 & 0.257 & 0.244 & 0.370 \\
\hline F38 & 7540 & 1548 & 3070 & 101 & 25 & 3.80 & 3.82 & 3.13 & 0.80 & 0.82 & 0.67 & 0.260 & 0.210 & 0.190 \\
\hline F39 & 9975 & 2008 & 5164 & 85 & 23 & 3.55 & 3.22 & 2.02 & 0.70 & 0.71 & 0.45 & 0.171 & 0.137 & 0.113 \\
\hline F40 & 24819 & 5074 & 16159 & 262 & 24 & 2.77 & 2.96 & 1.93 & 0.60 & 0.65 & 0.42 & 0.130 & 0.103 & 0.140 \\
\hline F41 & 10760 & 1069 & 1200 & 82 & 19 & 3.25 & 3.44 & 3.25 & 0.70 & 0.81 & 0.77 & 0.248 & 0.280 & 0.133 \\
\hline MR42 & 17514 & 4906 & 5893 & 383 & 20 & 3.09 & 2.06 & 2.98 & 0.70 & 0.48 & 0.70 & 0.100 & 0.124 & 0.244 \\
\hline $\mathrm{MR} 43$ & 6597 & 1835 & 5424 & 90 & 26 & 3.64 & 3.30 & 2.25 & 0.70 & 0.70 & 0.48 & 0.140 & 0.170 & 0.191 \\
\hline MR44 & 6048 & 1424 & 3285 & 69 & 24 & 3.98 & 3.11 & 1.80 & 0.80 & 0.68 & 0.40 & 0.135 & 0.143 & 0.138 \\
\hline $\mathrm{AB} 45$ & 11938 & 3106 & 8259 & 138 & 24 & 2.94 & 2.27 & 1.18 & 0.60 & 0.50 & 0.26 & 0.201 & 0.240 & 0.268 \\
\hline $\mathrm{AB} 46$ & 7226 & 1828 & 3521 & 94 & 28 & 3.95 & 3.54 & 2.10 & 0.80 & 0.74 & 0.44 & 0.209 & 0.241 & 0.313 \\
\hline $\mathrm{AB} 47$ & 13273 & 2476 & 3331 & 126 & 24 & 3.97 & 3.48 & 3.68 & 0.80 & 0.76 & 0.80 & 0.144 & 0.233 & 0.235 \\
\hline AB48 & 25761 & 4953 & 12648 & 264 & 28 & 3.26 & 3.13 & 2.53 & 0.60 & 0.65 & 0.53 & 0.154 & 0.151 & 0.195 \\
\hline $\mathrm{AB} 49$ & 23169 & 5227 & 10416 & 264 & 24 & 3.03 & 2.61 & 1.79 & 0.60 & 0.57 & 0.39 & 0.103 & 0.149 & 0.228 \\
\hline MASO & 11545 & 2514 & 4254 & 157 & 27 & 3.57 & 3.27 & 3.04 & 0.70 & 0.69 & 0.64 & 0.117 & 0.173 & 0.255 \\
\hline MASI & 26782 & 4385 & 5346 & 253 & 30 & 3.12 & 2.99 & 2.97 & 0.60 & 0.61 & 0.61 & 0.111 & 0.188 & 0.175 \\
\hline MAS3 & 21834 & 4377 & 6689 & 203 & 30 & 3.10 & 3.12 & 3.28 & 0.60 & 0.64 & 0.67 & 0.037 & 0.041 & 0.125 \\
\hline JS4 & 10289 & 2797 & 5104 & 143 & 23 & 3.80 & 3.39 & 2.24 & 0.80 & 0.75 & 0.49 & 0.137 & 0.173 & 0.193 \\
\hline J55 & 15394 & 2799 & 2803 & 184 & 26 & 3.67 & 3.40 & 3.84 & 0.70 & 0.72 & 0.82 & 0.158 & 0.206 & 0.232 \\
\hline 356 & 10210 & 2957 & 5933 & 194 & 18 & 3.01 & 2.44 & 2.38 & 0.70 & 0.59 & 0.57 & 0.160 & 0.211 & 0.253 \\
\hline $\mathrm{J} 57$ & 6597 & 1746 & 1923 & 108 & 22 & 3.15 & 2.79 & 3.49 & 0.70 & 0.62 & 0.78 & 0.183 & 0.209 & 0.221 \\
\hline JL58 & 35421 & 6809 & 8538 & 462 & 30 & 3.86 & 3.60 & 3.42 & 0.70 & 0.73 & 0.70 & 0.038 & 0.046 & 0.050 \\
\hline
\end{tabular}


TABELA 13 - VARIAÇÃO TEMPORAL DA RIQUEZA DE ESPÉCIES DO FITOPLÂNCTON DA REPRESA DE GUARAPIRANGA 1991-92. PONTO 4.

Identificação da coleta (ID); número de espécies.coleta': ${ }^{-1}$ bacilarioficeas (SB); centrales (SC); penales (SP); clorococales (SCHC); volvocales (SVOL); cloroficeas (SCHL); crisoficeas (SCHR); cianoficeas (SCY); dinoficeas (SDI); euglenoficeas (SEU); zignemaficeas (SZY).

\begin{tabular}{|c|c|c|c|c|c|c|c|c|c|c|c|c|}
\hline ID & $\mathbf{S B}$ & SC & SP & SCHC & SVOL & SCHL & SCHR & SCRY & SCY & SDI & SEU & SZY \\
\hline MA2 & 3 & 1 & 2 & 5 & 0 & 5 & 1 & 1 & 0 & 0 & 0 & 4 \\
\hline $\mathrm{MA3}$ & 3 & $i$ & 2 & 5 & 2 & 7 & 0 & 2 & 0 & 0 & 0 & 3 \\
\hline MA4 & 2 & 1 & 1 & 7 & 2 & 9 & 1 & 2 & 0 & 1 & 1 & 0 \\
\hline 15 & 2 & 1 & 1 & 4 & 1 & 5 & 0 & 2 & 1 & 0 & 1 & 2 \\
\hline J6 & 6 & 2 & 4 & 9 & 2 & 11 & 0 & 1 & 1 & 0 & 0 & 6 \\
\hline 37 & 3 & 1 & 2 & 7 & 1 & 8 & 0 & 2 & 1 & 0 & 0 & 1 \\
\hline JL8 & 1 & 0 & 1 & 4 & 1 & 5 & 0 & 2 & 0 & 0 & 1 & 0 \\
\hline Л 9 & 1 & 1 & 0 & 3 & 3 & 6 & 1 & 1 & 0 & 0 & 0 & 0 \\
\hline Л10 & 0 & 0 & 0 & 4 & 3 & 7 & 0 & 1 & 0 & 0 & 2 & 0 \\
\hline JL11 & 1 & 1 & 0 & 3 & 1 & 4 & 2 & 1 & 0 & 0 & 1 & 0 \\
\hline ЛL12 & 3 & 1 & 2 & 2 & 1 & 3 & 1 & 1 & 0 & 0 & 0 & 1 \\
\hline AG13 & 4 & 3 & 1 & 5 & 3 & 8 & 0 & 3 & 0 & 0 & 1 & 1 \\
\hline AG14 & 4 & 2 & 2 & 9 & 1 & 10 & 0 & 2 & 1 & 0 & 1 & 0 \\
\hline AG15 & 4 & 2 & 2 & 6 & 2 & 8 & 0 & 1 & 0 & 0 & 0 & 0 \\
\hline AGI6 & 1 & 0 & 1 & 3 & 1 & 4 & 1 & 3 & 0 & 0 & 0 & 2 \\
\hline S17 & 1 & 1 & 0 & 1 & 1 & 2 & 1 & 2 & 0 & 0 & 1 & 0 \\
\hline S18 & 1 & 0 & 1 & 4 & 2 & 6 & 3 & 3 & 0 & 0 & 0 & 0 \\
\hline S19 & 3 & 2 & 1 & 5 & 4 & 9 & 2 & 1 & 0 & 0 & 0 & 0 \\
\hline$\$ 20$ & 2 & 1 & 1 & 4 & 2 & 6 & 2 & 2 & 0 & 0 & 0 & 0 \\
\hline O21 & 3 & 2 & $i$ & 6 & 3 & 9 & 2 & 1 & 0 & 0 & 1 & 0 \\
\hline $\mathrm{O} 22$ & 6 & 4 & 2 & 5 & 2 & 7 & 0 & 2 & 0 & 1 & 0 & 0 \\
\hline $\mathrm{O} 23$ & 1 & 1 & 0 & 2 & 2 & 4 & 0 & 1 & 0 & 2 & 0 & 0 \\
\hline 024 & 2 & 1 & 1 & 5 & 3 & 8 & 0 & 1 & 0 & 0 & 1 & I \\
\hline 025 & 3 & 2 & 1 & 6 & 7 & 13 & 2 & 0 & 0 & 0 & 0 & 0 \\
\hline N26 & 4 & 3 & 1 & 6 & 1 & 7 & 0 & 1 & 1 & 1 & 1 & 1 \\
\hline N27 & 1 & 1 & 0 & 8 & 4 & 12 & 1 & 2 & 1 & 2 & 0 & 0 \\
\hline N28 & 6 & 3 & 3 & 17 & 2 & 19 & 2 & 1 & 1 & 1 & 0 & 0 \\
\hline N29 & 4 & 3 & 1 & 9 & 2 & 11 & 1 & 2 & 2 & 2 & 0 & 1 \\
\hline D30 & 2 & 1 & 1 & 8 & 1 & 9 & 1 & 2 & 2 & 1 & 1 & 1 \\
\hline D31 & 0 & 0 & 0 & 6 & 4 & 10 & 2 & 1 & 3 & 2 & 0 & 2 \\
\hline D32 & 5 & 2 & 3 & 8 & 2 & 10 & 0 & 1 & 2 & 1 & 1 & 4 \\
\hline D33 & 2 & 2 & 0 & 6 & 3 & 9 & 1 & 2 & 3 & 1 & 3 & 1 \\
\hline JA34 & 5 & 2 & 3 & 12 & 3 & 15 & 2 & 1 & 2 & 0 & 1 & 3 \\
\hline JA35 & 3 & 1 & 2 & 9 & 3 & 12 & 2 & 2 & 2 & 2 & 3 & 3 \\
\hline JA36 & 3 & 2 & 1 & 6 & 2 & 8 & 0 & 1 & 2 & 2 & 0 & 0 \\
\hline JA37 & 3 & 1 & 2 & 11 & 3 & 14 & 1 & 2 & 1 & 3 & 0 & 1 \\
\hline F38 & 3 & 2 & 1 & 12 & 2 & 14 & 0 & 2 & $i$ & 3 & 0 & 1 \\
\hline F39 & 3 & 3 & 0 & 7 & 5 & 12 & 1 & 2 & 2 & 1 & 1 & 1 \\
\hline F40 & 2 & 0 & 2 & 8 & 3 & 11 & 1 & 2 & 2 & 2 & 3 & 1 \\
\hline F41 & 2 & 1 & 1 & 7 & 3 & 10 & 1 & 2 & 3 & 0 & 0 & 1 \\
\hline MR42 & 3 & 1 & 2 & 7 & 2 & 9 & 0 & 1 & 2 & 2 & 0 & 3 \\
\hline MR43 & 5 & 3 & 2 & 10 & 2 & 12 & 1 & 0 & 2 & 3 & 2 & 1 \\
\hline MR44 & 2 & $i$ & 1 & 7 & 3 & 10 & 2 & 2 & 3 & 1 & 3 & 1 \\
\hline $\mathrm{AB} 45$ & $\overrightarrow{1}$ & $i$ & 0 & 11 & 2 & 13 & 2 & 1 & 2 & 0 & 2 & 3 \\
\hline $\mathrm{AB} 46$ & 2 & 1 & 1 & 9 & 4 & 13 & 3 & 3 & 2 & 1 & 0 & 4 \\
\hline $\mathrm{AB47}$ & 1 & 0 & 1 & 12 & 4 & 16 & 0 & 2 & 1 & 0 & 3 & 1 \\
\hline $\mathrm{AB} 48$ & 3 & 2 & 1 & 9 & 5 & 14 & 1 & 1 & 4 & 0 & 2 & 3 \\
\hline $\mathrm{AB} 49$ & 4 & 3 & 1 & 12 & 2 & 14 & $i$ & 1 & 2 & 0 & 1 & 1 \\
\hline MA50 & 5 & 3 & 2 & 12 & 3 & 15 & $i$ & 2 & 1 & 1 & 0 & 2 \\
\hline MASI & 3 & 2 & 1 & 15 & 1 & 16 & 1 & 2 & 4 & 0 & 2 & 2 \\
\hline MAS3 & 4 & 3 & 1 & 15 & 1 & 16 & 1 & 2 & 3 & 1 & 1 & 2 \\
\hline J54 & 8 & 5 & 3 & 11 & 2 & 13 & 0 & 1 & 0 & 0 & 0 & 1 \\
\hline J55 & 3 & 3 & 0 & 9 & 5 & 14 & 2 & 2 & 1 & 1 & 1 & 2 \\
\hline J56 & 5 & 5 & 0 & 4 & 3 & 7 & 1 & 1 & 1 & 1 & 2 & 0 \\
\hline J57 & 4 & 3 & 1 & 10 & 2 & 12 & $i$ & 2 & 0 & 0 & 1 & 2 \\
\hline ЛL58 & 4 & 3 & 1 & 17 & 2 & 19 & 0 & 2 & 3 & 0 & 1 & 1 \\
\hline
\end{tabular}


TABELA 14 - VARIAÇĀO TEMPORAL DA DENSIDADE DO FITOPLÂNCTON. REPRESA DE GUARAPIRANGA, 1991-92: PONTO 1.

Identificação da coleta (ID); densidade em células.ml' ${ }^{-1}$ : densidade total(D); de centrales (DC); penales (DP); clorococales (DCHC); volvocales (DVOL); crisoficeas (DCHR); criptoficeas (DCRY); cianoficeas (DCY); dinoficeas (DDI); euglenoficeas (DEU); zignemaficeas (DZY).

\begin{tabular}{|c|c|c|c|c|c|c|c|c|c|c|c|}
\hline ID & D & DC & DP & DCHC & DVOL & DCHR & DCRY & DCY & DDI & DEU & DZY \\
\hline MA2 & 16026 & 2199 & 5184 & 5656 & 472 & 236 & 0 & 1414 & 0 & 0 & 865 \\
\hline MA3 & 9976 & 2827 & 2278 & 3379 & 157 & 0 & 79 & 550 & 0 & 79 & 628 \\
\hline MA4 & 6440 & 550 & 2356 & 2670 & 707 & 0 & 0 & 0 & 0 & 79 & 79 \\
\hline 15 & 14768 & 1806 & 3456 & 5185 & 1963 & 79 & 158 & 1100 & 0 & 0 & 1022 \\
\hline$J 6$ & 10291 & 864 & 3848 & 3850 & 393 & 157 & 79 & 236 & 0 & 314 & 550 \\
\hline 57 & 9819 & 550 & 5105 & 2593 & 942 & 79 & 79 & 236 & 0 & 79 & 157 \\
\hline IL8 & 3379 & 236 & 1571 & 786 & 315 & 79 & 0 & 0 & 0 & 314 & 79 \\
\hline JL9 & 1258 & 0 & 472 & 236 & 79 & 0 & 472 & 0 & 0 & 0 & 0 \\
\hline J10 & 1573 & 0 & 79 & 708 & 472 & 0 & 79 & 0 & 0 & 236 & 0 \\
\hline Л11 & 944 & 0 & 0 & 0 & 315 & 236 & 314 & 0 & 0 & 79 & 0 \\
\hline Л12 & 2595 & 158 & 630 & 1022 & 314 & 0 & 472 & 0 & 0 & 0 & 0 \\
\hline AG13 & 8799 & 1885 & 2592 & 2593 & 865 & 314 & 314 & 0 & 0 & 158 & 79 \\
\hline AG14 & 5896 & 472 & 2121 & 708 & 1414 & 0 & 473 & 0 & 236 & 236 & 236 \\
\hline AG15 & 2435 & 236 & 864 & 707 & 471 & 0 & 0 & 79 & 0 & 79 & 0 \\
\hline AGI6 & 12727 & 471 & 1728 & 6048 & 3221 & 0 & 628 & 236 & 0 & 236 & 158 \\
\hline S17 & 2044 & 0 & 79 & 473 & 1100 & 79 & 157 & 79 & 0 & 0 & 79 \\
\hline S18 & 11702 & 707 & 79 & 1178 & 1492 & 7461 & 785 & 0 & 0 & 0 & 0 \\
\hline$\$ 19$ & 5423 & 629 & 158 & 1258 & 1963 & 942 & 79 & 158 & 79 & 79 & 79 \\
\hline S20 & 4008 & 707 & 1021 & 1022 & 629 & 236 & 158 & 236 & 0 & 0 & 0 \\
\hline 021 & 2515 & 785 & 314 & 944 & 393 & 0 & 0 & 79 & 0 & 0 & 0 \\
\hline 022 & 2593 & 629 & 471 & 393 & 393 & 79 & 314 & 236 & 0 & 79 & 0 \\
\hline 023 & 4006 & 0 & 550 & 3299 & 0 & 0 & 0 & 0 & 79 & 0 & 79 \\
\hline $\mathrm{O} 24$ & 12018 & 0 & 158 & 4242 & 79 & 79 & 2042 & 0 & 0 & 79 & 5341 \\
\hline 025 & 4949 & 393 & 236 & 2278 & 157 & 0 & 1571 & 0 & 0 & 0 & 314 \\
\hline N26 & 11001 & 158 & 79 & 9821 & 315 & 0 & 314 & 314 & 0 & 0 & 0 \\
\hline $\mathrm{N} 27$ & 21366 & 0 & 236 & 18852 & 157 & 79 & 550 & 942 & 0 & 393 & 157 \\
\hline N28 & 25449 & 0 & 236 & 22150 & 550 & 0 & 550 & 1806 & 0 & 79 & 79 \\
\hline N29 & 15476 & 394 & 158 & 12725 & 471 & 0 & 79 & 0 & 0 & 550 & 1100 \\
\hline D30 & 10920 & 236 & 550 & 9034 & 0 & 0 & 471 & 158 & 0 & 393 & 79 \\
\hline D31 & 13513 & 157 & 786 & 7698 & 550 & 79 & 158 & 1178 & 0 & 550 & 2357 \\
\hline D32 & 9426 & 0 & 79 & 8484 & 0 & 79 & 393 & 0 & 0 & 236 & 157 \\
\hline D 33 & 27651 & 79 & 157 & 8722 & 550 & 157 & 79 & 14923 & 0 & 236 & 2749 \\
\hline JA34 & 8879 & 0 & 3534 & 3379 & 786 & 0 & 158 & 785 & 0 & 79 & 158 \\
\hline JA35 & 10057 & 79 & 3220 & 2673 & 236 & 79 & 0 & 471 & 158 & 315 & 2827 \\
\hline JA36 & 19875 & 79 & 1571 & 7226 & 158 & 0 & 472 & 707 & 158 & 1179 & 8326 \\
\hline JA37 & 26786 & 79 & 3064 & 5501 & 79 & 0 & 236 & 236 & 0 & 0 & 17593 \\
\hline F38 & 39038 & 471 & 2200 & 7464 & 157 & 0 & 0 & 1178 & 0 & 157 & 27410 \\
\hline F39 & 72265 & 0 & 1572 & 17833 & 471 & 0 & 0 & 1257 & 158 & 0 & 50974 \\
\hline F40 & 81451 & 0 & 550 & 63697 & 0 & 0 & 473 & 471 & 0 & 158 & 16101 \\
\hline F41 & 58522 & 0 & 628 & 28279 & 158 & 158 & 79 & 0 & 0 & 1257 & 27962 \\
\hline MR42 & 27967 & 0 & 1571 & 17362 & 1807 & 0 & 0 & 158 & 0 & 158 & 6912 \\
\hline MR43 & 36131 & 0 & 5655 & 13118 & 0 & 0 & 0 & 1257 & 0 & 0 & 16101 \\
\hline MR44 & 35425 & 0 & 7854 & 18066 & 707 & 79 & 0 & 1649 & 0 & 0 & 7069 \\
\hline $\mathrm{AB} 45$ & 25922 & 158 & 2827 & 10604 & 393 & 0 & 157 & 4477 & 0 & 158 & 7148 \\
\hline AB46 & 36445 & 0 & 1885 & 26392 & 393 & 0 & 0 & 2042 & 0 & 79 & 5655 \\
\hline $\mathrm{AB} 47$ & 40300 & 472 & 1257 & 23569 & 2199 & 158 & 472 & 6283 & 0 & 314 & 5576 \\
\hline $\mathrm{AB} 48$ & 48311 & 0 & 472 & 38490 & 1100 & 79 & 0 & 5969 & 0 & 0 & 2201 \\
\hline $\mathrm{AB} 49$ & 122607 & 158 & 628 & 81607 & 314 & 0 & 0 & 33773 & 0 & 0 & 6127 \\
\hline MASO & 75955 & 0 & 1179 & 37781 & 4242 & 158 & 0 & 28746 & 0 & 314 & 3535 \\
\hline MASI & 82004 & 0 & 1414 & 47680 & 1021 & 0 & 158 & 21677 & 0 & 0 & 10055 \\
\hline MA53 & 36368 & 158 & 472 & 32674 & 1257 & 0 & 79 & 1257 & 0 & 0 & 472 \\
\hline $\mathrm{J} 54$ & 11930 & 287 & 215 & 9673 & 54 & 54 & 681 & 645 & 0 & 0 & 322 \\
\hline J55 & 21453 & 3221 & 786 & 14615 & 629 & 158 & 707 & 316 & 0 & 630 & 393 \\
\hline J56 & 12099 & 2749 & 158 & 5343 & 471 & 472 & 942 & 236 & 0 & 236 & 1492 \\
\hline $\mathrm{J} 57$ & 11314 & 3379 & 0 & 4555 & 0 & 0 & 79 & 2829 & 0 & 316 & 157 \\
\hline ЛL58 & 72732 & 1100 & 1257 & 34559 & 158 & 471 & 0 & 31888 & 0 & 471 & 2829 \\
\hline
\end{tabular}


TABELA 15 VARIAÇÃO TEMPORAL DAS ESTRATÉGLAS ADAPTATIVAS EM DENSIDADE. 'REPRESA DE GUARAPIRANGA 1991-92. PONTO 1.

Identificação da coleta (ID); densidade em células. $\mathrm{ml}^{-1}$ de organismos: com motilidade (CM); sem motilidade (SM); sem envoltório rígido (SER); com envoltório rígido (CER); da Classe 1 (C1); da Classe 2 (C2); da Classe 3 (C3); da Classe 4 (C4); nano-fitoplâncton (NA); micro-fitoplâncton (MI); macrofitoplâncton (MA); formas coloniais ou cenobiais (COL); filamentosas (FIL) e unicelulares (UNI).

\begin{tabular}{|c|c|c|c|c|c|c|c|c|c|c|c|c|c|c|}
\hline ID & $\mathbf{C M}$ & SM & SER & CER & Cl & $\mathrm{C} 2$ & $\mathrm{C3}$ & $\mathrm{CA}$ & NA & MI & $\mathbf{M A}$ & COL & FIL & UNI \\
\hline$\overline{\mathrm{MA} 2}$ & 708 & 15317 & 8407 & 7619 & 6834 & 8642 & 471 & 79 & 12334 & 3691 & 0 & 4007 & 157 & 11862 \\
\hline MA3 & 314 & 9662 & 4793 & 5184 & 4635 & 4556 & 628 & 157 & 6206 & 3691 & 79 & 2436 & 0 & 7540 \\
\hline MA4 & 785 & 5655 & 3456 & 2985 & 2356 & 3377 & 707 & 0 & 5027 & 1021 & 393 & 2513 & 79 & 3848 \\
\hline J5 & 2200 & 12569 & 9428 & 5341 & 5027 & 7148 & 1336 & 1257 & 10055 & 4400 & 314 & 6206 & 550 & 8013 \\
\hline 36 & 1021 & 9270 & 5107 & 5184 & 4949 & 4714 & 550 & 79 & 8013 & 2199 & 79 & 3456 & 236 & 6600 \\
\hline $\mathrm{J7}$ & 1178 & 8641 & 4007 & 5812 & 6362 & 2827 & 315 & 314 & 8561 & 1257 & 0 & 3378 & 0 & 6441 \\
\hline ЛL8 & 708 & 2672 & 1415 & 1964 & 2121 & 630 & 550 & 79 & 2672 & 629 & 79 & 472 & 158 & 2750 \\
\hline JL9 & 550 & 708 & 786 & 472 & 550 & 629 & 79 & 0 & 944 & 314 & 0 & 550 & 0 & 708 \\
\hline JL10 & 787 & 786 & 1258 & 315 & 393 & 865 & 157 & 158 & 1257 & 316 & 0 & 708 & 0 & 865 \\
\hline JL11 & 944 & 0 & 629 & 315 & 393 & 551 & 0 & 0 & 944 & 0 & 0 & 0 & 0 & 944 \\
\hline JL12 & 786 & 1809 & 1808 & 788 & 1101 & 1100 & 394 & 0 & 1729 & 866 & 0 & 1179 & 158 & 1259 \\
\hline AG13 & 1651 & 7149 & 3851 & 4949 & 1965 & 6441 & 393 & 0 & 3851 & 4870 & 79 & 3536 & 785 & 4478 \\
\hline AG14 & 2359 & 3536 & 3067 & 2829 & 1180 & 4400 & 315 & 0 & 3302 & 2515 & 79 & 2279 & 158 & 3459 \\
\hline AG15 & 550 & 1885 & 1335 & 1100 & 1021 & 1100 & 314 & 0 & 1728 & 707 & 0 & 707 & 0 & 1728 \\
\hline AGI6 & 4086 & 8641 & 10291 & 2435 & 7699 & 4477 & 550 & 0 & 11470 & 1257 & 0 & 4477 & 79 & 8171 \\
\hline $\mathrm{S} 17$ & 1336 & 708 & 1887 & 157 & 945 & 1100 & 0 & 0 & 2044 & 0 & 0 & 315 & 0 & 1729 \\
\hline S18 & 9739 & 1963 & 3456 & 8247 & 1963 & 9582 & 157 & 0 & 3613 & 8090 & 0 & 8325 & 0 & 3377 \\
\hline S19 & 3299 & 2123 & 3615 & 1808 & 1258 & 3928 & 236 & 0 & 4245 & 1178 & 0 & 1966 & 79 & 3379 \\
\hline S20 & 1023 & 2985 & 2044 & 1964 & 1337 & 2279 & 393 & 0 & 2123 & 1886 & 0 & 1807 & 472 & 1729 \\
\hline 021 & 393 & 2122 & 1416 & 1100 & 552 & 864 & 1100 & 0 & 1337 & 1178 & 0 & 1100 & 471 & 944 \\
\hline $\mathrm{O} 22$ & 864 & 1729 & 1335 & 1257 & 628 & 1807 & 157 & 0 & 1414 & 1178 & 0 & 785 & 0 & 1807 \\
\hline $\mathrm{O} 23$ & 79 & 3928 & 3456 & 550 & 2121 & 1886 & 0 & 0 & 3848 & 158 & 0 & 1178 & 0 & 2828 \\
\hline 024 & 2278 & 9740 & 11703 & 315 & 6049 & 2278 & 157 & 3534 & 8484 & 3534 & 0 & 4006 & 5341 & 2672 \\
\hline 025 & 1728 & 3222 & 4320 & 629 & 1022 & 2356 & 158 & 1414 & 2986 & 1963 & 0 & 1729 & 628 & 2593 \\
\hline N26 & 629 & 10372 & 10764 & 236 & 1415 & 4244 & 236 & 5105 & 5581 & 5420 & 0 & 8642 & 0 & 2358 \\
\hline $\mathrm{N} 27$ & 1257 & 20109 & 20737 & 629 & 1651 & 865 & 1650 & 17200 & 2751 & 18615 & 0 & 18694 & 158 & 2514 \\
\hline N28 & 1178 & 24271 & 25134 & 315 & 1651 & 2278 & 236 & 21284 & 4086 & 21363 & 0 & 22934 & 0 & 2515 \\
\hline N29 & 1100 & 14376 & 14374 & 1102 & 1963 & 1651 & 1494 & 10367 & 3614 & 11862 & 0 & 12333 & 1336 & 1807 \\
\hline D30 & 864 & 10056 & 9820 & 1100 & 708 & 1964 & 1414 & 6834 & 2672 & 8248 & 0 & 9034 & 0 & 1886 \\
\hline D31 & 1337 & 12176 & 11941 & 1572 & 4556 & 2359 & 1100 & 5498 & 6679 & 6834 & 0 & 7227 & 2593 & 3694 \\
\hline D32 & 707 & 8719 & 9034 & 393 & 629 & 1100 & 79 & 7618 & 1414 & 8012 & 0 & 7697 & 79 & 1651 \\
\hline D33 & 1100 & 26551 & 27180 & 471 & 3614 & 4952 & 1729 & 17357 & 8566 & 19085 & 0 & 23093 & 2749 & 1809 \\
\hline JA34 & 1022 & 7857 & 5266 & 3613 & 2358 & 5108 & 157 & 1257 & 4245 & 4635 & 0 & 2593 & 393 & 5893 \\
\hline JA35 & 787 & 9270 & 6443 & 3614 & 2670 & 4243 & 3064 & 79 & 7465 & 2592 & 0 & 786 & 3142 & 6129 \\
\hline JA36 & 2202 & 17673 & 17047 & 2828 & 11702 & 6679 & 708 & 785 & 17833 & 2042 & 0 & 3770 & 9268 & 6837 \\
\hline JA37 & 1963 & 24822 & 23643 & 3142 & 23014 & 3536 & 157 & 79 & 24585 & 2201 & 0 & 2278 & 18457 & 6050 \\
\hline F38 & 314 & 38724 & 36210 & 2828 & 33851 & 4558 & 628 & 0 & 38330 & 708 & 0 & 3064 & 27253 & 8720 \\
\hline F39 & 629 & 71636 & 70693 & 1572 & 58437 & 10450 & 2985 & 393 & 70927 & 1338 & 0 & 6835 & 53093 & 12337 \\
\hline $\mathrm{F} 40$ & 631 & 80820 & 80742 & 708 & 70766 & 5422 & 79 & 5184 & 75637 & 5813 & 0 & 11075 & 15866 & 54510 \\
\hline$F 41$ & 1651 & 56870 & 56478 & 2043 & 51288 & 7076 & 158 & 0 & 57263 & 1258 & 0 & 4009 & 27489 & 27023 \\
\hline MR42 & 1965 & 26002 & 26239 & 1729 & 22545 & 5423 & 0 & 0 & 26317 & 1651 & 0 & 5030 & 6833 & 16104 \\
\hline MR43 & 0 & 36131 & 30476 & 5655 & 27961 & 8013 & 157 & 0 & 33853 & 2278 & 0 & 6285 & 15944 & 13902 \\
\hline MR44 & 785 & 34639 & 27492 & 7933 & 24348 & 11076 & 0 & 0 & 30319 & 5105 & 0 & 6834 & 7461 & 21130 \\
\hline $\mathrm{AB45}$ & 708 & 25213 & 22779 & 3143 & 18223 & 7383 & 236 & 79 & 24507 & 1414 & 0 & 5891 & 9974 & 10056 \\
\hline AB46 & 471 & 35973 & 34481 & 1963 & 25840 & 10604 & 0 & 0 & 33617 & 2827 & 0 & 11311 & 5027 & 20107 \\
\hline$A B 47$ & 3143 & 37157 & 38100 & 2201 & 25449 & 13122 & 1729 & 0 & 38335 & 1965 & 0 & 15869 & 9740 & 14691 \\
\hline $\mathrm{AB} 48$ & 1179 & 47132 & 47760 & 550 & 29220 & 18775 & 316 & 0 & 46187 & 2123 & 0 & 19404 & 6440 & 22466 \\
\hline $\mathrm{AB} 49$ & 314 & 122293 & 121821 & 786 & 87573 & 32992 & 0 & 2042 & 118364 & 4243 & 0 & 34953 & 37700 & 49954 \\
\hline MA50 & 4792 & 71162 & 74304 & 1651 & 52782 & 22937 & 236 & 0 & 74539 & 1416 & 0 & 21836 & 30159 & 23959 \\
\hline MA51 & 1179 & 80826 & 80591 & 1414 & 55688 & 26080 & 79 & 158 & 79410 & 2594 & 0 & 26629 & 30788 & 24587 \\
\hline MA53 & 1336 & 35032 & 35739 & 630 & 16418 & 19872 & 0 & 79 & 34640 & 1729 & 0 & 21678 & 314 & 14376 \\
\hline J54 & 788 & 11142 & 11375 & 555 & 4424 & 6968 & 412 & 125 & 11124 & 806 & 0 & 6843 & 896 & 4192 \\
\hline$J 55$ & 2123 & 19330 & 16817 & 4636 & 7624 & 13277 & 394 & 158 & 16737 & 4638 & 79 & 8881 & 236 & 12335 \\
\hline$J 56$ & 2121 & 9977 & 8484 & 3614 & 5733 & 5893 & 236 & 236 & 9192 & 2749 & 158 & 2828 & 1492 & 7778 \\
\hline $\mathrm{J} 57$ & 394 & 10920 & 7620 & 3694 & 4871 & 4950 & 393 & 1100 & 6995 & 4320 & 0 & 2906 & 3065 & 5344 \\
\hline JL58 & 1100 & 71632 & 69434 & 3299 & 52939 & 9897 & 628 & 9268 & 60793 & 11939 & 0 & 17594 & 33615 & 21523 \\
\hline
\end{tabular}


TABELA 16 - VARIAÇÃO TEMPORAL DO BIOVOLUME DO FITOPLÂNCTON. REPRESA DE GUARAPIRANGA, 1991-92: PONTO 1

Identificação da coleta (ID); biovolume em $\mu \mathrm{m}^{3} . \mathrm{I}^{-1}$ da amostra (BV); de centrales (BC); de penales (BP); de clorococales (BCHC); de volvocales (BVO); de crisoficeas (BCHR); de criptoficeas (BCRY); de cianoficeas (BCY); de euglenoficeas (BEU); de zignemaficeas (BZY).

\begin{tabular}{|c|c|c|c|c|c|c|c|c|c|c|c|}
\hline ID & BV & BC & $\mathbf{B P}$ & $\mathrm{BCHC}$ & BVo & BCHR & BCRY & BCY & BDI & BEU & BZY \\
\hline MA2 & 4418 & 729 & 245 & 954 & 116 & 51 & 0 & 1626 & 0 & 0 & 697 \\
\hline MA3 & 2900 & 937 & 184 & 640 & 294 & 0 & 7 & 40 & 0 & 46 & 751 \\
\hline MA4 & 3224 & 182 & 628 & .775 & 1564 & 0 & 0 & 0 & 0 & 46 & 29 \\
\hline $\mathrm{J} 5$ & 6146 & 598 & 572 & 2442 & 726 & 54 & 15 & 1265 & 0 & 0 & 475 \\
\hline J6 & 2262 & 286 & 253 & 990 & 69 & 39 & 7 & 0 & 0 & 100 & 518 \\
\hline J7 & 1901 & 182 & 171 & 992 & 11 & 21 & 7 & 271 & 0 & 18 & 228 \\
\hline JLB & 3959 & 1202 & 167 & 34 & 2077 & 54 & 0 & 0 & 0 & 304 & 120 \\
\hline JLO & 552 & 0 & 213 & 189 & 46 & 0 & 103 & 0 & 0 & 0 & 0 \\
\hline JL10 & 4519 & 0 & 3 & 220 & 4170 & 0 & 1 & 0 & 0 & 126 & 0 \\
\hline JL11 & 276 & 0 & 0 & 0 & 101 & 60 & 68 & 0 & 0 & 46 & 0 \\
\hline JL12 & 2104 & 1176 & 231 & 525 & 140 & 0 & 32 & 0 & 0 & 0 & 0 \\
\hline$A G 13$ & 3925 & 885 & 1686 & 664 & 344 & 107 & 29 & 0 & 0 & 182 & 29 \\
\hline AG14 & 3885 & 1280 & 1175 & 156 & 651 & 0 & 110 & 0 & 113 & 207 & 193 \\
\hline AG15 & 1257 & 78 & 275 & 485 & 232 & 0 & 0 & 0 & 0 & 186 & 0 \\
\hline AG16 & 3147 & 156 & 62 & 1670 & 865 & 0 & 10 & 271 & 0 & 111 & 0 \\
\hline S17 & 607 & 0 & 3 & 27 & 512 & 21 & 9 & 6 & 0 & 0 & 30 \\
\hline S18 & 6477 & 221 & 3 & 556 & 561 & 5100 & 37 & 0 & 0 & 0 & 0 \\
\hline $\mathbf{S 1 9}$ & 2494 & 182 & 3 & 648 & 980 & 571 & 7 & 12 & 38 & 46 & 8 \\
\hline S20 & 3844 & 2459 & 677 & 307 & 244 & 126 & 15 & 17 & 0 & 0 & 0 \\
\hline 021 & 5014 & 3617 & 208 & 1033 & 150 & 0 & 0 & 6 & 0 & 0 & 0 \\
\hline $\mathrm{O} 22$ & 1047 & 182 & 312 & 155 & 231 & 54 & 5 & 17 & 0 & 90 & 0 \\
\hline $\mathrm{O} 23$ & 589 & 0 & 31 & 504 & 0 & 0 & 0 & 0 & 38 & 0 & 17 \\
\hline O24 & 6091 & 0 & 5 & 4262 & 6 & 9 & 1203 & 0 & 0 & 90 & 516 \\
\hline 025 & 3260 & 260 & 14 & 2021 & 12 & 0 & 925 & 0 & 0 & 0 & 28 \\
\hline N26 & 7089 & 26 & 3 & 6867 & 25 & 0 & 146 & 23 & 0 & 0 & 0 \\
\hline N27 & 22646 & 0 & 24 & 21364 & 450 & 44 & 207 & 30 & 0 & 382 & 146 \\
\hline N28 & 32093 & 0 & 14 & 24658 & 6028 & 0 & 51 & 1266 & 0 & 46 & 29 \\
\hline N29 & 23166 & 1242 & 105 & 19234 & 2240 & 0 & 1 & 0 & 0 & 239 & 106 \\
\hline D30 & 10181 & 39 & 24 & 9472 & 0 & 0 & 278 & 0 & 0 & 338 & 29 \\
\hline D31 & 8608 & 31 & 170 & 7581 & 122 & 14 & 93 & 4 & 0 & 182 & 410 \\
\hline D32 & 9319 & 0 & 9 & 8996 & 0 & 54 & 6 & 0 & 0 & 139 & 115 \\
\hline D33 & 26054 & 13 & 21 & 8201 & 81 & 86 & 1 & 17166 & 0 & 219 & 266 \\
\hline JA34 & 2640 & 0 & 374 & 1907 & 120 & 0 & 3 & 92 & 0 & 130 & 15 \\
\hline JA35 & 4639 & 27 & 305 & 676 & 139 & 10 & 0 & 7 & 76 & 414 & 2986 \\
\hline JA36 & 5293 & 27 & 106 & 3274 & 93 & 0 & 60 & 11 & 76 & 794 & 852 \\
\hline JA37 & 3334 & 27 & 135 & 1001 & 444 & 0 & 17 & 0 & 0 & 0 & 1709 \\
\hline F38 & 7417 & 3513 & 84 & 857 & 52 & 0 & 0 & 41 & 0 & 132 & 2737 \\
\hline F39 & 11065 & 0 & 64 & 3090 & 35 & 0 & 0 & 14 & 76 & 0 & 7787 \\
\hline $\mathrm{F} 40$ & 12799 & 0 & 31 & 11032 & 0 & 0 & 60 & 1 & 0 & 93 & 1583 \\
\hline $\mathrm{F} 41$ & 5217 & 0 & 53 & 1880 & 12 & 42 & 1 & 0 & 0 & 366 & 2863 \\
\hline MR42 & 2028 & 0 & 161 & 978 & 76 & 0 & 0 & 0 & 0 & 93 & 719 \\
\hline MR43 & 3548 & 0 & 338 & 1443 & 0 & 0 & 0 & 60 & 0 & 0 & 1707 \\
\hline MR44 & 2959 & 0 & 591 & 1524 & 28 & 10 & 0 & 20 & 0 & 0 & 786 \\
\hline$A B 45$ & 4905 & 4 & 130 & 1512 & 2002 & 0 & 93 & 175 & 0 & 182 & 808 \\
\hline $\mathrm{AB} 46$ & 2954 & 0 & 152 & 2044 & 24 & 0 & 0 & 44 & 0 & 46 & 645 \\
\hline$A B 47$ & 7602 & 2396 & 106 & 3741 & 25 & 131 & 20 & 67 & 0 & 361 & 755 \\
\hline$A B 48$ & 4616 & 0 & 41 & 3980 & 52 & 65 & 0 & 89 & 0 & 0 & 388 \\
\hline$A B 49$ & 9222 & 52 & 46 & 8150 & 23 & 0 & 0 & 172 & 0 & 0 & 779 \\
\hline MA5O & 5224 & 0 & 81 & 3877 & 302 & 42 & 0 & 60 & 0 & 185 & 677 \\
\hline MA51 & 6432 & 0 & 124 & 4839 & 61 & 0 & 93 & 36 & 0 & 0 & 1279 \\
\hline MA53 & 3667 & 54 & 41 & 3330 & 83 & 0 & 7 & 93 & 0 & 0 & 60 \\
\hline J54 & 4075 & 1354 & 11 & 2466 & 3 & 46 & 87 & 27 & 0 & 0 & 82 \\
\hline J55 & 4765 & 1120 & 142 & 2803 & 37 & 131 & 17 & 12 & 0 . & 399 & 103 \\
\hline J56 & 2808 & 889 & 227 & 944 & 5 & 99 & 33 & 271 & 0 & 139 & 201 \\
\hline J57 & 3637 & 1330 & 0 & 1324 & 0 & 0 & 7 & 552 & 0 & 274 & 149 \\
\hline JL58 & 15583 & 312 & 66 & 14000 & 2 & 390 & 0 & 181 & 0 & 278 & 354 \\
\hline
\end{tabular}


TABELA 17 - VARIAÇÃO TEMPORAL DAS ESTRATÉgLAS ADAPTATIVAS EM BIOVOLUME. REPRESA DE GUARAPIRANGA 1991-92. PONTO 1.

Identificação da coleta (ID); biovolume em $\mu \mathrm{m}^{3} .^{-1}$ de organismos: com motilidade (BCM); sem motilidade (BSM); sem envoltório rígido (BSER); com envoltório rigido (BCER); da Classe 1 (BCl); da Classe 2 (BC2); da Classe 3 (BC3); da Classe 4 (BC4); nano-fitoplâncton (BNA); micro-fitoplâncton (BMI); macro-fitoplâncton (BMA); formas coloniais ou cenobiais (BCOL); filamentosas (BFIL) e unicelulares (BUNI).

\begin{tabular}{|c|c|c|c|c|c|c|c|c|c|c|c|c|c|c|}
\hline ID & BCM & BSM & BSER & BCER & BC1 & BC2 & BC3 & BC4 & BNA & BMI & BMA & BCOL & BFIL & BUNI \\
\hline$\overline{\mathrm{MA2}}$ & 167 & 4251 & 3393 & 1025 & 211 & 3330 & 787 & 90 & 2947 & 1471 & 0 & 2149 & 13 & 2256 \\
\hline $\mathrm{MA3}$ & 348 & 2552 & 1733 & 1167 & 166 & 1393 & 1160 & 181 & 898 & 1888 & 113 & 897 & 0 & 2003 \\
\hline MA4 & 1610 & 1614 & 2368 & 856 & 81 & 1000 & 2144 & 0 & 1133 & 1527 & 564 & 507 & 17 & 2699 \\
\hline$\sqrt{5}$ & 794 & 5352 & 4922 & 1224 & 270 & 2085 & 2344 & 1446 & 3018 & 2677 & 451 & 3752 & 53 & 2341 \\
\hline J6 & 230 & 2032 & 1585 & 678 & 182 & 1246 & 744 & 90 & 1025 & 1125 & 113 & 889 & 0 & 1373 \\
\hline $\mathrm{J} 7$ & 57 & 1844 & 1509 & 392 & 198 & 616 & 726 & 361 & 1112 & 789 & 0 & 707 & 0 & 1194 \\
\hline JLB & 2435 & 1524 & 2489 & 1470 & 58 & 250 & 1667 & 1983 & 473 & 3373 & 113 & 2064 & 1176 & 718 \\
\hline פ פL & 150 & 402 & 339 & 213 & 21 & 375 & 156 & 0 & 344 & 208 & 0 & 397 & 0 & 155 \\
\hline JL10 & 4297 & 222 & 4391 & 129 & 12 & 276 & 246 & 3985 & 532 & 3988 & 0 & 4202 & 0 & 318 \\
\hline JL11 & 276 & 0 & 169 & 107 & 30 & 246 & 0 & 0 & 276 & 0 & 0 & 0 & 0 & 276 \\
\hline JL12 & 171 & 1933 & 696 & 1408 & 61 & 437 & 1606 & 0 & 518 & 1585 & 0 & 479 & 1176 & 449 \\
\hline AG13 & 661 & 3264 & 1066 & 2859 & 120 & 3265 & 541 & 0 & 1290 & 2523 & 113 & 1955 & 520 & 1450 \\
\hline AG14 & 1081 & 2804 & 1222 & 2662 & 44 & 2461 & 1379 & 0 & 1133 & 2639 & 113 & 1122 & 1176 & 1586 \\
\hline AG15 & 418 & 839 & 903 & 353 & 45 & 597 & 615 & 0 & 828 & 429 & 0 & 469 & 0 & 787 \\
\hline AG16 & 986 & 2161 & 2818 & 329 & 387 & 2062 & 698 & 0 & 2866 & 281 & 0 & 1698 & 17 & 1432 \\
\hline $\mathrm{S17}$ & 541 & 66 & 583 & 24 & 38 & 568 & 0 & 0 & 607 & 0 & 0 & 16 & 0 & 591 \\
\hline S18 & 5698 & 780 & 1154 & 5323 & 83 & 5990 & 404 & 0 & 1169 & 5308 & 0. & 5317 & 0 & 1160 \\
\hline S19 & 1645 & 849 & 1692 & 802 & 71 & 1953 & 470 & 0 & 1821 & 673 & 0 & & 8 & 1391 \\
\hline$\$ 20$ & 384 & 3460 & 583 & 3261 & 91 & 1213 & 2540 & 0 & 613 & 3232 & 0 & 1039 & 2377 & 429 \\
\hline 021 & 150 & 4864 & 1189 & 3825 & 40 & 451 & 4523 & 0 & 1099 & 3915 & 0 & 1230 & 35 & 272 \\
\hline 022 & 380 & 667 & 409 & 639 & 28 & 839 & 181 & 0 & 415 & 633 & 0 & 482 & 0 & 565 \\
\hline 023 & 38 & 551 & 558 & 31 & 137 & 452 & 0 & 0 & 571 & 18 & 0 & 282 & 0 & 307 \\
\hline 024 & 1308 & 4783 & 5986 & 104 & 556 & 1259 & 211 & 4066 & 2025 & 4066 & 0 & 4236 & 516 & 1339 \\
\hline 025 & 937 & 2323 & 2985 & 274 & 69 & 1251 & 314 & 1626 & 1363 & 1897 & 0 & 1968 & 283 & 1009 \\
\hline N26 & 171 & 6918 & 7060 & 29 & 82 & 802 & 332 & 58 & 1081 & 6008 & 0 & & 0 & 439 \\
\hline N27 & 1101 & 21545 & 22217 & 429 & 77 & 379 & 2404 & 19786 & 1213 & 21433 & 0 & 21367 & 35 & 1245 \\
\hline N28 & 6125 & 25968 & $\overline{32033}$ & 60 & 71 & 1588 & 271 & 30163 & 1921 & 30172 & 0 & 31764 & 0 & 329 \\
\hline N29 & 2480 & 20686 & 21581 & 1585 & 146 & 545 & 8655 & 138 & 1494 & 21672 & 0 & 20724 & 1300 & 1142 \\
\hline D30 & 616 & 9565 & 9800 & 381 & 20 & 673 & 1627 & 7861 & 929 & 9251 & 0 & 9472 & 0 & 709 \\
\hline D31 & 411 & 8197 & 8211 & 398 & 284 & 735 & 1265 & 6324 & 1973 & 6535 & 0 & 7562 & 387 & 658 \\
\hline & 199 & 121 & 9118 & 201 & 17 & 431 & 108 & 8764 & 382 & 8937 & 0 & 8817 & 8 & 494 \\
\hline$\overline{\mathrm{D} 33}$ & 406 & 25648 & 25887 & 167 & 321 & 3787 & 1979 & 19967 & 4196 & 21858 & 0 & 25259 & 266 & 530 \\
\hline JA34 & 252 & 2388 & 2136 & 504 & 72 & 902 & 220 & 1446 & 741 & 1900 & 0 & 1715 & 67 & 858 \\
\hline JA35 & 638 & 4001 & 4069 & 570 & 138 & 808 & 3602 & 90 & 4179 & 461 & 0 & 282 & 3055 & 1302 \\
\hline JA36 & 1080 & 4214 & 4366 & 927 & 916 & 2011 & 1463 & 903 & 4113 & 1181 & 0 & 2710 & & 1532 \\
\hline JA37 & 537 & 2797 & 3172 & 162 & 1871 & 838 & 534 & 90 & 2606 & 727 & 0 & 697 & 1901 & 736 \\
\hline F38 & 184 & 7233 & 688 & 3729 & 2749 & 979 & 3689 & 0 & 3882 & 3535 & 0 & 664 & 6101 & 652 \\
\hline & 110 & & 11001 & 64 & 4830 & 2368 & 3414 & 452 & 10525 & 539 & 0 & 2018 & 8237 & 810 \\
\hline $\mathrm{F} 40$ & 153 & 12647 & 12676 & 124 & 5406 & 1341 & 90 & 5963 & 6772 & 6027 & 0 & 7138 & & 4129 \\
\hline F41 & 422 & 4796 & 4756 & 461 & 3354 & 1681 & 182 & 0 & 4860 & 358 & 0 & 792 & 2656 & 1769 \\
\hline MR42 & 169 & 1859 & 1773 & 254 & 821 & 1207 & 0 & 0 & 1863 & 165 & 0 & 799 & 690 & 539 \\
\hline MR43 & 0 & 3548 & 3210 & 338 & 1839 & 1462 & 246 & 0 & 3099 & 449 & 0 & 1267 & 1589 & 692 \\
\hline MR44 & 38 & 2921 & 23 & 601 & 1053 & 1905 & 0 & 0 & 2381 & 577 & 0 & 1022 & 81 & 1118 \\
\hline & 2276 & & & 315 & 1048 & 1536 & 338 & 1983 & 2680 & 2225 & 0 & 3066 & 84 & 997 \\
\hline $\mathrm{AB} 46$ & 70 & 2884 & 2756 & 198 & 855 & 2099 & 0 & 0 & 2685 & 270 & 0 & 1832 & 43 & 687 \\
\hline$A B 47$ & 537 & 7065 & 4608 & 2994 & 762 & 2818 & 4022 & 0 & 4932 & 2670 & 0 & 3666 & 2825 & 1111 \\
\hline$A B 48$ & 117 & 4499 & 4509 & 106 & 687 & 3434 & 495 & 0 & 4122 & 494 & 0 & 3398 & 160 & 1058 \\
\hline$A B 49$ & 23 & 9199 & 9124 & 99 & 1387 & 5486 & 0 & 2349 & 6581 & 2641 & 0 & 7396 & 608 & 1219 \\
\hline MA50 & 563 & 4662 & 4916 & 309 & 878 & 3949 & 397 & 0 & 4830 & 394 & 0 & 3383 & 34 & 1499 \\
\hline MA51 & 153 & 6278 & 6308 & 124 & 1510 & 4620 & 120 & 182 & 5791 & 641 & 0 & 4247 & 916 & 1268 \\
\hline MA53 & 90 & 3577 & 3572 & 96 & 469 & 3108 & 0 & 90 & 3457 & 210 & 0 & 3227 & 30 & 410 \\
\hline J54 & 136 & 3940 & 2664 & 1411 & 191 & 1879 & 1796 & 210 & 2238 & 1837 & 0 & 2084 & 1377 & 614 \\
\hline J55 & 584 & 4181 & 3014 & 1751 & 234 & 3750 & 599 & 182 & 3048 & 1604 & 113 & 2377 & 112 & 2276 \\
\hline $\mathrm{J} 56$ & 277 & 2532 & 1454 & 1354 & 298 & 1923 & 317 & 271 & 1414 & 1168 & 227 & 993 & 189 & 1627 \\
\hline $\mathrm{J} 57$ & 282 & 3355 & 2033 & 1604 & 114 & 1776 & 482 & 1265 & 913 & 2724 & 0 & 1702 & 478 & 1456 \\
\hline JL58 & 670 & 14914 & 14537 & 1047 & 872 & 3327 & 723 & 10661 & 4204 & 11379 & 0 & 13783 & 512 & 1288 \\
\hline
\end{tabular}


TABELA 18 - VARIAÇĀO TEMPORAL DA DENSIDADE DO FITOPLÂNCTON. REPRESA DE GUARAPIRANGA, 1991-92: PONTO 4.

Densidade em células. $\mathrm{ml}^{-1}$ :densidade total (D); de centrales (DC); de penales (DP); clorococales (DCHC); volvocales (DVOL); crisoficeas (DCHR); criptoficeas (DCRY); cianoficeas (DCY); dinoficeas (DDI); euglenoficeas (DEU); zignemaficeas (DZY).

\begin{tabular}{|c|c|c|c|c|c|c|c|c|c|c|c|}
\hline ID & D & DC & DP & DCHC & DVOL & DCHR & DCRY & DCY & DDI & DEU & $\mathbf{D Z Y}$ \\
\hline MA2 & 6519 & 3377 & 785 & 1335 & 0 & 79 & 628 & 0 & 0 & 0 & 314 \\
\hline MA3 & 2278 & 471 & 157 & 471 & 157 & 0 & 785 & 0 & 0 & 0 & 236 \\
\hline MA4 & 2906 & 628 & 471 & 942 & 236 & 79 & 314 & 0 & 79 & 157 & 0 \\
\hline J5 & 3377 & 550 & 942 & 785 & 0 & 0 & 550 & 236 & 0 & 157 & 157 \\
\hline 36 & 7697 & 1178 & 2042 & 2592 & 393 & 0 & 393 & 393 & 0 & 0 & 707 \\
\hline J7 & 4477 & 314 & 1571 & 1335 & 157 & 0 & 707 & 314 & 0 & 0 & 79 \\
\hline JL8 & 1728 & 0 & 79 & 550 & 236 & 0 & 785 & 0 & 0 & 79 & 0 \\
\hline JL9 & 1021 & 236 & 0 & 236 & 236 & 157 & 157 & 0 & 0 & 0 & 0 \\
\hline JL10 & 1571 & 0 & 0 & 628 & 550 & 0 & 79 & 0 & 0 & 314 & 0 \\
\hline JLI1 & 1335 & 314 & 0 & 550 & 79 & 157 & 157 & 0 & 0 & 79 & 0 \\
\hline $\mathrm{JL} 12$ & 1963 & 79 & 236 & 550 & 550 & 79 & 157 & 0 & 0 & 0 & 314 \\
\hline AG13 & 6519 & 864 & 550 & 2278 & 2042 & 0 & 628 & 0 & 0 & 79 & 79 \\
\hline AGI4 & 6519 & 864 & 1335 & 1257 & 864 & 0 & 785 & 550 & 0 & 864 & 0 \\
\hline AGI5 & 1492 & 314 & 236 & 707 & 157 & 0 & 79 & 0 & 0 & 0 & 0 \\
\hline AGl6 & 1963 & 0 & 79 & 393 & 550 & 79 & 707 & 0 & 0 & 0 & 157 \\
\hline$\$ 17$ & 2278 & 471 & 0 & 79 & 314 & 157 & 1178 & 0 & 0 & 79 & 0 \\
\hline S18 & 3848 & 0 & 157 & 471 & 1571 & 314 & 1335 & 0 & 0 & 0 & 0 \\
\hline S19 & 5812 & 1728 & 79 & 864 & 1649 & 1257 & 236 & 0 & 0 & 0 & 0 \\
\hline S20 & 5027 & 1414 & 236 & 864 & 1257 & 314 & 942 & 0 & 0 & 0 & 0 \\
\hline $\mathrm{O} 21$ & 3063 & 550 & 393 & 628 & 628 & 157 & 628 & 0 & 0 & 79 & 0 \\
\hline 022 & 3220 & 1100 & 314 & 864 & 314 & 0 & 471 & 0 & 157 & 0 & 0 \\
\hline $\mathrm{O} 23$ & 628 & 79 & 0 & 157 & 157 & 0 & 79 & 0 & 157 & 0 & 0 \\
\hline $\mathrm{O} 24$ & 3142 & 471 & 236 & 1492 & 628 & 0 & 157 & 0 & 0 & 79 & 79 \\
\hline 025 & 5498 & 707 & 157 & 785 & 2985 & 864 & 0 & 0 & 0 & 0 & 0 \\
\hline N26 & 10446 & 550 & 79 & 8954 & 393 & 0 & 157 & 79 & 79 & 79 & 79 \\
\hline $\mathrm{N} 27$ & 19871 & 236 & 0 & 13273 & 5262 & 471 & 236 & 79 & 314 & 0 & 0 \\
\hline N28 & 18221 & 550 & 550 & 15472 & 707 & 471 & 79 & 157 & 236 & 0 & 0 \\
\hline N29 & 12488 & 236 & 157 & 9503 & 942 & 79 & 236 & 628 & 628 & 0 & 79 \\
\hline D30 & 22777 & 314 & 157 & 13195 & 157 & 79 & 2278 & 6283 & 79 & 157 & 79 \\
\hline D31 & 11153 & 0 & 0 & 8011 & 707 & 157 & 236 & 1100 & 157 & 0 & 785 \\
\hline $\mathrm{D} 32$ & 11231 & 236 & 314 & 4320 & 393 & 0 & 79 & 1806 & 79 & 79 & 3927 \\
\hline D33 & 8011 & 550 & 0 & 2985 & 628 & 79 & 157 & 864 & 79 & 236 & 2435 \\
\hline JA34 & 10092 & 471 & 1178 & 2042 & 628 & 471 & 393 & 2003 & 0 & 79 & 2827 \\
\hline JA35 & 9896 & 236 & 157 & 3220 & 393 & 707 & 1100 & 3220 & 314 & 314 & 236 \\
\hline JA36 & 3456 & 393 & 79 & 864 & 550 & 0 & 864 & 550 & 157 & 0 & 0 \\
\hline JA37 & 24504 & 79 & 157 & 3691 & 393 & 157 & 942 & 236 & 236 & 0 & 18614 \\
\hline F38 & 7540 & 157 & 1100 & 2435 & 628 & 0 & 393 & 550 & 314 & 0 & 1963 \\
\hline F39 & 9975 & 314 & 0 & 4006 & 1178 & 79 & 3770 & 157 & 236 & 79 & 157 \\
\hline F40 & 24819 & 0 & 393 & 15865 & 1257 & 157 & 707 & 628 & 707 & 550 & 4555 \\
\hline $\mathrm{F} 41$ & 10760 & 79 & 157 & 6754 & 1178 & 157 & 785 & 1414 & 0 & 0 & 236 \\
\hline MR42 & 17514 & 79 & 1571 & 7383 & 4555 & 0 & 157 & 550 & 236 & 0 & 2985 \\
\hline MR43 & 6597 & 236 & 393 & 4477 & 236 & 79 & 0 & 314 & 393 & 236 & 236 \\
\hline MR44 & 6048 & 236 & 157 & 3534 & 471 & 236 & 236 & 550 & 157 & 314 & 157 \\
\hline $\mathrm{AB} 45$ & 11938 & 79 & 0 & 9817 & 550 & 157 & 79 & 550 & 0 & 393 & 314 \\
\hline$A B 46$ & 7226 & 157 & 79 & 4006 & 393 & 393 & 393 & 1335 & 157 & 0 & 314 \\
\hline $\mathrm{AB} 47$ & 13273 & 0 & 79 & 7854 & 2121 & 0 & 785 & 864 & 0 & 1178 & 393 \\
\hline $\mathrm{AB} 48$ & 25761 & 314 & 157 & 16336 & 1492 & 157 & 550 & 5890 & 0 & 314 & 550 \\
\hline AB49 & 23169 & 2985 & 79 & 17357 & 157 & 157 & 471 & 1571 & 0 & 314 & 79 \\
\hline MA50 & 11545 & 1728 & 157 & 6754 & 550 & 79 & 864 & 1100 & 79 & 0 & 236 \\
\hline MASI & 26782 & 393 & 707 & 19871 & 0 & 79 & 785 & 3927 & 0 & 628 & 393 \\
\hline MA53 & 21834 & 707 & 79 & 18143 & 0 & 157 & 864 & 1414 & 79 & 236 & 157 \\
\hline $\mathrm{J} 54$ & 10289 & 1571 & 707 & 7304 & 393 & 0 & 157 & 0 & 0 & 0 & 157 \\
\hline J55 & 15394 & 1649 & 0 & 7147 & 4634 & 314 & 628 & 628 & 79 & 157 & 157 \\
\hline J56 & 10210 & 4712 & 0 & 2592 & 2199 & 79 & 236 & 157 & 79 & 157 & 0 \\
\hline J57 & 6597 & 1335 & 79 & 4555 & 79 & 79 & 157 & 0 & 0 & 157 & 157 \\
\hline Л.58 & 35421 & 2435 & 628 & 22855 & 157 & 0 & 236 & 4555 & 0 & 942 & 3613 \\
\hline
\end{tabular}


TABELA 19 - VARIAÇĀO TEMPORAL DAS ESTRATÉgIAS ADAPTATIVAS EM DENSIDADE. REPRESA DE GUARAPIRANGA 1991-92. PONTO 4.

Identificação da coleta (ID); densidade em células.ml ${ }^{-1}$ de organismos: com motilidade (CM); sem motilidade (SM); sem envoltório rígido (SER); com envoltório rigido (CER); da Classe 1 (C1); da Classe 2 (C2); da Classe 3 (C3); da Classe 4 (C4); nano-fitoplâncton (NA); micro-fitoplâncton (MI); macrofitoplâncton (MA); formas coloniais ou cenobiais (COL); filamentosas (FIL) e unicelulares (UNI).

\begin{tabular}{|c|c|c|c|c|c|c|c|c|c|c|c|c|c|c|}
\hline ID & CM & $\underline{\mathbf{S M}}$ & SER & CER. & C1 & $\mathrm{C} 2$ & $\mathrm{C} 3$ & C4 & NA & MI & MA & COL & FIL & UNI \\
\hline MA2 & 707 & 5812 & 2278 & 4241 & 707 & 5184 & 628 & 0 & 2827 & 3534 & 157 & 1178 & 0 & 5341 \\
\hline $\mathrm{MA3}$ & 1021 & 1257 & 1571 & 707 & 393 & 1492 & 393 & 0 & 1492 & 707 & 79 & 393 & 0 & 1885 \\
\hline MA4 & 864 & 2042 & 1414 & 1492 & 1100 & 1728 & 79 & 0 & 2042 & 864 & 0 & 314 & 0 & 2592 \\
\hline J5 & 707 & 2670 & 1885 & 1492 & 1649 & 1492 & 236 & 0 & 2670 & 707 & 0 & 628 & 0 & 2749 \\
\hline 16 & 942 & 6754 & 4084 & 3613 & 3770 & 2985 & 942 & 0 & 5341 & 2121 & 236 & 1571 & 79 & 6048 \\
\hline 57 & 864 & 3613 & 2435 & 2042 & 2592 & 1728 & 157 & 0 & 3927 & 550 & 0 & 1021 & 314 & 3142 \\
\hline ЛL8 & 1178 & 550 & 1649 & 79 & 628 & 942 & 157 & 0 & 1728 & 0 & 0 & 236 & 0 & 1492 \\
\hline IL9 & 628 & 393 & 550 & 471 & 157 & 550 & 314 & 0 & 785 & 236 & 0 & 157 & 236 & 628 \\
\hline JLIO & 942 & 628 & 1100 & 471 & 471 & 1021 & 79 & 0 & 1492 & 79 & 0 & 550 & 0 & 1021 \\
\hline JL11 & 471 & 864 & 785 & 550 & 79 & 864 & 393 & 0 & 942 & 393 & 0 & 79 & 314 & 942 \\
\hline ЛL12 & 785 & 1178 & 1571 & 393 & 864 & 942 & 157 & 0 & 1649 & 157 & 157 & 236 & 0 & 1728 \\
\hline$A G 13$ & 2749 & 3770 & 4712 & 1806 & 1728 & 3848 & 942 & 0 & 4320 & 2199 & 0 & 1963 & 314 & 4241 \\
\hline AG14 & 2513 & 4006 & 3534 & 2985 & 1806 & 4084 & 628 & 0 & 4477 & 2042 & 0 & 1963 & 314 & 4241 \\
\hline AGIS & 236 & 1257 & 864 & 628 & 471 & 707 & 314 & 0 & 1021 & 471 & 0 & 628 & 236 & 628 \\
\hline AGl6 & 1335 & 628 & 1806 & 157 & 550 & 1257 & 157 & 0 & 1571 & 314 & 79 & 0 & 0 & 1963 \\
\hline S17 & 1728 & 550 & 1649 & 628 & 236 & 1492 & 550 & 0 & 1806 & 471 & 0 & 0 & 471 & 1806 \\
\hline S18 & 3220 & 628 & 2749 & 1100 & 1963 & 1885 & 0 & 0 & 3691 & 157 & 0 & 393 & 157 & 3299 \\
\hline S19 & 3299 & 2513 & 1806 & 4006 & 1806 & 3063 & 942 & 0 & 2749 & 3063 & 0 & 1806 & 785 & 3220 \\
\hline $\mathrm{S} 20$ & 2513 & 2513 & 2827 & 2199 & 1021 & 4006 & 0 & 0 & 3299 & 1728 & 0 & 1178 & 0 & 3848 \\
\hline $\mathrm{O} 21$ & 1571 & 1492 & 1571 & 1492 & 707 & 1571 & 785 & 0 & 1885 & 1178 & 0 & 785 & 471 & 1806 \\
\hline $\mathrm{O} 22$ & 942 & 2278 & 1649 & 1571 & 942 & 1492 & 785 & 0 & 1728 & 1492 & 0 & 628 & 707 & 1885 \\
\hline $\mathrm{O} 23$ & 393 & 236 & 393 & 236 & 236 & 314 & 0 & 79 & 314 & 314 & 0 & 79 & 0 & 550 \\
\hline O24 & 1100 & 2042 & 2356 & 785 & 1100 & 1257 & 785 & 0 & 1649 & 1492 & 0 & 1178 & 0 & 1963 \\
\hline $\mathrm{O} 25$ & 3848 & 1649 & 2199 & 3299 & 3534 & 1571 & 79 & 314 & 3848 & 1649 & 0 & 1728 & 0 & 3770 \\
\hline N26 & 707 & 9739 & 9346 & 1100 & 628 & 707 & 9032 & 79 & 1178 & 9268 & 0 & 8954 & 236 & 1257 \\
\hline $\mathrm{N} 27$ & 6283 & 13587 & 18928 & 942 & 6283 & 1021 & 12252 & 314 & 6990 & 12881 & 0 & 13587 & 0 & 6283 \\
\hline N28 & 1492 & 16729 & 16101 & 2121 & 1806 & 3377 & 13038 & 0 & 4084 & 14059 & 79 & 14766 & 393 & 3063 \\
\hline $\mathrm{N} 29$ & 1885 & 10603 & 12017 & 471 & 942 & 1963 & 9111 & 471 & 2749 & 9739 & 0 & 9346 & 314 & 2827 \\
\hline D30 & 2827 & 19949 & 22070 & 707 & 3299 & 1257 & 18064 & 157 & 4634 & 17986 & 157 & 18064 & 0 & 4712 \\
\hline D31 & 1257 & 9896 & 10446 & 707 & 2670 & 2042 & 6440 & 0 & 4477 & 6676 & 0 & 8011 & 707 & 2435 \\
\hline D32 & 628 & 10603 & 10289 & 942 & 1414 & 5341 & 4477 & 0 & 6519 & 4634 & 79 & 5027 & 3848 & 2356 \\
\hline D33 & 1257 & 6754 & 6912 & 1100 & 3691 & 864 & 3456 & 0 & 4869 & 3142 & 0 & 2985 & 2906 & 2121 \\
\hline JA34 & 1571 & 8522 & 7501 & 2592 & 6008 & 2670 & 1414 & 0 & 7736 & 1806 & 550 & 1963 & 4202 & 3927 \\
\hline JA35 & 2827 & 7069 & 8482 & 1414 & 2827 & 3613 & 3456 & 0 & 5733 & 4163 & 0 & 4398 & 314 & 5184 \\
\hline JA36 & 1571 & 1885 & 2827 & 628 & 1100 & 1885 & 471 & 0 & 3142 & 314 & 0 & 314 & 157 & 2985 \\
\hline JA37 & 1806 & 22698 & 23641 & 864 & 19556 & 3691 & 1178 & 79 & 23326 & 1178 & 0 & 2278 & 19635 & 2592 \\
\hline F38 & 1335 & 6205 & $620 S$ & 1335 & 4320 & 2592 & 550 & 79 & 7304 & 236 & 0 & 1414 & 1963 & 4163 \\
\hline F39 & 5341 & 4634 & 9268 & 707 & 6283 & 3299 & 157 & 236 & 9503 & 471 & 0 & 1178 & 79 & 8718 \\
\hline F40 & 3456 & 21363 & 23169 & 1649 & 20028 & 3691 & 393 & 707 & 23483 & 1021 & 314 & 1492 & 4869 & 18457 \\
\hline F41 & 2121 & 8639 & 9268 & 1492 & 8168 & 2592 & 0 & 0 & 10524 & 236 & 0 & 1335 & 707 & 8718 \\
\hline MR42 & 4948 & 12566 & 11153 & 6362 & 12959 & 2513 & 1963 & 79 & 16101 & 157 & 1257 & 1492 & 2985 & 13038 \\
\hline MR43 & 942 & 5655 & 5576 & 1021 & 3927 & 2121 & 236 & 314 & 6048 & 393 & 157 & 1178 & 314 & 5105 \\
\hline MR44 & 1414 & 4634 & 4791 & 1257 & 3691 & 2199 & 0 & 157 & 5498 & 550 & 0 & 1178 & 314 & 4555 \\
\hline $\mathrm{AB45}$ & 1178 & 10760 & 10996 & 942 & 3220 & 2199 & 6519 & 0 & 5655 & 6283 & 0 & 7304 & 314 & 4320 \\
\hline$A B 46$ & 1335 & 5890 & 6362 & 864 & 4320 & 2670 & 79 & 157 & 6676 & 471 & 79 & 1492 & 1021 & 4712 \\
\hline $\mathrm{AB} 47$ & 4084 & 9189 & 11231 & 2042 & 6833 & 5576 & 864 & 0 & 12488 & 785 & 0 & 3299 & 314 & 9660 \\
\hline AB48 & 2513 & 23248 & 24347 & 1414 & 16336 & 6990 & 2199 & 236 & 24583 & 1021 & 157 & 7618 & 5105 & 13038 \\
\hline AB49 & 1100 & 22070 & 19478 & 3691 & 12095 & 8875 & 2199 & 0 & 19949 & 3220 & 0 & 7147 & 3456 & 12566 \\
\hline MASO & 1649 & 9896 & 9346 & 2199 & 5655 & 5576 & 236 & 79 & 9739 & 1728 & 79 & 2827 & 2749 & 5969 \\
\hline MAS1 & 1492 & 25290 & 25604 & 1178 & 16729 & 9346 & 707 & 0 & 25604 & 1178 & 0 & 8168 & 3299 & 15315 \\
\hline MA53 & 1414 & 20420 & 20656 & 1178 & 11231 & 9503 & 1021 & 79 & 20499 & 1335 & 0 & 8247 & 628 & 12959 \\
\hline J54 & 785 & 9503 & 7618 & 2670 & 5262 & 3927 & 1100 & 0 & 8090 & 2199 & 0 & 3377 & 1178 & 5733 \\
\hline J55 & 5812 & 9582 & 12488 & 2906 & 9817 & 5419 & 157 & 0 & 13666 & 1728 & 0 & 2513 & 314 & 12566 \\
\hline J56 & 2749 & 7461 & 4791 & 5419 & 5027 & 4477 & 628 & 79 & 5576 & 4634 & 0 & 157 & 3848 & 6205 \\
\hline J57 & 471 & 6126 & 4869 & 1728 & 3927 & 2278 & 393 & 0 & 5105 & 1492 & 0 & 785 & 157 & 5655 \\
\hline JL58 & 1335 & 34086 & 31259 & 4163 & 17907 & 14608 & 2906 & 0 & 30316 & 5105 & 0 & 13116 & 5262 & 17043 \\
\hline
\end{tabular}


TABELA 21 - VARIAÇÃO TEMPORAL DAS ESTRATÉGIAS ADAPTATIVAS EM BIOVOLUME. REPRESA DE GUARAPIRANGA 1991-92. PONTO 4.

Identificação da coleta (ID); biovolume em $\mu \mathrm{m}^{3} .^{1}$ de organismos: com motilidade (BCM); sem motilidade (BSM); sem envoltório rígido (BSER); com envoltório rígido (BCER); da Classe 1 (BC1); da Classe 2 (BC2); da Classe 3 (BC3); da Classe 4 (BC4); nano-fitoplâncton (BNA); micro-fitoplâncton (BMI); macro-fitoplâncton (BMA); formas coloniais ou cenobiais (BCOL); filamentosas (BFIL) e unicelulares (BUNI).

\begin{tabular}{|c|c|c|c|c|c|c|c|c|c|c|c|c|c|c|}
\hline ID & BCM & BSM & BSER & BCER & BC1 & BC2 & $\mathrm{BC} 3$ & BC4 & BNA & BMI & BMA & BCOL & BFIL & BUNI \\
\hline MA2 & 1461 & 2261 & 2304 & 1418 & 1394 & 684 & 1645 & 0 & 2230 & 1492 & 0 & 1801 & 226 & 1696 \\
\hline$M A 3$ & 643 & 559 & 1002 & 199 & 213 & 432 & 557 & 0 & 702 & 500 & 0 & 135 & 113 & 954 \\
\hline MA4 & 440 & 304 & 345 & 399 & 307 & 347 & 90 & 0 & 385 & 359 & 0 & 151 & 0 & 593 \\
\hline $\mathrm{J} 5$ & 561 & 361 & 667 & 255 & 271 & 295 & 357 & 0 & 433 & 489 & 0 & 268 & 0 & 655 \\
\hline 36 & 742 & 2141 & 2295 & 589 & 589 & 914 & 1380 & 0 & 2055 & 828 & 0 & 676 & 338 & 1870 \\
\hline J7 & 277 & 682 & 759 & 199 & 233 & 514 & 210 & 0 & 612 & 347 & 0 & 356 & 2 & 600 \\
\hline JL8 & 547 & 144 & 688 & 3 & 18 & 344 & 329 & 0 & 691 & 0 & 0 & 83 & 0 & 608 \\
\hline JL9 & 397 & 852 & 397 & 851 & 12 & 989 & 248 & 0 & 452 & 797 & 0 & 55 & 797 & 397 \\
\hline JL10 & 340 & 249 & 441 & 147 & 33 & 399 & 156 & 0 & 584 & 4 & 0 & 244 & 0 & 344 \\
\hline J11 & 221 & 1192 & 214 & 1199 & 4 & 1318 & 90 & 0 & 346 & 1067 & 0 & 28 & 1062 & 323 \\
\hline $\mathrm{JL} 12$ & 411 & 356 & 662 & 106 & 102 & 665 & 0 & 0 & 675 & 93 & 0 & 79 & 226 & 463 \\
\hline AG13 & 1305 & 1878 & 2555 & 627 & 267 & 1633 & 1283 & 0 & 1392 & 1790 & 0 & 1710 & 0 & 1473 \\
\hline $\mathrm{AG14}$ & 1325 & 2338 & 1379 & 2285 & 338 & 2806 & 520 & 0 & 1336 & 2327 & 0 & 1143 & 1062 & 1458 \\
\hline AG15 & 17 & 1424 & 471 & 970 & 30 & 1107 & 305 & 0 & 519 & 923 & 0 & 542 & 797 & 102 \\
\hline AG16 & 532 & 243 & 747 & 29 & 17 & 677 & 81 & 0 & 688 & 87 & 0 & 0 & 113 & 663 \\
\hline S17 & 634 & 1599 & 559 & 1674 & 17 & 2134 & 81 & 0 & 639 & 1594 & 0 & 0 & 1594 & 639 \\
\hline S18 & 868 & 74 & 785 & 157 & 148 & 794 & 0 & 0 & 874 & 68 & 0 & 114 & 35 & 793 \\
\hline$S 19$ & 1948 & 2796 & 981 & 3763 & 509 & 3739 & 496 & 0 & 1053 & 3691 & 0 & 776 & 2656 & 1312 \\
\hline S20 & 1594 & 242 & 1043 & 793 & 637 & 1199 & 0 & 0 & 1068 & 768 & 0 & 429 & 0 & 1407 \\
\hline $\mathrm{O} 21$ & 1485 & 2076 & 1552 & 2009 & 51 & 2303 & 1207 & 0 & 652 & 2909 & 0 & 925 & 1594 & 1043 \\
\hline $\mathrm{O} 22$ & 319 & 2791 & 366 & 2743 & 148 & 2871 & 90 & 0 & 337 & 2773 & 0 & 256 & 2390 & 463 \\
\hline $\mathrm{O} 23$ & 3656 & 23 & 90 & 3589 & 47 & 80 & 0 & 3551 & 79 & 3600 & 0 & 6 & 0 & 3673 \\
\hline 024 & 447 & 1082 & 1292 & 237 & 270 & 338 & 921 & 0 & 401 & 1128 & 0 & 935 & 0 & 594 \\
\hline 025 & 6762 & 181 & 5987 & 956 & 364 & 842 & 90 & 5647 & 395 & 6548 & 0 & 6475 & 0 & 468 \\
\hline N26 & 1454 & 10943 & 11377 & 1019 & 138 & 943 & 10119 & 1197 & 279 & 12118 & 0 & 10111 & 797 & 1488 \\
\hline $\mathrm{N} 27$ & 5867 & 14629 & 20062 & 435 & 537 & 402 & 14555 & 5002 & 1612 & 18884 & 0 & 16344 & 0 & 4153 \\
\hline N28 & 466 & 16184 & 15949 & 701 & 291 & 1387 & 14973 & 0 & 1240 & 15410 & 0 & 15937 & 199 & 514 \\
\hline N29 & 7662 & 12568 & 20095 & 135 & 121 & 540 & 12387 & 7182 & 576 & 19654 & 0 & 12402 & 69 & 7758 \\
\hline D30 & 686 & 23485 & 23897 & 274 & 52 & 668 & 20953 & 2498 & 1689 & 22457 & 25 & 23257 & 226 & 688 \\
\hline D31 & 466 & 8778 & 8885 & 360 & 163 & 1516 & 7566 & 0 & 1855 & 7390 & 0 & 8721 & 59 & 465 \\
\hline D32 & 129 & 7345 & 7095 & 379 & 128 & 2387 & 4960 & 0 & 2421 & 5053 & 0 & 5224 & 1710 & 540 \\
\hline D33 & 611 & 5482 & 4269 & 1823 & 307 & 1931 & 3854 & 0 & 1563 & 4529 & 0 & 3571 & 1795 & 727 \\
\hline JA34 & 674 & 2477 & 2595 & 555 & 345 & 1784 & 1022 & 0 & 2202 & 924 & 25 & 1544 & 1125 & 482 \\
\hline JA35 & 1581 & 4272 & 4816 & 1038 & 208 & 1382 & 4264 & 0 & 1711 & 4143 & 0 & 4428 & 59 & 1367 \\
\hline JA36 & 390 & 1149 & 871 & 669 & 42 & 1088 & 409 & 0 & 861 & 678 & 0 & 102 & 531 & 906 \\
\hline JA37 & 3651 & 3594 & 4116 & 3130 & 1814 & 872 & 1868 & 2692 & 3523 & 3723 & 0 & 1838 & 1767 & 3641 \\
\hline F38 & 1736 & 1334 & 2714 & 357 & 260 & 792 & 821 & 1197 & 1720 & 1350 & 0 & 586 & 163 & 2322 \\
\hline F39 & 4271 & 893 & 4741 & 423 & 230 & 1262 & 81 & 3591 & 1275 & 3889 & 0 & 343 & 266 & 4556 \\
\hline F40 & 14187 & 1972 & 10628 & 5531 & 731 & 1533 & 133 & 13762 & 2236 & 13922 & 0 & 502 & 898 & 14759 \\
\hline F41 & 355 & 846 & 1026 & 174 & 551 & 650 & 0 & 0 & 1181 & 19 & 0 & 363 & 124 & 713 \\
\hline MR42 & 2070 & 3823 & 5012 & 881 & 684 & 2493 & 1519 & 1197 & 4695 & 1198 & 0 & 1251 & 2084 & 2558 \\
\hline MR43 & 4441 & 983 & 5163 & 261 & 117 & 847 & 142 & 4318 & 1100 & 4318 & 6 & 338 & 262 & 4823 \\
\hline MR44 & 2723 & 563 & 3004 & 281 & 270 & 621 & 0 & 2394 & 787 & 2498 & 0 & 370 & 48 & 2868 \\
\hline $\mathrm{AB} 45$ & 519 & 7740 & 7999 & 260 & 164 & 633 & 7462 & 0 & 1184 & 7075 & 0 & 7371 & 48 & 840 \\
\hline $\mathrm{AB} 46$ & 2690 & 831 & 3276 & 245 & 210 & 914 & 2 & 2394 & 965 & 2555 & 0 & 558 & 150 & 2813 \\
\hline $\mathrm{AB} 47$ & 1246 & 2085 & 2461 & 870 & 323 & 1939 & 1069 & 0 & 2900 & 431 & 0 & 1312 & 69 & 1950 \\
\hline $\mathrm{AB} 48$ & 5899 & 6748 & 12400 & 247 & 306 & 2647 & 3618 & 6076 & 6100 & 6548 & 0 & 5069 & 246 & 7333 \\
\hline $\mathrm{AB} 49$ & 532 & 9885 & 3044 & 7372 & 468 & 9708 & 240 & 0 & 3208 & 7208 & 0 & 2498 & 6978 & 940 \\
\hline MA50 & 1756 & 2498 & 3133 & 1121 & 109 & 2607 & 341 & 1197 & 2009 & 2245 & 0 & 1110 & 1163 & 1981 \\
\hline MASI & 1117 & 4228 & 4477 & 869 & 279 & 4115 & 951 & 0 & 3518 & 1828 & 0 & 2996 & 858 & 1491 \\
\hline MA53 & 1846 & 4843 & 5444 & 1245 & 209 & 4036 & 1247 & 1197 & 4039 & 2650 & 0 & 3347 & 798 & 2544 \\
\hline $\mathrm{J} 54$ & 226 & 4878 & 1482 & 3622 & 253 & 4851 & 0 & 0 & 1407 & 3697 & 0 & 1126 & 3343 & 634 \\
\hline J55 & 1717 & 1087 & 1790 & 1013 & 1007 & 1306 & 490 & 0 & 1616 & 1187 & 0 & 634 & 163 & 2006 \\
\hline J56 & 1770 & 4162 & 3856 & 2077 & 609 & 1708 & 2418 & 1197 & 618 & 5314 & 0 & 2356 & 1594 & 1983 \\
\hline 157 & 557 & 1366 & 1070 & 854 & 645 & 646 & 632 & 0 & 704 & 1219 & 0 & 742 & 272 & 909 \\
\hline JLS8 & 1098 & 7440 & 7137 & 1401 & 1465 & 3686 & 3388 & 0 & 4531 & 4007 & 0 & 6315 & 638 & 1586 \\
\hline
\end{tabular}


TABELA 22 - CORRELAÇÕES: VARIÁVEIS ABIÓTICAS E CARACTERÍSTICAS DA COMUNIDADE FITOPLANCTÔNICA DO PONTO 1 - REPRESA DE GUARAPIRANGA 1991-92.

Varióveis abif́ticas: velocidade média do vento (W); radiação solar (RAD); insolação (INS); precipitação (P); elevacão (ELE); deficiência hidrica do solo (DEF); volume (VOL); excodente hídrion (EXC); temperatura da água (TAG); profumdidade (PROF); transparência (SEC); or (COR); turtidez (IUR); ondutividade (CON); $\mathrm{pH}(\mathrm{pH})$; oxigenio dissolvido (OD); demanda bioquímica de oxigenio (DBO); alcalinidade (ALC); dureza (DUR); sólidos totais em suspensão (SOT); fósforo solúvel reativo (PO4); fösforo total (PT); amónio (NH4); nitrato $\left(\mathrm{NO}_{3}\right)$; sulfato $\left(\mathrm{SO}_{4}\right)$; daro (Cl); alumínio (A); cálcio (Ca); cobre (Cu); ferro (Fe); potássio (K); magnésio (Mg); manganês (Mn); sódio (Na); silício (Si) e zinco (Zn); sulfataç̃o no dia anterior (SDA); sulfataç̃o no dia da coleta (SD); ponto 1 (P1); ponto 4 (P4).

Varíveis do fittoplâncton: densidade em células (DC); densidade em organismos (DO); bicárea (BA); biovolume (BV); GALD (G); número de tóxons (S); diversidade (H); uniformidade (U) e taxa de alteracão comunidade entre coletas sucessivas. dia ${ }^{-1}$ (TA)

\begin{tabular}{|c|c|c|c|c|c|c|c|c|c|c|c|c|c|c|c|c|}
\hline P1 & D & DO & $\mathbf{G}$ & SG & $\mathbf{B A}$ & BV & $\mathbf{S}$ & H'D & UD & H'BA & UBA & H'BV & UBV & TAD & TABA & TABV \\
\hline $\mathbf{w}$ & $\mathbf{N}$ & $\mathbf{N}$ & $\mathbf{N}$ & $N$ & $\mathbf{N}$ & $\mathbf{N}$ & $\mathrm{N}$ & $\mathrm{N}$ & $\mathbf{N}$ & $\mathbf{N}$ & $\mathbf{N}$ & $\mathbf{N}$ & $\mathbf{N}$ & $\mathrm{N}$ & $\mathrm{N}$ & $\begin{array}{c}-0.3171 \\
0.0198\end{array}$ \\
\hline $\mathbf{R A D}$ & $\mathbf{N}$ & $\mathbf{N}$ & $\mathbf{N}$ & $N$ & $\mathbf{N}$ & $\begin{array}{l}0.4601 \\
0.0006\end{array}$ & $\mathbf{N}$ & $\begin{array}{l}-0.4706 \\
0.0005\end{array}$ & $\begin{array}{l}-0.4719 \\
0.0005\end{array}$ & $\begin{array}{l}-0.5346 \\
0.0001\end{array}$ & $\begin{array}{l}-0.5295 \\
0.0001\end{array}$ & $\begin{array}{l}-0.4493 \\
0.0009\end{array}$ & $\begin{array}{l}-0.4648 \\
0.0006\end{array}$ & $N$ & $N$ & $\mathrm{~N}$ \\
\hline NS & $\mathbf{N}$ & $\mathbf{N}$ & $\mathbf{N}$ & $N$ & $\mathbf{N}$ & $\mathbf{N}$ & $\mathbf{N}$ & $\mathrm{N}$ & $\mathbf{N}$ & $\mathrm{N}$ & $\mathbf{N}$ & $\mathbf{N}$ & $\mathrm{N}$ & $N$ & $\mathbf{N}$ & $N$ \\
\hline $\mathbf{P}$ & $N$ & $\mathbf{N}$ & $\mathbf{N}$ & $N$ & $N$ & $\mathbf{N}$ & $\mathbf{N}$ & $\begin{array}{l}0.46 \\
0.0007\end{array}$ & $\begin{array}{l}-0.476 \\
0.0004\end{array}$ & $\begin{array}{c}-0.421 \\
0.0018\end{array}$ & $\begin{array}{l}-0.501 \\
0.0002\end{array}$ & $\begin{array}{l}-0.2706 \\
0.0148\end{array}$ & $\begin{array}{l}-0.2728 \\
0.0431\end{array}$ & $N$ & $\mathbf{N}$ & $\mathrm{N}$ \\
\hline DE & $N$ & $\mathbf{N}$ & $\mathbf{N}$ & $N$ & $\mathbf{N}$ & $\begin{array}{r}-0.316 \\
0.0191\end{array}$ & $\begin{array}{l}\mathrm{N} \\
\mathrm{N}\end{array}$ & $\begin{array}{l}\mathbf{N} \\
\mathbf{N}\end{array}$ & $\begin{array}{l}\mathrm{N} \\
\mathrm{N}\end{array}$ & $\begin{array}{l}0.3288 \\
0.0147\end{array}$ & $\begin{array}{l}0.5261 \\
0.0001\end{array}$ & $N$ & $\begin{array}{l}0.3612 \\
0.0074\end{array}$ & $N$ & $\mathrm{~N}$ & $N$ \\
\hline DEF. & $\mathbf{N}$ & $\begin{array}{l}0.3097 \\
0.0216\end{array}$ & $\begin{array}{l}0.2915 \\
0.0306\end{array}$ & $N$ & $N$ & $\mathbf{N}$ & $\begin{array}{l}0.348 \\
0.0099\end{array}$ & $\begin{array}{l}0.4391 \\
0.0011\end{array}$ & $\mathrm{~N}$ & $\begin{array}{l}0.4711 \\
0.0005\end{array}$ & $\begin{array}{l}0.2817 \\
0.0367\end{array}$ & $\begin{array}{l}-0.3762 \\
0.0053\end{array}$ & $\mathrm{~N}$ & $\begin{array}{c}-0.2841 \\
0.0368\end{array}$ & $\mathbf{N}$ & $N$ \\
\hline VOL & $N$ & $\mathbf{N}$ & $\mathbf{N}$ & $N$ & $\mathbf{N}$ & $\begin{array}{l}-0.3172 \\
0.0186\end{array}$ & $\mathbf{N}$ & $\mathbf{N}$ & $N$ & $\begin{array}{l}0.3286 \\
0.0148\end{array}$ & $\begin{array}{l}0.5262 \\
0.0001\end{array}$ & $\mathrm{~N}$ & $\begin{array}{l}0.3634 \\
0.007\end{array}$ & $N$ & $\mathbf{N}$ & $\mathbf{N}$ \\
\hline DXC & $\mathbf{N}$ & $\mathbf{N}$ & $\mathbf{N}$ & $\mathbf{N}$ & $N$ & $\mathbf{N}$ & $\mathbf{N}$ & $\begin{array}{l}-0.2817 \\
0.0367\end{array}$ & $\begin{array}{c}-0.301 \\
0.0256\end{array}$ & $\begin{array}{l}-0.3143 \\
0.0198\end{array}$ & $\begin{array}{l}-0.3711 \\
0.0059\end{array}$ & $\mathbf{N}$ & $\mathrm{N}$ & $N$ & $\mathbf{N}$ & $\mathbf{N}$ \\
\hline TAG & $\begin{array}{l}0.5552 \\
0\end{array}$ & $\begin{array}{l}0.4527 \\
0.0008\end{array}$ & $\begin{array}{l}0.5061 \\
0.0002\end{array}$ & $\begin{array}{l}0.5356 \\
0.0001\end{array}$ & $\begin{array}{l}0.5041 \\
0.0002\end{array}$ & $\begin{array}{l}0.4598 \\
0.0007\end{array}$ & $\begin{array}{l}0.3342 \\
0.0141\end{array}$ & $\begin{array}{l}-0.4396 \\
0.0012\end{array}$ & $\begin{array}{l}-0.7131 \\
0\end{array}$ & $\begin{array}{l}0.2434 \\
0.0737\end{array}$ & $\begin{array}{l}-0.5496 \\
0.0001\end{array}$ & $\mathbf{N}$ & $\begin{array}{l}-0.3076 \\
0.0226\end{array}$ & $N$ & $\mathbf{N}$ & $N$ \\
\hline FRO & $\mathbf{N}$ & $\mathbf{N}$ & $\mathbf{N}$ & $\mathbf{N}$ & $\mathrm{N}$ & $\begin{array}{l}-0.288 \\
0.0324\end{array}$ & $\mathbf{N}$ & $\mathrm{N}$ & $\mathbf{N}$ & $\begin{array}{l}0.2647 \\
0.0496\end{array}$ & $\begin{array}{l}0.3871 \\
0.0041\end{array}$ & $\begin{array}{l}0.3188 \\
0.0181\end{array}$ & $\begin{array}{l}0.4107 \\
0.0023\end{array}$ & $\mathrm{~N}$ & $\mathbf{N}$ & $N$ \\
\hline $\mathbf{S I C}$ & $\begin{array}{l}-0.609 \\
0\end{array}$ & $\begin{array}{l}-0.5638 \\
0\end{array}$ & $\begin{array}{l}-0.567 \\
0\end{array}$ & $\begin{array}{l}-0.621 \\
0\end{array}$ & $\begin{array}{r}-0.415 \\
0.0021\end{array}$ & $\mathrm{~N}$ & $\begin{array}{l}-0.294 \\
0.029\end{array}$ & $\begin{array}{l}0.3325 \\
0.0137\end{array}$ & $\begin{array}{l}0.4849 \\
0.0003\end{array}$ & $\mathrm{~N}$ & $\mathbf{N}$ & $\mathbf{N}$ & $\mathrm{N}$ & $\begin{array}{l}0.4734 \\
0.0005\end{array}$ & $\begin{array}{l}0.4176 \\
0.0021\end{array}$ & $\begin{array}{l}0.344 \\
0.0115\end{array}$ \\
\hline COR & $\mathbf{N}$ & $\mathbf{N}$ & $\mathbf{N}$ & $\mathbf{N}$ & $\mathbf{N}$ & $\mathrm{N}$ & $\mathrm{N}$ & $\mathbf{N}$ & $\mathrm{N}$ & $\begin{array}{l}-0.296 \\
0.0298\end{array}$ & $\begin{array}{l}-0.385 \\
0.0047\end{array}$ & $\begin{array}{l}-0.284 \\
0.0352\end{array}$ & $\begin{array}{l}-0.3537 \\
0.0087\end{array}$ & $\begin{array}{l}-0.285 \\
0.0382\end{array}$ & $\begin{array}{l}-0.312 \\
0.0232\end{array}$ & $\mathrm{~N}$ \\
\hline TUR & $\begin{array}{l}0.4057 \\
0.0029\end{array}$ & $\begin{array}{l}0.4104 \\
0.0023\end{array}$ & $\begin{array}{l}0.3846 \\
0.0047\end{array}$ & $\begin{array}{l}0.4308 \\
0.0015\end{array}$ & $\begin{array}{l}0.3155 \\
0.0204\end{array}$ & $\mathbf{N}$ & $\mathbf{N}$ & $\mathbf{N}$ & $\mathbf{N}$ & $\mathbf{N}$ & $\mathrm{N}$ & $\mathrm{N}$ & $\mathbf{N}$ & $\begin{array}{l}-0.355 \\
0.0098\end{array}$ & $N$ & $\mathbf{N}$ \\
\hline $\operatorname{cor}$ & $\begin{array}{l}0.5224 \\
0.0001\end{array}$ & $\begin{array}{l}0.4681 \\
0.0005\end{array}$ & $\begin{array}{l}0.5527 \\
0\end{array}$ & $\begin{array}{l}0.5148 \\
0.0002\end{array}$ & $\begin{array}{l}0.3232 \\
0.0176\end{array}$ & $\mathbf{N}$ & $\begin{array}{l}0.3825 \\
0.0049\end{array}$ & $\mathbf{N}$ & $\begin{array}{l}-0.366 \\
0.0071\end{array}$ & $\mathbf{N}$ & $\mathbf{N}$ & $\mathbf{N}$ & $\mathbf{N}$ & $\begin{array}{l}-0.348 \\
0.0113\end{array}$ & $\begin{array}{l}-0.452 \\
0.001\end{array}$ & $\begin{array}{c}-0.319 \\
0.0191\end{array}$ \\
\hline DH & $\begin{array}{l}0.4418 \\
0.0012\end{array}$ & $\begin{array}{l}0.393 \\
0.0036\end{array}$ & $\begin{array}{l}0.4371 \\
0.0013\end{array}$ & $\begin{array}{l}0.4317 \\
0.0015\end{array}$ & $\begin{array}{l}0.3197 \\
0.0188\end{array}$ & $\mathbf{N}$ & $\begin{array}{l}0.3928 \\
0.0039\end{array}$ & $\mathbf{N}$ & $\begin{array}{l}-0.304 \\
0.0255\end{array}$ & $\mathbf{N}$ & $\mathbf{N}$ & $\mathbf{N}$ & $\mathbf{N}$ & $\mathrm{N}$ & $N$ & $\mathrm{~N}$ \\
\hline OD & $\mathbf{N}$ & $\mathbf{N}$ & $\mathbf{N}$ & $\mathbf{N}$ & $\mathrm{N}$ & $\mathbf{N}$ & $\mathbf{N}$ & $\mathbf{N}$ & $\mathbf{N}$ & $\mathbf{N}$ & $\mathbf{N}$ & $\mathrm{N}$ & $\mathrm{N}$ & $\mathbf{N}$ & $\mathrm{N}$ & $\mathbf{N}$ \\
\hline DEO & $\begin{array}{l}0.3059 \\
0.0289\end{array}$ & $\mathbf{N}$ & $\begin{array}{l}0.2746 \\
0.0499\end{array}$ & $\begin{array}{l}0.3036 \\
0.0301\end{array}$ & $\begin{array}{l}0.2928 \\
0.0365\end{array}$ & $\mathbf{N}$ & $\mathbf{N}$ & $\begin{array}{c}-0.311 \\
0.0262\end{array}$ & $\begin{array}{l}-0.375 \\
0.0075\end{array}$ & $\mathbf{N}$ & $\mathbf{N}$ & $\mathbf{N}$ & $\mathbf{N}$ & $\mathbf{N}$ & $N$ & $N$ \\
\hline AlC & $\begin{array}{l}0.744 \\
0\end{array}$ & $\begin{array}{l}0.7247 \\
0\end{array}$ & $\begin{array}{l}0.7735 \\
0\end{array}$ & $\begin{array}{l}0.7725 \\
0\end{array}$ & $\begin{array}{l}0.5758 \\
0.0001\end{array}$ & $\mathbf{N}$ & $\begin{array}{l}0.6286 \\
0\end{array}$ & $\mathrm{~N}$ & $\begin{array}{l}-0.4035 \\
0.0052\end{array}$ & $\begin{array}{l}0.3318 \\
0.0215\end{array}$ & $\mathbf{N}$ & $\begin{array}{l}0.4136 \\
0.0022\end{array}$ & $\mathbf{N}$ & $\begin{array}{l}-0.4692 \\
0.0012\end{array}$ & $\begin{array}{c}-0.4793 \\
0.0009\end{array}$ & $\begin{array}{l}-0.412 \\
0.0025\end{array}$ \\
\hline $\mathbf{D R}$ & $N$ & $N$ & $\mathbf{N}$ & $\mathbf{N}$ & $\mathrm{N}$ & $\mathbf{N}$ & $\mathbf{N}$ & $\mathbf{N}$ & $\mathbf{N}$ & $\mathbf{N}$ & $\mathbf{N}$ & $\mathbf{N}$ & $\mathbf{N}$ & $\mathbf{N}$ & $\mathbf{N}$ & $\mathbf{N}$ \\
\hline PO4 & $\mathrm{N}$ & $\mathbf{N}$ & $\mathbf{N}$ & $\mathbf{N}$ & $\mathbf{N}$ & $\mathbf{N}$ & $\mathbf{N}$ & $\mathbf{N}$ & $\mathbf{N}$ & $\mathbf{N}$ & $\mathbf{N}$ & $\mathbf{N}$ & $\mathbf{N}$ & $\mathbf{N}$ & $\mathbf{N}$ & $\mathbf{N}$ \\
\hline POT & $N$ & $N$ & $\mathbf{N}$ & $\mathbf{N}$ & $\mathbf{N}$ & $\mathbf{N}$ & $\mathbf{N}$ & $\mathbf{N}$ & $\mathbf{N}$ & $\mathbf{N}$ & $\mathbf{N}$ & $\mathbf{N}$ & $\mathbf{N}$ & $\mathbf{N}$ & $N$ & $\mathbf{N}$ \\
\hline sor & $\mathrm{N}$ & $\mathbf{N}$ & $\mathbf{N}$ & $\mathbf{N}$ & $\mathbf{N}$ & $\mathbf{N}$ & $N$ & $\mathbf{N}$ & $\mathbf{N}$ & $\mathbf{N}$ & $\mathbf{N}$ & $\mathbf{N}$ & $\mathbf{N}$ & $\mathbf{N}$ & $\mathrm{N}$ & $\mathbf{N}$ \\
\hline NH4 & $\begin{array}{l}0.3633 \\
0.0076\end{array}$ & $\begin{array}{l}0.3176 \\
0.0196\end{array}$ & $\begin{array}{l}0.3956 \\
0.0037\end{array}$ & $\begin{array}{l}0.3918 \\
0.004\end{array}$ & $\mathrm{~N}$ & $\mathrm{~N}$ & $\mathbf{N}$ & $\mathbf{N}$ & $\begin{array}{c}-0.332 \\
0.0148\end{array}$ & $N$ & $N$ & $\mathbf{N}$ & $\mathbf{N}$ & $\begin{array}{l}-0.39 \\
0.0045\end{array}$ & $\begin{array}{l}-0.467 \\
0.0007\end{array}$ & $\begin{array}{l}0.3719 \\
0.0068\end{array}$ \\
\hline $\mathrm{No3}$ & $\mathrm{N}$ & $\mathbf{N}$ & $\mathrm{N}$ & $\begin{array}{l}-0.27 \\
0.0472\end{array}$ & $\mathbf{N}$ & $\mathbf{N}$ & $\mathbf{N}$ & $\mathbf{N}$ & $\begin{array}{l}0.301 \\
0.027\end{array}$ & $\mathbf{N}$ & $\mathbf{N}$ & $\mathbf{N}$ & $\mathbf{N}$ & $\mathrm{N}$ & $\mathrm{N}$ & $\mathrm{N}$ \\
\hline $\mathbf{S O 4}$ & $\begin{array}{l}0.4844 \\
0.0004\end{array}$ & $\begin{array}{l}0.3752 \\
0.0054\end{array}$ & $\begin{array}{l}0.4474 \\
0.001\end{array}$ & $\begin{array}{l}0.4606 \\
0.0007\end{array}$ & $\begin{array}{l}0.4292 \\
0.0016\end{array}$ & $\begin{array}{l}0.4048 \\
0.0029\end{array}$ & $\begin{array}{l}0.2731 \\
0.0448\end{array}$ & $\begin{array}{l}-0.2767 \\
0.042\end{array}$ & $\begin{array}{l}-0.4307 \\
0.0016\end{array}$ & $\mathrm{~N}$ & $\begin{array}{l}-0.4578 \\
0.0008\end{array}$ & $\mathbf{N}$ & $\begin{array}{l}-0.3265 \\
0.0155\end{array}$ & $\mathbf{N}$ & $\begin{array}{l}-0.3716 \\
0.0068\end{array}$ & $\begin{array}{l}-0.3446 \\
0.0113\end{array}$ \\
\hline Ca & $\begin{array}{l}0.6486 \\
0\end{array}$ & $\begin{array}{l}0.617 \\
0\end{array}$ & $\begin{array}{l}0.6431 \\
0\end{array}$ & $\begin{array}{l}0.638 \\
0\end{array}$ & $\begin{array}{l}0.4714 \\
0.0005\end{array}$ & $\begin{array}{l}0.3012 \\
0.0269\end{array}$ & $\begin{array}{l}0.4991 \\
0.0002\end{array}$ & $\mathrm{~N}$ & $\begin{array}{l}-0.4898 \\
0.0003\end{array}$ & $\mathbf{N}$ & $\begin{array}{l}-0.2753 \\
0.0431\end{array}$ & $\mathbf{N}$ & $\mathbf{N}$ & $\begin{array}{c}-0.4116 \\
0.0027\end{array}$ & $\begin{array}{l}-0.4284 \\
0.0018\end{array}$ & $\begin{array}{l}-0.2831 \\
0.0375\end{array}$ \\
\hline $\mathbf{a}$ & $N$ & $\mathrm{~N}$ & $\mathbf{N}$ & $\mathbf{N}$ & $N$ & $\begin{array}{l}0.2825 \\
0.0379\end{array}$ & $\mathrm{~N}$ & $\mathrm{~N}$ & $\mathbf{N}$ & $\begin{array}{l}-0.4078 \\
0.0027\end{array}$ & $\begin{array}{l}-0.4095 \\
0.0026\end{array}$ & $\begin{array}{l}-0.4209 \\
0.0018\end{array}$ & $\begin{array}{l}-0.3737 \\
0.0056\end{array}$ & $\mathbf{N}$ & $\mathrm{N}$ & $\mathrm{N}$ \\
\hline A & $\mathrm{N}$ & $\mathbf{N}$ & $\mathrm{N}$ & $\mathbf{N}$ & $\mathbf{N}$ & $\mathrm{N}$ & $\begin{array}{l}-0.2752 \\
0.0432\end{array}$ & $\mathbf{N}$ & $\mathbf{N}$ & $\mathbf{N}$ & $\begin{array}{l}0.2753 \\
0.0431\end{array}$ & $\mathbf{N}$ & $\mathbf{N}$ & $\mathbf{N}$ & $\mathbf{N}$ & $\mathbf{N}$ \\
\hline Cu & $\begin{array}{l}0.4834 \\
0.0004\end{array}$ & $\begin{array}{l}0.5302 \\
0.0001\end{array}$ & $\begin{array}{l}0.4712 \\
0.0005\end{array}$ & $\begin{array}{l}0.4955 \\
0.0003\end{array}$ & $\begin{array}{l}0.3141 \\
0.021\end{array}$ & $\mathbf{N}$ & $\begin{array}{l}0.428 \\
0.0017\end{array}$ & $N$ & $\mathbf{N}$ & $\mathbf{N}$ & $\mathbf{N}$ & $\begin{array}{l}0.3062 \\
0.0232\end{array}$ & $\mathbf{N}$ & $\mathbf{N}$ & $\mathbf{N}$ & $\mathbf{N}$ \\
\hline Fe & $\begin{array}{l}-0.376 \\
0.0057\end{array}$ & $\begin{array}{l}-0.3707 \\
0.0115\end{array}$ & $\begin{array}{l}-0.388 \\
0.0044\end{array}$ & $\begin{array}{l}-0.37 \\
0.0065\end{array}$ & $\mathrm{~N}$ & $\mathbf{N}$ & $\begin{array}{l}-0.327 \\
0.0163\end{array}$ & $\mathbf{N}$ & $\mathbf{N}$ & $\mathbf{N}$ & $\begin{array}{l}0.3084 \\
0.0234\end{array}$ & $\mathrm{~N}$ & $N$ & $\mathrm{~N}$ & $\begin{array}{l}0.2895 \\
0.0351\end{array}$ & $N$ \\
\hline $\mathbf{K}$ & $\begin{array}{l}0.6361 \\
0\end{array}$ & $\begin{array}{l}0.5392 \\
0.0001\end{array}$ & $\begin{array}{l}0.6107 \\
0\end{array}$ & $\begin{array}{l}0.6119 \\
0\end{array}$ & $\begin{array}{l}0.5453 \\
0.0001\end{array}$ & $\begin{array}{l}0.5011 \\
0.0002\end{array}$ & $\begin{array}{l}0.4051 \\
0.0029\end{array}$ & $\begin{array}{l}-0.372 \\
0.0063\end{array}$ & $\begin{array}{l}-0.656 \\
0\end{array}$ & $N$ & $\begin{array}{l}-0.496 \\
0.0003\end{array}$ & $\mathrm{~N}$ & $\begin{array}{l}-0.2763 \\
0.0405\end{array}$ & $\begin{array}{l}-0.335 \\
0.0146\end{array}$ & $\begin{array}{l}-0.411 \\
0.0027\end{array}$ & $\begin{array}{l}-0.3911 \\
0.0041\end{array}$ \\
\hline $\mathbf{M}$ & $\mathbf{N}$ & $\mathbf{N}$ & $\mathbf{N}$ & $\mathrm{N}$ & $\mathrm{N}$ & $\begin{array}{l}0.2776 \\
0.0414\end{array}$ & $\mathrm{~N}$ & $\begin{array}{l}-0.3511 \\
0.0099\end{array}$ & $\begin{array}{l}-0.3342 \\
0.0141\end{array}$ & $\begin{array}{l}-0.28 \\
0.0396\end{array}$ & $\begin{array}{l}-0.2848 \\
0.0364\end{array}$ & $N$ & $N$ & $N$ & $\mathrm{~N}$ & $N$ \\
\hline Mn & $\begin{array}{l}0.3772 \\
0.0056\end{array}$ & $\begin{array}{l}0.3669 \\
0.0065\end{array}$ & $\begin{array}{l}-0.3843 \\
0.0047\end{array}$ & $\begin{array}{l}0.391 \\
0.0041\end{array}$ & $\mathrm{~N}$ & $\mathrm{~N}$ & $\mathbf{N}$ & $\mathrm{N}$ & $\begin{array}{l}-0.2956 \\
0.0298\end{array}$ & $\mathrm{~N}$ & $\mathrm{~N}$ & $\mathbf{N}$ & $\mathbf{N}$ & $\begin{array}{l}-0.4747 \\
0.0005\end{array}$ & $\begin{array}{l}-0.4277 \\
0.0018\end{array}$ & $\begin{array}{l}-0.2881 \\
0.0342\end{array}$ \\
\hline $\mathbf{N}$ & $\mathbf{N}$ & $\mathbf{N}$ & $\mathbf{N}$ & $\mathbf{N}$ & $\mathbf{N}$ & $\begin{array}{l}0.3754 \\
0.0058\end{array}$ & $\mathbf{N}$ & $\begin{array}{c}-0.3891 \\
0.0042\end{array}$ & $\begin{array}{l}-0.3989 \\
0.0034\end{array}$ & $\begin{array}{l}-0.5196 \\
0.0001\end{array}$ & $\begin{array}{l}-0.5803 \\
0\end{array}$ & $\begin{array}{l}-0.488 \\
0.0003\end{array}$ & $\begin{array}{l}-0.4892 \\
0.0003\end{array}$ & $\mathrm{~N}$ & $\mathrm{~N}$ & $\mathrm{~N}$ \\
\hline $\mathbf{S}$ & $\begin{array}{l}-0.2947 \\
0.0303\end{array}$ & $\begin{array}{l}-0.282 \\
0.0365\end{array}$ & $\begin{array}{l}-0.3176 \\
0.0196\end{array}$ & $\begin{array}{l}-0.2884 \\
0.034\end{array}$ & $N$ & $\mathrm{~N}$ & $\begin{array}{l}-0.3282 \\
0.0159\end{array}$ & $\mathrm{~N}$ & $N$ & $\mathrm{~N}$ & $\mathbf{N}$ & $\mathrm{N}$ & $\mathrm{N}$ & $N$ & $\mathbf{N}$ & $\mathbf{N}$ \\
\hline $\mathbf{Z n}_{\mathbf{m}}$ & $\begin{array}{l}0.3576 \\
0.0086\end{array}$ & $\begin{array}{l}0.4403 \\
0.0011\end{array}$ & $\begin{array}{l}0.4152 \\
0.0023\end{array}$ & $\begin{array}{l}0.4289 \\
0.0016\end{array}$ & $\mathbf{N}$ & $\mathbf{N}$ & $\begin{array}{l}0.4201 \\
0.002\end{array}$ & $\mathbf{N}$ & $\mathbf{N}$ & $\begin{array}{l}0.4893 \\
0.0003\end{array}$ & $\mathbf{N}$ & $\begin{array}{l}0.462 \\
0.0006\end{array}$ & $\begin{array}{l}0.2738 \\
0.0423\end{array}$ & $\begin{array}{c}-0.398 \\
0.0037\end{array}$ & $\begin{array}{l}-0.296 \\
0.0313\end{array}$ & $\begin{array}{l}-0.2689 \\
0.0482\end{array}$ \\
\hline $\mathbf{S A}$ & $\begin{array}{l}0.4625 \\
0.0006\end{array}$ & $\begin{array}{l}0.4761 \\
0.0004\end{array}$ & $\begin{array}{l}0.4576 \\
0.0007\end{array}$ & $\begin{array}{l}0.4689 \\
0.0005\end{array}$ & $\begin{array}{l}0.3457 \\
0.0103\end{array}$ & $\mathrm{~N}$ & $\begin{array}{l}0.344 \\
0.0107\end{array}$ & $\mathbf{N}$ & $\begin{array}{l}-0.2774 \\
0.0397\end{array}$ & $\mathrm{~N}$ & $\mathbf{N}$ & $\begin{array}{l}0.3099 \\
0.0215\end{array}$ & $\mathrm{~N}$ & $\mathrm{~N}$ & $\mathrm{~N}$ & $\mathbf{N}$ \\
\hline $\mathbf{S D}$ & $\begin{array}{l}0.3769 \\
0.0002\end{array}$ & $\begin{array}{l}0.3619 \\
0.0073\end{array}$ & $\begin{array}{l}0.3576 \\
0.0081\end{array}$ & $\begin{array}{l}0.3772 \\
0.0052\end{array}$ & $N$ & $\mathrm{~N}$ & $\mathrm{~N}$ & $N$ & $\begin{array}{l}-0.32 \\
0.0176\end{array}$ & $N$ & $\mathbf{N}$ & $\mathrm{N}$ & $\mathrm{N}$ & $\mathrm{N}$ & $N$ & $N$ \\
\hline
\end{tabular}


TABELA 23 - CORRELAÇŌES: VARIÁVEIS ABIÓTICAS E ESTRATÉGLAS ADAPTATIVAS DA COMUNIDADE FITOPLANCTONICA. PONTO 1. REPRESA DE GUARAPIRANGA 1991-92.

Varívés abióticas: velocidade média do vento (W); radiação solar (RAD); insolação (INS); precipitação (P); elevação (ELE); deficiência hídrica do solo (DEF); volume (VOL); excodente hidrioo (EXC); temperatura da água (TAG); profindidade (PROF); transparência (SEC); or (COR); turbidez (TUR); condutividade (CON); $\mathrm{pH}(\mathrm{pH})$; axigénio dissolvido (OD); demanda bioquímica de oxigìnio (DBO); alcalinicade (ALO); dureza (DUR); sólidos totais em suspensão (SOT); fósforo solúvel reaưvo (PO4); fósforo total (PT); amônio (NH4); nitrato $\left(\mathrm{NO}_{3}\right)$; sulfato (SO $)$; doro (CI); aluminio (A); cálcio (Ca); cobre (Cu); ferro (Fe); poćssio (K); magnésio (Mg); manganés (Mn); sódio (Na); silicio (Si) e zinoo (Zn); sulfatacão no dia anterior (SDA); sulfatacäo no dia da ooleta (SD); panto 1 (P1); ponto 4 (P4).

Variáveis do fitoplâneton: densidade em células do nano-(NA); micro-(MI) e macro-fitoplâncton (MA); da Classe 1 (C1); da Classe 2 (C2); da Classe 3 (C)); da Classe 4 (CA); organismos: ocm (CM) e sern motilidade (SM); com (CER) e sem envoltório rígido (SER).

\begin{tabular}{|c|c|c|c|c|c|c|c|c|c|c|c|}
\hline PI & NA & MI & $\mathbf{M A}$ & $\mathrm{Cl}$ & C2 & C3 & C4 & CM & SM & CER & SER \\
\hline W & $\mathrm{N}$ & $\mathrm{N}$ & $\mathbf{N}$ & $\mathrm{N}$ & $\mathbf{N}$ & $\mathbf{N}$ & $\mathrm{N}$ & $\mathbf{N}$ & $\mathrm{N}$ & $\mathrm{N}$ & $\mathbf{N}$ \\
\hline RAD & $\mathbf{N}$ & $\begin{array}{l}-0.3088 \\
0.022\end{array}$ & $\begin{array}{l}-0.4318 \\
0.0014\end{array}$ & $\mathrm{~N}$ & $\begin{array}{l}-0.3314 \\
0.014\end{array}$ & $\begin{array}{l}0.4381 \\
0.0012\end{array}$ & $\mathrm{~N}$ & $\mathrm{~N}$ & $\mathrm{~N}$ & $\begin{array}{c}-0.3221 \\
0.0169\end{array}$ & $\mathbf{N}$ \\
\hline NS & $N$ & $\mathbf{N}$ & & $\mathrm{N}$ & & & $\mathbf{N}$ & $\mathrm{N}$ & $\mathrm{N}$ & & $\mathbf{N}$ \\
\hline P & $\mathrm{N}$ & $\mathbf{N}$ & $\begin{array}{l}-0.3233 \\
0.0165\end{array}$ & $\mathbf{N}$ & $\mathrm{N}$ & $\mathbf{N}$ & $\mathrm{N}$ & $N$ & $\mathrm{~N}$ & $\mathrm{~N}$ & $\mathrm{~N}$ \\
\hline DE & $\mathrm{N}$ & N & $\begin{array}{l}0.337 \\
0.0124\end{array}$ & $N$ & $\mathbf{N}$ & $\begin{array}{l}-0.3018 \\
0.0252\end{array}$ & $\mathbf{N}$ & $\mathbf{N}$ & $N$ & $\mathrm{~N}$ & $\mathrm{~N}$ \\
\hline DEF. & $\mathrm{N}$ & $\begin{array}{l}0.371 \\
0.0059\end{array}$ & & $\mathrm{~N}$ & 0.5586 & & $\mathrm{~N}$ & $\mathrm{~N}$ & $\mathrm{~N}$ & $\mathrm{~N}$ & $\mathrm{~N}$ \\
\hline Vot & $\mathrm{N}$ & & $\begin{array}{l}0.337 \\
0.0124\end{array}$ & $\mathbf{N}$ & $\mathbf{N}$ & $\begin{array}{l}-0.3048 \\
0.0238\end{array}$ & $\mathrm{~N}$ & $\mathrm{~N}$ & $N$ & $\mathrm{~N}$ & $N$ \\
\hline EXC & $\mathrm{N}$ & $\mathbf{N}$ & & $\mathrm{N}$ & $\mathbf{N}$ & & $\begin{array}{l}-0.3064 \\
0.0231\end{array}$ & $N$ & $N$ & $N$ & $\mathrm{~N}$ \\
\hline TAG & $\begin{array}{l}0.6459 \\
0\end{array}$ & $\mathbf{N}$ & $\begin{array}{l}-0.3876 \\
0.004\end{array}$ & $\begin{array}{l}0.4805 \\
0.0004\end{array}$ & $\mathrm{~N}$ & $\begin{array}{l}0.3035 \\
0.0244\end{array}$ & $\mathrm{~N}$ & $\mathrm{~N}$ & $\begin{array}{l}0.5831 \\
0\end{array}$ & $\mathrm{~N}$ & $\begin{array}{l}0.6322 \\
0\end{array}$ \\
\hline FROF & & $\mathrm{N}$ & $\begin{array}{l}0.3144 \\
0.0197\end{array}$ & & N & & $\mathbf{N}$ & $\mathrm{N}$ & $\mathrm{N}$ & $\mathrm{N}$ & $\mathrm{N}$ \\
\hline $\mathbf{S C}$ & $\begin{array}{l}-0.6344 \\
0\end{array}$ & $\mathrm{~N}$ & $\begin{array}{l}0.301 \\
0.0256\end{array}$ & $\begin{array}{l}-0.5942 \\
0\end{array}$ & $N$ & $\mathrm{~N}$ & $\mathrm{~N}$ & $N$ & $\begin{array}{l}-0.6464 \\
0\end{array}$ & $\mathrm{~N}$ & $\begin{array}{l}-0.6531 \\
0\end{array}$ \\
\hline COR & $\mathrm{N}$ & $\mathrm{N}$ & & $\mathrm{N}$ & $\mathrm{N}$ & $\mathbf{N}$ & $\mathrm{N}$ & $\mathrm{N}$ & $\mathrm{N}$ & $\mathrm{N}$ & $\mathbf{N}$ \\
\hline TUR & $\begin{array}{l}0.4136 \\
0.0022\end{array}$ & $N$ & $\mathrm{~N}$ & $\begin{array}{l}0.4416 \\
0.0011\end{array}$ & $\mathrm{~N}$ & $\mathrm{~N}$ & $\mathrm{~N}$ & $\mathrm{~N}$ & $\begin{array}{l}0.4578 \\
0.0007\end{array}$ & $\mathbf{N}$ & $\begin{array}{l}0.3931 \\
0.0035\end{array}$ \\
\hline CON & $\begin{array}{l}0.4681 \\
0.0005\end{array}$ & $N$ & $\begin{array}{r}-0.3291 \\
0.0147\end{array}$ & $\begin{array}{l}0.4447 \\
0.001\end{array}$ & $\begin{array}{l}0.3067 \\
0.0229\end{array}$ & $N$ & $\mathrm{~N}$ & $\mathrm{~N}$ & $\begin{array}{l}0.521 \\
0.0001\end{array}$ & $\mathrm{~N}$ & ${ }_{0}^{0.5659}$ \\
\hline dH & $\begin{array}{l}0.4072 \\
0.0025\end{array}$ & $\mathrm{~N}$ & & $\begin{array}{l}0.3353 \\
0.0129\end{array}$ & $\begin{array}{l}0.3301 \\
0.0144\end{array}$ & $\mathrm{~N}$ & $\mathbf{N}$ & $\begin{array}{l}0.2922 \\
0.0302\end{array}$ & $\begin{array}{l}0.4309 \\
0.0014\end{array}$ & $\mathrm{~N}$ & $\begin{array}{l}0.4919 \\
0.0003\end{array}$ \\
\hline OD & & $\mathbf{N}$ & $N$ & & & $\mathbf{N}$ & $\mathrm{N}$ & & & $\mathrm{N}$ & $\mathbf{N}$ \\
\hline DAO & $\begin{array}{l}0.3513 \\
0.0092\end{array}$ & $\mathrm{~N}$ & $N$ & $\mathbf{N}$ & $\mathbf{N}$ & $\mathbf{N}$ & $\mathrm{N}$ & $\mathrm{N}$ & $\begin{array}{l}0.3408 \\
0.0115\end{array}$ & $\mathrm{~N}$ & $\begin{array}{l}0.3344 \\
0.0131\end{array}$ \\
\hline ALC & $\begin{array}{l}0.655 \\
0\end{array}$ & $\begin{array}{l}0.4144 \\
0.0021\end{array}$ & $N$ & $\begin{array}{l}0.6541 \\
0\end{array}$ & $\begin{array}{l}0.505 \\
0.0002\end{array}$ & $\mathrm{~N}$ & $\mathbf{N}$ & $\mathrm{N}$ & $\begin{array}{l}0.7229 \\
0\end{array}$ & $\mathrm{~N}$ & 0.6948 \\
\hline DUR & $\mathbf{N}$ & & $\mathbf{N}$ & $\mathbf{N}$ & & $\mathbf{N}$ & $\mathbf{N}$ & $\mathbf{N}$ & $\begin{array}{l}0.3499 \\
0.4444\end{array}$ & $\mathrm{~N}$ & $\begin{array}{l}0.3608 \\
0.0382\end{array}$ \\
\hline 104 & $\mathrm{~N}$ & $N$ & $\mathbf{N}$ & $\mathbf{N}$ & $\mathbf{N}$ & $\mathrm{N}$ & $\mathbf{N}$ & $\mathrm{N}$ & $\mathbf{N}$ & $\mathbf{N}$ & \\
\hline POr & $\mathrm{N}$ & $\mathbf{N}$ & $\mathrm{N}$ & $\mathbf{N}$ & $\mathbf{N}$ & $\mathrm{N}$ & $\mathrm{N}$ & $\mathbf{N}$ & $\mathbf{N}$ & $\mathrm{N}$ & $\mathbf{N}$ \\
\hline sor & $\mathrm{N}$ & $\mathbf{N}$ & $\mathbf{N}$ & $\mathrm{N}$ & $\mathbf{N}$ & $\mathbf{N}$ & $\mathbf{N}$ & $\mathrm{N}$ & $\mathrm{N}$ & $\mathrm{N}$ & $\mathbf{N}$ \\
\hline NH4 & $\begin{array}{l}0.3303 \\
0.0152\end{array}$ & $\mathrm{~N}$ & $\mathrm{~N}$ & $\mathbf{N}$ & $\mathbf{N}$ & $\mathrm{N}$ & $\mathbf{N}$ & $\mathrm{N}$ & $\begin{array}{l}0.3795 \\
0.0035\end{array}$ & $\mathrm{~N}$ & $\begin{array}{l}0.3872 \\
0.0044\end{array}$ \\
\hline NoB & $\begin{array}{l}-0.2811 \\
0.0371\end{array}$ & $\mathrm{~N}$ & $\mathbf{N}$ & $N$ & $\mathrm{~N}$ & $\mathbf{N}$ & $\mathrm{N}$ & $N$ & $\begin{array}{l}-0.2683 \\
0.0466\end{array}$ & $\mathrm{~N}$ & \\
\hline SO4 & $\begin{array}{l}0.5421 \\
0.0001\end{array}$ & $\mathbf{N}$ & $\begin{array}{l}-0.31 \\
0.0215\end{array}$ & $\begin{array}{l}0.3648 \\
0.0068\end{array}$ & $\mathrm{~N}$ & $\begin{array}{l}0.2714 \\
0.0414\end{array}$ & $\mathrm{~N}$ & $N$ & $\begin{array}{l}0.5221 \\
0.0001\end{array}$ & $\mathrm{~N}$ & $\begin{array}{l}0.5574 \\
0\end{array}$ \\
\hline Ca & $\begin{array}{l}0.6731 \\
0\end{array}$ & $\mathrm{~N}$ & $\begin{array}{l}-0.315 \\
0.0195\end{array}$ & $\begin{array}{l}0.5871 \\
0\end{array}$ & $N$ & $\mathrm{~N}$ & $N$ & $\mathrm{~N}$ & $\begin{array}{l}0.688 \\
0\end{array}$ & $\mathrm{~N}$ & $\begin{array}{l}0.6919 \\
0\end{array}$ \\
\hline $\mathbf{a}$ & $\mathbf{N}$ & $\mathrm{N}$ & $\begin{array}{c}-0.378 \\
0.0051\end{array}$ & $\mathbf{N}$ & $\mathrm{N}$ & $\begin{array}{l}0.2873 \\
0.0331\end{array}$ & $\mathrm{~N}$ & $\mathrm{~N}$ & $\mathbf{N}$ & $\mathrm{N}$ & $\mathrm{N}$ \\
\hline N & $\mathrm{N}$ & $\mathbf{N}$ & & $\mathrm{N}$ & $\begin{array}{l}-0.3004 \\
0.0259\end{array}$ & & $\begin{array}{l}0.3902 \\
0.0038\end{array}$ & $N$ & $N$ & $\mathrm{~N}$ & $\mathrm{~N}$ \\
\hline$C_{u}$ & $\begin{array}{l}0.4728 \\
0.0005\end{array}$ & $\mathrm{~N}$ & $\mathrm{~N}$ & $\begin{array}{l}0.612 \\
0\end{array}$ & $\begin{array}{l}0.3365 \\
0.0126\end{array}$ & $\mathrm{~N}$ & & $\mathrm{~N}$ & $\begin{array}{l}0.4876 \\
0.0003\end{array}$ & $\mathrm{~N}$ & $\begin{array}{l}0.4868 \\
0.0003\end{array}$ \\
\hline Fe & $\begin{array}{l}-0.3477 \\
0.0099\end{array}$ & $\mathrm{~N}$ & $\begin{array}{l}0.3689 \\
0.0062\end{array}$ & $\begin{array}{l}0.3243 \\
0.0162\end{array}$ & & $\mathbf{N}$ & $\mathrm{N}$ & $\mathrm{N}$ & $\begin{array}{c}-0.3888 \\
0.0039\end{array}$ & $\mathrm{~N}$ & $\begin{array}{l}-0.4628 \\
0.0006\end{array}$ \\
\hline $\mathbf{K}$ & $\begin{array}{l}0.6872 \\
0\end{array}$ & $\mathrm{~N}$ & $\begin{array}{l}-0.3983 \\
0.0031\end{array}$ & $\begin{array}{l}0.5044 \\
0.0002\end{array}$ & $\mathbf{N}$ & $\begin{array}{l}0.2665 \\
0.0481\end{array}$ & $N$ & $\mathbf{N}$ & $\begin{array}{l}0.6709 \\
0\end{array}$ & $\mathrm{~N}$ & $\begin{array}{l}0.7104 \\
0\end{array}$ \\
\hline Me & $\begin{array}{l}0.2918 \\
0.0305\end{array}$ & $N$ & & & $N$ & $\begin{array}{l}0.2712 \\
0.0443\end{array}$ & $\mathrm{~N}$ & $\mathrm{~N}$ & $\mathrm{~N}$ & $\mathrm{~N}$ & $\begin{array}{l}0.2645 \\
0.0498\end{array}$ \\
\hline Mn & $\begin{array}{l}0.3484 \\
0.0098\end{array}$ & $N$ & $\mathbf{N}$ & $\begin{array}{l}0.3664 \\
0.0066\end{array}$ & $\mathbf{N}$ & & $\mathrm{N}$ & $\begin{array}{l}-0.267 \\
0.0477\end{array}$ & $\begin{array}{l}0.3801 \\
0.0048\end{array}$ & $\mathrm{~N}$ & $\begin{array}{l}0.3632 \\
0.0071\end{array}$ \\
\hline vin & & $\mathrm{N}$ & $\begin{array}{l}-0.4607 \\
0.0006\end{array}$ & & $\mathrm{~N}$ & $\begin{array}{l}0.3637 \\
0.007\end{array}$ & $\mathrm{~N}$ & & & $\begin{array}{c}-0.3074 \\
0.0226\end{array}$ & \\
\hline $\mathbf{S}$ & $\mathrm{N}$ & $\mathrm{N}$ & & $\mathrm{N}$ & $\begin{array}{c}-0.3276 \\
0.0151\end{array}$ & & $\mathrm{~N}$ & $\begin{array}{c}-0.2888 \\
0.0322\end{array}$ & $\begin{array}{c}-0.2831 \\
0.0358\end{array}$ & & $\begin{array}{c}-0.3212 \\
0.0172\end{array}$ \\
\hline $\mathbf{Z n}$ & $\begin{array}{l}0.3045 \\
0.0239\end{array}$ & $\begin{array}{l}0.3632 \\
0.0071\end{array}$ & $\mathrm{~N}$ & $\begin{array}{l}0.336 \\
0.0127\end{array}$ & $\begin{array}{l}0.4243 \\
0.0017\end{array}$ & $\begin{array}{l}-0.3461 \\
0.0103\end{array}$ & $\mathrm{~N}$ & & $\begin{array}{l}0.3813 \\
0.0047\end{array}$ & $\mathrm{~N}$ & $\begin{array}{l}0.311 \\
0.0207\end{array}$ \\
\hline SDA & $\begin{array}{l}0.4753 \\
0.0004\end{array}$ & & $\mathrm{~N}$ & $\begin{array}{l}0.5076 \\
0.0002\end{array}$ & $\begin{array}{l}0.2961 \\
0.0281\end{array}$ & & $\mathrm{~N}$ & $\mathrm{~N}$ & $\begin{array}{l}0.483 \\
0.0003\end{array}$ & $N$ & $\begin{array}{l}0.4477 \\
0.0009\end{array}$ \\
\hline SD & $\begin{array}{l}0.4158 \\
0.0028\end{array}$ & $\mathrm{~N}$ & $\mathrm{~N}$ & $\begin{array}{l}0.4027 \\
0.0028\end{array}$ & & $\mathbf{N}$ & $\mathrm{N}$ & $\mathrm{N}$ & $\begin{array}{l}0.399 \\
0.0031\end{array}$ & $\mathrm{~N}$ & $\begin{array}{l}0.3775 \\
0.0051\end{array}$ \\
\hline
\end{tabular}


TABELA 23 (continuação) - CORRELAÇŐES: VARIÁVEIS ABIÓTICAS E ESTRATÉGLAS ADAPTATIVAS DA COMUNIDADE FITOPLANCTONICA DO PONTO 1 - REPRESA DE GUARAPIRANGA 1991-92.

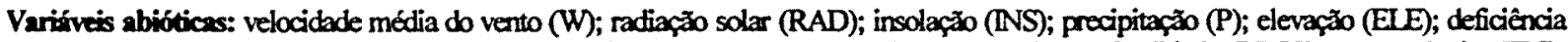
hidrica do soto (DEF); volume (VOL); excodente hídrioo (EXC); temperatura da água (TAG); profundidade (PROF); transparência (SEC); or (COR); turbidez (TUR); condutividade (CON); $\mathrm{pH}(\mathrm{pH})$; axigênio dissolvido (OD); demanda bioquímica de axigênio (DBO); alcalinidade (ALC); dureza (DUR); sólidos totais em suspensão (SOT); fósforo solúvel reativo (PO4); fósforo total (PT); amônio (NH4); nitrato $\left(\mathrm{NO}_{3}\right)$; sulfato $\left(\mathrm{SO}_{4}\right)$; doro $(\mathrm{Cl})$; alumínio $(\mathrm{Al})$; cálcio $(\mathrm{Ca})$; cobre (Cu); ferro (Fe); potássio (K); magnésio $(\mathrm{Mg})$; manganês $(\mathrm{Mn})$; sódio (Na); silicio (Si) e zinoo (Zn); sulfaçäo no dia anterior (SDA); sulfaçăo no dia da coleta (SD); panto 1 (P1); panto 4 (P4).

Variálveis do fitoplâncton: biovolume de organismos: com motilidade (CMV); sem motilidade (SMV); sem envoltório rígido (SERV); com envoltório rígido (CERV); densidade de formas coloniais ou cenobiais (COL); filamentosas (FIL) e unicelulares (UNI); bivolume de formas coloniais ou cenobiais (COLV); filamentosas (FILV) e unicetulares (UNIV).

\begin{tabular}{|c|c|c|c|c|c|c|c|c|c|c|}
\hline $\mathbf{P 1}$ & CMV & SMV & CERV & SERV & COLD & FILD & UNID & COLV & FILV & UNIV \\
\hline $\mathbf{w}$ & $\mathbf{N}$ & $N$ & $\mathrm{~N}$ & $\mathrm{~N}$ & $\mathrm{~N}$ & $\mathrm{~N}$ & $\bar{N}$ & $\mathrm{~N}$ & $\mathbf{N}$ & $\mathrm{N}$ \\
\hline RAD & $\mathrm{N}$ & \multirow{2}{*}{$\begin{array}{l}0.4676 \\
0.0005 \\
N\end{array}$} & $\mathbf{N}$ & \multirow{2}{*}{$\begin{array}{l}0.4472 \\
0.0009 \\
\mathrm{~N}\end{array}$} & $\mathrm{~N}$ & $\mathrm{~N}$ & $\mathrm{~N}$ & \multirow{2}{*}{$\begin{array}{l}0.2781 \\
0.0391 \\
\mathrm{~N}\end{array}$} & $\mathrm{~N}$ & \multirow{2}{*}{$\begin{array}{l}-0.2951 \\
0.0289 \\
\mathrm{~N}\end{array}$} \\
\hline $\mathbf{N S}$ & $\mathrm{N}$ & & $\mathbf{N}$ & & $\mathrm{N}$ & $\mathrm{N}$ & $N$ & & $\mathbf{N}$ & \\
\hline $\mathbf{P}$ & $\mathrm{N}$ & $\mathbf{N}$ & $\mathbf{N}$ & $\mathrm{N}$ & $\mathbf{N}$ & $\mathbf{N}$ & $\mathrm{N}$ & $\mathbf{N}$ & $\mathbf{N}$ & $\mathrm{N}$ \\
\hline EE & $\mathbf{N}$ & \multirow{2}{*}{$\begin{array}{l}-0.3373 \\
0.0124 \\
\mathrm{~N}\end{array}$} & $\mathrm{~N}$ & $\mathbf{N}$ & $\mathbf{N}$ & \multirow{2}{*}{$\begin{array}{l}-0.2975 \\
0.0274 \\
\mathrm{~N}\end{array}$} & $\mathrm{~N}$ & $\mathbf{N}$ & \multirow{2}{*}{$\begin{array}{l}-0.3622 \\
\stackrel{0.0072}{N}\end{array}$} & $\mathrm{~N}$ \\
\hline DEF. & $\mathrm{N}$ & & $N$ & $\mathrm{~N}$ & $\mathrm{~N}$ & & $\begin{array}{l}0.3529 \\
0.0089\end{array}$ & $\mathrm{~N}$ & & $\begin{array}{l}0.3743 \\
0.0055\end{array}$ \\
\hline Vot & $\mathbf{N}$ & \multirow{2}{*}{$\begin{array}{l}-0.3395 \\
0.0118 \\
\mathrm{~N}\end{array}$} & $\mathbf{N}$ & $\mathbf{N}$ & $\mathbf{N}$ & \multirow{2}{*}{$\begin{array}{l}-0.2978 \\
0.0272 \\
\mathrm{~N}\end{array}$} & & $\mathbf{N}$ & \multirow{2}{*}{$\begin{array}{l}-0.3622 \\
0.0072 \\
\mathrm{~N}\end{array}$} & \\
\hline Exc & $\mathrm{N}$ & & $\mathrm{N}$ & $N$ & $N$ & & $N$ & $N$ & & $\mathbf{N}$ \\
\hline IAG & $\mathbf{N}$ & \multirow{2}{*}{$\begin{array}{l}0.5491 \\
0 \\
\mathrm{~N}\end{array}$} & \multirow{2}{*}{$\begin{array}{l}-0.2789 \\
0.0389 \\
\mathrm{~N}\end{array}$} & \multirow{2}{*}{$\begin{array}{l}0.6042 \\
0 \\
\mathbf{N}\end{array}$} & \multirow{2}{*}{$\begin{array}{l}0.4304 \\
0.0014 \\
\mathrm{~N}\end{array}$} & \multirow{2}{*}{$\begin{array}{l}0.4771 \\
0.0004 \\
\mathrm{~N}\end{array}$} & \multirow{2}{*}{$\begin{array}{l}0.3166 \\
0.0189 \\
\mathrm{~N}\end{array}$} & \multirow{2}{*}{$\begin{array}{l}0.2938 \\
0.0293 \\
\mathrm{~N}\end{array}$} & \multirow{2}{*}{$\begin{array}{l}0.3879 \\
0.004 \\
\mathrm{~N}\end{array}$} & $\mathrm{~N}$ \\
\hline FROF & $N$ & & & & & & & & & $\mathbf{N}$ \\
\hline $\mathbf{S D C}$ & $\begin{array}{l}0.331 \\
0.0141 \\
N\end{array}$ & $\begin{array}{l}-0.3885 \\
0.004 \\
\mathrm{~N}\end{array}$ & $\begin{array}{l}0.3014 \\
0.0254 \\
\mathrm{~N}\end{array}$ & $\begin{array}{l}-0.3971 \\
0.0032 \\
\mathrm{~N}\end{array}$ & $\begin{array}{l}-0.4554 \\
0.0007 \\
\mathrm{~N}\end{array}$ & $\begin{array}{l}-0.5577 \\
0 \\
\mathrm{~N}\end{array}$ & $\begin{array}{l}-0.5537 \\
0 \\
\mathrm{~N}\end{array}$ & $\mathrm{~N}$ & $\begin{array}{l}-0.3146 \\
0.0197\end{array}$ & $\mathrm{~N}$ \\
\hline TUR & -0.3354 & $\mathrm{~N}$ & $\mathrm{~N}$ & $\mathrm{~N}$ & 0.2643 & 0.4505 & 0.3666 & $\mathrm{~N}$ & 0.3274 & $\mathrm{~N}$ \\
\hline$c a N$ & $\begin{array}{l}0.0129 \\
\mathrm{~N}\end{array}$ & $N$ & $N$ & $\begin{array}{l}0.295 \\
0.0287\end{array}$ & $\begin{array}{l}0.05 \\
0.423 \\
0.0017\end{array}$ & $\begin{array}{l}0.0007 \\
0.5036 \\
0.0002\end{array}$ & $\begin{array}{l}0.0066 \\
0.4197 \\
0.0019\end{array}$ & $\mathrm{~N}$ & $\begin{array}{l}0.0152 \\
0.3052 \\
0.0236\end{array}$ & $\mathrm{~N}$ \\
\hline DH & $\mathrm{N}$ & $\begin{array}{l}0.3186 \\
0.0121\end{array}$ & $\mathrm{~N}$ & $\begin{array}{l}0.2963 \\
0.028\end{array}$ & $\begin{array}{l}0.3896 \\
0.0039\end{array}$ & $\begin{array}{l}0.3888 \\
0.0039\end{array}$ & $\begin{array}{l}0.3115 \\
0.0209\end{array}$ & $\mathrm{~N}$ & & $\mathrm{~N}$ \\
\hline OD & $\begin{array}{l}0.2648 \\
0.0496\end{array}$ & $\mathrm{~N}$ & $\mathrm{~N}$ & & & & & $\mathrm{~N}$ & $\begin{array}{l}-0.2815 \\
0.0369\end{array}$ & $N$ \\
\hline DEO & $\mathrm{N}$ & $\begin{array}{l}0.2847 \\
0.0347\end{array}$ & $N$ & $\begin{array}{l}0.3601 \\
0.0076\end{array}$ & $\begin{array}{l}0.3103 \\
0.0214\end{array}$ & $\mathrm{~N}$ & $N$ & $\mathbf{N}$ & & $\mathrm{N}$ \\
\hline ALC & $\begin{array}{l}-0.4124 \\
0.0022\end{array}$ & $\begin{array}{l}0.3343 \\
0.0132\end{array}$ & $\mathrm{~N}$ & $\begin{array}{l}0.3352 \\
0.0129\end{array}$ & $\begin{array}{l}0.5011 \\
0.0002\end{array}$ & $\begin{array}{l}0.6551 \\
0\end{array}$ & $\begin{array}{l}0.6901 \\
0\end{array}$ & $\mathrm{~N}$ & $\begin{array}{l}0.3059 \\
0.0233\end{array}$ & $\mathrm{~N}$ \\
\hline DuR & $\mathbf{N}$ & & $\mathrm{N}$ & & & $\mathbf{N}$ & & $\mathrm{N}$ & & $\mathbf{N}$ \\
\hline POA & $\mathrm{N}$ & $N$ & $\mathrm{~N}$ & $\mathrm{~N}$ & $N$ & $N$ & $\mathrm{~N}$ & $\mathbf{N}$ & $\mathbf{N}$ & $\mathbf{N}$ \\
\hline FOT & $\begin{array}{l}0.2839 \\
0.0352\end{array}$ & $\mathrm{~N}$ & $\mathrm{~N}$ & $\mathrm{~N}$ & $\mathbf{N}$ & $\mathbf{N}$ & $\mathrm{N}$ & $\mathbf{N}$ & $N$ & $\mathbf{N}$ \\
\hline sor & $\mathrm{N}$ & $\mathrm{N}$ & $\mathrm{N}$ & $\mathbf{N}$ & $\mathrm{N}$ & $\mathbf{N}$ & $N$ & $\mathbf{N}$ & $N$ & $\mathbf{N}$ \\
\hline NH4 & $\begin{array}{l}-0.3834 \\
0.0048\end{array}$ & $\mathrm{~N}$ & $\mathrm{~N}$ & $\mathbf{N}$ & $\begin{array}{l}0.3928 \\
0.0039\end{array}$ & $\begin{array}{l}0.3017 \\
0.0266\end{array}$ & $\begin{array}{l}0.3381 \\
0.013\end{array}$ & $\mathrm{~N}$ & $\mathbf{N}$ & $\mathbf{N}$ \\
\hline NOB & $\mathrm{N}$ & $\mathrm{N}$ & $N$ & $\mathbf{N}$ & & & & $\mathbf{N}$ & $\mathbf{N}$ & $\mathbf{N}$ \\
\hline 504 & $\mathrm{~N}$ & $\begin{array}{l}0.4861 \\
0.0003\end{array}$ & $\begin{array}{l}-0.3011 \\
0.0241\end{array}$ & $\begin{array}{l}0.5462 \\
0.0001\end{array}$ & $\begin{array}{l}0.4162 \\
0.002\end{array}$ & $\begin{array}{l}0.5035 \\
0.0002\end{array}$ & $\begin{array}{l}0.2939 \\
0.0293\end{array}$ & $\begin{array}{l}0.3747 \\
0.0054\end{array}$ & $\mathbf{N}$ & $\mathrm{N}$ \\
\hline a & $\begin{array}{l}-0.281 \\
0.0372\end{array}$ & $\begin{array}{l}0.4034 \\
0.0028\end{array}$ & & $\begin{array}{l}0.4833 \\
0.0003\end{array}$ & $\begin{array}{l}0.467 \\
0.0005\end{array}$ & 0.641 & $\begin{array}{l}0.5256 \\
0.0001\end{array}$ & & $\begin{array}{l}0.3728 \\
0.0057\end{array}$ & $\mathrm{~N}$ \\
\hline a & & $\begin{array}{l}0.2755 \\
0.0411\end{array}$ & $N$ & & & $\stackrel{N}{N}$ & & $N$ & & $\mathrm{~N}$ \\
\hline $\mathbf{A}$ & $\mathrm{N}$ & $\mathrm{N}$ & $N$ & $\mathrm{~N}$ & $\mathrm{~N}$ & $\mathrm{~N}$ & $N$ & $\mathbf{N}$ & $\begin{array}{l}-0.3315 \\
0.014\end{array}$ & $\mathrm{~N}$ \\
\hline Ca & $N$ & $\mathbf{N}$ & $N$ & $\mathbf{N}$ & $N$ & $\begin{array}{l}0.5987 \\
0\end{array}$ & $\begin{array}{l}0.5269 \\
0.0001\end{array}$ & $\mathbf{N}$ & $\begin{array}{l}0.5341 \\
0.0001\end{array}$ & $\mathrm{~N}$ \\
\hline Fe & $\mathrm{N}$ & $\begin{array}{c}-0.3317 \\
0.0139\end{array}$ & $\mathrm{~N}$ & $\begin{array}{l}-0.3029 \\
0.0247\end{array}$ & $\begin{array}{l}-0.3065 \\
0.023\end{array}$ & $\begin{array}{l}-0.4216 \\
0.0018\end{array}$ & $\begin{array}{l}-0.2849 \\
0.0346\end{array}$ & $\mathrm{~N}$ & $\begin{array}{r}-0.2872 \\
0.0332\end{array}$ & $\mathrm{~N}$ \\
\hline $\mathbf{K}$ & $\mathrm{N}$ & $\begin{array}{l}0.597 \\
0\end{array}$ & $\begin{array}{l}-0.2832 \\
0.0357\end{array}$ & $\begin{array}{l}0.6248 \\
0\end{array}$ & $\begin{array}{l}0.5518 \\
0\end{array}$ & 0.5876 & $\begin{array}{l}0.3862 \\
0.0042\end{array}$ & $\begin{array}{l}0.3866 \\
0.0041\end{array}$ & $\begin{array}{l}0.3383 \\
0.0121\end{array}$ & $\mathrm{~N}$ \\
\hline ME & $\mathbf{N}$ & $\begin{array}{l}0.279 \\
0.0386\end{array}$ & $\begin{array}{l}-0.3117 \\
0.0208\end{array}$ & $\begin{array}{l}0.3889 \\
0.0039\end{array}$ & $\mathbf{N}$ & $\mathbf{N}$ & & & & $\mathbf{N}$ \\
\hline Mn & $\begin{array}{l}-0.3158 \\
0.0192\end{array}$ & & & & $\mathrm{~N}$ & $\begin{array}{l}0.3762 \\
0.0053\end{array}$ & $\begin{array}{l}0.3814 \\
0.0047\end{array}$ & $\mathrm{~N}$ & $\begin{array}{l}0.2189 \\
0.018\end{array}$ & $\mathrm{~N}$ \\
\hline $\mathbf{N}$ & & $\begin{array}{l}0.4068 \\
0.0026\end{array}$ & $\mathrm{~N}$ & $\begin{array}{l}0.3482 \\
0.0098\end{array}$ & $\mathrm{~N}$ & & & $\begin{array}{l}0.3105 \\
0.0213\end{array}$ & & $\begin{array}{c}-0.3108 \\
0.0212\end{array}$ \\
\hline $\mathbf{S}$ & $N$ & & $N$ & $\mathbf{N}$ & $\mathbf{N}$ & $\begin{array}{l}-0.2849 \\
0.0346\end{array}$ & $\mathrm{~N}$ & $\mathbf{N}$ & $\mathbf{N}$ & $\mathbf{N}$ \\
\hline $\mathbf{Z n}$ & $\begin{array}{l}-0.3951 \\
0.0034\end{array}$ & $\mathbf{N}$ & $\mathbf{N}$ & $\mathbf{N}$ & $\begin{array}{l}0.2969 \\
0.0277\end{array}$ & & $\begin{array}{l}0.5445 \\
0.0001\end{array}$ & $\mathbf{N}$ & $\mathrm{N}$ & $\mathrm{N}$ \\
\hline $\mathbf{S D A}$ & & $\mathbf{N}$ & $N$ & $\mathrm{~N}$ & & $\begin{array}{l}0.4795 \\
0.0004\end{array}$ & $\begin{array}{l}0.4463 \\
0.0009\end{array}$ & $\mathbf{N}$ & $\begin{array}{l}0.2884 \\
0.0324\end{array}$ & $\mathrm{~N}$ \\
\hline SD & $\mathbf{N}$ & $\mathrm{N}$ & $\mathbf{N}$ & $\mathbf{N}$ & $\mathbf{N}$ & $\begin{array}{l}0.4852 \\
0.0003\end{array}$ & $\begin{array}{l}0.2854 \\
0.0343\end{array}$ & $\mathrm{~N}$ & $\begin{array}{l}0.4251 \\
0.0016\end{array}$ & $\mathbf{N}$ \\
\hline
\end{tabular}


TABELA 24 - CORRELAÇÕES: VARIÁVEIS ABIÓTICAS E CARACTERÍSTICAS DA COMUNIDADE FITOPLANCTÔNICA. PONTO 1. REPRESA DE GUARAPIRANGA 1991-92.

Varíiveis abióticas: velocidade média do vento (W); radiação solar (RAD); insolação (INS); precipitação (P); elevaçăo (ELE); deficiència hidrica do solo (DEF); volume (VOL); excedente hidrico (EXC); temperatura da água (TAG); profundidade (PROF); transparéncia (SEC); cor (COR); turbidez (TUR); condutividade (CON); $\mathrm{pH}(\mathrm{pH})$; oxigènio dissolvido (OD); demanda bioquimica de oxjgènio (DBO); alcalinidade (ALC); dureen (DUR); sólidos totais em suspensåo (SOT); fósforo solúvel reativo (PO4); fósforo total (PT); amônio (NH4); nitrato (NO, $)$;

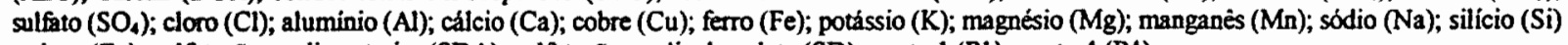
e zinco (Zn); sulfataçı no dia anterior (SDA); sulfataçăo no dia da coleta (SD); ponto 1 (P1); ponto 4 (P4).

Varifiveis do fitoplancton: densidade em células (DC); densidade em organismos (DO); bioárea (BA); biovolume (BV); GALD (G); número de taxons (S); diversidade $(\mathrm{H})$; uniformidade (U) e taxa de alteraçåo comunidade entre coletas sucessivas.dia ${ }^{-1}$ (TA).

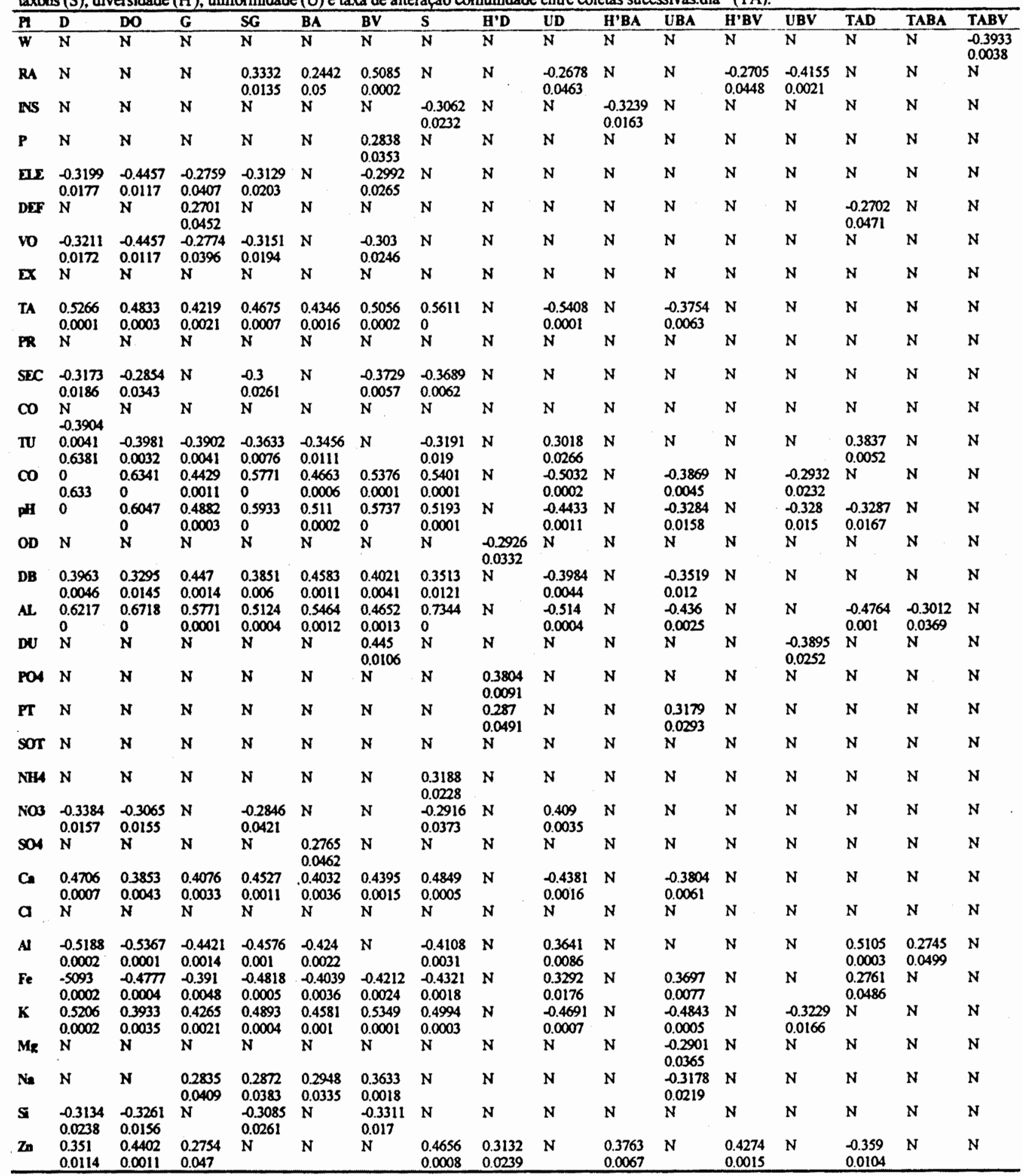


TABELA 25 - CORRELAÇŌES: VARIÁVEIS ABIÓTICAS E ESTRATÉGLAS ADAPTATIVAS DA COMUNIDADE FITOPLANCTONICA. PONTO 4. REPRESA DE GUARAPIRANGA 1991-92.

Varííveis abióticas: velocidade média do vento (W); radiaçăo solar (RAD); insolação (INS); precipitação (P); elevação (ELE); deficiència hidrica do solo (DEF); volume (VOL); excedente hídrico (EXC); temperatura da água (TAG); profundidade (PROF); transparência (SEC); cor (COR); turbidez (TUR); contutividade (CON); $\mathrm{pH}(\mathrm{pH})$; oxigênio dissolvido (OD); demanda bioquimica de oxigênio (DBO); alcalinidade (ALC); dureza (DUR); sólidos totais em suspensão (SOT); fósforo solúvel reativo (PO4); fósforo total (PT); amônio (NH4); nitrato (NO 3 ); sulfato ( $\mathrm{SO}_{4}$ ); cloro (Cl); aluminio (Al); cálcio (Ca); cobre (Cu); ferro (Fe); potássio (K); magnesio (Mg); manganès (Mn); sódio (Na); silicio (Si) e zinco (Zn); sulfataçăo no dia anterior (SDA); sulfatação no dia da coleta (SD); ponto l (P1); ponto 4 (P4).

Variáveis do fitoplâncton: densidade em células do nano- (NA); micro-(MI) e macro-fitoplâncton (MA); da Classe 1 (C1); da Classe 2 (C2); da Classe 3 (C3); da Classe 4 (C4); organismos: com (CM) e sem motilidade (SM); com (CER) e sern envoltório rígido (SER).

\begin{tabular}{|c|c|c|c|c|c|c|c|c|c|c|c|}
\hline P1 & NA & MI & MA & $\mathrm{Cl}$ & $C 2$ & $\mathbf{C 3}$ & C4 & CM & SM & CER & SER \\
\hline$w$ & $\mathbf{N}$ & $\mathbf{N}$ & $\mathbf{N}$ & $\mathrm{N}$ & $\mathbf{N}$ & $\mathbf{N}$ & $\mathrm{N}$ & $\mathbf{N}$ & $\mathbf{N}$ & $\mathrm{N}$ & $\mathbf{N}$ \\
\hline RAD & $\begin{array}{l}0.2939 \\
0.0293\end{array}$ & $\mathbf{N}$ & $N$ & $\mathrm{~N}$ & $\mathbf{N}$ & $\begin{array}{l}0.3488 \\
0.0097\end{array}$ & $\begin{array}{l}0.3597 \\
0.0076\end{array}$ & $\begin{array}{l}0.2797 \\
0.038\end{array}$ & $\mathbf{N}$ & $\mathbf{N}$ & $\begin{array}{l}0.29 \\
0.0315\end{array}$ \\
\hline INS & $\mathrm{N}$ & $\mathbf{N}$ & $N$ & $\mathbf{N}$ & $\mathbf{N}$ & $\mathrm{N}$ & $N$ & $\mathbf{N}$ & $\mathbf{N}$ & $\mathbf{N}$ & $\mathbf{N}$ \\
\hline PEL & $N$ & $N$ & $\mathbf{N}$ & $N$ & $\mathbf{N}$ & $\mathbf{N}$ & $\begin{array}{l}0.3065 \\
0.023\end{array}$ & $\mathbf{N}$ & $\mathbf{N}$ & $N$ & $\mathbf{N}$ \\
\hline ELE & $\mathbf{N}$ & $N$ & $\mathbf{N}$ & $N$ & $N$ & $\mathbf{N}$ & $\mathbf{N}$ & $\mathbf{N}$ & $N$ & $\mathbf{N}$ & $\mathbf{N}$ \\
\hline DEF & $\mathbf{N}$ & $\begin{array}{l}0.4335 \\
0.0013\end{array}$ & $N$ & $N$ & $\begin{array}{l}0.5348 \\
0.0001\end{array}$ & $N$ & $N$ & $\mathbf{N}$ & $\mathbf{N}$ & $\begin{array}{l}0.2765 \\
0.0403\end{array}$ & $\mathbf{N}$ \\
\hline VOL & $\begin{array}{l}-0.3301 \\
0.0144\end{array}$ & $\mathrm{~N}$ & $\mathbf{N}$ & $\begin{array}{l}-0.387 \\
0.0041\end{array}$ & $N$ & $\mathbf{N}$ & $N$ & $\begin{array}{l}-0.4487 \\
0.0009\end{array}$ & $\mathbf{N}$ & $\mathbf{N}$ & $\begin{array}{l}-0.4498 \\
0.0009\end{array}$ \\
\hline EXC & $\mathbf{N}$ & $N$ & $\mathrm{~N}$ & $\mathrm{~N}$ & $\mathbf{N}$ & $N$ & $\mathrm{~N}$ & $\mathbf{N}$ & $\mathbf{N}$ & $\mathbf{N}$ & $\mathbf{N}$ \\
\hline TAG & $\begin{array}{l}0.5477 \\
0\end{array}$ & $\mathbf{N}$ & $\begin{array}{l}0.2848 \\
0.0347\end{array}$ & $\begin{array}{l}0.4245 \\
0.0016\end{array}$ & $N$ & $\mathbf{N}$ & $\begin{array}{l}0.4939 \\
0.0002\end{array}$ & $N$ & $\begin{array}{l}0.5209 \\
0.0001\end{array}$ & $\begin{array}{l}0.4733 \\
0.0004\end{array}$ & $\begin{array}{l}0.2998 \\
0.0262\end{array}$ \\
\hline PROF & $\mathbf{N}$ & $\mathbf{N}$ & $\begin{array}{l}0.2784 \\
0.039\end{array}$ & $\mathbf{N}$ & $\mathrm{N}$ & $N$ & $N$ & $\begin{array}{l}-0.3279 \\
0.015\end{array}$ & $\mathrm{~N}$ & $\mathbf{N}$ & $\mathrm{N}$ \\
\hline SEC & $\begin{array}{l}-0.3434 \\
0.0109\end{array}$ & $\mathbf{N}$ & $\mathbf{N}$ & $\mathbf{N}$ & $\mathbf{N}$ & $\mathbf{N}$ & $\begin{array}{l}-0.2928 \\
0.0299\end{array}$ & $\mathbf{N}$ & $\begin{array}{l}-0.3013 \\
0.0255\end{array}$ & $\begin{array}{l}-0.3086 \\
0.0221\end{array}$ & $N$ \\
\hline COR & $\mathrm{N}$ & $N$ & $\mathbf{N}$ & $\mathbf{N}$ & $N$ & $\mathbf{N}$ & $\mathbf{N}$ & $N$ & $\mathbf{N}$ & $\mathbf{N}$ & $\mathbf{N}$ \\
\hline TUR & $\begin{array}{l}-0.3716 \\
0.0056\end{array}$ & $\begin{array}{l}-0.3235 \\
0.0164\end{array}$ & $\mathbf{N}$ & $\begin{array}{l}-0.3499 \\
0.0095\end{array}$ & $\begin{array}{l}-0.3451 \\
0.0105\end{array}$ & $\mathrm{~N}$ & $N$ & $\begin{array}{l}0.2791 \\
0.0384\end{array}$ & $\begin{array}{c}-0.3689 \\
0.0062\end{array}$ & $\begin{array}{l}-0.3858 \\
\mathbf{0 . 0 0 4 2}\end{array}$ & $\mathbf{N}$ \\
\hline CON & $\begin{array}{l}0.6439 \\
0\end{array}$ & $\mathbf{N}$ & $\mathbf{N}$ & $\begin{array}{l}0.5927 \\
0\end{array}$ & $\begin{array}{l}0.3974 \\
0.0032\end{array}$ & $N$ & $\begin{array}{l}0.3454 \\
0.0104\end{array}$ & $\begin{array}{l}0.3068 \\
0.0229\end{array}$ & $\begin{array}{l}0.62 \\
0\end{array}$ & $\begin{array}{l}0.6166 \\
0\end{array}$ & $\begin{array}{l}0.2656 \\
0.0489\end{array}$ \\
\hline $\mathrm{pH}$ & $\begin{array}{l}0.617 \\
0\end{array}$ & $\mathrm{~N}$ & $N$ & $\begin{array}{l}0.5566 \\
0\end{array}$ & $\begin{array}{l}0.5047 \\
0.0002\end{array}$ & $\mathbf{N}$ & $\begin{array}{l}0.4207 \\
0.0018\end{array}$ & $\begin{array}{l}0.4718 \\
0.0005\end{array}$ & $\begin{array}{l}0.5457 \\
0.0001\end{array}$ & $\begin{array}{l}0.5521 \\
0\end{array}$ & $\begin{array}{l}0.4672 \\
0.0005\end{array}$ \\
\hline OD & $N$ & $N$ & $\mathbf{N}$ & $\mathbf{N}$ & $\mathbf{N}$ & $N$ & $\mathbf{N}$ & $\mathbf{N}$ & $\mathbf{N}$ & $\mathbf{N}$ & $\mathbf{N}$ \\
\hline DBO & $\begin{array}{l}0.358 \\
0.00779\end{array}$ & $\mathbf{N}$ & $\mathbf{N}$ & $\begin{array}{l}0.2966 \\
0.0278\end{array}$ & $\mathrm{~N}$ & $N$ & $\begin{array}{l}0.3768 \\
0.0052\end{array}$ & $\mathbf{N}$ & $\begin{array}{l}0.4155 \\
0.0021\end{array}$ & $\begin{array}{l}0.3418 \\
0.0113\end{array}$ & $\mathbf{N}$ \\
\hline ALC & $\begin{array}{l}0.5824 \\
0 .\end{array}$ & $\begin{array}{l}0.31 \\
0.0215\end{array}$ & $\mathbf{N}$ & $\begin{array}{l}0.4815 \\
0.0004\end{array}$ & $\begin{array}{l}0.5084 \\
0.0002\end{array}$ & $N$ & $\mathbf{N}$ & $\mathbf{N}$ & $\begin{array}{l}0.626 \\
0\end{array}$ & $\begin{array}{l}0.6021 \\
0\end{array}$ & $\mathbf{N}$ \\
\hline DUR & $\mathbf{N}$ & $\mathbf{N}$ & $\mathbf{N}$ & $\mathbf{N}$ & $\mathbf{N}$ & $\mathbf{N}$ & $\begin{array}{l}0.4174 \\
0.0165\end{array}$ & $\mathbf{N}$ & $N$ & $\mathbf{N}$ & $\mathbf{N}$ \\
\hline P04 & $\mathbf{N}$ & $N$ & $\mathbf{N}$ & $\mathbf{N}$ & $\mathbf{N}$ & $\mathbf{N}$ & $\mathbf{N}$ & $\mathbf{N}$ & $\mathbf{N}$ & $\mathbf{N}$ & $\mathbf{N}$ \\
\hline POr & $\mathbf{N}$ & $N$ & $\mathbf{N}$ & $\mathbf{N}$ & $\mathbf{N}$ & $N$ & $\begin{array}{l}-0.3734 \\
0.0056\end{array}$ & $\mathbf{N}$ & $\mathbf{N}$ & $\mathbf{N}$ & $\mathbf{N}$ \\
\hline SOT & $\mathbf{N}$ & $\mathbf{N}$ & $\mathbf{N}$ & $\mathrm{N}$ & $\mathbf{N}$ & $\mathrm{N}$ & $\mathbf{N}$ & $\mathbf{N}$ & $\mathbf{N}$ & $\mathbf{N}$ & $\mathbf{N}$ \\
\hline NH4 & & & & & . & & & & & & \\
\hline NO3 & $\begin{array}{l}-0.3444 \\
0.0106\end{array}$ & $N$ & $\mathbf{N}$ & $\mathbf{N}$ & $\mathbf{N}$ & $N$ & $\mathbf{N}$ & $\mathbf{N}$ & $\mathbf{N}$ & $\begin{array}{l}-0.3261 \\
0.0156\end{array}$ & $\mathrm{~N}$ \\
\hline SO4 & $\mathbf{N}$ & $\begin{array}{l}0.326 \\
0.0156\end{array}$ & $\mathbf{N}$ & $\mathbf{N}$ & $\mathbf{N}$ & $\begin{array}{l}0.3178 \\
0.0184\end{array}$ & $\mathbf{N}$ & $\mathbf{N}$ & $\mathbf{N}$ & $\mathbf{N}$ & $N$ \\
\hline $\mathrm{C} \mathbf{a}$ & $\begin{array}{l}0.4754 \\
0.0004\end{array}$ & $\mathrm{~N}$ & $\mathbf{N}$ & $\begin{array}{l}0.3116 \\
0.0208\end{array}$ & $\mathbf{N}$ & $\begin{array}{l}0.3505 \\
0.0093\end{array}$ & $\mathbf{N}$ & $\mathbf{N}$ & $\begin{array}{l}0.4969 \\
0.0002\end{array}$ & $\begin{array}{l}0.4168 \\
0.002\end{array}$ & $\begin{array}{l}0.2699 \\
0.0453\end{array}$ \\
\hline Cl & $\mathrm{N}$ & $N$ & $\mathbf{N}$ & $\mathrm{N}$ & $\mathbf{N}$ & $\begin{array}{l}0.3153 \\
0.0194\end{array}$ & $N$ & $\mathbf{N}$ & $\mathbf{N}$ & $\mathbf{N}$ & $\begin{array}{l}0.2863 \\
0.0337\end{array}$ \\
\hline AI & $\begin{array}{l}-0.4998 \\
0.0002\end{array}$ & $\begin{array}{l}-0.3715 \\
0.0059\end{array}$ & $N$ & $\begin{array}{l}-0.4116 \\
0.0023\end{array}$ & $\begin{array}{l}0.4457 \\
0.0009\end{array}$ & $\mathbf{N}$ & $\mathbf{N}$ & $\begin{array}{l}-0.3177 \\
0.0185\end{array}$ & $\begin{array}{l}-0.4763 \\
0.0004\end{array}$ & $\begin{array}{l}-0.553 \\
0\end{array}$ & $\mathbf{N}$ \\
\hline Fe & $\begin{array}{l}-0.4875 \\
0.0003\end{array}$ & $\begin{array}{l}-0.3041 \\
0.0241\end{array}$ & $N$ & $\begin{array}{l}-0.442 \\
0.001\end{array}$ & $\begin{array}{l}-0.3862 \\
0.0042\end{array}$ & $\begin{array}{l}-0.3039 \\
0.0242\end{array}$ & $N$ & $\begin{array}{l}-0.3758 \\
0.0053\end{array}$ & $\begin{array}{l}-0.448 \\
0.0009\end{array}$ & $\begin{array}{l}-0.5124 \\
0.0001\end{array}$ & $\begin{array}{l}-0.3146 \\
0.0196\end{array}$ \\
\hline $\mathbf{K}$ & $\begin{array}{l}0.4939 \\
0.0002\end{array}$ & $\mathbf{N}$ & $\mathbf{N}$ & $\begin{array}{l}0.3183 \\
0.0182\end{array}$ & $\mathrm{~N}$ & $\begin{array}{l}0.2786 \\
0.0388\end{array}$ & $\begin{array}{l}0.3496 \\
0.0095\end{array}$ & $\mathbf{N}$ & $\begin{array}{l}0.501 \\
0.0002\end{array}$ & $\begin{array}{l}0.4755 \\
0.0004\end{array}$ & $\mathbf{N}$ \\
\hline Mg & $\mathrm{N}$ & $\mathbf{N}$ & $\mathbf{N}$ & $\mathrm{N}$ & $\mathbf{N}$ & $\begin{array}{l}0.3454 \\
0.0104\end{array}$ & $\mathbf{N}$ & $\mathbf{N}$ & $\mathbf{N}$ & $\mathrm{N}$ & $\mathbf{N}$ \\
\hline $\mathrm{Na}$ & $\mathbf{N}$ & $\mathbf{N}$ & $\mathbf{N}$ & $\mathbf{N}$ & $\mathbf{N}$ & $\begin{array}{l}0.3384 \\
0.0121\end{array}$ & $\mathbf{N}$ & $\begin{array}{l}0.2657 \\
0.0487\end{array}$ & $\mathbf{N}$ & $N$ & $\begin{array}{l}0.3749 \\
0.0054\end{array}$ \\
\hline Si & $\begin{array}{l}-0.2872 \\
0.0332\end{array}$ & $\begin{array}{l}-0.286 \\
0.0339\end{array}$ & $\mathbf{N}$ & $\begin{array}{c}0.454 \\
0.0008\end{array}$ & $\mathbf{N}$ & $N$ & $\mathbf{N}$ & $\mathbf{N}$ & $\begin{array}{l}-0.2723 \\
0.0434\end{array}$ & $\begin{array}{l}-0.3159 \\
0.0191\end{array}$ & $\mathbf{N}$ \\
\hline $\mathrm{Zn}$ & $\begin{array}{l}0.3493 \\
0.0096\end{array}$ & $\mathrm{~N}$ & $\mathbf{N}$ & $\begin{array}{l}0.3093 \\
0.0218\end{array}$ & $\begin{array}{l}0.3795 \\
0.0049\end{array}$ & $N$ & $\mathbf{N}$ & $\mathbf{N}$ & $\begin{array}{l}0.3689 \\
0.0062\end{array}$ & $\begin{array}{l}0.3592 \\
0.0077\end{array}$ & $\mathbf{N}$ \\
\hline
\end{tabular}


TABELA 25 (continuaçăo) - CORRELAÇōES: VARIÁVEIS ABIóTICAS E ESTRATÉGIAS ADAPTATIVAS DA COMUNIDADE FITOPLANCTÓNICA DO PONTO 4 - REPRESA DE GUARAPIRANGA 1991-92.

Variíveis abióticas: velocidade média do vento (W); radiaço solar (RAD); insolacăo (INS); precipitaça (P); elevação (ELE); deficiência hidrica do solo (DEF); volume (VOL); excedente hídrico (EXC); temperatura da água (TAG); profundidade (PROF); transparência (SEC); cor (COR); turbidez (TUR); condutividade (CON); pH ( $\mathrm{pH}$ ); oxigènio dissolvido (OD); demanda bioquímica de oxigènio (DBO); alcalinidade (ALC); dureza (DUR); sólidos totais em suspensåo (SOT); fósforo solúvel reativo (PO4); fósforo total (PT); amônio (NH4); nitrato (NO 3 ); sulfato $\left(\mathrm{SO}_{4}\right)$; cloro $(\mathrm{Cl})$; alumínio (Al); cálcio (Ca); cobre (Cu); ferro (Fe); potássio (K); magnésio (Mg); manganès (Mn); sódio (Na); silicio (Si) e zinco (Zn); sulfataçăo no dia anterior (SDA); sulfatação no dia da coleta (SD); ponto 1 (P1); ponto 4 (P4).

Varifveis do fitoplâncton: biovolume de organismos: com motilidade (CMV); sem motilidade (SMV); sem envoltorio rígido (SERV); com envoltório rígido (CERV); densidade de formas coloniais ou cenobiais (COL); filamentosas (FIL) e unicelulares (UNI); bivolume de formas coloniais ou cenobiais (COLV); filamentosas (FILV) e unicelulares (UNIV).

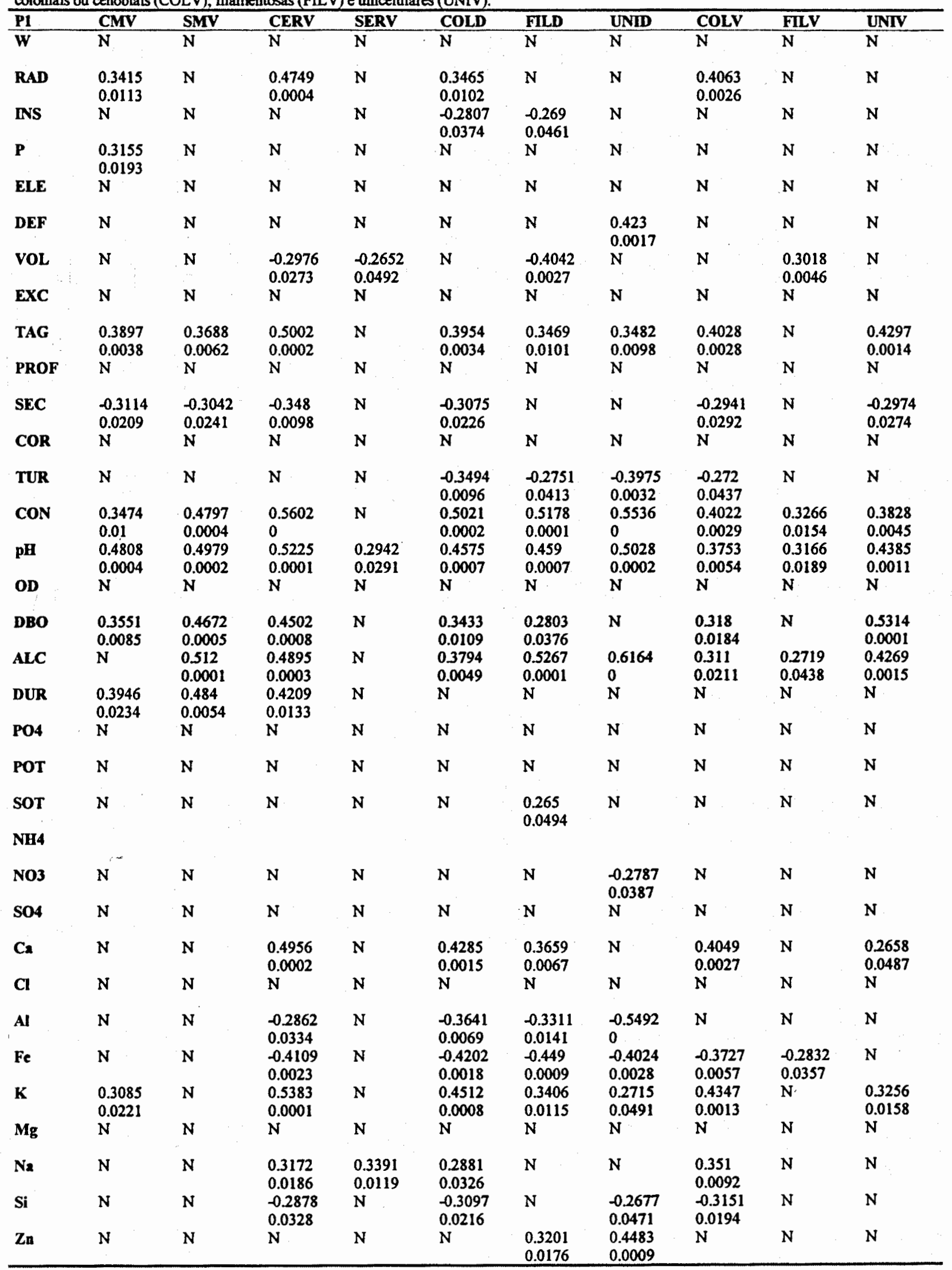




\section{A-27}

TABELA 27 - ANALISE DOS COMPONENTES PRINCIPAIS. REPRESA DE GUARAPIRANGA 1991-92 . PONTO 4. PROGRAMA UTILIZADO: CANOCO (TER-BRAAK, 1983)

TRANSFORMAÇÃO DOS DADOS: LOG(X+1)

VALOR DOS ELXOS:

EIXO 1: 0.40447 EIXO 2: 0.20646

EIXO 3: 0.1 EIXO 4: 0.07

ORDENAÇÃO: DISTÂNCIA EUCLIDEANA

\section{VALOR DAS ESTAÇŌES}

ESTAÇAO EIXO1 EIXO2 EIXO3 EIXO 4

$\begin{array}{lllll}\text { MA2 } & 41 & -4 & -24 & -10\end{array}$

$\begin{array}{lllll}M A 3 & -18 & 59 & -13 & -1\end{array}$

$\begin{array}{lllll}\text { MA4 } & -21 & 75 & -8 & -2\end{array}$

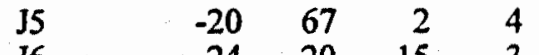

$\begin{array}{lllll}\mathrm{J} 6 & -24 & 20 & 15 & 3\end{array}$

$\mathrm{J} 7$

ЛL8

ЛL9

JL10

JL11

JL12

AG13

AG15

AG16

S17

$\mathrm{S} 18$

S19

S20

021

$\mathrm{O} 22$

023
024

$\mathrm{O} 25$

N26

N27

N28

N29

D30

D31

D32

D33

JA34

JA35

JA36

JA37

F38

F39

F40

F41

MR42

MR43

MR44

$\mathrm{AB} 45$

AB46

AB47

AB48

AB49

MA50

MA51

MA53

J54

$\mathrm{J} 55$

$\mathrm{J} 56$

$\mathrm{J} 57$

JL58 $\begin{array}{rrrr}-24 & 20 & 15 & 3 \\ -19 & 68 & 9 & 0 \\ 3 & 96 & -5 & 8\end{array}$

$\begin{array}{rrrr}1 & 71 & -21 & 22 \\ 4 & 93 & 3 & 24\end{array}$

$\begin{array}{llll}-1 & 61 & -14 & 11\end{array}$

$\begin{array}{llll}34 & 77 & -12 & 14\end{array}$

$\begin{array}{llll}57 & -21 & -36 & 72\end{array}$

$\begin{array}{rrrr}79 & -3 & 2 & -40\end{array}$

$\begin{array}{llll}73 & 28 & -12 & -3\end{array}$

$\begin{array}{llll}78 & 54 & -6 & 7\end{array}$

$\begin{array}{llll}-26 & 32 & -6 & -23\end{array}$

$\begin{array}{lllr}-33 & 63 & -10 & 0\end{array}$

$\begin{array}{llll}-40 & 12 & 69 & 32\end{array}$

$\begin{array}{llll}-44 & -3 & 81 & -9\end{array}$

$\begin{array}{llll}-41 & -5 & 80 & 7\end{array}$

$\begin{array}{llll}-40 & 5 & -21 & -5\end{array}$

$\begin{array}{llll}-36 & 42 & -5 & -24\end{array}$

$\begin{array}{llll}-37 & -13 & -9 & -31\end{array}$

$\begin{array}{llll}-51 & -61 & -32 & 64\end{array}$

$\begin{array}{llll}-40 & -61 & -21 & 4\end{array}$

$\begin{array}{llll}-43 & -68 & -9 & 31\end{array}$

$\begin{array}{llll}-57 & -92 & 13 & 83\end{array}$

$\begin{array}{llll}-57 & -68 & -39 & -31\end{array}$

$\begin{array}{llll}-54 & -33 & -14 & -41\end{array}$

$\begin{array}{llll}-53 & -32 & 7 & -26\end{array}$

$\begin{array}{llll}-51 & -35 & 61 & -22\end{array}$

$\begin{array}{llll}-50 & 3 & -11 & -25\end{array}$

$\begin{array}{llll}-51 & -17 & 0 & -30\end{array}$

$\begin{array}{llll}-62 & 4 & 82 & 22\end{array}$

$\begin{array}{llll}-54 & -32 & -12 & -23\end{array}$

$\begin{array}{rrrr}-41 & 8 & 7 & -34\end{array}$

$\begin{array}{llll}-43 & -8 & -21 & -36\end{array}$

$\begin{array}{llll}-49 & -59 & -53 & 4\end{array}$

$\begin{array}{llll}-50 & 31 & -11 & 32\end{array}$

$\begin{array}{llll}-64 & -37 & -47 & 41\end{array}$

$\begin{array}{llll}-63 & -32 & 16 & 6\end{array}$

$\begin{array}{llll}-54 & 0 & -6 & -26\end{array}$

$\begin{array}{llll}-19 & -17 & -26 & -2\end{array}$

$\begin{array}{llll}-16 & 5 & 66 & 8\end{array}$

$\begin{array}{llll}58 & 5 & -12 & -29\end{array}$

$\begin{array}{llll}121 & -86 & 73 & -13\end{array}$

$\begin{array}{llll}112 & -63 & -7 & -16\end{array}$

$\begin{array}{llll}36 & -17 & 2 & -1\end{array}$

$\begin{array}{llll}43 & -19 & -17 & -1\end{array}$

$\begin{array}{rrrr}38 & -28 & -29 & -14 \\ 78 & 4 & -26 & 28\end{array}$

$\begin{array}{llll}161 & -7 & 40 & 28\end{array}$

$\begin{array}{llll}154 & -25 & -18 & 6\end{array}$

$\begin{array}{llll}162 & 12 & 7 & 7\end{array}$

$\begin{array}{llll}133 & -49 & 1 & -40\end{array}$ $\begin{array}{llll}-41 & -1 & -23 & -6\end{array}$
VALOR DAS VARIÁVEIS AMBIENTAIS NOS RESPECTIVOS EIXOS

VARIAVEL

TEMPERATURA DAÁGUA

PROFUNDIDADE

TRANSPARENCLA

COR

TURBIDEZ

CONDUTTVIDADE

pH

OD

DBO

ALCALINIDADE

DUREZA

$\mathrm{PO} 4$

POT

SOT

NH4

NO3

$\mathrm{SO} 4$

$\mathrm{Cl}$

Al

$\mathrm{Ca}$

$\mathrm{Fe}$

$\mathrm{K}$

$\mathrm{Mg}$

Mn

$\mathrm{Na}$

$\mathrm{Si}$

$\mathrm{Zn}$

ELEVAÇĀO

PLUVIOSIDADE (ELETROPAULO)

DEFICIENNCIA HIDRICA DO SOLO

VELOCIDADE DO VENTO

INSOLACุÃO

RADIAÇĀO SOLAR

BIOVOLUME ALGÁCEO
EIXO1 EIXO2 EIXO3 EIXO4

$\begin{array}{rrrr}-28 & -43 & -13 & -17 \\ 6 & 6 & -10 & 16 \\ 33 & 35 & -37 & 36 \\ -53 & -14 & 68 & -46\end{array}$

$\begin{array}{rrrr}-53 & -14 & 68 & -46 \\ -55 & 42 & 62 & -15\end{array}$

$\begin{array}{llll}12 & -55 & -22 & -14\end{array}$

$\begin{array}{rrrr}4 & -17 & -9 & 4 \\ 19 & 1 & -28 & 22\end{array}$

$\begin{array}{rrrr}19 & 1 & -28 & 22 \\ -1 & -91 & -117 & 79\end{array}$

$\begin{array}{llll}16 & -45 & 33 & -82\end{array}$

$\begin{array}{llll}-38 & -84 & 92 & -39\end{array}$

$\begin{array}{llll}50 & 36 & 148 & -311\end{array}$

$\begin{array}{llll}103 & 142 & 213 & -519\end{array}$

$\begin{array}{llll}104 & -20 & 47 & -48\end{array}$

$\begin{array}{llll}16 & 17 & 10 & 27\end{array}$

$\begin{array}{rrrr}6 & 7 & 10 & 4 \\ -2 & -24 & 11 & 22\end{array}$

$\begin{array}{llll}1 & -28 & 15 & -4\end{array}$

$\begin{array}{rrrr}-7 & 7 & 13 & 2\end{array}$

$\begin{array}{llll}-19 & -37 & 23 & 19\end{array}$

$\begin{array}{llll}-9 & 38 & -3 & 34\end{array}$

$\begin{array}{rrrr}-6 & -26 & 13 & 3 \\ -13 & -15 & 13 & 19\end{array}$

$\begin{array}{llll}-1 & -1 & 2 & -1\end{array}$

$\begin{array}{llll}-2 & -33 & 14 & -10\end{array}$

$\begin{array}{llll}-23 & 24 & -6 & 43\end{array}$

$\begin{array}{rrrr}3 & -3 & 0 & 1 \\ 0 & 0 & 0 & 0\end{array}$

$\begin{array}{llll}-361 & -177 & 36 & -286\end{array}$

$\begin{array}{llll}622 & -190 & 17 & -47\end{array}$

$\begin{array}{rrrr}-4 & -14 & -21 & -42 \\ 37 & 169 & -659 & -268\end{array}$

$\begin{array}{rrrr}-65 & -69 & 12 & -29\end{array}$

$\begin{array}{llll}-40 & -636 & -134 & -98\end{array}$ 
TABELA 28 - RESULTADOS DO TESTE DE HENDRICKSON (1978) APLICADO AOS DADOS DE PRESENÇA E AUSENCIA DE ESPECCIES DO FITOPLÂNCTON. REPRESA DE GUARAPIRANGA 1991-92.

Número de espécies (NSP); número de coletas (NC); valor encontrado para Q (Q); graus de liberdade para Q (GLQ);nivel de valor critico de $Q(Q)$; nivel de significância $(P)$; valor encontrado para $M(M)$; graus de liberdade para $M(G L M)$; número de coincidências positivas encontradas (NP); não há pares significa que não há coincidências positivas de ocorrências das espécies. Probabilidade de erro: $\mathrm{N}>0.050 ;^{*}=0.026$ a $0.050 ;{ }^{* *}=0.006$ a $0.025 ;{ }^{* * *}=<0.005$.

\section{TOTAL DE COLETAS: PONTO 1}

\begin{tabular}{lcccccccc} 
CONJUNTO AMOSTRAL & NSP & NC & Q GLQ & QQc & P & M & GLM M Mc \\
\hline CONJUNTO TOTAL & 183 & 56 & 237 & 55 & $\mathrm{Q}>\mathrm{Qc}$ & $* * *$ & 4815,70 & $1485 \mathrm{M}>\mathrm{Mc}$ \\
\hline CENTRALES & 9 & 56 & 82 & 55 & $\mathrm{Q} \times \mathrm{Qc}$ & $* *$ & 1684,57 & $1485 \mathrm{M}>\mathrm{Mc}$ \\
\hline CLOROFICEAS EXCETO VOLV. & 77 & 56 & 219 & 55 & $\mathrm{Q} \times \mathrm{Qc}$ & $* * *$ & 4526,79 & $1485 \mathrm{M}>\mathrm{Mc}$ \\
\hline CRISOFICEAS & 11 & 56 & 67 & 55 & $\mathrm{Q}<\mathrm{Qc}$ & $\mathrm{N}$ & 1586,21 & $1485 \mathrm{M}>\mathrm{Mc}$ \\
\hline CRIPTOFICEAS & 7 & 56 & 65 & 55 & $\mathrm{Q}<\mathrm{Qc}$ & $\mathrm{N}$ & 1592,11 & $1485 \mathrm{M}>\mathrm{Mc}$ \\
\hline CIANOFICEAS & 14 & 56 & 79 & 55 & $\mathrm{Q} \times \mathrm{Qc}$ & $* *$ & 1857,77 & $1485 \mathrm{M}>\mathrm{Mc}$ \\
\hline DINOFICEAS & 1 & 56 & 55 & 55 & $\mathrm{Q}>\mathrm{Qc}$ & $\mathrm{N}$ & 1485,00 & $1485 \mathrm{M}<\mathrm{Mc}$ \\
\hline EUGLENOFICEAS & 12 & 56 & 67 & 55 & $\mathrm{Q}<\mathrm{Qc}$ & $\mathrm{N}$ & 1476,66 & $1485 \mathrm{M}<\mathrm{Mc}$ \\
\hline VOLVOCALES & 11 & 56 & 49 & 55 & $\mathrm{Q}<\mathrm{Qc}$ & $\mathrm{N}$ & 1387,43 & $1485 \mathrm{M}<\mathrm{Mc}$ \\
\hline PENALES & 9 & 56 & 51 & 55 & $\mathrm{Q}<\mathrm{Qc}$ & $\mathrm{N}$ & 1993,93 & $1485 \mathrm{M}>\mathrm{Mc}$ \\
\hline ZIGNEMAFICEAS & 32 & 56 & 89 & 55 & $\mathrm{Q}>\mathrm{Qc}$ & $* * *$ & 1671,93 & $1485 \mathrm{M}>\mathrm{Mc}$
\end{tabular}

\section{PONTO 1: PERIODO DE SECA}

CONJUNTO AMOSTRAL

CONJUNTO TOTAL PONTO

NSP NC Q GLQ QQ

CENTRALES

CLOROFICEAS EXCETO VOLV.

CRISOFICEAS

CRIPTOFICEAS

CIANOFICEAS

DINOFICEAS

VOLVOCALES

PENALES

$\begin{array}{rrrrr}183 & 28 & 143 & 27 & Q>0 \\ 9 & 28 & 43 & 27 & Q>0\end{array}$

\section{$\mathbf{P}$}

M GLM M Mc

TOTAL: $\frac{661}{11339}$

\begin{tabular}{l} 
PENALES \\
ZIGNEMAFICEAS \\
\hline
\end{tabular}

$\begin{array}{llllll}77 & 28 & 143 & 27 & \mathrm{Q}>\mathrm{Q} \\ 11 & 28 & 36 & 27 & \mathrm{Q}<\mathrm{Q}\end{array}$

$\begin{array}{lllll}7 & 28 & 37 & 27 & Q<Q \\ 14 & 28 & 47 & 27 & Q>Q\end{array}$

4
4

\begin{tabular}{c} 
*** \\
\hline$* *$ \\
\hline$* *$ \\
\hline $\mathrm{N}$ \\
\hline $\mathrm{N}$ \\
\hline $\mathrm{N}$ \\
\hline $\mathrm{N}$ \\
\hline $\mathrm{N}$ \\
\hline $\mathrm{N}$ \\
\hline
\end{tabular}

$1437,97 \quad 351 \mathrm{M}>\mathrm{Mc}$

$361.17 \quad 351 \mathrm{M}>\mathrm{Mc}$

$1422,11 \quad 351 \mathrm{M}>\mathrm{Mc}$

$383.05 \quad 351 \mathrm{M}>\mathrm{Mc}$

$390,47 \quad 351 \mathrm{M}>\mathrm{Mc}$

$565,11 \quad 351 \mathrm{M}>\mathrm{Mc}$

$323.73 \quad 351 \mathrm{M}<\mathrm{Mc}$

$261,01 \quad 351 \mathrm{M}<\mathrm{Mc}$

$476,85 \quad 351 \mathrm{M}>\mathrm{Mc}$

PONTO 1: PERIODO DE CHUVA

CONJUNTO AMOSTRAL

NSP NC QGLQ QQC P

CONJUNTO TOTAL PONTO 1 $390,36 \quad 351 \mathrm{M}>\mathrm{Mc}$

\begin{tabular}{|rr}
\hline P & NP \\
\hline$* * *$ & 3307 \\
\hline$* *$ & 150 \\
\hline$* * *$ & 1779 \\
\hline$* * *$ & 39 \\
\hline$* * *$ & 144 \\
\hline$* * *$ & 112 \\
\hline N NAO HA PARES \\
\hline $\mathrm{N}$ & 87 \\
\hline $\mathrm{N}$ & 303 \\
\hline$* * *$ & 536 \\
\hline$* *$ & 157 \\
\hline
\end{tabular}

\section{CENTRALES}

CLOROFICEAS EXCETO VOLV.

$\begin{array}{rllll}183 & 28 & 86 & 27 & Q>Q \\ 9 & 28 & 43 & 27 & Q>0\end{array}$

\begin{tabular}{llllll}
\hline CRIPTOFICEAS & 11 & 28 & 29 & 27 & $\mathrm{Q}<\mathrm{Q}$ \\
\hline & 7 & 28 & 29 & 27 & $0<0 c$
\end{tabular}

$\begin{array}{llllll}\text { CLANOFICEAS } & 14 & 28 & 31 & 27 & 0<0 C\end{array}$

\begin{tabular}{llllll}
\hline DINOFICEAS & 1 & 28 & 27 & 27 & $\mathrm{Q}<\mathrm{Qc}$ \\
\hline
\end{tabular}

EUGLENOFICEAS

VOLVOCALES

PENALES

$\begin{array}{lllll}12 & 28 & 39 & 27 & \mathrm{Q}<\mathrm{Q} \\ 11 & 28 & 27 & 27 & \mathrm{Q}<\mathrm{QC}\end{array}$

$\begin{array}{lllll}11 & 28 & 27 & 27 & Q<Q c \\ 9 & 28 & 15 & 27 & Q<Q c\end{array}$

$\frac{0 Q c}{Q 0 c}$

\begin{tabular}{|c|c|c|}
\hline & $\mathbf{M}$ & GLM M Mc \\
\hline$* *$ & 888,15 & $351 \mathrm{M}>\mathrm{Mc}$ \\
\hline 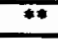 & 361,17 & $351 \mathrm{M}>\mathrm{Mc}$ \\
\hline 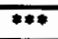 & 760,05 & $351 \mathrm{M}>\mathrm{Mc}$ \\
\hline $\bar{N}$ & 395,92 & $351 \mathrm{M}>\mathrm{Mc}$ \\
\hline $\mathbf{N}$ & 376,76 & $351 \mathrm{M}>\mathrm{Mc}$ \\
\hline$\overline{\mathbf{N}}$ & 360,41 & $351 \mathrm{M}>\mathrm{Mc}$ \\
\hline $\bar{N}$ & 351,00 & $351 \mathrm{M}<\mathrm{Mc}$ \\
\hline $\bar{N}$ & 363,64 & $351 \mathrm{M}>\mathrm{Mc}$ \\
\hline $\bar{N}$ & 388,15 & $351 \mathrm{M}>\mathrm{Mc}$ \\
\hline$\overline{\mathbf{N}}$ & 451,66 & \\
\hline & 403,60 & $351 M>1$ \\
\hline
\end{tabular}

\begin{tabular}{cr}
\hline$P$ & NP \\
\hline$* * *$ & 2438 \\
\hline$* * *$ & 150 \\
\hline$* * *$ & 1330 \\
\hline$* * *$ & 14 \\
\hline$* * *$ & 89 \\
\hline$* *$ & 104 \\
\hline$N$ & 10 \\
\hline$* * *$ & 95 \\
\hline$* * *$ & 162 \\
\hline$* * *$ & 380 \\
\hline$* *$ & 196 \\
\hline
\end{tabular}

PONTO 1: PERIODO DE CHUVAS INTENSAS COLETAS 30 A 44

CONJUNTO AMOSTRAL

CONJUNTO TOTAL PONTO

NSP NC QGLQ QQC

\begin{tabular}{lrrrrr}
\hline CENTRALES & 9 & 15 & 12 & 14 & $\mathrm{Q}<\mathrm{QC}$ \\
\hline CLOROFICEAS EXCETO VOLV. & 77 & 15 & 30 & 14 & $\mathrm{Q}>\mathrm{QC}$ \\
\hline
\end{tabular}

\begin{tabular}{llllll}
183 & 15 & 34 & 14 & $\mathrm{Q}>\mathrm{Oc}$ \\
\hline & 15 & 12 & 14 & $\mathrm{Q}<\mathrm{Oc}$
\end{tabular}

\begin{tabular}{lllllll}
\hline CRISOFICEAS & 11 & 15 & 13 & 14 & Q<Qc
\end{tabular}

\begin{tabular}{llllll}
\hline CRPPTOFICEAS & 7 & 15 & 21 & 14 & $0<Q c$ \\
\hline
\end{tabular}

\begin{tabular}{llllll}
\hline CIANOFICEAS & 14 & 15 & 16 & 14 & $\mathrm{Q}<\mathrm{CC}$
\end{tabular}

DINOFICEAS

\begin{tabular}{llllll}
\hline EUGLENOFICEAS & 12 & 15 & 20 & 14 & $\mathrm{Q}<\mathrm{Qc}$ \\
\hline & 11 & 15 & 16 & 14 & $\mathrm{Q}<\mathrm{Qc}$ \\
\hline
\end{tabular}

VOLVOCALES

PENALES

\begin{tabular}{lllll}
11 & 15 & 16 & 14 & $0<0 c$ \\
\hline
\end{tabular}

ZIGNEMAFICEAS

$\begin{array}{lllll}9 & 15 & 10 & 14 & 0<Q c\end{array}$

\begin{tabular}{|c|c|c|c|c|c|}
\hline $\mathbf{P}$ & $\mathbf{M}$ & GLM & $\mathbf{M} \mathbf{M c}$ & $\mathbf{P}$ & $\mathbf{N P}$ \\
\hline$* * *$ & 233,57 & 91 & $\mathrm{M}>\mathrm{Mc}$ & $74 *$ & 1042 \\
\hline $\mathbf{N}$ & 89,67 & 91 & $\mathrm{M}<\mathrm{Mc}$ & $\mathbf{N}$ & 4 \\
\hline$*$ & 228.58 & 91 & $\mathrm{M}>\mathrm{Mc}$ & 40.4 & 577 \\
\hline $\mathbf{N}$ & 91,00 & 91 & $\mathrm{M}<\mathrm{Mc}$ & $\mathbf{N}$ & 1 \\
\hline $\mathbf{N}$ & 123,07 & 91 & $M>M c$ & $*$ & 15 \\
\hline $\mathrm{N}$ & 98,52 & 91 & $M<M c$ & $\mathrm{~N}$ & 55 \\
\hline $\mathrm{N}$ & 91,00 & 91 & $M<M c$ & $\mathrm{~N}$ & 3 \\
\hline $\bar{N}$ & 101,90 & 91 & $M<M c$ & $\mathrm{~N}$ & 48 \\
\hline $\mathrm{N}$ & 104,58 & 91 & $\mathrm{M}<\mathrm{Mc}$ & $\mathrm{N}$ & 36 \\
\hline$N$ & 79,47 & 91 & $M<M c$ & $\mathbf{N}$ & 183 \\
\hline $\bar{N}$ & 96,68 & 91 & $\mathrm{M}<\mathrm{Mc}$ & $\bar{N}$ & 120 \\
\hline
\end{tabular}

PONTO 1: PERIODO DE CHUVAS MODERADAS COLETAS 17 A 29

\begin{tabular}{|c|c|c|c|c|c|c|c|c|c|c|c|}
\hline CONJUNTO AMOSTRAL & NSP & $\mathrm{NC}$ & & & $Q Q_{c}$ & $\mathbf{P}$ & $\mathbf{M}$ & GLM & M Me & $\mathbf{P}$ & NP \\
\hline CONJUNTO TOTAL PONTO 1 & 183 & 13 & 25 & $\overline{12}$ & $Q>0 c$ & *\# & 98.25 & 66 & $\mathrm{M}>\mathrm{Mc}$ & $*$ & $\overline{339}$ \\
\hline CENTRALES & 9 & 13 & 20 & 12 & $Q<Q_{c}$ & $\overline{\mathrm{N}}$ & 114,49 & 66 & $\mathrm{M}>\mathrm{Mc}$ & $* *$ & 33 \\
\hline CLOROFICEAS EXCETO VOLV. & 77 & 13 & 22 & 12 & $\mathrm{Q} \times \mathrm{Qc}$ & 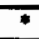 & 56.69 & 66 & $M<M c$ & $\mathrm{~N}$ & 169 \\
\hline CRISOFICEAS & 11 & 13 & 15 & 12 & $\overline{Q<Q c}$ & $\overline{\mathbf{N}}$ & 84,67 & 66 & $\mathrm{M}<\mathrm{Mc}$ & $\mathbf{N}$ & 7 \\
\hline CRIPTOFICEAS & 7 & 13 & 7 & 12 & $\overline{Q<Q c}$ & $\bar{N}$ & 64,15 & 66 & $\mathrm{M}<\mathrm{Mc}$ & $\overline{\mathrm{N}}$ & 29 \\
\hline CIANOFICEAS & 14 & 13 & 10 & 12 & $\overline{Q<Q c}$ & $\bar{N}$ & 61,14 & 66 & $\bar{M}<\mathrm{Mc}$ & $\overline{\mathrm{N}}$ & $\overline{10}$ \\
\hline DNOFICEAS & 1 & 56 & 12 & 12 & $\overline{\mathrm{Q}<\mathrm{Qc}}$ & $\bar{N}$ & 66,00 & 66 & $\mathrm{M}<\mathrm{Mc}$ & $\mathrm{N}$ & $\overline{1}$ \\
\hline EUGLENOFICEAS & 12 & 13 & 13 & 12 & $\overline{Q<Q c}$ & $\bar{N}$ & 63,36 & 66 & $\mathrm{M}<\mathrm{Mc}$ & $\bar{N}$ & 6 \\
\hline VOLVOCALES & II & 13 & $\overline{8}$ & 12 & $Q<Q c$ & $\bar{N}$ & 71,90 & 66 & $M<M c$ & $\overline{\mathrm{N}}$ & $\overline{40}$ \\
\hline PENALES & 9 & 13 & $\overline{3}$ & $\overline{12}$ & $\overline{Q<Q c}$ & $\overline{\mathrm{N}}$ & 63,69 & 66 & $\mathrm{M}<\mathrm{Mc}$ & $\bar{N}$ & 37 \\
\hline ZIGNEMAFICEAS & 32 & 13 & 9 & 12 & $Q<Q c$ & $\bar{N}$ & 64,44 & 66 & $\mathrm{M}<\mathrm{Mc}$ & $\bar{N}$ & 7 \\
\hline
\end{tabular}


PONTO 1:PRIMEIRO PERIODO DE SECA

\begin{tabular}{lrrrrr} 
CONJUNTO AMOSTRAL & NSP & NC & Q GLQ & Q Qc \\
\hline CONJUNTO TOTAL PONTO I & 183 & 15 & 62 & 14 & $\mathrm{Q}>\mathrm{Qc}$ \\
\hline CENTRALES & 9 & 15 & 13 & 14 & $\mathrm{Q}<\mathrm{Qc}$ \\
\hline CLOROFICEAS EXCETO VOLV & $\mathbf{7 7}$ & 15 & 57 & 14 & $\mathrm{Q}>\mathrm{Qc}$ \\
\hline CRISOFICEAS & 11 & 15 & 18 & 14 & $\mathrm{Q}<\mathrm{Qc}$ \\
\hline CRIPTOFICEAS & 7 & 15 & 19 & 14 & $\mathrm{Q}<\mathrm{Qc}$ \\
\hline CIANOFICEAS & 14 & 15 & 8 & 14 & $\mathrm{Q}<\mathrm{Qc}$ \\
\hline DINOFICEAS & 1 & 15 & & 14 & $\mathrm{Q}<\mathrm{Qc}$ \\
\hline EUGLENOFICEAS & 12 & 15 & 11 & 14 & $\mathrm{Q}<\mathrm{Qc}$ \\
\hline VOLVOCALES & 11 & 15 & 9 & 14 & $\mathrm{Q}<\mathrm{Qc}$ \\
\hline PENALES & 9 & 15 & 20 & 14 & $\mathrm{Q}<\mathrm{Qc}$ \\
\hline ZIGNEMAFICEAS & 32 & 15 & 33 & 14 & $\mathrm{Q}>\mathrm{Qc}$ \\
\hline
\end{tabular}

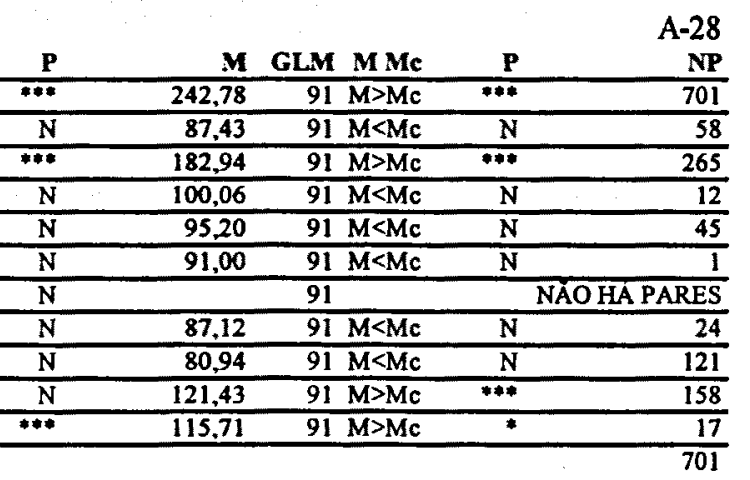

\section{PONTO1: SEGUNDO PERIODO DE SECA}

\begin{tabular}{|c|c|c|c|c|c|c|c|c|c|c|c|}
\hline CONJUNTO AMOSTRAL & NSP & NC & \multicolumn{2}{|c|}{ QGLQ } & $\mathbf{Q Q c}$ & $\mathbf{P}$ & $\mathbf{M}$ & GLM & $\mathbf{M} \mathbf{M c}$ & $\mathbf{P}$ & $\mathbf{N P}$ \\
\hline CONJUNTO TOTAL PONTO I & 183 & 13 & 33 & 12 & $Q>Q c$ & **** & 159,57 & 66 & $\mathrm{M}>\mathrm{Mc}$ & *** & 1188 \\
\hline CENTRALES & 9 & 13 & 24 & 12 & $\mathrm{Q}>\mathrm{Qc}$ & 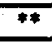 & 96,46 & 66 & $\mathrm{M}>\mathrm{Mc}$ & $* *$ & 31 \\
\hline CLOROFICEAS EXCETO VOLV. & 77 & 13 & 29 & 12 & $Q>Q c$ & 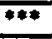 & 145,11 & 66 & $\mathrm{M}>\mathrm{Mc}$ & $\neq *$ & 743 \\
\hline CRISOFICEAS & 11 & 13 & 19 & 12 & $Q<Q c$ & $\bar{N}$ & 62,38 & 66 & $\mathbf{M}<\mathbf{M c}$ & $\mathbf{N}$ & 9 \\
\hline CRIPTOFICEAS & 7 & 13 & 17 & 12 & $\overline{Q<Q c}$ & $\bar{N}$ & 94,88 & 66 & $\mathrm{M}>\mathrm{Mc}$ & ** & $\overline{23}$ \\
\hline CIANOFICEAS & 14 & 13 & 13 & 12 & $Q<Q c$ & $\mathbf{N}$ & 74,69 & 66 & $\mathrm{M}<\mathrm{Mc}$ & $\mathbf{N}$ & 93 \\
\hline DINOFICEAS & 1 & 13 & & 12 & $\overline{Q<Q c}$ & $\mathbf{N}$ & & 66 & & & ARES \\
\hline EUGLENOFICEAS & 12 & 13 & 16 & 12 & $Q<Q c$ & $\bar{N}$ & 60,92 & 66 & $\mathrm{M}<\mathrm{Mc}$ & $\mathrm{N}$ & $\overline{18}$ \\
\hline VOLVOCALES & 11 & 13 & 16 & 12 & $Q<Q_{c}$ & $\bar{N}$ & 69,57 & 66 & $\mathrm{M}<\mathrm{Mc}$ & $\mathrm{N}$ & 76 \\
\hline PENALES & 9 & 13 & 14 & 12 & $Q<Q c$ & $\mathbf{N}$ & 124,48 & 66 & $\mathrm{M}>\mathrm{Mc}$ & $* * *$ & 111 \\
\hline ZIGNEMAFICEAS & 32 & 13 & 9 & 12 & $Q<Q c$ & $\overline{\mathrm{N}}$ & 62,07 & 66 & $\mathrm{M}<\mathrm{Mc}$ & $\bar{N}$ & 84 \\
\hline
\end{tabular}

\section{CONJUNTO TOTAL PONTO 4}

CONJUNTO AMOSTRAL

CONJUNTO TOTAL PONTO 4

CENTRALES

CLOROFICEAS EXCETO VOLV.

NSP NC QGLQ QQC

$12.56: 49: 55 \quad Q<0$

\begin{tabular}{llllll}
\hline CRIPTOFICEAS & 8 & 56 & 32 & 55 & $\mathrm{Q}<\mathrm{Q}$ \\
\hline CANOFICEAS & 9 & 56 & 81 & 55 & $\mathrm{Q} \times \mathrm{QC}$
\end{tabular}

\begin{tabular}{llllll}
\hline CLANOFICEAS & 9 & 56 & 81 & 55 & $\mathrm{Q}>\mathrm{Q}$
\end{tabular}

\begin{tabular}{lllllll}
\hline DINOFICEAS & 11 & 56 & 75 & 55 & $\mathrm{Q}<\mathrm{QC}$
\end{tabular}

\begin{tabular}{llllll}
\hline EUGLENOFICEAS & 13 & 56 & 72 & 55 & $\mathrm{Q}<\mathrm{Q}_{c}$
\end{tabular}

\begin{tabular}{lllllll}
\hline VOLVOCALES & 10 & 56 & 89 & 55 & $\mathrm{Q}>0$
\end{tabular}

\begin{tabular}{llllll}
\hline PENALES & 10 & 56 & 58 & 55 & $\mathrm{Q}<\mathrm{QC}$ \\
\hline
\end{tabular} \begin{tabular}{rrrr} 
M & GLM M Mc & P & NP \\
2957.10 & 1485 M>Mc & $* * *$ & 9280 \\
\hline
\end{tabular}

PONTO 4: PERIODO DE SECA

CONJUNTO AMOSTRAL

CONJUNTO TOTAL PONTO 4

NSP NC QGLQ QQC

CENTRALES

$\begin{array}{rrrrr}178 & 28 & 114 & 27 & \mathrm{Q}>\mathrm{Qc} \\ 11 & 28 & 42 & 27 & \mathrm{O}>0 \mathrm{c}\end{array}$

$\begin{array}{lllllll}\text { CLOROFICEAS EXCETO VOLV. } & 71 & 28 & 101 & 27 & \mathrm{Q}>\mathrm{QC}\end{array}$

\begin{tabular}{llllll}
\hline CRISOFICEAS & 12 & 28 & 30 & 27 & $\mathrm{O}<\mathrm{Q}_{C}$
\end{tabular}

\begin{tabular}{llllll} 
CRIPTOFICEAS & 8 & 28 & 14 & 27 & $\mathrm{Q}<\mathrm{QC}$ \\
\hline & 9 & 28 & 48 & 27 & $\mathrm{Q} \times \mathrm{QC}$
\end{tabular}

$\begin{array}{llllll}\text { CIANOFICEAS } & 9 & 28 & 48 & 27 & \mathrm{Q}>\mathrm{QC}\end{array}$

\begin{tabular}{llllll}
\hline DINOFICEAS & 11 & 28 & 24 & 27 & $\mathrm{Q}<\mathrm{Qc}$ \\
\hline
\end{tabular}

\begin{tabular}{llllll}
\hline EUGLENOFICEAS & 13 & 28 & 29 & 27 & $\mathrm{O}<\mathrm{CC}$ \\
\hline
\end{tabular}

$\begin{array}{llllll}\text { VOLVOCALES } & 10 & 28 & 40 & 27 & \mathrm{Q}<\mathrm{Q}\end{array}$

\begin{tabular}{llllll}
\hline PENALES & 10 & 28 & 31 & 27 & $Q_{<} Q_{C}$
\end{tabular}

ZIGNEMAFICEAS

$\begin{array}{llll}28 & 44 & 27 & \mathrm{Q}>\mathrm{OC}\end{array}$

$\mathbf{P}$ $\mathrm{N} \quad 1644,44 \quad 1485 \mathrm{M}>\mathrm{Mc}$

$\begin{array}{lll}\text { *** } & 2985,05 & 1485 \mathrm{M}>\mathrm{Mc}\end{array}$

$1457,46 \quad 1485 \mathrm{M}<\mathrm{Mc}$

\begin{tabular}{lllll}
$\mathrm{N}$ & 1474,07 & $1485 \mathrm{M}<\mathrm{Mc}$ & $\mathrm{N}$ & 1228 \\
\hline
\end{tabular}

*** $\quad \begin{array}{ll}1712.29 & 1485 \mathrm{M}>\mathrm{Mc}\end{array}$

\begin{tabular}{ll}
1587.28 & $1485 \mathrm{M}>\mathrm{Mc}$ \\
\hline 1547.55 & 1485 \\
\hline
\end{tabular}

\begin{tabular}{rrrrr}
$\mathrm{N}$ & 1547,55 & $1485 \mathrm{M}<\mathrm{Mc}$ & $\mathrm{N}$ & 145 \\
$* * *$ & 1536,71 & $1485 \mathrm{M}<\mathrm{Mc}$ & $\mathrm{N}$ & 1433 \\
\hline
\end{tabular}

$\begin{array}{lll}\mathrm{N} & 1493,66 & 1485 \mathrm{M}<\mathrm{Mc}\end{array}$

$\begin{array}{rrrr}1484,10 & 1485 \mathrm{M}<\mathrm{Mc} & \mathrm{N} & 229 \\ & & & 9280\end{array}$

\section{PONTO 4: PERIODO DE CHUVA}

CONJUNTO AMOSTRAL NSP NC Q GLQ Q QC $\begin{array}{llllll}\text { CONIUNTO TOTAL PONTO } 4 & 178 & 28 & 74 & 27 & \mathrm{Q} \times \mathrm{QC}\end{array}$ CENTRALES

CLOROFICEAS EXCETO VOLV.

CRISOFICEAS

CRIPTOFICEAS

CIANOFICEAS

DINOFICEAS

EUGLENOFICEAS

VOL VOCALES

PENALES

ZIGNEMAFICEAS

\section{PONTO 4: PERIODO DE CHUVAS INTENSAS}

CONJUNTO AMOSTRAL

CONתNTOO TOTAL PONTO 4

\begin{tabular}{cc} 
NSP & NC \\
\hline 178 & 15
\end{tabular}

NC QGLQ QQe

$\begin{array}{lll}13 & 14 & Q<Q c \\ 12 & 14 & Q<Q c\end{array}$

CENTRALES

CLOROFICEAS EXCETO VOLV.

$\begin{array}{lllll}11 & 15 & 12 & 14 & Q<Q c \\ 71 & 15 & 14 & 14 & Q<Q c\end{array}$

$\mathbf{P}$

$M$ GLM MMc \begin{tabular}{rrrr}
873,40 & $351 \mathrm{M}>\mathrm{Mc}$ & $\ldots *$ & NP \\
\hline
\end{tabular} \begin{tabular}{llll}
873,40 & $351 \mathrm{M}>\mathrm{Mc}$ & $* . *$ & 2401 \\
\hline 11.21 & $351 \mathrm{M}>\mathrm{Mc}$ & $* * *$ & 240 \\
899,70 & $351 \mathrm{M}>\mathrm{Mc}$ & &
\end{tabular} $\begin{array}{llll}899,70 & 351 \mathrm{M}>\mathrm{Mc} \quad * * & 1212 \\ 343,38 & 351 \mathrm{M} & \mathrm{Mc} & \mathrm{M}\end{array}$ $343,38 \quad 351 \mathrm{M}<\mathrm{Mc}$ $323,46 \quad 351 \mathrm{M}<\mathrm{Mc}$ $419.91351 \mathrm{M}>\mathrm{Mc}$ $351,00 \quad 351 \mathrm{M}<\mathrm{Mc}$ $341,25 \quad 351 \mathrm{M}<\mathrm{Mc}$ $380.55351 \mathrm{M}>\mathrm{Mc}$ $324,17 \quad 351 \mathrm{M}<\mathrm{Mc}$ $356,44 \quad 351 \mathrm{M}>\mathrm{Mc}$ \begin{tabular}{lr}
$\mathrm{N}$ & 66 \\
$\mathrm{~N}$ & 304 \\
\hline
\end{tabular} $\begin{array}{rr}N & 48 \\ N & 6\end{array}$ \begin{tabular}{|lr}
$\mathrm{N}$ & 6 \\
$\mathrm{~N}$ & 40 \\
\hline$* *$ & 262 \\
\hline
\end{tabular} $\mathrm{N}$ *** $\quad 157$ $\frac{66}{2401}$ CRISOFICEAS

\begin{tabular}{|c|c|c|c|c|c|c|c|c|c|c|}
\hline NSP & $\mathrm{NC}$ & \multicolumn{2}{|c|}{ Q GLQ } & $\mathbf{Q Q c}$ & $\mathbf{P}$ & $\mathbf{M}$ & GLM & $\mathbf{M} \mathbf{M c}$ & $\mathbf{P}$ & NP \\
\hline 178 & 28 & 74 & 27 & $Q>Q c$ & 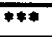 & 635,68 & 351 & $M>M c$ & 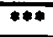 & 2390 \\
\hline 11 & 28 & 28 & 27 & $\overline{Q<Q c}$ & $\overline{\mathbf{N}}$ & 351,48 & 351 & $\mathrm{M}>\mathrm{Mc}$ & **** & 235 \\
\hline 71 & 28 & 62 & 27 & $\bar{Q}>\mathrm{Qc}$ & $* * *$ & 589.86 & 351 & $M>M c$ & $+\infty$ & 884 \\
\hline 12 & 28 & 21 & 27 & $Q<Q_{c}$ & $\bar{N}$ & 328,99 & 351 & $\mathrm{M}<\mathrm{Mc}$ & $\mathbf{N}$ & 50 \\
\hline 8 & 28 & 18 & 27 & $\overline{Q<Q c}$ & $\overline{\mathrm{N}}$ & 370,54 & 351 & $\mathrm{M}>\mathrm{Mc}$ & **** & 291 \\
\hline 9 & 28 & 36 & 27 & $\overline{Q<Q c}$ & $\overline{\mathrm{N}}$ & 412,07 & 351 & $\mathrm{M}>\mathrm{Mc}$ & **** & 169 \\
\hline 11 & 28 & 29 & 27 & $\mathrm{Q}<\mathrm{Q}_{\mathbf{c}}$ & $\mathrm{N}$ & 366,58 & 351 & $M>M c$ & $* * *$ & 77 \\
\hline 13 & 28 & 43 & 27 & $Q>Q c$ & * & 388,04 & 351 & $M>M c$ & $*$ & 26 \\
\hline 10 & 28 & 41 & 27 & $Q>Q C$ & $\div$ & 318,14 & 351 & $\mathrm{M}<\mathrm{Mc}$ & $\mathrm{N}$ & 448 \\
\hline 10 & 28 & 27 & 27 & $\overline{Q<Q c}$ & $\mathbf{N}$ & 366,32 & 351 & $M>M c$ & *** & 140 \\
\hline 23 & 28 & 42 & 27 & $Q>Q c$ & * & 354,43 & 351 & $\mathrm{M}>\mathrm{Mc}$ & $* *$ & 70 \\
\hline
\end{tabular}

\begin{tabular}{rrrrrr}
$\mathbf{P}$ & M & GLM & M Mc & P & NP \\
\hline $\mathrm{N}$ & 134,28 & 91 M>Mc & $* * *$ & 921 \\
\hline $\mathrm{N}$ & 78,18 & $91 \mathrm{M}<\mathrm{Mc}$ & $\mathrm{N}$ & 51 \\
\hline $\mathrm{N}$ & 156,27 & 91 & $\mathrm{M}>\mathrm{Mc}$ & $* * *$ & 358 \\
\hline $\mathrm{N}$ & 84,92 & 91 & $\mathrm{M}<\mathrm{Mc}$ & $\mathrm{N}$ & 11 \\
\hline
\end{tabular}




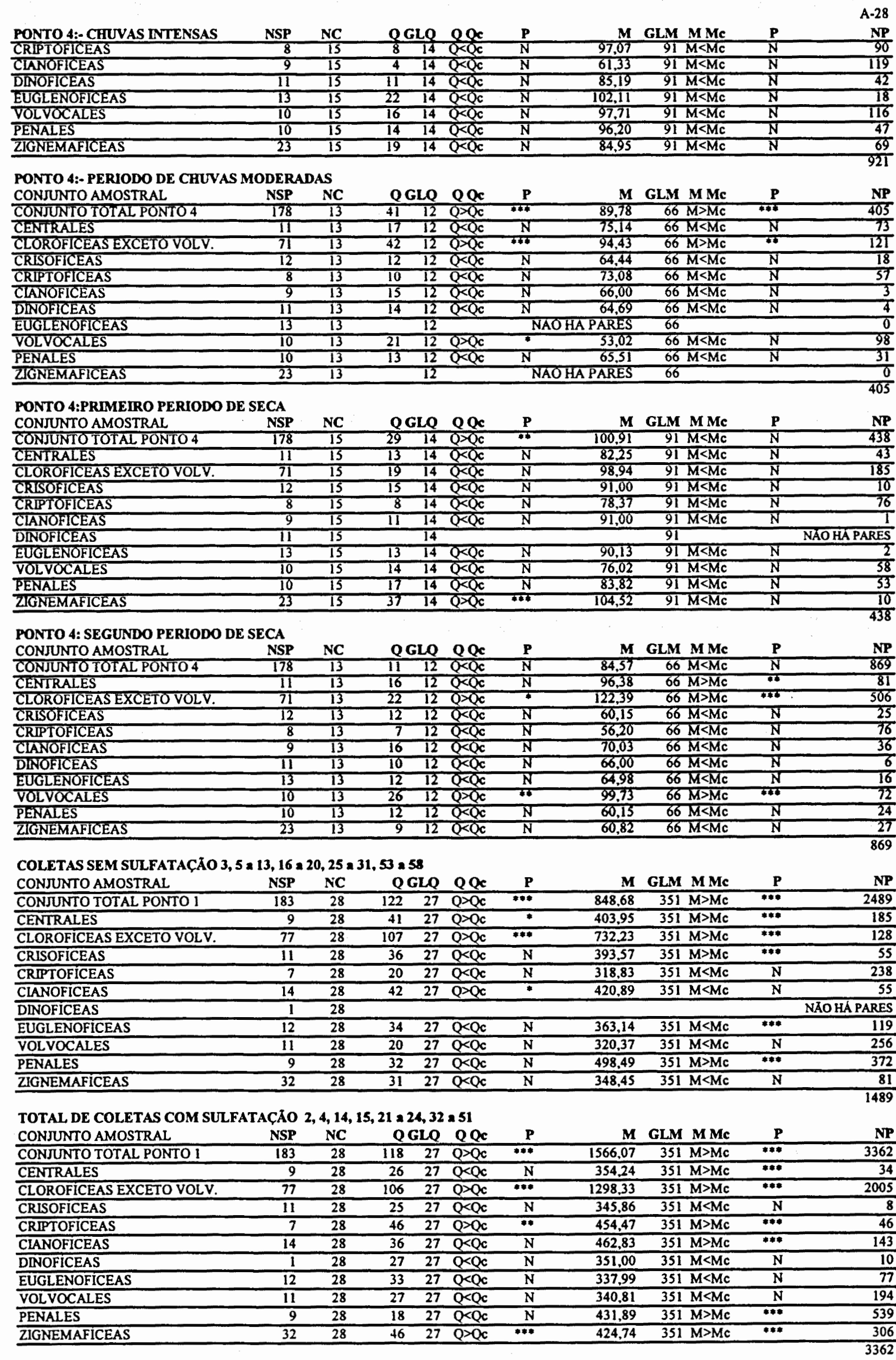


PONTO $I$ COLETAS SEM SULFATAÇĀO

CONJUNTO AMOSTRAL

SECA NS

PONTO I COLETAS COM SULFATACAO

CONJUNTO AMOSTRAL

CHUVAS

NS

$\begin{array}{llll} & \text { NC } & \text { Q GLQ } & \text { Q Q } \\ 17 & 104 & 16 & 0>0\end{array}$

\begin{tabular}{rrrrrrr} 
Qc & P & M & GLM M Mc & P & A-28 \\
\hline$Q c$ & $* * *$ & 413,54 & 120 & M $>$ Mc & $* * *$ & NP \\
\hline Qc & P & M & GLM & M Mc & P & 1065 \\
\hline C & N & 60,91 & 45 & $M<M c$ & N & NP \\
\hline
\end{tabular}

PONTO 1 COLETAS COM SULFATAÇĀO

CONJUNTO AMOSTRAL NSP

SECA 183

CHUVAS

I83

NC 11

Q GLQ Q Qc

M GLM M Mc

258,04

$45 \mathrm{M}>\mathrm{Mc}$

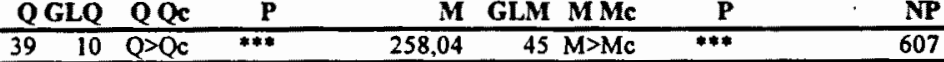

TOTAL DE COLETAS COM SULFATAÇ̇O PRIMEIRA SECA: 2,4,14,15

CONJUNTO AMOSTRAL

CONJUNTO TOTAL PONTO $\begin{array}{cccc}\text { NSP } & \text { NC } & \text { Q GLQ } & \text { Q Qc } \\ 183 & 4 & 7 & 3<0\end{array}$

P

M GLM M Mc 3,00

TOTAL DE COLETAS COM SULFATAÇÃO SEGUNDA SECA: 45 A 51

CONJUNTO AMOSTRAL NSP NC Q GLQ Q Qc

CONJUNTO TOTAL PONTO 1 NSP NC Q GLQ QQ

$\mathbf{P}$ $\begin{array}{llll}6 & 6 & Q<Q c & N\end{array}$

M GLM M Mc $4,89 \quad 15 \mathrm{M}<\mathrm{Mc} \quad \mathrm{N}$ 372

TOTAL DE COLETAS COM SULFATACÃO CHUVAS MODERADAS : 21 A 24

CONJUNTO AMOSTRAL

CONJUNTO TOTAL PONTO

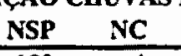

P M GLM M Mc 3,53 $3 \mathrm{M}<\mathrm{Mc}$

\begin{tabular}{lr}
$\mathbf{P}$ & $\mathbf{N P}$ \\
\hline $\mathrm{N}$ & $\frac{16}{16}$
\end{tabular}

TOTAL DE COLETAS COM SULFATAÇAO CHUVAS INTENSAS: 32 A 44

CONJUNTO AMOSTRAL

CONJUNTO TOTAL PONTO 1

NSP NC OGLO OQc

CENTRALES

CLOROFICEAS EXCETO VOLV.

CRISOFICEAS

CRIPTOFICEAS

CIANOFICEAS

DINOFICEAS

EUGLENOFICEAS

VOLVOCALES

PENALES

ZIGNEMAFICEAS

$\begin{array}{lllll}183 & 13 & 30 & 12 & 0>0 c\end{array}$

$P$

$\begin{array}{llll}\text { GLM M Mc } & \mathbf{P} & \text { NP }\end{array}$

COLETAS SEM SULFATAÇĀO PRIMEIRA SECA: 3, 5 A 13,16

CONJUNTO AMOSTRAL

CONJUNTO TOTAL PONTO

CENTRALES

CLOROFICEAS EXCETO VOLV

CRISOFICEAS

CRIPTOFICEAS

CIANOFICEAS

DINOFICEAS

EUGLENOFICEAS

$\begin{array}{lll}9 & 12 & Q<Q C\end{array}$

*** 168,34

$66 \mathrm{M}>\mathrm{Mc}$

$66 \mathrm{M<Mc}+* * *$

$\begin{array}{rrrrrrrr}77 & 13 & 24 & 12 & \mathrm{Q}>\mathrm{Qc} & * & 159,20 & 66 \mathrm{M}>\mathrm{Mc} \\ 11 & 13 & 12 & 12 & \mathrm{Q}<\mathrm{Qc} & \mathrm{N} & 66,00 & 66 \mathrm{M}<\mathrm{Mc}\end{array}$

$\begin{array}{lllll}7 & 13 & 22 & 12 & Q<Q c\end{array}$

$\mathrm{N} \quad 66,00$

$66 \mathrm{M}<\mathrm{Mc}$

$75,96-66 \mathrm{M}<\mathrm{Mc}$

$\begin{array}{lllll}14 & 13 & 15 & 12 & Q<0 \\ 1 & 13 & 12 & 12 & Q<0\end{array}$

$\begin{array}{ll}N & 75,96 \\ N\end{array}$

$\begin{array}{lll}12 & 12 & Q<Q c \\ 18 & 12 & Q<Q c\end{array}$

\begin{tabular}{rrrrr}
12 & 13 & 18 & 12 & $Q<Q c$ \\
11 & 13 & 8 & 12 & $Q<Q c$ \\
\hline & 13 & 13 & 12 & $0<0 c$
\end{tabular}

$\mathrm{N} \quad 66,00$

$66 \mathrm{M}<\mathrm{Mc}$

$70,47 \quad 66 \mathrm{M}<\mathrm{Mc}$

$\begin{array}{ll}\mathrm{N} & 70,47 \\ \mathrm{~N} & 56,46\end{array}$

$46 \quad 66 \mathrm{M}<\mathrm{Mc}$

$\begin{array}{rrrrr}9 & 13 & 13 & 12 & Q<Q c \\ 32 & 13 & 16 & 12 & Q<Q c\end{array}$

$\begin{array}{lll}77,92 & 66 & \mathrm{M}<\mathrm{Mc} \\ 64,12 & 66 \mathrm{M}<\mathrm{Mc}\end{array}$

\begin{tabular}{|rr}
\hline$P$ & NP \\
\hline$* * *$ & 846 \\
\hline$N$ & 3 \\
\hline$* * *$ & 494 \\
\hline$N$ & 1 \\
\hline$*$ & 15 \\
\hline$N$ & 38 \\
\hline$N$ & 3 \\
\hline$N$ & 29 \\
\hline$N$ & 133 \\
\hline$N$ & 27 \\
\hline$N$ & 103 \\
\hline
\end{tabular}

VOLVOCALES

PENALES

ZIGNEMAFICEAS NSP NC

QGLO QQC

$\mathrm{N} \quad 64,12$

$\begin{array}{lllll}183 & 11 & 53 & 10 & \mathrm{Q}>\mathrm{OC}\end{array}$

P M GLM M Mc

\begin{tabular}{cr} 
P & NP \\
\hline$* * *$ & 371 \\
\hline$N$ & 22 \\
\hline$N$ & 141 \\
\hline$N$ & 9 \\
\hline$N$ & 32 \\
\hline & NAO HA PARES \\
\hline NAO HÁ ESPECIES \\
\hline$N$ & 17 \\
\hline$N$ & 58 \\
\hline$*$ & 79 \\
\hline$*$ & 13 \\
\hline
\end{tabular}

COLETAS SEM SULFATAÇ̄̃ CHUVAS MODERADAS 17 A 20, 25 A 29

CONJUNTO AMOSTRAL

CONJUNTO TOTAL PONTO

NSP NC

0 GLO 0 Oc

$\begin{array}{rrrrrrrrr}11 & 11 & 12 & 10 & \mathrm{Q}<\mathrm{Qc} & \mathrm{N} & 50,39 & 45 \mathrm{M}<\mathrm{Mc} \\ 7 & 11 & 9 & 10 & \mathrm{Q}<\mathrm{Qc} & \mathrm{N} & 39,41 & 45 \mathrm{M}<\mathrm{Mc} \\ 14 & 11 & & 10 & & & & 45\end{array}$

45

$\begin{array}{rrrrllllll}1 & 11 & & & & & & & \\ 12 & 11 & 9 & 10 & \mathrm{Q}<\mathrm{Qc} & \mathrm{N} & 42,63 & 45 & \mathrm{M}<\mathrm{M} \\ 11 & 11 & 8 & 10 & \mathrm{Q}<\mathrm{Qc} & \mathrm{N} & 46,21 & 45 \mathrm{M}<\mathrm{M} \\ 9 & 11 & 16 & 10 & \mathrm{Q}<\mathrm{Qc} & \mathrm{N} & 66,46 & 45 \mathrm{M}>\mathrm{M} \\ 32 & 11 & 20 & 10 & \mathrm{Q}>\mathrm{Oc} & * & 65,05 & 45 \mathrm{M}>\mathrm{M}\end{array}$

COLETAS SEM SULFATAÇĀO CHUVAS INTENSAS 30 E 31

CONJUNTO AMOSTRAL

NSP NC QGLQ QQC P 1 NAOHA CALCTLO

M GLM M Mc

(

183 $1 \mathrm{NA}$

TOTAL DE COLETAS SEM SULFATAÇÃO SEGUNDA SECA 53 A 58

CONJUNTO AMOSTRAL

CONJUNTO TOTAL PONTO 1

NSP NC Q GLQ Q Q

$\begin{array}{lllllll}183 & 6 & 26 & 5 & Q>Q c & * * * & 18,74\end{array}$

8,74

GLM M Mc

$10 \mathrm{M}>\mathrm{Mc}$


TABELA 29 - VARLAÇÃo TEMPORAL DAS ESPÉCIES DO FITOPLÂNCTON. FREQOÊNCIA RELATIVA DA DENSIDADE (CÉlULAS). REPRESA DE GUARAPIRANGA 1991-92. PONTO 1.

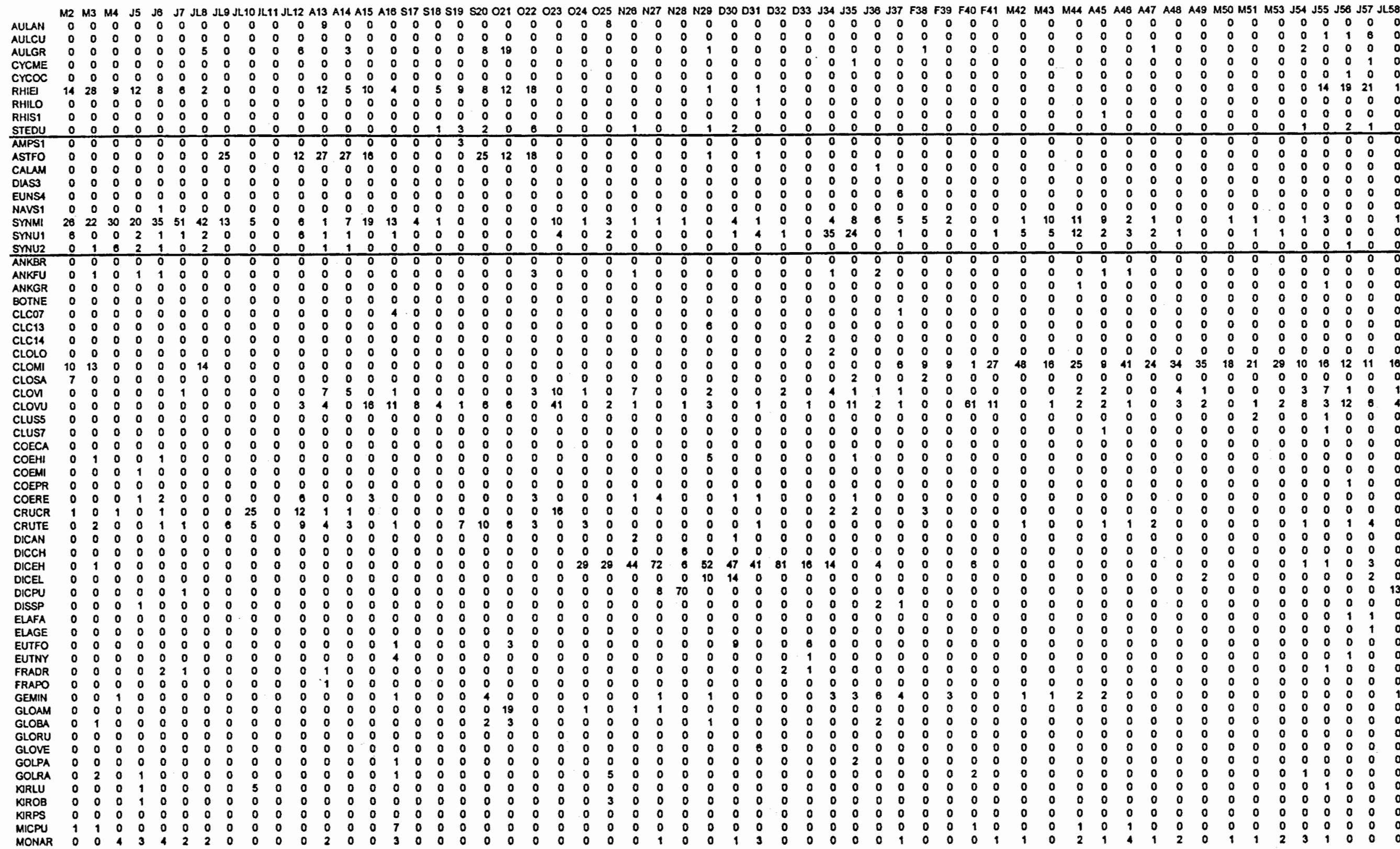


TABELA 29 - VARIAÇÃo TEMPORAL DAS ESPÉCIES DO FTTOPLÂNCTON. FREQUENCIA RELATIVA DA DENSIDADE (CÉLULAS). REPRESA DE GUARAPIRANGA 1991-92. PONTO 1.

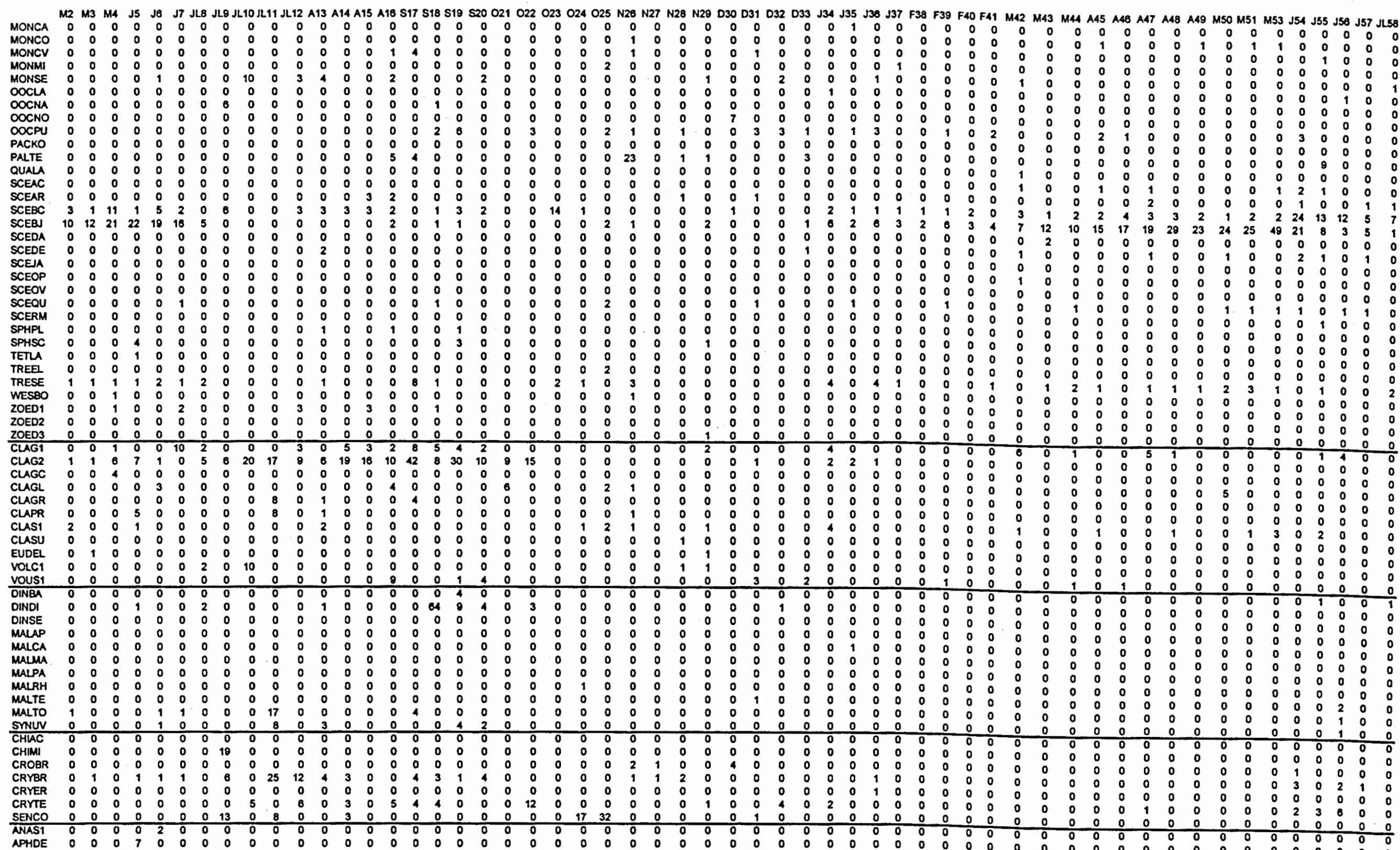


TABELA 29 - VARIAÇÃo TEMPORAL dAS ESPÉCIES DO FITOPLÂNCTON. FREQOÊNCIA RELATIVA DA DENSIDADE (CÉLULAS). REPRESA DE GUARAPIRANGA $1991-92$. PONTO 1.

M2 M3 M4 J5 J6 J7 JL8 J19 JL10 J11 JL12 A13 A14 A15 A18 S17 S18 S18 S20 O21 022023 O24 O25 N26 N27 N28 N29 D30 D31 D32 D33 J34 J35 J36 J37 F38 F39 F40 F41 M42 M43 M44 A45 A46 A47 A48 A49 M50 M51 M53 J54 J55 J56 J57 JL58

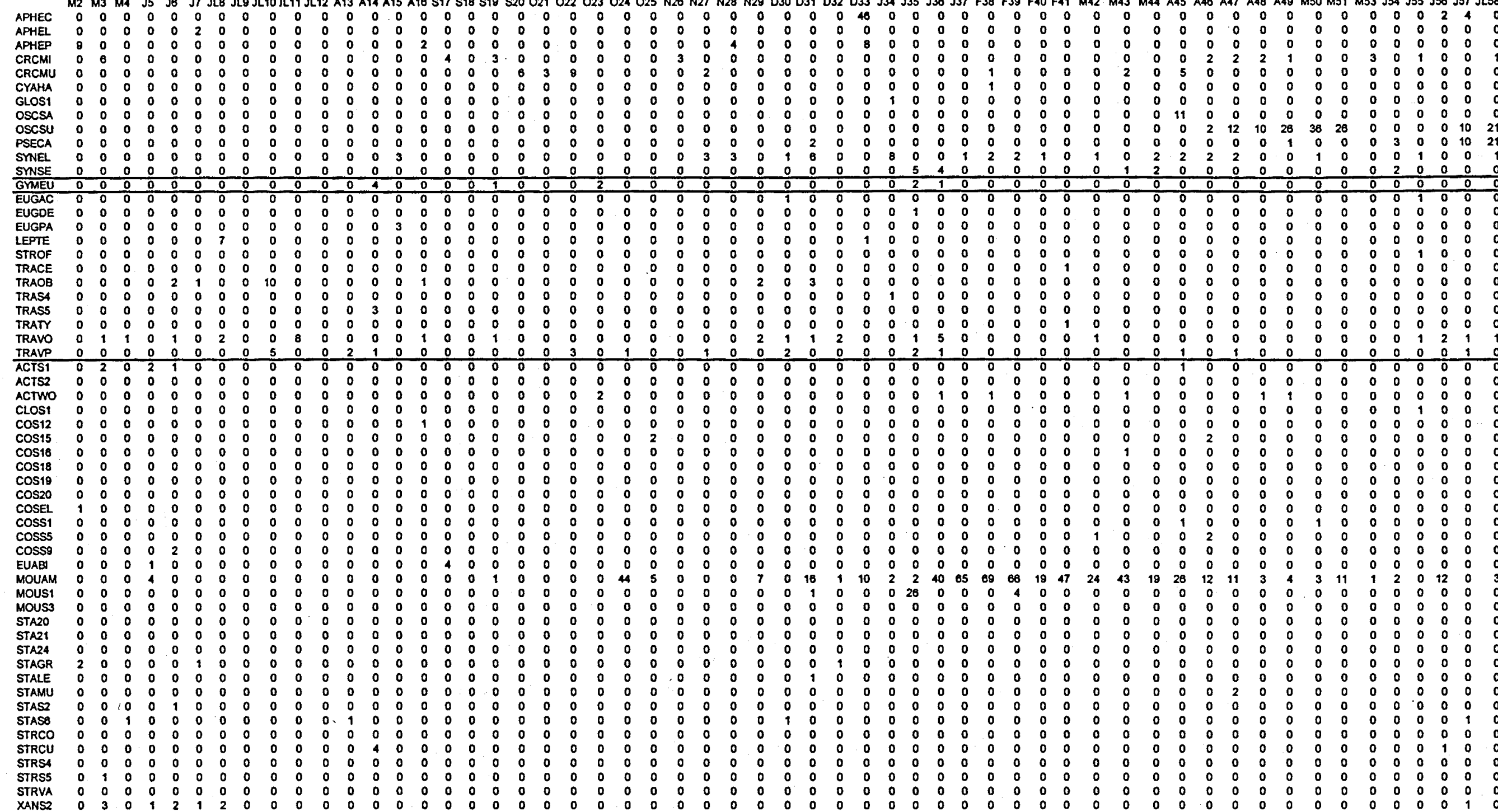

100100100100100100100100100100100100100100100100100100100100100100100100100100100100100100100100100100100100100100100100100100100100100100100100100100100100100100100100 OBS: AS SIGLAS UTILZADAS PARA IDENTIFICAR AS ESPEECIES ESTRO RELACIONADAS NA LSTA DAS ESPÉCIES NO ITEM 5.3.1. DO TEXTO DESTE TRABALHO. 
TABELA 30 - VARIAÇÃo TEMPORAL DAS ESPÉCIES DO FITOPLÂNCTON. FREQOÊNCIA RELATTVA DO BIOVOLUME. REPRESA DE GUARAPIRANGA, $1991-92$. PONTO 1.

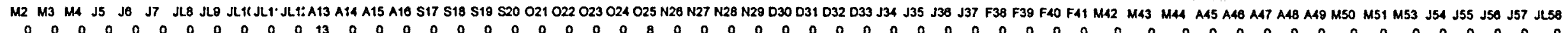

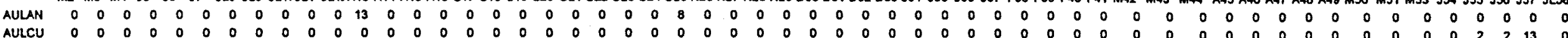

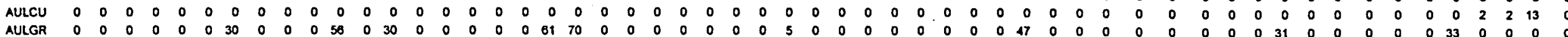

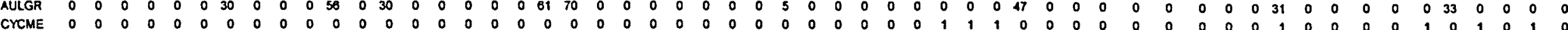
CrCME

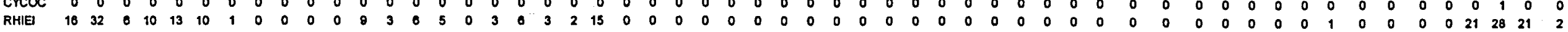

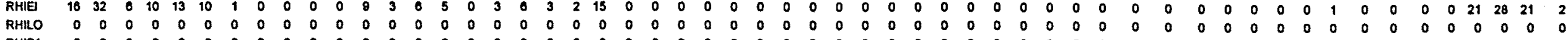

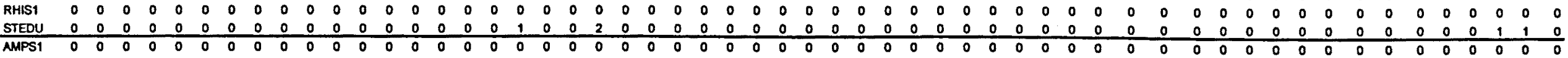

ASTFO

CALAM

EUNS

STAS1

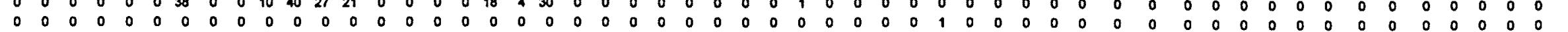

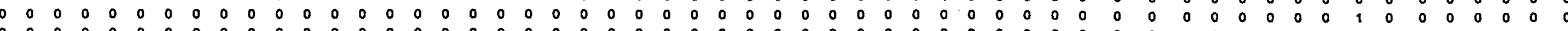

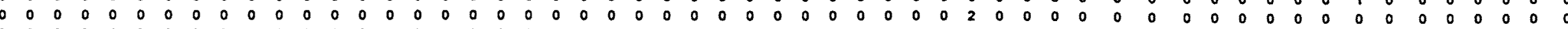

STMU

SWU2

ANKGR

BOTNE

CLC14

CLOMI

CLOSA

clust

COECA

COEMI

COEPR

COERE

CRUTE

DICAN

DICCH

DICEH
DICEL

EISSP

ELAGE

EUTNY

FRADR

FRAPO

GLOAM

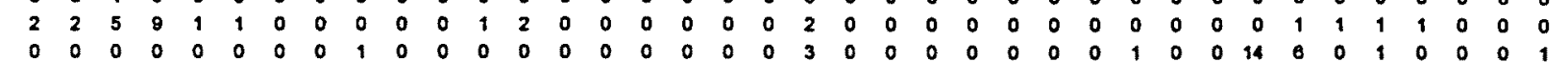

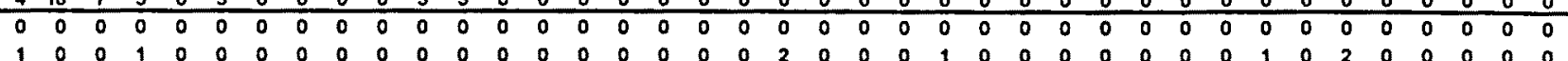

$\begin{array}{lllllll}0 & 0 & 0 & 0 & 0 & 0 \\ 0 & 1 & 2 & 1 & 0 & 0 & 0\end{array}$

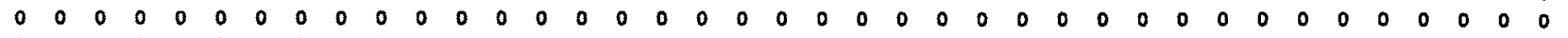
$\begin{array}{llllllllllllllllllllllllllllllllllllllll}0 & 0 & 0 & 0 & 0 & 0 & 0 & 0 & 0 & 0 & 0 & 0 & 0 & 0 & 0 & 0 & 0 & 0 & 0 & 0 & 0 & 0 & 0 & 0 & 0 & 0 & 0 & 0 & 0 & 0 & 0 & 0 & 0 & 0 & 0 & 0 & 0 & 0 & 0 & 0 \\ 0 & 0 & 0 & 0 & 0 & 0 & 0 & 0 & 0 & 0 & 0 & 0 & 0 & 0 & 0 & 0 & 0 & 0 & 0 & 0 & 0 & 0 & 0 & 0 & 0 & 0 & 0 & 0 & 0 & 0 & 0 & 0 & 0 & 0 & 4 & 0 & 0 & 0 & 0 & 0\end{array}$

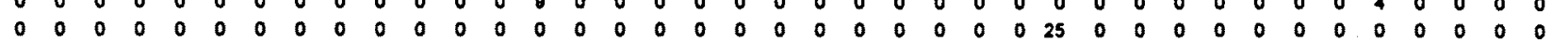

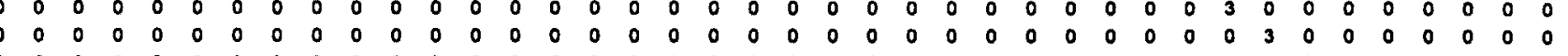
$\begin{array}{lllllllllllllllllllllllllllllllllllllllll}0 & 0 & 0 & 0 & 0 & 0 & 0 & 0 & 0 & 0 & 0 & 0 & 0 & 0 & 0 & 0 & 0 & 0 & 0 & 0 & 0 & 0 & 0 & 0 & 0 & 0 & 0 & 0 & 0 & 0 & 0 & 0 & 0 & 0 & 0 & 0 & 0 & 1 & 0 & 3 \\ 1 & 0 & 0 & 0 & 0 & 0 & 0 & 0 & 0 & 0 & 0 & 0 & 0 & 0 & 0 & 0 & 0 & 0 & 0 & 0 & 0 & 0 & 0 & 0 & 0 & 0 & 0 & 0 & 0 & 0 & 0 & 0 & 0 & 0 & 0 & 0 & 1 & 0 & 0 & 0 & 0\end{array}$

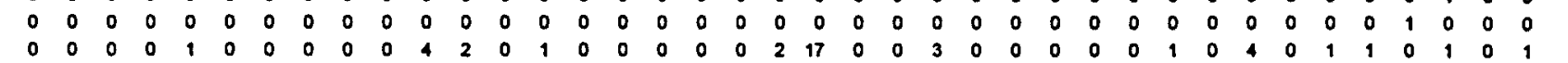

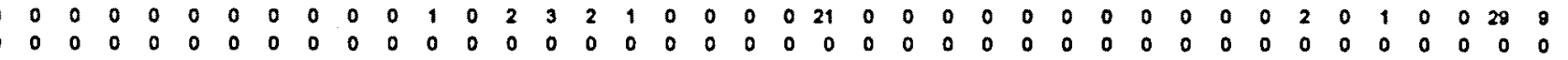

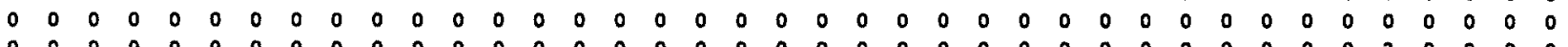

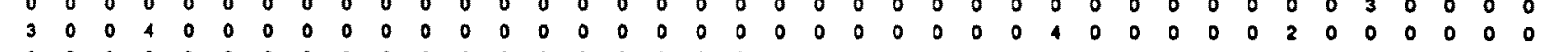

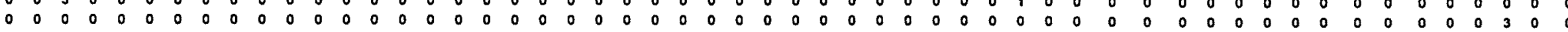

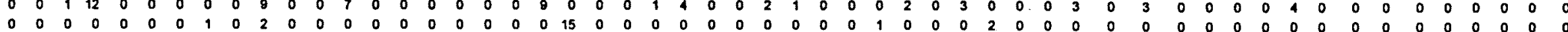

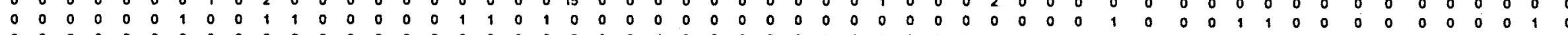

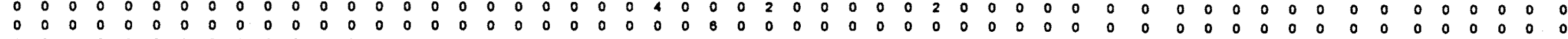

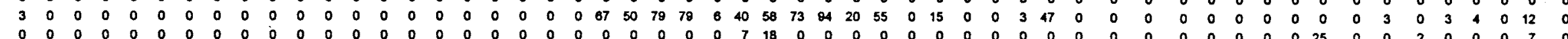

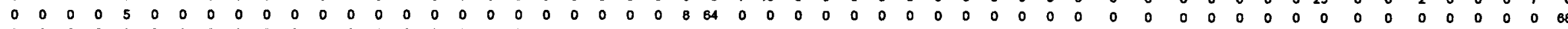

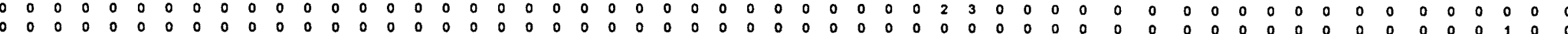

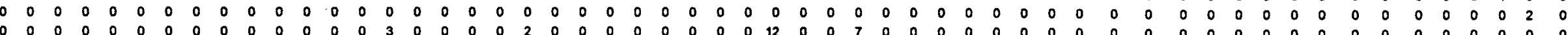

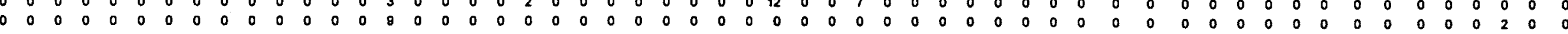

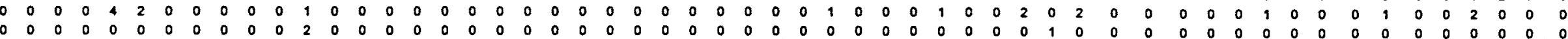

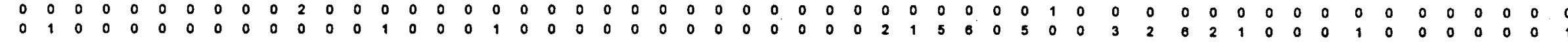


TABEla 30 - VARIAÇÃo TEMPORAL dAS ESPÉCIES DO FITOPLÂNCTON. FREQUENCIA RELATIVA do BIOVOLUME. REPRESA DE GUARAPIRANGA, $1991-92$. PONTO 1.

M2 M3 M4 J5 J6 J7 JL8 JL9 JL1 JL1.JL1:A13 A14 A15 A18 S17 S18 S19 S20 O21 O22 O23 O24 O25 N28 N27 N28 N29 D30 D31 D32 D33 J34 J35 J38 J37 F38 F39 F40 F41 M42 M43 M44 A45 A46 A47 A48 A49 M50 M51 M53 J54 J55 J56 J57 JL58

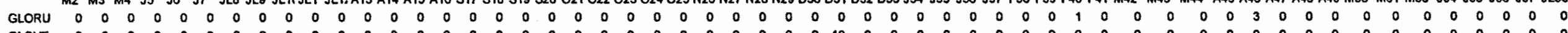

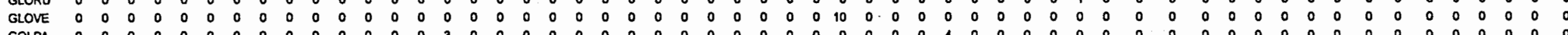

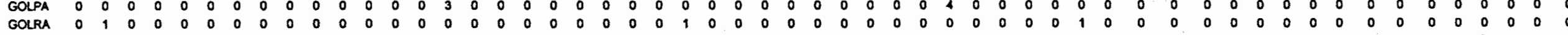

KIRIU

KIRPS

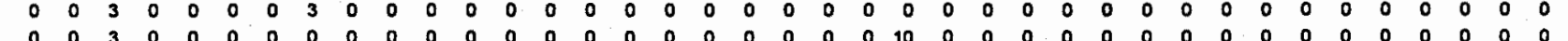

MICPU

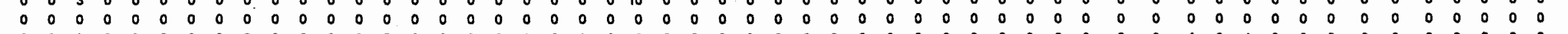

MONCA

MONCO

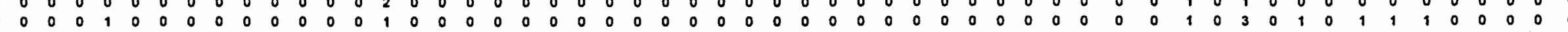

MONMI

MONSE

OOCLA

DONO

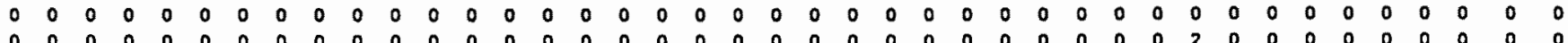

PALTE

SCEAC

SCEAR

SCEBS

SCEDA

SCEJA

SCEOV
SCEOU

SCERM

SPHPL

TETL

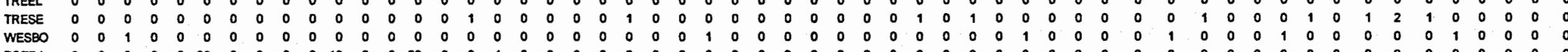

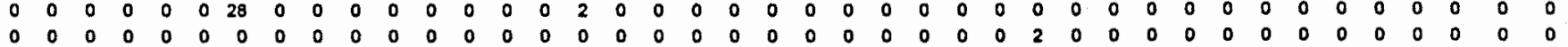

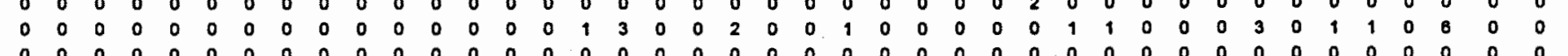

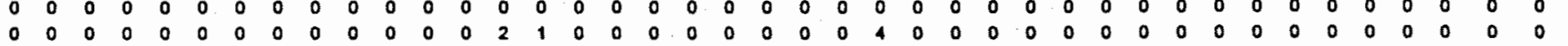

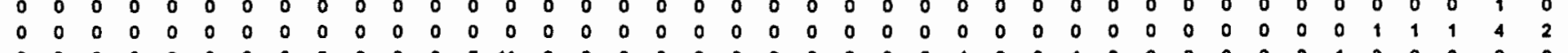
$\begin{array}{lllllllllllllllllllllllllllllllll}1 & 8 & 1 & 0 & 4 & 0 & 5 & 0 & 0 & 1 & 2 & 1 & 2 & 3 & 0 & 0 & 2 & 1 & 0 & 0 & 33 & 0 & 0 & 0 & 0 & 0 & 0 & 1 & 0 & 0 & 0 & 2 & 1\end{array}$

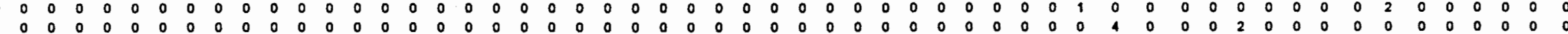

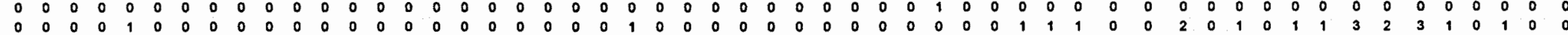

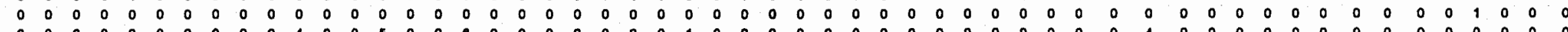

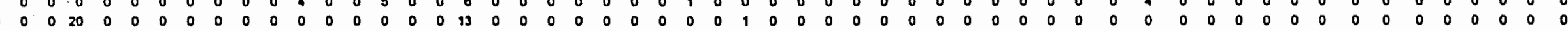

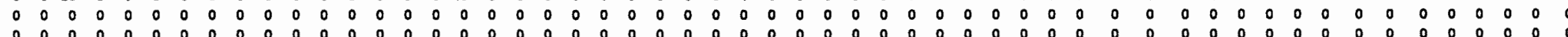
ZOED1 ZOED3

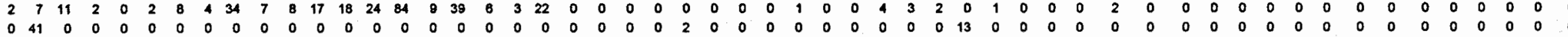

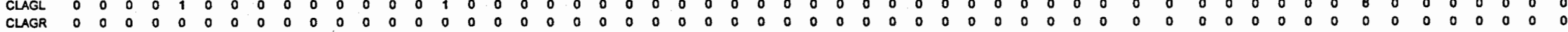

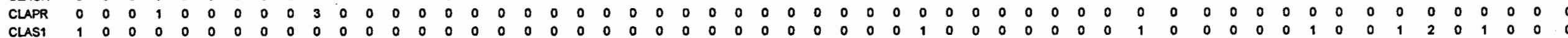

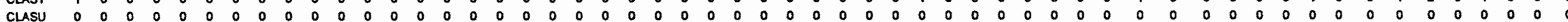

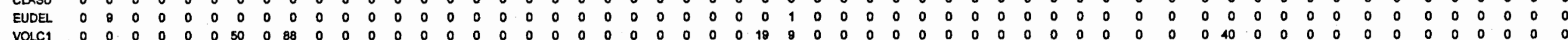

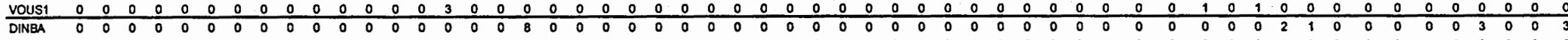


TABELA 30 - VARIAÇÃo TEMPORAL DAS ESPÉCIES DO FITOPLÂNCTON. FREQOENCIA RELATIVA DO BIOVOLUME. REPRESA DE GUARAPIRANGA, $1991-92$. PONTO 1.

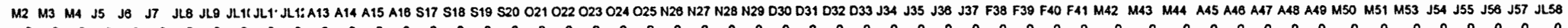

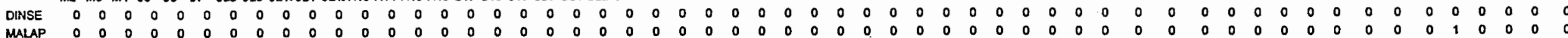

MALCA

MALPA

MALRH

SHUV

CROBR

CRYBR

CRYER

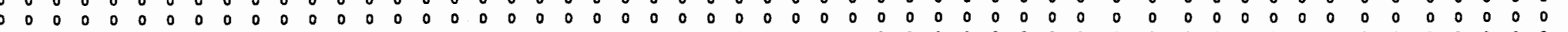

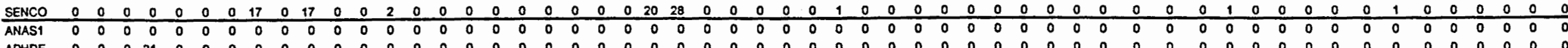

APHEP

CRCMU

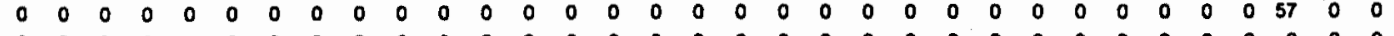

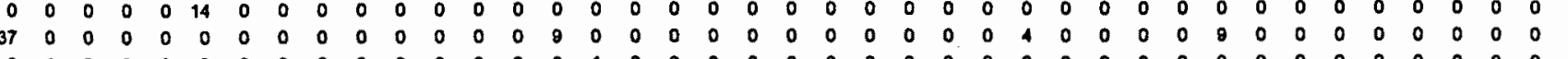

$\begin{array}{lllllllllll}0 & 0 & 0 & 0 & 0 & 0 & 0 & 0 & 0 & 0 \\ 0 & 0 & 0 & 0 & 0 & 0 & 0 & 0 & 0 & 1\end{array}$

Oscsu

$\begin{array}{lllllllllllllllllllllllllllllllll}0 & 0 & 0 & 0 & 0 & 0 & 0 & 0 & 0 & 0 & 0 & 0 & 0 & 0 & 0 & 0 & 0 & 0 & 0 & 0 & 0 & 0 & 0 & 0 & 0 & 0 & 0 & 0 & 0 & 0 & 0 & 3 & 0\end{array}$

PSECA

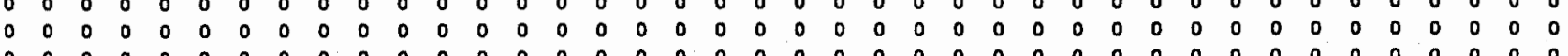

$0 \begin{array}{lllllllllllllll}0 & 0 & 0 & 0 & 0 & 0 & 0 & 0 & 0 & 0 & 0 & 0 & 0 & 0 & 0\end{array}$

SWEI

EUGAC

EUGDE

EUGPA

TRAOB

TRASA

TRAS5

TRAVO

TRAVP

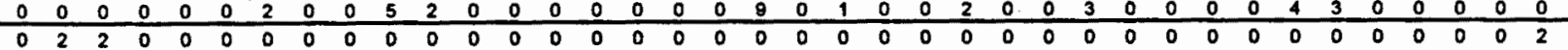

ACTwO

CLOS1

$\cos 18$

$\cos 18$

$\cos 20$

$\begin{array}{llllllllllllllllllllllllllllllllllllllll}0 & 0 & 0 & 0 & 0 & 0 & 0 & 0 & 0 & 0 & 0 & 0 & 0 & 0 & 0 & 0 & 0 & 0 & 0 & 0 & 0 & 0 & 0 & 0 & 0 & 0 & 0 & 0 & 0 & 0 & 0 & 0 & 0 & 0 & 0 & 0 & 0 & 0 & 0 & 0\end{array}$

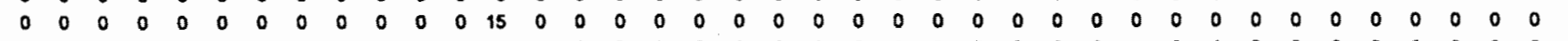

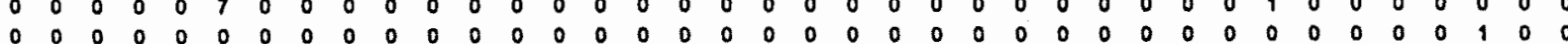

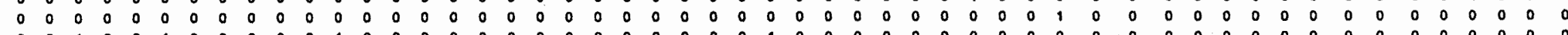

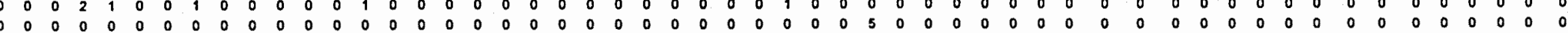

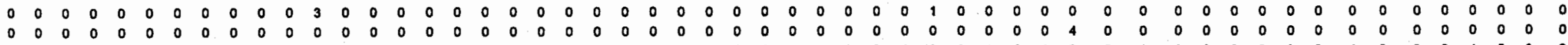

0

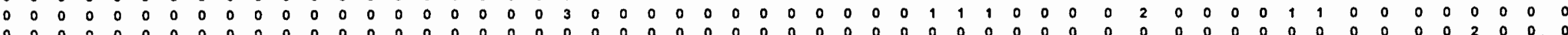

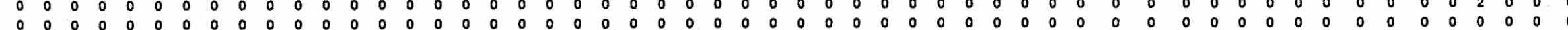

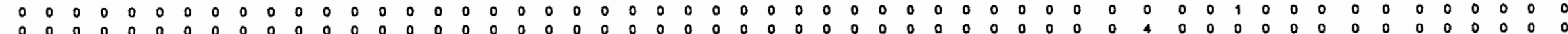

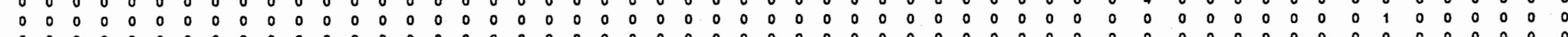


TABELA 31 - VARIAÇÃO TEMPORAL DA FREQUêNCIA RELATIVA DAS ESPÉCIES DO FITOPLÂNCTON EM DENSIDADE (CÉLULAS). REPRESA DE GUARAPIRANGA 1991-92. PONTO 4.

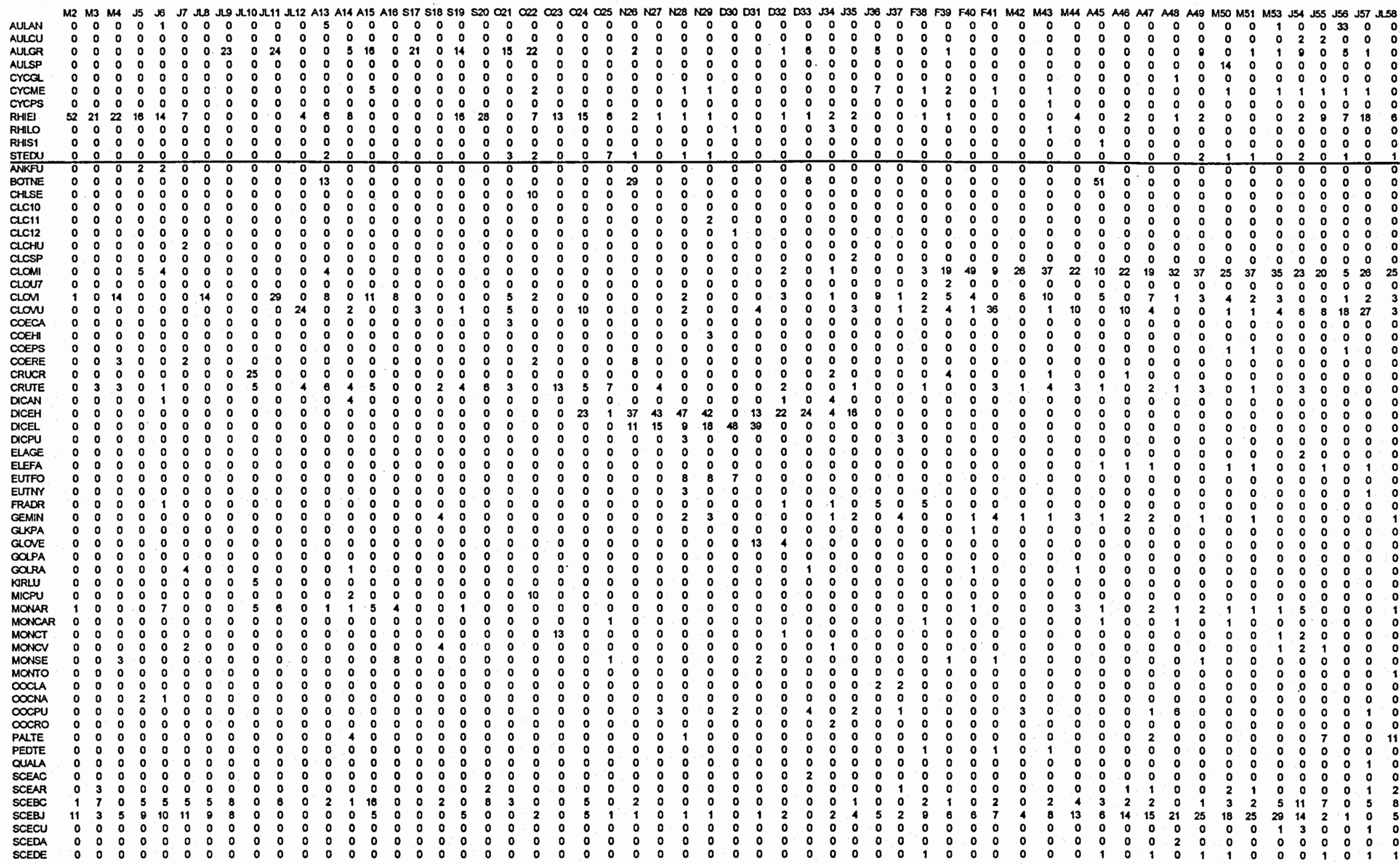


TABELA 31 - VARIAÇÃo TEMPORAL DA FREQUENCIA RELATIVA DAS ESPÉCIES DO FITOPLÂNCTON EM DENSIDADE (CÉLULAS). REPRESA DE GUARAPIRANGA 1991-92. PONTO 4.

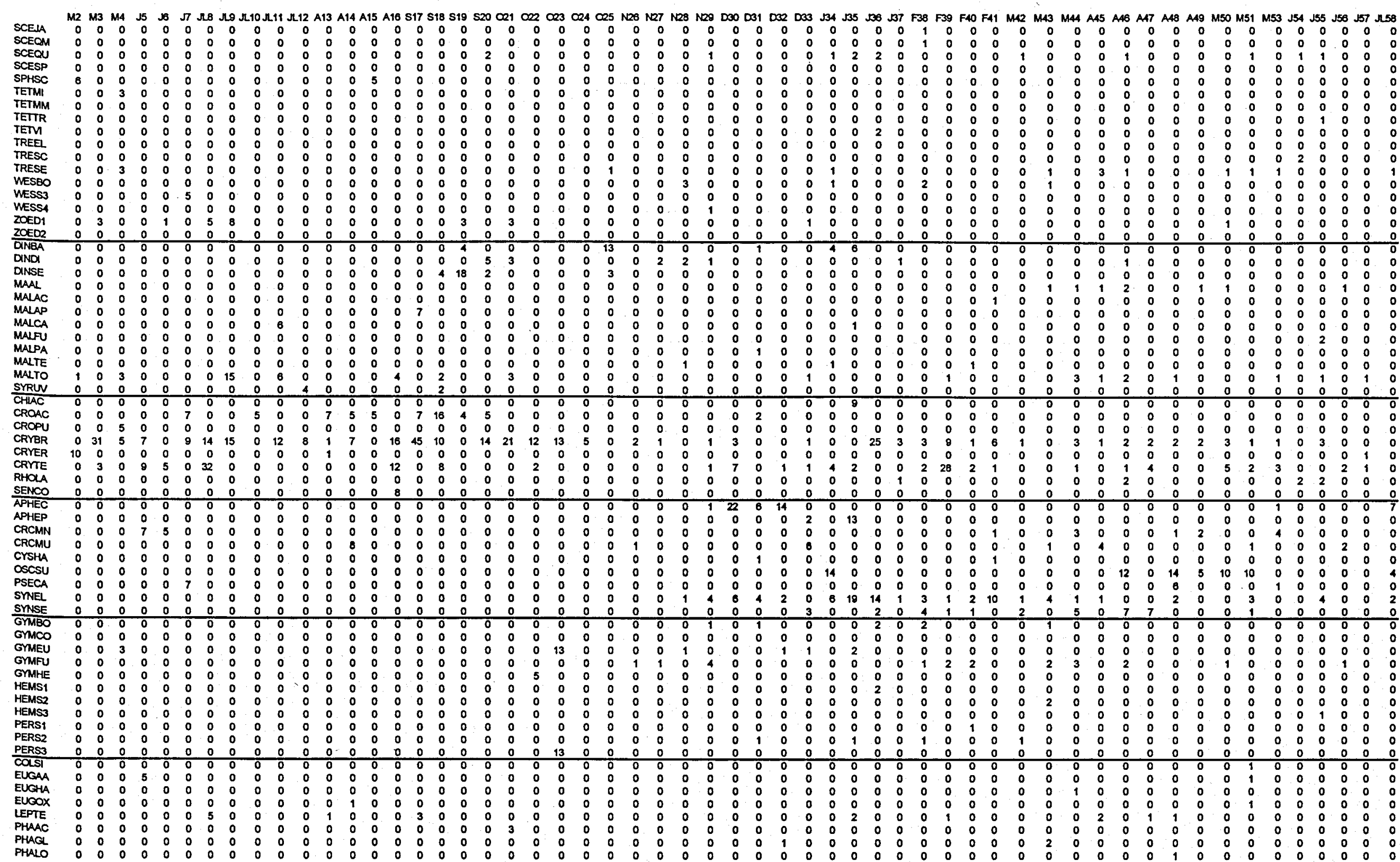


TABELA 31 - VARIAÇÃO TEMPORAL DA FREQUENCIA RELATIVA DAS ESPÉCIES DO FITOPLÂNCTON EM DENSIDADE (CÉLULAS). REPRESA DE GUARAPIRANGA 1991-92. PONTO 4.

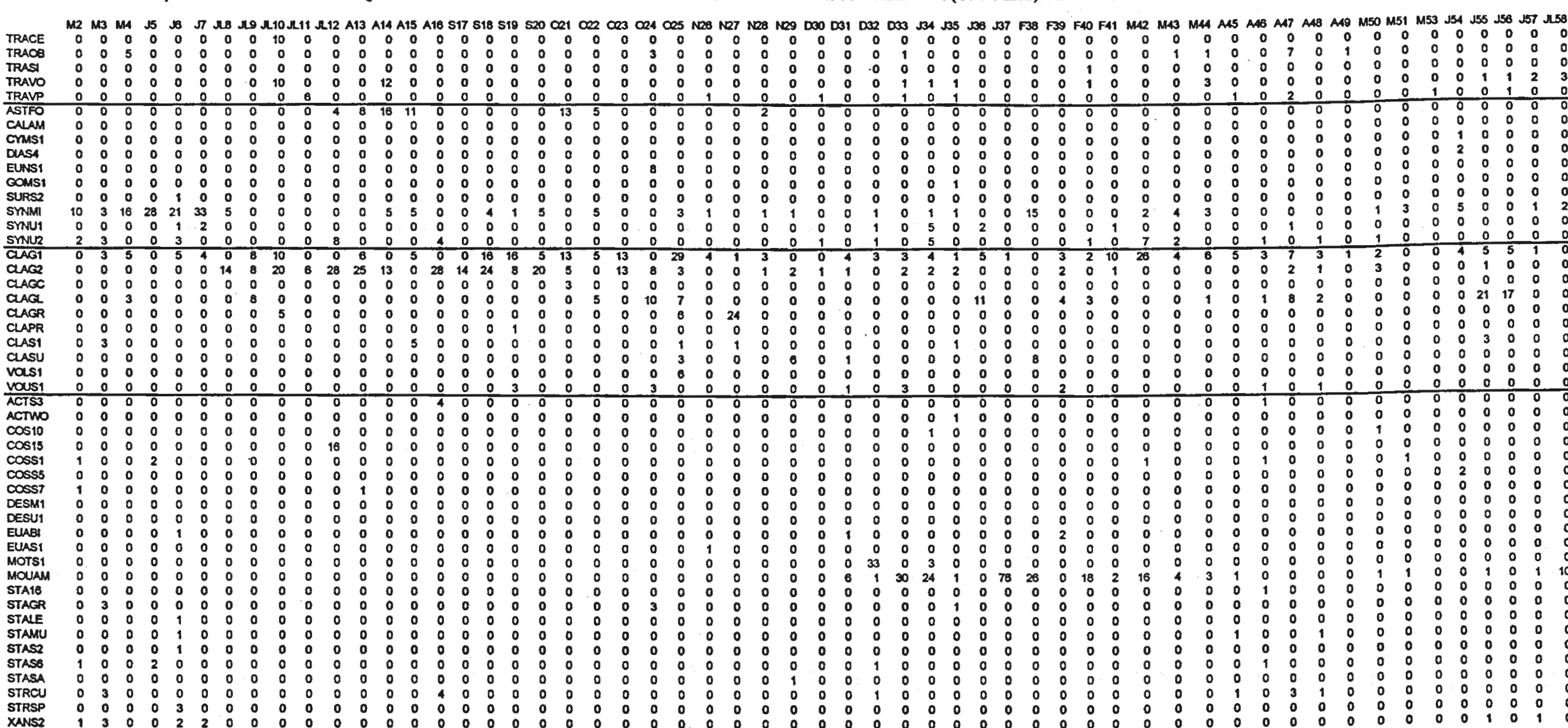

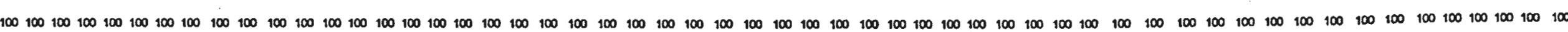

OBS: AS SIGUAS UTIUZADAS PARA IDENTIFICAR AS ESPÉCIES ESTROREAACIOMDAS NA USTA DAS ESPEGES NO ITEM 5.3.1. DO TEXTO DESTE TRABALHO. 
TABELA 32 - VARIAÇÃo TEMPORAL DAS ESPÉCIES DO FITOPLÂNCTON. FREQOENCIA RELATIVA DO BIOVOLUME. REPRESA DE GUARAPIRANGA 1991-92. PONTO 4.

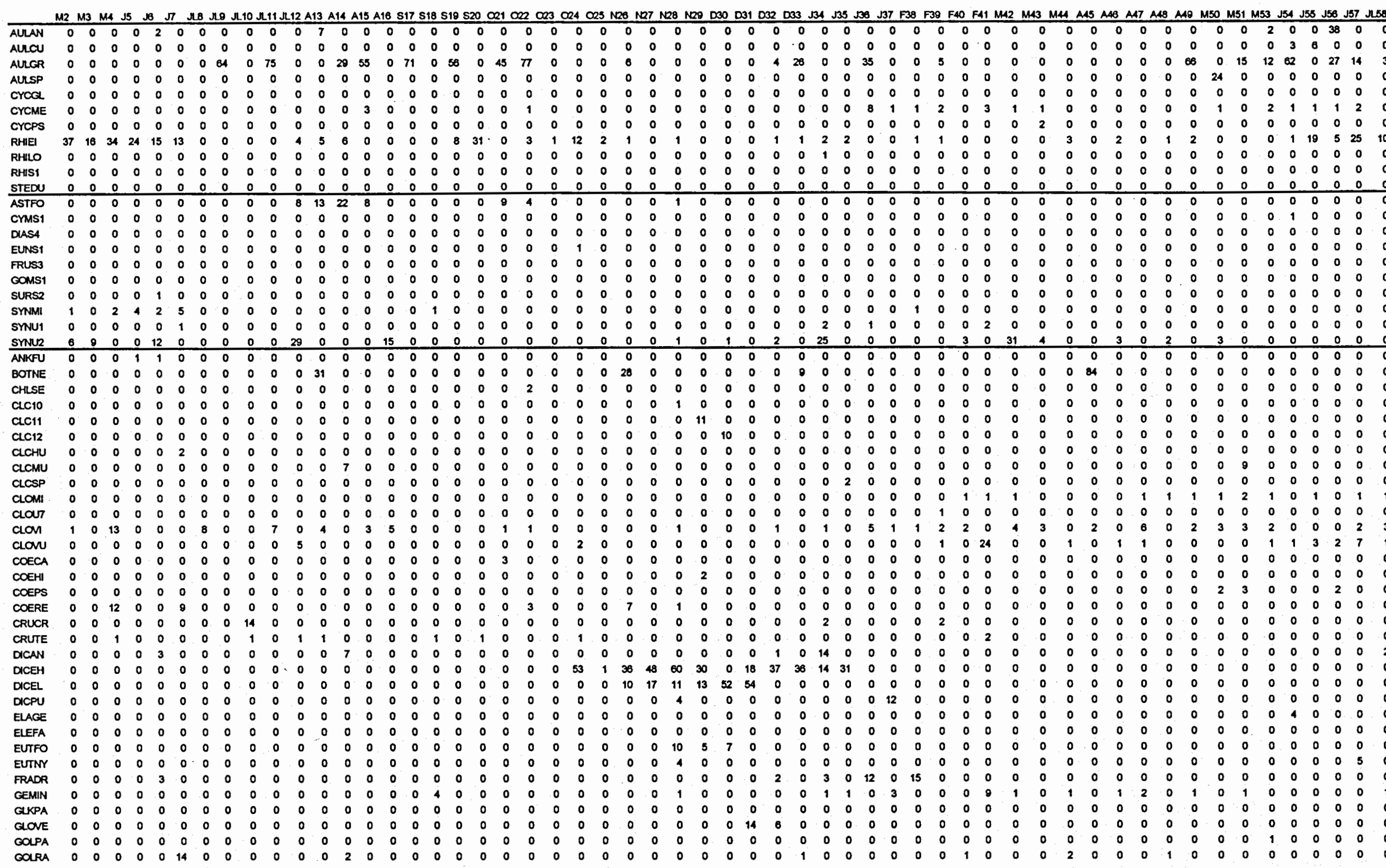


TABELA 32 - VARIAÇÃO TEMPORAL DAS ESPÉCIES DO FITOPLÂNCTON. FREQÚENCIA RELATIVA DO BIOVOLUME. REPRESA DE GUARAPIRANGA 1991 -92. PONTO 4.

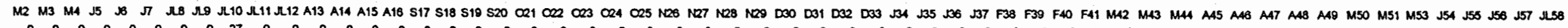

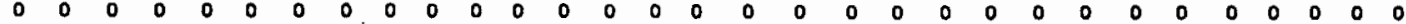

Maras

MONCV

cocen

$\infty$

OCRO

PALTE

CUALA

SCEAC
SCEAR
SCESC

SCEES

SCECU
SCEDA

SCEDE

SCEOM

SCEOU
SCESP

SPHSC

TEIMI
TETMM

TETMM
TETR

TETM

TRESC

WESBO

WESSA

ZOED1

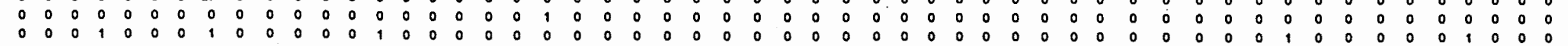

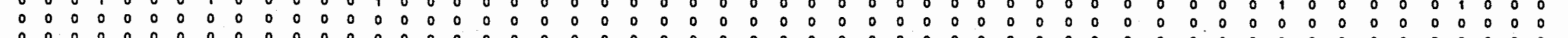

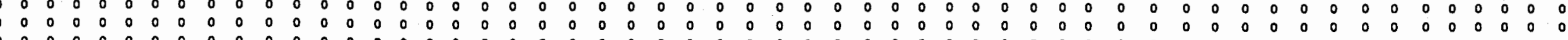

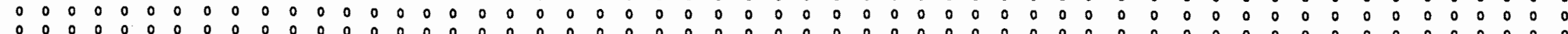

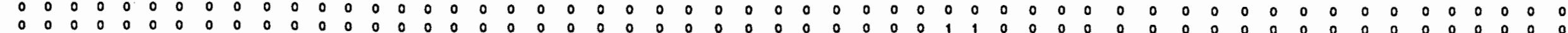

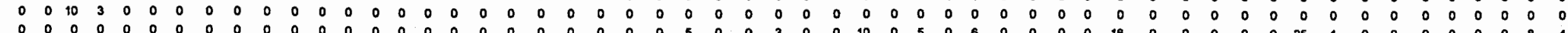

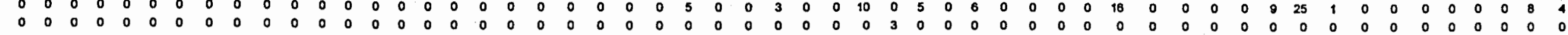

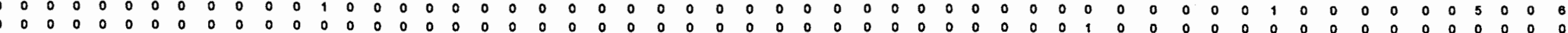

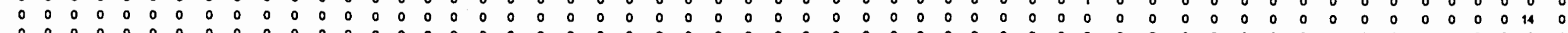

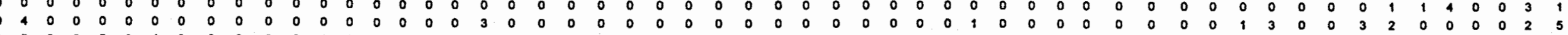

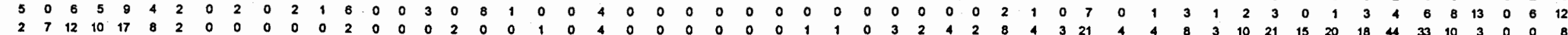

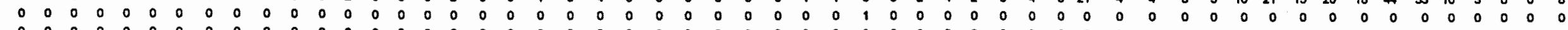

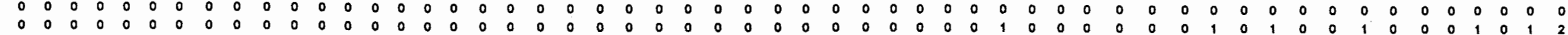

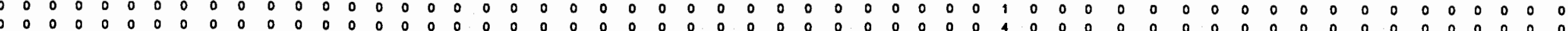

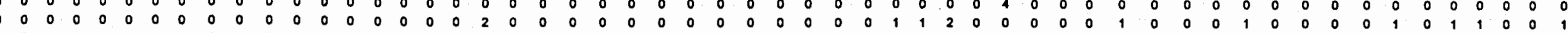

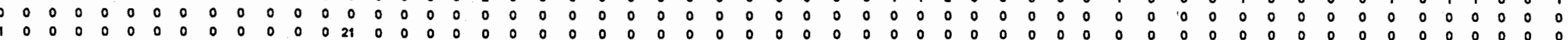

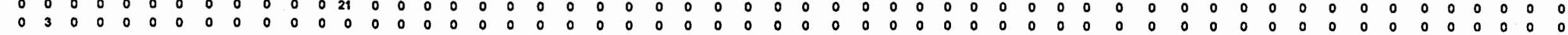

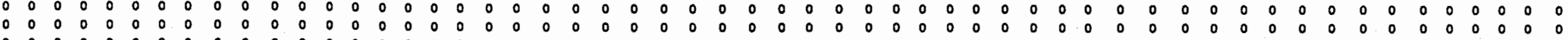
$\begin{array}{llllllllllllllllllllllllllllllllllllllllllllllllllllllll}0 & 0 & 0 & 0 & 0 & 0 & 0 & 0 & 0 & 0 & 0 & 0 & 0 & 0 & 0 & 0 & 0 & 0 & 0 & 0 & 0 & 0 & 0 & 0 & 0 & 0 & 0 & 0 & 0 & 0 & 0 & 0 & 0 & 0 & 0 & 0 & 0 & 0 & 0 & 0 & 0 & 0 & 0 & 0 & 0 & 0 & 0 & 0 & 0 & 0 & 0 & 0 & 0 & 0 & 0\end{array}$

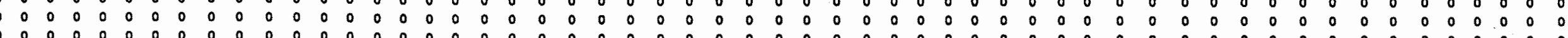

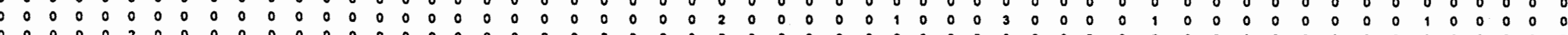

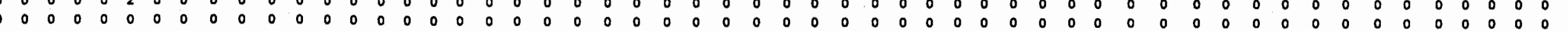

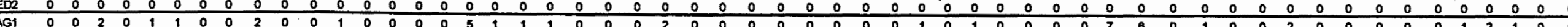

CAAG

chach.

GLAPR

CLASI

vosi

VOUS1
DINEA
DNOI

$\begin{array}{lllllllllllllllllllll}0 & 0 & 0 & 0 & 0 & 20 & 4 & 31 & 3 & 42 & 31 & 14 & 0 & 8 & 8 & 50 & 0 & 33 & 3 & 0\end{array}$

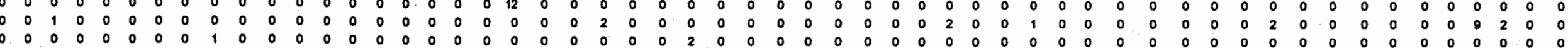

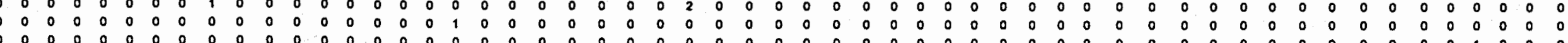

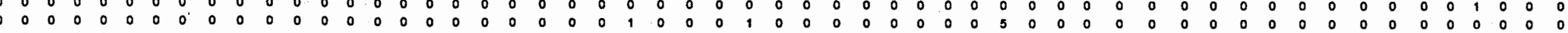

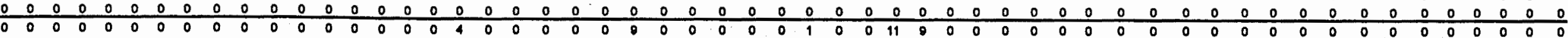

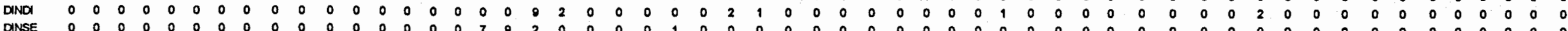

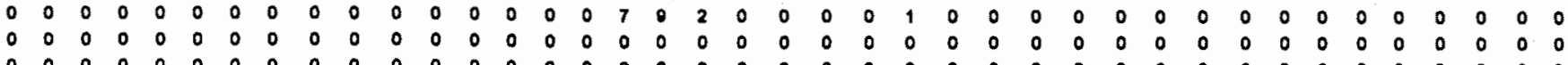

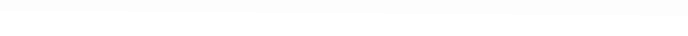


TABELA 32 - VARIAÇÃo TEMPORAL DAS ESPÉCIES DO FITOPLÂANCTON. FREQŨÊNCIA RELATIVA DO BIOVOLUME. REPRESA DE GUARAPIRANGA 1991-92. PONTO 4.

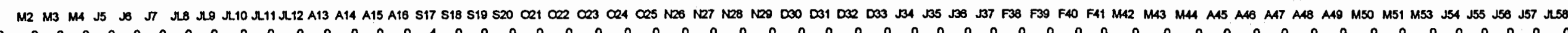

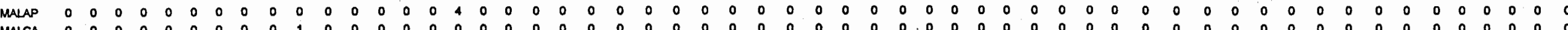

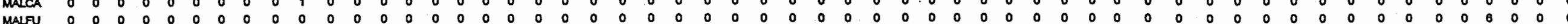

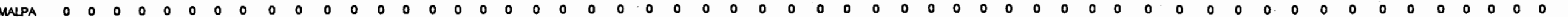

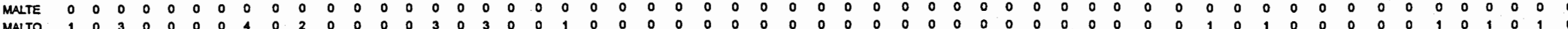
SYRW

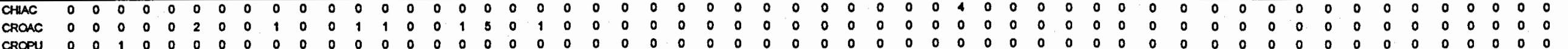

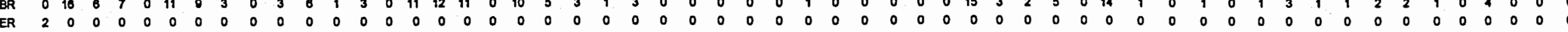

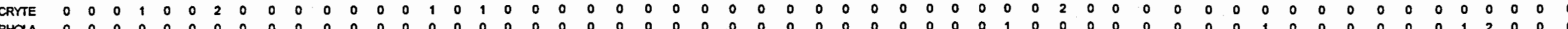

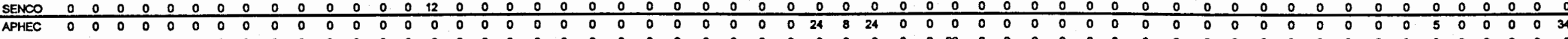

CRCMN

CrSHA

OSCSU

STNEL

STMSE

Grmeo

GrMEU

GVM

HEMS2

HEMS3

PERS3

EUGAA

LEPTE

PHAG

PHALO

TRAOB

TRASI

TRAVP

AcTWO

$\cos 10$
$\cos 15$

coss1

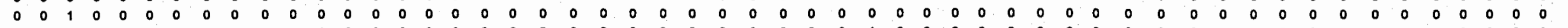

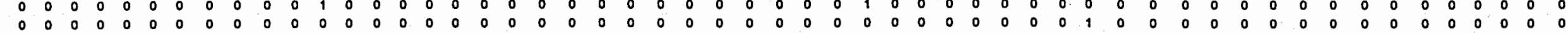

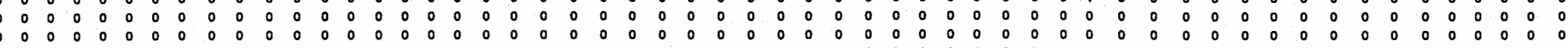

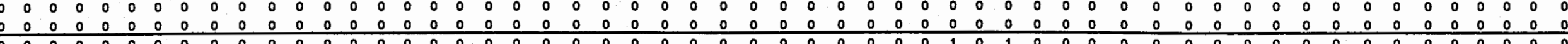

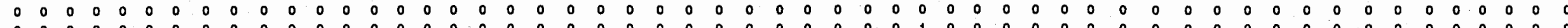

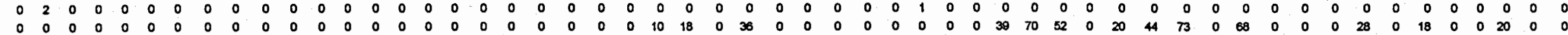

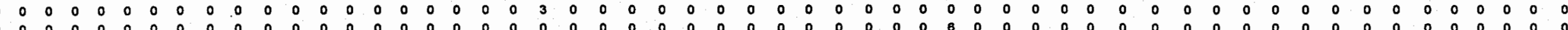

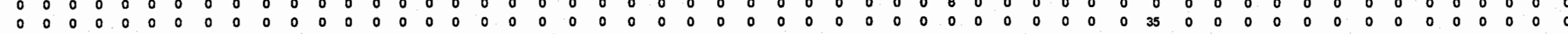

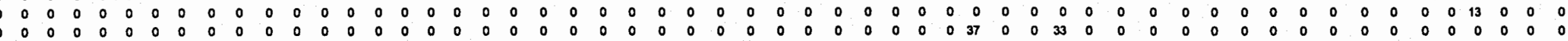

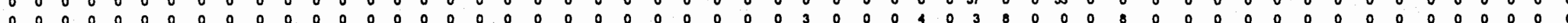

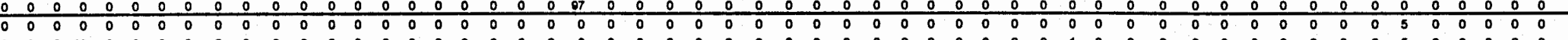

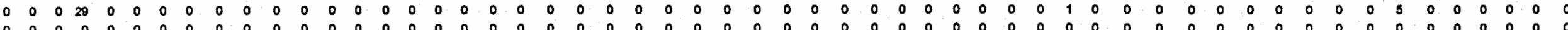

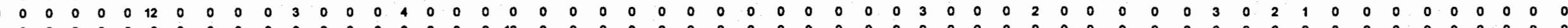

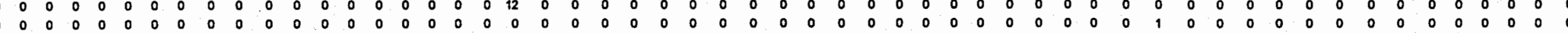

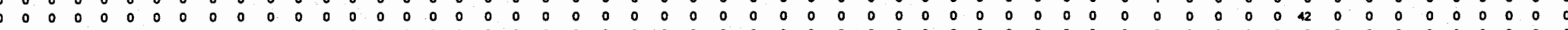

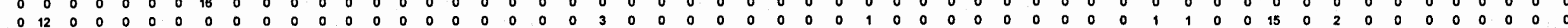

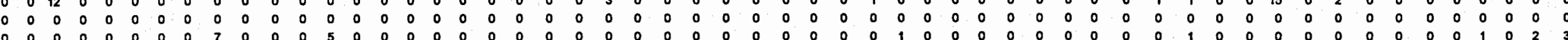

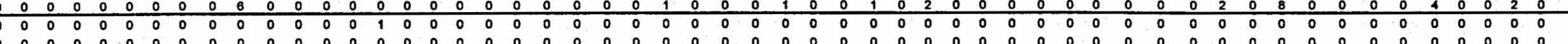

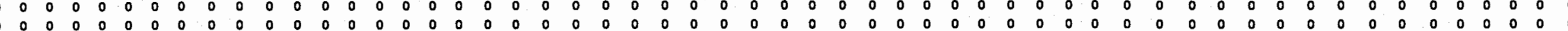

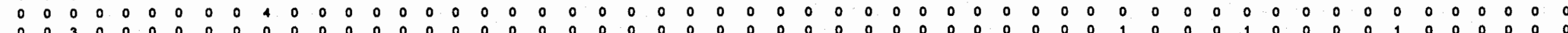

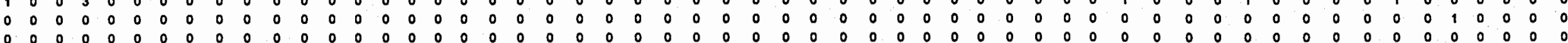


TABELA 32 - VARIAÇAO TEMPORAL DAS ESPÉCIES DO FITOPLÂNCTON. FREQOENCIA RELATIVA DO BIOVOLUME. REPRESA DE GUARAPIRANGA I991-92. PONTO 4.

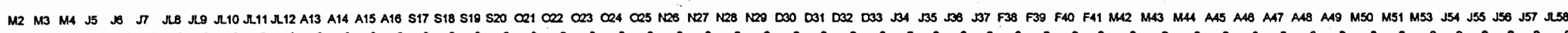

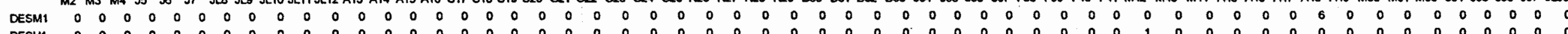

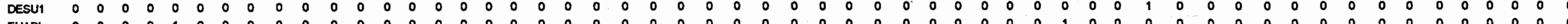

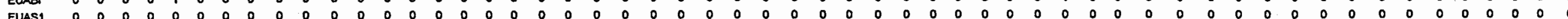

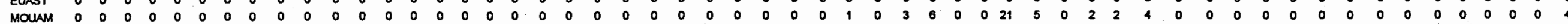

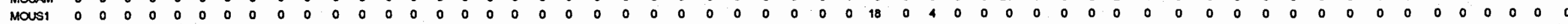

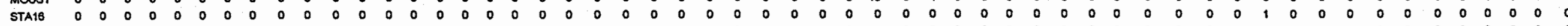

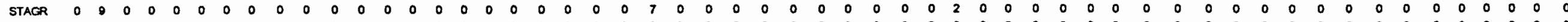

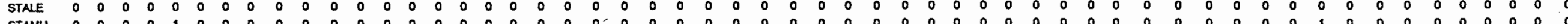

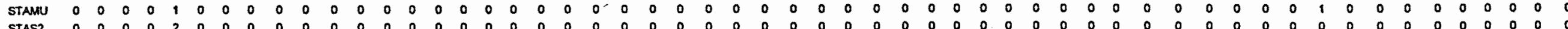

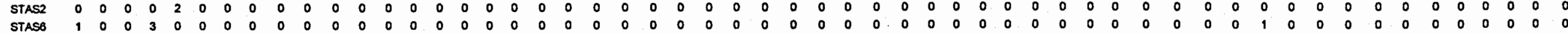

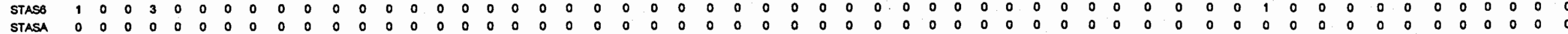

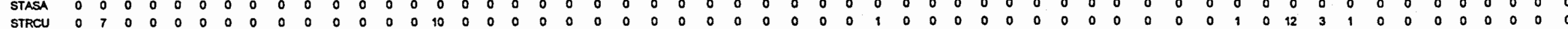

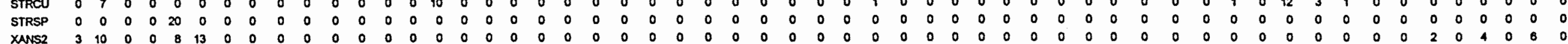

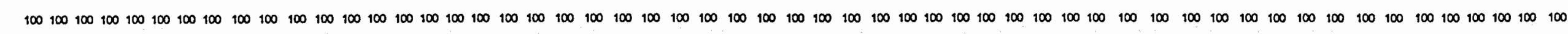

OBS: AS SIELAS UTILZADAS PARA IDENTIFCAR AS ESPEGGES ESTKO RELACIONUDAS MA LSTA DAS ESPEGIES NOITEM 5.3.1. DO TEXTO DESTE TRABALHO. 
TABELA 33 - ESPÉCIES DOMINANTES, ABUNDANTES OU COM ELEVADA FREQUENCIA DE OCORRENCIA. REPRESA DE GUARAPIRANGA, 1991-92.

\section{PONTOS 1 E 4.}

Identificação da espécie (IDSP); número de coletas em que a espécie ocorreu (NO*); densidade em cél bioárea em UPA.ml-1 (BA); biovolume em um3.ml-1 (BV);dominantes (DOM**); abundantes ( $\mathrm{AB}^{* *}$

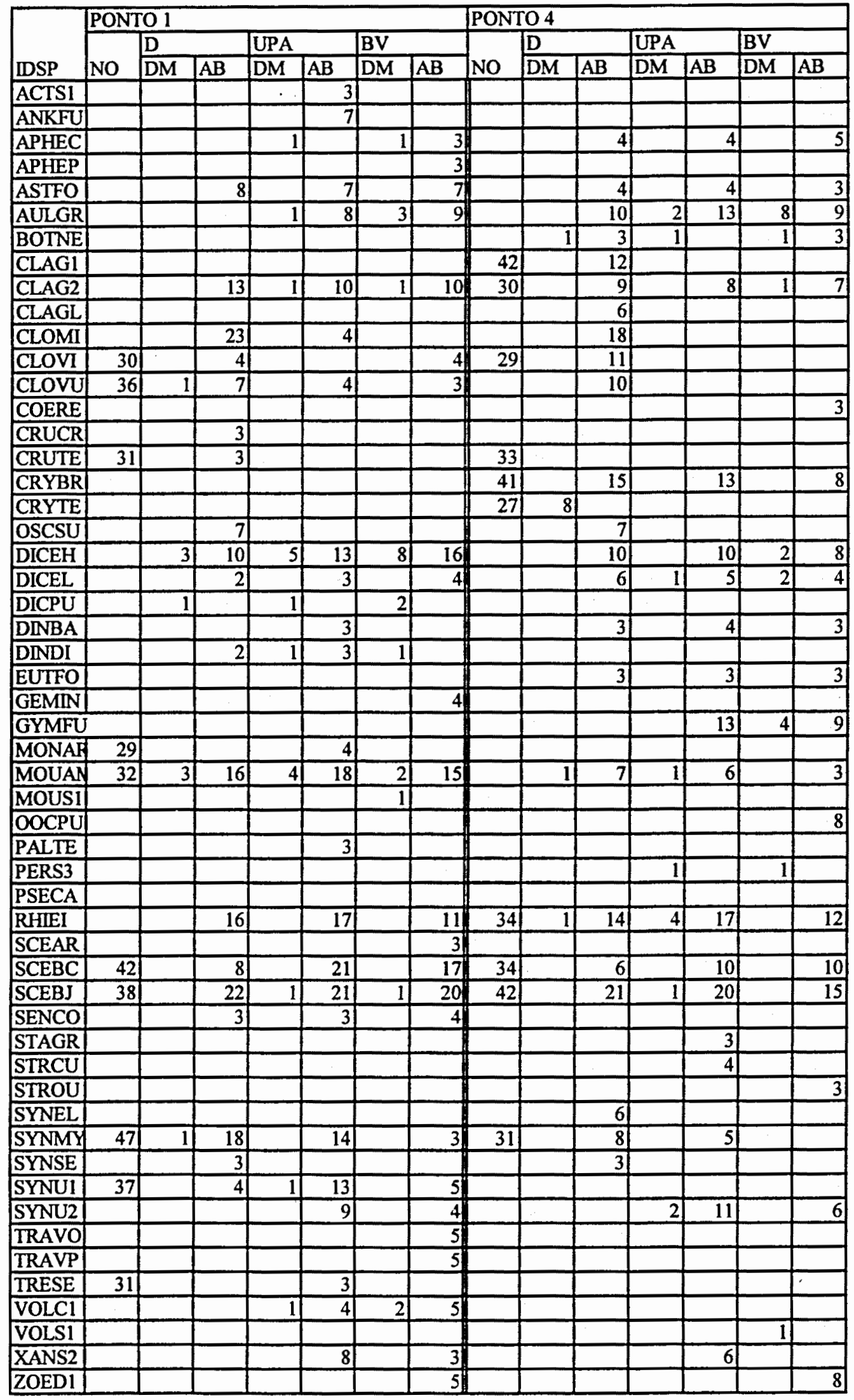

- REFERE-SE AO NÚMERO DE COLETAS EM QUE O TÁXON OCORREU. TENDO-SE REGISTRADO APENAS AS DEZ MAIS FREQUEN:

** NÚMERO DE COLETAS EM QUE A ESPÉCIE ATINGIU VALOR SUPERIOR A SO\% DA DENSIDADE TOTAL DA AMOSTRA

** NÚMERO DE COLETAS EM QUE A ESPÉCIE ATINGIU VALOR SLPERTOR A MÉDIA DA DENSIDADE DA AMOSTRA, EM TRÉS OL AMOSTRAS 
A-34

TABELA 34 - MEdIANAS dos PARÂMETROS Climatológicos E dA QUALIDAdE dA ÁGUA POR PERIOdO.

Identificaçio dos periodos: periodo total de seca (S); periodo total de chuvas (C); primeiro periodo de seca (S1); período de chuvas moderadas (CI periodo de chuvas intensas (CI); segundo periodo de seca (S2).

\begin{tabular}{|c|c|c|c|c|}
\hline PARA AMBOS OS RONTOS & $\mathbf{s}$ & c & s1 & $\mathbf{c M}$ \\
\hline PRECIPITACCXO 24h & 0,00 & 0,00 & 0,00 & 0,00 \\
\hline PRECIPTACCAO 72h & 0,00 & 3,65 & 0,00 & 0,20 \\
\hline PRECIPITACAO I68h & 0,40 & 15,90 & 0,00 & 9,20 \\
\hline VAZOES NATURAIS & 6,40 & 9,75 & 9,30 & 7,80 \\
\hline V.RECALCADAS & 0,15 & 0,00 & 0,00 & $0, \infty$ \\
\hline AFLUENTE TOTAL & 6,45 & 9,75 & 9,30 & 9,20 \\
\hline EFLUENTE CANAL & 0,00 & 0,00 & 0,00 & 0,00 \\
\hline $\begin{array}{l}\text { ERL SABESP } \\
\text { ER }\end{array}$ & 1270 & 13,05 & 13,10 & 13,20 \\
\hline EFL. TOTAL & 1270 & 13,05 & 13,10 & 13,20 \\
\hline EEVACAO & 735,53 & 734,88 & 735,63 & 735,22 \\
\hline VOLUME & 162615 & 143675 & 165663 & 153394 \\
\hline PREC. ELETROPAULO & 40,70 & 148,40 & 41,00 & 101,20 \\
\hline EIP (mm) & 53,00 & 98,00 & 50,00 & 76,00 \\
\hline EXCEDENTE HIDRICO & $0, \infty$ & 50,40 & 0,00 & 17,20 \\
\hline ESCOAMENTO & 29,27 & 59,81 & 29,27 & 9,63 \\
\hline VELOCIDADE DO VENTO & 6,25 & 6,30 & 6,80 & 6,30 \\
\hline NSOLACCAO & 7,20 & 0,10 & 8,80 & 4,90 \\
\hline RADIACCAO SOLAR & 300,00 & 434,00 & 300,00 & $417, \infty$ \\
\hline DEFICIENCLA HIDRICA DO SOL & 4,50 & 0,00 & 0,00 & 0,00 \\
\hline SULFATACCAO NO PONTO I & 0,00 & 1,43 & $0, \infty$ & 0,00 \\
\hline
\end{tabular}

\begin{tabular}{|c|c|c|c|c|c|c|c|}
\hline \multirow[b]{2}{*}{ cr } & \multicolumn{7}{|c|}{ PERIODO COM APLICACCAO DE SULFATO DE OOBRE } \\
\hline & $\mathbf{s 2}$ & $\mathbf{s}$ & c & si & CM & a & 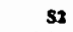 \\
\hline 0,00 & 0,00 & 0,00 & $0, \infty$ & 0,00 & 0,50 & 0,00 & 0,00 \\
\hline 7,40 & 0,00 & 0,00 & 3,30 & 0,00 & 0,00 & 7,40 & 0,80 \\
\hline 31,00 & 0,80 & 0,00 & 34,20 & 0,00 & 34,90 & 31,00 & 220 \\
\hline 1280 & 5,50 . & 9,30 & 12,80 & 9,30 & 9,50 & 13,30 & 8,00 \\
\hline $0, \infty$ & 0,30 & $0, \infty$ & $0, \infty$ & $0, \infty$ & 0,85 & 0,00 & 0,00 \\
\hline 12,80 & 5,70 & 9,30 & 12,80 & 9,30 & 9,85 & 13,30 & 8,30 \\
\hline 0,00 & 0,00 & 0,00 & 0,00 & 0,00 & 0,00 & 0,00 & 0,00 \\
\hline 13,00 & 12,00 & 13,20 & 13,10 & 13,20 & 13,25 & 13,00 & 12,40 \\
\hline 13,00 & 12,00 & 13,20 & 13,10 & 13,20 & 13,25 & $13, \infty$ & 12,40 \\
\hline 734,87 & 735,39 & 735,84 & 734,88 & 735,84 & 735,37 & 734,87 & 735,54 \\
\hline 143395 & 158407 & 172182 & 143675 & 172182 & 157664 & 143395 & 162918 \\
\hline 210,20 & 40,70 & 55,10 & 148,40 & 55,10 & 105,90 & 210,20 & 40,70 \\
\hline 106,00 & 67,00 & 55,00 & $98, \infty 0$ & 55,00 & 76,00 & 103,00 & 76,00 \\
\hline 102,00 & 0,00 & 0,10 & 50,40 & 0,10 & 29,90 & 104,20 & 0,00 \\
\hline 65,20 & 27,29 & 100,77 & 65,20 & 100,7 & 19,25 & 80,01 & 54,58 \\
\hline 6,30 & 5,30 & 6,90 & 6.10 & 6,90 & 6,35 & 6,10 & 5,20 \\
\hline 6,30 & 5,90 & 9,20 & 6,30 & 9,20 & 7,90 & 5,90 & 5,20 \\
\hline 457,00 & 270,00 & 337,00 & $434, \infty$ & 337,00 & 417,00 & 434,00 & 372,00 \\
\hline 0,00 & 5,90 & 0,00 & $0, \infty$ & 0,00 & 0,00 & 0,00 & 4,50 \\
\hline 2,00 & $0, \infty$ & 2,00 & 200 & 2,00 & 1,50 & 2,00 & 3,00 \\
\hline
\end{tabular}

PARÄMETROS FISICOS E QUTMIOOS DA QUALIDADE DA AGUA

\begin{tabular}{|c|c|c|c|c|}
\hline PONTO 1 & $\mathbf{s}$ & c & s1 & $\mathbf{C M}$ \\
\hline TEMPERATURA DO AR & 21,00 & 22,75 & 18,50 & 20,90 \\
\hline T.DAAGUA & 19,20 & 24,25 & 18.35 & 21,50 \\
\hline PROFUNDDADE & 11,50 & 10,78 & 11,86 & 10,58 \\
\hline TRANSPARENCIA & 2,07 & 2,00 & 228 & 200 \\
\hline COR & 23,00 & 25,00 & 25,00 & 25,00 \\
\hline TUR & 1,40 & 1,25 & 1,20 & 1,20 \\
\hline CONDUTTVDDADE & 54,00 & 58,00 & 51,00 & $56, \infty$ \\
\hline $\mathrm{pH}$ & 7,19 & 7,17 & 6,60 & 7,13 \\
\hline OD & 7,44 & 7,18 & 7,62 & 7,67 \\
\hline DBO & 1,13 & 1,30 & 1,04 & 1,49 \\
\hline ALCALNDADE & 23,10 & 19,70 & 15,65 & 18,10 \\
\hline DUREZA & 25,55 & 43,25 & 20,50 & 38,60 \\
\hline SOLIDOS EM SUSPENSĀO & 58,50 & 49,00 & - & 30,50 \\
\hline a & 8,90 & - & - & - \\
\hline $\mathbf{S i}$ & 6,96 & $6, \infty$ & - & - \\
\hline $\mathrm{PO4}$ & 4,08 & 3,26 & 3,26 & 4,89 \\
\hline POT & 13,04 & 16,30 & 9,78 & 17,93 \\
\hline NH4 & $0, \infty$ & 0,00 & $0, \infty$ & 0,00 \\
\hline NO3 & 0,40 & 0,40 & 0,50 & 0,50 \\
\hline $\mathrm{SO4}$ & 430 & 4,75 & 4,00 & 4,60 \\
\hline at & 6,10 & 7,10 & 5,90 & 7,10 \\
\hline A & 0,10 & $0, \infty 0$ & 0,10 & 0,10 \\
\hline$c_{2}$ & 6,00 & 6,35 & $3, \infty 0$ & 5,80 \\
\hline $\mathrm{Cu}$ & 0,04 & 0,04 & 0,02 & 0,04 \\
\hline $\mathrm{Fe}$ & 0,07 & 0,05 & 0,20 & 0,06 \\
\hline $\mathbf{K}$ & 2,30 & 2,60 & 2020 & 240 \\
\hline Mg & 1,50 & 1,60 & 1,50 & 1,50 \\
\hline Mo & 0,00 & $0, \infty 0$ & $0, \infty$ & $0, \infty$ \\
\hline $\mathrm{Nz}$ & 5,20 & 5,80 & 4,90 & 5,90 \\
\hline Si & 1,70 & 1,60 & 2,00 & 1,50 \\
\hline $2 n$ & 0,03 & $0, \infty$ & 0,02 & $0, \infty$ \\
\hline
\end{tabular}

\begin{tabular}{|c|c|c|c|c|c|c|c|}
\hline \multirow[b]{2}{*}{ cI } & \multicolumn{7}{|c|}{ PERIODO COM APLAICACCAOO DE SULFATO DE COBRE } \\
\hline & s2 & $\mathbf{s}$ & c & si & $\mathbf{c m}$ & $\mathbf{c}$ & $\mathbf{5 2}$ \\
\hline 24,00 & 2200 & 20,75 & 23,50 & 20,73 & $21, \infty$ & 24,00 & 22,50 \\
\hline 24,80 & 22,00 & 20,75 & 24.50 & 20,75 & 19,23 & 25,00 & 22,20 \\
\hline 10,80 & 11,06 & 12,00 & 10,78 & 12,00 & 9,27 & 11,00 & 11,06 \\
\hline 2,00 & 1,60 & 2,13 & $2, \infty$ & 2,13 & $2, \infty$ & 2,00 & 1,32 \\
\hline 25,00 & 22,50 & 30,00 & 25,00 & 30,00 & 20,00 & 25,00 & 25,00 \\
\hline 1,40 & 1,55 & 1,45 & 1,40 & 1,45 & 1,20 & 1,40 & 1,60 \\
\hline 58,00 & 64,50 & $45, \infty$ & 57,00 & 45,00 & 53,50 & 58,00 & 61,00 \\
\hline 7,17 & 7,27 & 6,50 & 7,14 & 6,50 & 7,06 & 7,23 & 7,27 \\
\hline 6,85 & 7,22 & 7,86 & 7,11 & 7,86 & 7,63 & 6,85 & 0,70 \\
\hline 1,21 & 1,37 & 1,85 & 1,02 & 1,86 & 0,96 & 1,21 & 1,37 \\
\hline 20,70 & 24,10 & - & 20,70 & - & $17, \infty$ & 20,70 & 24,20 \\
\hline 51,80 & 29,60 & - & 47,25 & $\longrightarrow$ & 45,30 & 57,60 & 26,40 \\
\hline 48,00 & 58,50 & - & 48,00 & 一 & 43,00 & 48,00 & 65,00 \\
\hline- & 8,90 & - & - & - & - & - & 8,45 \\
\hline 6,00 & 6,96 & - & 6,00 & - & - & 6,00 & 7,07 \\
\hline 326 & 9,78 & - & 3,26 & - & 4,89 & 3,26 & 14,67 \\
\hline 16,30 & 14,67 & - & 14,67 & - & 14,67 & 14,67 & 14,67 \\
\hline $0, \infty$ & 0,15 & 0,00 & 0,00 & 0,00 & 0,00 & $0, \infty 0$ & 0,30 \\
\hline 0,30 & 0,40 & 0,30 & 0,40 & 0,30 & 0,50 & 0,30 & 0,40 \\
\hline 5,00 & 4,80 & 4,00 & 4,70 & 4,00 & 4,40 & 4,90 & 4,70 \\
\hline 6,80 & 6,35 & 5,50 & 6,80 & 5,50 & 7,20 & 6,50 & 6,00 \\
\hline $0, \infty 0$ & 0,00 & 0,10 & 0,00 & 0,10 & 0,05 & $0, \infty$ & 0,00 \\
\hline 6,60 & 6,60 & 5,90 & 6,40 & 5,90 & 5,90 & 6,60 & 6,00 \\
\hline 0,06 & 0,04 & 0,04 & 0,05 & 0,04 & 0,04 & 0,06 & 0,05 \\
\hline 0,03 & 0,04 & 0,40 & 0,04 & 0,40 & 0,05 & 0,04 & 0,04 \\
\hline 270 & 200 & 2,20 & 260 & 2,20 & 2,35 & 270 & 2,60 \\
\hline 1,60 & 1,55 & 1,50 & 1,60 & 1,50 & 1,55 & 1,60 & 1,50 \\
\hline 0,00 & 0,00 & 0,00 & $0, \infty 0$ & $0, \infty$ & 0,00 & $0, \infty$ & 0,02 \\
\hline 5,80 & 5,30 & 4,40 & 5,80 & 4,40 & 5,75 & 5,80 & 5,30 \\
\hline 1,60 & 1,10 & 2,00 & 1,60 & 2,00 & 1,50 & 1,60 & 1,00 \\
\hline & & & & & & & \\
\hline
\end{tabular}

MEDUNAS DOS PARAMETROS FISICOS E QUTMICOS DA QUALIDADE DA AGUA

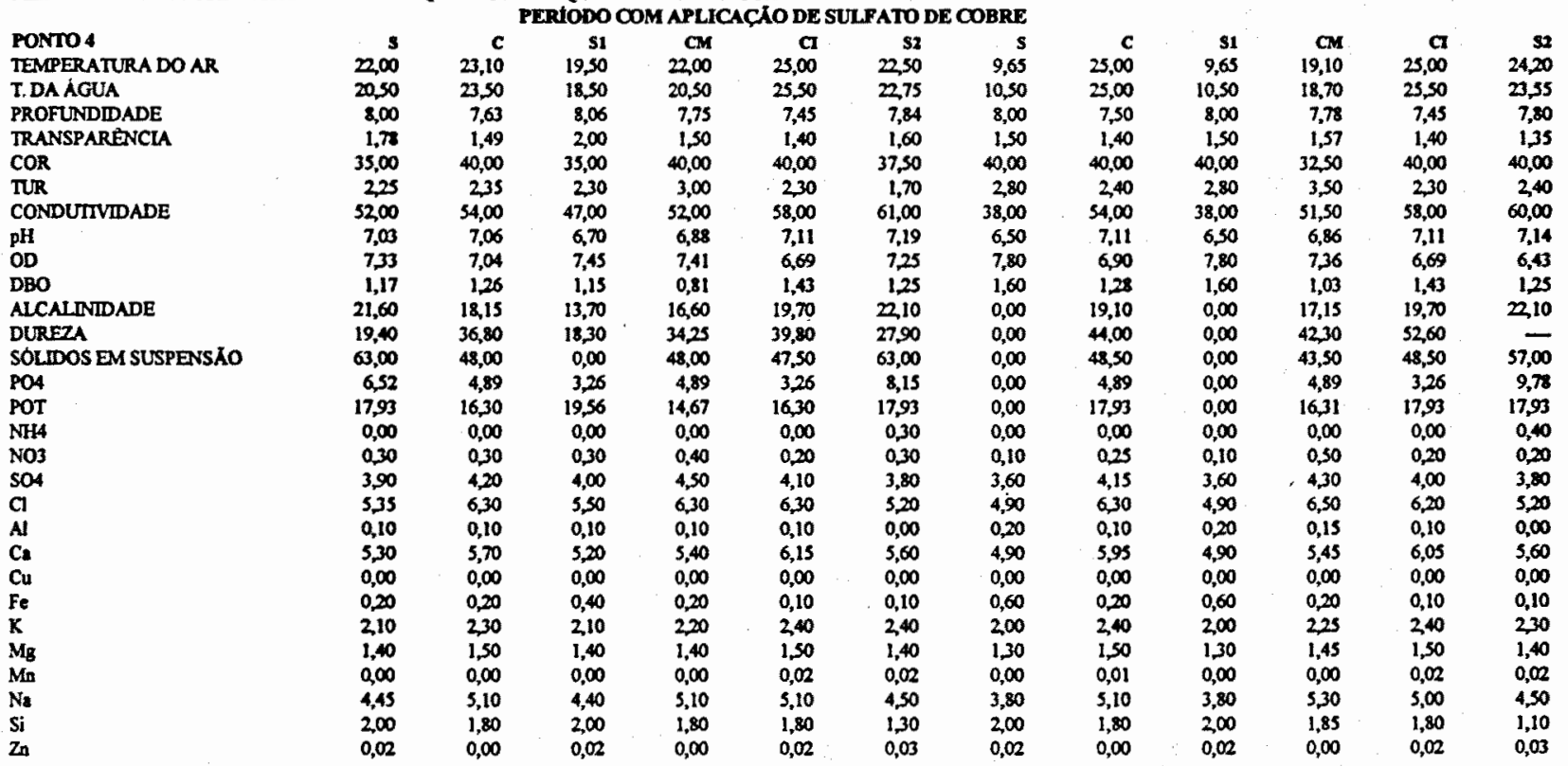


TABELA 35 - SAZONALIDADE E VARIAC̄̇O DEVIDA Ȧ SULFATAÇÃO: MEDIANAS DAS VARIÁVEIS DO FITOPLÂNCTON

REPRESA DE GUARAPIRANGA 1991-92 - PONTO 1 .

Identificação dos periodos: periodo total de seca (S); periodo total de chuvas (C); primeiro periodo de seca (S1); periodo de chuvas moderadas (CM); periodo de chuvas intensas (CD); segundo periodo de seca (S2).

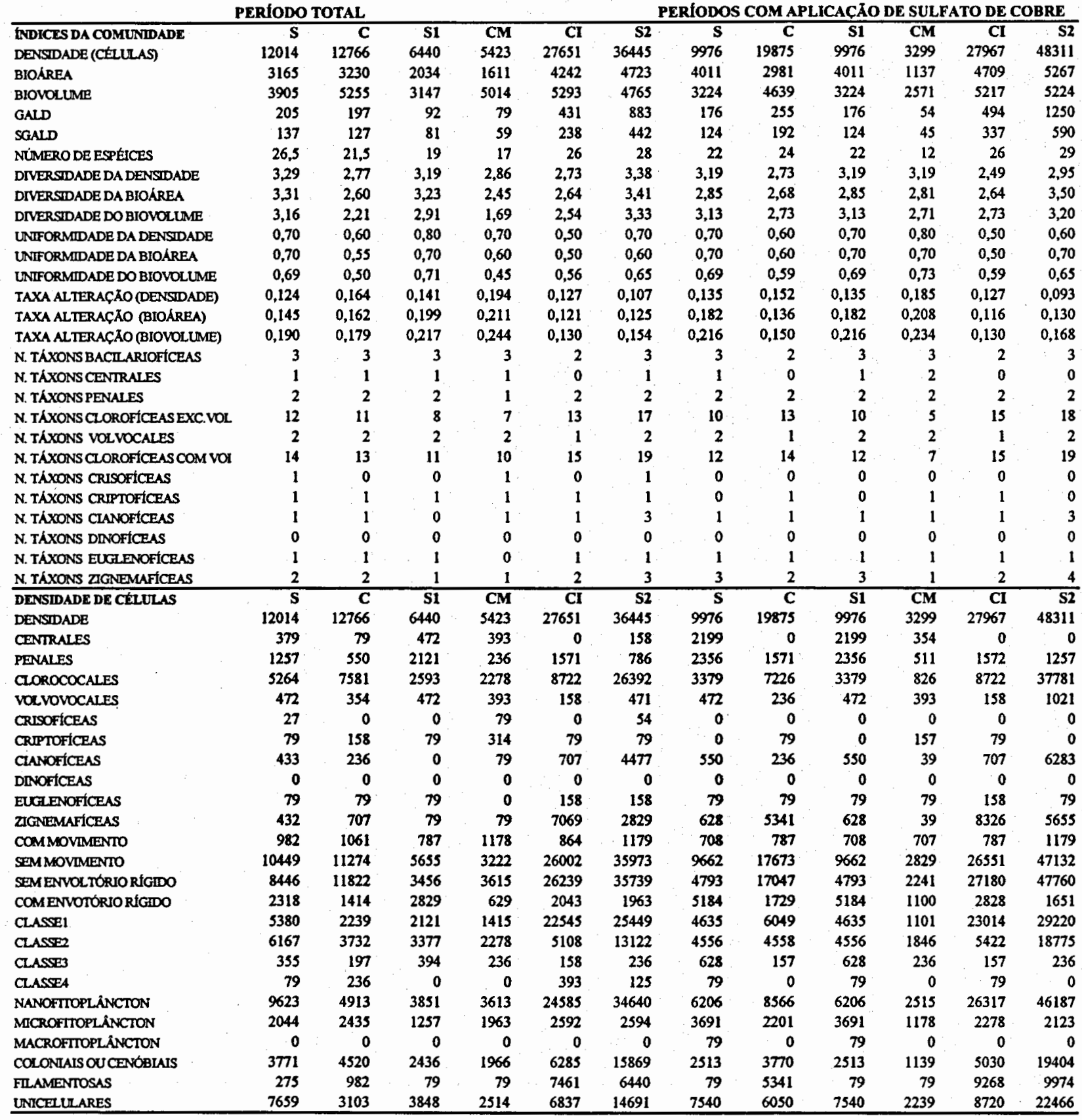


TABELA 35 (Continuaç̃o) -SAZONALIDADE E VARIAÇĀo DEVIDA À SULFATAÇÃo: MEDIANAS DAS VARLÁVEIS DO FITOPLÂNCTON REPRESA DE GUARAPIRANGA $1991-92$ - PONTO 1 .

Identificaço dos periodos: perfodo total de seca (S); periodo tocal de chavas (C); primeiro periodo de seca (S1); período de chuvas moderadas (CM); periodo de chuvas intenses (CI); segundo periodo de seca (S2).

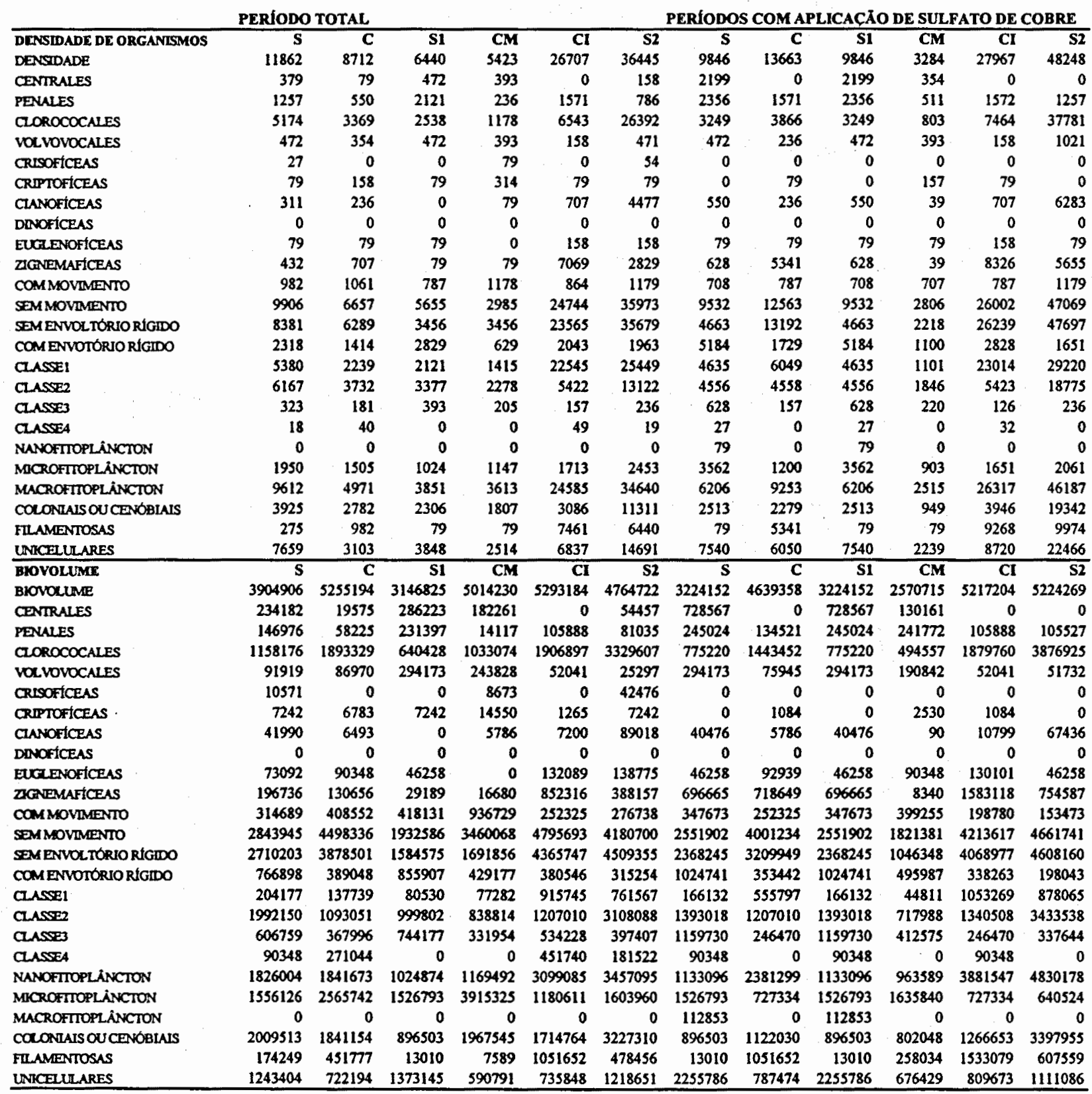


TABELA 36 - SAZONALIDADE E VARIAÇĀo DEVIDA À SULFATAÇÃO: MEDIANAS DAS VARIÁVEIS DO FITOPLÂNCTON REPRESA DE GUARAPIRANGA 1991-92 - PONTO 4.

Identificaça dos periodos: periodo total de seca (S); período total de chuvas (C); primeiro periodo de seca (S1); periodo de chuvas moderadas (CM); periodo de chuvas intensas (CI); segundo periodo de seca (S2).

\begin{tabular}{|c|c|c|c|c|c|c|c|c|c|c|c|c|}
\hline INDICES DA COMUNIDADE & $\mathbf{s}$ & $\mathbf{C}$ & S1 & OM & $\mathbf{a}$ & $\mathbf{S z}$ & $\mathbf{s}$ & $\mathbf{C}$ & S1 & CM & a & S2 \\
\hline DENSIDADE (CELULAS) & 6558 & 8954 & 2278 & 5027 & 10092 & 13273 & 2906 & 7540 & 2906 & 3102 & 9975 & 13273 \\
\hline BIOAREA & 1951 & 1984 & 837 & 1918 & 2884 & 2957 & 1399 & 1835 & 1399 & $\$ 157$ & 2008 & 3106 \\
\hline BIOVOLUME & 3033 & 5294 & 1202 & 3679 & 5854 & 5346 & 1202 & 3663 & 1202 & 3335 & 5424 & $\$ 346$ \\
\hline GALD & 117 & 119 & 64 & 98 & 139 & 184 & 69 & 90 & 69 & 59 & 111 & 157 \\
\hline SGALD & 46 & so & 17 & 35 & 61 & 84 & 20 & 46 & 20 & 25 & 60 & 116 \\
\hline NUMERO DE ESPÉICES & 18 & 20 & 13 & 16 & 24 & 26 & 15 & 22 & 15 & 15 & 24 & 27 \\
\hline DIVERSIDADE DA DENSIDADE & 3,25 & 3,24 & 3,24 & 3,20 & 3,36 & 3,26 & 3,27 & 3,53 & 3,27 & 3,54 & 3,51 & 3,26 \\
\hline DIVERSIDADE DA BIOAREA & 3,01 & 2,91 & 2,77 & 2,69 & 3,15 & 3,13 & 2,55 & 3,14 & 2,55 & 2,80 & 3,18 & 3,13 \\
\hline DIVERSIDADE DO BIOVOLUME & 2,65 & 2,36 & 2,61 & 2,24 & 2,79 & 2,97 & 3,03 & 2,69 & 3,03 & 2,24 & 2,94 & 2,53 \\
\hline UNIFORMDADE DA DENSIDADE & 0,80 & 0,75 & 0,80 & 0,80 & 0,70 & 0,70 & 0,80 & 0,80 & 0,80 & 0,90 & 0,70 & 0,60 \\
\hline UNIFORMIDADE DA BIOAREA & 0,74 & 0,68 & 0,78 & 0,66 & 0,69 & 0,65 & 0,64 & 0,70 & 0,64 & 0,76 & 0,70 & 0,65 \\
\hline UNIFORMLADE DO BIOVOLUME & 0,69 & 0,57 & 0,73 & 0,54 & 0,63 & 0,61 & 0,76 & 0,63 & 0,76 & 0,60 & 0,63 & 0,53 \\
\hline TAXA ALTERACCAOO (DENSWADE) & 0,172 & 0,195 & 0,185 & 0,195 & 0,194 & 0,144 & 0,184 & 0,199 & 0,184 & 0,198 & 0,199 & 0,144 \\
\hline TAXA ALTERAÇĀO (BIOÁREA) & 0,191 & 0,210 & 0,191 & 0,224 & 0,201 & 0,188 & 0,177 & 0210 & 0,177 & 0,226 & 0,201 & 0,188 \\
\hline TAXA ALTERACCAO (BIOVOLUME) & 0,221 & 0,222 & 0,209 & 0,231 & 0,191 . & 0,228 & 0,209 & 0,194 & 0,209 & 0,258 & 0,191 & 0,235 \\
\hline N. TAXONS BACLLARIOFICEAS & 3 & 3 & 3 & 3 & 3 & 4 & 3 & 3 & 3 & 4 & 3 & 3 \\
\hline N. TÁXONS CENTRALES & 2 & 2 & 1 & 2 & 1 & 3 & 1 & 2 & 1 & 2 & 2 & 2 \\
\hline N. TÁXONS PENALES & 1 & 1 & 1 & 1 & 1 & 1 & 2 & 2 & 2 & 2 & 2 & 1 \\
\hline N. TAXONS CLOROFICEAS EXC.VOI & 8 & 7 & 5 & 5 & 8 & 11 & 5 & 7 & 5 & 6 & 8 & 12 \\
\hline N. TAXXNS VOLVOCALES & 2 & 3 & I & 2 & 3 & 2 & 2 & 3 & 2 & 2 & 3 & 3 \\
\hline N. TAXXNS CLOROFICEAS COM VO & 10 & 10 & 7 & 8 & 10 & 14 & 7 & 10 & 7 & 8 & 11 & 14 \\
\hline N.TAXONS CRISOFICEAS & i & $i$ & 0 & i & 1 & 1 & 1 & 1 & 1 & 0 & 1 & 1 \\
\hline N. TAXONS CRPTOFICEAS & 2 & 2 & 2 & 1 & 2 & 2 & 2 & 2 & 2 & 1 & 2 & 2 \\
\hline N. TAXONS CLANOFICEAS & 1 & 2 & 0 & 0 & 2 & 2 & 0 & 2 & 0 & 0 & 2 & 2 \\
\hline N. TAXXNS DINOFICEAS & $\mathbf{0}$ & 1 & 0 & 0 & 2 & 0 & 0 & 1 & 0 & 0 & 2 & 0 \\
\hline N. TÁXONS EUGLENOFICEAS & 1 & 0 & 0 & 0 & 1 & 1 & 0 & 1 & 0 & 1 & 1 & 2 \\
\hline N. TÁXONS ZIGNEMAFICEAS & 1 & 1 & 1 & 0 & 1 & 2 & 3 & 1 & 3 & 0 & 1 & 2 \\
\hline DENSWADE DE CELULAS & $\mathbf{S}$ & C & Si & $\mathbf{C M}$ & a & S2 & $\mathbf{S}$ & $\mathbf{C}$ & S1 & CM & CI & S2 \\
\hline DENSIDADE & 6558 & 8954 & 2278 & 5027 & 10092 & 13273 & 2906 & 7540 & 2906 & 3102 & 9975 & 13273 \\
\hline CENTRALES & s1t & 275 & 314 & 550 & 236 & 1335 & 628 & 236 & 628 & 511 & 236 & 314 \\
\hline PENALES & 157 & 157 & 236 & 157 & 157 & 79 & 471 & 236 & 471 & 275 & 157 & 79 \\
\hline CLOROCOCALES & 2435 & 3377 & 707 & 864 & 4006 & 7854 & 942 & 2985 & 942 & 785 & 3691 & 9817 \\
\hline VOLVOVOCALES & 314 & 628 & 236 & 707 & 628 & 393 & 157 & 628 & 157 & 471 & 623 & 550 \\
\hline CRISOFICEAS & 79 & 157 & 0 & 157 & 79 & 79 & 79 & 79 & 79 & 0 & 79 & 157 \\
\hline CRIPTOFICEAS & 511 & 314 & 550 & 236 & 393 & 471 & 628 & 393 & 628 & 314 & 393 & 550 \\
\hline CIANOFICEAS & 196 & 275 & 0 & 0 & 628 & 1100 & 0 & 550 & 0 & 0 & 550 & 1335 \\
\hline DINOFICEAS & 0 & 157 & 0 & 0 & 157 & 0 & 0 & 157 & 0 & 0 & 236 & 0 \\
\hline EUGLENOFICEAS & 118 & 0 & 0 & 0 & 79 & 236 & 0 & 79 & 0 & 39 & 79 & 314 \\
\hline ZGNEMAFICEAS & 157 & 79 & 79 & 0 & 785 & 236 & 236 & 236 & 236 & 0 & 1963 & 314 \\
\hline COMMOVIMENTO. & 1139 & 1649 & 864 & 1728 & 1571 & 1414 & 864 & 1571 & 864 & 1021 & 1571 & 1492 \\
\hline SEM MOVIMENTO & 5851 & 6480 & 1257 & 2273 & 852 & 9896 & 2042 & 5655 & 2042 & 1767 & 7069 & 10760 \\
\hline SEM ENVOLTORIO RIGIDO & 4398 & 7206 & 1649 & 2356 & 9268 & 11231 & 1571 & 6205 & 1571 & 1610 & 8482 & 11231 \\
\hline COM ENVOTORIO RIGIDO & 1492 & 1100 & 707 & 1100 & 1100 & 2042 & 1492 & 1257 & 1492 & 1139 & 1257 & 1414 \\
\hline CLASSE1 & 2906 & 2749 & 707 & 1021 & 3927 & 6833 & 707 & 3691 & 707 & 825 & 4320 & 6833 \\
\hline CLASSE2 & 2827 & 2081 & 1492 & 1571 & 2592 & 5576 & 1728 & 2513 & 1728 & 1374 & 2592 & 5576 \\
\hline CLASSE3 & 393 & 785 & 314 & 785 & 1178 & 864 & 393 & 628 & 393 & 707 & 550 & 864 \\
\hline CLASSEA & 0 & 0 & 0 & 0 & 79 & 0 & 0 & 0 & 0 & 0 & 79 & 0 \\
\hline NANOFTTOPLÄNCTON & 4791 & 4555 & 1728 & 2749 & 6519 & 12488 & 2042 & 5733 & 2042 & 1689 & 7304 & 12488 \\
\hline MICROFITOPLÄNCTON & 1100 & 1492 & 350 & 1649 & 1021 & 1728 & 864 & 1021 & 364 & 1335 & 550 & 1178 \\
\hline MACROFTTOPLÂNCTON & 0 & 0 & 0 & 0 & 0 & 0 & 79 & 0 & 79 & 0 & 0 & 0 \\
\hline COLONIAIS OU CENOBLAIS & 1335 & 1492 & 550 & 1178 & 1492 & 3377 & 393 & 1335 & 393 & 207 & 1492 & 7147 \\
\hline FILAMENTOSAS & 314 & 353 & 0 & 236 & 707 & 1178 & 0 & 471 & 0 & 275 & 1963 & 2749 \\
\hline UNICEIULARES & 4516 & 3259 & 1963 & 2827 & 4555 & 9660 & 2592 & 3927 & 2592 & 1846 & 4555 & 9660 \\
\hline
\end{tabular}




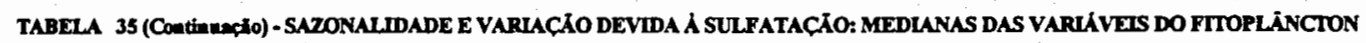

REPRESA DE GUARAPIRANGA 1991-92 - PONTO 1 -

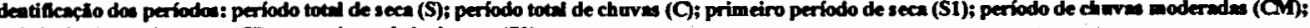
periodo de churve interses (C); sezundo periodo de seca (S2).

\begin{tabular}{|c|c|c|c|c|c|c|c|c|c|c|c|c|}
\hline \multicolumn{6}{|c|}{ FEDODO TOTAL } & \multicolumn{7}{|c|}{ FERIODOS COM APUICACAO DE SULFATO DE COBRE } \\
\hline DENSIDADE DE ORGANISMOS & $\mathbf{S}$ & $\mathbf{C}$ & S1 & $\mathbf{O M}$ & $\mathbf{a}$ & S2 & $\mathbf{s}$ & $\mathbf{C}$ & s1 & $\mathbf{M}$ & $\mathbf{a}$ & $\mathbf{5 2}$ \\
\hline DENSIDADE & 6564 & 6170 & 2278 & 3848 & 7941 & 13273 & 2875 & 6597 & 2875 & 2763 & 7941 & 13273 \\
\hline CENTRALES & sil & 275 & 314 & 550 & 236 & 1335 & 628 & 236 & 628 & 511 & 236 & 314 \\
\hline PENALES & 157 & 157 & 236 & 157 & 157 & 79 & 471 & 236 & 471 & 275 & 157 & 79 \\
\hline CLOROCOCALES & 2107 & 2124 & 707 & 860 & 3534 & 7304 & 911 & 1816 & 911 & 770 & 3095 & 7854 \\
\hline VOLVOVOCALES & 314 & 628 & 236 & 707 & 628 & 393 & 157 & 628 & 157 & 471 & 628 & 550 \\
\hline CRISOFICEAS & 79 & 157 & 0 & 157 & 79 & 79 & 79 & 79 & 79 & 0 & 79 & 157 \\
\hline CRIPTOFICEAS & 511 & 314 & 550 & 236 & 393 & 471 & 628 & 393 & 628 & 314 & 393 & 550 \\
\hline CIANOFICEAS & 196 & 275 & 0 & 0 & 621 & 1100 & 0 & 550 & 0 & 0 & 550 & 1335 \\
\hline DNOFICEAS & 0 & 157 & 0 & 0 & 157 & 0 & 0 & 157 & 0 & 0 & 236 & 0 \\
\hline EUGLENOFICEAS & 118 & 0 & 0 & 0 & 79 & 236 & 0 & 79 & 0 & 39 & 79 & 314 \\
\hline ZIGNEMAFICEAS & 157 & 79 & 79 & 0 & 785 & 236 & 236 & 236. & 236 & 0 & 1963 & 314 \\
\hline COM MOVIMENTO & 1139 & 1649 & 864 & 1728 & 1571 & 1414 & 864 & 1571 & 864 & 1021 & 1571 & 1492 \\
\hline SEM MOVIMENTO & 3851 & 4613 & 1257 & 2246 & 6205 & 9582 & 2011 & 4634 & 2011 & 1428 & 5205 & 10014 \\
\hline SEM ENVOLTORIO RIGIDO & 4071 & 5152 & 1649 & 2129 & 6998 & 11231 & 1571 & 5576 & 1571 & 1571 & 6998 & 11231 \\
\hline COM ENVOTORIO RIGIDO & 1492 & 1100 & 707 & 1100 & 1100 & 2042 & 1492 & 1257 & 1492 & $\$ 139$ & 1257 & 1414 \\
\hline CLASSE1 & 2906 & 2749 & 707 & 1021 & 3927 & 6833 & 707 & 3691 & 207 & 825 & 4320 & 6833 \\
\hline CLASSE2 & 2827 & 2160 & 1492 & 1571 & 2592 & 5576 & 1728 & 2513 & 1728 & 1374 & 2592 & 5576 \\
\hline CLASSE3 & 373 & 660 & 268 & 738 & 582 & 864 & 393 & sso & 393 & 501 & 550 & 942 \\
\hline CLASSEA & 0 & 0 & 0 & 0 & 79 & 0 & 0 & 0 & 0 & 0 & 79 & 0 \\
\hline NANOFITOPLÄNCTON & 4820 & 4634 & 1728 & 2749 & 6591 & 12488 & 2012 & 5733 & 2042 & 1689 & 7304 & 12488 \\
\hline MICROFTIOPLAANCTON & 1060 & 1076 & 519 & 1579 & $\$ 82$ & 1559 & 833 & 582 & 833 & 996 & 550 & 1178 \\
\hline MACROFITOPLÂNCTON & 0 & 0 & 0 & 0 & 0 & 0 & 79 & 0 & 79 & 0 & 0 & 0 \\
\hline COLONIAIS OU CENOBLAIS & 1233 & 1492 & 350 & 1178 & 1492 & 3220 & 393 & 1178 & 393 & 613 & 1492 & $33 \pi$ \\
\hline FILAMENTOSAS & 314 & 353 & 0 & 236 & 707 & 1178 & 0 & 471 & 0 & 275 & 1963 & 2749 \\
\hline UNICEUULARES & 4438 & 3259 & 1963 & 2827 & 4555 & 9582 & 2592 & 3927 & 2592 & 1846 & 4555 & 9582 \\
\hline BIOVOLUME & $\mathbf{s}$ & C & S1 & CM & a & S2 & $\mathbf{S}$ & $\mathbf{C}$ & Si & कM & $\mathbf{G}$ & $\mathbf{S z}$ \\
\hline BIOVOLUME & 3033202 & 5293880 & 1201576 & 3678895 & 5853789 & 5345707 & 1201576 & 3663355 & 1201576 & 3335294 & 5423686 & 5345707 \\
\hline CENIRALES & 616535 & 123819 & 254420 & 190815 & 88180 & 806782 & 254420 & 180696 & 254420 & 1060394 & 95408 & 122151 \\
\hline PENALES & 23460 & 11655 & 112754 & 5421 & 20599 & 9035 & 115465 & 37946 & 115465 & 125494 & 20599 & 24394 \\
\hline CLOROCOCALES & 687442 & 1024273 & 382520 & 421988 & 1334142 & 1673085 & 382520 & 766347 & 382520 & 428667 & 1140872 & 2852660 \\
\hline VOLVOVOCALES & 34694 & 141666 & 46258 & 314411 & 106249 & 28911 & 11565 & 127210 & 11565 & 109863 & 127210 & 40476 \\
\hline CRISOFICEAS & 10842 & $\$ 5564$ & 0 & 80952 & 24394 & 17347 & 24394 & 8673 & 24394 & 0 & 24394 & 17347 \\
\hline CRIPTOFICEAS & 70878 & 44519 & 64509 & 44519 & 67897 & 83549 & 69387 & 67897 & 69387 & 75113 & 67897 & 97983 \\
\hline CIANOFICEAS & 1807 & 2168 & 0 & 0 & 6324 & 11565 & 0 & 3433 & 0 & o & 5240 & 13043 \\
\hline DINOFICEAS & 0 & 10037 & 0 & 0 & 286946 & 0 & 0 & 108237 & 0 & 0 & 1480625 & \\
\hline EUGLENOFICEAS & 81313 & 0 & 0 & 0 & 19815 & 185033 & 0 & 19515 & 0 & 23129 & 19515 & 424636 \\
\hline ZGNEMAFICEAS & 75193 & 20182 & 14595 & 0 & 130961 & 126599 & 188897 & 41699 & 188897 & 0 & 162627 & 100078 \\
\hline COM MOVIMENTO & 602135 & 1533083 & 531992 & 1484871 & 1581295 & 1245765 & 642804 & 1484871 & 642804 & 886044 & 1736445 & 1245765 \\
\hline SEMMOVMENTO & 1650859 & 2276404 & 681625 & 2076195 & 2476614 & 4228464 & $558 \mathrm{~m}$ & 1971713 & 558772 & 1750192 & 1971713 & 4228464 \\
\hline SEM ENVOLTORIO RIGIDO & 1636311 & 4192736 & 689451 & 1291747 & 4741097 & 3275735 & 1002268 & 2713594 & 1002268 & 881611 & 4269391 & 3275735 \\
\hline COM ENVOTORIO RIGIDO & 852461 & 685112 & 399158 & 956328 & 422978 & 1013164 & 399158 & 881075 & 399158 & 2146844 & 555099 & 868905 \\
\hline CLASSE1 & 259912 & 245052 & 212848 & 148001 & 260168 & 306266 & 306682 & 260168 & 306682 & 99439 & 270132 & 279161 \\
\hline CLASSE2 & 1048008 & 1143422 & 677069 & 942732 & 1262031 & 2607439 & 432111 & 1262031 & 432111 & 1705081 & 1262031 & 2607439 \\
\hline CLASSE3 & 123493 & 871021 & 304923 & 495830 & 1022198 & 951463 & 556617 & st9502 & 556617 & 412213 & 821132 & 951463 \\
\hline CLASSEA & & 0 & 0 & & 1196932 & 0 & 0 & 0 & 0 & 0 & 1196932 & 0 \\
\hline NANOFTOPLAANCTON & 1074547 & 1140390 & 674848 & 639484 & 1710705 & 2009102 & 702059 & 1274802 & 702059 & 459915 & 1710705 & 2900419 \\
\hline MCROFITPPLANACTON & 1202809 & 3706867 & $499 \$ 17$ & 3600191 & 3889273 & 2649744 & 499517 & 2772675 & 499517 & 2549867 & 3722974 & 2555219 \\
\hline MACROFITOPLÂNCTON & & 0 & & & 0 & 0 & & o & & 0 & 0 & \\
\hline COLONIAIS OU CENOBLAIS & 708241 & 929602 & 244468 & 924595 & 1251464 & 2355698 & 151086 & 585670 & 151086 & 733451 & 585670 & 2490014 \\
\hline FILAMENTOSAS & 235646 & 243940 & 112754 & 69387 & 265591 & 637681 & 112754 & 796774 & 112754 & 929570 & 531183 & 245783 \\
\hline UNICEIULARES & 947329 & 1177660 & 608336 & 1042923 & 1367307 & 1949881 & 954216 & 1367307 & 954216 & 818567 & 2321991 & 1949881 \\
\hline
\end{tabular}


FIGURA 1 - REDE HIDROGÁFICA DO ESTADO DE SÃO PAULO.

AMÉRICA DO SUL, BRASIL, SÃO PAULO, REGIÃO DA GRANDE SÃO PAULO.
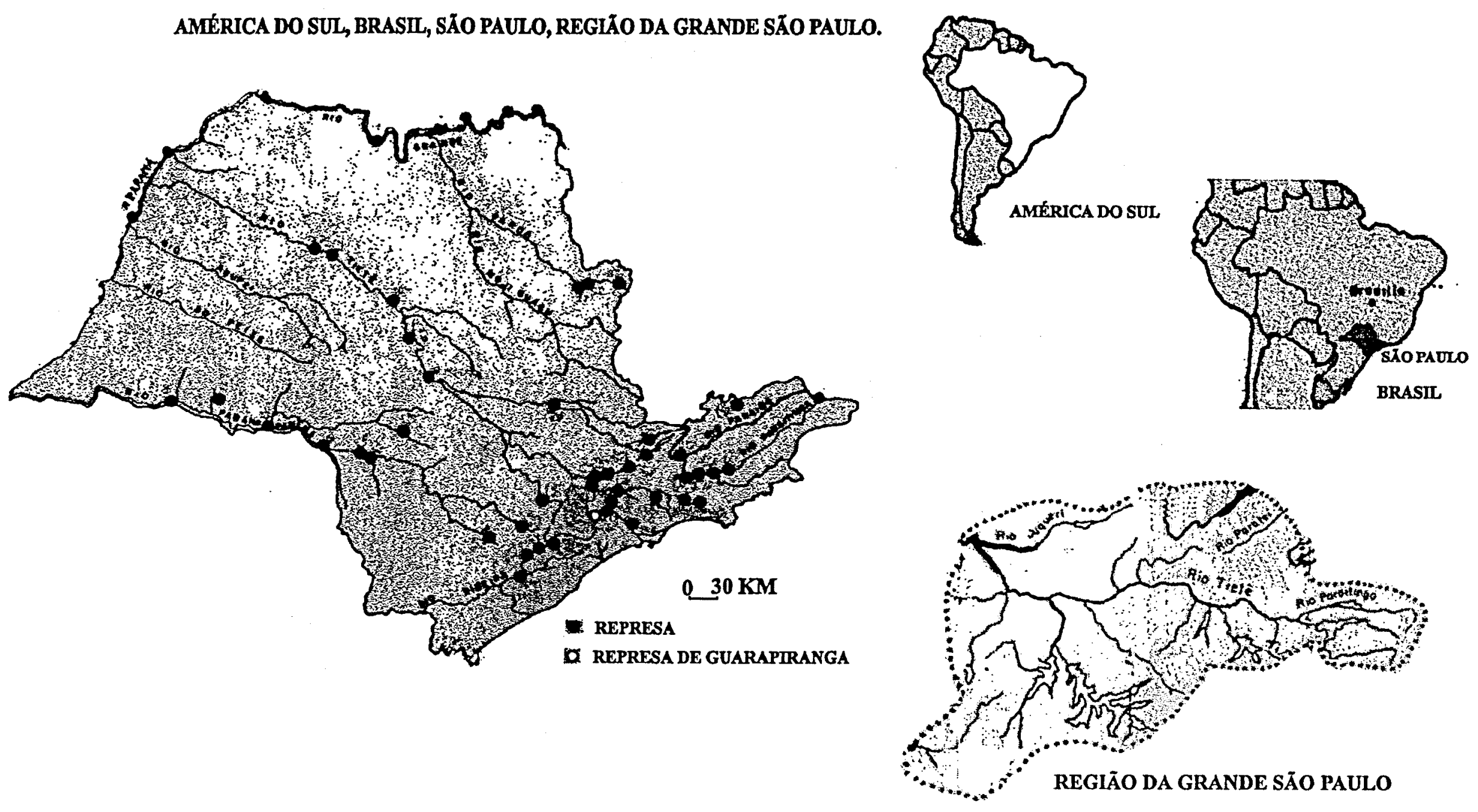
Figura 2 - Imagem de Satélite: vista da área urbana em 1984. Represa de Guarapiranga.
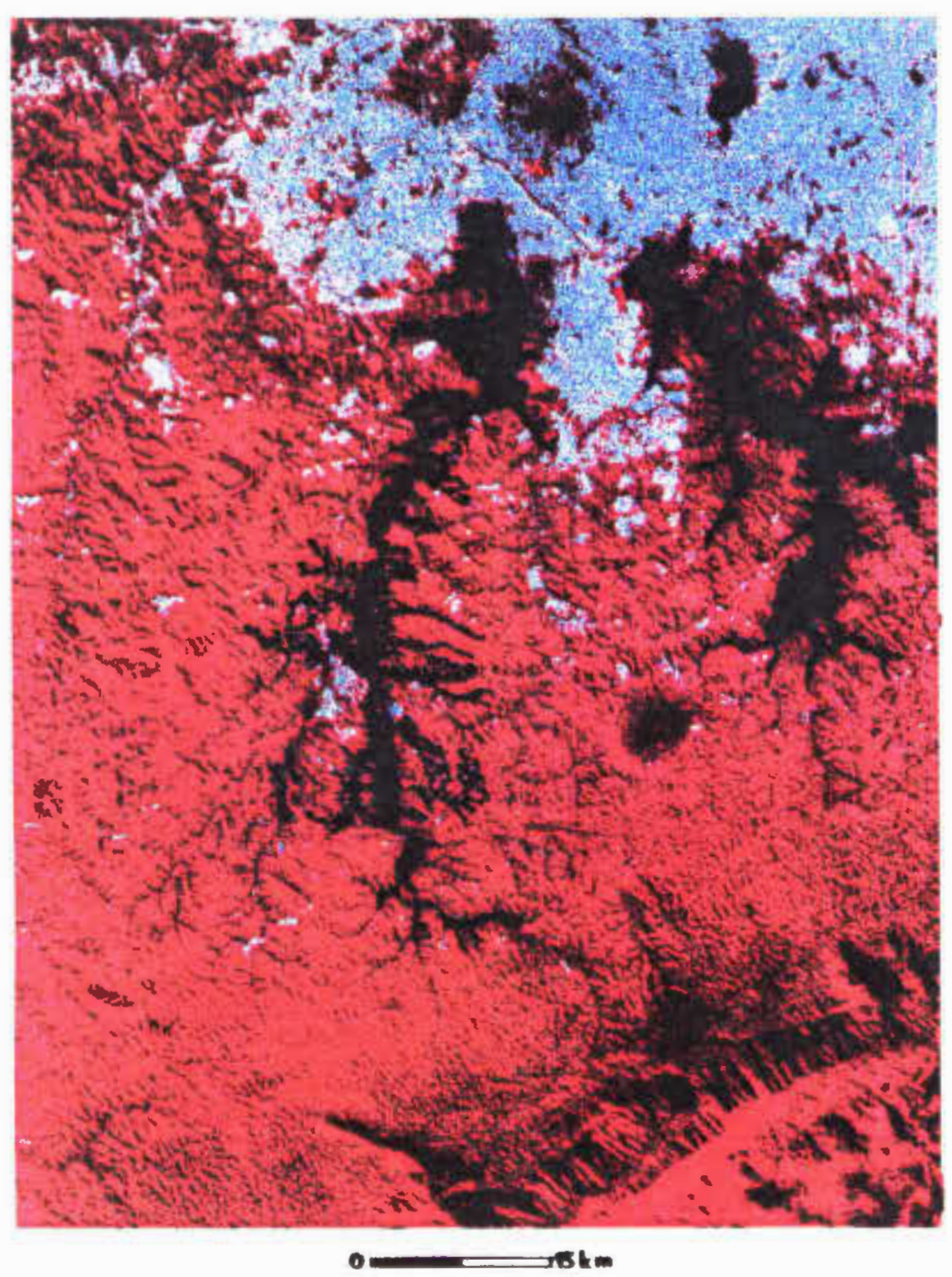

Imagem de satélite: LANDSAT 5 (TM-2,3 e 4). DATA: 10.03 .1984

Mata Atlântica

Área urbana 
FIGURA 3 - DEMARCAÇÃo dOS PONTOS DE COLETA. REPRESA DE GUARAPIRANGA, 1991-92.

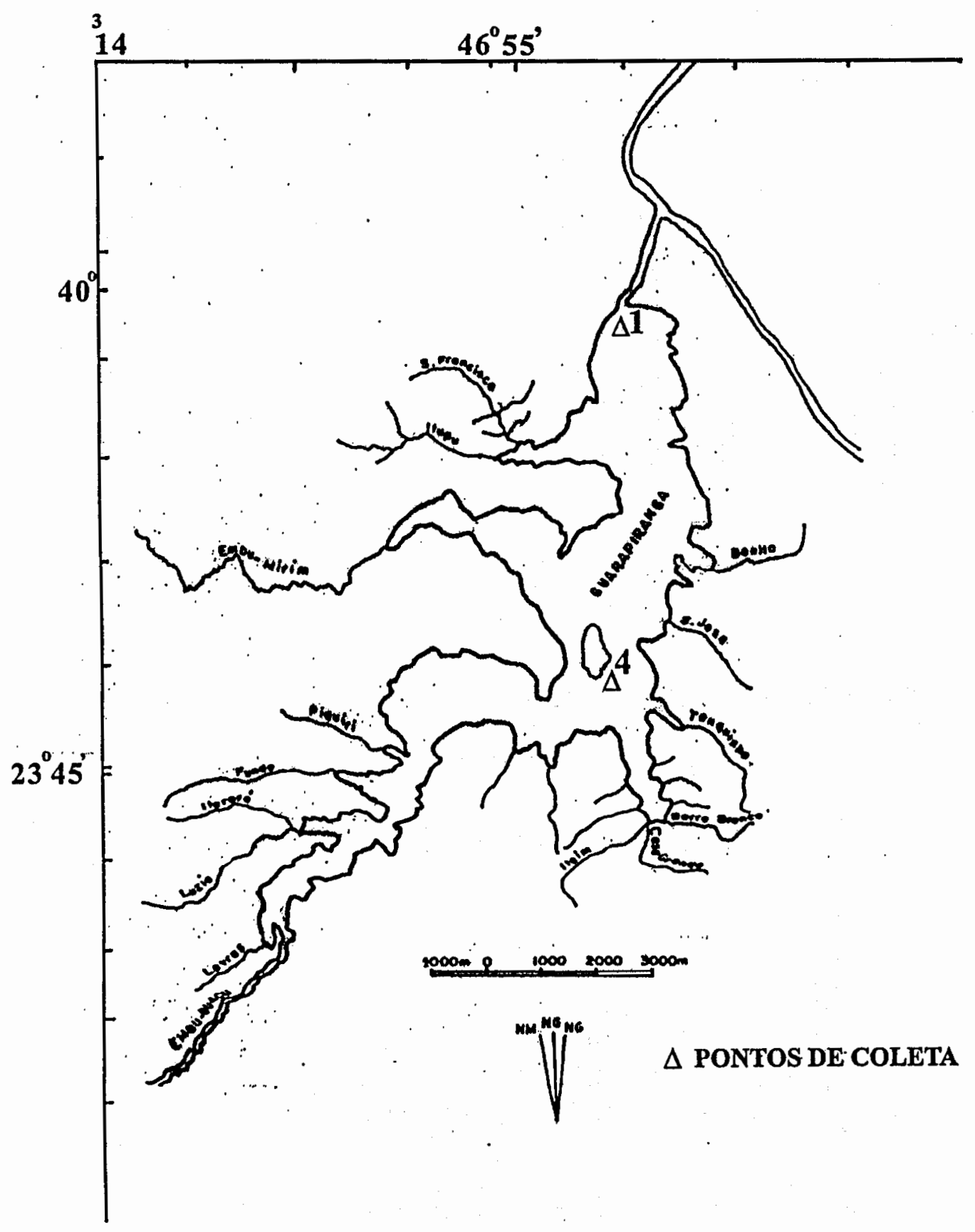




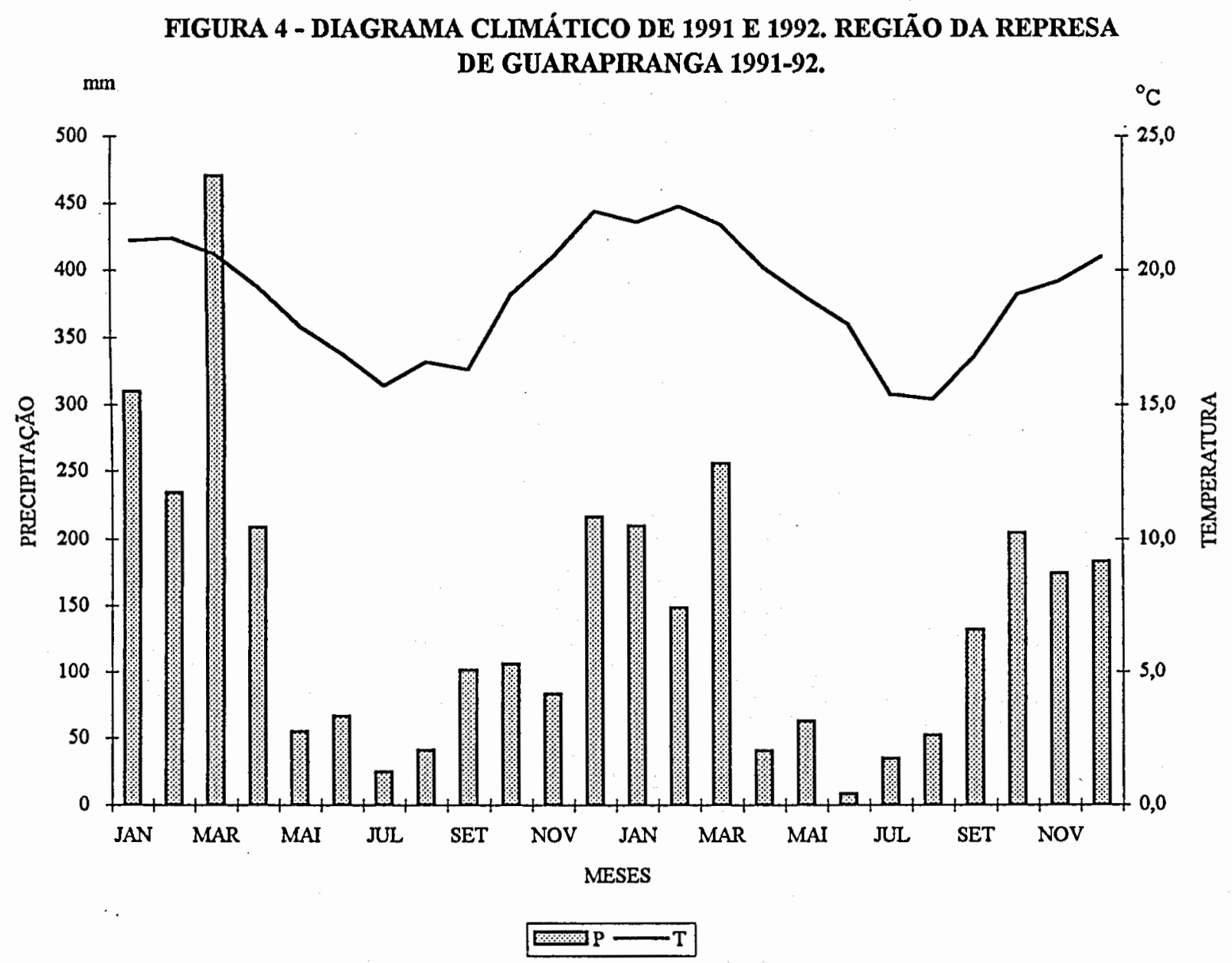

FIGURA 5 - REPRESENTAÇÃo GRÁFICA DO BALANÇO HÍDRICO NA REGIÃo

DA

REPRESA DE GUARAPIRANGA 1991-92.

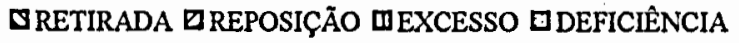

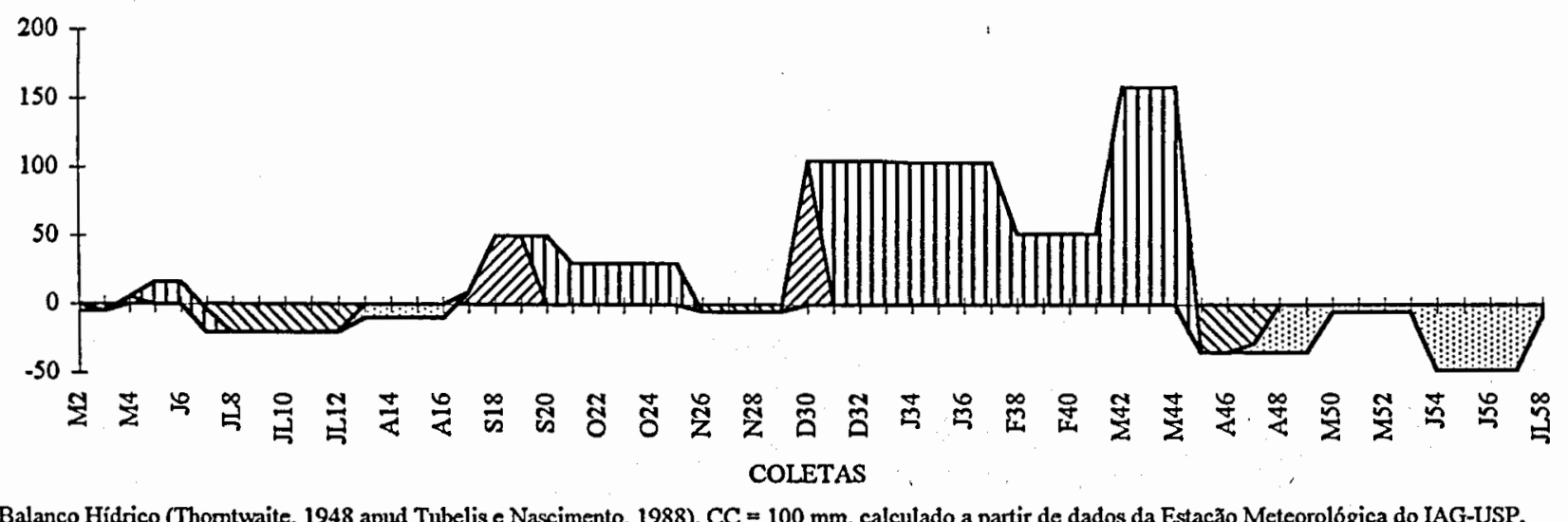

Balanço Hidrico (Thorntwaite, 1948 apud Tubelis e Nascimento, 1988), $C \mathrm{C}=100 \mathrm{~mm}$, calculado a partir de dados da Estação Meteorológica do LAG-USP. 
FIGURA 6 - DISTRIBUIÇÃO TEMPORAL DO BIOVOLUME NAS CLASSES DE TAMANHO. GUARAPIRANGA 1991-92. PONTO 1.

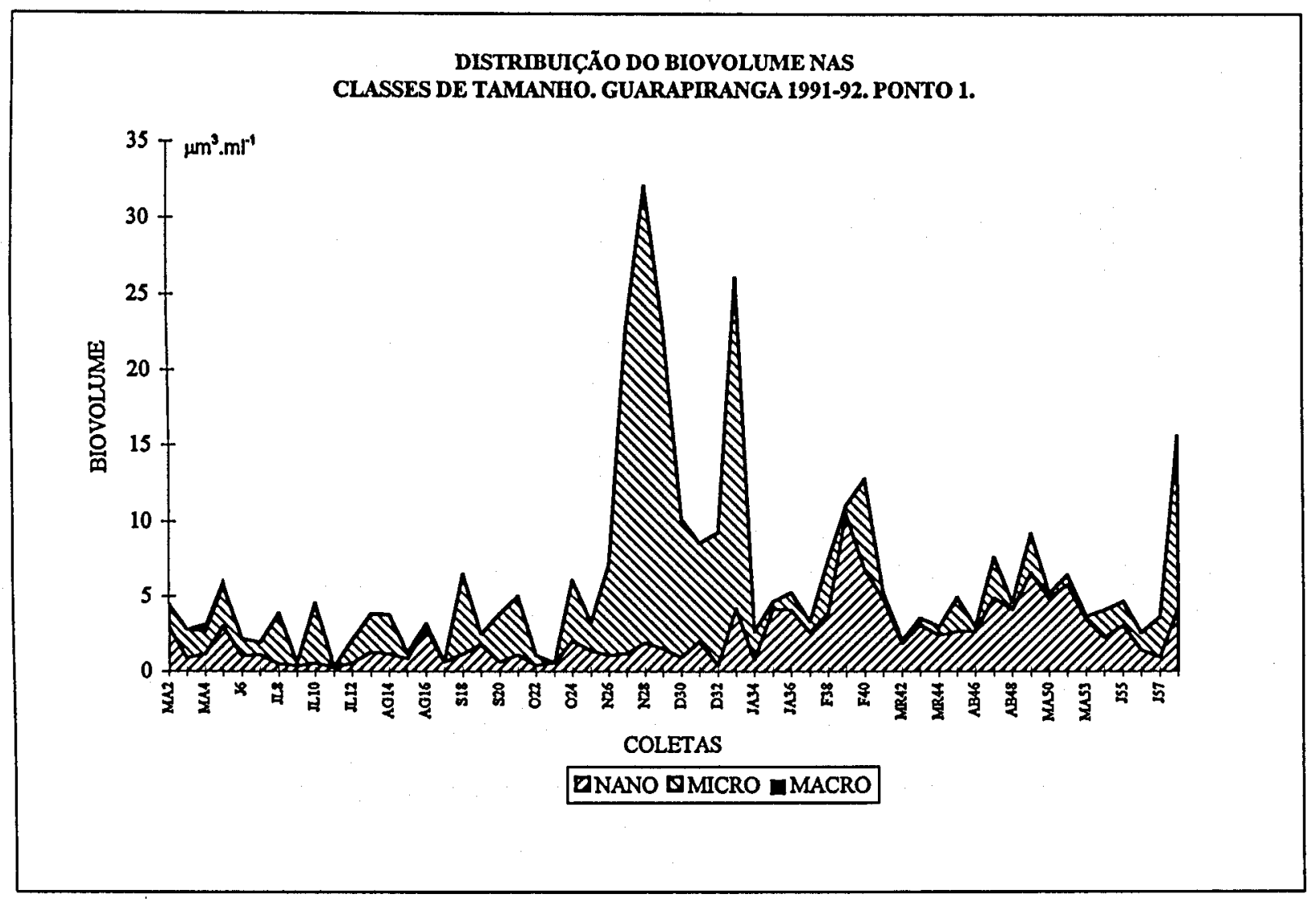

FIGURA 7 - DISTRIBUIÇẠO TEMPORAL DO BIOVOLUME NAS CLASSES DE TAMANHO. GUARAPIRANGA 1991-92. PONTO 4.

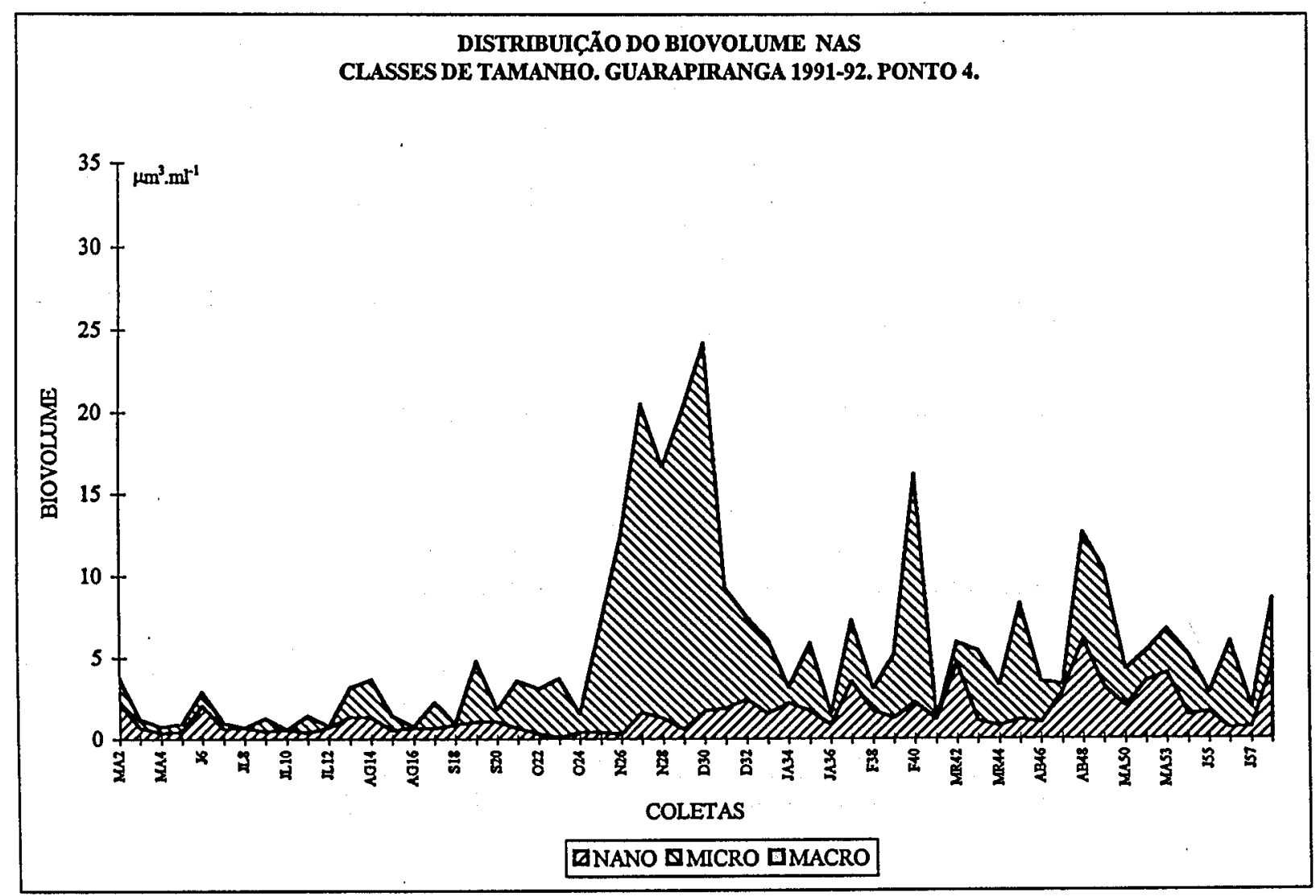


FIGURA 8 - DISTRIBUIÇÃO TEMPORAL DOS INDICES DA ESTRUTURA DA COMUNIDADE FITOPLANCTÔNICA. REPRESA DE GUARAPIRANGA, 1991-92. PONTO 1.

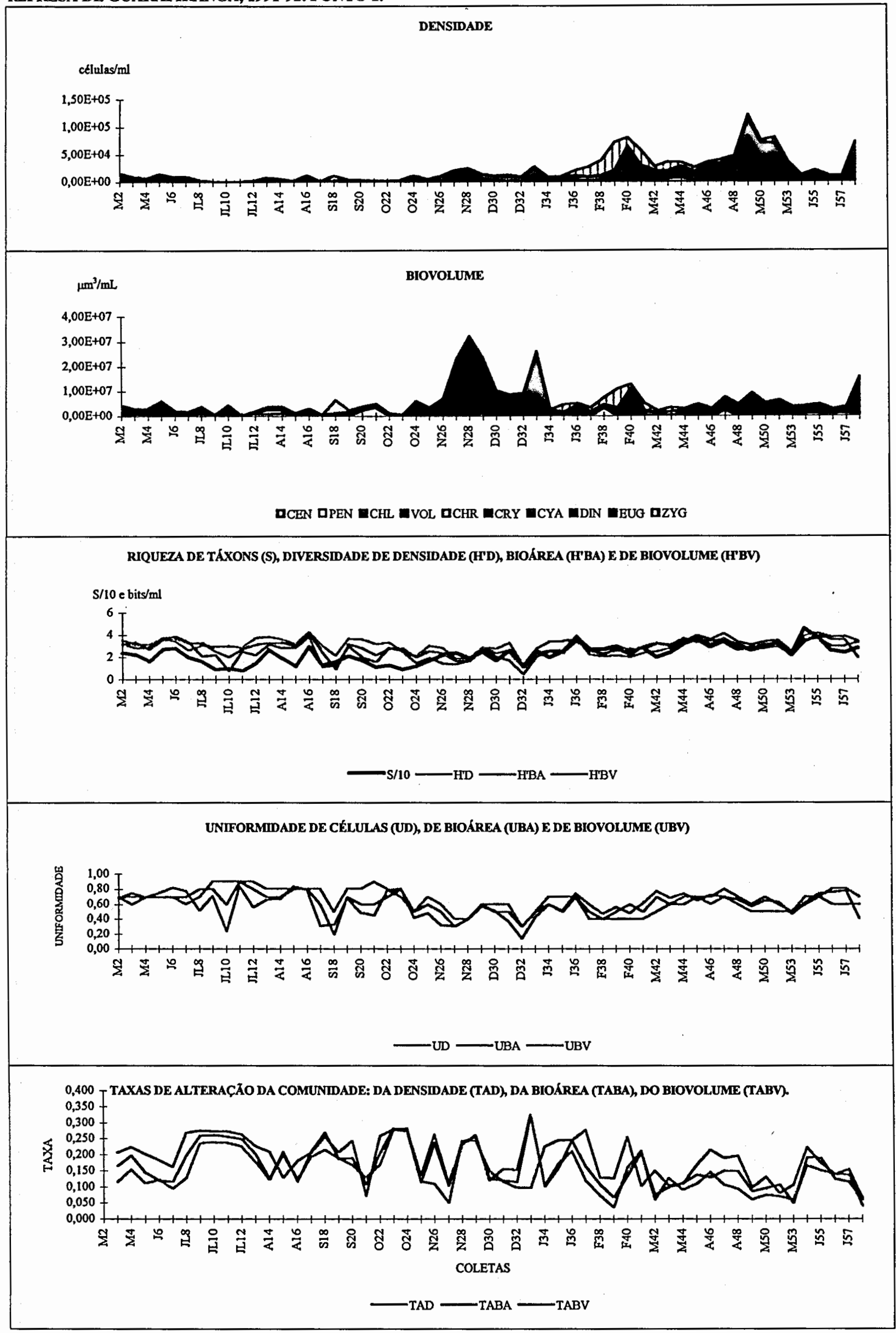


FIGURA 9 - DISTRIBUIÇÃO TEMPORAL DOS ÍNDICES DA ESTRUTURA DA COMUNIDADE FITOPLANCTÔNICA. REPRESA DE GUARAPIRANGA, 1991-92. PONTO 4.

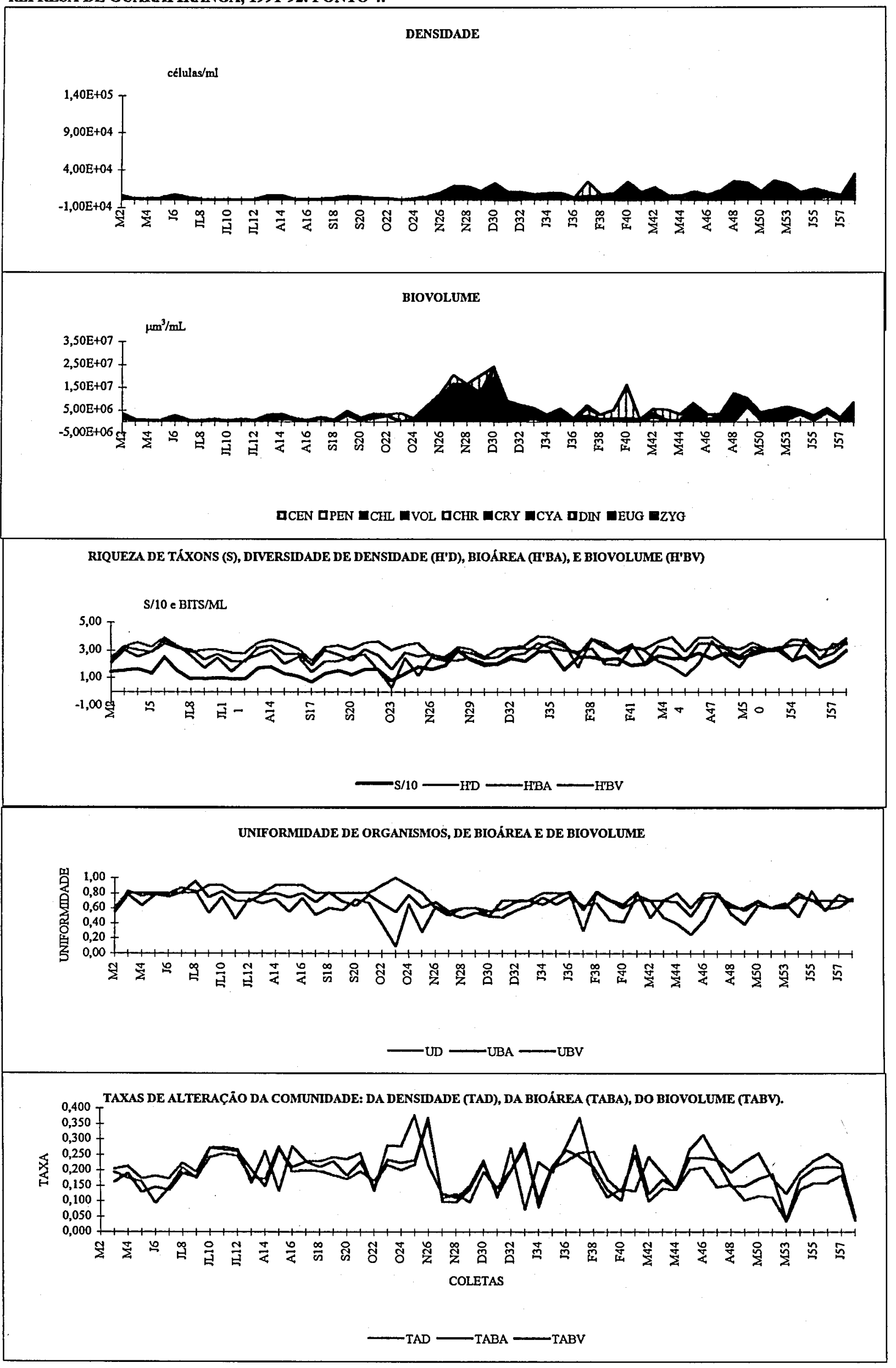


FIGURA 10 - DISTRIBUIÇÃO TEMPORAL DOS GRUPOS SISTEMÁTICOS DO FITOPLÂNCTON. REPRESA DE GUARAPIRANGA, 1991-92. PONTO 1.

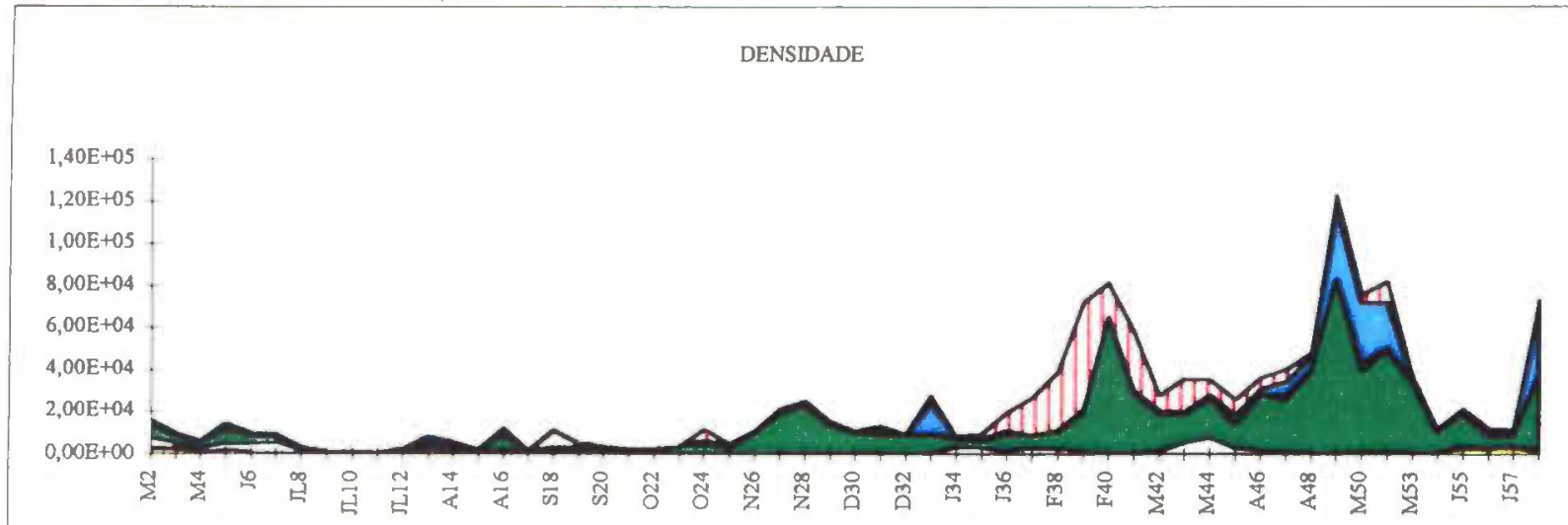

PORCENTAGEM DA DENSDADE
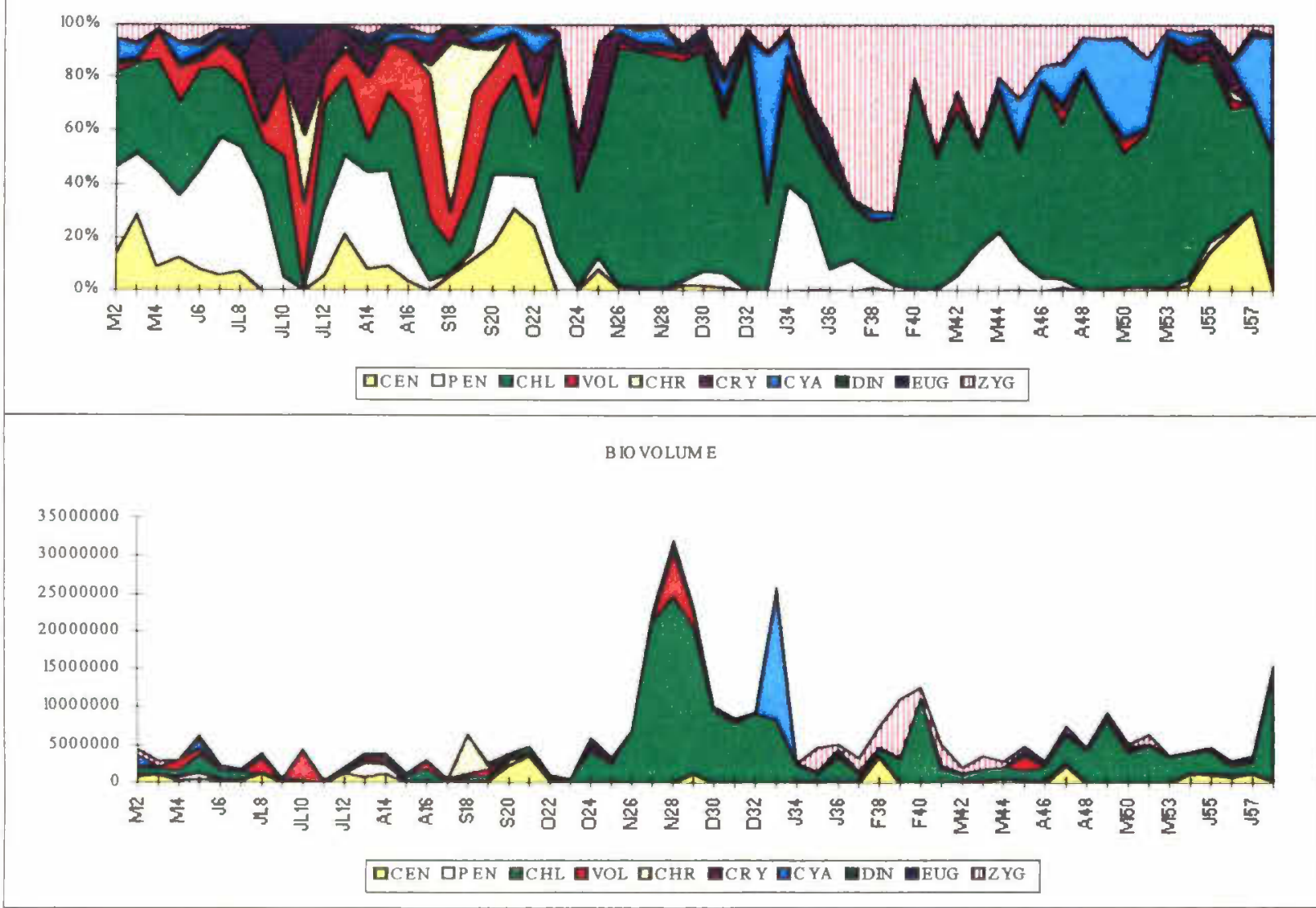

P ORCENTAGEM DO B ЮVOLUME

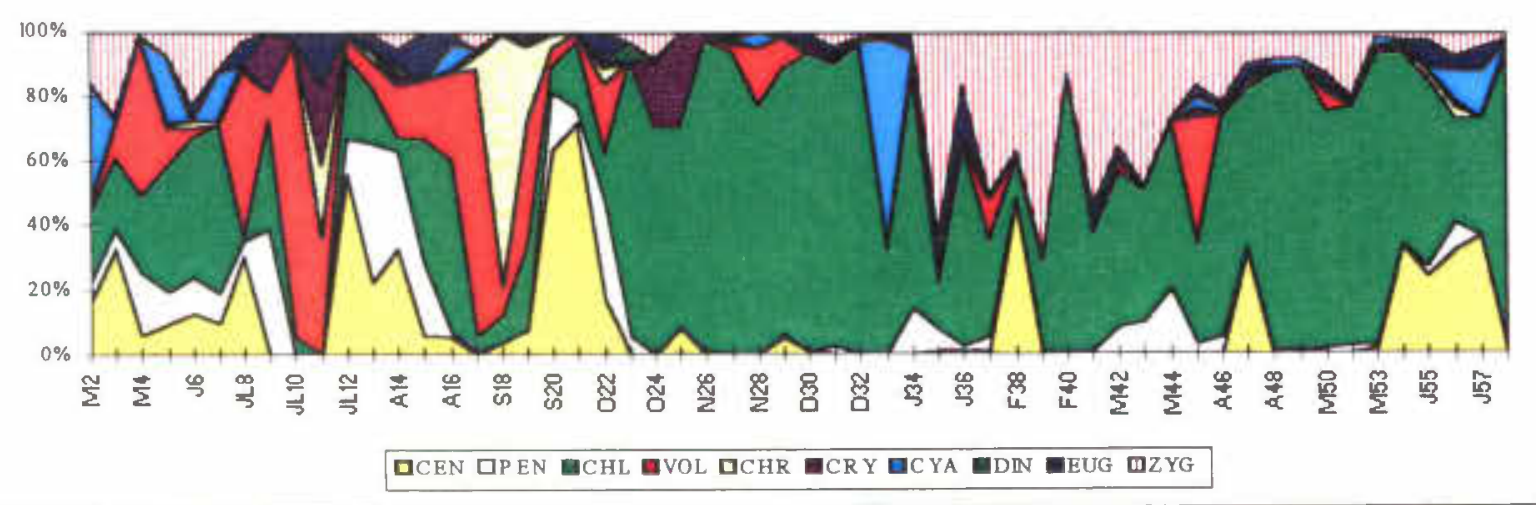


FIGURA 11 - DISTRIBUIĊ̃̃O TEMPORAL DOS GRUPOS SISTEMÁTICOS DO FITOPLÂNCTON. REPRESA DE GUARAPIRANGA, 1991-92. PONTO 4.

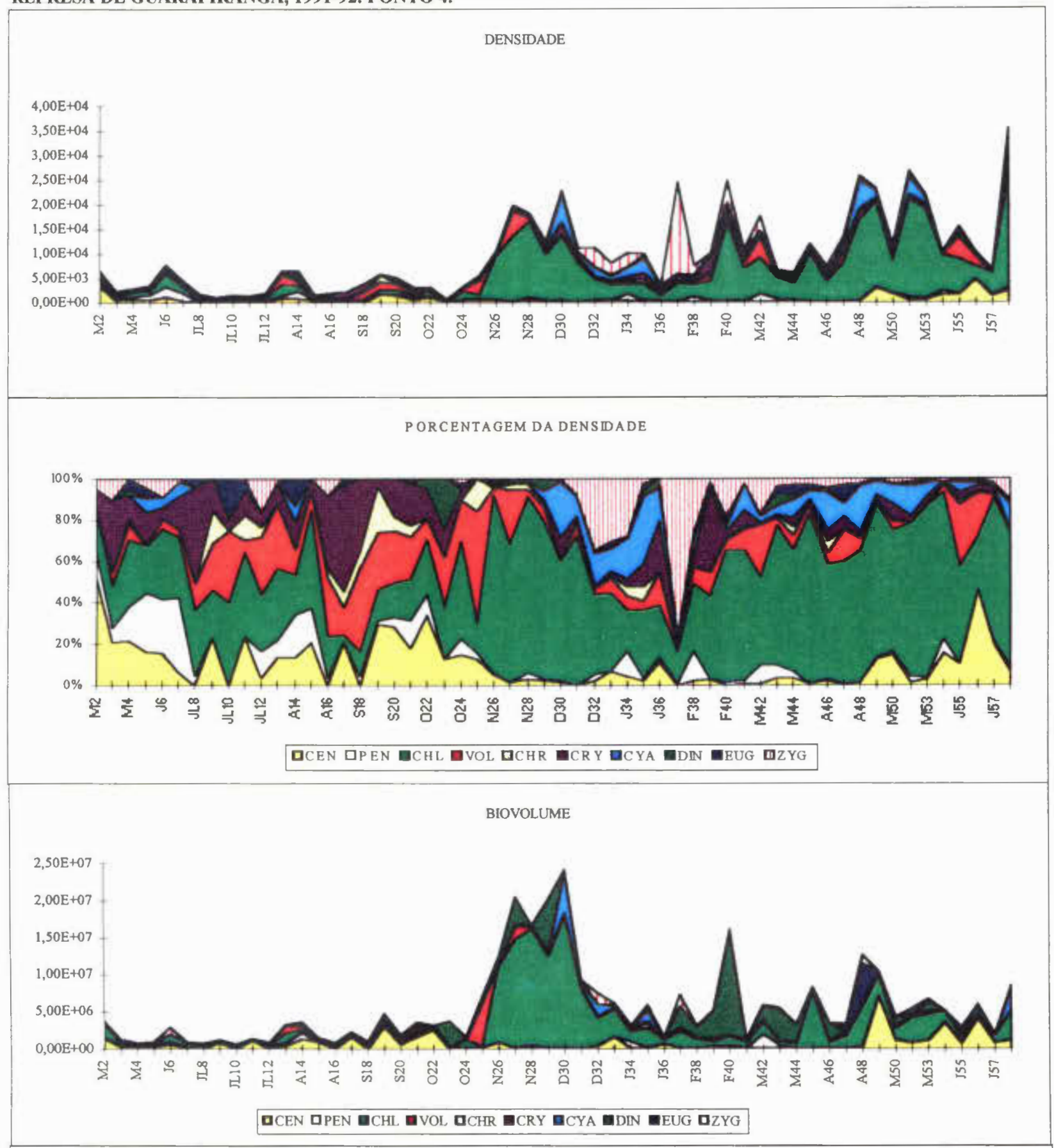

PORCENTAGEM DO BIOVOUME

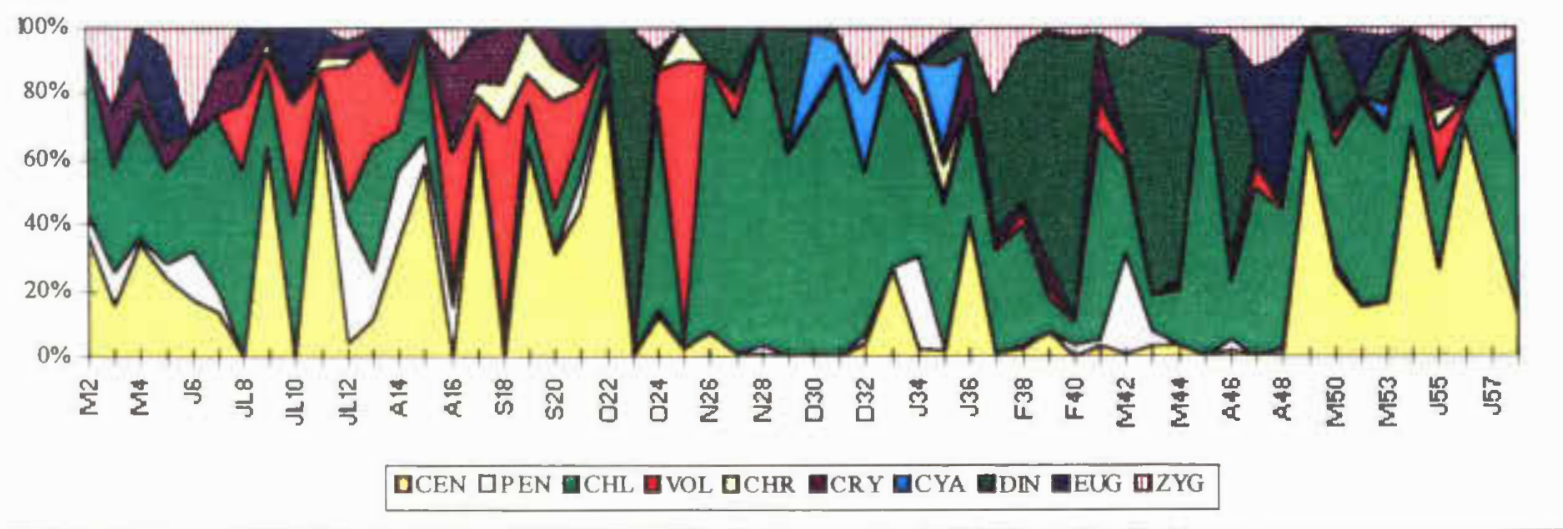


FIGURA 12 - QUADRO RESUMO DA DINÂMICA TEMPORAL DA COMUNIDADE FITOPLANCTÓNICA DA REPRESA DE GUARAPIRANGA 1991-92. PONTO 1.

CRITERIO: MEDLANAS POR PERIODO

PLUMOSIDADEEAFLUENTES

SADASDEAGUA

AGUAS PERCOLADAS OU CARREADAS

DEFICIENCAA HIDRICADO SOLO

EIEVAGAO

VELOCIDADE MAXMA DO VENTO

RADMCAO SOLAR

INSOLACAO

SULFATAGAO

TEMPERATURA DAAGUA

TRANSPARENCIA

PH

CONDUTMDADE

ALCALINIDADE

FOSFORO TOTAL (PT)

NIROGENIO TOTAL $\left(\mathrm{NH}_{4}+\mathrm{NO}_{3}\right)$

ZOOPLANCTON

DENSIDADE DO FTTOPLANCTON

BOVOLUMEDO FTOPLANCTON

NUUMERO DE ESPECIES

DNERSIDADE DE DENSIDADE

DMERSIDADE DE BIOVOLUME

ESTRATEGGA PREDOMINANTE

ESPÉCIES MAIS MPORTANTES

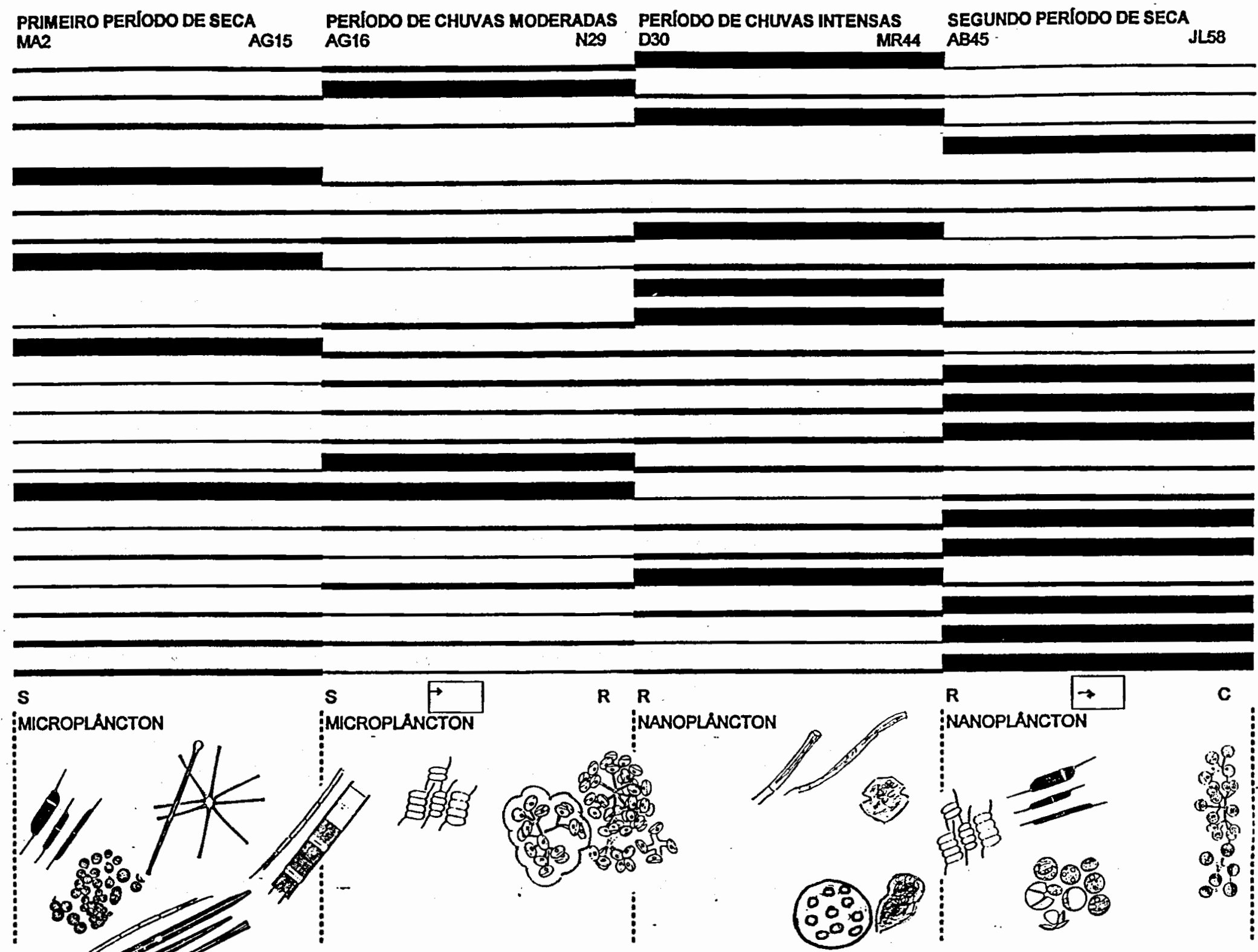


FIGURA 13 - QUADRO-RESUMO DA DINÂMICA TEMPORAL DA COMUNIDADE FITOPLANCTÔNICA DA REPRESA DE GUARAPIRANGA $1991-92$. PONTO 4.

CRITÉRIO: MEDIANAS POR PERIODO

PLUVIOSIDADE E AFLUENTES

SAIDAS DEAGUA

AGUAS PERCOLADAS OU CARREADAS

DEFICIENNCLA HIDRICA DO SOLO

ELEVACAO

VELOCIDADE MAXIMA DO VENTO

RADIACAO SOLAR

INSOLAGAO

TEMPERATURA DA AGUA

TRANSPARENCIA

$\mathrm{pH}$

CONDUTMMDADE

ALCALINIDADE

FOSFORO TOTAL (PT)

NITROGENIO TOTAL $\left(\mathrm{NH}_{4}+\mathrm{NO}_{3}\right)$

ZOOPLANCTON

DENSIDADE DO FTTOPLANCTON

BIOVOLUME DO FTTOPLANCTON

NÜMERO DE ESPECIES

DNERSIDADE DE DENSIDADE

DIVERSIDADE DE BIOVOLUME

ESTRATÉGLA PREDOMINANTE

ESPÉCIES MAIS IMPORTANTES
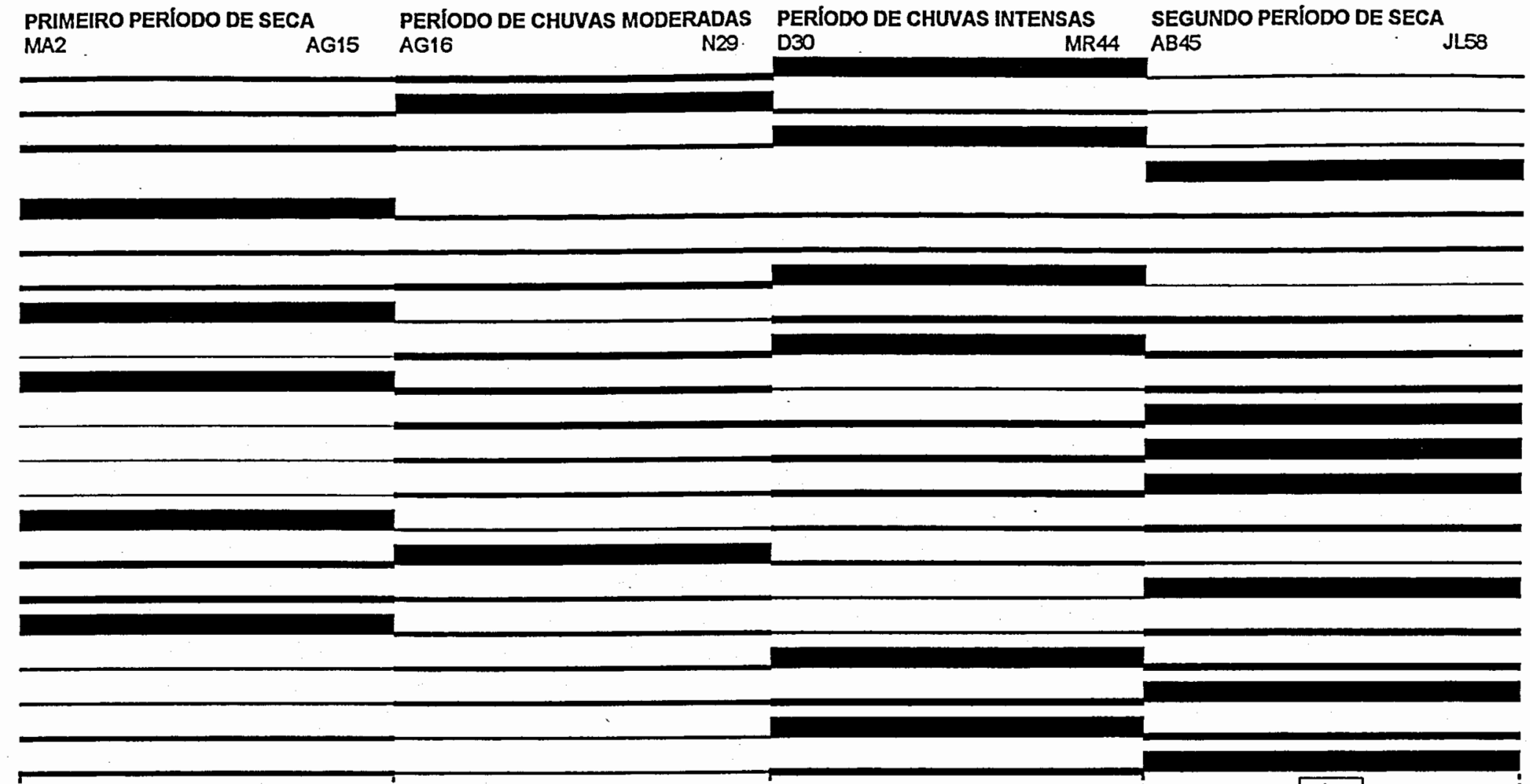

$$
\text { s }
$$

NANOPLÂNCTON

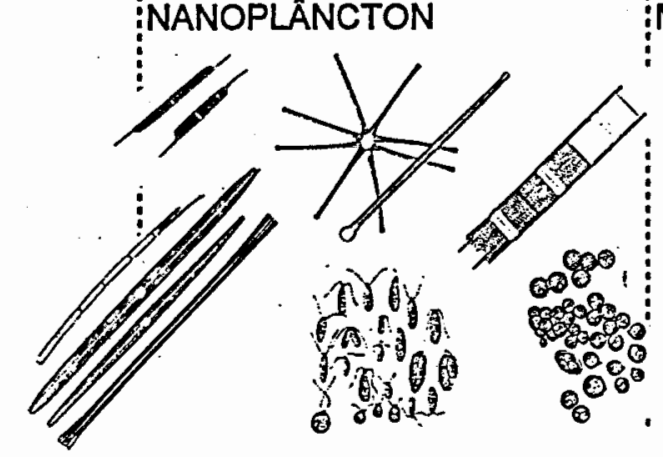

is

MICROPLÂNCTON

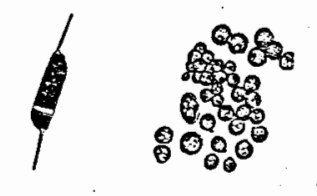

MICROPLÂNCTON

邀

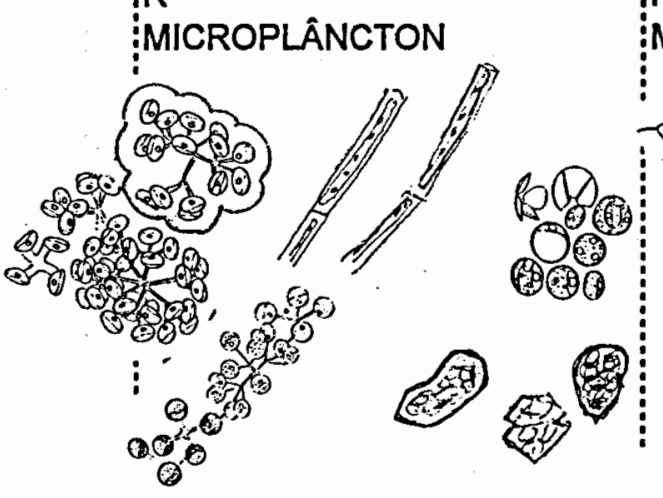

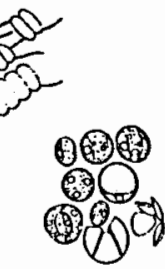

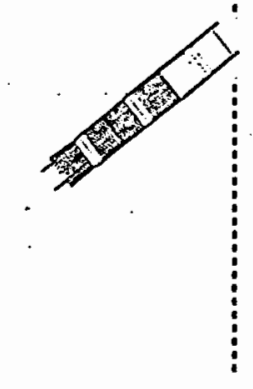




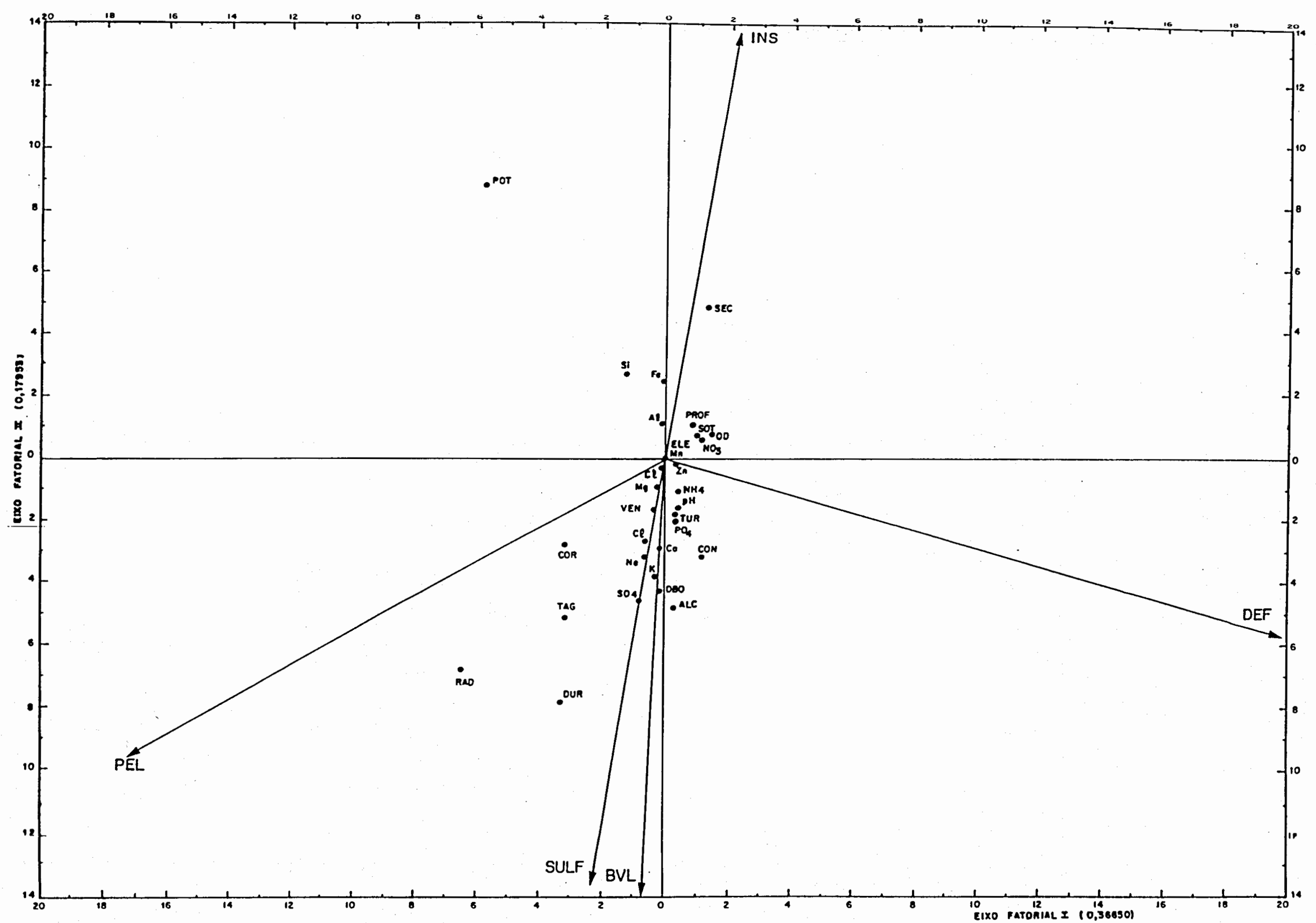

FIGURA 14 - ANÁLISE DOS COMPONENTES PRINCIPAIS. POSIÇÃO DAS CAMPANHAS. PONTO 1. MATRIZ DAS VARIÁVEIS AMBIENTAIS [LOG(X+1)]. ORDENAÇÃO: DISTÂNCIA EUCLIDEANA. PORCENTAGEM DE EXPLICAÇĀO DOS DOIS PRIMEIROS EIXOS: 54.60. 


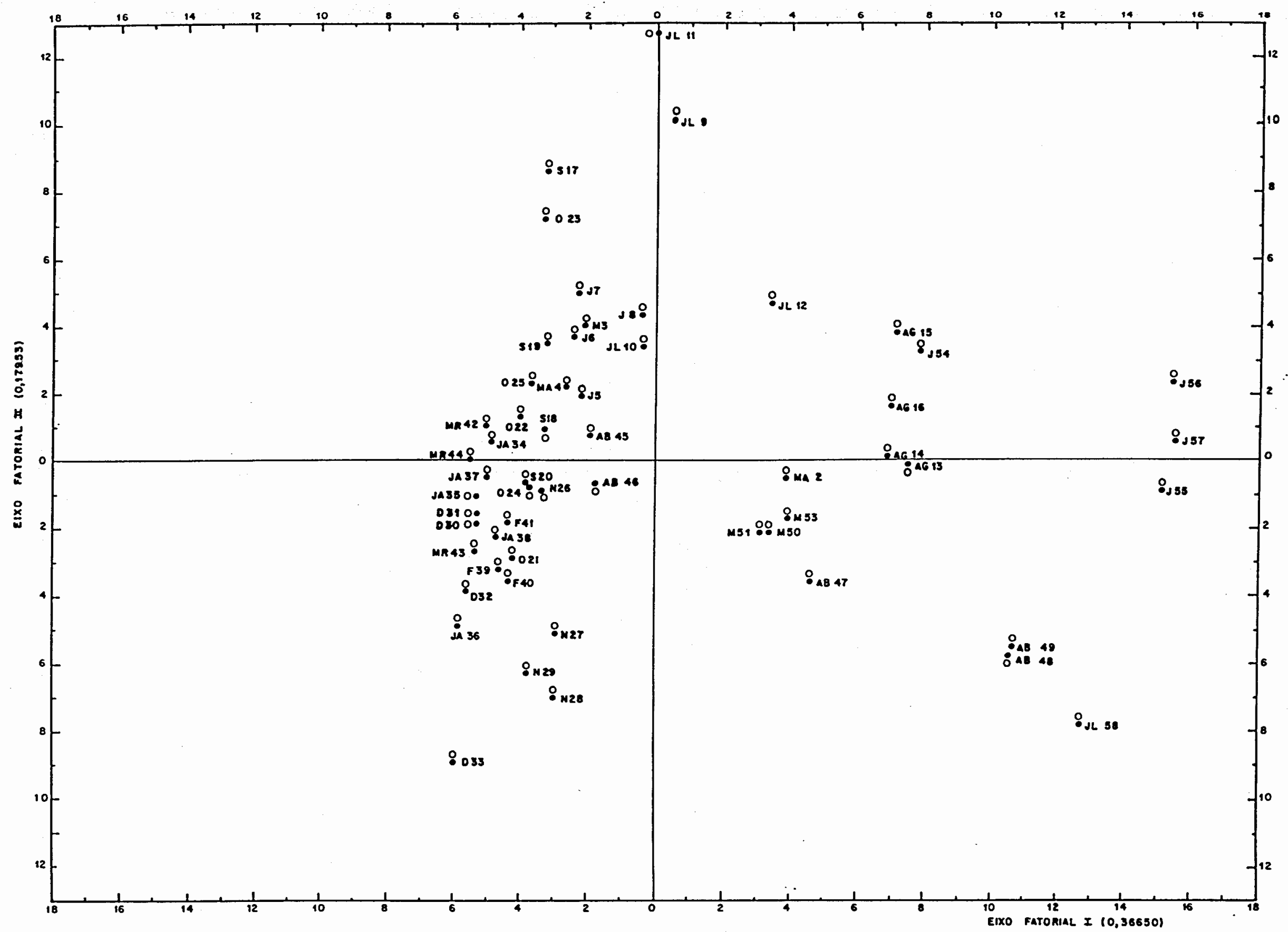

FIGURA 15 - ANÁLISE DOS COMPONENTES PRINCIPAIS. POSIÇÃO DAS CAMPANHAS. PONTO 1. 


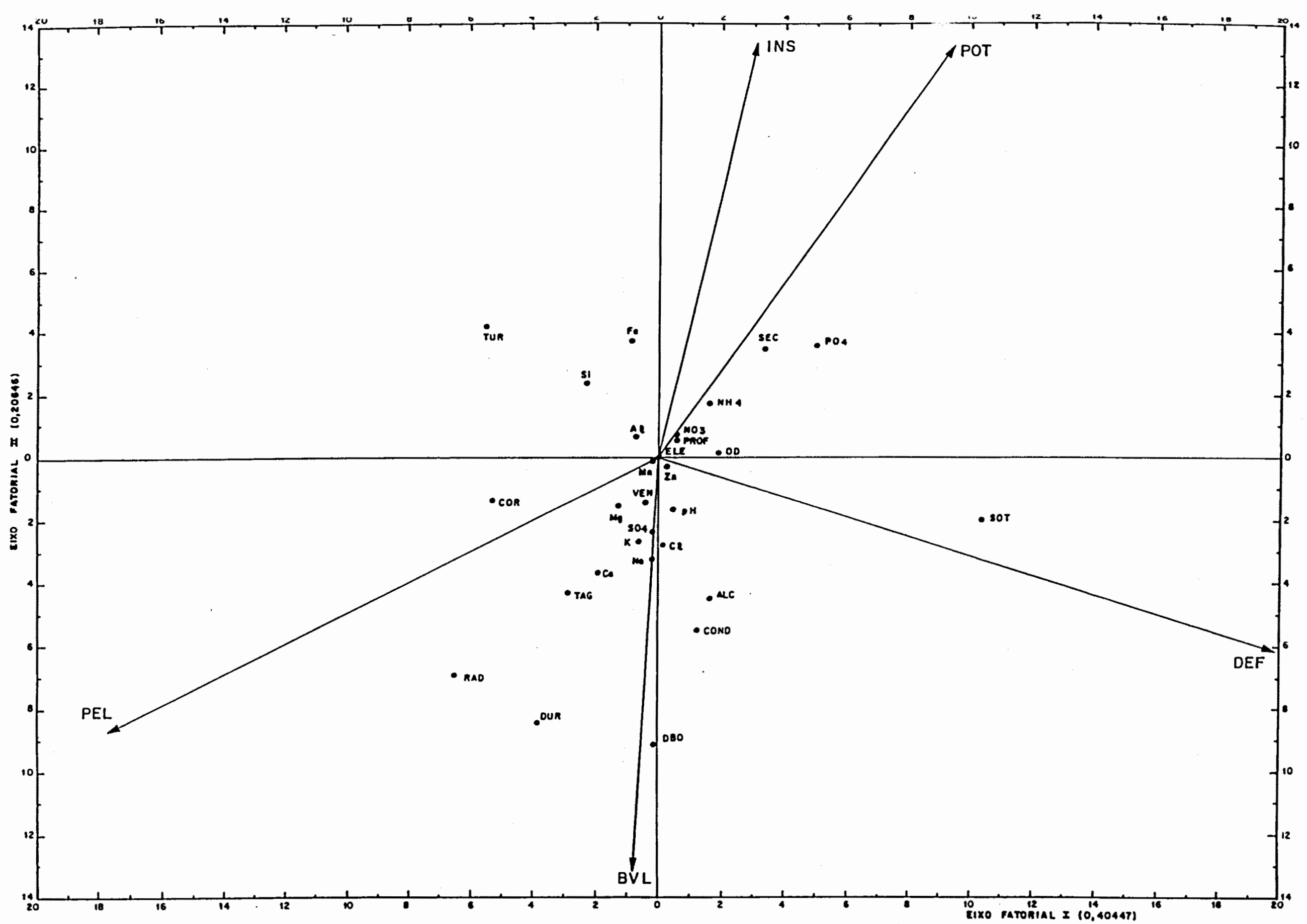

FIGURA 16 - ANÁLISE DOS COMPONENTES PRINCIPAIS. POSICAOO DAS CAMPANHAS. PONTO 4. MATRIZ DAS VARIÁVEIS AMBIENTAIS [LOG(X+1)]. ORDENAÇÃO: DISTÂNCIA EUCLIDEANA, PORCENTAGEM DE EXPLICAÇAO DOS DOIS PRIMEIROS EIXOS: $61.0 \%$. 


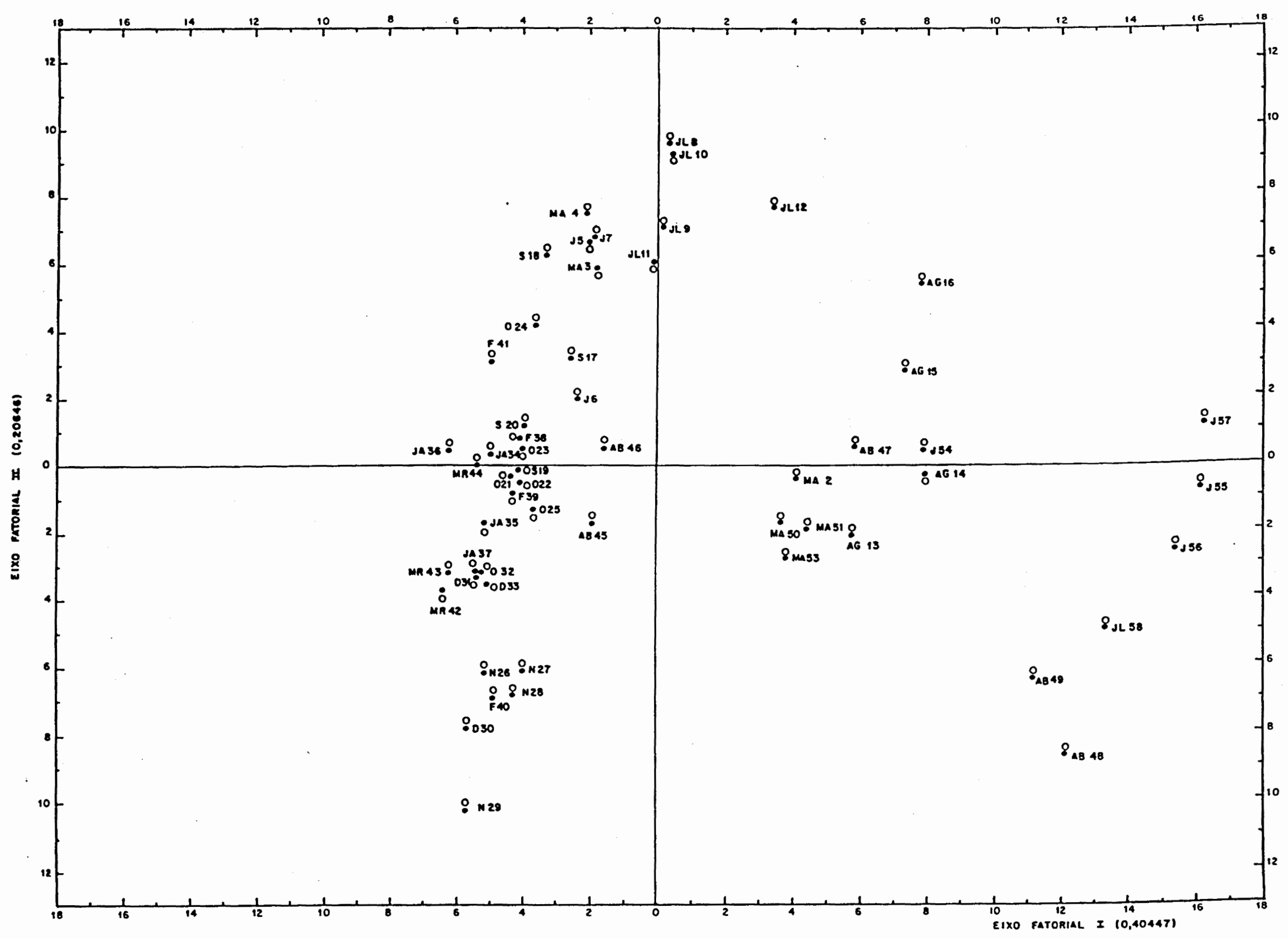

FIGURA 17 - ANÁLISE DOS COMPONENTES PRINCIPAIS. POSIÇÃO DAS CAMPANHAS. PONTO 4. 

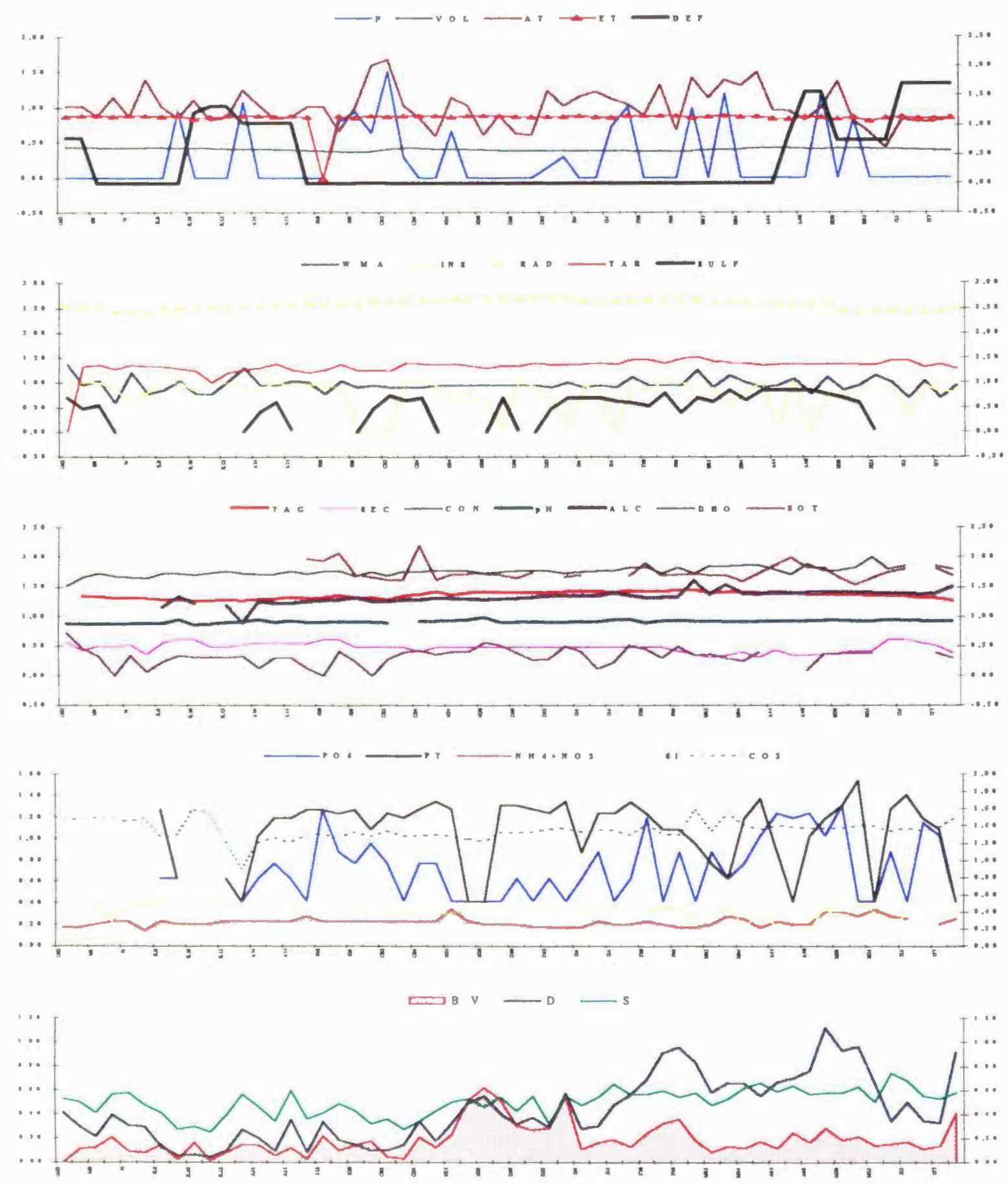

Gráfico 1: Precipitação (P); volume (VOL); vazão afluente (AT); vazão efluente (ET); deficiência hídrica do solo (DEF). Gráfico 2: velocidade máxima do vento (WMA); insolação (INS); radiação solar (RAD); temperatura do ar (TAR); sulfatação (SULF).

Gráfico 3: temperatura da água (TAG); transparência (SEC); condutividade (CON); potencial hidrogeniônioo (pH); alcalinidade (ALC); demanda bioquímica de oxigênio (DBO); sólidos totais em suspensão (SOT).

Gráfico 4: teor de fosfato solúvel reativo (PO4); fỏsforo total (PT); nitrogênio (NH4+NO3); silício (Si); gás carbônico (CO2).

Gráfico 5: biovolume (BV); densidade (D) e número de táxons (S) em cada coleta.

OBS.: os valores encontrados foram transformados em $\log (x+1)$. As unidades de medida de cada parâmetro estão relatadas no Capítulo Materiais e Métodos. 

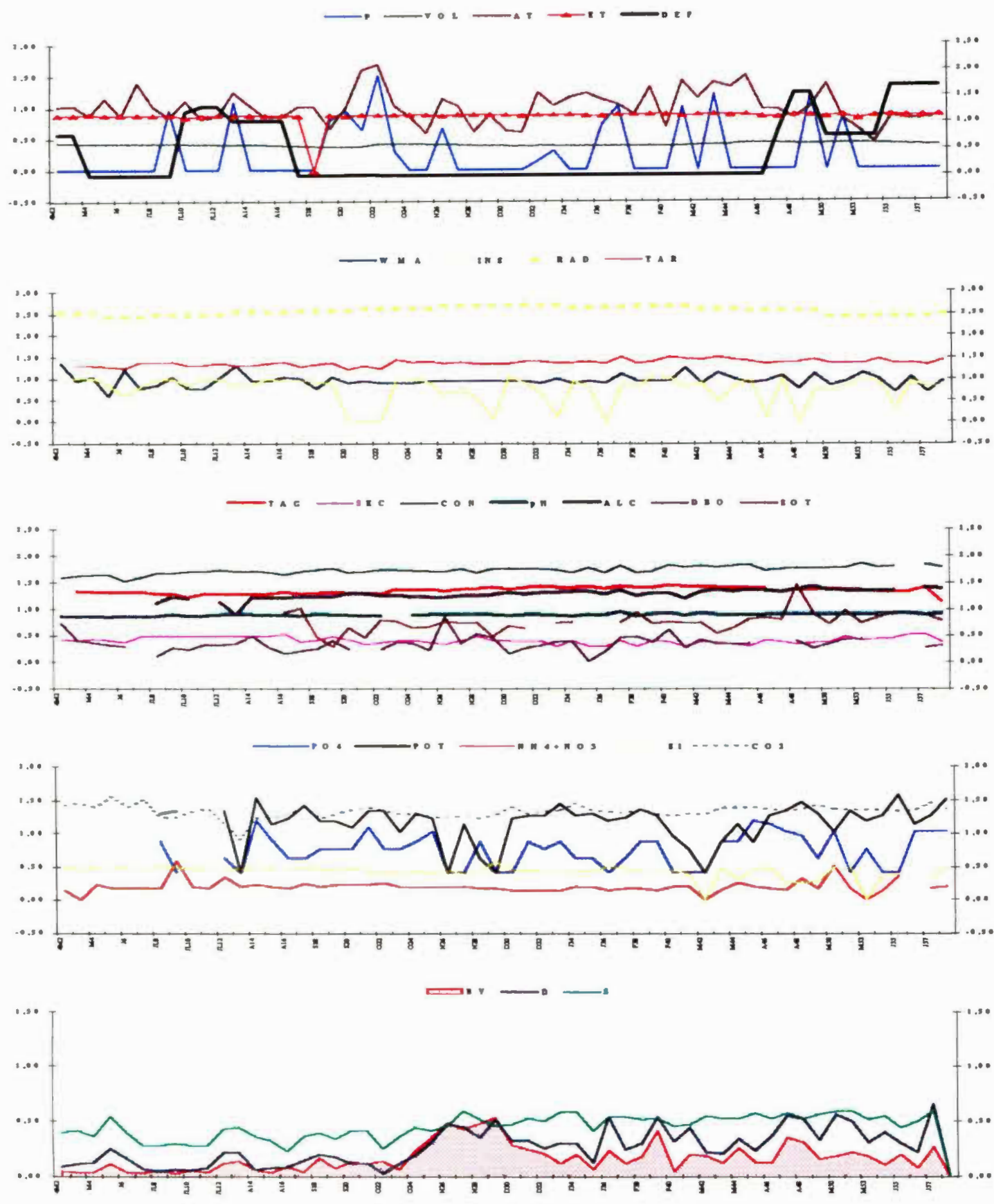

Gráfico 1: Precipitação (P); volume (VOL); vazão afluente (AT); vazão efluente (ET); deficiência hídrica do solo (DEF). Gráfico 2: velocidade máxima do vento (WMA); insolação (INS); radiação solar (RAD); temperatura do ar (TAR); sulfatação (SULF).

Gráfico 3: temperatura da água (TAG); transparência (SEC); condutividade (CON); potencial hidrogeniônico (pH); alcalinidade (ALC); demanda bioquímica de oxigênio (DBO); sólidos totais em suspensão (SOT).

Gráfico 4: teor de fosfato solúvel reativo (PO4); fósforo total (PT); nitrogênio (NH4+NO3); silício (Si); gás carbônico (CO2).

Gráfico 5: biovolume (BV); densidade (D) e número de táxons (S) em cada coleta.

OBS.: os valores encontrados foram transformados $\mathrm{em} \log (\mathbf{x}+1)$. As unidades de medida de cada parâmetro estāo relatadas no Capítulo Materiais e Métodos. 
FIGURA 20 - ANÁLISE DAS FLORAÇÕES. REPRESA DE GUARAPIRANGA 1991-92. PONTO 1

Variáveis ambientais abióticas: razão nitrogênio : fósforo (N:P) $\left[\mathrm{NH}_{4}+\mathrm{NO}^{3}: \mathrm{PT}\right]$; gás cartbonico total $\left(\mathrm{CO}_{2}\right)$; $\mathrm{pH}$; Variáveis biológicas: densidade-número de células por amostra (D); biovolume-micrômetros cúbicos por mililitro (B); biovolume de clorococales (CLORO); biovolume de cianoficeas (CIANO).

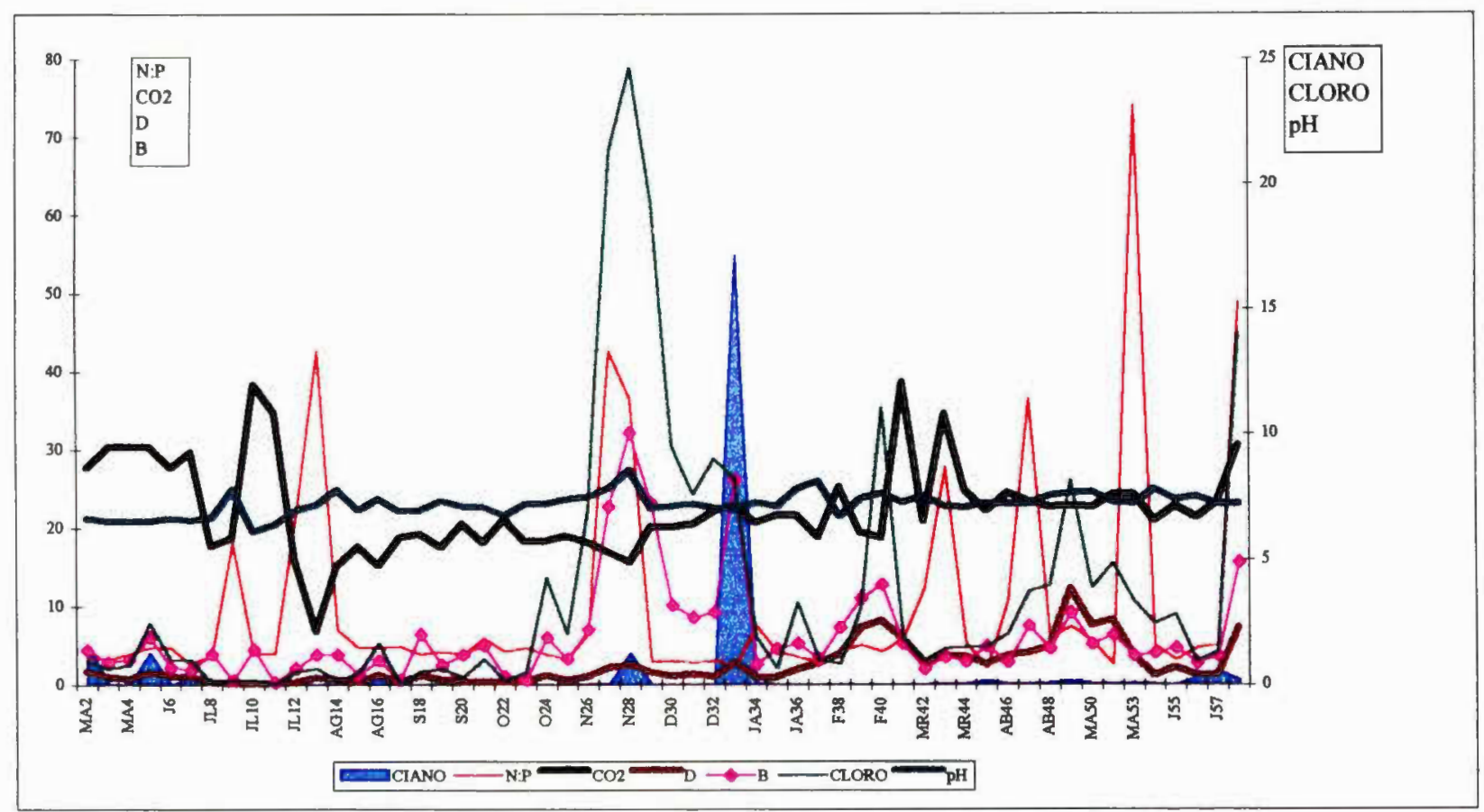

FIGURA 21 - ANÁluSE DAS FLORAÇÕES. REPRESA DE GUARAPIRANGA 1991-92. PONTO 4.

Variáveis ambientais abióticas: razão nitrogênio : fósforo (N:P) $\left[\mathrm{NH}_{4}+\mathrm{NO}^{3}: \mathrm{PT}\right]$; gás carbônico total $\left(\mathrm{CO}_{2}\right) ; \mathrm{pH}^{\text {; }}$ Variáveis biológicas: densidade-número de células por amostra (D); biovolume-micrômetros cúbicos por mililitro (B); biovolume de clorococales (CLORO); biovolume de cianoficeas (CIANO).

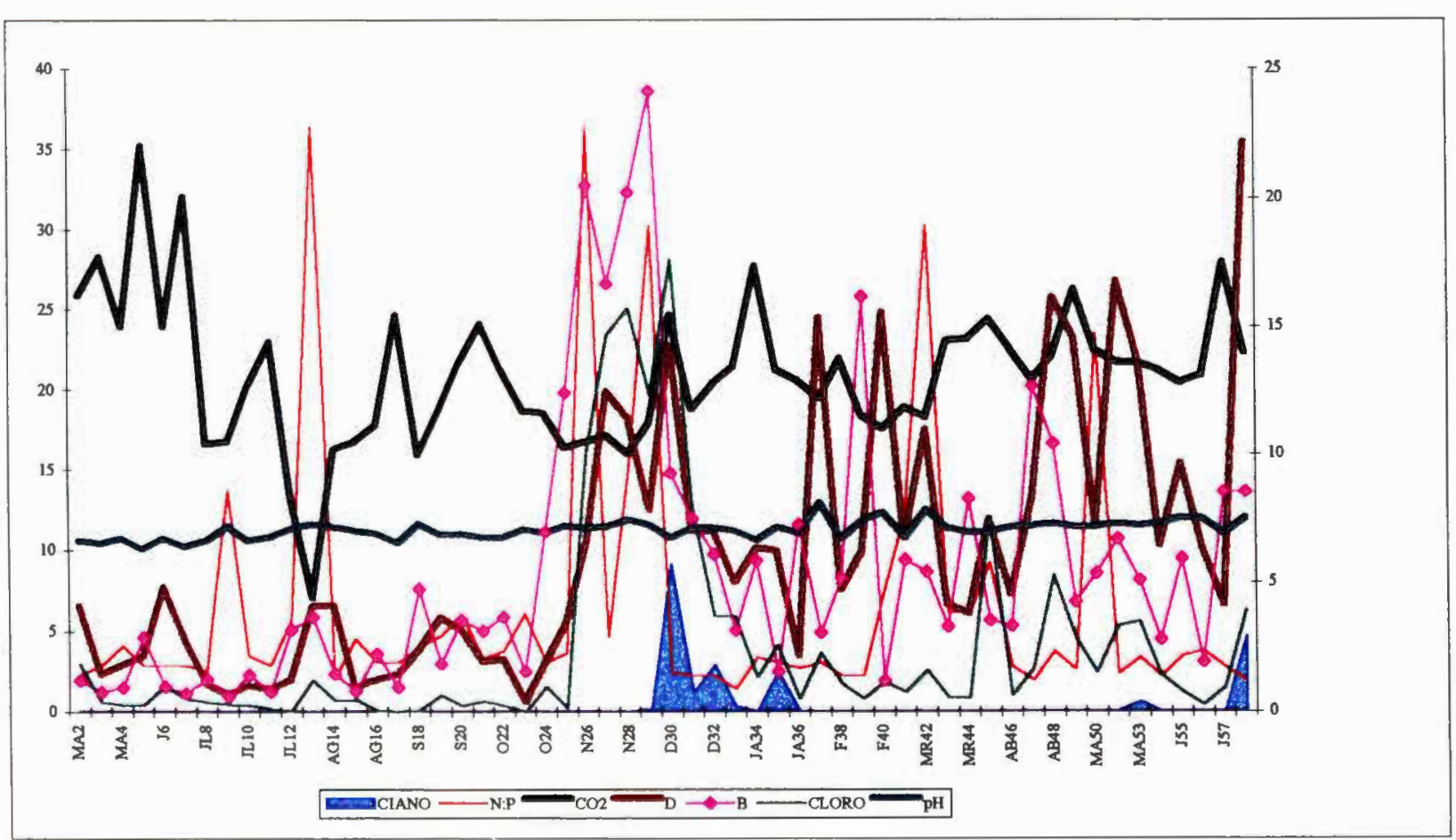


Figura 22 - Imagens de algumas cspécies de algas encontradas na Represa de Guarpiranga, 1991-92.

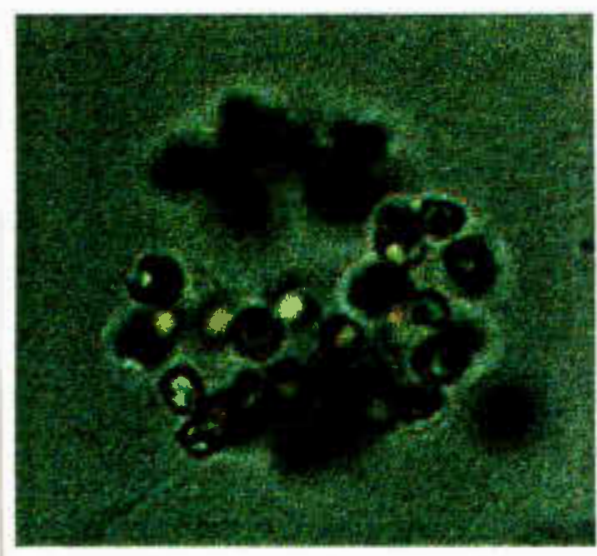

Dictyosphaeriwn ehrenherghanum

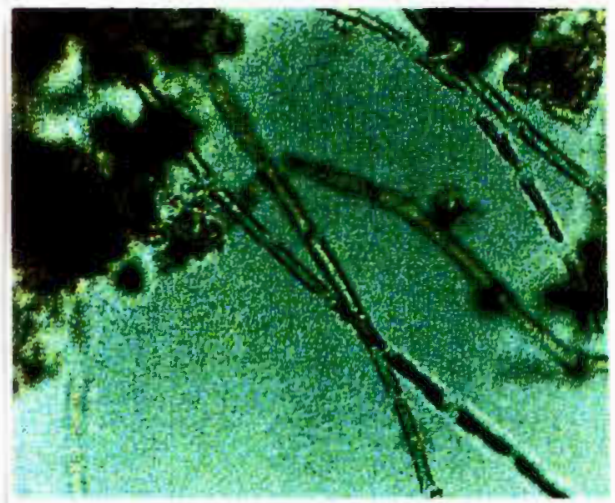

Mongendier ef americana

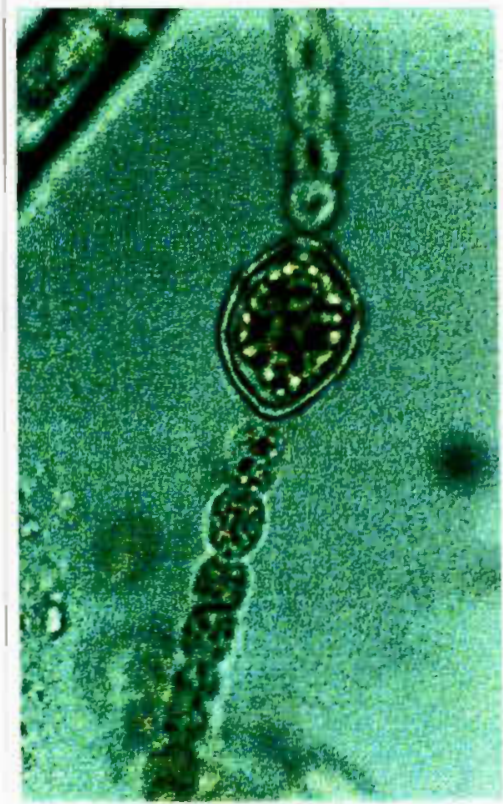

Anabaena solilaria

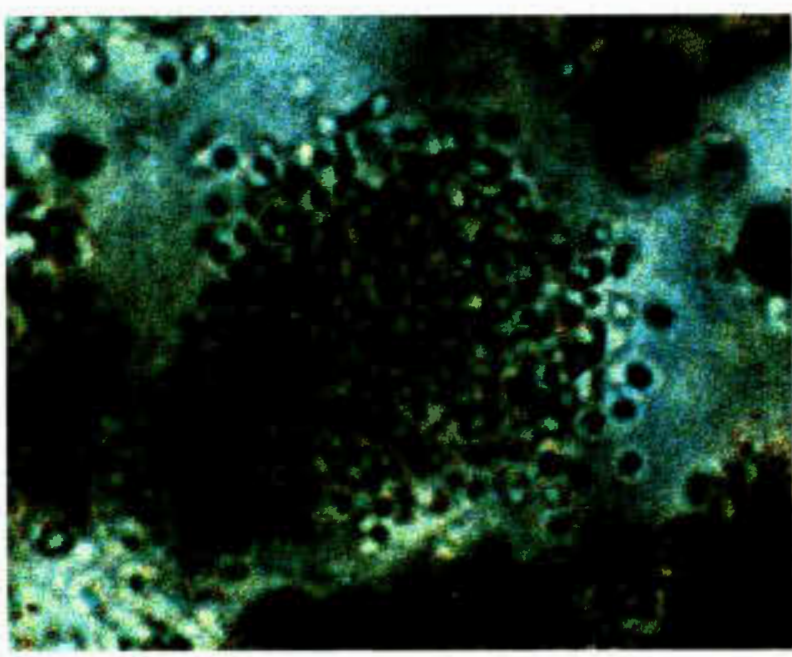

Aphanocopsa efachista

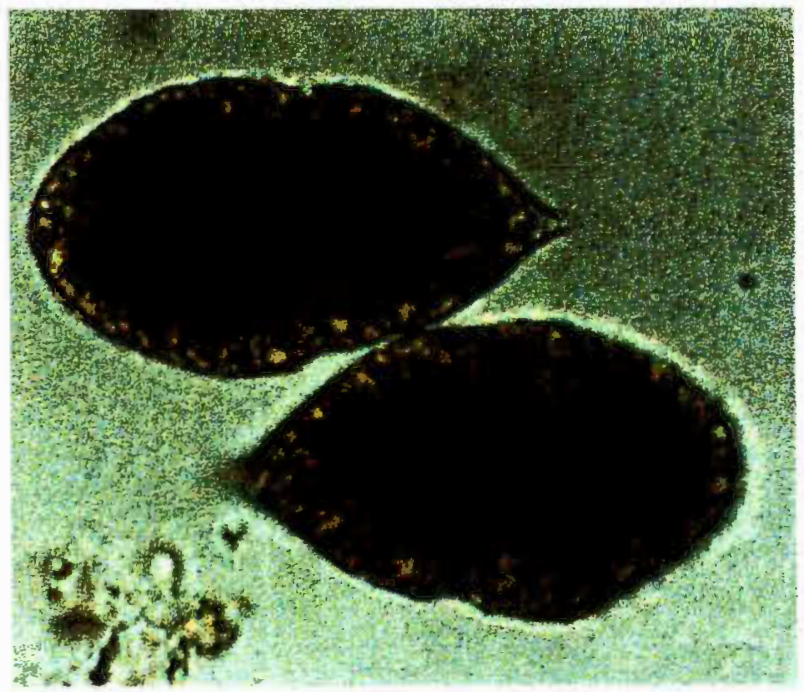

Gymnodintrm fuscrom

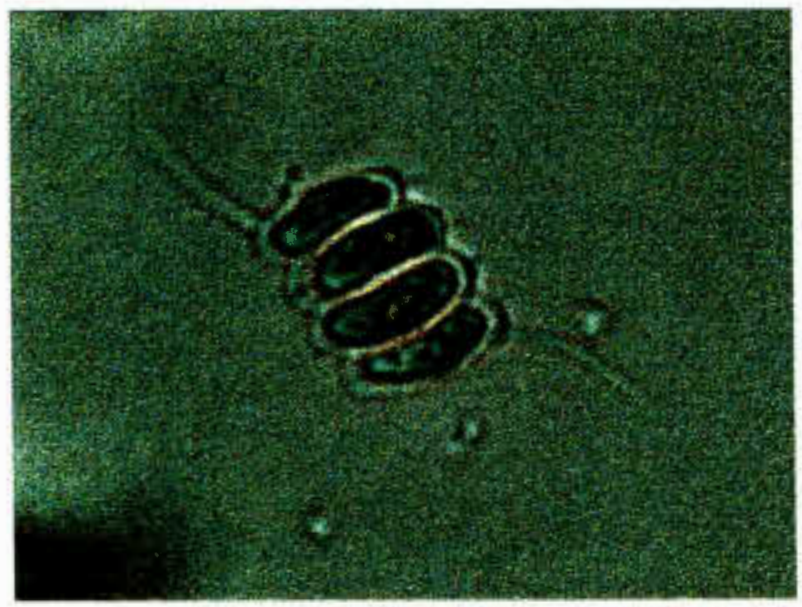

Scenedesmus bicardams 